UNIVEASITY OF

CALIFORNIA

Bloscience \& Natural

Pesources Library

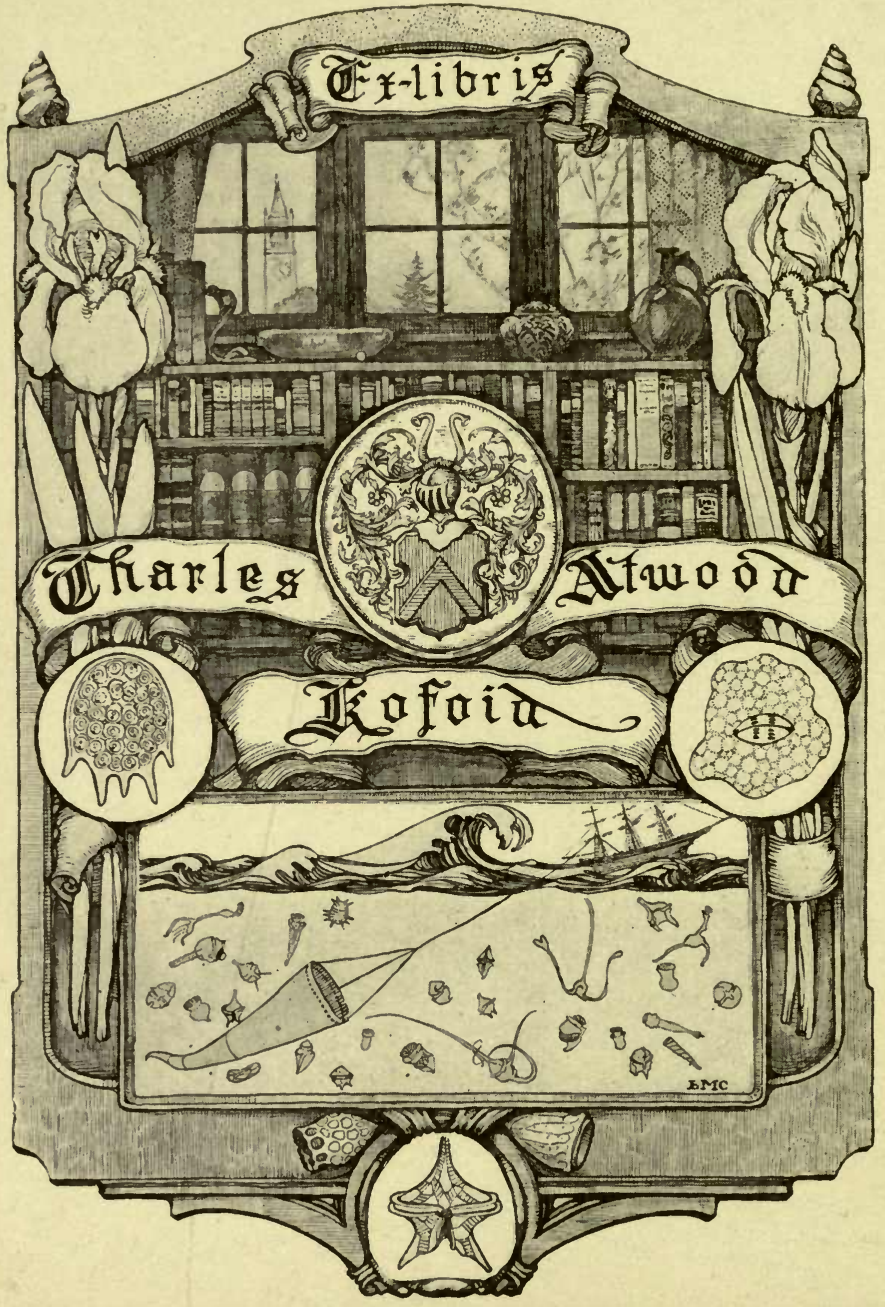








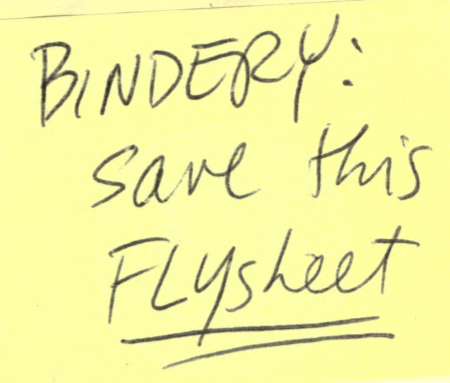

\section{THE LIBRARY OF}

THE UNIVERSITY OF CALIFORNIA

PRESENTED BY

PROF. CHARLES A. KOFOID AND MRS. PRUDENCE W. KOFOID 
Ls

The Esitor of the trunab of hotoral Afistory; with the Anthor Complinento. 


\section{N A T U R A L H I S T 0 R Y}

\section{Q U A D R U P E D S;}

CONTAINING MANY

MODERN DISCOVERIES, ORIGINAL OBSERVATIONS, AND

NUMEROUS ANECDOTES.

\section{B Y J A M E S H. F E N N E L L.}

WITH TWO HUNDRED WOOD CUTS.

"Science should be stripped of whatever tends to clothe it in a strange and repulsive garb; and every thing which, to keep up an appearance of superiority in its professors over the rest of mankind, assumes an unncecssary guise of obscurity, should be sacrificed without mercy." Sir John Herschel.

\section{O N D O N :}

JOSEPH THOMAS, FINCH LANE, CORNHILL. 
LONDON :

Palmer and Clayton, Printers,

9, Crane Court. 


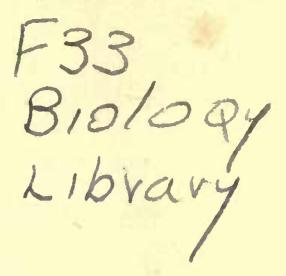

\section{P REF A C E.}

Although many modern works are to be found descriptive of particular groups of the higher animals, or of the miscellaneous, but generally very imperfect, collections in our zoological gardens, yet a long time has elapsed since the publication of any work like the present, giving a concise, but comprehensive view of the characteristic appearances, habits, and uses, of this class of animals in general. The progress which this department of zoology has made since the time of Buffon, renders his work, as well as the volumes which Goldsmith, Bewick, and others, have chiefly compiled from him, but ill-adapted for popular instruction. Buffon will ever claim our respect and our praise, for the zeal with which he accumulated facts on his favourite study; but his predilection for theories which he could not support without a violation of truth, and his invincible prejudices against many animals, which he determined to depict in the worst colours, often led him, unfortunately, to draw wrong inferences from facts, and sometimes to exaggerate and distort them; while, on the other hand, he has often embellished them, so that they might promote those efforts at ensuring an eloquent effect, which are so apparent throughout his work, and which, like the will-o'-the-wisp, display an effulgence more calculated to deceive than to assist. By the experienced and discriminating naturalist alone, can Buffon's work be perused without fear of being misled by the persuasions of eloquence; which, in philosophic inquiries, generally prove delusive to the unwary. Even, putting these considerations aside, 
the circumstance of many popular errors having been detected, many discussions settled, many new species and important facts discovered, and some valuable leading principles of classification developed since his time, renders the works to which I am now alluding, and which are the only ones of the kind generally accessible, most imperfect instructors in the present much-advanced state of zoological science.

Having devoted myself, for some years, to this delightful and most useful branch of natural history, I have here attempted to furnish those who also feel interested in the subject, but who may not happen to possess the same facilities as myself, with a work containing the result of no little research and observation, instituted without prejudice, or pre-conceived theory; and which result is conveyed to the reader in a style as homely and frank as "a round unvarnish'd tale:" void of all eloquence, unless it be such as Nature herself imparts to the discourse. My wish has been, that the perusal of this book should prove, if possible, as agreeable and lively a recreation as a walk through the Zoological Gardens; that the solemn and melancholy strain which is generally affected in works of this kind, should give way to a tone more congenial with that warm and lively emotion with which the actions and the frolics of animals are contemplated by the visitors to those instructive and diverting exhibitions. Coleridge, in his reproof of poets who assume a doleful strain in their descriptions of the nightingale, assures them that " in nature there is nothing melancholy," but the human mind; and another poet asks,

"Who can refrain to smile with Nature?"

Still I have not been regardless of the just observation of Paley, who says, "If one train of thinking be more desirable than another, it is that which regards the phenomena of nature, with a constant reference to a supreme intelligent Creator." The earnestness with which the admirable adaptation of the structure of animals to their necessities and situ- 
ations is pointed out, will impress the mind of every reader with a constant conviction of Almighty wisdom and benevolence. But everything in nature is so well contrived, so well ordained, that it is hardly prudent to select from the whole particular things as special instances of creative wisdom, and as deserving our admiration more than others.

Wonder lies
Tn the mind merely of the wondering man:
Treading the steps of common life, with eyes
Of curious inquisition, some will stare
At each discovery of Nature's ways,
As it were new to find that God contrives.
The contrary were marvellous to me,
And till I find it I shall marvel not;
Or all is wonderful, or nothing is."

To revert more directly to the materials of this volume, it may be permitted to me to observe, that I believe it will be found to contain a greater collection of well-anthenticated facts than any similar work of the same size. Nature is so extensive, and man's life so inadequate to acquire the whole of this kind of knowledge, that it is well to convey, to those who seek it, as much as possible in a given space, rather than to administer it on the homœopathic principle. But while I have placed facts before the reader, I have also called attention to many agenda, or matters which still remain to be ascertained; and also to such statements as are vague, indecisive, or contradictory, contenting myself with merely suggesting what may appear to be most probably true, instead of attempting to impose a dogmatical opinion. By pursuing the former course, which I trust will be appreciated, as it instructs all and deceives none, I have neglected the example of many professors of science, who are ever fearful lest their pupils should find they cannot supply them with positive information on everything. Lord Bacon had the temerity to complain of a similar failing in his period. "As knowledge is now," he observes, "there is a kind of 
contract of error between the deliverer and the receiver; for he that delivereth desireth to deliver it in such a form as may be best believed, and not as may be best examined; and he that receiveth knowledge, desireth rather present satisfaction than expectant inquiry, and so rather not to doubt than not to err : glory maketh the author not to lay bare his weakness, and sloth maketh the disciple not to know his strength."

I would hope, however, that there are some readers who will feel thankful for my having pointed out to them certain subjects which they, perhaps, may have peculiar facilities for investigating, with pleasure to themselves and benefit to science. Indeed, almost every one possessing the use of his eyes, a habit of careful and scrutinising observation, and a love of truth, has it in his power to contribute to our knowledge of the works and phenomena of creation. He is, indeed, unfortunate who feels that he cannot say with Shakespeare,

"In Nature's infinite book of secrecy,

A little I can read."

To pursue this study it is not absolutely necessary that a man should be an F.L.S. or an F.R.S., or that he should be able to " nickname God's creatures" in classic languages. All that is requisite is a frequent reference from books to nature, and then again from nature to books; for the latter are certainly essential, although a vast deal has bcen said in favour of "field naturalists," by those who have published most books for their perusal.

Although doubtful matters in natural history are often entirely omitted by writers from the apprehension just intimated, yet it is more frequently the case that only one view of the question is concealed, the other being arbitrarily adduced from no better motive than that it is favourable to some cherished theory, or that it is better adapted to the style of the discourse. What a recent writer has said of political history is too often true of natural history. "Where, as is 
generally the case, an effort is made to form a smooth and flowing narrative, in elegant modern phraseology, the objects and events all suffer a kind of translation or paraphrase, which greatly alters their character, and in many instances is attended with the effect of both suppressing the true and creating the false. No one who has not compared the elegant narratives of the last and present age with the simple and homely chronicles from which they have mostly been compiled, could form any adequate idea of the perversion which history [natural as well as political] is thus made to suffer. Sometimes a bare and rigid fact is amplified and clothed; sometimes new facts are imagined and added, in order that the only one for which there is authority may tell a little better. There is a great deal of rounding off and polishing down to make all fair, straight, and fluent. Carelessness also has its effect in bringing about alterations. Even in the change from the homely expressions of an early age to those suitable to the modern writer, the real character of the events is sometimes falsified."

That this should not be the case in the present volume, I have attentively considered every statement, collated one author with another, and often gone over the ground afresh, and traced errors to their sources; and in many instances it will be found that I have exposed this objectionable system of suppressing one side of the question, and of perverting and garnishing the real facts. Theories are not to be despised, but they are ever to be suspected. There is as much of truth as of pleasantry in Cowper's observation, that " one generation blows bubbles and the next breaks them; but in the mean time your philosopher is a happy man. He escapes a thousand inquietudes to which the indolent are subject, and finds his occupation, whether it be the pursuit of a butterfly or a demonstration, the wholesomest exercise in the world; and should his discoveries eventually prove to be only dreams, they are to him realities while he proceeds."

The study of nature and that of the muses are so akin to 
each other, that it is not only undesirable but difficult to separate them; and none will make the attempt but those who wish to render knowledge unpopular, harsh, and monotonous. All who really love nature must love poetry, and feel an additional charm when they hear her sing the manifold works, beauties, and achievements of the former. With this conviction, I have not suppressed such poetic recollections as occurred to me during the writing of this work. Herbert, in his Remains, says, " there is no knowledge but, in a skilful hand, serves either positively as it is, or else to illustrate some other knowledge." Now the truth of the latter part of this observation is well exemplified on several occasions in the poetic quotations I have inserted, especially in those from poets who lived in the comparative infancy of science. So frequently is this the case in the writings of Shakespeare, that I have often thought that if philosophical journals had existed in his period, we should have found him amongst the most frequent of their contributors, and that his master-mind would have been as much engaged in teaching a knowledge of physical nature as in pourtraying the virtues and vices of mankind. In the absence of such convenient vehicles, we find that he has most ingeniously made his plays and poems subservient to the diffusion of many of his philosophical remarks; or, to use his own words, " he hath strange places crammed with observation." What Ben Jonson has said in his poem on The Mind, may well be applied to Shakespeare :-

"Our sense you do with knowledge fill, And yet remain our wonder still."

Having thus noticed the peculiar features of this volume, I have only to express the hope, that the reader may find as much pleasure and instruction in perusing it as I found in composing it.

James H. FenNell. 


\section{N T ROD UCT I O N.}

"IN entering upon any scientific pursuit," says Sir John Herschel, " one of the student's first endeavours ought to be to prepare his mind for the reception of truth, by dismissing, or at least loosening, his hold on all such crude and hastily adopted notions respecting the objects and relations he is about to examine, as may tend to embarrass or mislead him; and to strengthen himself by something of an effort and a resolve, for the unprejudiced admission of any conclusion which shall appear to be supported by careful observation and logical argument, even should it prove of a nature adverse to notions he may have previously formed for himself, or taken up, without examination, on the credit of others. Such an effort is, in fact, a commencement of that intellectual discipline which forms one of the most important ends of all science. It is the first movement of approach towards that state of mental purity which alone can fit us for a full and steady perception of moral beauty as well as physical adaptation. It is the 'euphrasy and rue' with which we must 'purge our sight,' before we can receive and contemplate as they are the lineaments of truth and Nature." 
To those whose notions of the faculties and economy of animals are merely derived from popular belief, or supported only by casual observation, the preceding most excellent advice is particularly necessary to be observed when commencing the study of natural history, respecting the objects of which there have always been so many misconceptions, prejudices, and superstitions afloat, that they have been great impediments to the general diffusion of a correct knowledge of the subject.

Although the Linnæan system of botany has still its admirers and followers, despite the more philosophical system of Jussieu, yet the Linnæan system of zoology may be said to have been universally superseded by that of Cuvier. The Cuvierian Classification of the first class of animals has therefore been adopted here. It may be advisable, in this place, to quote his prefatory observations on classification as applied to the animal kingdom. "The essential characters in animals, on which their primary divisions are to be founded, it is evident should be those which are drawn from the animal functions, that is, from the sensations and motions; for both these not only make the being an animal, but in a manner establish its degree of animality. Observation confirms this position by showing that the degrees of development and complication accord with those of the organs of the vegetative functions. The heart and the organs of the circulation form a kind of centre for the vegetative functions, as the brain and the trunk of the nervous system do for the animal functions. Now we see these two systems become imperfect and disappear together. In the lowest class of animals, where the nerves cease to be visible, the fibres are no longer distinct, and the digestive 
organs are simple excavations in the homogeneous mass of the body. In insects the vascular system even disappears before the nervous one; but in general the dispersion of the medullary masses accompanies that of the muscular agents : a spinal marrow, on which the knots or ganglions represent so many brains, corresponds to a body divided into numerous rings, supported by pairs of limbs longitudinally distributed, \&c. This correspondence of general forms, which results from the arrangement of the organs of motion, the distribution of the nervous masses, and the energy of the circulating system, should then be the basis of the primary divisions of the animal creation. If we divest ourselves of the prejudices founded on the divisions formerly admitted, we shall find there are four principal forms - four general plans, if it may be so expressedon which all animals seem to have been modelled, and whose ulterior divisions, whatever may be the titles which naturalists have given them, are merely slight modifications, founded on the development or addition of certain parts, which produce no essential change in the plan itself. In the first of these forms, which is that of man, and of the animals most nearly resembling him, the brain and principal trunk of the nervous system are inclosed in a bony envelope, formed by the cranium and vertebræ; to the sides of this intermedial column are attached the ribs and bones of the limbs, which form the frame-work of the body; the muscles generally cover the bones, whose motions they occasion, while the viscera are contained within the head and trunk. Animals of this form [comprising mammals, ${ }^{*}$

* As the number of feet is immaterial in classification, and as the terms quadruped and tetrapod have already led to a most incongruous association of 
birds, reptiles, and fishes,] are called vertebrated animals. They have all red blood, a muscular heart, a mouth furnished with two jaws situated either above or before each other, distinct organs of sight, hearing, smell, and taste, placed in the cavities of the face, never more than four limbs, the sexes always separated, and a very similar distribution of the medullary masses and the principal branches of the nervous system."

The first class of vertebrated animals consists of mammals, technically termed MAMMALIA, both names alluding to the peculiar and unexceptionable characteristic of their possessing teats (mamma), and of course suckling their young. The MAMMALIA are divided by Cuvier into nine orders; but as the publication of a treatise on system is not the object here proposed, it will be necessary to refer the reader to Cuvier's Rène Animal itself, or to some of the several translations of it, for the details. His observations, however, on the division of this class into orders must not be omitted :-

crocodiles, tortoises, frogs, and other four-footed creatures with the first class of animals, from which they are far removed by nature, it is desirable that those terms should be abandoned for the more discriminating and more euphonious term mammal, which is therefore adopted throughout this volume, with the exception of the title-page. It may here be mentioned, that I use the word vegetal instead of vegetable, because the latter term, from its being more particularly applied to cabbages, potatoes, turnips, \&c., frequently conveys a restricted notion, when a writer intends it to comprise all that vegetates, from the most stupendous and graceful cabbage-palm to the lowly and clumsy-looking cabbage; from this to the little delicate violet, and from this "infant of the spring" to the most diminutive moss. Vegetable is as ugly and unpoetic a term as constable; but vegetal, used by Burton in his Anatomy of Melancholy, and by other old writers, is a good word deserving of being restored to our language, and agrees well with the terms which describe the other grand divisions of nature thus, the animal, vegetal, and mineral kingdoms. 
"The variable characters which form essential differences among mammals are taken from the organs of touch, on which depend their degree of ability or address; and from the organs of mastication, which determine the nature of their food, and are all closely connected, not only with everything relative to the digestive function, but also with numerous other differences concerning even their intelligence. The degree of perfection of the organs of touch is estimated by the number and pliability of the fingers, and from the greater or less extent to which their extremities are enveloped by the nail or the hoof. A hoof which completely envelopes the end of the toe, blunts its sensibility, and renders the foot incapable of seizing. The opposite extreme is when a nail, formed of one single layer, covers only one of the surfaces of the end of the finger, leaving the other surface possessed of all its delicacy. The nature of the food is known by the grinders, to the form of which the articulation of the jaws always corresponds. To cut flesh, grinders as trenchant as a saw, and jaws fitted like scissors, having merely a vertical motion, are required. For bruising roots or grains, flat-crowned grinders, and jaws having a lateral motion, are necessary : and in order that the crowns of these teeth may always possess inequalities, their substance is composed of parts of unequal hardness, so that some may wear away faster than others. Hoofed animals are all necessarily herbivorous, and have flat-crowned grinders, inasmuch as their feet incapacitate them for seizing living prey. Animals with fingers are susceptible of more variety, their food is of all kinds; and, independently of the form of their grinders, they greatly differ from each other in the pliability and sen- 
sitiveness of their fingers. When they possess a thumb, which is opposable to the finger for the purpose of seizing minute objects, the power of the hand is greatly increased, and has an immense influence on their dexterity. The opposable power of the thumb exists in the highest perfection in the human hand, the whole of which is free and capable of prehension." It is upon these various combinations, which strictly determine the nature of the different mammals, that Cuvier has divided the whole class of MAMMALIA into the following Orders, namely,

I. BIMANA, consisting of man only, who, in addition to his peculiar privileges, possesses hands at the extremities of his arms alone, the extremities of his legs being designed merely for his support in an erect position.

II. QUADRUMANA, having hands at all four extremities.

III. CARNARIA, with the thumb not free, and it cannot be opposed to the anterior extremities.

** Each of the preceding orders has the three sorts of teeth; namely, molars, or grinders, canines, and incisors, or cutting teeth.

IV. RODENTIA, with toes differing but little from those of the third Order, but this has no canine teeth, and the incisors are placed in front of the mouth, and adapted to a very peculiar sort of manducation.

V. EDENTATA, with toes much cramped, and deeply sunk in large nails, which are generally curved; they have no incisor teeth, and in some the canine teeth disappear, while others have none of any kind.

VI. MARSUPIALIA, consists of animals possessing abdo- 
minal pouches, and a general similarity of organization; some of them, however, in their teeth and the nature of their diet, correspond to the CARNARIA, others to the RODENTIA, and a third to the EDENTATA.

VII. RUMINANTIA, with cloven feet; no true incisors in their upper jaw ; and with four stomachs.

VIII. PACHYDERMATA, containing all the remaining hoofed animals, and most of them remarkable for the thickness of their hides.

IX. CETACEA, without posterior extremities, have a fishlike form, but resemble the other mammals in their economy, are aquatic, and are also the most gigantic of animals. To this order belong the whale, manati, rorqual, cachalot, narwhal, bottle-head, porpoise, grampus, and dolphin, which were formerly classed among fishes. Man and these animals, that is to say, the first and last orders, will not be treated of here, but only those mammals which are four-footed. 



\title{
NATURAL HISTORY OF QUADRUPEDS.
}

\author{
ORDER-QUADRUMMANA.
}

A P E S.

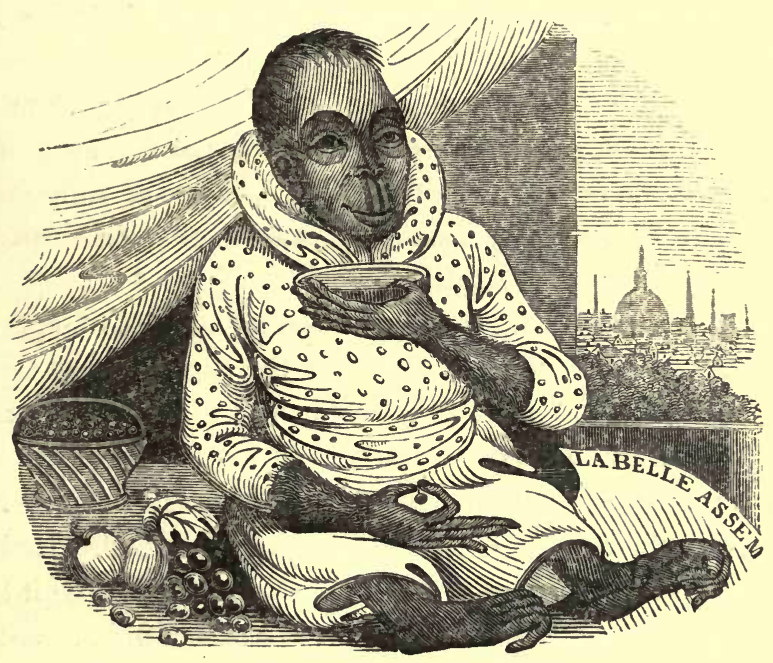

The Chimpanzee.-(Simia Troglodytes.)

Black Orang. Pigmy. Jocko.

The terms ape, monkey, and bahoon are very indiscriminately applied to quadrumanous, or four-handed animals by the generality of writers ; but here, as in all other matters of science, it is very important that some precision in nomenclature should be observed. I shall therefore, as I proceed, particularize some of the most obvious characters by which the apes may be readily distinguished from the other two groups. 
The apes have neither tails nor cheek-pouches; organs which are separately absent or nearly so in some baboons and monkeys, but not absent together. Another very great distinction consists in the peculiar circumstance of their arms being disproportionately long in comparison with the legs; the arms of some species being so long, indeed, that when standing upright they can touch the ground with the fingers.

They are most admirably adapted for a life among woods and forests, and they climb and swing from tree to tree with astonishing facility.

In a state of nature they feed on wild fruits, bulbous roots, small reptiles, insects, birds, and eggs ; but in confinement they will eat cooked beef or mutton. In the latter state their favourite beverage is milk or water; and though at first they will reject wine or spirits, yet, like the savages of America and Australia, they soon lay aside the habits of temperance and learn to enjoy stimulating drinks.

The Chimpanzee, the most interesting species of ape, inhabits all the forests comprised between the banks of the Gambia, in the north, the kingdom of Congo in the south, and extending from the western coast of Africa.

With the exception of man, the chimpanzee holds a higher rank in the chain of creation than any other animal. Its bodily conformation and its intellectual faculties fully entitle it to this secondary station. In some points it resembles the orang-outan, but it materially differs from it in organic structure, and in various external characters.

The average height of the full grown chimpanzee, when standing upright, is computed to be about four feet. The skull is small and of an oval shape; its muzzle is slightly prominent; its facial angle, when full-grown, is thirty-five degrees, being five degrees less than in the orang-outan; its ears are large, broad, and prominent; and its countenance has a less grave or melancholy expression than that of the orang-outan. It differs remarkably from the latter animal in having the round ligament of the thigh-bonc, which better adapts it for standing upright, 
and in having the last joint of the great toe perfect. The arms, though long, reach only a little way below the knee, and both the hands and feet are broad and short. The thumb of the hand has not the same relative length, otherwise the shape and appearance of the whole hand greatly resemble that of man; but the thumb of the foot is of considerable length. The hair is long, thin, and coarse ; on the fore-arms it is pointed towards the elbow; in young ones, it is black; in adults, it is orangered. It expresses its anger by loud cries, or a succession of short quick sounds, resembling a bark. The temper, disposition, and intellect of the adult chimpanzee remain yet to be ascertained; for, as far as is known, no adult apecimen of this species, or even of the orang-outan, has ever been kept and observed in captivity. The few specimens which have been brought ro Europe have been young ones, as was evident from their teeth and small stature, the largest not having exceeded three feet six inches.

The shores of the Bullom country, on the north of the River Sierra Leone, are infested by chimpanzees, in numbers quite equal to the commonest species of monkey; and the natives say these animals always travel in large troops, armed with sticks, which they can wield with great dexterity. They are very watchful, and give signals of the approach of strangers by a noise similar to that of human beings in great distress. M. De Grandpré says, chimpanzees often behave very roughly to the negroes; and Hanno, a Carthaginian Admiral, who lived three hundred and thirty-six years before the Christian era, says of some chimpanzees which were pursued, that "all the males escaped with astonishing swiftness, and threw stones at us; but we took three females, who defended themselves with so much violence that we were obliged to kill them." *

In 1836, a young male chimpanzee was added to the collection in the Zoological Society's Gardens. He was obtained by shooting his mother, who was nursing him in her arms, about one hundred and twenty miles from Grand Bassan, on the south-west coast of

* Hannonis Periplus, translated by V. Berkel. 
Africa. The young one had an aged appearance, somewhat like that of an old bent negro, and this appearance was increased by a spare beard of short white hairs growing on his muzzle, and by the deep furrows on his cheeks. His age, however, was, according to the test of his dentition, not more than eighteen or twenty months. His frame was thick-set and broad, but the abdomen, as in the orang-outan, was protuberant.

His lively and playful actions resembled those of a child; but though very watchful and inquisitive, he was neither mischievous nor petulant. He delighted to assume a variety of attitudes on his swing, giving the beholder some idea of the agility with which he might have been swinging and climbing among the branches of his native forest. Sometimes he would stand in the swing, grasping the rope with the hind feet, and, holding with one hand, then he would swing by one foot or hand, or turn a summerset over the rope. When tired of this play, he would roll about the floor, climb the bars, or hobble about very quickly, generally assisting himself by resting the knuckles of the two first fingers of the hand on the ground, to do which he stooped his shoulders slightly forward; but he frequently walked perfectly upright. His gait was a sort of waddle, and at each step the whole foot was raised at once, and again set down flat at once. He would often stamp. Sometimes, while firmly grasping with the broad and strong hind-feet the back of a chair or a perch, he would fall completely backwards, and then raise himself again into his previous upright position;-a gymnastic performance displaying his strong muscular powers.

He would play with the keepers in the most familiar manner, now running round them, now dodging them, now climbing up them, and embracing them. When tickled smartly, his eyes twinkled, the corners of his half-opened mouth were drawn upwards, and his teeth displayed, while at the same time he uttered a chuckling noise. If this was not laughter, expressive of agreeable bodily sensations caused by external circumstances, it was certainly the nearest approach to it which any inferior animals ever exhibit. 
The keeper, and the cook who dresses the meals of the men employed in the gardens, were his especial favourites. He recognised even their footsteps, and watched for them with evident impatience. When he saw them approach, he would utter a low sound of satisfaction, and, if at liberty, immediately climb upon them, and fondle them. The cook sometimes found it difficult to get away from him; and, if permitted, he would walk about the place with her, holding by her gown like a child. Once he opened the lattice-window of the kitchen, and looked very composedly about him, as if admiring the novelties which attracted his attention, but being ordered to come away, he closed the window and descended.

He had a remarkable propensity of putting everything into his mouth. When given a tin-rattle, he took no notice of its sound, but at once tried to crush the instrument between his teeth. After carrying it about, he would abandon it, take up something else, leave that, and return to the rattle again.

He was not easily put out of temper; but whenever this happened, he would evince his displeasure by a hoarse guttural sound, and by pouting the lips, while he looked intently and angrily at the offender. This expression was rendered more marked by the vivacity of his dark hazel eyes, which, though small and deeply set, were quick and penetrating.

A large snake was shown to him, on seeing which he became terrified, and hid in a corner. The lid of the basket, containing the snake, was then closed, and an apple placed upon it; but though he desired the fruit, he would not venture near the lurking-place of his dreaded foe, but by actions and gestures, too plain to be misunderstood, expressed his consternation;nothing, indeed, could induce him to approach the basket. The snake having been removed, the apple was placed upon a chair; when, after much cautious scrutiny and hesitation, he ventured to take the offered prize. From this experiment it has been concluded, that the chimpanzee has an instinctive fear of its enemy the snake; but as he regarded tortoises with equal aversion, the inference is not conclusive. It is not impossible, 
indeed, that the chimpanzee, although young, had seen in his native forests enough of the habits of the snake to cause him to cherish a hatred of it; and in the case of the tortoise, which had no power to inflict an injury, his consternation probably arose entirely from his never having seen such a creature previously, and being, therefore, in doubt whether it could hurt him or not. The fact of the chimpanzee receding from the snake has been adduced by Mr. Blyth, as an argument in favour of the theory which ascribes all the actions of animals to instinct or innate knowledge, and which denies that they perform any of them either from example or from experience. " Place," says he, " a juvenile chimpanzee in the presence of one of its natural enemies-a snake for instance-and it instinctively recoils with dread." But before any writer adduced such an illustration, it would have been well to have learned whether this dread is exhibited by the young chimpanzee soon after birth, and not infer that it is instinctive, because it is witnessed in one which has lived in the world some months, during which period it may have learned to shun its enemies, either from its own experience, or from observing that older individuals, of its own species, always avoided them. It it said, indeed, that this young chimpanzee showed a great aversion to soldiers, which has been attributed, and perhaps correctly, to the circumstance, that when he was captured his mother was shot by a soldier. Before he arrived in this country, he may have found that his child-like appearance rendered him secure in the presence of dogs, for he had no fear of one. In spite of the barking and snarling of a bitch of the Maltese breed, he would intrude upon her kennel, take up her puppies one by one, and after gravely examining them, replace them with the greatest care.

He would not drink beer or fermented liquors, but would take a cup of tea or milk; and, in imitation of our actions, gravely sip the contents, and then set the cup down with due propriety. When drinking he always protruded his lips into the cup, and then sucked up the fluid. In this way he would 
suck the milk out of a cocoa-nut, through a bole bored in the shell, which he held up with both hands. His food consisted of bread, fruit, and cooked meat. The gentleness with which he would receive a cake, and the deliberate manner in which he would eat it, would have been deemed good breeding in a child. In fact he was regarded and treated as a child. He used to be regularly combed, washed, and dressed; and he submitted to these toilet operations without a murmur or a struggle, but with perfect willingness.

His costume, a Guernsey jacket and cap, his marked countenance, which somewhat resembled that of the Connaught people, his human-like demeanour, his gentleness, and his intelligence, elicited the surprise and admiration of his numerous visitors. When sleepy or tired, Tommy (for that was his name) would retire to a corner of his cage, and there cover himself up with a blanket, fold his arms, bury his face upon them, and thus go to sleep. He died in April, 1836, deeply regretted by his proprietors, and a large circle of friends; and had, we believe, the distinguished honour of being dissected by four learned savans.

A young male chimpanzee was exhibited in the Egyptian Hall, Piccadilly, in 1831, along with a female orang-outan, of about the same age. The chimpanzee, though in a declining state of health, and rendered peevish and irritable by bodily suffering, displayed much greater intelligence than his companion. He was active, quick, and awake to everything that passed around him; no visitor entered or left the room without attracting his attention. Mr. Ogilby says, that on one occasion, while the chimpanzee's head was turned, his plate of potatoes and boiled chicken was stealthily withdrawn and secreted; but in a few moments he looked about for it, and not finding it, he began to pout and fret, till at length, seeing a young lady laughing near him, he flew at her with the greatest fury, and would probably have bitten her or scratched her, had she not got beyond his reach. When his plate was restored, he took care to hold it firmly with one hand, whilst he fed 
himself with the other. He was very cleanly in his mode of feeding, and always used his fingers to convey the food to his mouth. He was far advanced in that catarrhal complaint which never fails to carry off the ape after a few months' residence in our moist and variable climate; and though it was fine summer weather, he carefully wrapped himself up in his small blanket, as if aware of the benefit he derived from it. When forced to throw it aside for the purpose of showing himself to the company, the mild but expressive looks with which he reproached what he, no doubt, considered the harsh and cruel commands of his keeper, conveyed his feelings as plainly as if they had been expressed in the most eloquent language.

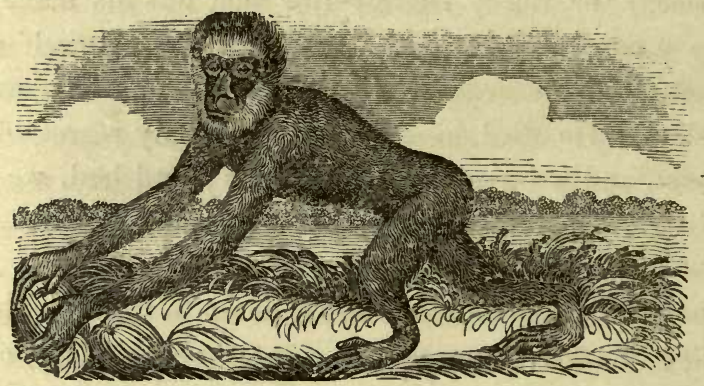

The UngKa-etam.-(Hylobates Raflesii.)

This species was discovered by Sir Stamford Raffles, and is said to be so scarce, that M. Duvaucel, who first made it known, saw nothing of it until he had been fifteen months zoologising in Sumatra; and it was only a short period before leaving the island, that he met with it in the neighbourhood of Padang. Mr. Ogilby, who has examined a fine specimen in the British Museum, and numerous others in the Museum des Pays Bas, at Leyden, gives the following description of this species:-

"The hair is thick, furry, and of an uniform glossy black colour, and assuming in certain lights a shade of deep brown, most conspicuous on the loins and outer face of the thighs, 
which are manifestly of a lighter hue than the rest of the body, and assume more of a pale coffee colour. The face is completely surrounded by a circle of white hair, narrow across the forehead, but expanded over the cheeks in the form of large bushy whiskers, and extending beneath the chin so as to unite the whiskers on either side. This circle, according to M. Duvaucel, is reduced in the female to a narrow white band across the forchead, the whiskers and chin being of the same black colour as the rest of the body; that sex is further said to be distinguished by the union of the index and middle toes of the hind-feet.

" The back of the hands and feet are of the same uniform black colour as the rest of the body; and judging at least from M. Duvaucel's figures, published in the Histoire Naturelle des Mammiferes, the face, palms, and soles, are dark blue, and the hair of the fore-arm reversed towards the elbow. It is distinguished from all other apes by having fourteen pairs of ribs; a fact which should teach naturalists to appreciate even slight external differences, since they may be accompanied by interior characters of so much importance."*

Sir Stamford Raffles merely informs us, that this animal is of a timid and gentle disposition.

\section{MONKE Y S.}

Monkeys have cheek-pouches, callosities, and very long muscular tails. They walk on all-fours, and spend the greater part of their time among the branches of forest trees, and they make great use of their long tails in directing their course and securing their equilibrium, during their rapid and varied movements. Waterton says, of the American monkeys, that " those with hairy and bushy tails climb just like the squirrel, and make no use of the tail to help them from branch to branch. Those which have the tail bare underneath, towards the end, find it of 
infinite advantage to them in their ascent and descent. They apply it to the branch of a tree as though it were a supple finger, and frequently swing by it from the branch like the pendulum of a clock. It answers all the purposes of a fifth hand to the monkey."

Monkeys are not, therefore, so well fitted for a terrestrial as an arboreal life; being pre-eminently adapted for a residence among trees. Hence they are found running, jumping, swinging, and even sleeping in the thick-growing forest trees of Asia. Africa, and South America, and in the greatest number in the tropical regions.

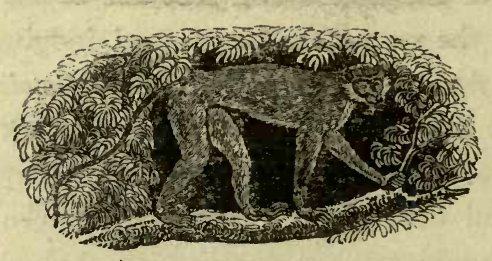

The Green, or Cape de Verd Monkey.

(Cercopithecus Sabcus.)

This species is only found in Senegal and the Cape de Verd Islands, in which places it is very abundant. It is very often seen in menageries, and bears our variable climate better than most other monkeys. It is from sixteen to eighteen inches in length, not including the tail, which measures somewhat more. It is a handsome animal, all the outer and upper parts of its body displaying a mixture of very dark green and brown, with a shade of deep yellow; the under and inner parts bright yellow; the neck and chest white. The face, which is of a triangular shape, is naked and jet black; above the eyes, is a straight line of stiff black hairs; and the whiskers, which are long, copious, and of a very beautiful bright orange colour, meet in a point beneath the chin. The ears, palms of the hands, and soles of the feet are hairless and deep black; the limbs and tail are long, of a lighter shade than the body, and the end of the tail 
has a small but not very conspicuous tuft of long yellowish hair.

The green monkey is more admired for its beauty and lively habits, than for its disposition. While young it is full of gaiety and good nature, but as it grows older it becomes captious and malicious. Yet like other monkeys, and even all animals, different individuals vary greatly in their disposition. M. F. Cuvier has described an adult specimen which was perfectly gentle and good-natured, fond of being scratched and petted by its acquaintances, seldom getting enraged or attempting to bite, and expressing its pleasure or contempt by a low gentle kind of purring noise.

Adanson, in his Travels in Senegal, has given the only account yet published, of its habits in a state of nature This traveller, who confesses that, for the sake of mere sport, he shot three-and twenty of these creatures in the course of one hour, informs us that within six leagues of Podor, on the landes (downs ?) to the south of Donai, otherwise called Coq, the country was very woody, and full of green monkeys, which he did not perceive but by their breaking the boughs and the tops of the trees, from whence they tumbled down on him; for, in other respects, they were so silent and nimble in their tricks that it would have been difficult to perceive them. He killed two or three of them before the others seemed to be much frightened; however, when they found themselves wounded, they began to seek shelter, some by hiding themselves behind the larger boughs, others by descending to the ground, but the majority by jumping from one tree to another. Nothing, he says, could be more entertaining, when several of them jumped together on the same bough, than to see it bend under them, and the hindmost drop down to the ground, whilst some got further on, and others were still suspended in the air. Although he shot so many, yet not one of them screeched the whole time, notwithstanding that they united in companies, knit their brows, gnashed their teeth, and seemed as if they meditated an attack on him. This statement of their silence is at variance with M. F. Cuvier's notice of the purring 
noise of his specimen; but it accords with a remark made by Mr. Ogilby, who says, that of the many specimens which he has observed in the Regent's Park Zoological Gardens and in other menageries, he does not remember to have heard any one attempt to utter a sound.

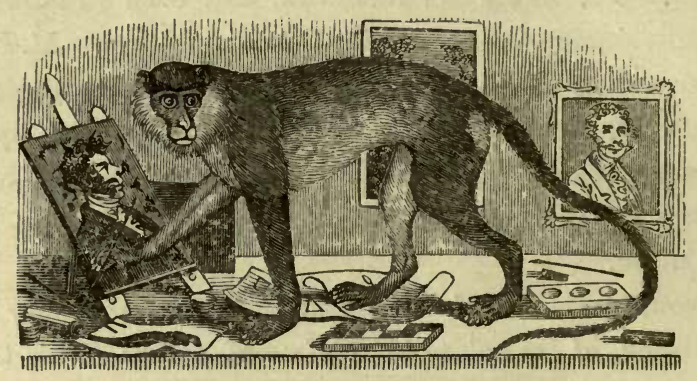

The Mona Monkey.-(Cercopithecus Mona.)

The mona monkey, which is less frequently seen in England than the preceding species, is a native of Guinea.

It is a very beautiful and graceful creature. The crown of its head is of greenish yellow tinged with black, and the neck, back, and sides are of a bright chesnut brown, extending downwards as far as the shoulders and haunches, whence the colour is dusky slate. The under surface of the body and the inside of the limbs are snowy white; the outer surface of the legs and thighs are speckled with black and grey; the hands and ears are of a livid flesh colour; the upper part of the face is naked and purplish; the lips and bare part of the chin are flesh-coloured; the whiskers are large, of a light colour with black rings, and nearly cover the cheeks. The eyebrows are surmounted by a black band, extending from ear to ear, and above this is a narrow grey crescent, which is sometimes scarcely perceptible; the tail is much longer than the body, and has on each side of its base, or on the hips, a conspicuous oval spot of most brilliant white, by which it may at once be distinguished from any other known species.

Naturalists are unacquainted with its disposition and habits in 
a state of nature. Fréderic Cuvier speaks very highly of its docility, gentleness, and intelligence in a state of confinement; but Mr. Ogilby says, that though the females and young males are at all times gentle and playful, he has seen adult males exhibit considerable caprice, and become as intolerant of familiarity as an aged green monkey.

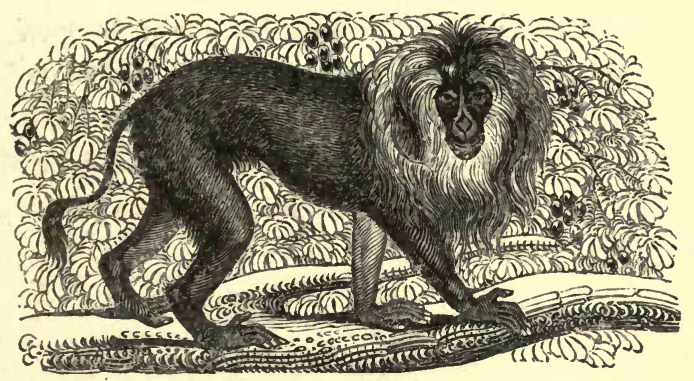

The Lron-tailed Monkey, or Wanderoo.-(Papio Silenus.)

This species, which is very often brought to England, is said to inhabit both the coast of Malabar and in the island of Ceylon.

Its hair is 'of a jet black colour throughout, except that which forms its long dense mane, which is of a white or greyish colour, and descends on each side of the face and extends over the chest, bearing resemblance to a judge's wig, and giving my lord chief justice Wanderoo a vast appearance of wisdom and importance, which, together with his habitual gravity, is often indescribably ludicrous. He has large cheek pouches, and flesh-coloured callosities of large size; a muzzle perfectly black; a tail about as long as the body, and terminating in a tuft of hairs.

Robert Knox, in his History of Ceylon (1681), says, that the wanderoos " do but little mischief, keeping in the woods, eating only leaves and buds of trees; but when they are caught they will eat anything." Mr. E. T. Bennett, writing in 1830, says that a specimen "which had remained for some months in the Zoological Society's Museum, then in Bruton-street, was extremely active, and occasionally very troublesome, but, at the 
same time, a perfectly good-tempered fellow. His favourite exercise appeared to consist in throwing himself, together with his chain, over the transverse bar which passed from pole to pole, and swinging himself backwards and forwards, while thus suspended, by his loins. When a party entered the room, he usually descended the pole with rapidity, and watched a favourable opportunity for jumping upon some of them unawares, and carrying off a hat or whatever else he might happen to seize, with which he instantly reascended the pole, and seated himself at the top, enjoying the success of his scheme. He was very strong, and had his teeth been fully grown, would in all probability have proved a dangerous animal; but he was too young to be seriously mischievous." *

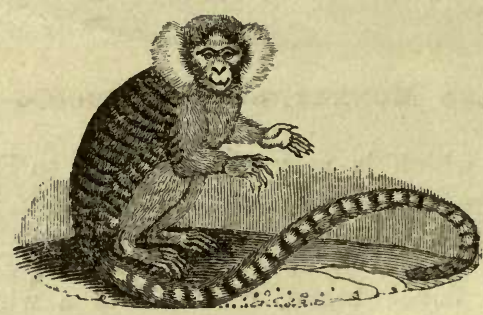

The Ouistiti, Striated Monirey, or Marmozet.

(Jacchus vulgaris.)

This pretty monkey, which is one of the smallest of the tribe, inhabits nearly every part of South America.

Its head and body together are hardly twelve inches in length; it has a very long tuft of white hairs before and behind the ears, which organs are large and very like those of man, but are nearly hid in the hair ; its face is naked and of a dull flesh colour; its body is beautifully marked with alternate bands of grey and brown; and its tail is long, bushy, and decorated with alternate rings of brown and white. It feeds on fruits, vegetables, snails, insects, spiders, and their eggs, and is said to be fond of fish.

* Zoological Society's Gardens Delineated (1831), vol.i. p. 24. 
A pair of these monkeys bred in the menagerie of the Jardin des Plantes, at Paris. On April 27, 1819, the female brought forth three young ones, a male and two females. They instantly embraced their mother and hid themselves in her fur. However, previously to their sucking, she cruelly deprived one of them of life, and tore its head off. The two others took the breast, and from that moment she bestowed on them the natural attentions of a mother, and her cares were shared by the father. When the mother was tired of carrying the young ones, she would approach the male, and utter a little plaintive cry, when he would immediately take them and place them under him, or on his back, where they held fast, and thus he would carry them about until they showed uneasiness for want of food, when he returned them to the mother, who, after satisfying their wants, got rid of them again as soon as possible. The care of the young devolved principally upon the father, their mother not evincing for them that degree of tenderness and affection so usual in the females of most species.

Mr. Gavin Milroy published, in May, 1828, the following account of the habits of a marmozet, which he purchased in the previous June at Bahia, the capital of the province of San Salvador, in Brazil. "At first he was exceedingly fierce and wild, screeching most vehemently when any one dared to approach him. I was about to sail for England, and took him with me on board of our vessel immediately. I laid in a few oranges, bananas, mangoes, and Indian corn, to feed him with during the voyage. A little kennel or box was made, wherein he slept or retired when frightened. It was long before he was so reconciled, even to those who fed him, as to allow of the slightest touching or patting of his body; and it was almost impossible to do this by surprise, or by the most quiet and cautious approach, as he was not steady a moment, but was constantly turning his head round from side to side, eyeing every person with the most suspicious and angry look : his sense of hearing appeared to be excessively acute, so that the slightest whisper was sure to arouse him. His voice was peculiarly sharp and disagreeable, consisting of a very quick 
succession of harsh and shrill sounds (imitated in the name ouistiti), so loud, that they might be heard from the remotest part of the ship. For a considerable time there was no evident change in his habits, as he continued to be nearly as wild as when I first got him, and showed none of the playfulness and vivacity which characterize most of the monkey tribe.

"As long as the fruits which we had on board lasted, he would eat nothing else; but when these failed, we soon discovered a most agreeable substitute, which he appeared to relish above everything. By chance we observed him devouring a large cockroach, which he had caught running along the deck of the vessel; and from this time to nearly the end of the voyage, a space of four or five weeks, he fed almost exclusively on these insects, and contributed most effectually to rid the vessel of them. He frequently eat a score of the largest kind, which are two inches or two inches and a half long, and a very great number of the smaller ones, three or four times in the course of the day. It was quite amusing to see him at his meal. When he had got hold of one of the large cockroaches, he held it in his fore-paws, and then invariably nipped the head off first; he then pulled out the viscera, and cast them aside, and devoured the rest of the body, rejecting the dry wing-cases and wings, and also the legs of the insect, which are covered with short stiff bristles. The small cockroaches he eat without such fastidious nicety. In addition to these he was given milk, sugar, raisins, and bread crumbs. Hitherto, the weather was warm, the thermometer never being below $65^{\circ}$ or $60^{\circ} \mathrm{Fahr}$.; but as we reached a more northern latitude, and approached England, the change of temperature affected him very sensibly : his appetite failed very considerably; and now he would not even touch the cockroaches when given to him : the hair, especially that on the tail, fell off; and, at the end of the voyage, this organ was almost entirely bare and naked. He kept constantly in his kennel, rolling himself up in a piece of flannel, which had been put in for warmth, except when he could reach a sunny part of the deck, where he might bask in the heat. There was a long continuance of cold north-easterly winds, the ther- 
mometer as low as from $42^{\circ}$ to $36^{\circ} \mathrm{Fahr}$; and the monkey eat little or nothing, and was quite inactive.

"When I got him ashore, I kept him for some days in a warm room; he gradually recovered his nimbleness, running about the room, and dragging his kennel after him. Even then he would not eat any insects, and his food consisted of milk and bread-crumbs; he was particularly fond of any sweet preserve, as jelly, \&c., and of fresh ripe fruits. From London I brought him with me to Edinburgh last November, and have kept him here till now (May, 1828). During all this time he has thriven perfectly well; he is considerably plumper than he was, and his tail is now completely covered with long darkish hair. Linnæus says this animal is a great enemy to cats; so far, however, is this from being the case with the present one, that he feeds and sleeps with the cat, and they are on the best terms imaginable.

"Though now much tamer than he was, he is by no means tractable or docile; he will allow himself to be patted, or gently stroked, but all attempts to handle or play with him are quite unsuccessful. When teased or enraged, he exhibits a most ludicrous physiognomy of passion; the white hairs on his cheeks are erected; he grins and shows his teeth; he dilates his nostrils, and his little eyes beam with the most passionate fury. Though he does not possess any of that imitative playfulness, which is so amusing in many of the monkeys, there is a something, an air of intelligence, a look of observation, which we search for in vain in animals lower in the scale of animated nature."*

The most extraordinary account I have met with respecting this species, is the following from the fifteenth volume of the Mirror:- "On February 21, 1830, died, much lamented, Jenny, a favourite ring-tailed monkey, aged thirty-seven years. She was brought to England from Oporto, by Mr. George Holland, of Great Bircham, Norfolk, in whose family she

\footnotetext{
* Abridged from the Magazine of Natural History, vol. i. p.18.
} 
resided several years, and afterwards (and till her death) in the family of Mr. Pullyn, of Beccles, Suffolk, where she lived twenty-two years; her sagacity and engaging manners attracting the notice of every one. In 1814 she removed with them to Yarmouth, and then appeared first to suffer from change of climate; and, indeed, it will hardly be credited the extreme heat she could endure, and, apparently, enjoy; for the last seven or eight years of her life, sitting or lying almost constantly at the back of the kitchen-range, where it is probable a small saucepan would have boiled; she was often observed to lie on the top of the fire itself when fresh coals had been put on, and to warm her hands and arms by clasping them round a kettle of boiling water. Her hair, which in her youth was very beautiful, and had a fine musky perfume, was entirely destroyed, and her skin so much scorched and hardened by the excessive heat, that in cold weather she would frequently lay hot cinders, which she took from the fire, on her head, and suffer them to roll slowly down her back. She was particularly fond of eggs, and would, if they were left on the fire, take them out of the water when boiling, and eat them very quickly, from a dread of being caught in the theft. A remarkable instance occurred, from which it would appear that she must have sensibly felt, and also remembered a chiding, for no harsher means were ever used to correct her. She was one day very troublesome, and inclined to purloin some eggs boiling on the fire, when she was threatened by the servant, with having her hands scalded if ever she committed the fault again; and she never afterwards attempted to touch one, though frequently left near her, nor was she ever known to beg for them in her customary way of clapping her hands, though she gladly received them when offered. In short, it is impossible to give an accurate description of the apparent knowledge she possessed, without seeming to exaggerate. She endured great suffering for a week previous to her death, and her illness was as remarkable as her habits when in health. She was first attacked with a restless motion as if catching flies, and holding them very 
closely in her right hand, the fingers of which were so contracted, that it was believed, from the agony she felt, that she had eaten them off; nor was it till after her death that the tips of her nails could be discovered, and they appeared as if slipped into the palm of her hand. Until the last moment of her existence, she was, to an affecting degree, sensible of, and particularly grateful for, any kindness and attention shown her; in fact, her manner was such as almost to make one doubt that it was an inferior animal to oneself that was claiming attention; and she often looked despairingly and intently at her poor hand, and endeavoured much to use the other, which appeared to be so inconvenient to her that she was obliged to be fed. She was buried in the garden adjoining the house where she died, and was honored with an epitaph."

Some years ago, a beautiful specimen of the marmozet might be seen in a sort of doll's house, placed outside a parlour window on the Clapham Road, near the Common. I have often stood to watch the movements of this little fellow in his house, which was fitted up in an elegant style, having, as I remember, chairs, tables, and every other convenience which is generally found in the dwellings of mankind. The most amusing sight was to see him before his looking-glass, in which he seemed either to be admiring himself and studying attitudes, or else imagining that he beheld another of his own species. He appeared to be very tame and gentle.

\section{B A B O O N S.}

Baboons possess cheek-pouches and callosities, but short tuberculous tails, never extending beyond the houghs, deficient in muscular power, and incapable of assisting in progression. They are seldom, if ever, found in forests; but live among rocks and mountains, and walk on all-fours.

They are very ferocious and powerful animals; and, while the apes and monkeys possess some resemblance to mankind, 
the baboons remind us more of brute animals, by their appearance and manners.

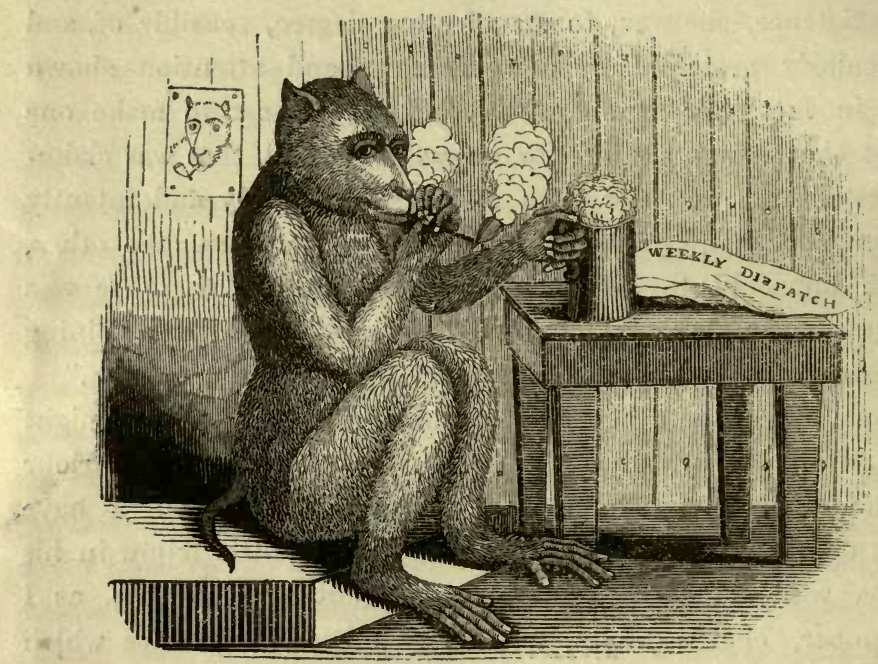

The Dog-faced Baboon, or Derrias.

(Cynocephalus Hamadryas.)

This species inhabits the mountains of Arabia and Abyssinia, and when full grown it is four feet high when standing upright, and two feet and a half when sitting. Its face is very long, hairless, and of a dirty flesh-colour, with a lighter ring encircling the eyes. The hair of the head, neck, and fore part of the body, is a mixture of light grey and ashy brown, each hair being marked with several alternate rings of those colours; the hair of the hips, thighs, and extremities, is of a brown colour; and there is an almost hairless patch on each side of the callosities, which are large and of a dark flesh colour; the palms and soles are dark brown.

"When these animals arrive at their full growth and mature 
age, that is, after they have completed their second dentition, they undergo a great change in their mental disposition as well as in their physical appearance. While young they are gentle, docile, and playful ; but as soon as they have acquired their full development, they become morose, sulky, and malicious. Hemprich and Ehrenberg found large troops of them in Wadi Kanun, and the mountains near the city of Gainfud, in the country of the Wahabees, as well as in the mountains above Arkeeko, on the Red Sea; and we learn from Salt and Pearce, that they are extremely common on the high lands in Tigre. The travellers above-mentioned found troops of a hundred and upwards in the neighbourhood of Eilet, in the chain of the Taranta. These were usually composed of ten or a dozen adult males, and about twenty adult females, the remainder of the troop being made up of the young of the four or five preceding years. When seen at a short distance, approaching a small stream for the purpose of quenching their thirst, they bore a close resemblance to a flock of wild hogs; and it was observed that the young ones always led the van, whilst the old males brought up the rear, probably for the purpose of having the whole family continually under their immediate inspection. They did not appear to pay the slightest attention to the Gallas and Abyssinians ; but when the European travellers approached, whom they probably mistrusted from the appearance of their fire-arms, the old males abandoned their station in the rear, and placed themselves between the troop and their enemies, so that it was found extremely difficult to procure specimens of either the females or young. When they first observed the travellers approaching, they all stood upon their hind legs to examine them; the old males, having driven away the females and young ones, remained in this position till the near approach of the party compelled them also to retire, when the whole troop scampered up the sides of the mountains, making them resound with their shrill clamour."*

In the Tower menagerie, now broken up, there was a large * Menageries (1838), vol. iii. p. 430. 
specimen of the dog-faced baboon, which exhibited an extraordinary resemblance to humanity in form, appearance, and manners; the right arm especially might have been, at first sight, mistaken for that of a brawny blacksmith or pugilist, had it not been for its hairy covering, and the somewhat unusual length of the fingers. His attentions to a dog which used to visit his cage, were in the best style of dignified patronage; nor did the dog recognise any difference between the pat of his hand and that of a man. Like many dignified folks, however, his habits were not very refined, and his greatest enjoyment consisted in immoderate potations of porter. Indeed, his porter carried him to his bier, for he died from excessive drinking, in the year 1828 .

\section{E M U R S.}

Lemurs are chiefly found in the island of Madagascar, where they appear to be the representatives, or substitutes, of the monkey tribe. From their pointed heads and monkey-like appearance they have been called Fox-nosed Monkeys. "Their hands and feet are," says Mr. E. T. Bennett, " equally well-formed for grasping with those of the monkeys, to which they approximate very closely in the more essential points of their internal structure; the forefingers of the posterior extremities have long subulate claws, while the nails of all the other fingers are flat; their eyes are large and directed forwards; and their nostrils terminate in a naked muzzle. None of the group exceed two feet and a half in length exclusive of the tail ; and the greater number of them are scarcely more than half that size."

Not much is known of their habits in a natural state. They are said to congregate in great numbers upon the trees, and to subsist on fruits and insects. In captivity they are observed to be exceedingly tame, fond of being noticed, and constantly 
climbing and leaping with surprising agility; and, being of a chilly nature, they delight in basking in the sunshine or the warmth of a fire. When undisturbed, however, they roll themselves up into the form of a ball, and, with their long tails wound round their bodies, sleep in this position during a great portion of the day.

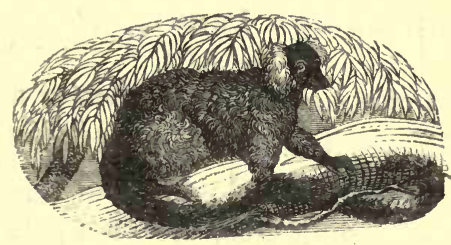

The Red Lemur.-(Lemur ruber.)

This is one of the most beautiful and, certainly, the rarest species of lemur hitherto discovered.

It measures more than two feet from the nose to the base of the tail, which appendage is itself longer than the body. The back, the sides of the body, the sides of the face, the ears, and the outer surface of the limbs, are of a bright reddish brown; the forehead, the face, the throat, the breast, the belly, the inside of the limbs, and the entire feet are of a deep black, except where a narrow stripe of white crosses over the hinder feet. On the back of the neck is a large oval patch of white, extending from behind the ears to between the shoulders. The naked face and hands, the moustaches, and the long tail are perfectly black. The hair of the upper parts of the body and tail is extremely long, soft, and woolly; the dark fur underneath is shorter and close. The eyes are lively and expressive, and their irides are of a lighter yellow than those of the other species of lemurs. 


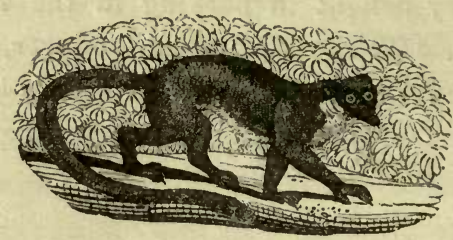

\section{The BLaCK-Fronted Lemur.-(Lemur nigrifrons.)}

The upper parts of the body of this species are of a dark ashy colour; the outside of the limbs is of a lighter grey; the chin, throat, and chest are pure white; the under parts of the body, and the inside of the hind legs, are of a pale red; the face is black, and the hair on the forehead and sides of the face is short, smooth, and even; the hands are blackish; and the tail is light grey at the base, and darker towards the tip.

In confinement, the black-fronted lemur is perfectly tame, good tempered, and very agile. 


\section{ORDER-CARNARIA. FAMILY-Che्रrifoptera.}

\section{B A T S.}

When the situation of an animal in a classification was decided by a fanciful comparison of its exterior and general appearance to that of other creatures, or at best by a hasty and unscientific inspection of it, the bat gave rise to much discussion respecting the place that ought to be assigned to it. Pliny, Gesner, and many other writers placed it among the birds, merely because it flies through the air. But this class could but ill contain an animal which has neither feathers, beak, nor gizzard, builds no nest, and lays no eggs. What are called the bat's wings, which led to this improper idea of its nature, are nothing more than a large, expansive, and collapsive membrane connecting its long, thin fingers, and united to the body of the animal, whose hindfeet are quite unconnected with the membrane, and possess five toes, furnished with claws. The aërial motion of the bat can hardly be called flying, but is better described by the word fluttering, and hence its name of flutter or flitter-mouse.

The bat's thin and delicate membranes possess great sensibility to the slightest diversity of temperature at different distances from surrounding objects, and this faculty probably forewarns it of, and protects it from encountering, any objects which otherwise might prove obstructions to it, during its rapid and apparently careless evolutions. The air that surrounds a body warmer than the prevailing temperature of the great mass of air, will partake of that warmth, while if it surrounds a cold body it will become cold; and these changes of temperature, slight as they are, seem to be readily felt by the sensitive membrane of the bat, which, profiting from the hint, steers a middle course. The 
experiments of Spallanzani proved that bats possess some such faculty as that I am led to attribute to them; for, having deprived some specimens of the use of their eyes, he found that even then they flew about and avoided, with as much adroitness as ever, any objects which were placed in their way.

Though it is usual for bats to fly only in the evenings, yet they have been occasionally seen, and even shot flying in the broad day; and though they become torpid during the winter, yet a mild evening occurring during that season, will summon them forth to feast on the insects which it has also invited to emerge from their lurking places.

On the thumb of the fore-feet (or wings, as they are improperly called) is a small toe or claw, by means of which they can creep, and suspend themselves to the sides of walls, caverns, the hollows of trees, \&c. ; their hind-feet are disengaged from the membrane, and have five toes, almost always of equal length, and armed with nails; their eyes are very small: the ears of some species are very much dilated.

The flying membrane often serves as a cloak to envelope the animal itself, or to keep the young warm and close to the breast; and the posterior portion of the membrane is bent forward by the female, so as to form a kind of cradle to receive her young as they enter into the world. They have (according to most zoologists) generally two young ones at a birth, which they keep attached to their teats, even when flying, and whose size is considerable in proportion to that of the mother.

In Britain, seventeen species of bats are found, which, as well as all the other European species, are strictly insectivorous. 


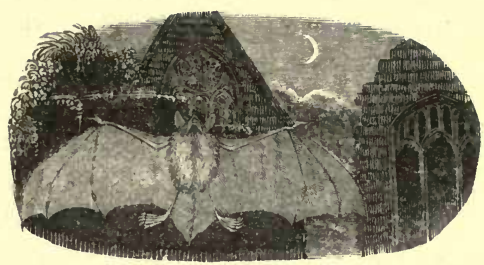

The Pipistrelle, Common Bat, Flutter-mouse, or Rere-mouse.-(Vespertilio pipistrellus.)*

The common bat is two inches and three-quarters in length from the head to the tail, and eight inches and one-third in the extent of its membranes. Mr. Jenyns says, that in young specimens the fur is entirely of a dusky brown or brownish grey, in some instances almost black, without any tinge of red, which appears to come afterwards, and to increase in intensity with the animal's age and size.

During the warmer season of the year, this bat comes forth every evening; but during the severity of winter, it remains in a state of torpidity.

The usual places of retirement, during the day-time, of those bats which fly about our dwellings, are under the roofs of houses, or behind the leaden water-pipes, or in the crevices of old brick walls; but those which live in unpopulated places remain, during that time and the winter, in the hollows of old trees and in caverns. That they conceal themselves naturally in the hollows of trees would be proved, in the absence of all other evidence, by the circumstance of their having been often found dead inside timber when it has been sawn through. Mr. Jesse says, that ten bats were found some time since in an old tree

* In most zoological works, our common bat is erroneously ealled the Vespertilio murinus of Linnæus, which, in fact, is very rare in Britain (having been caught only in the garden of the British Museum), although it is common on the Continent. The Rev. L. Jenyns, a zealous and acute zoologist, has satisfactorily proved, however, that the common bat of Great Britain is the Vespertilio pipistrellus, described by Geoffroy, Desmarest, Daubenton, Buffon, Kuhl, and other foreign naturalists.-J. H. F. 
in Richmond Park. Great numbers of bats repose in the natural caves in mountains and rocks, a situation in which Homer notices them:-

"As in the cavern of some rifted den,

Where flock nocturnal bats and birds obscene;

Cluster'd they hang, till, at some sudden shock,

They move, and murmurs run through all the rock."

In Egypt they not only inhabit caves, but also the subterranean excavations which were made by the ancient Egyptians. Mr. Davison, when descending a well in one of the largest pyramids at Djizeh, in Egypt, disturbed a multitude of bats; and when exploring a passage in the same pyramid, he was obliged to retire, owing to its being, in a great measure, choked up with bats' dung, which in some places was nearly a foot deep; and when Mr. Caviglia, some years afterwards, pursued the same path, their dung had increased to the depth of a foot and a half.

Though the night is the proper or usual time for the bat's flight, yet it has been seen more than once flying in the daytime. Gilbert White records his having seen a bat flying after insects, during sunshine, on the 27 th of July; and expresses a suspicion that it was a female, which was, perhaps, hungry from feeding her young. He also notices that the swallows struck at it,-which, I may add, is not surprizing, for they strike at owls also, and probably from the same reason. Mr. Gould shot a common bat in the middle of a bright, sunny, but frosty day, just before Christmas; and Dr. T. B. Salter says, that on March 6,1838, during a bright sunshine, at one o'clock, he observed one flying about in search of food in a garden at Poole, in Dorsetshire.

What the swallow is among birds the bat is among mammals; and while the day is the period for the former to chace the insects, the night-time is the period for the bat to pursue them; and should he reverse this arrangement by daring to encroach upon her airy way, she is perfectly justified in striking at him, to teach him to know his proper time and season. When the swallow has ceased her elegant flight after the insects that sport 
in the bright rays of the sun, it was intended that the bat should come forth, to continue the war where she had left off,- -and, with equal ardour, pursue and lessen the number of those that fly and dance in the moon-beams. Indeed, it might almost be received as an unexceptionable axiom, that whatever office is fulfilled by an animal of any particular class, nearly all the other classes contain some species which afford good and efficient assistance in performing the same task, though the mode and time for going about it may differ materially. Still, however, the work is done in every place and at every hour; thus, the air is cleared from the swarms of tormenting insects by the bat, the swallow, the carp, the toad, the dragon-fly, and the spider, while the earth is swept clean from dead or decayed matter by the hyæna, the vulture, the shark, the crocodile, the crab, the carrion-beetle, and the slug.

"During its winter torpidity," says Captain Brown, "the circulation of its blood is so slow, that its motion is hardly perceptible. From some experiments of Spallanzani, it would almost appear that a total suspension of vital energy takes place in animals, during this state of torpor, for he kept a torpid bat four hours in carbonic acid gas, the thermometer marking twelve degrees; yet it continued to live in this gas, which is so very deleterious, that a bird and a rat, which he exposed to its influence at the same time, perished instantaneously."*

"It makes its appearance, after its short period of torpidity, as early as the middle of March, and does not wholly retire into a state of undisturbed hibernation until the winter has decidedly set in: its torpidity, therefore, can hardly be said to continue more than from two to three months. Their final retirement does not depend exclusively upon temperature; for although before the severe frosts set in, they continue to fly even when it is below the freezing point, they do not again appear until the above time, notwithstanding the thermometer, as Mr. Jenyns has observed, may have often risen considerably above $50^{\circ}$ Fahrenheit. This peculiarity is of easy solution. The bat's

* Sketches and Anecdotes of Quadrupeds (Glasgow), 1831, p. 97. 
fondness for different species of gnats has been observed even from the earliest period [from the time of Pliny]; and from the diminutive size of the pipistrelle bat, it is probable that they are its principal food. These, and many other dipterous insects, after having disappeared during the ungenial fogs and rains of the close of autumn, often appear again in smaller numbers, on every fine, warm day, until the severe cold of the depth of winter finally destroys the greater part of them.* The same impulse of hunger equally accounts for its appearance in the day-time at this period of the year, as it is only at that time that the temperature is sufficiently elevated to summon into temporary activity its insect food." $\dagger$

I am generally first led to notice bats by hearing the sharp snapping noise they make while they fly about, and which I can compare to nothing so aptly as the noise which accompanies an electric spark. Perhaps, as in the case of the swallow, this snapping noise is caused by the act of shutting the mouth quickly when it has seized its victim.

It is a very common notion, that if a bat be placed on a table, or other smooth surface, it cannot raise itself into the air therefrom, owing to the table preventing it flapping its wings below the plane of its own body; and, doubtless, in, this case, when the action of them is thus obstructed, it is not always that they can succeed in doing so. I have once or twice seen a bat remain on a table, and use its wings ineffectually; and Geoffroy says, that the present species is sometimes found on the ground, exhausted with ineffectual efforts to resume its flight, from its not being able, in such a predicament, to fall upon the air and freely expand its wings. It may, however, have happened that these specimens were previously enfeebled, and that others, in perfect

* "Mr. John Greig, author of the Heavens Displayed, saw a bat flying about in February, in England, during a very hard frost and deep snow."White's Natural History of Selborne, edited by Captain Brown, p. 28. Dr. T. B. Salter says, that while he was riding from Brading to Ryde, in the Isle of Wight, at about half-past five in the evening of February 23, 1839, the weather being warm and serene, he observed three bats flying about.-J.H.F.

+ Bell's British Quadrupeds, p. 25. 
health and strength, might have easily accomplished this feat. At any rate it must not be supposed to be a thing impossible for a bat to perform, for Professor Bell assures us, that he has often seen this species rise from a plain surface with a sort of spring, instantly expand its wings and take flight, and that one which he kept did so repeatedly in the course of an hour, and without the slightest appearance of difficulty or effort, and expresses his conviction, that it is a natural and usual action, and adds that he has observed the same habit in the reddish-grey (V.Nattereri), and in the long-eared bat (Plecotus auritus).

The common bat runs along the ground in an almost prostrate position, and climbs with more ease and celerity than would be expected. Professor Bell, whose account of our native bats contains many interesting and novel observations, notices that " a small portion of the tail is produced beyond the margin of the interfemoral membrane. Not only does the animal employ the tail in horizontal progression-in which case it assists in throwing forward the body, by being brought into contact with the ground on either side alternately, corresponding with the action of the hinder foot on the same side, - but in ascending and descending a rough surface, this little caudal finger holds by any projecting point, and affords an evident support. This is particularly conspicuous when the bat is traversing the wires of a cage."

Gilbert White mentions a tame bat which would take flies out of a person's hand, and exhibited great adroitness in shearing off their wings, which it always rejected. When given anything to eat, it brought its wings round before the mouth, hovering and hiding its head-as predacious birds do when they feed. Insects seemed to be most acceptable, though it did not refuse raw flesh when offered it. Indeed the bat is so fond of meat, that it will sometimes enter a larder, cling to a joint, and make a hearty supper upon it. Mr. Thomas Scandrett informs me, that the children in Worcestershire repeat the following rhyme while they throw their hats up at the bat : -

Leather-wing bat,

Come under my hat, And I'll give you a rasher of bacon. 
It is, indeed, a popular notion, and perhaps not an unfounded one, that bats will descend chimneys and gnaw the bacon and other meats, suspended there to be smoke dried.

Bats are said to drink on the wing by sipping the surface of pools or streams, in the same way as swallows do,

From the time of Pliny, till recently, bats have been reported to produce two young ones at a time; but four females of the great bat ( $V$. noctula) and five of the present species, which were procured by Mr. George Daniell, had only a single one.

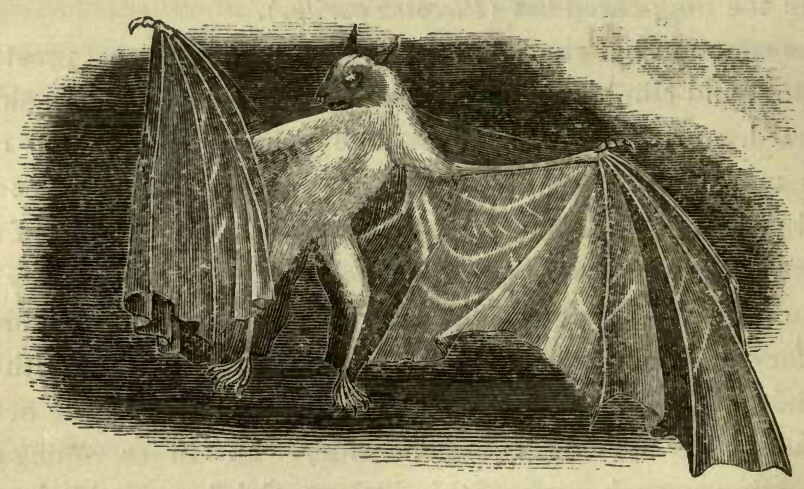

The Spectre, or Vampire Bat.-(Phyllostoma spectrum.)

All the species of the genus Phyllostoma are natives of America. They differ from our bats in several respects, but especially in the tongue, which is very extensible, and terminates in papillæ, which appear to be so disposed as to form an organ of suction.

In the places they inhabit they seem to be very abundant. Mr. Foster tells us, that he has seen as many as five hundred hanging, some by their fore-feet and others by their hind-feet, to a large tree in one of the Friendly Islands ; and about twenty thousand are said to have been seen within the space of a mile at Rose Hill, New South Wales. The author of Notes of Voyages made from Canton in the Ship Morrison (New York, 1839), says, the Burmese bats, which are as large as a crow, with a head shaped like that of a dog, and a thick long tongue, well adapted 
for extracting the juices of fruit, live in society about some spot where there are two or three tamarind trees, from which, during the day, they hang in crowds, rank and file, uttering a loud noise in concert.

The food of the vampire bats appears to differ according to the species, some feeding chiefly on fruit, and others on small birds and mammals. M. de Condamine says, the vampires are a scourge to most of the hot countries of America, and that they suck the blood of horses, mules, and even men, when not guarded against by sleeping under the shelter of a pavilion; and he asserts that, in his time, they had even destroyed at Barja, and several other places, the breed of great cattle introduced there by the missionaries.

The common vampire bat of South America is of a reddish brown colour; its body is about six inches long, and the extent of its wings is upwards of two feet.

It is said to suck the blood, not only of animals but of men, and sometimes to such an excess that they die the victims of its gratuitous phlebotomy; but Cuvier remarks, that the truth appears to be, that it merely inflicts very small wounds which may sometimes inflame, and become gangrenous from the influence of climate. Captain Stedman, who travelled in Surinam, from 1772 to $177 \%$, relates, that on awaking in his hammock about four o'clock one morning, he was extremely alarmed at finding himself weltering in congealed blood, but without feeling any pain whatever. "The mystery was," says he, " that I had been bitten by the vampire, or spectre of Guiana, which is also called the flying dog of New Spain. Knowing by instinct that the person they intend to attack is in a sound slumber, they generally alight near the feet, where, while the creature continues fanning with his enormous wings, which keeps one cool, he bites a piece out of the tip of the great toe, so very small, indeed, that the head of a pin could scarcely be received into the wound, which is, consequently, not painful; yet, through this orifice he sucks the blood until he is obliged to disgorge. He then begins again, and thus continues sucking and disgorging, until he 
is scarcely able to fly, and the sufferer has often been known to pass from time to eternity. Cattle they generally bite in the ear; but always in places where the blood flows spontaneously. Having applied tobacco ashes as the best remedy, and washed the gore from myself and hammock, I observed several small heaps of congealed blood, all round the place where $I$ had lain upon the ground; on examining which, the surgeon judged that I had lost, at least, twelve or fourteen ounces of blood." *

Waterton says there are two species of vampires in Demerara; that the smaller one confines its attacks chiefly to birds, while the larger one sucks men and other animals. "I could only find," says he, "two species of bats in Guiana with a membrane rising from the nose. Both these kinds suck animals and eat fruit; while those bats without a membrane on the nose seem to live entirely upon fruits and insects. While I was passing a day or two at the house of Mr. Walcott, who lived high up the River Demerara, the vampires sucked his son, who was about ten or eleven years old, some of his fowls, and his jackass. The youth showed me his forehead at daybreak : the wound was still bleeding apace, and $I$ examined it with minute attention. The poor ass was doomed to be a prey to these sanguinary imps of night; he looked like misery steeped in vinegar. I saw by the numerous sores on his body, and by his apparent debility, that he would soon sink under his afflictions. Mr. Walcott told me that it was with the greatest difficulty he could keep a few fowls, on account of the smaller vampire; and that the larger kind were killing his poor ass by inches. It was the only quadruped he had brought up with him into the forest. Some years ago I went to the river Paumaron, with Mr. Tarbet, a Scotch gentleman. We hung our hammocks in the thatched loft of a planter's house. Next morning I heard this gentleman muttering in his hammock, and now and then letting fall an imprecation or two, just about the time he ought to have been saying his morning prayers. As soon as there was light enough, I went to his hammock, and saw it much stained with blood. 'Here,' said he,

* Narrative of an Expedition to Surinam (1806). 
thrusting his foot out of the hammock, 'see how these infernal imps have been drawing my life's blood.' On examining his foot, I found the vampire had tapped his great toe. There was a wound somewhat less than that made by a leech. The blood was still oozing from it, and I conjectured he might have lost from ten to twelve ounces of blood."* He adds, that he never could discover how the vampire actually draws the blood, although he has repeatedly seen men and beasts who had been sucked by it. To ascertain its modus operandi, he put himself in the way of it repeatedly; but it would not accept the invitation held out by his feet. He slept in the loft of a house in the forest for eleven months, and the vampire flew into the place every night, and often hovered over his hammock, yet never condescended to touch him, but seemed to have a personal dislike to him, though it would tap the toe of an Indian, who slept in a hammock within a few yards of him.

The vampire of India is a species distinct from those of South America. "I have never yet seen," says Waterton, "a bat from India with a membrane rising perpendicularly from the end of its nose ; nor have I ever been able to learn that bats in India suck animals, though I have questioned many people on the subject." Bishop Heber says that "the vampire bat of India is a very harmless creature, of habits entirely different from the idea entertained of it in England. It only eats fruits and vegetables, and, indeed, its teeth are not indicative of carnivorous habits; and it turns away from blood when offered to it. During the daytime it is, of course, inert; but at night it is lively, affectionate, and playful, knows its keeper, but has no objection to the approach and touch of others."

In July, 1839, the Surrey Zoological Gardens contained a living specimen of the Indian vampire-a young male from Sumatra. It was entirely black ; its wings were nearly two feet in extent; and its tongue was long and pointed. Cuvier says the vampire bats run on the ground more easily than other bats; yet this specimen was never seen even to descend to the floor 
of its cage, but susperided itself from the roof or bars, head downwards, with its wings wrapped round its body. Its appearance was by no means ferocious. It was active yet docile, and while in the Gardens it used to devour cherries.

The British Museum contains specimens of the true bloodsucking bats (Glossophaga ecaudata) from Brazil; the vampire bat (Phyllostoma spectrum); the Egyptian bat (Pteropus AEgytiacus); the striped-eared bat ( $P$.marginatus) from India; and the Kiodate bat $(P$. rostratus) from Java: and the three last mentioned are not " carnivorous sinners," but fruit-eaters. 


\section{ORDER-CARNARIA. FAMILY-Insectivora.}

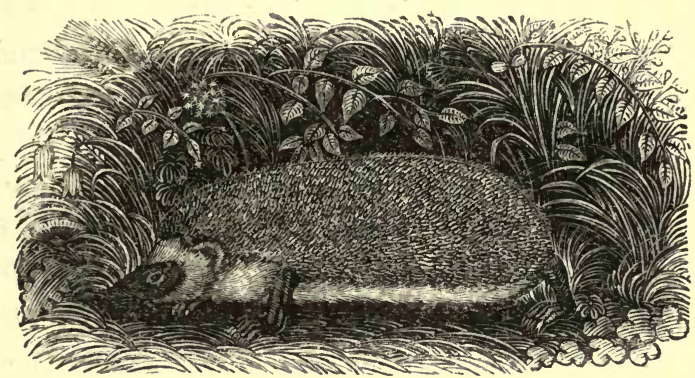

The Hedgehog, or Urchin.-(Erinaceus Europaus.)

The hedgehog inhabits most of the temperate countries of Europe. It is found throughout England; in Donegal,* and probably other counties of Ireland. Mr. George Duncan says it is found in Renfrewshire, in Scotland; $\dagger$ but a well-known newspaper, $\ddagger$ edited by a Scotchman, stated some few years ago that the hedgehog is seldom seen so far north as Elgin, and then only in caravans.

It is about eleven inches long, from the nose to the end of the tail, which is so concealed by its spines or bristles as to be scarcely visible; the whole upper part of its body and sides are closely covered with strong sharp-pointed spines of an inch in length; its mouth is small but well furnished with teeth; its eyes are small and placed high in the head; and its ears are short, broad, and rounded. Dr. Farrar says, that many sportsmen and gamekeepers have assured him that the hedgehog's sense of hearing is very acute; but adds, that when they have been closely pressed, as to whether or not its alarms are received through the organs of vision or. hearing, they seemed doubtful.

* Magazine of Natural History, vol. v. p. 579.

† Ibid. p. 571.

$\ddagger$ Morning Advertiser, August 20, 1830. 
Mr. John Denson, sen., says however, that one evening, when his hedgehog was running about the room, his clock commenced striking the hour and with considerable intervals between each stroke. At the sound of the first stroke the hedgehog contracted itself, as if in fear; before the next stroke was sounded, the hedgehog had partly relaxed itself; but at the sound of the stroke, it again contracted; and so on with the successive strokes.

The hedgehog generally lies concealed during the day, among the grass or fallen leaves at the bottom of hedge-rows or thickets, which it leaves at night for the purpose of seeking food and society. Shakespeare, whose immortal works are replete with zoological observations, is probably the first writer who notices that the hedgehog utters a whining cry at night-time :-

"When they show'd me this abhorred pit,

They told me here, at dead time of the night,

Ten thousand- urchins,

Would make such fearful and confused cries,

As any mortal body, hearing it,

Should straight fall mad, or else die suddenly."

(Titus Andronicus, ii. 3.)

And he makes one of the witches in Macbeth (iv. 1) remark that " the hedge-pig whines" at midnight. This appears to be correct; for persons who have kept tame hedgehogs assure me that they run about at night uttering sharp cries : and Mr. Denson says he has been informed that the wild ones also whine by night, frequently and at short intervals, and so audibly as to alarm the lonely pedestrian who may be unfamiliar with its voice.

When assailed by enemies, the hedgehog erects its sharp and formidable prickles, and, by means of very powerful muscles it clasps its extremities closely together into the shape of a ball, only exposing to view such parts of its body as are well protected. Very cruel means have often been adopted to force the hedgehog to unfold itself ; and I would, therefore, have it remembered, that should anybody particularly wish to make it unfold, the readiest and the most harmless method is to pour cold water 
upon it, if it be in warm weather, but in winter time the gentle and gradual warmth of a fire must be substituted.

Much confusion and error exists in zoological books concerning the natural food of this animal. Some writers, especially those who have a great affection and respect for their grandmothers' stories, say that it draws the new milk from the cow; and others persist that it climbs up into apple-trees and carries off its tithes of the fruit after sticking them on its sharp thorny bristles. But none of those persons, who tell us that the hedgehog plays all these vagaries, these ingenious and wonderful tricks, have the kindness to render it clear to our comprehension how the hedgehog manages to get at the cow's teat, and how he takes it into his little mouth; or how he climbs up the perpendicular trunks of trees, how he pulls off the fruit, how he raises them above his back and thrusts his prickles through them, and how he gets down again. These questions must be satisfactorily answered before any jury of naturalists will find him guilty on these several charges. But that the hedgehog will prey even upon those creatures which man is jealous to preserve for his own food alone, there can be little doubt.

The keepers of Richmond Park assured Mr. Jesse that hedgehogs extract young rabbits from their nests, and eat them when they are only a few days old; * and an anecdote is recorded, affording some grounds for suspecting that it also kills young leverets. $\dagger$ It will also eat mice, snakes, $\ddagger$ toads, frogs, slugs,

* Gleanings, vol. ii. p. 255.

$\uparrow$ Anecdotes of Quadrupeds, p. 102.

¥ Professor Buckland, having reason to suspect that the hedgehog occasionally devours snakes, placed a hedgehog and a common British snake, which is quite a harmless animal, in a box together. At first, the hedgehog did not see the snake; when the professor laid the former on the back of the latter, and in such a way that it was in contact with that part where the head and tail of the hedgehog were pressed together. As soon as the snake began to move, the hedgehog started, opened slightly, gave the snake a sharp bite, and instantly rolled itself up again. Three times it opened and shut in this manner, after biting the snake each time, and by the third bite it broke the snake's back. The hedgehog then, standing by the side of the snake, took up and passed the dislocated body through its jaws, cracking and breaking the bones at intervals 
snails, beetles, worms; and, according to Sir William Jardine, it will enter a hen-house, drive the hen off her nest, and devour the eggs, and is frequently caught in traps baited with eggs for carrion-crows. Pallas says it can eat hundreds of blistering beetles (Cantharides) without inconvenience, though a single one of these insects produces the most horrible pain in a dog or cat. The hedgehog will also eat butcher's meat, either raw or cooked. Its appetite is not, however, restricted to animal food; for it will eat the ripe fruit which falls from the trees, and when turning up the earth, probably to find insects, it will eat the roots of grass and other plants. Gilbert White says the hedgehog used to eat the roots of the plantain in his garden by boring under the plant with its upper jaw, which is much shorter than the lower, and then eat off the root upwards, leaving the leaves above ground untouched. In confinement the hedgehog will eat sopped bread and potatoes.

At the commencement of winter, the hedgehog retires into a bed which it forms of moss, dried grass, and leaves, in which it lies in a torpid state during the cold season. This winter-bed, or hybernaculum, is generally made in a round hole, which it digs at the bottom of a hedge. It is a notion as old as Pliny, that the hedgehog lays up a store of food against winter; but as it lies torpid during that period, it has then no need of any provision.

The female has four or five young ones at a birth. They are at first blind and covered with white, soft, and flexible prickles, which become hard in a few days.

The hedgehog is easily tamed, and then becomes very familiar in doors, fearlessly associating with the other domestic animals, and eating with them from the same dish. In kitchens and bake-houses it is of great service, in killing cockroaches and crickets, both of which are very destructive insects. Bingley says that, in 1799, Mr. Sample, of the Angel Inn, at Felton,

of about half an inch. This done, it commenced eating the snake, beginning at the tip of the tail, and proceeding without interruption, though slowly (eating it upwards in the way Gilbert White noticed it to eat roots), until it had clespatched about one half of its victim, the remainder of which it finished on the next evening.-See the Zoological Journal, ii. p. 19. 
Northumberland, had a hedgehog which performed the duty of a turnspit, quite as well as a turnspit-dog.

When killed, the hedgehog may be turned to good account. Lovell says that "the skin being pulled off, the flesh larded, and stuck with cloves, may be roasted, and so some commend it as a pleasant meat."* Mr. John Denson, jun., says that its flesh is occasionally eaten in England by poor people, and is said to be agreeable meat, looking very nice, and having yellow fat. Mr. L. W. Clarke, of Birmingham, says that some years ago he observed a gang of gipsies roasting a hedgehog, which they ate in his presence, and declared to be very good meat. The farmers on some parts of the Continent fix the prickly skin of a hedgehog on the muzzle of a calf that they wish to wean; and I have known coach-horses in England to be broken of their habit of hugging the pole by a hedgehog's skin being fastened round it.

The ancient Romans used to employ the skin of a hedgehog to raise the nap on cloth, for which purpose the prickly heads of the teasel were also used, as they still are.

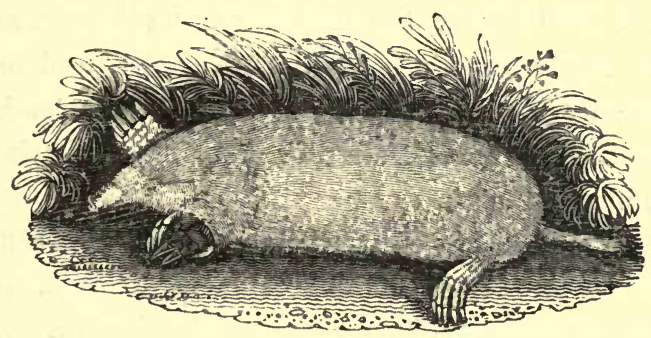

The Common Mole.-(Tulpa vulgaris.)

Moldiwarp, Munt, Want, or Hoont.

He, not unlike the great ones of mankind, Disfigures earth ; and, plotting in the dark, Toils much to earn a monumental pile, That may record the mischiefs he has done.-Cowper.

The common mole inhabits the whole of England and the * Panzoologicomineralogia, 1661, p. 73. 
European Continent; * but it is not found in the northern extremity of Scotland, the islands of Orkney, Zetland, nor Ireland. As it is very numerous in every kind of soil in England, even including the peat-bogs of Staffordshire and other counties, those writers must be mistaken who assert that its total absence from Ireland is owing to the boggy nature of that country.

The length of the mole is about five inches and a quarter. The body is thick, long, and nearly cylindrical. The fur is as soft as silk, short, and black; but it is liable to great variation from its proper colour, some specimens having been found of a white or cream-colour; some of a silvery ash-grey with an orange mark under the lower jaw, and a line of the same colour down the belly; some of a perfectly orange-colour, except the head; and others of an orange-colour throughout. All the hairs of the fur grow in a perpendicular position, so that they can easily be made to lie in any direction, and can offer no resistance whatever to the animal's retrograde or forward movements through its burrows. Its head tapers to the end of the nose, which is well fitted for boring in the ground, the nostrils being strengthened by a little bone at the extremity; its fore-feet are very strong and robust, and admirably constructed and articulated for digging; its tail is nearly an inch and a quarter in length, scaly, rather bristly, and is raised or laid over the back when the creature is burrowing

Though the mole has no outward ears, but only an auditory aperture on either side of the head, it is remarkably quick of hearing; and Franzius says, that if we make a noise down a hole in the earth " the mole will hear it a great way off ; as we hear any one speaking through a hollow pipe better than in the open air." +

Its eyelids are only partially open; and its eyes are black, and very small. "A slight depression serves as an orbit. There is no optic nerve; but its place is supplied by a branch from the

* The common mole of America is the Scalops Canadensis, which so much resembles our mole in exterior appearance that ${ }_{\Lambda}$ one may be easily mistaken for the other.

+ History of Brutes, translated by N. W. (1670), p.248. 
superior maxillary nerve. It is very certain that the mole possesses some of the senses acutely enough; for if a person approaches one which happens to be out of the ground, it will escape, with astonishing rapidity, beneath the surface, either by burrowing a hole, or entering one already made."*

Its sense of smelling is also acute, which is one reason why this animal is not very easily taken in some traps.

"Within the last thirty years," says Mr. Samuel Jackson, of Winsford, in Cheshire, "I have read several articles professing to be descriptions of the mole, but each of them has been erroneous and defective; and having been trained to the business of a mole-catcher from my youth, and having followed that occupation for about thirty-five years, in which time $I$ have decoyed and killed from 40,000 to 50,000 of these creatures, perhaps it will not be considered vanity in me if $I$ attempt to describe the habits of this little miner. The mole dwells in runs or burrows, excavated with wonderful skill, many rods in length, and some parts of them only a few inches below the surface of the earth; while others are some yards deep. It will make several yards of these runs in a day; and, in some lands, will drive the soil before it by small portions, to a length of from three to six yards, before it reaches the place where it throws up the hillock. When it thinks it too far to take the soil to the last hillock, it works another perpendicular opening to the surface, out of which it throws another heap. This is the case when the mole is making his deep runs. In these excavations it will travel at a wonderful speed. Even the weasel, which is a great enemy to the mole; cannot keep up with it; though, on the surface of the earth, it would perhaps travel four rods before the mole could travel one. I have frequently observed, in the bottom of these runs, a perpendicular hole or well, at which the mole probably drinks. Some of them are of considerable depth, and apparently dry; but, not being able to see the bottom, I have dropped a little earth into the well, and by this means perceived that it contained water. Down these the mole can safely travel and

* Magazine of Natural History, vol. viii. p. 106. 
return at pleasure. In some kinds of land, and in wet weather, these wells are full to the brim. That moles have frequent recourse to water will be seen from the well-known fact, that they are easily taken, and in great numbers, in a run which leads to a brook or pit, in dry weather. The nest is sometimes made under the root of a tree or thorn bush; often in dry hedges; also in solid marl banks, several feet, or even yards deep. It is composed of dry grass, but sometimes mixed with green grass; the inside is composed of old dry leaves, frequently oak leaves ; $*$ its form resembles that of a wren's nest. The mole has many roads from the nest; as it is not only formed for receiving its young, but for a comfortable lodging throughout the year. In land where moles are not much destroyed, they will frequently make nests in the middle of fields, where they throw up a heap of earth six or seven times larger than usual."

Sometimes the mole forms its nest in a windrow, that is, a bank of earth which is meant to be spread over the land; and in Cornwall, according to Mr. Couch, the nest is always in a high thick hedge of earth, except the field be of unusual size; and the tracks proceed from the hedge across to the middle of the field, or to the opposite side. In severely cold weather they confine themselves to these earthen hedges, generally near the centre, where a little fine earth, thrown out on the snow, marks the exact spot.

Mr. Jackson says, the number of young is generally four or five, and that he never knew more than six to be found in one nest; but an Essex correspondent to the Magazine of Natural History (viii. 106), says, that in June, 1834, a mole's nest was discovered containing seven young ones, most odd-looking little things, covered with a fine down, like young rats. Mr. Couch says that they do not quit their nests until about half grown.

"In June," continues Mr. Jackson, "the mole leaves its bur-

*. The English translator of Henderson's edition of Cuvier's Animal Kinydom (1834), says that " moss forkas the principal lining of the mole's nest."-J. H. F. 
rows, and runs on the surface of the earth at night, in search of food. It is commonly said that it thus runs for one month; but that depends much on the dryness or wetness of the season.* Few animals will bite more savagely than the mole, especially at a certain time of the year. When fighting with each other, they will hold like the bull-dog. When a boy I used to save the live moles for the purpose of seeing them fight. For this barbarous work my fingers suffered greatly. At one time I was obliged to use my teeth in order to loose the hold of one of them from my hand, the other not being sufficient for that purpose. I have frequently caught them with their flesh torn in various parts with fighting. It is often said that the mole will die should it lose one drop of blood; but this is incorrect. Once, when trying to throw up a mole with my mole-spade, I cut off one of its hind-feet, and yet it escaped. Some months after this, I caught the same mole in a trap, with its stump healed up and sound." + Mr. Hawkins says that when the fall traps, which are in use near Monmouth, " remain for some length of time uninspected, the moles devour each other." +

Mr. Couch says, that his observations lead him to think that when moles change their quarters, the journey is made above ground, and by night; and, in this case, the mouth of the subterranean passage will be found open. The same zealous naturalist says, that " having procured a couple of lively moles, that had not been at all injured, he placed them in a birdcage with some straw, that he might study their actions. The snout, at this time, appeared moist, capable of great variety of action, and endued with fine sensibility; "and the head, chest, and arms capable of quick motion, at short turns, under the skin, as if muscular action were independent of the motion of the integuments. When placed in the cage, they immediately buried themselves, heaving up the straw as they proceeded; lifting it

* Lovell, writing in 1661, also notices this fact:- "In July," says he, " they run upon the earth to seck food, worms being then scant." (Panzool. p. 92.)-J. H. F.

† The Youth's Instructor, January, 1834.

¥ The Gardeners' Magazine, ix. 80 . 
chiefly by the force of the hands and arms, a little by the back of the head, but not at all by the snout. The hinder legs had but little force, except for progression; but they were not unfrequently employed to scratch the body. In the forward half of the body it is probable that this animal exerts more force, in proportion to its size, than any other creature in existence. For several hours this pair were exceedingly active, but they were unable to climb; and in passing each other beneath the straw, they seemed to be quarrelsome, the conquered sending forth a stridulous squeak. When, at last, one of this pair effected its escape, it was by turning the wire backward, not by thrusting it before it. It then passed through a hole in the floor, and finally through a crevice in the stone step leading to the street, thrusting much earth before it. From the orifice thus opened, it passed over five or six feet of the parement, and then began to burrow; but as often as an attempt was made to seize it, it returned to the hole by which it had emerged, as rapidly and directly as if in possession of perfect sight. When placed in rather hard ground in a garden, it began to burrow horizontally, by thrusting the earth above, and at the sides; but the mouth of the burrow was not closed by a heap of earth until above an hour; consequently, in finally filling the orifice, the earth must have been brought from within. In all these actions, the tail was carried erect."*

The mole is most active in throwing up its hillocks of earth immediately before rain or a thaw, because worms and insects then begin to be in motion, and approach those parts of the surface which will afford them a supply of decayed vegetal matter, as under the dung of cattle, which by smothering the herbage has caused it to decay. To such spots the worms repair, and are soon pursued by the mole. The translator of Henderson's edition of Cuvier's Animal Kingdom says, that the mole skins the worms, stripping off the integument from end to end, and that then " the contents are squeezed out by pressure on the part of the mole."

* Magazine of Natural History, vol. viii. p. 104. 
Besides worms, it eats grubs ; and it will exercise considerable stratagem to get within reach of small birds, mice, lizards, and frogs, and when it has got near enough it springs upon them most furiously; and, having seized them, it tears them open, and, intruding its muzzle among their entrails, begins its bloody feast.

A mole which was kept in a tub of earth for several days, never came to the surface, except for its food. "It fed on bread, little pieces of roast meat, pieces of fruit, and several other things. One day it was given some dead minnows, which it licked all over with its tongue, and then ate. A cup of water having been placed in the earth, in his tub, in such a manner that the top of the cup was level with the earth, he soon came up, looked all round timidly, and began to drink very eagerly. The moment he saw he was observed, he buried himself; but he quickly returned to the water. He was fierce, and when touched, he squeaked like a rat, and tried to bite with his sharp teeth."*

The mole is not only an expeditious excavator, and a tolerable runner, but also an expert swimmer :- "At the Loch of Clunie," says Mr. Arthur Bruce, "I often observed upon a small island, at the distance of 180 yards from the nearest land, the appearance of fresh mole-hills. The gardener of Lord Airly, the proprietor of the island, told me he had caught one or two moles lately. Five or six years previously he caught two, and for two years after this he had observed none. But about four years ago, coming ashore one summer's evening in the dusk, he and the butler saw, at a short distance, upon the smooth water, some animal paddling to, and not far distant from, the island. They found it to be a common mole, making its passage from the nearest point of land (the Castle-hill), to take possession of this desert island. It had been, at the time of my visit, for the space of two years, quite free from any subterraneous inhabitant; but the mole has for more than a year past, appeared again, and its operations I have since witnessed." $†$

* The Parent's Cabinet of Amusement, No. xvii. p. 220.

† Linncan Transactions, vol. iii. 
Mr. Henry Turner says, that one morning, as he sat by a river, which runs at the bottom of the Botanic Garden, Bury St. Edmunds, he saw a mole come out of an osier-holt, and run across a grass path, and take to the water; when it was about half across the river, he ran to the edge of the water, and the mole then attempted to dive; but merely immersed his nose in the water for half a minute, and rapidly gained the shore, and soon disappeared in a hole of the bank. A few mornings after, he saw a mole take to the water as before; but on this occasion he did not alarm it, and the mole, therefore, swam so leisurely, that it was nearly four minutes in swimming six yards, and appeared as if it rather enjoyed its morning's bathing. An old mole-catcher, on hearing these facts, replied that he had seen them swim across very wide rivers.

It is a curious fact, that when pasture lands have been freed from the mole, they will not afford so much sustenance for the sheep as they did previously, and fewer sheep, indeed, can be kept upon them. I presume that this is either owing to the growth of the herbage being less rapid and luxuriant then, than when the mole frequently stirred the soil, and eased the spread of the roots; or else from the increase of some herbivorous insects, \&c. which the mole used to destroy. Indeed, there are good reasons for suspecting that the mole feeds upon the common slug. It has been observed in Selkirkshire, that where the moles were extirpated upon the Duke of Buccleugh's pasture lands, slugs greatly increased; and according to Sir Walter Scott, two direful diseases, the pine and foot-rot, ensued, and almost annihilated the cattle on the farms : the tenants of which petitioned for the return of the moles, and a renewal of the breed. Mr. Jesse, also, says he has been " assured that where old mole-hills are most abundant, sheep are generally in a healthy condition, as they feed on the wild thyme and other salubrious herbs, which grow on these heaps of earth. Where these have been levelled and carried away, the sheep have not thriven so well as they did previously. This fact was confirmed to me by Hogg, the Ettrick Shepherd, who deprecated the practice of 
removing mole-hills. In the fine and extensive pastures of Leicestershire, where old mole-hills are extremely abundant, sheep thrive well, and are generally healthy. I have been told that after the destruction of the mole-hills in a park, which formerly belonged to the present Earl of Essex, in Herefordshire, the deer never throve well."*

An old mole-catcher is recorded to have stated that he was in the habit of eating moles when cooked, and that "if folks generally knew what good eating they are, fewer would fall to his share." + Of the skin of the mole, pouches and other articles are made.

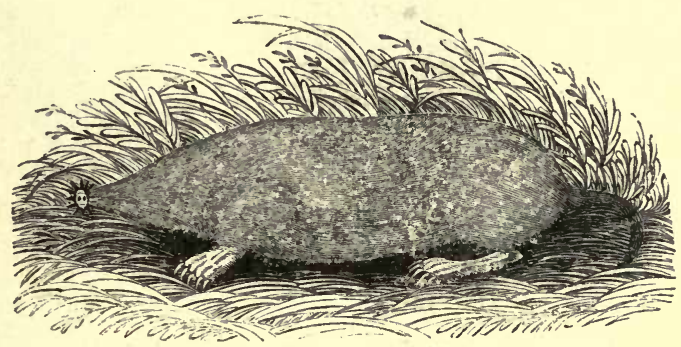

The Radiated Mole.-(Condylura cristata.)

This species is found in North America. It is about four inches long; its eyes are very small and hidden; its nostrils are surrounded on the edges with little moveable cartilaginous points, which, when they separate, radiate into a star-like form; and its tail is twice as long as that of the European mole.

It is reported to frequent the banks of rivulets, and the soft soil of adjoining meadows, where its burrows are so numerous that travellers can hardly help breaking them down in walking.

Dr. Harlan, author of the Fauna Americana, has described another species (C.macroura), which has but very short points about the nostrils, and a scaly compressed tail.

* Gleanings in Natural History, vol. ii. (18 $\left.{ }^{34}\right)$, p. 27.
+ Magazine of Natural History, vol. viii. p. 106. 
OrDER-CARNARIA. Family-Carnivora.

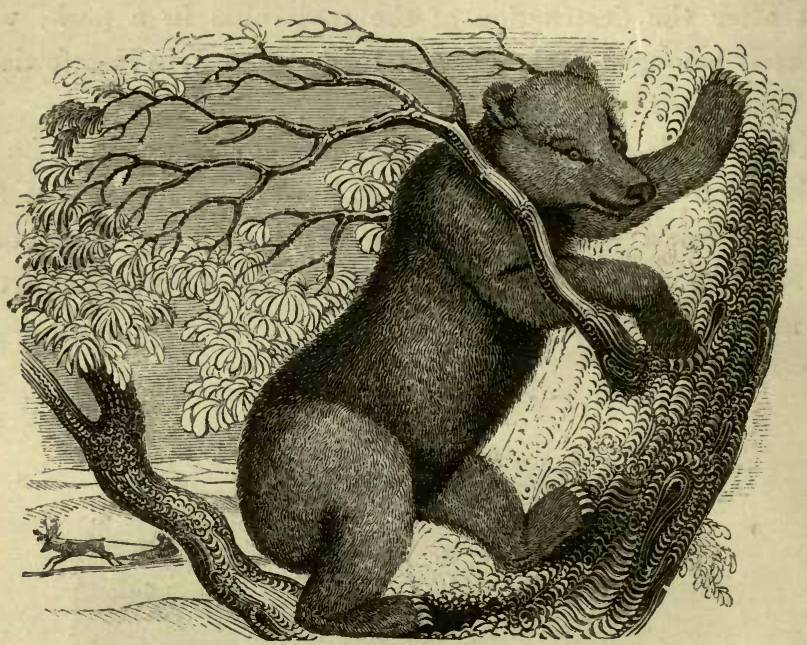

The Brown Bear.-(Ursus Arctos.)

In the Systema Natura of Linnæus, this was the only known species of bear described by him; but more than eight species have been discovered and described since his time.

The bodies of all the species are generally thick-set and bulky, and their limbs are of a proportionate thickness though comparatively short. Their fur is long, rough, and woolly. Their heads might be said to be nearly round, were it not for their broad and projecting muzzle, which possesses considerable powers of mobility and extension; their ears are of moderate size; the pupils of their eyes circular; their tongues are soft, smooth, and extensible; their teeth are almost solely adapted for the detrition of vegetable substances, which in fact constitute the chief food of these animals. On each foot they have five claws, which are well fitted for climbing and burrowing, being very strong, sometimes much curved, but rounded on their sur- 
faces, more or less blunt, and, as they are not retractile, they are constantly and wholly exposed. Their tails are so extremely short, that they are almost concealed among the adjacent long fur.

The walk of the bear is of that kind which zoologists term plantigrade; - that is to say, that at each step they apply the full expanse of the sole of the paw to the ground, instead of the heel touching the ground before the toes reach the surface. Hence the broad and heavy paws of the bear seem to pat or slap the earth at every step.

They dig caves or construct huts for their residences, in which they pass the winter in a state of slumber, and without taking any food.

The Brown Bear inhabits the Alps, the mountain forests of Bohemia, Poland, Russia, Sweden, Siberia, Kamtschatka, and Japan, and a considerable portion of the northern regions of America. He is not often found in poor hilly countries, his favourite haunts being in the wildest recesses of the forest, where there are morasses and plenty of fruit.

The average length of the brown bear is about four feet, and its height about two feet and a half. His forehead rises abruptly from behind the eyes, assuming a regularly convex form. In young specimens the fur is of a dark brown with a greyish tinge on the body, while the legs and feet are almost black; but in adults, the fur is intermixed with yellowish grey and fawn colour.

He can run with great fleetness, and, in his natural haunts, can walk well on his hind legs, and, in that position, carry the heaviest burdens. He is an excellent climber : when he descends trees or precipices, he always come down backwards, like a sailor descending a mast. In addition to these agile and expert accomplishments, he is also a fast and good swimmer; and during hot weather, frequently takes a bath, and afterwards runs about to dry himself in the air and the sun.

In Scandinavia this species is sometimes of a silvery colour, frequently black, and occasionally attains a very great size. Mr.Lloyd killed one that weighed four hundred and sixty pounds, and as it was in the winter time, when its stomach was con- 
tracted, it was probably fifty or sixty pounds lighter than it would have been during the autumnal months. Professor Nillson speaks of one that, when slung on a pole, ten men could with difficulty carry a short distance, and that weighed, he thinks, not less than seven hundred and fifty pounds English. It was killed during the autumn; and it had so enormous a stomach, as almost to resemble a cow in calf. After receiving several balls, he dashed at the cordon of people who surrounded him, and severely wounded seven of them in succession-one, in thirty-seven different places, and so seriously in the head that his brains were visible. One of Mr. Falk's under-keepers assured Mr. Lloyd, that he had killed one even much larger, the fat of which alone weighed one hundred pounds; and its wrists were so immense, that with both of his own two huge hands, he was unable to span either of them by upwards of an inch. "It was," says Mr. Lloyd, " a Daniel Lambert among its species." The powers of such animals must indeed be tremendous ; for, as the Swedes say, " together with the wit of one man, the bear has the strength of ten."

A bear is a match for a dozen wolves, and Mr. Lloyd thinks he would be a match for at least a score of them if his hindquarters were protected, as in a den. Daniel Jansson, one of his guides, informed him, that once during the chase, when he and his companions were far behind both the bear and a dog that was pursuing it, a drove of five wolves - as they knew by their tracks in the snow-attacked and devoured the dog. They had subsequently attacked the bear, but after a severe conflict, as was apparent from the state of the snow, and the quantity of hair both from the bear and the wolves that was lying about the spot, the bear came off victorious, but was killed by the hunters, its skin however being rendered useless from the bites of the wolves. Jan Finne, a Swede, mentioned two instances of bears having been killed by wolves-in the one case, seven wolves, and in the other, eleven having been engaged in the combat.

The brown bear feeds on animals and vegetables. He eats roots, the leaves and small branches of the aspen, mountain-ash, 
and other trees, such succulent plants as angelica and mountainthistle, and devours, during the autumn, vast quantities of ripe cranberries, blaeberries, raspberries, strawberries, cloudberries, and others common to the Scandinavian forests; and there can be no doubt that he would be an ugly customer in a fruit garden. Ripe corn he also eats, and, seating himself on his haunches in a field, he collects, with his out-stretched arms, nearly a sheaf of it at a time, and munches the ears at his leisure. By way of condiment, he sucks honey-plundering the peasants of their bee-hives ; and to subdue the excess of sweetness, he ever and anon takes a mouthful of ants, of which the taste is known to all amateurs of acids to be pungent. "If any of these little creatures," says Professor Nillson, "sting him in a tender part, he becomes angry immediately, and scatters around the whole ant-hill." This is scarcely decorous ; but Mr. Lloyd says, "it may be perfectly true, for all I know to the contrary; if so, however, I apprehend the bear is generally in an ill-humour with the ants; because, wherever I have met with any of their nests at which the bear had been feeding, they had most commonly been turned inside out." *

The brown bear is also fond of flesh; but vegetables and ants compose his principal food. Indeed that excellent authority, Mr. Falk, very justly observes, than an animal which is able to devour a moderate-sized cow in twenty-four hours, would, if flesh formed the chief part of its sustenance, destroy all the herds in the country. He thinks that the destruction which the bear commits among cattle is often owing to the latter attacking him in the first instance; and that, when provoked by the bellowing and pursuit, which not unfrequently commence as soon as they get a view of him, he displays his superior strength, falls foul of them, and feasts upon some of them before sunset. $\mathrm{Mr}$. Falk says bears may reside in the neighbourhood of cattle for years without doing them any injury, if they will but keep quiet; yet it is notorious that they will sometimes visit herds solely from the desire of prey. Young bears seldom molest cattle; but 
old bears, after having been insulted by them, and eaten a few, often become very destructive, and passionately fond of beef. Sometimes they climb on to the roofs of cow-houses; tear them off; and having thus gained admittance, they slaughter and carry away the cattle, by shoving or lifting them through the aperture by which they themselves had entered. Mr. Lloyd says, that on one occasion, a bear dashed in among some cattle, and first despatching a sheep, slew a well-grown heifer, and carried it over a strong fence, four or five feet high, into a wood. Having been frightened from his prey, he absconded, and the peasants felled several trees, which they placed over the dead carcass. But the bear soon returned to the spot, and having by his enormous strength removed the trees, he left not an ounce of flesh on the bones-and of the bones themselves, only a few fragments. Jan Finne informed Mr. Lloyd, that a bull was attacked by a rather small bear in the forest, when, striking his horns into his assailant, he pinned him against a tree. In this situation they were both found dead; the bull from starvation, and the bear from wounds. The bear frequently attacks horses. With one of his terrible paws the ferocious brute keeps his hold of the poor horse, while with the other he retards his progress by grasping at the trees. He thus destroys, and then devours him. Sometimes the bear, by grasping with one of his paws at the surrounding trees, as he is carried along by the wounded horse, tears them up by the roots; but if the tree stands fast, so does the horse-such is the enormous power of the bear's muscular arm. That a bear should run down a horse seems strange; but the Swedish horses are often not very speedy, and, doubtless, lose their senses through fear. The bear never uses his teeth till he brings his victim down; but strikes him on the back and sides with his dreadful paws, as with a sledge-hammer. Professor Nillson says, that the bear has been seen walking on his hinder feet, along a small tree that lay across a river, bearing a dead horse in his fore-paws. The hunters often kill bears which already have their faces disfigured apparently by the kicks of horses. Hideous wounds are inflicted on cattle by 
bears. In the back and neck of a horse, Mr. Lloyd saw holes so deep that he could have buried both his hands in them; and he has heard of the whole hind-quarters of a cow or a horse having been actually devoured, and yet the poor creatures found alive.

Bears seldom-if ever-eat up the children that watch the herds. Occasionally they devour adults, but only when they foolishly attack them; as in a case recorded by Dr. Mellerlong, who saw a hand, which was all that a bear had left, of a woman who had chosen to hit him on the head with a billet of wood. Mr. Lloyd heard of a bear that, in the agonies of death, thinking he had got his opponent in his arms, hugged a tree, and tore it up by the roots in his fall. Inferior animals he strikes at once with his paws on the forepart of the head, laying bare the whole skull and beating it in ; but Mr. Lloyd never knew of any case in which a bear either hugged a person in his arms, or struck at him with his fore-paw in the same manner as a tiger or a cat. He seems to tumble men down, and then to fasten his teeth in their arms or throat. A Swedish boor alleged, as the reason of this difference in the bear's procedure with men and animals, that " he supposed he was forbidden by Providence."

During the summer the bear is always lean; but in autumn he gets very fat. Towards the end of October, he leaves off eating altogether for that year; his bowels and stomach become quite empty, and contracted into a very small compass, while the extremity of them is closed by an indurated substance, which in Sweden is called tappen.* He retires to his den, and very wisely falls asleep. Professor Nillson avers he gets fatter and fatter in his slumbers on to the end of February; but Mr. Lloyd is sceptical on that point, because, says he, "in the first place

* The tappen is a hard substance which blocks up the last bowel during the period of hybernation; but it is voided about the middle of April when the animal leaves his den and resumes his more active life. By chemical analysis, Mr. Lloyd found it to consist of brown resin, green volatile oil, chlorophyle, or the colouring matter of leaves, fat, oil, starch, woody matter, pectic acid, formic acid, sulphates, phosphates, and muriates. The ashes of it contain oxides of iron and manganese kali.-J. H. F. 
it seems contrary to reason; and in the next, I do not know how the point is to be ascertained." One thing is certain, that let the bear be killed at whatever part of the winter he may, he is always em-bon-point, nor can you feel his ribs. He retains his fat from the time he lies down in the early part of winter, till he rises in spring. As spring approaches, he shakes off his lethargy-parts with his tappen - and enters on a new career of cows, ants, honey, branches, plants, berries, and corn. Rarely-very rarely-he passes his tappen during winter-and then he becomes a scarecrow. At first his stomach is nice, and he eats sparingly-not more, perhaps, than a large $\operatorname{dog}$; confining himself to ants and other delicacies, till his stomach has resumed its natural tone, and then he devours almost everything eatable that comes in his way, according to his usual practice during the preceding autumn.

The notion of the bear sucking his paws for nourishment, $\mathrm{Mr}$. Lloyd justly says, has long since been exploded; but still he does suck his paws : and the question is-Why? Mr. Lloyd says, he has reason to believe that the bear obtains a new skin on the balls of its feet during the winter, and he asks if the sucking of them may not be done to facilitate this operation of nature. Some tame bears in his possession, were constantly sucking or mumbling their paws; the operation, which was often continued for hours together, being attended with a murmuring kind of noise, which might be heard at some distance. In consequence of this, their legs or feet were covered with saliva, or rather foam, which by ignorant people might not improbably be taken for the milk which it was at one time said the bear was in the habit of extracting from his paws. But it was not the want of food that caused Mr. Lloyd's bears to be so continually mouthing, for they were to be seen thus engaged most commonly immediately after they had been fed.

The female brings forth about the end of January or in the course of February, and has from one to four cubs at a birth. She suckles them until summer is well advanced; and should she be enceinte again in the same year, she does not suffer her 
former cubs to share her den next winter, but prepares quarters for them in the neighbourhood, within an easy walk. The succeeding summer, however, she is followed by both litters, who pass the ensuing winter altogether in the mother's den. Some people have talked of seeing thirty bears in one "squad" scampering through the Swedish woods; but, as they are not gregarious, such tales are either altogether false, or are overestimated accounts of two litters, amounting, perhaps, to some half-dozen individuals, which have been seen together and with their mother at their head.

Falk says the brown bear continues to grow until its twentieth, and lives until its fiftieth year.

This species formerly inhabited Great Britain. Martial tells us, that the Scotch bears were used to increase the torture of the unhappy sufferers on the cross ; and Plutarch says, that bears used to be exported from Britain to Rome, where they were much admired. In some old Welch manuscripts relating to hunting, we not only learn that the bear was included among our beasts of chase, but that its flesh was as much esteemed as that of the boar or the hare. Another evidence of their former existence in Wales, is the fact that from an early period many places in that country have been known by the name of Pennarth, or the bear's head. But long after their extirpation from this kingdom, they were imported to gratify the cruel propensities of our ancestors, who found pleasure in bear-baiting, We learn from Stowe (1562), that bear-baiting was one of the sports exhibited for the entertainment of an ambassador; and on another occasion for the amusement of Queen Elizabeth at Kenilworth. Those who love ancient customs only because they are ancient, may deplore the discontinuance of bear-baiting, and sigh for such Queens as Old Bess ; but we hail these changes as proofs of a more humanized state of society; and we believe that Victoria is quite contented with merely beholding the bears in the Zoological Gardens-and as a punster would say, she cannot bear the bare idea of bear-baiting. 


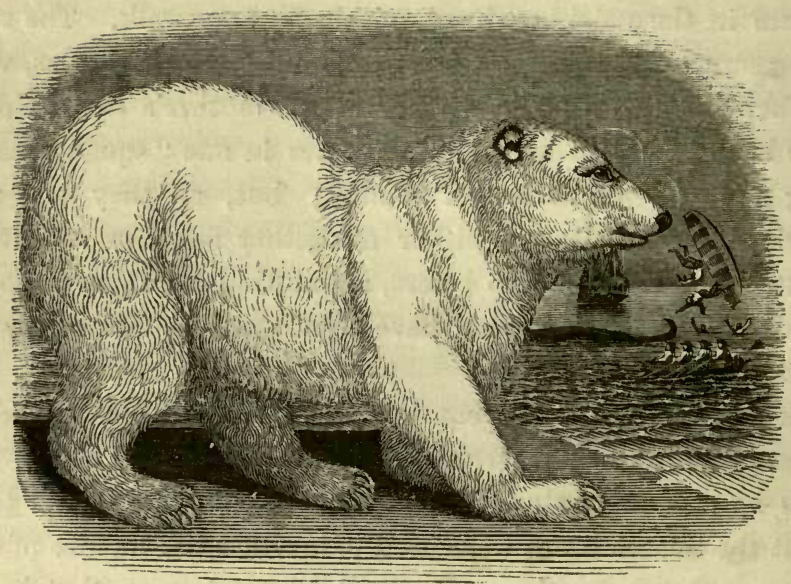

The Polar Bear.-(Ursus maritimus.)

White Bear, or Ice Bear.

The Polar bear is found in Greenland, Lapland, and as far north as eighty degrees.

Its length has been very greatly exaggerated by various authors. Those specimens which have been observed by our adventurous countrymen in the late northern voyages, have never much exceeded seven feet in length, with the exception of one mentioned by Captain Lyon, which measured eight feet seven inches and a half, and weighed sixteen hundred pounds. A male specimen in the Jardin des Plantes, in 1795, measured about six English feet at its first arrival, and had not increased in size at the end of seven years. Pallas mentions an adult female which was only six feet nine inches from the tip of the nose to the root of the tail; and Dr. Richardson mentions another female as having been accompanied by two cubs, and, therefore, unquestionably an adult, and which "was so small that two or three men were able to lift her into a boat." The fur is smooth and white, with a slight tinge of yellow, which becomes deeper 
as the animal advances in age. The head is long and flattened; the outline of its profile is nearly straight; the ears and mouth are very small. The claws are short, thick, black, and but slightly curved; and the soles are almost entirely clothed with long hair, which serves to secure a firm footing on the slippery ice. It has a heavy walk, like that of all plantigrade animals; but it swims and dives well, and can remain submersed for a considerable time.

The voice of the specimen at the Jardin des Plantes was never heard, except when the animal was irritated by teazing, and then it uttered an uniformly strong and hoarse sound.

Its senses of hearing and seeing are feeble; but its sense of smelling is very acute. Captain Parry says, that in Davis's Straits, a large Polar bear approached the Griper, and that it was probably attracted by the smell of some red herrings which were being fried at the time, as the Greenland sailors are in the habit of thus enticing these animals near their ships.

It is said, that although it is usually of solitary habits, it will join others of its species, and, in a troop, set out in pursuit of fish. Cartwright saw a Polar bear dive after a salmon, and succeed in capturing it. Besides fish, it preys on walruses, seals, the remains of dead whales, and other marine animals.

"On one occasion a Polar bear was seen to swim cautiously to a large rough piece of ice, on which two female walruses were lying asleep with their cubs. The bear crept up some hummocks behind them, and with his fore-feet loosened a large block of ice, which, with the help of his nose and paws, he rolled and carried until immediately over the heads of the sleepers, when he let it fall on one of the old animals, which was instantly killed. The other walrus, with its cubs, rolled into the water; but the younger one of the stricken female remained by its dam; on this helpless creature the bear now leaped, and thus completed the destruction of two animals which it would not have ventured to attack openly. The stratagems practised by it in taking the large seal are not much less to be admired. These creatures are remarkably timid, and for 
that reason always lie to bask or sleep on the very edge of the pieces of floating ice, so, that on the slightest alarm, they can by one roll tumble into their favourite element. They are extremely restless, constantly moving their head from side to side, and sleeping by very short naps. As with all wild creatures, they turn their attention to the direction of the wind, as if expecting danger from that quarter. The bear, on seeing his intended prey, gets quietly into the water, and swims until he is to leeward of him, from whence, by frequent short dives, he silently approaches, and so arranges his distance, that at the last dive he comes up at the spot where the seal is lying. If the seal attempt to escape by rolling into the water, he falls into the bear's clutches; if, on the contrary, he lie still, his enemy makes a powerful spring, kills him on the ice, and devours him at leisure."*

Polar bears are sometimes floated to the shores of Iceland on detached pieces of ice, and when they land they generally prove destructive to the sheep.

These creatures are not, however, exclusively restricted to animal food. In autumn, according to Dr. Richardson, an accomplished zoological traveller, they frequent the shores in search of berries and other vegetable substances.

The Regent's Park Zoological Gardens contain a female Polar bear, in a large iron cage, barred on all sides, and adapted in many respects to the animal's habits and temperament. In the centre of its brick floor is a large stone tank of water, into which the animal frequently plunges to enjoy a cold bath. "Its favourite postures are lying flat at its whole length; sitting upon its haunches, with its fore legs perfectly upright, and its head and neck in a dependent position; or standing upon all fours, with its fore paws widely extended, and its head and neck swinging alternately from side to side, or upwards and downwards in one continued and equable libration. It feeds ravenously upon fish, and refuses no kind of flesh that is offered to it; but that it may be kept entirely upon

* King's Journal of a Journey to the Shores of the Arctic Ocean, in 1833-5. 
vegetable food, was proved on two individuals in the Paris menagerie. One of them lived five years on bread alone, and the other throve upon the same diet for no less than seven years." * "This accounts for the fact, that some bears are extremely dangerous enemies both to man and animals, while others pass them by with apparent contempt. Thus the Polar bears, in their native regions, accustomed to fish, would pass by flocks and herds without attacking them, unless stimulated by very violent hunger." $\dagger$

Captain Ross states, that during his voyage of discovery to the arctic regions, the master of a whaler had his thigh very severely lacerated by a wounded bear, which attacked and dragged him out of the boat. The animal was speared by three lances before he would relinquish his grasp; and then he disengaged himself from the weapons, swam to the ice, and decamped.

The mate of the Dundee, " after killing a cub, fired at its mother, and struck her on the jaw, which remained gasping as if dislocated; and believing her hors de combat, he got upon the floe to take possession of her slain offspring. The mother had fled, but she now returned; and, rushing towards her enemy, threw him down, but was unable to mangle him, for her mouth was wide open, and she had lost the ability to close it; nevertheless, she mounted upon his prostrate body, and trampled it severely, before the crew of his boat could come to his rescue. When they did arrive, a sailor, who brought a gun, lost his presence of mind at the sight before him, and stood staring inactive; but others, more bold, thrust the bear aside with lances; and the mate, being freed from its weight, arose, took the gun and shot away its lower jaw completely. She then fell a victim to the weapons of the men." $\ddagger$

The female brings forth two young ones at a time; and her strong affection towards them has been the theme of many well

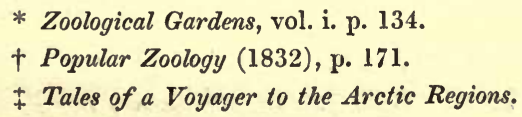


authenticated anecdotes. Voyagers inform us that she carries her cubs on her back in swimming, or when they are tired, as swans and many other aquatic birds will sometimes carry their young.

A half-grown cub, which was captured and brought on board ship, after its companions had been killed and itself slightly wounded, afforded a pitiable sight "as it sat upon the jawbone of a whale, which projected between the taffrail, at one moment devouring pieces of its mother and sister with avidity, and at the next stretching its throat and blaring out mournfully when a fragment of ice met its view, passing astern as we sailed on our course."*

Though cold appears to be the greatest luxury to the polar bear, yet some writers say that he passes the severest period of the arctic winter in a torpid state, sheltered from the intense cold by the snow that has accumulated upon him. But some doubt exists on this matter. "Our navigators," Dr. Richardson observes, "confirm the statements of Fabricius and Hearne, that the Polar bear does not hibernate, having occasionally seen them in the winter, and actually pursued one in December. The Esquimaux killed eight or ten in the winter of 1822 ; and Mr. Edwards learnt from the hunters, that they often saw and killed the males when roaming at large during that season, and as often dug the dams with their cubs from under the snow. These facts seem conclusive as to the uniform hibernation of the gravid females, and the, at least, occasional appearance of the males abroad in the winter. It is possible, however, that the latter may also become torpid in the winter, when the local circumstances of their native districts are such as to preclude them from reaching open water at that season; and thus the opposite opinions of naturalists may be in some degree reconciled." $†$

The Polar bear is hunted for the sake of its beautiful fur, which makes excellent rugs and warm wearing apparel. The

* Tales of a Voyager to the Arctic Regions.

† Appendix to Parry's Second Voyage, p. 229. 
Icelanders make cloaks of it, and they cure and eat the flesh of those they kill that occasionally invade their country. But some parts of the animal prove highly injurious to those who have eaten them. Scoresby says, that those sailors who, while in the arctic regions, have been obliged to eat the flesh of bears, and have not taken the precaution of rejecting the liver, have almost always been attacked with sickness, a peeling off of the skin, and, sometimes, have died from its effects. During the stay of Captain Sir John Ross at Fury Beach, some of his party being tempted by the fine appearance of the meat of some Polar bears, made a hearty meal of the first that was shot. All who partook of it soon complained of a violent headache, which, with some, continued two or three days, and was followed by the skin peeling off the face, hands, and arms; and, in others, who probably had eaten more largely, the skin peeled off the whole body. On a former occasion, he witnessed a similar occurrence, when, on Sir Edward Parry's Polar journey, having lived for several days wholly on two bears that were shot, the skin peeled of the feet, legs, and arms of many of the party; but it was then attributed rather to the quantity than the quality of the meat, and to their having been, for some time previous, on very short allowance of provision.

\section{The Labiated, or Thick-lipped Bear.}

(Ursus Labiatus, Blainville: Prochilus Labiatus, Illiger.)

This curious animal, the largest of the Indian bears, is a native of Hindostan, more particularly the mountainous districts. It is common in Bengal, on the mountains of Silhet, and in the Deccan Ghauts; residing in caverns or holes, which it digs.

It is distinguished from all its tropical congeners by its denser coat of hair, which is of a deep glossy black colour, and, in old individuals, almost touches the ground. It is doubtless owing to this natural protection that it is enabled to brave our winters with impunity, even when its den is placed in a comparatively unsheltered situation. The hair on the back of the 


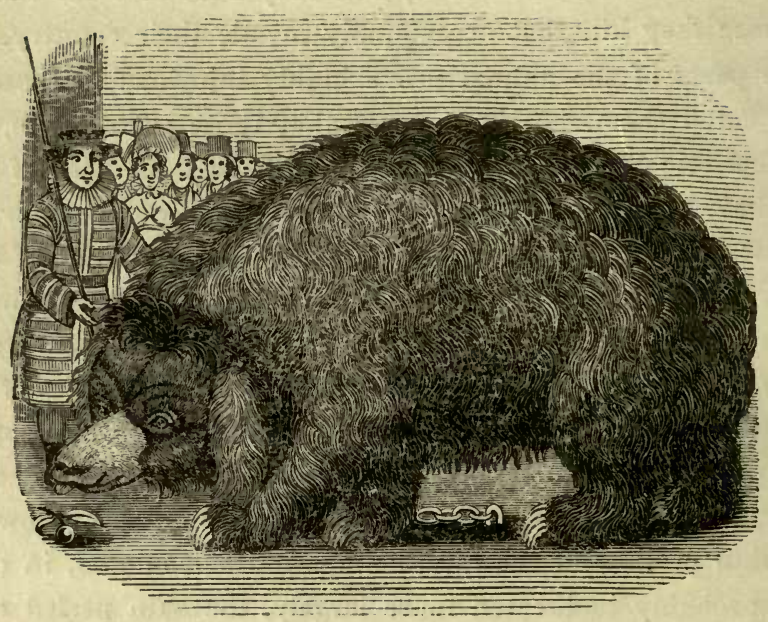

head and neck is so remarkably long that it forms a sort of mane, more than a foot in length, and almost hiding its large ears. On the chest is a white mark, shaped like a chevron or horse-shoe, the two branches of which extend over the arms. The body is long; the head small; the muzzle of a yellowish white colour; the lips are soft and fleshy, and capable of varied and extensive motion, often being elongated in a tubular form three or four inches beyond the jaws-hence the specific name labiatus. Its nostrils are supported by a peculiarly large and moveable cartilaginous plate, by means of which it can readily open or close their apertures; and in this way it probably protects the nasal passages from being entered by insects when it thrusts its snout into their nests. It differs from the rest of the genus in losing, at an early age, the whole, or the greater part, of the incisor or front teeth. Judging from the form of its teeth, we should predicate that it is as carnivorous as any allied species. Bewick says it will eat marrow or the fat of meat either raw or cooked; but refuses the lean and muscular parts of flesh, and all kinds of roots. The extremities of the feet are yellowish white, and are furnished with long, crooked, 
white claws, which, one may fairly suppose, are of great use in enabling it to dislodge the ants, which form part of its food, and to get at the stores of bees; which, also, contribute to form the diet of this animal in its wild state. Dr. Francis Hamilton says that, besides insects, it subsists on fruits.

When young it is active, and runs with so much agility that it cannot easily be overtaken, though pursued by a horseman at full speed.

It appears to be more docile and more intelligent than the other species; and, according to M. Duvaucel, it is educated and exhibited by the Indian Jugglers for the amusement of the people.

In 1792, a specimen of this animal, from Patna in Bengal, was exhibited in London as the lion-monster; but Pennant and Shaw, who examined it, gave it the name of ursine sloth-a name equally objectionable, for its dentition and anatomy, as described by Bewick, Cuvier, and Tiedmann, sufficiently prove its relationship to the bear tribe. Yet it is still exhibited as the sloth in the travelling menageries; though the true species of sloth (Bradypus didactylus and B. tridactylus) are peculiar to South America, and do no not appear to have been, hitherto, brought alive to this country. 


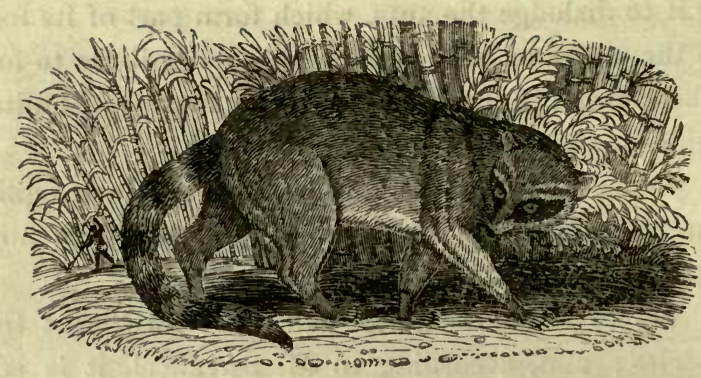

The Racoon.

(Procyon Lotor. Cuvier.-Ursus Lotor. Linnæus.)

The Racoon inhabits North America, and even the more extreme parts of it. Mackenzie met with it on the borders of the Red River, in forty-five or fifty degrees north latitude. It is still numerous about several of the populous parts of the United States. Mr. Bennett observes, that " it may admit of doubt whether it ever advances further south than the Isthmus of Darien, the animal described by D'Azara, as identical with it, being evidently a distinct species."*

The present animal is about three feet in length from the nose to the end of the tail, and about one foot in height. Its body is entirely covered with long, thick, and soft fur, of a greyish black colour. The shape of the head somewhat resembles that of the fox, being broad betwixt the ears, and very sharp at the muzzle, which is white; the eyes are large and yellow, and surrounded by a black band, from which a dusky stripe runs along the nose; the ears are moderately long, rounded, and erect. The legs are slender, and the feet are armed with five sharp and strong claws; which, together with his teeth, enable him to make a vigorous resistance. The back is considerably arched; the tail is bushy and one foot in length,

* Tower Menagerie (1829), p. 113. 
and is decorated with about seven transverse bands of blackish brown, alternating with bands of a whitish colour.

When standing still the entire sole of the foot rests on the ground; but in walking or running, the heel is raised before the toe is lifted from the surface; hence the progression of the racoon is not so strictly plantigrade as that of the bear. Its gait is heavy and awkward, and, when walking, the body is not kept in a straight position, but in an oblique one, so that it proceeds somewhat sideways; yet it moves actively, and often succeeds in escaping from its pursuers.

It climbs trees easily, sports among the branches with great agility, and runs along the surface of a slanting trunk or stem as nimbly as upon the ground. It can easily stand on the hind feet. It grasps objects with its paws, not, however, by contracting a single paw, but by opposing the one to the other, and in this way it conveys its food to the mouth.

Though the pupils of its eyes are round, it does not perceive objects very distinctly in a strong light, and it is not very necessary that it should, for it remains still and coiled up inside the hollows of trees and other retreats during the day; the night being the time when it is most active, and chiefly in search of food.

The racoon feeds on crabs, * snails, worms, beetles, and other insects. It also devours birds and their eggs, to obtain which it sometimes climbs to the very tops of the highest trees. Mr. Goodrich, an American, says, that whenever racoons can enter a poultry-yard, they kill great numbers of fowls, eating only the head or sucking the blood, which flows from the neck. Some tame specimens will eat oysters and other mollusks, and display great dexterity in opening the shells, and extracting the contents. But besides the above-mentioned animals, they also feed upon sugar-cane, corn, maize, fruits, roots, and other vegetable substances. They are exceedingly fond of sweets, and to obtain

* The South American species is so partial to these crustaceans, that it has acquired the name of crab.eater, which is also the meaning of its technical name-P. cancrivorus. 
these will incur every danger. In Jamaica, great numbers of racoons often descend from the mountains to feed upon the sugar-canes, the planters of which regard them as among their greatest pests; and though traps, fire-arms, and various other means are used to destroy them, they still abound to such an extent, as to commit serious ravages in a single night. Mr. Richard C. Taylor, in his valuable account of the geology of the north-eastern extremity of the Alleghany Mountain Range, in Pennsylvania, says these animals "swarm about the newly cleared lands of Lycoming Valley, eating and destroying much corn in the fall. Not less than a hundred of them were taken, in October and November, 1834, by traps and dogs, during the autumn evenings, in a few fields near me." *

The racoon is very fond of water, and it drinks both by suction and lapping. Before it eats its food, it generally dips it into water, if there be any within its reach, and then rolls the moistened morsel between its paws. Cuvier says it eats nothing without having dipped it; but Mr. Bennett says it frequently entirely neglects to do so. It is, however, from this curious practice, the purpose of which is not very obvious, that the racoon derives its specific name-lotor.

When kept in confinement, it soon becomes tame, affectionate, and playful; and shows a great partiality for sweetmeats, and will drink spirits until overcome by intoxication. But although, while under restraint, it may appear attached to its owner, and reconciled to its reclaimed state, yet directly it is permitted to regain its liberty, it exhibits wild and independent conduct.

If ill-treated, the racoon is very resentful. A man having given a tame one several lashes with a whip, could never afterwards induce the animal to tolerate his presence; neither eggs nor fish, of which it was exceedingly fond, could appease its resentment. At the approach of this man, the racoon always flew into a rage, its eyes kindled, it endeavoured to spring upon him, uttered the most mournful cries, and refused every proferred dainty, till the object of its hatred retired. It disliked 
children; their crying irritated it, and it tried to spring upon them. It was very fond of a small bitch, but would give her a severe correction if she barked too loud.

Linnæus says that a racoon which he kept, had a strange antipathy to hog's bristles, and was, therefore, much affected at the sight of a brush.

Racoons are hunted for their fur, which is used by hatters, and considered as next in value to that of the beaver. It is also used as lining for dresses; and the skin, when properly prepared, makes good gloves, and upper leathers for shoes. The natives eat the flesh, which they reckon excellent food. Hunting the racoon generally takes place at night, and with dogs.

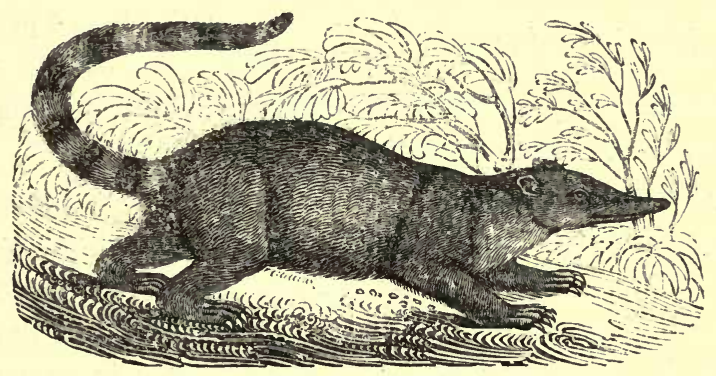

The Brown Coatimondi.-(Nasua fusca.)

\section{Brazilian Weasel.}

The brown coatimondi inhabits the woods of Brazil, Paraguay, and other parts of South America.

It is about three feet long from the tip of the nose to the end of the tail, which appendage is nearly as long as the body. The neck and body are rather long; the fur short; the ears are small and round; the eyes are small; the upper jaw protrudes about an inch beyond the lower one; the snout, which is turned up at the end, is extremely flexible, and when the animal's attention is excited, this organ is kept in constant agitation and moved 
about in every direction, to feel whatever objects are presented to its notice. The snout, also, assists the fore paws in the operation of digging for worms. The feet are semi-palmate; and their sharp black claws enable it to climb with agility and to dig rapidly. In descending a tree, it comes down headforemost, hooking by its hinder claws, which have the extraordinary faculty of reversing to a great extent. When on its legs, it usually carries the tail erect, but when lying down, it places it between the legs.

Coatimondis are nocturnal animals, seeking food at nighttime. They feed on birds, reptiles, insects, worms, and fruits. Small troops of them sometimes visit the sugar plantations, where they commit great devastation. Goldsmith, probably alluding to imprisoned specimens, says they are "very apt to eat their own tails; but this strange appetite is not peculiar to them, the macaco (Lemur Macaco) and some of the monkey tribe do the same, and seem to feel no pain in wounding a part of the body so remote from the centre of circulation."

They sit up on the hind legs when feeding, and use both paws to carry the food to the mouth. When pleased, they utter a gentle hissing, but if angry or hurt, they send forth a very shrill and piercing cry. Preparatory to sleeping, they roll themselves up into the shape of a ball, and often remain in that position for fourteen or fifteen consecutive hours.

In confinement, the coatimondi becomes tame, playful, and fond of caresses; but evinces no symptoms of strong attachment, and is furious on any sudden alarm. One in the Zoological Society's Gardens attacked the keeper, and hurt him so severely in the leg, that the wound was not cured for several weeks. If restored to liberty, it soon kills the poultry and every other living creature weaker than itself.

Three supposed species of coatimondi have been described, but most zoologists acknowledge only two, the brown ( $N$. fusca) and the red ( N. rufa); and, indeed, we have not yet sufficient evidence of these being more than strongly marked varieties of one species. The former is distinguished from the latter, chiefly 
by its darker colour, and by the blackness of the sides of its snout. In both species the eye is surrounded by three milk white spots, and the tail is usually encircled by alternate bands of black and fulvous.

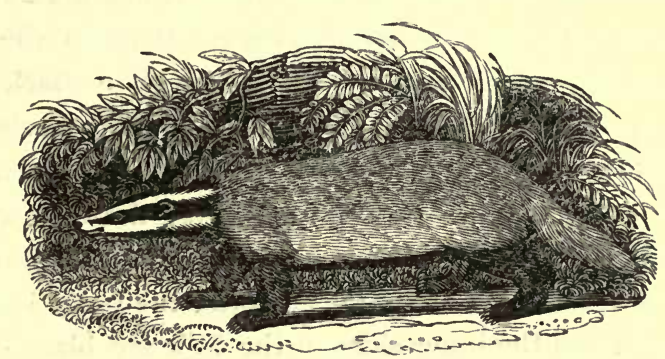

The Badger.-(Meles taxus.)

Brock. Grey. Bawsened-Pate.

The badger is found in many parts of England, Scotland, and other European countries. Its favourite haunts are the deepest recesses of woods, and the thick coppices covering the sides of hills. In England, the country people speak of dog-badgers and hog-badgers, believing that there are two kinds; and assert that the former prefers light and sandy soils, and the latter, which according to them is of a more clumsy shape, prefers those which are more rich and loamy. The fact is, however, that the dog-badger and hog-badger of the rustic zoologist, are neither distinct species nor varieties, for both may belong to the same litter, or the same individual may frequent a light soil one year, and be called a dog-badger, and the next year betake itself to a richer soil, become fatter, and be called a hog-badger. This notion is probably very ancient, for I find that the learned and laborious Lovell says, on the authority of Schroderus, that badgers are either " doggish or porcine."

The badger is two feet and a quarter in length, from the end 
of the snout to the rump, or nearly two feet nine inches from the former extremity to the end of the tail : the weight varies in different specimens, and according to the season, some weighing only fifteen pounds, and others exceeding thirty. The body is long and robust; the skin is loose and tough; the hair is coarse and wiry; that on the back is long, and of a fine reddish grey, varying in tint in different parts; that on the belly is particularly long; the head is white, but with a black band on either side, and dividing the cheek from the forehead, and including the eyes and ears in its own space; the muzzle is long, and terminates in a moveable snout; the eyes are small, as also are the ears, which are semi-circular, and nearly concealed in long hair; the tongue is smooth; the lower jaw, throat, breast, belly, and the inner sides of the legs are black; the feet are hairy, each with five toes armed with strong curved claws, fitted for digging; and the tail is very short, and light grey.

The walk of the badger is plantigrade, like that of the bear. The two sexes are seldom seen together. They are probably led to discover each other by the fetid odour emitted from a peculiar white secretion contained in a glandular pouch under the tail. In their secluded haunts they dig two or three deep subterranean apartments, the only entrance to which is by a slanting and even winding passage. In these burrows they sleep during the greater part of the day, and emerge only for a short period in the evening or night, to go in search of food. In the summer time, the female forms a nest of moss and grass, in which she gives birth to her young, three or four in number. The task of excavating the burrow and attending to the cubs, appears to devolve chiefly upon the female. M. Frederic Cuvier tells us that two young badgers, male and female, were removed from the nest of their mother, and placed in a paved yard, which was so fenced in that they could not escape, but yet had considerable range. They soon raised up some of the pavement and dug a burrow, wherein they passed the day. At night-time they used to leave their subterranean retreat, to eat the food which was placed in readiness for them. After living a year in 
the yard, they were put into a small enclosure, walled round with stone, and having an earthen mound in the centre. True to their habits of digging on sloping banks, where there are stones to support their entrance, they first tried the walls all round, to find a place where they could dig a habitation. They then chose an opening between two stones, which was a little elevated above the ground, and had the upper stone projecting over it, serving like a tent-house to protect the burrow from the rain, and partially to conceal it. They could, however, work with but little effect, as the height of the spot obliged them to raise themselves, standing on their hind-legs ; the fore-feet had, in consequence, only slight influence upon the plaster and stones. To obviate this difficulty, the male stretched himself upon the ground, and the female, standing on him, was enabled to reach the spot of her desired operations with more effect. Yet their industry and perseverance proved unavailing; so they abandoned that spot, and made their attempts at another aperture, also under a projecting stone. The second attempt proving equally abortive, they attacked the mound, the female still leading the way and being the most active and principal operator. Even here they did not immediately begin to form the burrow, but ran trial lines or trenches over a great part of the surface, till they came to a place which suited them, and there they began their regular operations. In the first loosening of the earth, they used their snouts ; then they dug deeper with the fore-paws, flinging the earth backwards between the hind ones, and soon using these to remove it still further to the rear. When the heap behind them accumulated, they retreated backwards upon it, and, using all the paws, gradually removed it from the hole. Sometimes one of them would lie down to rest by the side of the other at work, and remain, though half-buried in the earth, and apparently giving considerable interruption to its fellow. The male was most prone to indulge in these lazy fits, while the female was by far the most industrious labourer. Before the morning their work was successfully terminated.

Two travellers in France, accompanied by a dog, started a badger, 
which they pursued till it took shelter in a burrow under a tree. With some difficulty it was hunted out and killed. They then dragged it to a neighbouring village, called Chapellatiere to obtain from the commune a reward for its destruction, and to sell the skin. But they had not proceeded far, when they heard the cry of an animal in seeming distress, and, stopping to listen whence it proceeded, they observed another badger approaching them slowly. They threw stones at it; notwithstanding which it came up to the dead animal, began to lick it, and continued its mournful cry. They ceased pelting it, and again drew the dead one along; when the living badger, determined to adhere to its dead companion, laid down on it, taking it gently by one ear, and in that manner was drawn into the village; nor even there could it be induced to quit its hold by dogs, boys, or men, who at length killed the poor animal, and burnt it as a witch.

The badger feeds upon rabbits, birds' eggs, lizards, frogs, beetles, snails, and worms. In countries where the wild honeybees form their nests in the ground, they are often disturbed by the badger, who, having a great taste for sweets, plunders their stores without ceremony. A writer in the Magazine of Natural History (viii. 228) mentions some circumstances which he has frequently observed in Selkirkshire, and which induce him to suspect that it digs up the nests of our common groundwasp and wild bee, and devours the larve or maggots which they contain. It is also a vegetable feeder, eating the fallen beech-nuts, earth-nuts, fruits, and the roots of various plants. Not being able to climb, it does no injury to anything which either grows or perches at a height from the ground; but if they fall within its reach, it will eat them.

In confinement, Fleming says that he has seen it not only eat rabbits and lick the contents out of birds' eggs, of which it seemed very fond, but " greedily devour crows." *

The badger possesses great general strength, which, together with the toughness and looseness of its skin, enables it to offer

* History of British Animals (1828), p. 9. 
considerable resistance when attacked, at which time it also increases the emission of its offensive odour. It defends itself with much agility, biting its assailants very severely, and sometimes holding them fast between its teeth. It is'killed with difficulty, except by a blow on the snout,-a part where most mammals are very sensitive to injury.

If caught while young, the badger may be easily and perfectly tamed. It soon becomes playful with the domestic dog, and will follow its owner about the house. It is very fond of the fire, and will sometimes approach so near to it as to be much scorched.

One which was taken when very young was brought up as a playmate in the family of a cottager, in the neighbourhood of Shaftesbury, whose children used to sport with it as familiarly as they would with a puppy. But their father, finding that it had become rather too rough in its fondness, disposed of it to Mr. James Buckland, who sent it to Professor Bell, in whose house it soon became a great favourite; showing, too, on its part, great attachment to the zoologist and his family. "He followed me like a dog," says the Professor, "yelping and barking with a peculiar, sharp cry, when he found himself shut out of the room in which I happened to be sitting. He was accustomed to come into the dining-room during dinner, of which he was generally permitted to partake, and he always ate his morsels in a very orderly manner. He was, in fact, an affectionate, gentle, good-tempered fellow, and very cleanly withal."*

The badger is not without its uses when dead. The skin, dressed with the hair on, is made into pistol-cases, and the pendant pouches of those Highland regiments that wear kilts. Of the long hairs are made what artists term "sweetening tools," which are painting-brushes used only to brush lightly over oil-paintings, for the purpose of softening and blending the tints before they dry. "When in proper season, the flesh of the badger is wholesome and palatable food; as such, it is much used in China [Italy, and Germany], where the animals

* British Quadrupeds (1837), p. 126. 
are encouraged for the table; but from the fetid odour, and some other causes, it is not generally used in Europe. The odour belongs to its peculiar apparatus only, and that can easily be removed without giving the least taint to the flesh of the animal. Both skin and body could thus be turned to as valuable account as those of any of the animals which are called game. The hind quarters, when properly cured, make excellent hams. In Britain, however, the badger is seldom brought into public notice, except in some of those unmeaning and disgusting exhibitions to which the ignorant and the worthless give the prostituted name of 'sports ;' but which, to the credit of the age, are fast becoming as unfashionable as they are useless and brutalizing."*

It is not many years, however, since this cruel and barbarous sport was permitted even in the British metropolis. In the Sporting Magazine of October, 1801, we are informed, that badger-baiting takes place, on every Monday afternoon, between Field Lane and Black-Boy Alley. To every humane mind, it must be a lamentable fact that the objects of cruelty, under the cloak of manly sports, are generally those animals which are the least offensive, and the most timid.

\section{The Ratel.-(Mellivora Capensis. F. Cuvier.)}

\section{Indian Badger. Honey Weasel. Honey Bear.}

The ratel inhabits the Cape of Good Hope. It is about ten inches or a foot in height, and two feet and a half in length from the snout to the rump; and its tail is about six inches long. The fur, though rather smooth, is stiff and wiry; and the hide is exceedingly tough, and so loose that, according to Sparrman, "if any body catches hold of him by the hind parts of his neck, he is able to turn round, as it were, in his skin, and bite the arm of the person that seizes him." So impenetrable is 


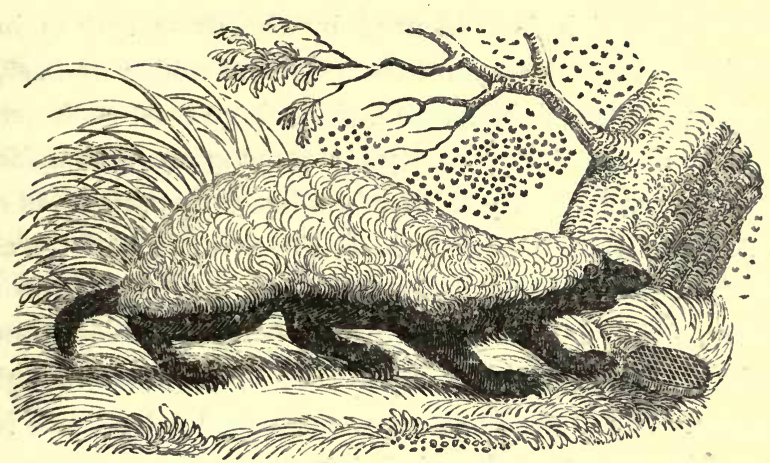

its hide, that it is said a pack of dogs, sufficient in number to overcome a moderate sized lion, have sometimes failed in their attack upon a ratel. The crown of the head is of a whitish grey colour; and, from the back of the head to the root of the tail, the upper surface of the body is of a dull ash grey, which colour strongly contrasts with the jet black of the under parts of the animal. It has no external ears, but merely a slightly elevated margin, surrounding an auditory aperture; the snout protrudes beyond the lower jaw, and terminates in a soft and hairless muzzle; and the tongue is rough, and resembles that of the feline tribe in having its horny papillæ sharp, elevated, and pointing towards the root. The legs are short and stout, and the feet have five toes, surmounted by arched unretractile claws, which are grooved beneath, and those of the fore-feet are about an inch and a half in length, being longer than those of the hinder pair, and well adapted for digging.

Sparrman, and all subsequent travellers to the Cape of Good Hope, give us to suppose that the ratel subsists entirely by plundering the subterranean nests of the African bees. But it has been justly observed, that it would require more positive evidence to convince a zoologist, " that an animal, whose teeth in number and disposition correspond more closely with those of the cat than any other mammal with which we are acquainted, 
and which exhibit a carnivorous character scarcely, if at all, inferior to that which is evidenced by the same organs in the hyæna, should subsist only on the rapine of a hive of bees, and the honied produce of their cornb. Still there exist such decisive marks of a diminished capacity for preying on animal food in the thick-set and clumsy form of its body, the shortness of its limbs, its partially plantigrade walk, the structure of its claws, the elongation of its muzzle, and even in the form of the teeth themselves, as to induce us to pause before we determine to reject the general testimony as worthy of credit, although we must regard it as doubtful on some particular points, and insufficient and imperfect on the whole."*

The above traveller says, on the authority of the Hottentots and Dutch Colonists, that at sunset when the ratel requires food, it sits upon the ground with one paw raised, so as to shade its eyes from the rays of the sun, and peers cautiously on either side of its paw, until it perceives several bees flying in one direction. It then keeps its eye upon them, and follows them to their nest, which is generally in some hole in the ground. Having reached the nest, it immediately begins to pillage it, using the claws of its fore-feet to remove the intervening earth. When the bee's nest is in a hollow tree, the ratel, being unable to climb, becomes enraged, and wreaks its vengeance by biting round the trunk; and the Hottentots know well that the marks thus produced on the lower part of the tree, are sure signs of the presence of a bee's nest. It is said that the ratel, like those extraordinary people, is sometimes led to the discovery of a bee's nest by observing the flight of the honey-cuckoo (Cuculus Indicator). The toughness of the ratel's hide protects it, no doubt, from the stings of the bees.

In Central Africa it is reported to be so ferocious as, at certain seasons, to venture singly to attack a man; but the natives of those parts informed Major Denham, that one blow on its nose will kill it almost instantly : which is probably owing to the thinness of the skull adjoining the nasal bone.

* Zoological Gardens Delineated, vol. i. p.13. 
General Hardwicke, speaking of the ratel of India,* says that there it prowls at night, round the abodes of the Mahommedan natives, scratching up their recently buried dead, unless their graves are defended by thorny bushes. It burrows with such celerity, that it can bury itself in the hardest ground in the space of ten minutes. The Indians sometimes capture them alive, by digging them out of their holes. Old ones are with difficulty secured, and seldom live long in captivity; but young ones are tractable, docile, and playful. Their general food is flesh in any state, but they appear to prefer birds and living rats. They are fond of climbing, but perform this operation clumsily; although they will ramble securely along every arm of a branching tree, provided it is sufficiently strong to bear their weight. They sleep much during the day, but become watchful at night, and manifest their uneasiness by a hoarse call or bark.

\section{THE WEASEL KIND.}

Animals of the weasel kind have the body long, slender, and very flexible. This vermiform shape of the body, together with the wedge shape of the head and the shortness of the feet, affords them every facility for insinuating themselves through small apertures or tortuous passages in search of prey. They have the mouth well provided with teeth, admirably adapted for carnivorous purposes. Beneath the tail they have a small gland, from which they can exude a secretion which emits a fetid odour.

In Britain three species are found in a wild state; namely, the fitch (Mustela putorius), the stoat (M. erminea), and the common weasel (M. vulgaris).

* The ratel of India was regarded by Pennant and Shaw as a distinct species; but Bennett considered it a mere variety. It appears that in colour and markings it does not materially differ from the African specimens; but it is at least worthy of observation, that those of Africa are described as incapable of climbing, whereas those of India, according to General Hardwicke, are fond of climbing.-J. H. F. 


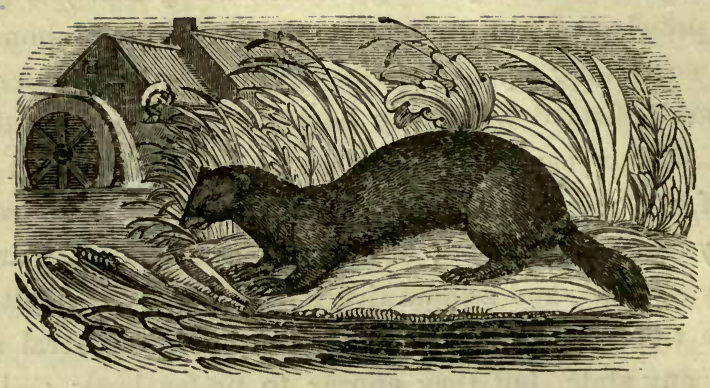

The Fiтch.-(Mustela putorius. Linn.)

Fitchet, Fitchew, Foumart. Fulimart. Polecat.

The fitch inhabits the temperate parts of Europe, its range extending from Italy to Poland. In Britain, France, and many other countries, it is very common.

From the nose to the extremity of the body, its length is nearly eighteen inches; or, including the tail, about one foot and eleven inches. The edges of both the jaws are white; the ears are short, semi-circular, and tipped with white; the feet are short, the toes long, and separated to the very origin; the claws are sharp, and hooked, white underneath, and brown above; the head and legs are entirely of a dark chocolate colour, approaching to black. The hairs on the sides of the body are of a blackish brown colour about the tips, but yellowish about the middle and base. The coat consists of two sorts of fur, the shorter of which is the more warm and downy, and the adult animal retains both throughout the year; but the young have only one sort of fur, which is of a very uniform dark brown, close and woolly.

It generally resides in woods or thick coppices, in the neighbourhood of farm-houses. In such places it burrows under ground, forming a shallow retreat from two to three yards in length, generally terminating in a round chamber, situated for better security among the roots of some tree. Some, however, 
instead of forming a subterranean retreat, content themselves with a lodging under hayricks, During the day-time they usually remain in close concealment, but at night they sally forth in search of prey.

The fitch is very nimble and active in its movements, running very fast, and accelerating its progress by a succession of leaps, arching its back each time it is about to spring from the ground : it also creeps up walls with great facility. In walking, the belly seems to touch the ground, owing to the shortness of the legs.

Being a pursuing, rather than a pursued, animal, it has its external organs for conveying impressions to the senses placed as forward as possible. "Its external auditory tube," Dr. Farrar observes, " is similar in length and diameter to the hare'splaced at an angle of forty-five degrees, but pointing from behind, in a direction downwards and forwards ; in fact, the very opposite to its position in the hare. When we consider the habits of the fitch, and behold the structure containing one sense, acting in concert with and supporting another still more valuable to the animal's existence, we cannot but wonder at the excellence of these arrangements. From this tube being placed very forward, we should naturally conclude that this animal's sense of hearing is necessarily much less acute from behind than before; and this supposition is strongly supported by the following circumstance. A farmer in my neighbourhood had his poultry disturbed on several successive nights, and one day he discovered near his residence a couple of fitches, gamboling in a very frolicksome manner. Approaching them cautiously from behind, he was enabled to come within a very few yards of them. He levelled his loaded gun, but it missed fire. This occurred five or six times without a single spark being elicited from his flint; and notwithstanding all this hammering in their rear, the animals were never in the least alarmed. At last, however, he was successful in obtaining one of them; but the other made its escape. On my examining the skull of the one he had shot, I was satisfied that though the fitch may hear sounds behind 
it, yet they are only heard imperfectly; otherwise, indeed, it must have taken alarm at the many attempts to fire the gun."*

It preys upon various species of mammals, birds, reptiles, fish, and mollusks. Dr. Weissenborn says, that in Germany it wages an unrelenting war against the hamster, feeding chiefly upon it during the autumn, penetrating into its burrows, and taking up an abode there, if convenient, and laying up a store of frequently as many as ten dead hamsters. In England, and elsewhere, it commits great destruction among hares and rabbits, and with that insatiable thirst for blood which is natural to all the weasel kind, it kills much more than it can devour. Goldsmith says, he has seen taken out of the burrow twenty dead rabbits at a time, and which it had destroyed by a wound hardly perceptible. Lovell says it kills mice. Generally speaking, some feeling of fear deters both the fitch and the stoat from attacking the poultry, or other animals belonging to man; but when once they conquer their fear, they slaughter them to a great extent. A writer, residing in Selkirkshire, says, he has had indubitable evidence of a single fitch killing fifteen turkeys ? turkey poults] in one night. "The animal had dragged them all in beneath a large stack of firewood, where, with his killed prey lying around him, he was put to death on the following morning." + Pheasants, partridges, fowls, and pigeons, are equally liable to its attacks. Goldsmith says that, when it gets among pigeons, "it dispatches each with a single wound in the head,-and after killing a great number, and drinking their blood, it then begins to carry them away one by one to its hole; but if the opening by which it entered the dove-house, be not large enough for the bodies of the pigeons to be drawn through, the fitch contents itself with carrying away the heads, and makes a feast upon the brains." In Lorraine, and several of the adjoining provinces of France, where the fitch abounds to an excess, it is almost impossible to keep any poultry, in consequence of its frequent ravages. Aquatic birds are also

* Magazine of Natural History (1831), vol. iv. p. 12.

† Ibid. (1833), vol. vi. p. 207. 
the victims of its sanguinary disposition. Geese and ducks are frequently destroyed by it. Mr. Neville Wood says, that one morning he found, on entering an out-house at Foston Hall, in Derbyshire, ten young ducks lying dead, each with a hole in the neck; and in a few moments, a fitch marched out towards him, licking its yet bloody jaws, and without manifesting the slightest alarm. It drains both mammals and birds so thoroughly of their blood, that their flesh is soon rendered as white as veal. While a drop of blood is to be got it does not eat much, if any, of the flesh ; and it would appear to carry off and stow away the carcases, merely in case of their being required for food, when perchance it cannot procure enough of its favourite fluid:- at any rate the stolen carcases are frequently found in a putrid state, which would imply that the animal cares little about them.

The reptiles which it preys upon are frogs and toads. The Selkirkshire naturalist before quoted says, that in the month of June he noticed a narrow track leading from the long grass of a meadow, towards the bank of the river Ettrick, and which track he concluded was the morning path of a fitch. Having traced it to its termination at a hole in the ground, he procured a spade, and dug out five young fitches, nearly half-grown, sleek, clean, well-fed, and really pretty innocent-looking things. They were comfortably reposing in dry withered grass. From an apartment or larder at the side of them, he poked out and counted forty large frogs and two toads, all of which possessed enough life, and only enough, to sprawl their limbs out a little, but were incapable of moving away or intruding into the nursery. On examining them, he found that they had all been dexterously bitten through the brain, and, as he conjectures, for the purpose of keeping them in a state of reduced vitality until intended to be eaten. No other animals were found in its larder.

That the fitch will prey upon fish is attested by Aldrovand, Jonston, and several other ancient zoologists; and the fact is confirmed by more recent observers, especially by one who has described the habits of our native animals with as much correctness as he has displayed in representing their forms and attitudes 
to the eye by the means of his justly admired engravings on wood. Bewick says, that a fitch was repeatedly seen to resort to the bank of a river to catch eels, and that eleven of them were found in its retreat. In Germany, also, according to Dr. Weissenborn, large stores of eels have been found in its burrows in the neighbourhood of rivers.

" On some of the sea lochs on the west of Ross-shire, it has been observed to descend to the shore at night time, to feed upon the mollusks, particularly the large basket-mussel (Mytilus modiolus)."*

Besides the above various articles of food, it also feeds upon birds' eggs, and drinks milk when it has the opportunity.

The female makes her nest either in a rabbit-burrow, a hole in a rock, or amongst a heap of stones, grown over with grass or shrubs, situated in some retired spot, though usually in the vicinity of a farm. She has from three to six young ones at a litter. As the young have been found in the nests in April, May, and June, it is not altogether improbable that the fitch has two or more litters in the year.

In winter the fitch, which can neither stand excessive cold nor heat, leaves its abode in the woods and betakes itself to barns, hay-lofts, \&c.; remaining hidden about them during the day, and only leaving them at night-time, when it makes its attacks in the hen-roosts or the dairy.

It is almost impossible to thoroughly tame this animal. Formerly some of the Italian organ-boys used to exhibit specimens in our streets as tame ones, but they were always muzzled. It is recorded that a Mr. Craven having caught a fitch, and also a rat, both young and about half grown, he kept them for nearly two years in a hutch, along with a couple of cats; and that they all lived together on the most friendly terms. On one occasion the fitch and the rat were kept without food for two days, but even the pangs of hunger could not induce the one to attack the other.t Perhaps in this instance, however,

* Magazine of Natural History (1833), vol. viii. p. 227.

† Field Naturalist's Magazine (1833), vol. i. p. 324. 
all the animals mentioned felt themselves to be so equally matched, that neither had courage to commence an attack.

Painting brushes, called fitch brushes, are made of the hairs. The entire fur, when properly dressed, and especially if obtained in the winter, is both excellent and beautiful; but the process required to rid it of its fetid odour is a difficult one. Numbers of the skins are annually imported into this country, from the North of Europe. As the animal is commercially known by the name of Fitch, I have preferred calling it so throughout the present article; and it is under this name only that Lovell speaks of it in his curious Panzoologicomineralogia (1661). The name of pole-cat, which is certainly an objectionable name as it implies relationship to the feline tribe, has puzzled the etymologists; and a late writer conjectures that it is merely a contraction for Polish cat: but as I find that in the History of Brutes, by W. Franzius, translated by N. W. (16;0), pages $21 \%$ and 218, the animal is called poltcat every time it is mentioned, I suspect that the latter was its original name, and was meant to express its attachment to the poults, or young poultry.

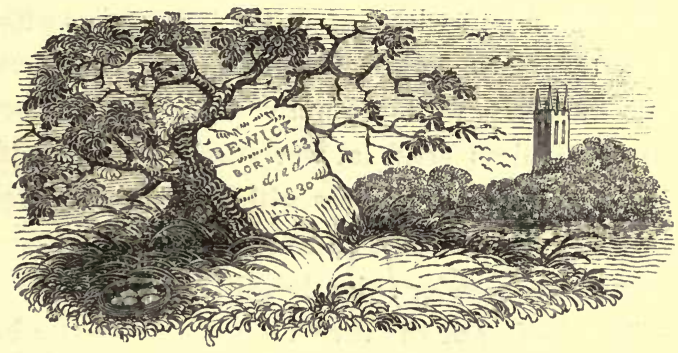




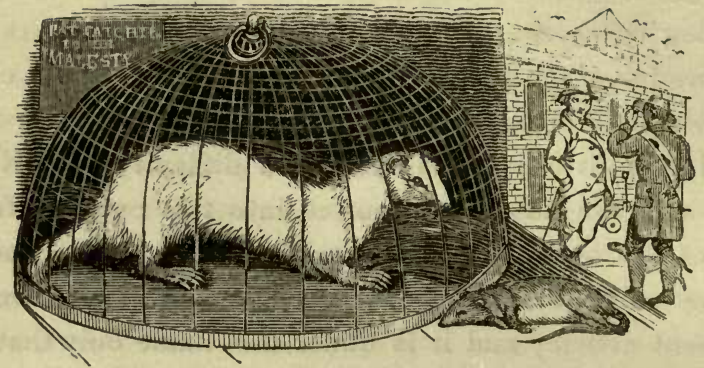

The Ferret.-(Mustela furo. Linn.)

The ferret was originally a native of Africa. Strabo mentions its importation from that quarter of the world into Spain,* from whence it has become distributed over Britain, France, Italy, Germany, and other European countries. Owing to the obscurity which prevails respecting the natural colour and appearance of this animal as it exists in Africa, many persons have concluded that it is merely an albino, or white variety, of our common fitch; but the geographical range of the latter is limited to the northern and temperate parts of Europe, where it bears a considerable degree of cold with impunity, and pursues its prey for miles across the snow; while the ferret perishes if exposed to the cold of a moderate winter in our country, -in whose southern parts, even, it requires artificial warmth. Moreover, if the two animals be compared, differences will be observed, not only in their colours, but in their size and form. The ferret is somewhat smaller and more slender; its head is rather narrower; its cranium a little higher at the vertex; and its muzzle longer and more pointed.

The length of the ferret from the nose to the end of the body is one foot two inches, or, including the tail, one foot seven inches and a half. The eyes are fiery red, or pink; and the body is usually of a yellowish colour, with more or less white intermixed, owing to the long fur being partly white, whilst the

* Strabo, edit. Casaubon, lib. iii. p. 144. 
shorter is almost wholly yellow. Franzius describes the ferret of his time as having "a little head, a red back, and a white belly,"*-a description which, as far as it goes, would agree with the African fitch (Putorius Africanus, Desmarest).

In temperate climates the utmost care and great warmth are required to preserve this delicate animal. It is usually kept in a hutch or box containing wool, of which it forms a warm and snug bed for itself. It sleeps during the greater part of the day; but towards night it wakes up, and shows great impatience for a supply of food, which, in its domesticated state, generally consists of bread and milk. It is not difficult to be tamed, and then will permit itself to be handled and played with, and this appearance of gentleness and good temper sometimes leads to its being indulged with the run of the house. But no reliance can be placed on its conduct; for unless carefully watched, and well fed, it will make savage and indiscriminate attacks upon all around, if it should chance to smell or taste blood. It is easily irritated while in its hutch, and will then bite severely, diffusing at the same time a more strongly offensive smell than ordinary.

In its half-reclaimed state, the ferret is a useful animal to man; for he employs it to pursue and kill rats and other vermin, and to assist him in catching rabbits by driving them out of their burrows, for which purpose it was also used in the time of Pliny. $\dagger$ It was introduced into Spain expressly to reduce a most inconvenient superabundance of rabbits in that country. When it is required to assist in catching the rabbits alive, it is muzzled previously to its being sent down their burrows. The ferret being thus rendered incapable of injuring the rabbits, can still alarm them, so that in their fright they attempt to make a hasty retreat from the mouth of the burrow, where, however, they become inextricably entangled in the meshes of the net, which the warrener has placed there to catch them. Should the ferret, while in the warren, get disengaged from its muzzle, it

* History of Brutes, translated by N. W. (1670), p. 216.

† Hist. Nat. lib. viii. cap. iv. 
will seize the rabbits, gorge itself with their blood, and then fall asleep instead of returning to its master. When the ferret is guilty of this dereliction of duty, the warrener has either to dig his way down to it, or to smoke it out. Sometimes, however, the ferret has been known to succeed in maintaining this state of liberty all the summer, regaling itself with the blood of the rabbits during the whole season; but when the winter has set in, it has either perished from cold, or been obliged to leave its lodging, and submit to be recaptured. If permitted to seize a rabbit above ground, it generally seizes it by the neck, winds itself round it, sucks its victim's blood, and does not leave it until completely satiated.

Frequent attempts have been made to keep the ferret on board ship, for the purpose of killing the rats, which prove so destructive to vessels and their cargoes; but this mode of life appears so badly suited to it, that it seldom stands it for any length of time.

Besides rabbits and rats, it will feed upon pigeons, fishes, and milk.

The ferret breeds twice in a year, and the female goes with young six weeks. She has from six to nine at a litter, and is reported to bring forth more females than males. Sometimes she will devour her young as soon as they are born, and will breed again soon afterwards. "Warreners assert," says Pennant, " that the fitch will intermix with the ferret, and they are sometimes obliged to procure an intercourse between these animals to improve the breed of the latter, which, by long confinement, will abate its savage nature, and become less eager after rabbits, and consequently less useful. The Rev. Mr. Lewis, viear of Llansowel in Caermarthenshire, had a tame female ferret, which was permitted to go about the house. At length it absented itself for several days, and on its return proved to be with young, and produced nine of a deep brown colour, more like the fitch than the ferret. What makes it more certain that they were begotten by a fitch is, that Mr. Lewis had no male ferret; neither was there any within three miles, and these 
closely confined."* Buffon denies that these animals ever breed together, yet he has published a figure of what he calls le futre putois, + or fitch ferret, which, as Pennant observes, has much the appearance of being the spurious offspring of such an intermixture. Professor Bell says, he can obtain no authentic verification of the assertion that the breeders of ferrets have recourse to the fitch to improve the breed; but Mr. Yarrell assures me that it is a fact, and that he has often seen ferrets whose coats were, consequently, of a brown colour. Goldsmith speaks of brown, blackish, and also parti-coloured ferrets. Mr. Blyth says, that " the stoat and pine-marten, in confinement, have been known to breed with the ferret, or domesticated fitch." $\ddagger$

Goldsmith says, the ferret has been known to attack and kill children in the cradle; and Mr. Jesse relates, that at Kingston in Surrey, some years ago, a poor woman, having left her child (about six months old) in a cradle, while she went to market, a large ferret, which was formerly shy and gentle, made a ferocious attack upon the helpless infant. The neighbours heard the child's screams for more than half an hour; and it was not until the return of the mother, that it was found almost killed. She carried the child to a surgeon, who found that the face, neck, and arms were dreadfully lacerated, the jugular vein and temporal artery were opened, and the eyes greatly injured. Having stopped the flow of blood, the surgeon accompanied the mother to her home, on entering which, the child, somewhat recovering from its exhausted state, began to cry, and in an instant the ferret rushed from his hiding place, and with his head erect, boldly approached towards the infuriated parent, who still had the infant in her arms. The surgeon kicked the ferret, but the animal tried to seize his leg; and not until his back was broken by repeated kicks, did he discontinue his eager attempts to renew his sanguinary feast; and, indeed, whilst in the agonies of death, he seemed to make vain efforts to regain his prey.

* British Zoology (1768), vol. i. p. 79.

+ Histoire Naturelle (1749), tome vii. tab. 25.

$\ddagger$ Mag. Nat. Hist. (1835), vol. viii. p. 199. 
" A bargeman, of the name of Isles, procured a ferret to kill the rats which did great mischief in his barge. Not seeing the ferret for a considerable time, and supposing that it was feasting on some of its prey, the man went to sleep, but was awakened carly next morning by the ferret making a regular attack upon him. The animal had seized him near his eyebrow; and the man having vainly attempted to shake him off, at length cut off the body with a knife, but the head still stuck so fast as to be with difficulty removed."*

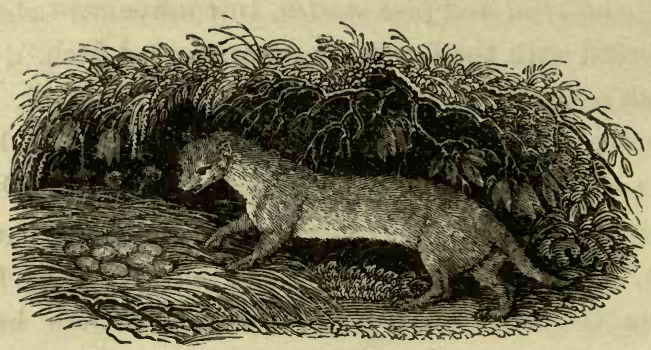

The Common Weasel.-(Mustela vulgaris.)

Whittret, or Withret.

The common weasel inhabits England, Wales, Scotland, Ireland, and most other parts of Europe. $\uparrow$

The male is ten inches and a half in length, from the nose

* Brown's Anecdotes of Quadrupeds (1831), p. 150.

$\uparrow$ Neither our common weasel (Mustela vulgaris) nor our ermine ( $M$. erminea) are found in America; the most common species inhabiting that quarter being a distinct though intermediate one, according to that zealous and acute zoologist, Charles Lucien Bonaparte, who has given it the name of Mustela cicognanii. These distinctions should be remembered, as much confusion has already occurred in European and American publications on zoology, owing to the authors of them taking it for granted that the commonest animals of a genus in both these quarters of the globe are the same. Thus a redbreasted thrush, improperly called the American robin, has had its habits introduced into the natural history of the true robin of Britain; and a species of grosbeak, improperly called the Virginian nightingale, has had its history mixed up with that of the true Philomel of the poet and naturalist. 
to the tip of the tail; but the female, which in Surrey and Hampshire, is called a cane or kine, is only nine inches in length; both, however, are much longer than they are high. The upper part of the body, the sides, and tail are of a chesnut brown; and the belly and throat are pure white. The eyes are small and black, the whiskers long, and the tail pointed. From the fact that the weasel is sometimes found entirely white, Linnæus named it $M$. nivalis.

A gland beneath the tail emits a very strong fetid smell, which is more offensive in summer than in winter, and still more so when the animal is molested. It hisses when thwarted or alarmed, and squeaks when hurt.

The deserted gallery, or burrow of a field mouse, is the favourite summer residence of the weasel; and it usually chooses one in a bank, over-grown with the roots of bushes, and having two openings, so that if one is besieged, it can make its exit at the other. In winter it chiefly resides in barns and farm houses.

The weasel is remarkably active and vigilant:-hence the proverb, “You'll never catch a weasel asleep." It has ordinarily a creeping pace; but when in pursuit of prey, it will run, spring several feet from the ground, ascend a wall, or swim across the water. Dr. Kidd, of Godalming, observes that " it runs very awkwardly on level ground; the great length and slenderness of body, and the shortness of the legs, being very much against speed; but in climbing trees, or threading the long and narrow galleries of field mice, this seeming disproportion is of the greatest use to it. I have seen it coursing along the boughs of a tree, winding itself round, above, or below, just as suited its purpose, with all the ease and agility of a squirrel. I have watched it enter a wheat-rick at the bottom, and in less than a minute have seen it peeping from under the thatch, having travelled there, most probably, through some of the numerous galleries which had been made in the rick either by rats or mice." *

At the approach of evening, the weasel comes forth in search * Mag. Nat. Hist. (1833), vol.vi. p. 196; abridged. 
of prey, which it hunts not only by sight but by scent.* Usually the prey is hunted by only one, or a pair of weasels, but sometimes several associate together in a pack, consisting of a dozen or more; and thus united, they chase and kill hares, rabbits, and sometimes even the bolder species of mammals. Dr. Kidd says, that as he and a friend were sitting on a stile at Northbrook, a very large rat came bustling down an adjoining bank, pursued by a weasel. "The rat," the Doctor says, " had crossed the path, and got into a little low bank on the other side of the footpath, over which he scrambled, and came out in the adjoining field, at the very moment the weasel went into the low bank hunting him. The rat ran in and out of some small turnips, sown wide apart, and then making a little circle, he came to the bank a good way from where we sat, and, climbing over it, got into the footpath about a hundred yards from us. He then ran towards us with all his might, straight along the middle of the path, and passed under the stile on which we were perched as motionless as statues, he then entered a thick bank, and was lost to our sight. The weasel hunted well in the little low bank, and seemed a good deal puzzled, staying there much longer than the rat; at last he seemed to have found out that his game had taken to the turnips, and he pursued him with great earnestness; but, finding the trick that had been played to puzzle him, he, like a reasoning creature, made a large circle, going completely outside all the trail : by this scheme he recovered the scent just where the rat had last gone over the little bank. In a few moments the weasel was in the footpath, and came galloping towards us in fine style, his back arched, his head up like a fox-hound running breast high, and his tail in a straight line behind him. He passed under us, and, in his eagerness, overshot the spot where the rat had gone into the bank; but he soon came back, quartered the ground, found the trail, and immediately entered the bank. Presently we saw the rat ascend the stem of a black-

* Captain Lyon appears to be the first observer of this habit of the weasel tribe, for he says that in North America he has seen an ermine ( $M$. cicognanii) hunt the footsteps of mice like a hound after a fox. 
thorn which overhung the path. The weasel was close after him, and gained on him; when the rat dropped down into the footpath, and the weasel did the same, and followed him up the bank within a foot. We heard a shrill cry, then short, shorter, then all was still : we went quietly to the place, and then the weasel left his prey, hissing at us like an angry cat. I picked up the rat, and found that his brain was laid completely bare, but his little heart continued beating for nearly a minute."*

The late Mr. White, farmer, in Derbyshire, speaks thus highly of the weasel's services. "It was of great value to me during the years 1802, 1803, and 1804, in killing the mice which infested my wheat-ricks. One day I saw on the roof of a wheatrick a weasel, seemingly intent upon watching for its prey : he suddenly entered a hole in the thatch, and brought out a mouse, and was immediately followed by another weasel, also carrying a mouse. They entered another hole in the rick, and came out at the bottom, each bearing its prey. They crossed the rick-yard, and entered a hole in a bank, which led under an ash-tree. In about five minutes they returned without their loads, crossed the yard, and entered the same rick again; when one of them stationed itself by the hole, as before. On the approach of a mouse to the hole, in the hope of escaping, the weasel again darted into the hole, and very shortly both the weasels returned, each bearing a mouse, as before, which they conveyed to their nest under the ash-tree; and this they repeated four times in about an hour and a half-thus destroying eight mice. I soon afterwards saw them, accompanied by four young ones, enter the wheat-ricks again. This favourite pair continued for three years, each year producing a young brood, which disappeared the following spring." $\dagger$

Mr. Thomas Blair, of Stamford-hill, says, that some years ago, while he was standing on the top of a ladder, he observed " a mouse come from a thick yew hedge, in a peculiarly hurried manner, and make various doublings among some beds of very

* Mag. Nat. Hist. (1833), vol. vii. p. 195. abrilged.

+ Itid. (1835), vol. viii. p. 610 ; abridged. 
young asparagus : it appeared to be in search of a hole to escape into, and disappeared, at last, amongst some bushes at the end of a wall. At about the same instant a weasel appeared from the same spot in the hedge from which the mouse had started, and followed all the several windings it had taken, exactly in the manner of a dog 'on scent,' and disappeared at the same spot."*

Nearly two hundred years ago, it was stated by Lovell and Franzius, that the weasel feeds on moles; and, in later times, Gilbert White suspected that it preys on them, from the fact of its being sometimes caught in mole-traps. In 1831, however, an instance was published of a weasel having been actually seen to make several attempts to get a captured mole out of the wires of a trap. "The weasel ran up the stick which formed the spring of the trap, and then descended on the captive, which he seized; and tried, by wriggling, twisting, and hanging by it, to appropriate to his own use, but without success. When exhausted with his efforts, he relinquished his hold, and dropped on the ground; where, having taken breath, he ran up the stick again, and renewed his task with redoubled ardour." $\dagger$ Mr. Couch, of Polperro, in Cornwall, also states that the weasel preys on moles. $\ddagger$

Besides hares, rabbits, moles, common rats, and mice, it destroys water-rats and field-mice; even birds are not free from the attacks of this little but most determined animal. It destroys common fowls, ducks, partridges, pigeons, and sparrows, and is most partial to young birds. It is also fond of eggs, and will kill the hen if she attempt to protect them from its invasion. Before eating an egg it makes a small hole at one end, through which it sucks the contents, leaving the shell entire, with the exception of this little orifice. It has been stated to destroy great quantities of insects; $\S$ and though this

* Mag. Nat. Hist. (1833), vol.vi. p. 268; abridged.

+ Ibid. (1831), vol.iv. p. 337.

$\ddagger$ Ibid. (1834), vol. vii. p. 500 .

§ Dictionary of Nat. Hist. or a Summary of Zoology. (No date.) 
statement is $n_{0}$ t repeated by recent writers, still it is not unlikely to be true.

After all, however, the weasel chiefly preys on rats, and the smaller species of mice; hence, to give him " his due," he is, " take him for all in all," a useful creature; but where few poultry are reared, and agriculture is the principal occupation, he ought not to be molested, in consideration of his services among the corn-stacks* and flour-mills, where he is more useful indeed than either the dog or the cat. Goldsmith says, that in confinement it will not touch its food until it begins to putrefy. Sometimes, when pressed by hunger, or emboldened by the strength of numbers, weasels will pursue and attack mankind-of which fact several instances have occurred. It is, indeed, a very serious thing to encounter a pack of weasels, for their great activity renders it impossible to watch and frustrate the designs of all. When it is known that two weasels are a match for a dog, it may be easily imagined what sort of chance an unarmed person must have when beset by a dozen or more.

" One fine summer's evening, about forty years ago, as a Mr. Brown was returning from Gilmerton, near Edinburgh, by the Dalkeith-road, he observed a man, who was leaping about, and endeavouring to defend himself from the assaults of fifteen or twenty weasels; and which he was tearing from him, and trying to keep from his throat, to which they seemed to direct their course. Mr. Brown joined in the combat,- -and, having a stick, contrived to hit and kill several of them. Seeing this, the others became intimidated, and speedily disappeared in the fissures of an adjacent rock. The man was nearly overcome with fatigue and exhaustion, having been engaged in his struggle with the weasels, as well as he could guess, for above twenty minutes; and, but for the timely assistance of $\mathrm{Mr}$. Brown, he said, he must have inevitably fallen a victim to

* Dr. Johnson, in his Dictionary, which abounds in the most absurd definitions of animals and plants, tells us, that the weasel is " a little animal that eats corn and kills mice." This is worse than his definition of a guinea-hen: " a showy bird, with fine feathers." 
their fury, as he found himself quickly losing strength from the violence of his exertions. He had squeezed two to death, while tearing them from him. His hands were much bitten, and were streaming with blood. The account he gave of the beginning of the affray was, that he was walking slowly through the park, when he perceived a weasel; he ran at it, and made several unsuccessful attempts to strike it; on coming near the rock above mentioned, he got betwixt it and the animal, and so cut off its retreat; the weasel squeaked aloud, when an instantaneous sortie was made by the whole colony, and the attack commenced upon him."*

"In January, 1818, a man in the parish of Glencairn, Dum. friesshire, was suddenly attacked by six weasels, which rushed upon him from an old dike in a field. Alarmed at such a furious onset, he took to his heels, but he soon found he was closely pursued; and, although he endeavoured to protect himself by several back-handed strokes with a horsewhip, yet, so eager was their pursuit, that they were about to seize him by the throat, when he hastily snatched up the fallen branch of a tree, with which he killed three of them, and put the other three to flight." $\dagger$

Several years ago, a boy was hoeing a young quick-set fence, when several weasels rushed upon him, and attacked his legs with the most determined ferocity; terrified almost out of his senses, he roared out lustily, and his father, who was near at hand, ran to his help, and beat off the assailants with a hoe. Scarcely, however, had he turned his back, before they made a second attack, as furious as the first, and were obliged to be repelled in a similar manner; a third was even menaced before they were finally put to the rout.

"A young woman, walking from the town of Kirkcudbright, heard some shrill shrieks proceeding from the bottom of a dike over which she was climbing; being a little alarmed at this, she hastened a few steps forward, and upon looking back

* Brown's Anecdotes of Quadrupeds (Glasgow), 1831, p. 142.

+ Ibid. p. 141. 
she observed two weasels running after her, and which were soon followed in the chase by upwards of a dozen more. She set off at full speed to reach another dike, over which she jumped, hoping thereby to place a barrier between herself and her pursuers; but, to her great surprise, they came bolting through the holes of the second dike also, chasing her apparently with the most determined fury. For upwards of a quarter of a mile the furious creatures continued close behind her; and it was not until she reached a piece of rising ground, on the other side of the bog, that she fairly outstripped them, and reached home safely.

"Several years ago, in another district in Scotland, a farmer, while riding on horseback through boggy land, over which he could make but little speed, roused by accident upwards of twenty weasels from an old dike, in which they had burrowed. They sprung up upon the horse's legs and the boots of the rider, and though he defended himself dexterously with the whip, yet, what with the jumping about of the terrified animal he rode, and the agility of his assailants, he declared he fought, as for his life, to beat them off." *

The nest of the weasel is usually placed either in a hole in a bank or dry ditch, or in a hollow tree; and is formed of grass, hay, leaves, and moss. Buffon tells us that the putrid carcase of a wolf having been hung up as a terror to others, a weasel entered its throat and formed a nest there, and had produced her litter, before the fact was discovered by a peasant. The young, from four to five in number, are born with their eyes closed; but they are soon able to leave the nest and hunt with their parents, who shew great affection towards them, and will fight for them against a dog, if he should attempt to touch them. Even if a man seizes her young, the weasel, although alone, will make some attempt to regain them as the following anecdote will shew :- “A labourer was standing in a footpath close to a hedge, at Chilwell, near Nottingham, when he saw a weasel with a young one in her mouth, advancing towards him.

* The Times, Oct. 18, 1839. 
The animal was so intent on her burden that she did not see the man till he kicked her, when she dropped her young one and retreated into the bottom of the hedge. The man then stood over her helpless offspring, with a large stick in his hand, merely to see how the parent would proceed. She soon peeped out of her covert, and then made several feints to get her charge ; but was obliged to run into the hedge again, apparently intimidated at the stick which he flourished and knocked about. At last she summoned up all her resolution for one grand effort; and in spite of the opposition of the man, after a great deal of dodging to avoid the stick, which he used in cvery way to keep her off without hurting her, she fairly succeeded in obtaining the object of her solicitude, and bore it off in triumph from between his legs."*

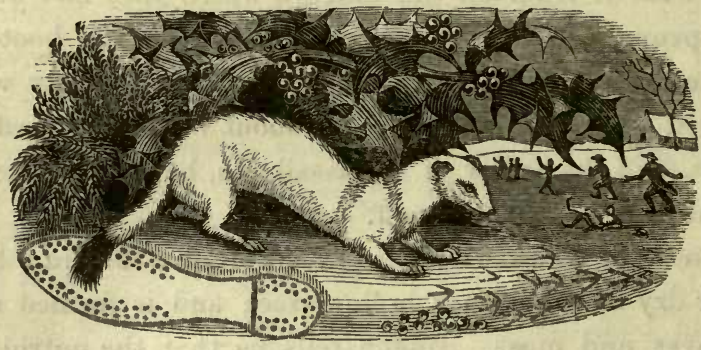

The Stoat or Ermine.-(Mustela erminea, Linn.)

Greater Weasel. Stout.†

The stoat or ermine, though common in Britain, is most abundant in the wilds of Russia, Norway, Siberia, Lapland, and other cold countries of Europe and Asia.

It is nearly ten inches in length from the nose to the rump; and the tail is about four inches and three-quarters. It is about one-third larger than the weasel, with which it is often confounded owing to a close resemblance in form. The other points

* Mag. Nat. Hist. (1831), vol. iv. p. 338.

+ A writer in the Quarterly Review (Sept. 1836, p. 90), says that in Yorkshire the stoat is also called clubster, clubstart, and clubtail; and, in Norfolk, is known by the name of lobster. 
of distinction are, that the head of the stoat is broader in proportion to its length, and the tail longer, more bushy, and tipped with black. The upper part of the head, neck, and body, and more than half of the tail, are light reddish brown; the under parts white, slightly tinged with yellow; the edges of the ears and the ends of the toes are yellowish white. Such is the description of this species when in that garb by which it is known as the stoat; but when it has been long exposed to the action of cold, either from its choosing to inhabit bleak mountainous localities, or from its being overtaken by a severe winter, the whole of the fur becomes white, with a slight tinge of yellow, except the end of the tail which retains its black colour. Towards the end of autumn, and in the beginning of spring, its fur presents a pied or mottled appearance, owing to the transitions which the variations of temperature are then affecting in its colour. In its lighter coat it is called the ermine, and its fur is then most prized, and especially if obtained in a very cold northern climate, in which case the hairs are not only longer and thicker, but of a purer and brighter colour. It is not strictly correct to say that the stoat changes to white at the period we assign to the winter, whether it be cold or otherwise, for during mild winters, hardly deserving of the name, only a few stoats become white, and some of those not until the latter part of the season. Mr. Henry Berry, of Bootle, near Liverpool, says he has seen ermines " in every season of the year, on what are called the Mosses, on the western coast of Lancashire; and says that while resident in Worcestershire, a week seldom passed without his observing an ermine which used to emerge from a coppice and excite much attention by its singular practice of invariably pursuing its course over a gate-post, which stood in a fence in front of the house. Stoats abounded in the same neighbourhood, and were captured at all seasons and always of the same [reddish brown] colour."* Mr. Blyth thinks that the ermines alleged to have been seen in summer were albino varieties with white tails, or else had been prevented by constitutional debility from resuming 
their summer dress.* But I am inclined to conjecture that the ermines said to have been seen in summer, are such as have resided, during that season, in the higher and colder parts of the rocks and mountains.

Professor Bell thinks this change of colour is effected, "not by the loss of the summer coat, and the substitution of a new one for the winter, but by the actual change of colour in the existing fur. It is not perhaps easy to offer a satisfactory theory of this phenomenon, but we may perhaps conclude that it arises from a similar cause to that which produces the grey hair of senility in man, and some other animals : of this instances have occurred in which the whole hair has become white in the course of a few hours, from excessive grief, anxiety, or fear ; and the access of very sudden and severe cold has been known to produce, almost as speedily, the winter change, in animals of those species which are prone to it. This transition from one state of the coat to the other, does not take place through any gradation of shade in the general hue, but by patches here and there, the winter colour being intermixed with that of the summer, and giving a pied coat to the animal.

"In northern latitudes, even in the alpine districts of Scotland, this change is universal; but further south it becomes an occasional, and even rare occurrence. In Northumberland, Durham, and other counties in the north of England, it is very frequent, although far from general: in Lincolnshire, and the midland counties generally, it is sometimes seen; and two specimens of the ermine taken in Cambridgeshire are contained in the museum of the Cambridge Philosophical Society. Mr. Couch states, that he has seen it more than once in Cornwall.

"It appears to be established that, whatever may be the change which takes place in the structure of the hair, upon which the alteration of colour immediately depends, this transition from the summer to the winter colours is primarily occasioned by actual change of temperature, and not by the mere advance of the season.

* Mag. Nat. Hist., vol. viii. p. 50. 
" One object of this change of colour, is the safety the animal obtains by an approximation in its colour to that of the earth's winter covering. The alpine hare, the ptarmigan, and many other mammals and birds, are more or less liable to become the prey of rapacious birds or other creatures, which are directed in the chace by their sight. The mottled browns which form the principal summer colours of these creatures, are well adapted for their concealment amongst the brown heaths and fern of the summer and autumn; but such colours would render them conspicuous by contrast among the snows of winter.

"But this, though perhaps the most obvious, is not the most important advantage gained by the assumption of the white clothing in the winter season. It is well known that although the darker colours absorb heat to a greater degree than lighter ones, so that a dark is much warmer than a light-coloured clothing, when the wearer is exposed to the sun's rays-the radiation of heat is also much greater from a dark than from a light-coloured surface, and consequently the animal heat from within is more completely retained by a white than by a dark covering: the temperature therefore of an animal having white fur, would continue more equable than that of one clothed in darker colours, although the latter would enjoy a greater degree of warmth while exposed to the sun's influence. Thus the mere presence of a degree of cold, sufficient to prove hurtful if not fatal to the animal, is itself the immediate cause of such a change in its condition, as shall at once negative its injurious influence." *

The stoat haunts woods, hedges, and meadows; especially where there are brooks, whose sides are covered with small bushes; and sometimes, though not so often as the weasel, it inhabits barns and other buildings. In Siberia it burrows in the fields; and in Britain it is known often to lodge during the winter in the excavations of the mole.

It pursues its prey by tracing the scent, exactly in the manner

* Abridged from A History of British Quadrupeds (1837), p. 150-154. 
of a hound.* When the scent is its only guide, the stoat runs with its nose close to the ground all the time, until it has its prey within sight, and then it holds its head up high. If the fugitive take to the water, the stoat will do so likewise; and a writer says, that one fine evening in spring, he observed a stoat swim gently across the deep and wide expanse of the river Wear, between Schincliffe Bridge and Old Durham, and that while swimming, "it lifted its head and neck out of the water like a dog." +

Hares, rabbits, rats, water-rats, mice, pheasants, partridges, pigeons, and, indeed, all kinds of birds, and of every size, are the victims of its rapacity, and to capture them it displays great boldness, cunning, and agility. It is said that it always seizes hares and rabbits between the ears, and then bites them through the brain,- the way in which the ferret, when not muzzled, kills the latter animals. + Professor Bell says, that because it cannot follow mice into their runs, which are often not much larger than their own bodies, "the stoat leaves such small game to its little congener the weasel, and betakes itself to prey more suited to its own bulk." I have no doubt, however, that he is mistaken in thus asserting that the stoat despises such small game as field mice. Pennant states most distinctly that it feeds upon mice. But lest the professor should be dissatisfied with the statement of one whom he has most ungratefully attempted to stigmatize as " a celebrated drawing-room zoologist," $§ I$ will

* Captain Lyon mentions his having seen an ermine (? M. Cicognanii) hunt the footsteps of mice like a hound after a fox. Fleming, in his Natural History of British Animals (1828), says " he has seen it tracing the steps of a hare with as much accuracy as a harrier." Further testimony of this interesting fact is published in the Magazine of Natural History, vol. v. (1832), p. 721; vol. vi. (1833), p. 202.

† Mag. Nat. Hist. vol. v. (1832), p. 723. $\quad \ddagger$ Ibid. vol. vi. (1833), p. 202.

$\S$ Bell's History of British Reptiles (1839), p. 107-a work containing much interesting information, derived from Dr. Robert Townson's Tracts on the Physiology of the Amphibia, first published in Germany, and subsequently printed in London, " for the author," in 1799. Though the professor's work exhibits the clearest evidence of a knowledge of Dr. Townson's Tracts, yet he neither mentions them nor the author. I apprehend that Pennant would have adopted a different course. 
adduce the testimony of more recent writers. W. L. of Selkirkshire, who has written an interesting essay on animals of this genus, says that " the stoat, by no means refuses a field-mouse any time that it may come in his way."* Sir Oswald Mosley says, that " during a severe winter, some years ago, he observed an ermine emerge from a tuft of grass with a field-mouse in its mouth; and then, having entered a contiguous plantation, it quickly ascended again, ran about under some leaves, and afforded its observer an opportunity of catching it. His thick gloves were proof against its bites, and the firmness of his grasp prevented it from escaping. After having given it several sharp blows it appeared to be dead, and he thought it was so; but as soon as he threw it on the ground, the little creature recovered its former liveliness and strength, and ran off with the greatest agility. On examining the fir-tree which was fifteen feet high, it was found that the ermine had safely deposited the mouse in a small bird's-nest built near the top." + These accounts I think sufficient to establish the fact of its preying upon mice, although the most frequent objects of its pursuit are the common rat and the water rat. Mr.W.H. White says, that in September 1834, he witnessed a furious contest between a stoat and a water rat. "The rat defended himself with great courage and ferocity, but was at length overpowered by the stoat, which seized him just under the ear, and bore him off to its retreat." $\ddagger$

"Some hay-makers on Chapelhope meadow, at the upper end of St. Mary's Loch, in Selkirkshire, saw an eagle rapidly soaring above the steep mountains, in a singular and agitated manner. They kept their eyes upon him until he was nearly out of sight. In a short time, however, they were all convinced that he was falling with great rapidity, like a shot bird; the convulsive fluttering of his powerful wings stopping the descent but very little, until he fell at a small distance from the party. On their approach, a stoat ran from the body, turned with the usual

* Mag. Nat. Hist. (1833), vol. vi. p. 203.

+ Abridged from the Analyst (1837), vol. v. p. 250.

$\ddagger$ Mag. of Nat. Hist., vol. viii. (1835), p. 609 . 
nonchalance and impudence of the tribe, stood up upon its hindlegs, crossed its fore-paws over its nose, and surveyed its enemies for a moment or two, and then bounded into a saugh* bush. The eagle was dead, and covered with blood which had issued from a wound in the throat.

"On another occasion, a person observed on the snow the track of a stoat, which is easily distinguished from that of the smaller species, by the larger foot-print and length of the bound or spring. He followed the track for some time, along the side of a hill, until he came to the marks where a pair of grouse had been sitting, when he lost all trace of the stoat. As there was no appearance of a hole, he was much surprised; but on close attention he felt convinced that it had seized one of the birds, which had flown away with it." $\dagger$

"About the middle of July, 182\%, a gentleman at Cathcart wounded a stoat. The animal having escaped into a hole in an old stone wall, the gentleman explored its retreat, when the first victims he met with, were a couple of leverets, unmutilated; a little further on, two young partridges, also entire; and a pheasant's egg, unbroken. Beyond these, were found the heads of two other leverets, in a state of putrefaction; and at the extremity of the hole, the little marauder was lying dead. It might have been thought that this extraordinary accumulation was the result of a provident disposition in the animal; but the putrid state of the detached heads of the two leverets, seems to confirm the common statement of naturalists, that the weasel tribe seldom devour any of their prey till it begins to putrefy." Fleming says that the stoat is fond of eggs and putrid flesh.

The female stoat brings forth about five young ones in April or May. Mr. Blyth says that, in confinement, the stoat has been known to breed with the ferret and the domesticated polecat. $\S$

Sir Oswald Mosley thinks that the stoat, whose propensities

* Id est, a willow.

† Mag. Nat. Hist., vol. viii. (1835), p. 609.

$\ddagger$ Brown's Sketches and Anecdotes of Quadrupeds (Glasgow), 1831, p. 148.

§ Mag. Nat. Hist., vol. viii. p. 199. 
are the same as those of the ferret, though it is much more bardy and less liable to disease, might be tamed and made as practically useful as the latter animal. At present, however, the stoat is turned to no account except when dead, and then the fur is the only useful part of it. The fur in the white or ermine state is the most prized, and is chiefly employed for the winter dresses of ladies, and the state robes of kings and nobles, and also forms a portion of their crowns and coronets. The few skins which are obtained in Britain, even in the northern districts, are sold at only two or three pounds per hundred; being very inferior, in beauty and value, to those which are imported from Russia, Norway, Siberia, and Lapland.

Ermine, in heraldry, is represented by black spots on a white ground. Sir George Mackenzie says, that the first who used this fur in arms was Brutus, the son of Silvius, who having by accident killed his father, left the scene of his misfortune, and travelling in Bretaigne in France, fell asleep, and when he awoke, he found one of these animals upon his shield, and from that time wore a shield ermine:

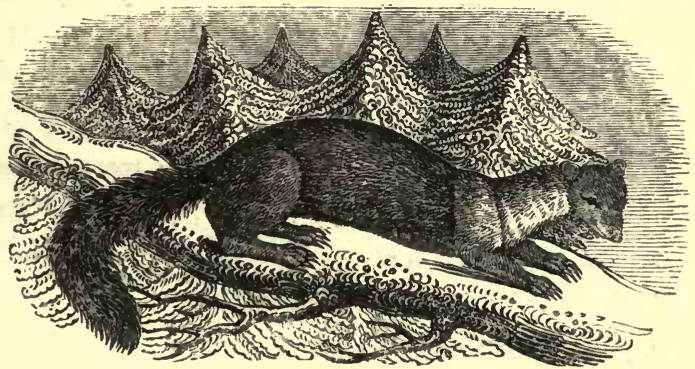

The Pine Marten, or Sweet Marten. (Martes Abietum, Ray. Mustela martes, Linn.)

"The martens reside chiefly in trees, and their structure is admirably suited for such haunts. Creeping from branch to branch in silent and stealthy pursuit of birds and other [arboreal] 
animals, their sharp and long claws afford them a firm and secure hold of the bark, while the long and somewhat bushy tail must considerably aid them in maintaining their balance on the boughs; the ears, too, are large and open,-a circumstance which is of great advantage to them in discovering and pursuing their prey, amid the dense foliage wherein they love to conceal themselves; and upon the whole the typical structure of the martens is evidently intended to fit them for living in trees, though it is true that they often descend to the ground to destroy small mammals." * The walk of the martens is of that kind which is technically termed digitigrade, meaning that they walk on their toes.

Most works on zoology contain separate histories of the Pine Marten, the Beech Marten, $\uparrow$ and the Sable; as though the animals so named had been ascertained to be distinct species. But the remarks which Mr. E. T. Bennett published on the propriety of this nominal distinction, ten years ago, are still applicable :-

"The justice of the separation of the pine marten from the beech marten, and of both from the sable, still remains open to investigation, with little chance of being speedily or permanently

* Bell's History of British Quadrupeds (1837), p. 168.

† The Beech Marten is the Martes foina of modern zoologists, the $M$. Fagorum of Ray, the M. Saxorum of Klein, the Mustela Martes of Linnæus, and the Mustela foina of Gmelin. Its English synonymes are not less numerous, for, besides beech marten, it is called stone marten, martern, marteron, martlett, and mouse-hunt. The last name I insert on the authority of Henley, the dramatic commentator, who says that it is the animal to which "charming Willie Shakespeare" thus alludes in Romeo and Juliet :-

Capulet. I have watch'd ere now All night

Lady Capulet. Ay, you have been a mouse-hunt in your time.

(Act iv. scene 4.)

In Knight's Pictorial Edition of Romeo and Juliet (1839), this and many other terms equally requiring explanation are left quite unelucidated; though one picture of the said mouse-hunt would doubtless have been more assistant to the professed object of the work than the two unnecessary pictures it contains of certain winged monstrosities called Cupids.-J. H. F. 
settled. After the most patient and attentive consideration which we have been enabled to bestow upon the subject, aided by the consultation of the best printed authorities, and the examination of numerous specimens, we have been unable to arrive at any satisfactory conclusion. On the one side we have the weight of great names in zoology, as well as the common consent of popular tradition, for regarding them as three distinct species; and this opinion is in some degree confirmed by the apparent permanence of certain characters, trifling in themselves, but which have been regarded as sufficiently important to establish a real distinction between them: on the other side we have authorities equally great for considering two at least out of the three as mere varieties of one common species; while the facts that have been observed tend to throw considerable doubt on the permanence of the distinctive marks, and to render it probable that these may be nothing more than the effects of climate, of seasons, of sex, and of age."*

The most conspicuous differences between the pine marten and the beech marten are those of colour; but as these seem " in some cases at least to be associated with certain slight diversities in size and proportion, and as the habits of the two animals also offer a trifling variation, there appears to be some, though far from satisfactory, ground for considering them as specifically distinct." $†$

In the voluminous work of Buffon and Daubenton, the latter who supplied most of the descriptive and all the anatomical details, seems to have hesitated whether to regard the pine marten and beech marten as mere varieties or not; and to have been at last induced to consider them as distinct species, merely by the fact that he had never met with a mixed or intermediate breed. "They resemble one another so closely," he says, " in external form and internal structure, that the sole distinction between them consists in the colours of the fur. The pine marten has the throat yellow, while that of the beech marten is white;

* Zoological Gardens Delineated (1831), vol. i. p. 230.

$\uparrow$ Bell's History of British Quadrupeds (1837), p. 175. 
and the tints of colour are altogether more beautiful, and their lustre more brilliant in the pine marten than in the other. Both are found in all kinds of woods, and even in those which have neither firs nor beeches:- the beech martin is also improperly called a [semi-] domestic animal, for although it seeks its prey in inhabited places, it is but little less wild than the pine marten."*

Pennant, in his History of Quadrupeds (1793), treats of the pine marten and beech marten as distinct, and observes that "all foreign authors agree that the pine marten never lodges near houses, as the other species is said to do ; $\dagger$ but even those beech martens which inhabit my neighbourhood always keep in the woods, except in their nocturnal excursions." In his British Zoology (1768), he remarks that " the claws of the beech marten are well adapted for climbing trees, which in this country," he adds, " are its constant residence."

So lightly did Linnæus value the distinctions indicated between the pine marten and the beech marten, that it was not until he published the twelfth edition of his Systema Natura that he intimated the existence of any difference between them. "The country people," he says, "reckon two varieties; the beech marten, with a white throat, and the pine marten, with a yellow." But it is evident from the manner in which he has introduced this reference to the popular notion, that he gave little credence to it.

To institute other comparisons between them it may be mentioned, that the legs of the pine marten appear to be longer and the head smaller than in the beech marten, and the fur is much more profuse, with a finer and softer texture, and a much brighter colour; hence it is more valuable than that of the beech marten, though very inferior to that of the sable.

* Histoire Naturelle, Générale et Particulière, avec les continuations par Daubenton, Montbeillard, et Lacepède, 45 vols. 4 to (1749-1804).

t The zoologists who have imputed to the beech marten a familiar and sociable disposition, and a partiality for the neighbourhood of inhabited places, are Gesner, Aldrovand, Jonston, Franzius, and Ray; the latter in his Synopsis Quadrupedem (1693). 
The beech marten inhabits the woods and forests of most parts of Europe. The odour it emits from its posterior glands is far from being fotid; but that emitted by the pine marten is thought by some persons to be really agreeable, and hence one of its names-sweet marten.

The pine marten is more rare in Britain than the other sort, and in England neither is found except in the northern parts. They are not very often observed, because being timid, they retreat before the advance of cultivation, to dwell unmolested in the more remote and secluded depths of the forest. The beech marten does sometimes, in the highlands of Scotland, where it is common and called tuggin, take to killing lambs, and makes sad havoc. Luckily, however, it is now nearly exterminated in the south of that country."* In Selkirkshire, the beech marten has been observed to descend to the shore at night time, to feed upon mollusks, particularly upon the large basket mussel (Mytilus modiolus). $t$ But the ordinary prey of both this and the pine marten appears to be hares, rabbits, squirrels, moles, rats, mice, game birds, turkeys, pigeons, and other domestic poultry, and also the wild singing birds.

The female pine marten makes her nest of moss and leaves in hollow trees, or else takes possession of the nest of the squirrel or the woodpecker. She is said to bring forth only two or three young ones at - a birth-a statement which, if correct, would materially tend to establish a distinction of species between this and the beech marten, which brings forth from two to seven, but usually four or five. But Albertus Magnus, who speaks of the beech and pine marten as distinct, asserts that they breed together; and if this statement were verified, it would go far towards establishing the identity of their origin. 


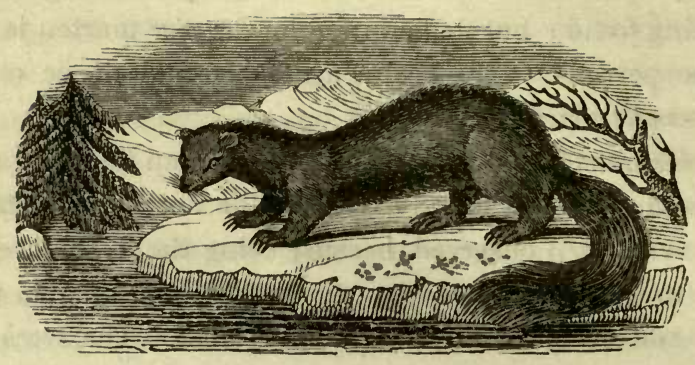

The SABLe.

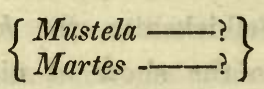

It has already been intimated in the preceding article, that it is questionable whether the sable be a distinct species from the beech and pine martens.

George Bauer, who, under the assumed name of Agricola, wrote a Treatise on Subterraneous Animals, published at Basil in 1549, speaks of a fulvous or tawny-coloured marten, which has a yellow throat, and rarely quits the shelter of the forest, and he adds that some think there are two kinds, the one living in beech, and the other in pine forests. The one that lives in pine forests, he says, is called zobel by the Germans, is rather smaller than the white throated blackish marten, and is wholly of an obscure tawny, except the throat which is ash-colour. It is, he continues, the most beautiful of all, and its skin is more precious than cloth of gold, insomuch that forty skins of the best quality have been sold for more than a thousand pieces of gold. From this account of the great price paid for its skin, we should judge that the Germans regarded the marten of the pine forests as identical with the sable.

Linnæus's character of the sable is principally derived from that of Ray, who says, "Dr. Tancred Robinson had seen the 
animal itself in the possession of Dr. Charlton. Its size was that of a cat of Cyprus ; its colour a dark tawny; the fore-part of its head and its ears of a whitish ash-colour ; and the bristles on its eyebrows, nose, and face, very long."

Pennant's history of the sable is more copious than that of previous naturalists, being partly taken from an account of the animal given by John George Gmelin, in $\mathbf{1 7 6 0}$ in the Memoirs of the Petersburgh Academy, and partly from Müller's Collection of Russian Histories, published in German, and containing many commercial particulars concerning it.

Though the sable is noticed by Albertus Magnus, George Bauer (Agricola), Gesner, Aldrovand, Jonston, Ray, Linnæus, Klein, Brisson, Buffon, Daubenton, and Pennant, yet none of these authors speak of it as an animal which they knew otherwise than by report. "It is said by most of them to inhabit not only Northern Asia and Russia, but Poland also, Scandinavia, and even Lapland. These latter habitats may, however, probably be considered as indicating nothing more than the countries through the medium of which the skins called sables were procured. The only two naturalists who have described this animal from personal observation, are J. G. Gmelin and Pallas, both of whom became acquainted with it while travelling in Siberia, to which country its range is expressly limited by the latter. The first of these writers had an opportunity of examining two specimens in the palace of the Governor of Siberia at Tobolsk, where they were kept alive for an entire year. He describes them as resembling the martens in their form and habit of body; the one being throughout the winter of an ashy black, cinereous on the chin, and yellowish round the ears; the other smaller, and of a yellowish brown, becoming somewhat paler on the chin and ears. On the approach of spring, the former animal became yellowish brown, and the latter pale yellow. A figure of the darker coloured specimen accompanies the account, and well deserves the epithet 'pessima' applied to it by Pallas. It affords no assistance in the discrimination of the species; but has, nevertheless, been copied in the Encyclopédie Methodique and 
many other works, as the truest and most authentic figure of the sable extant.

"In fact, were it not for the authority of Pallas, the great zoologist, we should scarcely hesitate in discarding the sable from the list of genuine species, and considering it as a mere variety of the pine marten, produced by climate and other concomitant circumstances. But his judgment, founded on a comparison of specimens both living and dead, carries with it too much weight to be shaken by any but the most positive evidence. In the absence of unquestionable proof to the contrary, we must necessarily take for granted the correctness of his decision, and regard the Siberian sable as distinguished from the European and Asiatic martens by the characters which he has pointed out; although these characters are not altogether in accordance with the statements of previous zoologists, and do not appear to have fallen under the notice of any subsequent observer.

"The general description of the sable given by Pallas is accompanied by a comparison of its several parts with those of a pine marten found in the same forest, almost the only one in which the two animals are met with intermixed, and the most western habitat of the true sable. The distinctive marks of the latter are made to consist in its somewhat larger size; a slight depression of the top of its head; a trifling elongation of its muzzle; the fur of the ears being on the outside exceedingly soft, pale, and silky, and their inside being lined with whitish hairs; the soles of the feet more woolly; the toes ending in a tuft of crisp wool completely enveloping the claws; the tail shorter than the legs when extended, and consequently much more abbreviated than in the marten,* and becoming perfectly black towards the tip, the blackness of the fur of the body, which in the marten had a yellowish tinge; and the ashy grey of the head, becoming brown on the muzzle, hoary about the eyes,

* " M. Desmarest has omitted the most important characters given by Pallas for the sable, and has, on his own authority, furnished it with a tail of twothirds the length of the body, while that of the pine and beech martens is stated to measure but little more than the half." 
and of a more obscure and dirty colour on the throat. Some of these characters, it will be seen, are very trivial, and others susceptible of variation. The slight differences in the form of the head are not greater than are found to exist in the same animal at different ages; and the colour, as we have seen from Gmelin's description, varies greatly in different individuals and in different seasons. The woolliness of the toes, supposed to be peculiar to the sable, had already been mentioned by Pennant in his description of the [beech] marten, in some specimens of which we have ourselves observed the same fact. And lastly, even the comparative length of tail, on which the greatest stress is laid, affords no absolute criterion; for Pallas himself states, that this organ is a little longer in the males, at least when young. His authority must, however, be allowed to overweigh all such considerations; and to indicate the existence of a true sable, as a distinct species from the martens, although unknown to later zoologists. It is certainly not a little singular that an animal so highly valued and so anxiously sought after, should still be a desideratum to the scientific world; but it is perhaps no less so that the opinion which has been so lightly adopted with respect to such well known animals as the indigenous martens, should never yet have been put to the test of direct experiment."*

Professor Bell says, that he has found " in the examination of numbers of the finest sable skins, that the yellow patch on the throat had always an irregular outline, and that there were also small spots of the same fine colour scattered on the sides of the neck;" and he adds that, he has never observed this distribution of colour either on the beech-marten or pine-marten, and he mentions the fact merely as one which, combined with other characters, may possibly assist in deciding the question of specific difference when we have gained fuller information on the subject.

* Zooiogical Gardens Delineated (1831), p. 240. 


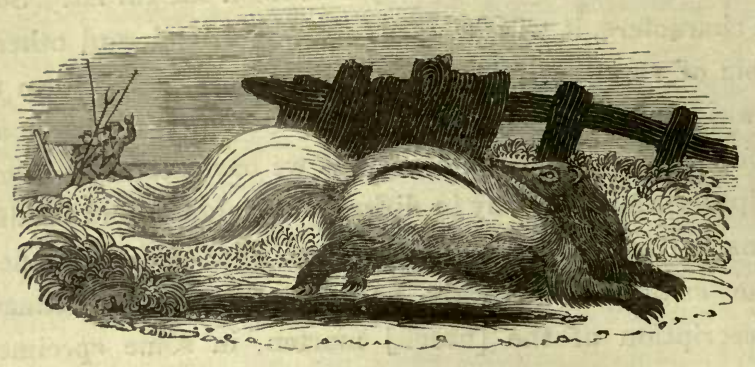

The Sкunk.-(Mephitis Americanus.)

Stinkard. Squash. American Polecat.

The present species of skunk is said to be peculiar to North America, where it is commonly known by the name of polecat. It is found as far north as Canada, and, according to Mr. R. C. Taylor, it also inhabits the north-eastern extremity of the Alleghany Mountains.

Its body is about a foot and a half in length, and its large bushy tail is nearly as long. The colour is generally brownishblack, with a large white patch on the back of the head; but there are many differently coloured varieties, in some of which the broad white bands of the back are very conspicuous.

The skunk burrows or forms a subterranean habitation among the roots of trees, or in rocky places. It feeds on young hares, rats, mice, and birds : like the European polecat, it also commits great depredations on the domestic poultry.

" The most remarkable peculiarity of this animal," as Audubon observes, "is its power of squirting for its defence a most nauseously scented fluid, from a receptacle situated under the tail, which it can do to the distance of several yards. It does not, however, for this purpose, sprinkle its tail with the fluid, as some allege, unless when extremely harassed by its enemies. A foreigner who was travelling with me from Louisville to Henderson in Kentucky, spied a beautiful specimen of the skunk, marked with black and pale yellow. My companion 
dismounted, and, with his large cloak floating in the breeze, laid his stick gently across the body of the animal to secure it. The skunk raised its fine bushy tail, and showered such a discharge of its offensive fluid, that my friend, dismayed and infuriated, began to belabour the poor animal. Its swiftness, however, saved its bones; and at every step as it retreated towards its hole, it continued the ejectment, which fully convinced the foreigner that the pursuit of it was at best an unprofitable employment. This was not all, however. I could not suffer his approach, nor could my horse; it was with difficulty he mounted his own; and we were forced to continue our journey far asunder, and he much to leeward. A heavy snow storm having begun, and almost impeded our progress, we made for the first cabin we saw. We entered, and found ourselves amongst a crowd of men and women, who had met for the purpose of corn-shucking. When we had stood the few stares which strangers must everywhere expect, we approached the fire. What a shock for the whole party! The scent which had been almost stifled on my companion's vestments by the cold of the evening air, now recovered its primitive strength. The cloak was put out of the house, but its owner could not be well used in the same way. The company, however, took to their heels, and there only remained a single black servant, who waited on us until supper was served. I felt vexed to see the discomfiture of the good traveller, who was not only deficient in zoological knowledge, but, fresh as he was from Europe, felt more than uneasy in this out of the way house. Some years afterwards, I met him in a far distant land, when he assured me, that whenever the sun shone on his cloak, or it was brought near a fire, the scent of the skunk became so perceptible, that he at last gave it to a poor monk in Italy.

"The skunk, however, is frequently domesticated. The removal of the glands prevents the secretion of the nauseous fluid; and after this precaution has been taken, the animal becomes a great favourite, and performs the offices of the common cat with great dexterity." 
Dr. Richardson says, that when care is taken not to soil the carcase with any of the fluid, the meat is considered by the natives to be excellent food.

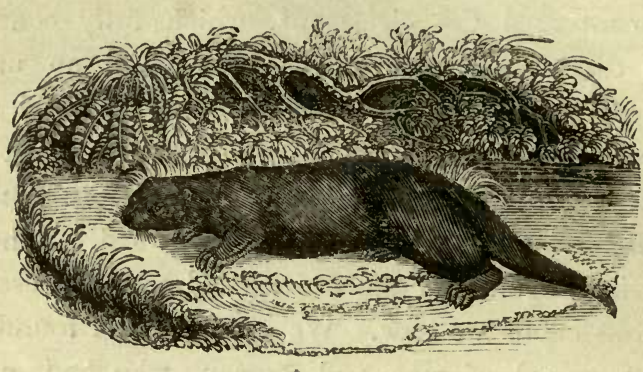

The Common Otter.

(Lutra vulgaris, Erxleben. Mustela lutra, Linn.)

This species inhabits England, Scotland, Wales, and probably many other European countries, but the extent of its geographical distribution does not appear to have been correctly ascertained.* In England, excepting the northern countries, the animal is now so scarce that the discovery of one is generally thought worthy of being recorded in the newspapers.

Pennant gives its usual full length, from the nose to the end of the tail, as three feet three inches; Captain Brown as three feet four inches; Professor Bell as three feet five inches and six lines; while a specimen, recorded $\dagger$ to have been recently shot by a $\mathrm{Mr}$. Wyatt, of Iffley Pound, near Abingdon, is stated to have been four feet eleven inches in length. Notwithstanding the various

* The Zoological Society's Museum contains a beautiful stuffed specimen of the otter of Ireland, which Mr. Ogilby contends is distinct from the above species; but Professor Bell does not think it possesses characters sufficiently apparent to induce the belief that it is more than a very dark and handsome variety of it.

+ Wiltshire Independent, March 5, 1840. 
statements of the greatest length to which the otter attains, all writers agree in stating the length of the tail to be one foot four inches. Bell says, that the usual weight of a fine male is from twenty to twenty-four pounds, and that of the female about four pounds less. We have, however, the record of an otter killed on the 1st of January, 1828, in the old river Deben, at Letheringham, and which weighed twenty-nine pounds; * and Pennant says, that, in 1794, an otter, weighing forty pounds, was found in the river Lea, between Hertford and Ware. All these statements, though greatly at variance with each other, may be perfectly true, and would, perhaps, be more easily reconciled if the recorders of them had informed us of the sex and probable age of the individuals to which they refer. In the history of the Polar bear, I have already pointed out the great variance in the statements of the length of adult specimens of that animal, which have been published by Pallas, Captain Lyon, and Dr. Richardson, men whom we cannot discredit.

The upper parts of the body of the otter are of a brownish or chesnut colour; the nose is black; the lips are whitish; the cheeks, inner sides of the legs, and the throat, breast, and belly, are brownish grey.t The head is compressed; the ears are short, semi-circular, and erect; and the eyes are so situated, that the animal can see objects above, even while the head is in a horizontal position; the feet are palmated, or webbed; the toes are covered with hair, and the surface of the tail is flattened. Its favourite haunts are the sides of rivers, streams, and lakes, especially such as have gravelly bottoms and high banks. Pennant says, it forms a habitation " by burrowing under ground on the banks of some river or lake, and always makes the entrance to its hole under water; works upwards to the surface of the earth, and there makes a minute orifice for the admission of air: it is further observed, that this animal, the more effectually to conceal its retreat, contrives to make

* Bury and Norwich Post, January 9, 1828.

+ In Scotland, the common otter is sometimes found spotted with white, and this variety is called by the common people, the King of the Otters. 
even this little air hole in the middle of some thick bush." On this statement, Goldsmith observes, "In some places it may be true, but I have never observed any such contrivance; the retreat indeed was always at the edge of the water; but it was only sheltered by the impending bank, and the otter itself seemed to have but little share in its formation." Its lurking place, which Goldsmith has so correctly described, may be detected by the quantity of its excrements, and the remains of its prey lying on the shore or the banks.

The otter can run tolerably fast, and it dives and swims with greater expertness and celerity than even the finny tribes themselves.

It lives chiefly upon fish, not only devouring great numbers, but destroying more than it consumes; so that it has been known to kill every fish in a pond in the course of one evening. It either catches its prey by rising under it, or by pursuing it into some little creek, and seizing it there. Mr. Stoddart observes, that " the otter, although naturally shy, and no lover of daylight, will, at times, when in the pursuit, show a bold front, and has been known to contest its prey with man himself.

A gentleman, when angling for pike on the Loch of the Lowes, \& about to land a fine fish of ten or twelve pounds weight, was surprised to observe a large otter swim ferociously towards it; nor did it cease its attack until it had succeeded in carrying away the pike, hook, and all.

Another person, when angling in St. Mary's Loch at night, has frequently been followed at a short distance by an otter, ready to pounce upon such fish as he might happen to hook. The same angler, lately a resident at the head of the loch, close to Corsecleugh, once observed one of these animals lying asleep upon a piece of meadow-ground, close to the water, and on attempting to kill it, was forthwith assailed in return, and compelled to retreat." *

The old ones are extremely strong and fierce, and never let go * Stoddart's Art of Angling. 
when once they have got hold of their enemy. In the Regent's Park Zoological Gardens there are two otters in a railed enclosure, containing a pond and an isolated dwelling for them, constructed of rock-work. They are partitioned from each other to prevent angry conflicts, as one of them is so exceedingly vicious, that it has been thought necessary to put up a notice, telling the visitors to beware of its biting them. Lately, to try the power of its teeth, I presented a walking-stick towards it, which it seized angrily, and held firmly for some time; and, when it let go of it, the marks of the teeth were visible to some depth. On throwing pebbles into the water, either of the otters dived after them, and in almost the next instant, so rapid are their movements, they emerged and brought them on shore. The feeding of these otters is one of the most interesting sights of the many to be witnessed in these delightful and instructive gardens.

In its wild state, if fish happen to become scarce or inaccessible, the otter preys upon terrestrial animals, and, approaching the farm-yards, attacks lambs and young pigs. Several writers say, that at such times it also feeds upon rats and insects; and Lovell says, it feeds on the " tops of plants, fruits, and bark."

With respect to the breeding season of the otter, the statements of zoologists are again at variance. Buffon says, that in France they couple in winter, and bring forth in the beginning of spring. M. Lots says, that in Sweden they couple about the middle of summer, and bring forth at the end of nine weeks, generally three or four at a time. Professor Bell says, that in Britain they produce from three to five young ones in March or April ; but Goldsmith, who appears to have carefully observed the animal's habits, asserts, that "with us the young are never found until the latter end of summer;" in which season, he says, he has frequently discovered them when he was a boy. The female litters under the hollow banks, upon a bed of rushes, flags, or other aquatic plants.

When tamed, the otter will follow its owner about like a dog, 
and will catch fish for him. It is said, however, that the old ones can never be thoroughly tamed; and, if kept for the purpose of fishing, are always apt to take the first opportunity of escaping. The young ones, before they have got accustomed to a life of independence, are, therefore, more easily managed. When they are captured they are taken home, and carefully nurtured with small fish and water. In proportion, however, as they gather strength, Goldsmith tells us, they have milk mixed with their food, the quantity of the fish provision is reduced, and that of vegetables is increased, until at length they are fed wholly upon bread, which perfectly agrees with their constitution. It requires both assiduity and patience to train them up to fishing; but their activity and use when taught, amply repays all trouble,-and, perhaps, no animals are then more beneficial to their master. The usual plan is, first to teach them to fetch and carry, employing for this purpose a piece of leather, shaped like a fish, and stuffed with wool. When they have seized it with their teeth, they are made to drop it at the word of command; to run after it again when thrown forward, and to return with it to their master. They are next exercised with real, but dead fish, which are thrown into the water for them to fetch from thence. Lastly, living fish are thrown into the water, until the otters are perfectly disciplined into the art of catching fish for the benefit of the lords of creation.

\section{The Sea Otter.-(Lutra marina.)}

This animal, which is twice the size of the common otter, is evidently of the same genus; yet Schreber's figure of it, apparently drawn from a badly-prepared specimen, presents an exaggerated resemblance to the seal, and has induced some zoologists to believe that its place in the systematic classification should be near to the genus comprising the latter.

Its body is very long; the hind feet are short, and the tail 


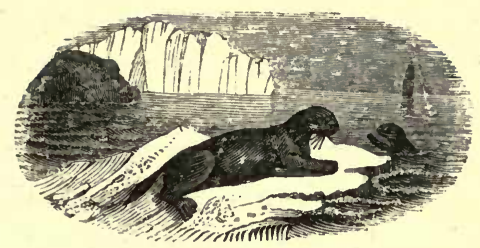

is one-third the length of the body. "Its blackish fur, with a marked velvetty character, is," says Cuvier, "the most valuable of all the otter furs; it is often whitish on the head. The English and Russians go in search of this animal in the whole of the northern portion of the Pacific Ocean, for the purpose of making a traffic with its skin in China and Japan."

\section{O G S.}

In treating of the several kinds of dogs, it would naturally be expected that I should take some notice of the disputed point relating to their early origin. On this interesting topic the remarks of Colonel Hamilton Smith so perfectly accord with my own views, that I shall lay them before the reader:-

"In the social condition of nations long congregated and civilized, and necessarily under the impulses of utilitarianism, dogs do not obtain that universal consideration which is granted to other animals, in many respects their inferiors; and it is true, that many tribes of the south-east abhor their presence, and view them only as scavengers, little better than the jackal and hyæna.

But when the intellectual endowments of the domesticated races of dogs are permitted to weigh in the scale, when we begin to consider the faculties which the bounty of Nature has bestowed upon them, the sincerity and disinterestedness of their attachment, the sagacity, strength, velocity, courage, and perfect obedience which they proffer to man, we cannot refuse them our 
admiration and affection. To what other species could we look for voluntary association with our fortunes? Which of them would, like the dog, lend us the full use of senses so acute as his ? Which other can rejoice in our joy, be vigilant and bold in our defence, obedient to order, faithful in our adversity, understand our least words and signs, and die on our graves from pure attachment? These qualities, we all know, dogs possess. Here, then, we find the source of that consideration which is granted them by all men near a state of nature; and although conceded by them with niggardly hands, the wild man of the Old World, the stoical hunter of the New, the half-frozen Esquimaux, and the savage of Australia, differ only in their mode of acknowledgment from the expressions of favour with which the drover, the shepherd, the sportsman, and the fine lady of civilized society, regard them.

"As the dog alone, of all the brute creation, voluntarily associates himself with the condition of man's existence, it is fair to presume also, that he was the first, and, therefore, the oldest of man's companions; that to his manifold good qualities the first hunters were indebted for their conquest and subjugation of other species. We do even now perceive, notwithstanding the advance of human reason, and the progress of invention, that, in a thousand instances, we cannot dispense with his assistance.

"If we still feel the importance of his services in our state of society, what must have been the admiration of man, when, in the earliest period of patriarchal life, he was so much nearer to a state of nature? When the wild hunter first beheld the joyous eyes of his voluntary associate, and heard his native howl modulated into barking; when he first perceived it assuming tones of domestication, fit to express a master's purposes, and intonate the language which we still witness cattle, sheep, and cven ducks and hawks, learn to understand: what exultation must he have felt when, with the aid of his new friend, he was enabled to secure and domesticate the first kid and the first lamb of the mountain race! When, with greater combinations 
of force and skill between man and his dogs, the bull, the buffalo, the camel, the wild ass, and then the horse, were compelled to accept his yoke; and, finally, when, with the same assistance, the wild boar was tamed, the lion repelled, and even attacked with success. Although the total development of canine education must have been the work of ages, yet that it was very early of great acknowledged importance, is attested by the prominent station assigned to the $d o g$ in the earliest theologies of Paganism.

"But if these animals were thus early an object of deep felt interest, we are naturally led to ask the question, - whence dogs originated? For, as there must have been a period when that species, or the genus whence the domestic races have sprung, were in a state of nature, the original and typical kind is to be sought in existing wild dogs, or their real progenitors have totally disappeared. In the present state of our knowledge on this particular subject, no reply can be made which is wholly free from objections. The oldest records represent the dogs then noticed, though they were less educated, as not very dissimilar in natural qualities from the present races; for, referring to the most ancient authorities (if we except a passage in Aristotle, attesting the co-existence of wild and domesticated animals in his time in Europe, among which the dog is enumerated; and another in Pliny, acknowledging that there were no domesticated animals then to be found which had not their counterparts in a wild state); writers of the classic period seem not to have bestowed much real attention on the question.

"We leave it to physiologists to inform us of the facts, if such there be, in the whole circle of mammalious animals, where the influence of man, by education and servitude, has been able to develope and combine faculties and anatomical forms so different and opposite as we see them in different races of dogs, unless the typical races were first in possession of their rudiments. We do not pretend to deny a certain influence to education, even on the external form; and to servitude and misery that degeneracy which will produce some corresponding decrease of size. 
But climate cannot have effected much difference in the growth, since the two extremes are found both in hot and cold countries. Nor can food have had a material influence, since man, existing entirely on vegetables or on fish, retains all his faculties as well as when he subsists on flesh; and to a late period in the history of Europe, the fiercest dogs, such as the packs kept by the feudal nobility for boar and wolf hunting, were invariably fed on bread. If the dog proceeded solely from one typical species, allowance being made for some modifications as above specified, all his developments would continue within the circle of powers and faculties belonging to the original type. They might diminish, but increase only in a trifling degree. We may infer, that food or climate would not truncate and widen the muzzle, nor raise the frontals, nor greatly alter the posterior branches of the lower jaw-bone, as in mastiffs.* It would scarcely have the effect, in other cases, of producing a high and slender structure, while it took away the sense of smelling, and several of the best moral qualifications resulting from domesticity and education, as occurs in greyhounds. All these qualities appear to us indications of different types, whose combinable properties have enabled man to multiply the species of dogs into the several races his wants required. In these views we expect to have the concurrence of all sportsmen, who have studied the characters of the animals more than the books of systematic writers, and are led by inferences from their own observations, rather than by the authority of names. We know it to be the opinion of foresters and huntsmen of the north and east of Europe, men generally well educated, and who live wholly in the presence of Nature. We are assured it is the doctrine of the Chinese and Tartars, particularly in the notice on dogs in the treatise on hunting, under the names of Id, Ist, and Kuschuk. We know

* "The deep jaw-bones of some domestic dogs are independent of the more general character of the family, and indicate a corresponding possession of actual physical power, as in the lion and jagaur, compared with the more insiduous habits of the puma, we find a similar correspondence."-Captain Brown's Translation of the Animal Kingdom (Edinburgh). 
from personal enquiry, that both the North and South American Indians do not doubt their dogs being of the same origin with the wild canines of their forests; and, lastly, we may appeal to the work of Baron Cuvier, where, bearing in mind that he made it a law not to assert, as fact, that which he had not verified by personal inspection, speaking of dogs as a species, he, nevertheless, admits that ' some naturalists think that the dog is a wolf, others that it is a tame jackal; yet dogs, which have returned to a wild state in desert islands, do not resemble either the one or the other.' He then notices the matin, a breed not known in England, but approaching our great farmyard and drover dogs, as possessing a skull most similar to that of the wolf, though the ears are drooping. Speaking of the jackal, he says, 'it is a voracious animal, which hunts in the manner of the dog, and appears to resemble him more than any other wild species, in conformation and the ease with which it is tamed.'

"Without recapitulating the various arguments adduced in the foregoing pages, we are inclined to believe there are sufficient data to doubt the opinion that the different races of domestic dogs are all sprung from one species, and still more that the wolf was the sole parent in question; on the contrary, we are inclined to lean, for the present, to the conjecture that several aboriginal species, constructed with faculties to intermix, including the wolf (Canis lupus, Linn.), the buansu (C. primavus, Hodgson), the anthus (C. anthus, F. Cuv.), the dingo (C. Australia), and the jackal (C. aurens), were parents of domestic dogs. That even a dhole (Chryseus scylax, Smith), or a Thoa wild dog (Thous), may have been progenitors of the greyhound races; and that a lost or undiscovered species, allied to Canis tricolor, or Hyana venatica of Burchell, was the source of the short muzzled and strong jawed races of primitive mastiffs.

"We know already enough of the kindlier moral instincts of several wild canines, to render their aptitude for domestication, during the pressure of a series of ages, not very problematical; 
and if the education of some of the races nearer to the wild condition, do not appear to be advanced to a great degree of tractability, we must reflect that domestic qualities are of very slow growth, as long as wild congeners exist in the same country; and that, where man is a savage, his dog cannot be expected to be civilized. This truth is, indeed, of such universal application, that in some measure we may determine the social condition of a nation by the degree of education its dogs have acquired."*

Having introduced these arguments of Colonel Hamilton Smith, an eminent and talented zoologist, it may prove interesting to the reader to hear Sir John Sebright, who with considerable ability attempts to account for the different habits of the several breeds, though adopting at the outset the common notion that they are all varieties of one species :-

"Perhaps the strongest proof that what is commonly called instinct in animals is not implanted in them by nature is, that very different propensities are found in the various breeds of domestic dogs, and that they are always such as are particularly suited to the purposes to which each of these breeds has long been, and is still, applied. The performances of the shepherd's dog, which would seem to be the result of little less than human intelligence, are much too artificial, and too much in opposition to the nature of the animal, to be attributed to instinct; and yet the young dogs of this breed appear to have a propensity to the performance of these services, or, as the shepherds say, a thorough-bred one will take to them naturally. I do not believe that the same things could be taught to dogs of other breeds, such as the hound, the greyhound, or the pointer, by the most skilful training.

"No one can suppose that nature has given to the several varieties of the same species, such very different instinctive propensities, and that each of these breeds should possess those that are best fitted for the particular uses to which it is applied. It

* The Natural History of Dogs (Edinburgh, 1839), p. 78-105. 
seems more probable that these breeds, having been long treated as they now are, and applied to the same uses, should have acquired habits, by experience and observation, which in course of time have become hereditary. From these and many other observations, I am led to conclude that by far the greater part of the propensities that are generally supposed to be instinctive, are not implanted in animals by nature, but that they are the result of long experience, acquired and accumulated through many generations, so as, in the course of time, to assume the character of instinct. I cannot but think that part of what is called the national character of the different varieties of mankind may, in some degree, be influenced by acquired habits having become hereditary." *

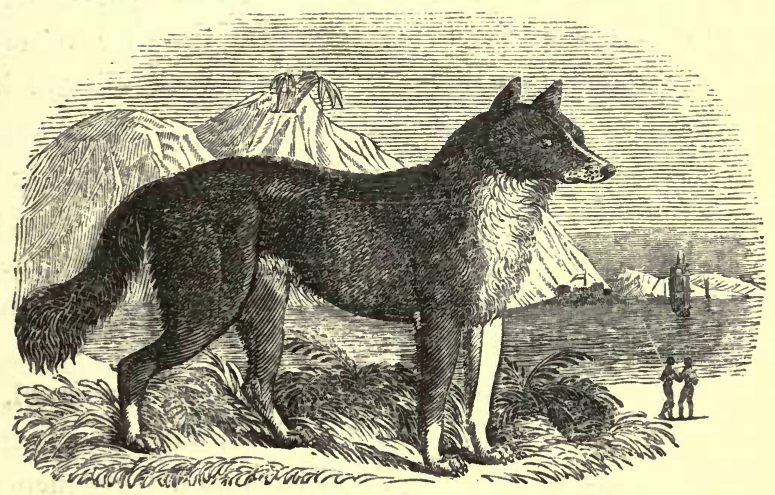

The Dingo, or Australian Dog:

(Canis Australasia.)

This dog inhabits the whole of New South Wales, either in a wild or half-domesticated state; but the wild dingos are larger

* Observations upon the Instinct of Animals (1836), p. 15. 
and more powerful than the reclaimed ones, which are less than two feet high at the shoulder, and do not exceed in size our shepherd's dog.

The wild dingos are very courageous, and they hunt in pairs or small families of five or six. Their fierceness and activity are equal to, if not more than a match for, the most powerful domestic dogs, not excepting the European breeds, and they immediately devour these, their more civilized brethren, if they fall into their power. They attack sheep and kill as many as they can overtake; and few that they leave merely wounded ever survive the severity of their bite. When prowling they utter a melancholy howl, and bend the tail down; but when they are chasing their prey, they keep the tail in a horizontal position, raise the head high, erect the ears, and turn them forwards.

The female litters in some thicket, hollow tree, deserted ant-hill, or hole in the earth. Mr. Oxley, Surveyor-General of New South Wales, records the following instance of mutual attachment among these dogs. "About a week ago we killed one, and threw his body on a small bush; in returning past the same spot to-day, we found the body removed three or four yards from the bush and the female, in a dying state, lying close beside it. She had apparently been there from the day the dog was killed, being so weakened and emaciated as to be unable to move on our approach."

In confinement, these dogs neither howl, bark, nor growl, but are quite mute. They emit a strong odour, and when irritated they erect the hairs of the body, and assume a truly menacing appearance. Those which the natives of Australia possess in a half tamed state, are employed in hunting the kangaroo and emu. 


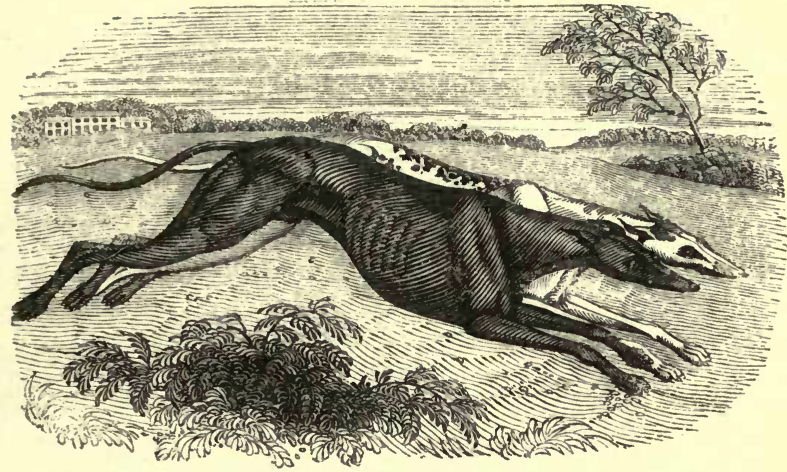

The Greyhound.-(Canis Graius.)

The qualities which are most essential to a greyhound are swiftness, good wind, keen steady sight, and the power of enduring sudden and violent exertion. $\mathrm{He}$ is remarkable for hunting by sight and not by scent. The whole shape of his lank body, and the length of his slender limbs, admirably adapt him for speed. Daniel, in his Rural Sports, says, that though " upon a flat a first-rate horse would be superior to a greyhound; yet in a hilly country, as in Wiltshire, the greyhound would have the advantage." He says that a brace of greyhounds, in Lincolnshire, hunted a hare for upwards of four miles, in the short space of twelve minutes; during the course there were several turns, which very considerably increased the space traversed; the hare became exhausted and dropped dead before the greyhounds touched her.

\section{The Irish Greyhound, or Irish Wolf-dog.}

The general appearance of this dog is such as to indicate that it was originally produced from the great Danish dog crossed by the greyhound. No pure unmixed specimens, however, now exist even in Ireland, where it was anciently so highly prized for its services in hunting the native wolves, which are now, also, 


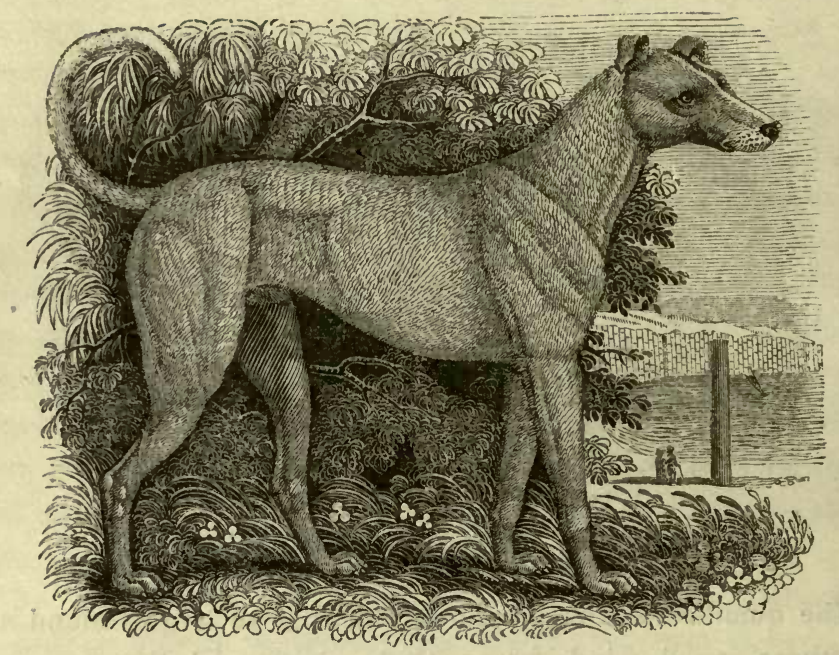

extinct. In the year 1780, Lord Altamont had eight of these tall and noble dogs. The largest of them measured five feet one inch from the nose to the end of the tail, which, itself, was one foot five inches long. Its height from the top of the shoulder to the ground was two feet four inches and a half.

In the figure of one of Lord Altamont's dogs, which Mr. A. B. Lambert has published in the third volume of the Linncan Transactions, the resemblance to the common greyhound is very slight; but he says, however, from the account he received, that they had "degenerated in size : they were formerly much larger and more like a greyhound," and were good tempered animals.

\section{The Italian Greyhound.}

This sub-variety of the greyhound is among the most elegant and nimble of all the several breeds of dogs. It is of a very light make, with a short smooth coat. It is very watchful, quick in its movements, gentle and timid in its disposition, and 


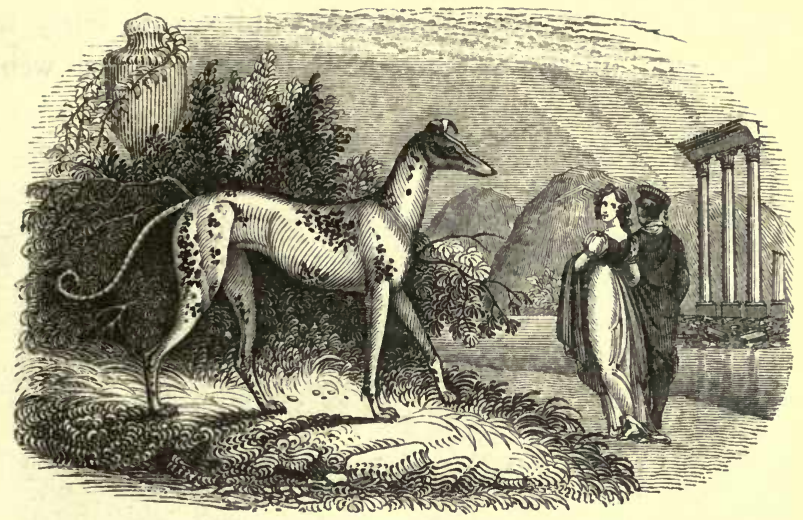

remarkable for the constant trembling of its whole body, arising probably from excessive sensibility. The common greyhound is also similarly excited if caressed, when the palpitation of its heart may be observed to be most violent and irregular.

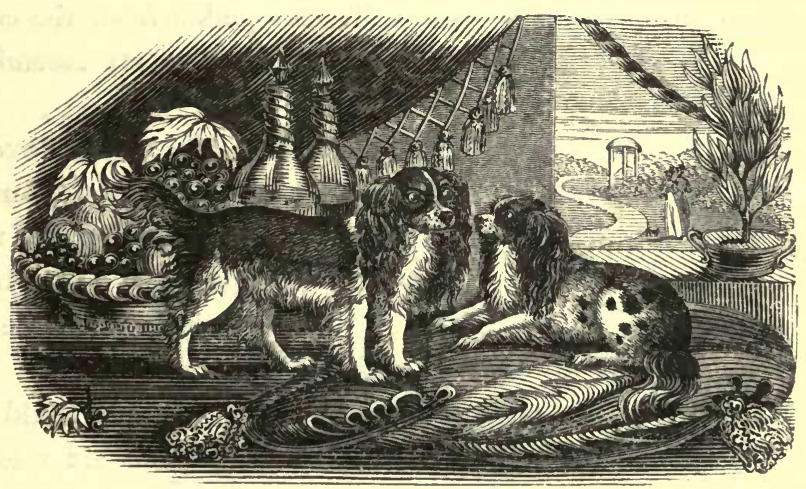

King Charles's Spaniel.--(Canis brevipilis, Linn.)

This beautiful breed received its name from having been the favourite dog of that ill-fated monarch Charles the First, 
who rarely walked out without being attended by several of these spaniels. They were black and white, with curly hair, small rounded heads, short muzzles, long ears, and webbed feet.

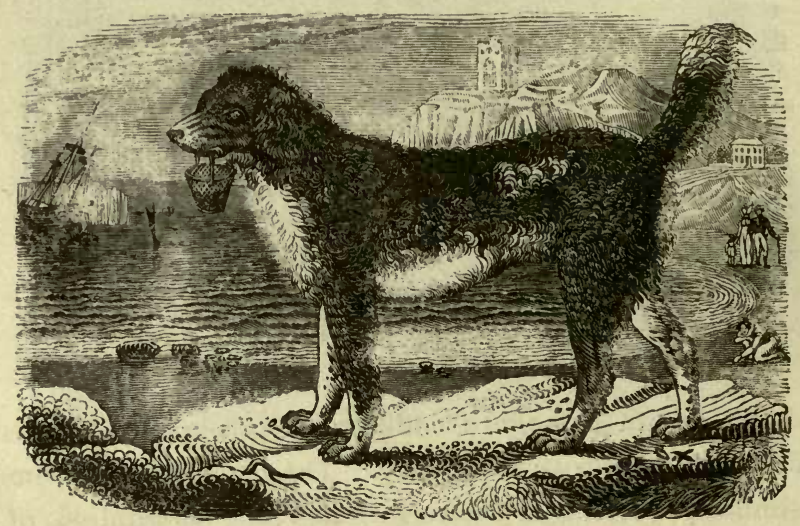

The Large Water-Spaniel.-(Canis aquaticus, Linn.)

The large water-spaniel is probably descended from the common spaniel and the large water-dog. It somewhat resembles the latter in the roughness of its coat.

On August 13, 1836, Mr. Phillips, of the Swan Tavern, Hungerford Market, gave a large water-spaniel to a gentleman about to journey into Kent. The dog was taken by his new master and embarked in a steamer for Ramsgate, where both landed the same evening. They were travelling thence to Canterbury, when, at Sarre, a village about midway, the dog was missed. No tidings or traces of the animal could be obtained, until some days afterwards, when, about six o'clock one evening, he presented himself at his old master's house in Hungerford Market, evidently fatigued and foot-sore by his journey, which was, doubtless, a circuitous one, by the time he was in performing it-a distance of nearly seventy miles by the direct road. Mr. Phillips does not believe that the dog was 
ever previously away from London, and is certain that it had never before been in any part of Kent.

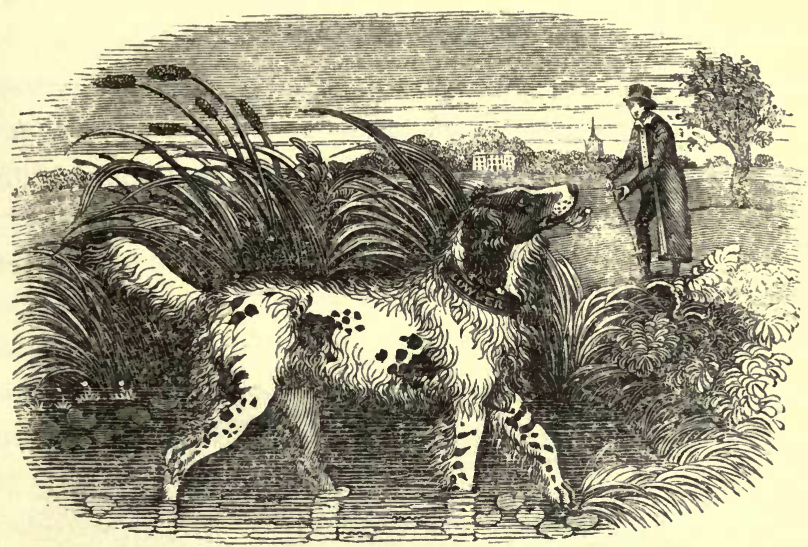

The Small Water-Spaniel.-(Canis aquaticus, minor.)

This is a sub-variety of the preceding breed, like which it has also a rough coat. Both are highly intelligent and useful animals, combining the aquatic propensities of the large water-dog with the fine hunting qualities of the spaniel, from which breeds they are supposed to have originally descended.

The poet Cowper has left us an interesting anecdote of one of these dogs which used to accompany him in his walks :-

"It was the time when Ouse displayed

His lilies newly blown!

Their beauties I intent surveyed, And one I wished my own.

With cane extended far I sought

To steer it close to land;

But still the prize, though nearly caught,

Escaped my eager hand.

Beau marked my unsuccessful pains

With fixed considerate face,

And puzzled sat his puppy brains

To comprehend the case. 
But with a chirrup clear and strong,

Dispersing all his dream,

I thence withdrew, and followed long

The windings of the stream.

My ramble finished, I returned;

Beau tottering far before,

The floating wreath again discerned,

And plunging left the shore.

I saw him with that lily cropped

Impatient swim to meet

My quick approach, and soon he dropped

The treasure at my feet."

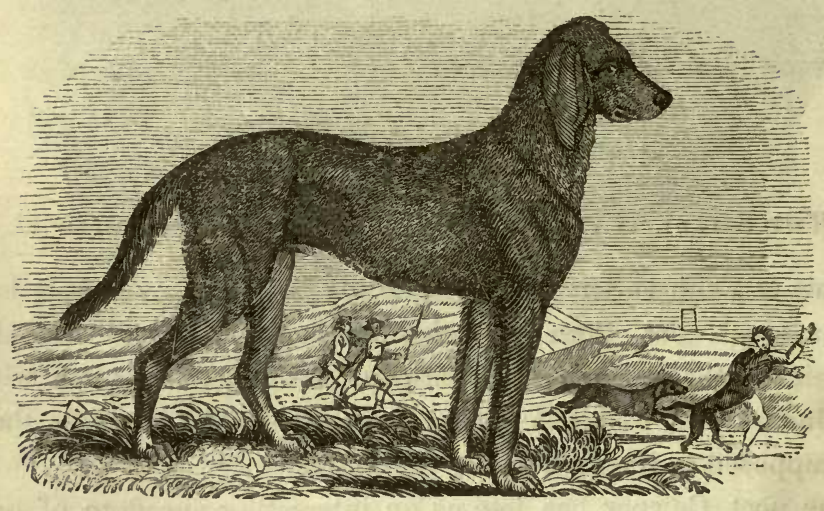

The Blood-Hound.-(Canis sanguinarius, Ray.)

Sleut-Hound.

This breed of dogs is very scarce, at least in its pure unmixed state. Mr. Swainson, in Murray's Encyclopadia of Geography, has stated that the blood-hound is now extinct in Great Britain; but the Duke of Marlborough and some other persons have retained the breed unimpaired. The height of the blood-hound, when full grown, is usually two feet four inches. Its limbs are strong and muscular; its chest wide; its muzzle broad, and the upper lip is large and pendulous.

Some writers suppose that the blood-hound is the stock from 
which the old southern-hound, the stag-hound, the fox-hound, the harrier, and the beagle, have been successively derived. "Whether this be the case or not cannot now be ascertained; but there is no doubt that it is of very ancient use in England, and was probably the Talbot of olden time, though that name appears to have been afterwards indiscriminately applied to hounds of other breeds also. The qualities for which it has acquired so high a reputation, are the acuteness and certainty of its scent, and the pertinacity and sagacity with which it will track any object it has been trained to pursue. This propensity, originally made subservient only to the usual objects of the chase, has, in subsequent ages, been applied to the purpose of tracking felons and other persons. In this occupation, the acuteness, sagacity, and perseverance which these animals displayed were almost incredible; and many instances are recorded in which, after the lapse of a considerable time, the hound, being put upon the scent, followed the fugitive for hours, and even days, with a searching and unflinching pertinacity, which at length overcame all impediments, and ensured the capture of his unhappy quarry. At various times, and in every part of the United Kingdom; in the clan feuds of Scotland, in the border contests of the debatable land of the two kingdoms, and in the unhappy Irish rebellion, its extraordinary powers have been taken advantage of without much regard to the claims either of justice or of mercy."*

Somerville has minutely described the conduct of the bloodhound when pursuing a felon :-

"Soon as the morn

Reveals his wrongs, with ghastly visage wan

The plunder'd owner stands, and from his lips

* Bell's British Quadrupeds (1837), p. 207. The blood-hounds which the Spaniards introduced into the South American continent and islands, to hunt the poor Indians, were perhaps distinct from the British blood-hounds. For very interesting but dreadful accounts of this inhuman misuse of the dog the reader is, therefore, referred to Bartholemew de Las Casas' Bprevissima Reiacion de la Detruycion de las Indias (1552); the History of the Buccaneers of America (third edit. 1704), p. 25; Herrara's History of the American Continent and Islands (1740); and Irving's Life and Voyages of Columbus (1828). 


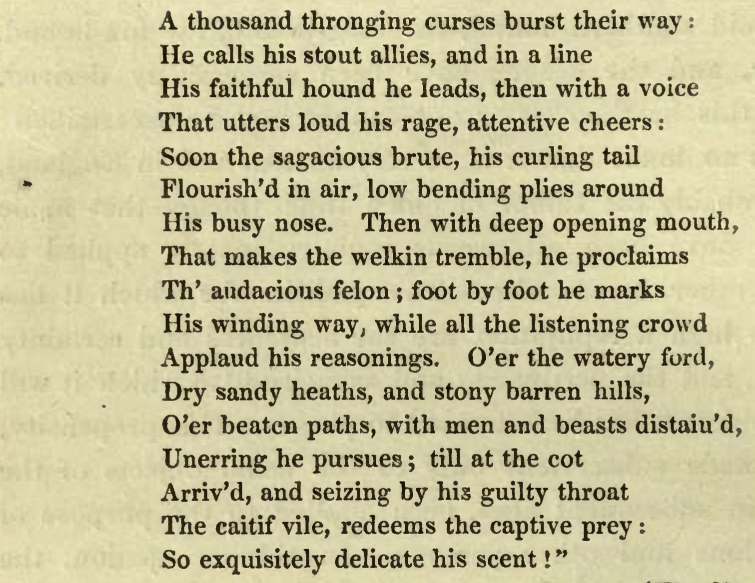

(The Chase, Book I.)

Boyle relates that " a person of quality, to make trial whether a young blood-hound was well instructed, caused one of his servants to walk to a town four miles off, and then to a markettown three miles further. The dog, without having seen the man he was to pursue, followed him by the scent, notwithstanding the multitude of market-people that went along the same way, and of travellers that had occasion to cross it; and when the blood-hound came to the chief market-town, he passed through the streets, without taking notice of any of the people there, and left not till he had gone to the house where the man he sought rested himself, and found him in an upper room, to the wonder of those that followed him."

This acuteness of smell is not quite so inexplicable as it may appear to some readers. Mr. Rennie has aptly observed that " the very subtle nature of odours, tends to strip these instances of sagacity of their apparent magic; for a particle of camphor, less than the two-millionth part of a grain, has been found distinctly perceptible to smell.* This has led Von Walther and others into the opinion, that odours are analogous to heat, light, and magnetism; in support of which they

* Haller, Eilementa Physiol., vol. v. p. 58. 
urge many very curious and plausible arguments; though the French chemists, on the other hand, consider aroma as a distinct element."

Even among mankind, especially in an uncivilized and therefore a more animal-like state, we meet with individuals hardly to be matched for their acuteness of scent. It is credibly reported, for example, of the negroes of the Antilles, that they can follow their master as a dog does, by smelling his footmarks;-yea more, that they can distinguish the track of a Frenchman from that of a negro.* Humboldt says, that the American Indians have distinct terms to express the odour of a negro, an European, and a native American. $\uparrow$ Sir Kenelm Digby mentions a boy whose smell was equally acute with that of the negroes of the Antilles; and a monk, who could distinguish different persons in the dark by smell, began a treatise on odours, but did not live to execute his savoury task. The singular boy Mitchel, born deaf and blind, had the same faculty of distinguishing persons by smell.

Leaving this "Chapter on Noses," let us return to the sharpscented animal that has induced this slight digression. It would have better accorded with my general plan to have spoken of the original colour of the blood-hound at the commencement of this article, when describing the animal's personal appearance -if I may use the Hibernianism; but had I done so, the observations I should have had to adduce on this point, would have forestalled what in that case would have had to follow.

Somerville, in his poetical account of the several kinds of dogs, identifies the blood-hound with

$$
\text { " }
$$

but Scott, speaking of two staunch blood-hounds, describes them as

"Two dogs of black Saint Hubert's breed."

(Lady of the Lake, Canto I. vii.)

Thus, though both poets are speaking of the blood-hounds that

\footnotetext{
* Journ. des Sgavans (1667), p. 60.

+ Political Essay on New Spain (1811), p. 10
} 
were anciently employed on the borders of England and Scotland, Somerville describes them as snowy white, and Scott as black; whereas Professor Bell, on what authority I know not, says the original colour was a deep tan, with large black spots. But that it was either a pure white or a pure black, I think may be gathered from the following quotation from a work on hunting, published in 1611: "Saint Hubert's hounds are commonly all blacke, yet, nevertheless, their race is so mingled at these days, that we find them of all colours. These are the hounds which the abbots of St. Hubert have always kept some of their race or kind, in honour or remembrance of the saint, who was a hunter with St. Eustace. These dogs have been dispersed through the countries of Henault, Lorayne, Flanders, and Burgoyne. They are mightie of body, nevertheless their legs are low and short; likewise they are not swift, although they be very good of scent; hunting chases which are far straggled, fearing neither water nor cold, and do more covet the chases that smell, as foxes, bores, and such like, than other, because they find themselves neither of swiftness nor courage to hunt and kill the chases that are lighter and swifter. The blood-hounds of this colour prove good, especially those that are coal-blacke, but I make no great account to breed on them, or to keep the kind; and yet I found a book which a hunter did dedicate to a prince of Lorayne, who seemed to love hunting much, wherein was a blason which the same hunter gave to his blood-hound, called Souyllard, which was white :-

My name came first from holy Hubert's race,
Souyllard my sire, a hound of singular grace.

Whereupon we may presume that some of the kind prove white sometimes, but they are not of the kind of the Greffiers or Bouxes, which we have at these days." *

* The Noble Art of Venerie or Hunting (1611), p. 15. 


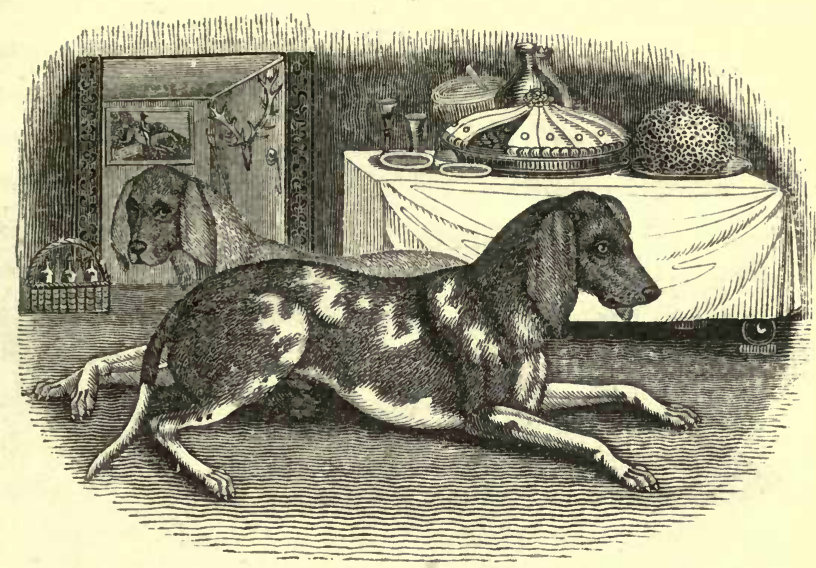

The Old Southern-Hound.

This handsome breed is supposed to be the first remove from the blood-hound, which is probably the progenitor of our various breeds of hounds. It is spotted like the more swift and active fox-hound, to which it has now very generally yielded.

\section{The Fox-Hound.}

The fox-hound probably originated from a cross between the old southern-hound and the harrier.

The average height of the most esteemed breed of fox-hounds is about one foot ten inches. They are unrivalled for their union of fine scent, speed, and perseverance. Colonel Thornton's celebrated fox-hound, called Merkin, ran four miles in seven minutes. The fox-hound will continue the chase for a considerable time : a good pack will often follow the fox for six or eight hours. In January, 1738, the Duke of Richmond's hounds found their fox at a quarter before eight in the morning, and killed. him at ten minutes before six, after a chase of ten hours' hard. running. Many of the sportsmen tired three horses each : eleven couple and a half of the hounds only were in at the death; and several horses died during the chase. 


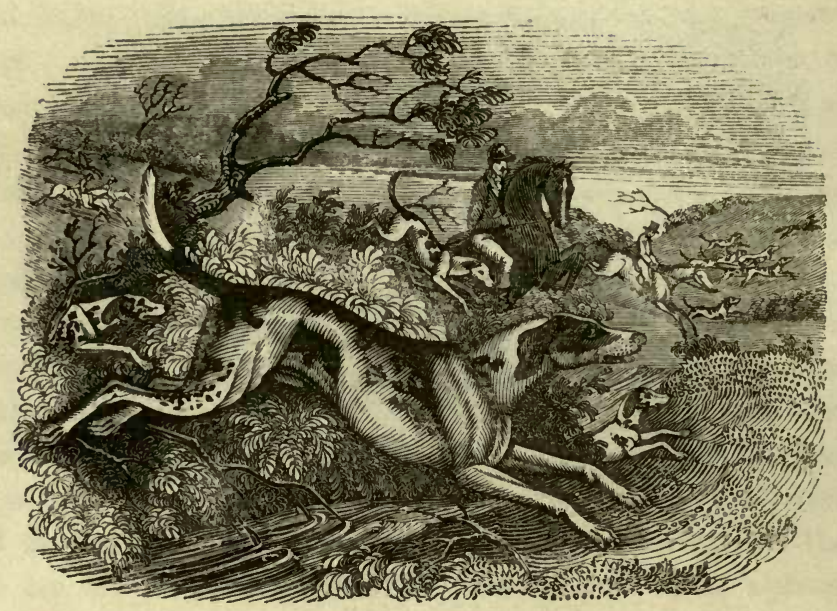

" Those who have studied the training of sporting dogs have observed that gentle chastisement, often repeated, and mixed with kindness, produce the most perfect obedience, while hasty severity frightens the animal for the moment, but leaves no permanent impression. The feeding of a kennel of fox-hounds is one of the most striking illustrations of the power of training to produce complete obedience. The energy and even fierceness of these dogs cannot be overlooked; there is nothing slavish and crouching in their demeanour. They are hungry, and they know they are about to be fed; but they manifest no rebellious impatience. The feeder stations himself at the door which separates the outer kennel from the feeding-room. At his presence a joyful cry is set up by the whole pack, but it is instantly silenced at his command. He calls 'Juno'-Juno passes out; 'Ponto'-Ponto follows; and so on through the pack, even if there be thirty couple. If a young dog should attempt to go out of his order, he is turned back, he recollects the punishment, and he seldom again transgresses. The pack has arrived at this state of perfect discipline by gentle correction, and, what is more important, by a system of mutual 
instruction, if we may venture so to express this particular force of example.

"In the kennels of packs of fox-hounds, the following barbarous custom of the dogs towards one another has been sometimes observed. If a hound gets down of his own accord from the bench on which he was lying, no notice of it is taken by the others: but if a hapless hound falls off the bench from awkwardness, his companions fly at him, and bite him to death." *

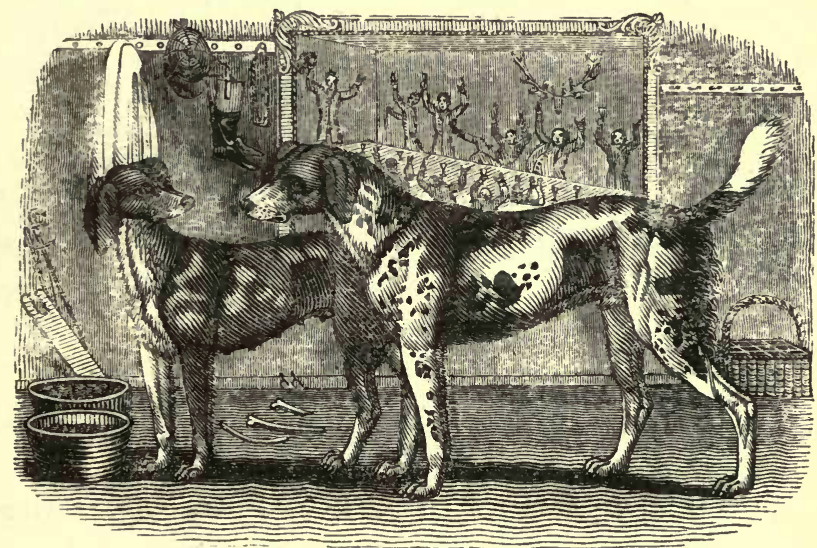

The Harrier.-(Canis Leverarius; $)$
and
The Beagre.-(C. Leverarius minor.)

The harrier derives its name from its use, that of hunting the hare. It is usually from sixteen to eighteen inches in height.

"Harriers and fox-hounds, even when taken out for the first time, have a very different mode of hunting; the fox-hound will press forward, and cast wide; the harrier will keep to, or, as the sportsmen say, stick to the scent, and cast back." $\dagger$

* Menageries, vol. i. (1829), p. 53.

† Sebright's Observations upon the Instinct of Animals (1836), p. 16. 
The otter-hound, a rough, wiry-haired, thick-quartered and thinshouldered animal, is a cross between this and the larger terrier.

The right hand figure in the preceding engraving represents the harrier, and the opposite figure the beagle, which is a still smaller variety - its height being not more than from twelve to fourteen inches.

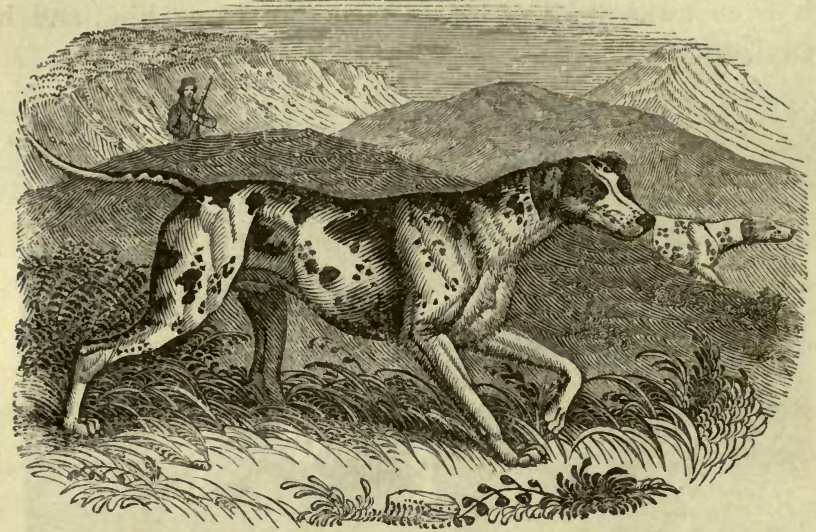

The Pointer.

This beautiful breed is exceedingly steady and persevering in the field. "A staunch pointer will not only stand at the scent of a bird or hare, but if he be in company, he will instantly back, as it is termed, if he see another dog point. The perfection to which this propensity to stand at the scent of game is brought, is one of the most striking examples of the docility of the dog. Whether it be absolutely superadded to the original instinct of the animal, or a mere modification of it, can scarcely perhaps, be satisfactorily determined."*

To ascertain whether pointers carried naturally, M. Magendie procured a full grown couple from England. A handsome bitch bred from these, in France, was kept constantly under his eye, and, without receiving any sort of instruction, she pointed and * Bell's British Quadrupeds (1837), p. 218. 
carried game the first day she was taken out, and showed as much firmness and assurance, as dogs who had been carefully bred under the influence of the whip and collar.

Colonel Montagu relates an instance of extraordinary friendship which subsisted between a Chinese goose and a pointer who had killed the gander. The pointer was most severely punished for the misdemeanour, and had the dead bird tied to his neck. The solitary goose became extremely distressed for the loss of her partner, and only companion; and probably, having been attracted to the dog's kennel by the sight of her dead mate, she seemed determined to persecute the culprit by her constant attendance and continual vociferations; but after a little time, a strict friendship subsisted between these incongruous animals. They fed out of the same trough, lived under the same roof, and in the same straw-bed kept each other warm; and when the dog was taken to the field, the inharmonious lamentations of the goose for the absence of her friend were incessant.

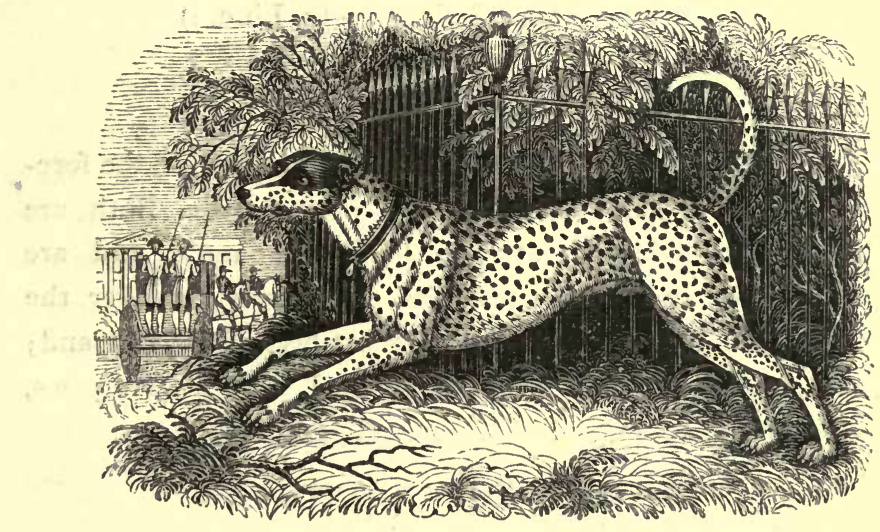

The Coach-Dog, or Dalmatian Dog.

Buffon has classed the coach-dog with the hounds, but it has neither scent nor sagacity sufficiently acute to entitle it to rank among dogs of the chase. In shape, it certainly somewhat 
partakes of the pointer and the hound. Its white coat is besprinkled with numerous small black spots.

This dog is common in England, but is kept merely as a good travelling servant-a sort of out-rider. His attendance upon the carriage-horses during the journey, and his exulting consciousness of dignity in preceding the equipage, as if to announce its approach, seem to constitute the highest gratification of his existence.

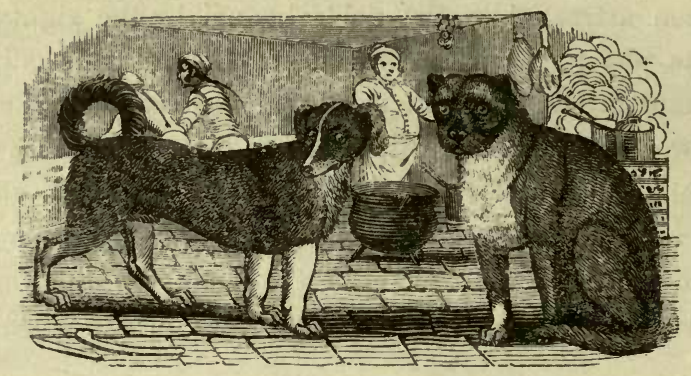

The Turnspit.-(Canis vertagus, Linn.;) and

The Pug.-(Le Doguin, Buff.)

There are two breeds of the turnspit, the one having the forelegs straight, and the other with them crooked. Both are long-backed, short-legged, strange looking animals, and are now rarely kept except as curiosities. Formerly, however, the turnspit had the honour of turning the roast-beef of Old England; but since machinery has been substituted for his fore-paws, Othello's occupation's gone. He's no longer

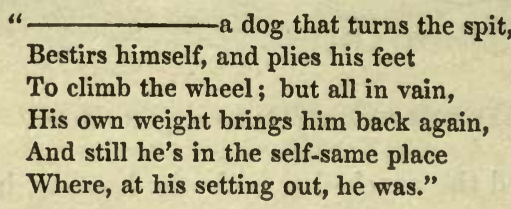

(Hudibras.)

The right-hand figure in the above engraving represents the pug, a common pet dog a few years ago, but now seldom seen. 
It is tolerably good tempered towards its master and family, but generally an annoyance to every one else, by barking and assuming a threatening attitude, and yet frequently without the courage to make an attack even on a proper occasion.

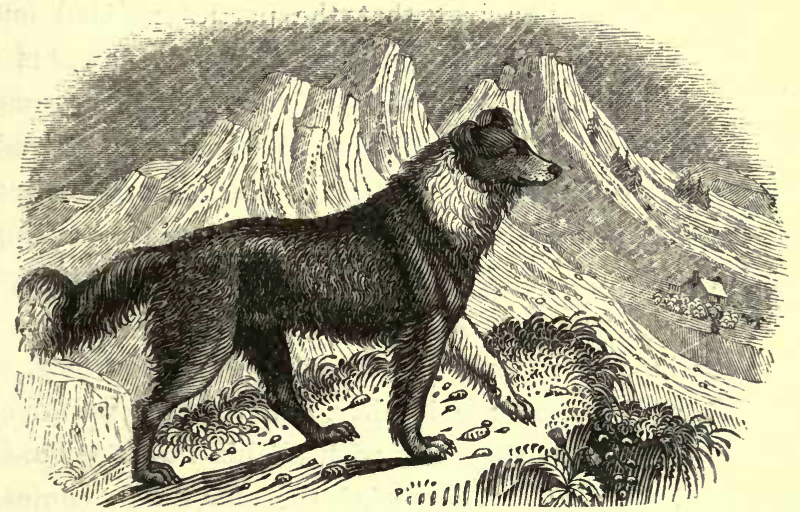

The Shepherd's Dog, or Coliey.

The height of the sheep-dog is generally about fifteen inches, and its colour is chiefly black or dark grey.

He is of all dogs the most intelligent and faithful, and at the same time the most useful. In the wild and mountainous parts of Scotland and Wales, more particularly, must we look for proofs of his invaluable services. There we shall find him left in care of hundreds of sheep, and displaying the greatest activity, vigilance, and courage in minding his charge.

Some of these dogs possess the faculty of discovering by the smell any sheep which may have had the misfortune to be overblown by the snow, in which scores of them are frequently buried to a depth of several feet in a very few hours after the snow has commenced. When the dog is used for this purpose he is called a sheep-setter, or sheep-finder. A sheep-setter, named Corby, was so celebrated in Scotland, where he practised his vocation for many years with wonderful success, that his owner was frequently requested to lend him to the sheep-farmers 
in the distant parts of the upland country, where portions of the sheep-flocks were often beneath the snow. The sagacious animal, we are told, always took advantage of the wind, where that was practicable, and the moment he was told to "seek the sheep-be careful," his whole attention was bestowed upon those parts of the snow-drift that the parties pointed out to him. With his nose close to the surface of the snow, his eyes beaming with intelligence, and anxiously watching every motion of the person that accompanied him, his ears in an attitude of listening, as if he expected to assist the sense of smelling by that of hearing, would he traverse the hard, soft, or slippery snow-drift. When he had first satisfied himself that there were sheep buried somewhere in the vicinity, he would examine, with peculiar caution, every part of the surrounding surface, until he had detected the precise locality, and then he would commence scratching away the snow with all his might. This was a sure signal for those who carried the shovels to commence digging, but the dog was never contented unless he were allowed to continue his scratching, as if he were anxious to set the imprisoned sheep at liberty as soon as possible. In a single severe winter this dog set, as it is termed, upwards of three hundred sheep; and though it may be true that a portion of them might have been discovered through other means, the probability is, that he rescued several scores that otherwise inevitably would have perished.

In the summer of 1836 , several of the sheep in the neighbourhood of Ard Stinchar, were affected with maggots in the skin : to rid them of which it is necessary to cut off the wool over the part attacked, and apply a small quantity of tobacco juice, or some other liquid. For this purpose a shepherd set off to the hill one morning, accompanied by Laddie, his faithful colley. Arrived among the flock, the shepherd pointed out a maggotty sheep, and making the accustomed signal for the dog to capture it, he speedily did so by laying her sprawling on her back, and gently holding her down till the arrival of her keeper, who proceeded to clip off a portion of her wonl, and apply the healing 
balsam. During the operation, Laddie continued to gaze on the operator with close attention, and the sheep having been released, he was directed to capture in succession two or three more, which underwent similar treatment. The sagacious animal had now become initiated in the mysteries of his master's proceeding, for off he set unbidden through the flock, and picked out with unerring precision those sheep which were affected with maggots in their skin, and held them down until the arrival of his master, who was thus saved a deal of trouble, and the operation of clipping and smearing most materially facilitated.

The duties of the sheep-dog, when attending a flock on the road, demand his constant watchfulness and exertion. One minute he is barking with all his might to urge on the main body-now he is bounding forward to restrain stragglers-now circling the flock,-and now again returning to his master's side, to receive his look of approbation or his further commands.

A good sheep-dog possesses the sense of sight so perfectly, that he can readily discover a strange sheep among a very large flock under his care. When there is an intruder among the flock, the drover has only to give the word to his dog, and the sagacious animal dashes forward over the several fleecy backs, singles out the runaway without the least hesitation, and seizing him by the loose skin of the neck, bears him to the ground, and holds him fast until assistance arrives.

A flock of two-hundred sheep while advancing towards London, met a flock of only about a dozen in the village of Tottenham. The drover of the latter being fearful that the small flock would, as usual, unite with the larger body, tried to keep his few sheep to one side of the road until the others should have passed. One of them, however, eluded the drover's vigilance, and sprang into the midst of the other flock, and among so many he appeared completely safe from detection; but the drover of the larger flock, who seemed to enjoy the affair, gave the command to his dog, and the stray sheep was instantly in custody.

Seven hundred lambs which Hogg, the Ettrick Shepherd, had 
under his care, broke away in the middle of the night, and scampered off in three different parties across the hills, in spite of all that the shepherd and his assistant could do to keep them together. "Sirrah," cried the shepherd to his dog, " they're a' awa." The night was so dark that he did not see the dog, but the faithful animal heard his master's words, and he immediately set off in quest of the flock. Meanwhile, the shepherd and his companion spent the night in traversing the hills for miles round, but could find neither the flock nor the dog. On their way home in the morning, however, they discovered the lambs at the bottom of a deep ravine called the Flesh Clench, and the dog standing in front of them looking all around for some relief, but still standing true to his charge. Not one lamb of the whole flock was missing.

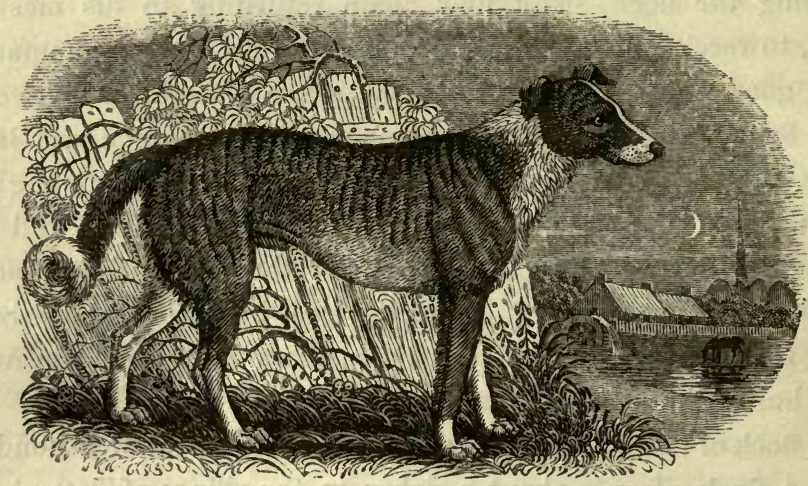

The English Sheep-Dog, or Southern Sheep-Dog.

This breed seems to have originated in a cross of the colley with the mastiff. While the former is the Scottish and Welsh sheep-dog, the present animal is the original or true English one, although the colley is now in general use on the extensive downs of Wiltshire, and in some other parts of this country. Our old English authors term it the shepherd's mastiff; and this perhaps will account for some modern writers having 
improperly termed it the ban-dog, whereas that name belongs to the true English mastiff alone.

The English sheep-dog is larger and less shaggy than the colley. In some individuals the ears are quite erect, and others have the tail very short,- the latter peculiarity being apparently inherited from parents whose tails have been cut.

"The shepherd's-masty that is for the folde, must neither be so gaunt nor swifte as the greyhound, nor so fatte nor heavy as the masty of the house, but verie strong, and able to fighte and follow the chase, that he may beat away the woolfe or other beasts, and to follow the theef, and to recover the prey, and therefore his body should rather be long than short and thick: in all other points he must agree with the ban-dog. His head must be great, smooth, and full of veins, his ears great, and hanging, his joints long, his fore-legs shorter than his hinder, but very straight and great, his claws wide, his nails hard, his heel neither fleshy nor too hard, the ridge of his back not too much appearing, nor crooked, his ribs round, and well knitte, his shoulder points well distant, his buttocks fatte, and broad."*

\section{The Cur, or Drover's Dog.}

Though the true sheep-dog is frequently used to conduct flocks of sheep along the roads leading to the markets, yet the cur, or mongrel breed, is generally employed for that purpose, as well as to attend herds of oxen. The colour is generally black and white.

Cur dogs are usually doomed to wear very short tails to their coats. A shepherd assured Mr. Jesse that his bitch had seldom a litter of puppies, without one of them being born with a bob tail,-like that of its parent. When, however, it is remembered that the tails of animals help to facilitate their movements, and to beat off the flies and other annoying insects, no one can

* Foure Bookes of Husbandrie, by Conrad Heresbatch : newly Englished and Increased by Barnaby Googe. (London, 1586,) p. 154. 


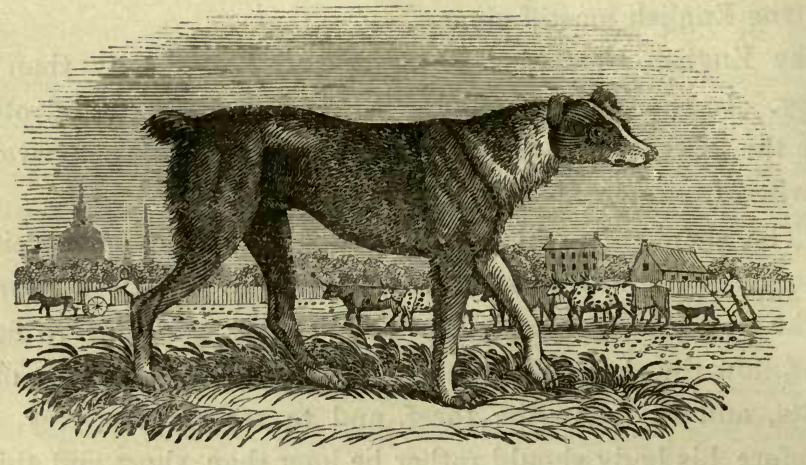

defend the barbarous taste of those persons who deprive them of so useful an appendage.

Mr. P. J. Brown says that, in August, 1827, a traveller in Switzerland set off for the Canton of Glarus, accompanied by a young cur. When crossing a bed of snow he trod on a stone concealed beneath the surface, and having sprained his foot, he sank down, became insensible, and, remaining in this predicament all night, was covered by a great depth of snow. His dog remained by him, and, in the morning, seeing some men passing on the snow at a considerable distance, he barked, howled, ran towards them, and returned showing every mark of distress. They followed him, removed the snow, found his master unconscious of all that was passing; and by bearing him to the nearest asylum, succeeded in restoring him to life.

\section{The Lurcher.}

This breed is supposed to have originated in a cross of the greyhound with the sheep-dog. It is lower than the former, and has a rough, wiry haired coat, usually of a sandy red colour, but sometimes black or dark grey.

Professor Bell has well remarked that, if the lurcher in its lengthened muzzle and limbs, resemble the greyhound, its stout, rough, homely form, together with its sagacity and 


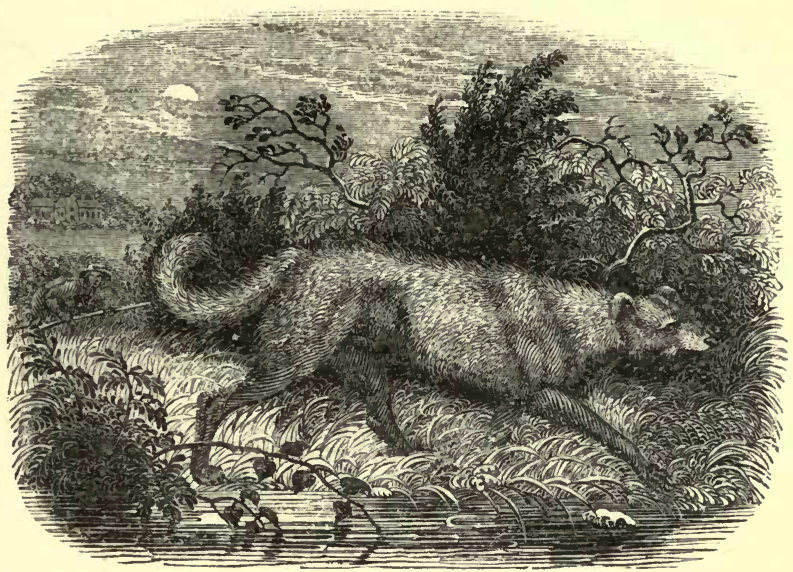

attachment, " evince more clearly still its descent from the sheep-dog; and the lurking, sly, and downward expression of its eye, is but a mask for qualities which render it one of the most useful assistants to a class of men who require the aid of the most trusty, intelligent, and attached of the canine race. It is, in short, peculiarly the poacher's dog. For the nocturnal trade of these men, the silent, stealthy habits of the lurcher are admirably adapted; and one which is well educated, or broken to the business, will serve all the purposes of every other kind of sporting dog, in a manner the most efficient for the objects of its master's pursuit. If he be hunting rabbits, and should start one at a little distance from its place of resort, the dog runs for the burrow, and here is sure to secure it. In driving partridges into the net, it uses all the circumspection which so delicate and so difficult a task requires; hares often fall before its combined speed and cunning; and a well-bred lurcher will seize and pull down a fallow-deer, and then quietly return to its master, to lead him to the scene of its successful adventure. In all these offices a well-bred lurcher never gives tongue, but pursues its object in silence, and with a great degree of sagacity and intelligence." 


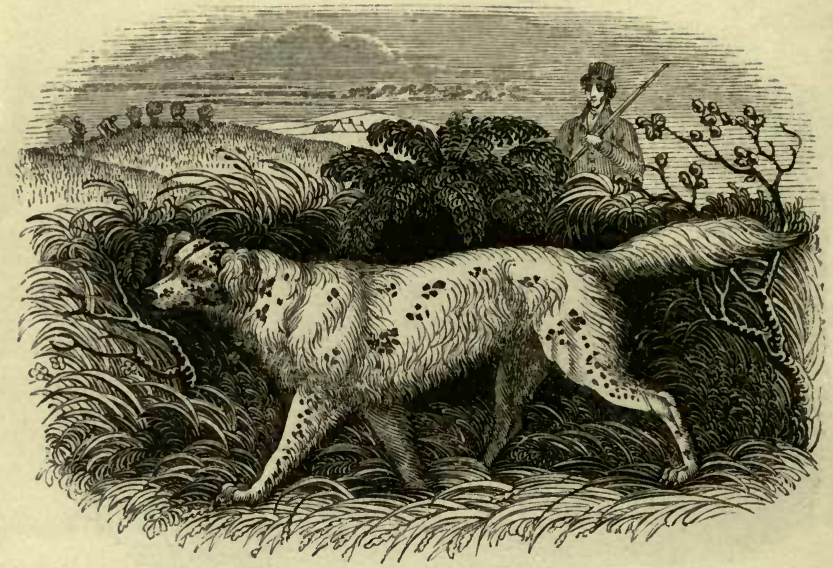

\section{The Setrer.-(Canis Index.)}

England has long been celebrated for her setter, particular care having been taken to preserve the breed in the utmost purity. The great sagacity and docility of this elegant animal, together with the exquisite acuteness of its scent, and its power of enduring much fatigue, render it one of the most highly prized of the sporting dogs. When it scents the birds, it crouches down or sets, as it is termed, and thus indicates their presence. Somerville has very correctly described its proceedings in the field:-

"When Autumn smiles, all beauteous in decay, And paints each chequer'd grove with various hues, My setter ranges in the new shorn fields, His nose in air erect; from ridge to ridge Panting he bounds, his quarter'd ground divides In equal intervals, nor carless leaves One inch untried. At length the tainted gales His nostrils wide inhale; quick joy elates His beating heart, which, awed by discipline Severe, he dares not own, but cautious creeps, Low-cowering, step by step, at last attains His proper distance; there he stops at once, And points with his instructive nose upon The trembling prey." 


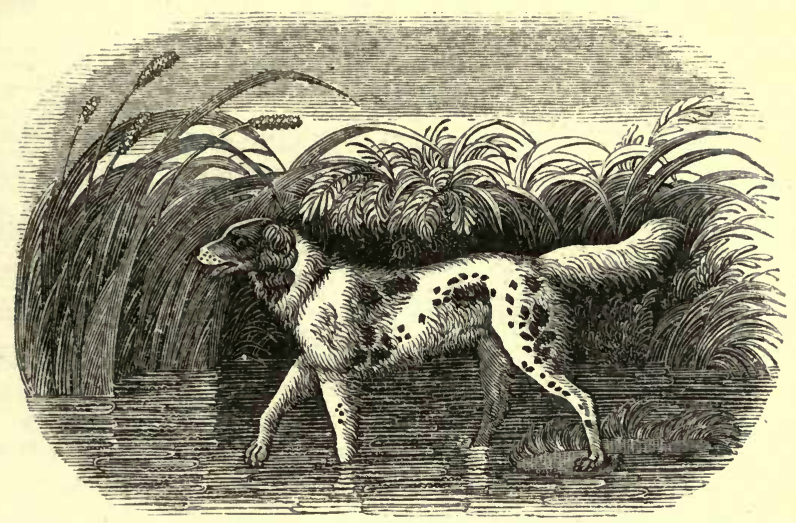

The Cocker, or Springer.

The cocker is a lively little dog, very expert in raising woodcocks and snipes from their haunts in woods and marshes, through which it ranges with indefatigable perseverance. I am informed that it is this kind of dog which is employed in decoying wild ducks, as mentioned by Pennant in the following passage :-

"It often happens that the wild-fowl are in such a state of sleepiness and dozing, that they will not follow the decoy-ducks. Use is then generally made of a dog, who is taught his lesson : he passes backwards and forwards between the reed-screens, in which are little holes, both for the decoy-man to see and for the little dog to pass through. The wild-fowl, not choosing to be interrupted, advance towards this small animal, that they may drive him away. The dog, all this time, by direction of the decoy-man, plays among the screens of reeds, nearer and nearer to the purse-net; till at last, perhaps, the decoy-man appears behind a screen, and the wild-fowl, not daring to pass by him in return, not being able to escape upwards on account of the net-covering, rush on into the purse-net. Sometimes the dog will not attract their notice unless a red handkerchief or something very singular, is put about him." *

* British Zoology (1768), vol. ii. p. 465. 


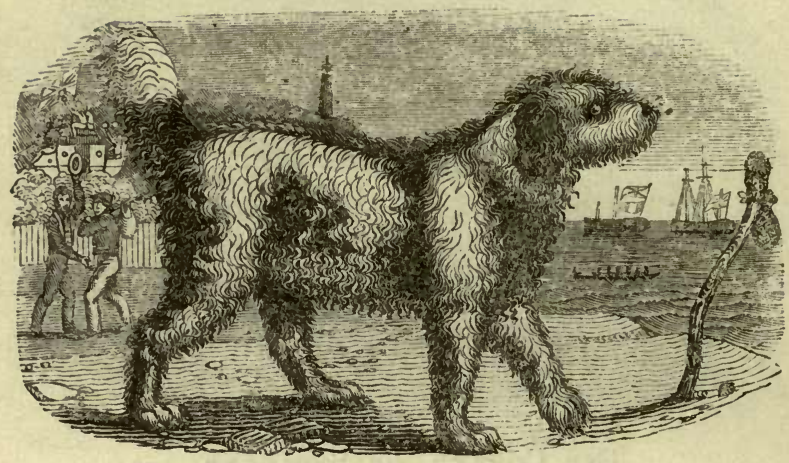

The Water-Dog.

The water-dog must not be confounded with the water-spaniel; compared with which it will be found to be much more robust. Its coat is curly and shaggy, and generally variegated with black and white; but some individuals are brown and white, or nearly all white. The muzzle is short and abrupt, the ears moderately long, and the tail rather short and erect.

The aquatic habits of this dog, the acuteness of its sense of smell, its great sagacity and strength, render it a highly useful servant to the numerous gunners of the north of England and Scotland, who live chiefly by shooting water-fowl, in the retrieving of which it exhibits the highest degree of docility and hardihood.

"The unerring accuracy with which this dog can be taught to search for and bring back to his master, articles which have either been lost or purposely left for the exercise of his powers, forms one of the most surprising instances of sagacity and intelligence to be found in the history of the species. If a coin or other small article be shown to the dog, and then put in a place of concealment, and the dog be sent even long 
afterwards, and from a distance, he searches the spot where it had been placed, until he finds it, and then returns it to his master. This power has often been carried to a great degree of perfection, and employed in perpetrating a destructive robbery of ducks, and other water-fowl." *

The rough water-dog is often kept on board ship, to recover articles which may chance to fall into the water. Sir John Sebright observes that, although there are many breeds of water-dogs, varying in size and appearance, from the large Newfoundland dog to the little poodle, yet there is one propensity common to them all-they will fetch and carry, or bring the game to their masters with very little or no teaching. This property, he adds, may be considered as peculiar to water-dogs, although it may be found in some few individuals of other breeds; but it would require a great deal of time, and some skill, to teach it to hounds, greyhounds, and other dogs.

\section{The French Poodle.}

The French poodle may be easily recognised by the cut of its coat, which is designed after the most fantastic patterns conceivable. It is a quiet and sagacious creature, and, perhaps on account of its trim dandified appearance, is more particularly the canine companion of the effeminate exquisities during those hours when they condescend to walk in the public parks or streets. If well treated, the poodle shows great attachment to its master, whether he be one of the common folk or one of the beau monde.

Among all the biographies of poodles, none will be found more interesting than that of Moustache, who was born at Falaise in Normandy, in 1799. At the tender age of six months, he was disposed of to an eminent grocer, at Caen, who treated him in the kindest manner. But strolling about 


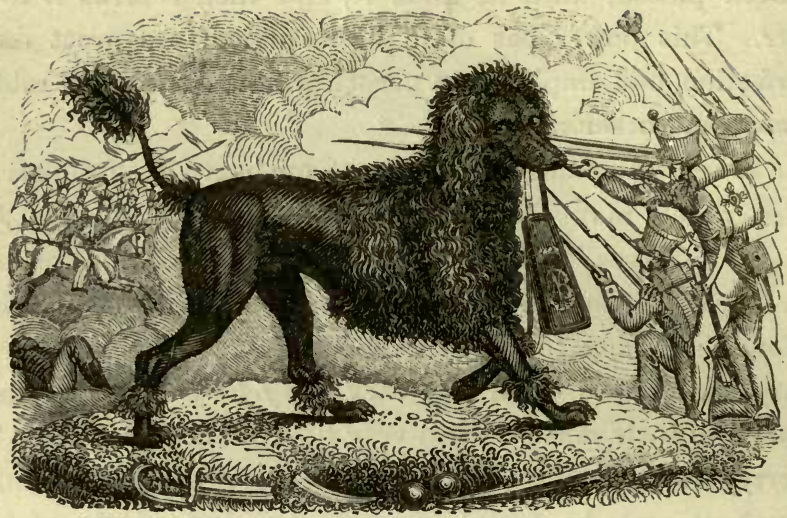

the town one day, not long after his arrival, Moustache happened to come upon the parade of a company of grenadiers. They were brilliantly equipped-their spirits were high-and their drums loud. Moustache, instantly smitten with their fine appearance and military enthusiasm, cut the grocer for ever, slunk out of that town, and joined the grenadiers ere they had marched an hour. He was dirty-he was tolerably ugly-but there was an intelligence, a sparkle, a brightness about his eye that could not be overlooked. "We have not a single dog in the regiment," said the petit tambour, "and, at any rate, this one looks clever enough to forage for himself." The drummajor nodded assent; and Moustache attached himself to the band, and was soon found to possess considerable tact and talent. He already fetched and carried admirably, and, ere three weeks were over, he could stand with as erect a back as any private in the regiment, act sentinel, and keep time in the march. Soldier like, he lived from paw to mouth. He endured the fatigues of Mont St. Bernard with as good a grace as any veteran in the army. They were soon near the enemy, and Moustache, having become familiar with the sound of musketry as well as of drums, seemed to be inspired with new ardour 
as he approached the scene of action. The first occasion on which he distinguished himself was this:-His regiment being encamped on the heights above Alexandria, a detachment of Austrians, from the vale of Belbo, attempted a surprise during the night. The weather was stormy, and the French had no notion that the Austrians were close advancing. The camp was in danger, but Moustache was on the alert. Walking his rounds as usual, with his nose in the air, he soon detected the greasy Germans, perhaps by the smell escaping from their knapsacks, full of sour krout and rancid cheese. He gave the alarm, and the foul feeders " fled for safety and for succour." Next morning it was resolved that Moustache should thenceforth receive the ration of a grenadier per diem. He was now cropped a la militaire; a collar with the name of the regiment was hung round his neck, and the barber was ordered to comb and shave him once a week.

In a skirmish which occurred, Moustache received a bayonet wound in his left shoulder. He was not perfectly recovered from this accident when the great battle of Marengo took place. Lame as he was, he could not keep away from so grand a scene. He kept close to that banner which he had learned to recognise among a hundred; and never gave over barking until the evening closed upon the combatants. The Sun of Austerlitz found him with his chasseurs. In the heat of the action he perceived the ensign, who bore the colours of his regiment, surrounded by a detachment of the enemy. He flew to his rescue-barked with all his might-did all he could-but in vain. The ensign fell, covered with a hundred wounds, but not before, feeling himself about to fall, he had wrapped his body in the folds of the standard. Five or six Austrians still remained by the ensign to obtain possession of the colours he had so nobly defended. Moustache having thrown himself on the dead body, was on the point of being pierced with half-a-dozen bayonets, when a timely discharge of grape-shot swept the Austrians into oblivion. The moment that Moustache perceived he was delivered from his assailants, he took the staff of the 
French banner in his teeth, and strenuously endeavoured to disengage it; but ineffectually. He succeeded, however, in tearing away the silk, and with this glorious trophy returned to the camp limping and bleeding,

One day a chasseur, mistaking the dog, hit him a chance blow with the flat side of his sabre. Moustache, piqued to the heart, deserted from the regiment, attached himself to some dragoons, and followed them into Spain. On the eleventh of March, 1811, he was killed by a cannon ball, at the taking of Badajoz. He was buried on the scene of his last glories, collar, medal, and all. A plain stone with the simple inscription, " $\mathrm{Ci}$ git le brave Moustache" was placed over his grave; but the Spaniards afterwards broke the stone, and the bones of the poor animal were burnt by order of the Inquisition.

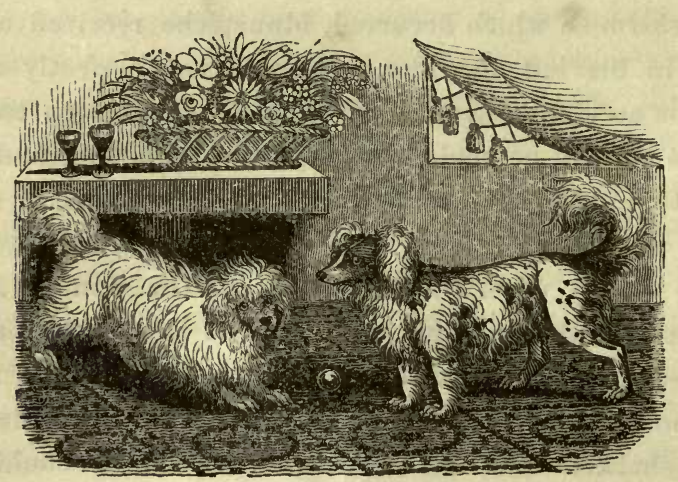

The Shock and Comforter.

The shock, though a common favourite with the fair sex, and generally kept as white as snow, has not much pretension to beauty, and more resembles a white muff than a dog. Its long woolly hair continually dangling over the eyes, to its seeming annoyance, gives it a most pitiable appearance. 
No wonder that the eccentric preference which ladies give to these unshapen and comparatively ignoble dogs, should have elicited severe remarks from several writers. In the New European Magazine (1822), a correspondent says, "When I meet one of these pampered animals, waddling and wheezing its panting way after its fashionable mistress, I am much perplexed which to dislike most ; but as I venerate all petticoats, I usually satisfy my spleen by disliking the dog instead of its mistress. When I have seen a tall manly fellow, a lady's lacquey, hoisting one of these white enormities under his arm, and dogging the heels of his superior, I have felt indignation, that even a man in a livery should be degraded to so vile and unmanly an office. But when I have met some fair spinster, hugging one of these obnoxious affection-stealers to her bosom, I have wished myself bitten by a mad-dog, that I might run about the Parks and other polite places, in an unsuspicious shape, and bite every dog's tail that was to be caught dangling from the dexter bend of a fair spinster's elbows, and thus inoculate those alien protegées with the dog-day variolus of death. The old fashion of a following black boy, was a more human folly than the attendance of a waddling and useless shock-dog."

In a very scarce and valuable tract on English Dogges, their diversities, names, natures, and properties, newly translated, by Abraham Fleming, and published in $15 \% 6$, it is observed that "Use and custum hath intertained dogges of an outlandish kinde; I meane Iseland dogges, curled and rough all over, which by reason of the length of their heare, make showe neither of face nor body, and yet these curs forsooth, because they are so straunge are greatly set by, esteemed, taken up, and made of many times in the roome of the spaniel-gentle or comforter."

Alluding to the fact of this kind of dog being better fed than taught, Massinger, in his celebrated play of "The Picture," says :-

"—— would I might lie

Like a dog under her table, and serve for a footstool, 
So I might have my belly-full of that Her Iceland cur refuses."

(Act V. Scene 1.)

The right hand figure in the preceding wood-cut represents the comforter or spaniel-gentle, another sort of lap-dog, and which, in comparison with the shock, is as "Hyperion to a satyr."

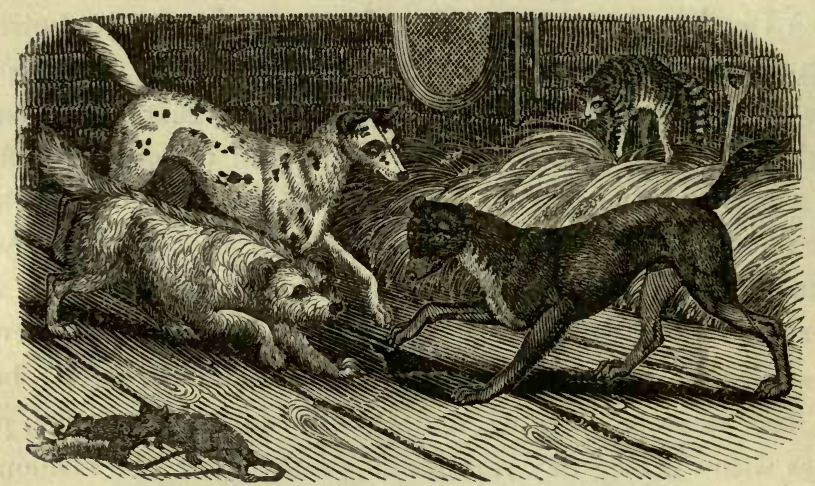

The Terrier.-(Canis terrarius.)

The terrier receives its name from its use in unearthing foxes, badgers, polecats, rats, and other animals from their holes, and in this employment it displays great sagacity, strength, and courage. The adroitness with which it seizes the boldest vermin, and the rapidity with which it dispatches them, are truly surprising. On a betting occasion, Billy, a celebrated terrier, was turned into a room where there were one hundred rats, and he killed them all in less than seven minutes.

Professor Bell remarks that " the terrier bears in its form but a very remote relation to any of the other varieties, and appears to have existed from a very remote period as a distinct race, which in the present day is preserved in its purity with the greatest care." But, strange to say, Sir John Sebright, whom 
the professor recommends to our notice as " an acute, sensible, practicable observer, and one whose judgment can well be relied on," tells us that the "terrier is now almost extinct in England." This, however, is incorrect, for thorough-bred terriers are still common in Middlesex, Surrey, Kent, and probably most other English counties.

"A gentleman had a terrier, which he was sometimes in the habit of tying up. He frequently missed the dog's collar, and at last discovered that the animal carried it off in its mouth in order to hide it, being aware that it was one of the instruments of its confinement.

"Two small terriers were in the habit of leaving their home together to hunt rabbits in a warren at some distance from it. One of them having got so far into a rabbit-burrow that he could not extricate himself, his companion returned to the house, and by whining, and using many significant gestures, attracted the notice of his master. When he had done this, he ran a short way forward, and then returned; and after repeating this some time, his master was induced to follow him. The dog led him to the rabbit-burrow, where he began to bark and scratch violently; and, on procuring a spade, the other dog was dug out." *

When a boy I had a very faithful terrier, a bob-tailed, eccentric, but sagacious specimen of the breed. He entered fully into all my amusements. At home, he would be by my side, while I attended to my collection of tame pigeons, rabbits, Guinea-pigs, squirrels, and mice, and though all these animals were permitted to run under his very nose, yet he always spared them. In the fields he was also my constant companion. One morning I went out on a botanical ramble, and was accompanied by my dog, Dandy as he was called. While endeavouring to gather some plants growing on a ditch-bank, my foot slipped, and I fell up to my knees in the black mud below. The dog saw my predicament, and I endeavoured to catch hold of him, imagining that with the assistance of his strength I could more easily 
extricate myself: but he took to his heels. I called Dandy repeatedly, but he would only stop for an instant, look back, and then continue his former course. It seemed as though he thought that, after such an occurrence, I was not suitable company for a dandified dog. After some trouble I got out, and walked homewards, very much displeased at being so deserted. The first house I came to was a chemist's, and in passing I perceived the dog inside the shop. On my claiming him, I was informed that he had entered the shop in a great flurry, and that he had been pulling the apprentice's apron for the last half hour. When I told what had occurred, the man agreed with me that the dog had repaired to the shop in order to induce some one to come to my assistance. On another occasion this dog displayed a curious example of his attachment for a cat, which had lived for some time in our family. We removed to a new house, and left the cat in the possession of some friends near the old house, as we wished to get rid of her. The first night of Dandy being at his new residence, which was about a mile and a half from the former one, he was evidently distressed at the absence of his feline companion; and at a late hour he barked continually and ran towards the door, and on its being opened for him, he went out, and was not seen any more that night. In the morning when the door was opened, in walked Dandy,-not, however, alone, but accompanied by the cat, whom he seemed extremely pleased to introduce to the new abode. The dog had, doubtless, been in search of the cat, and having found her, had induced her to follow him through the streets to his home.

\section{The Bull-Dog.}

In the bull-dog the most ugly and forbidding appearance is found united with great animal strength and the most savage ferocity. It is the least sagacious and the most brutish of its tribe, and therefore the favourite dog of the least intellectual and the most cruel of men. The bull-dog is as peculiarly the 


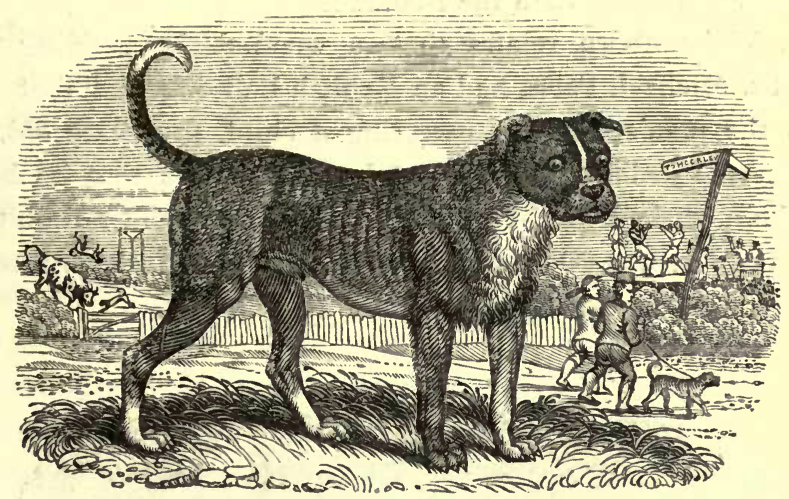

blackguard's dog as the lurcher is the poacher's. The Newfoundland dog will save the drowning man, the sheep-dog guard the flock, and the coach-dog gratify the eye by its elegance and sprightliness; but the bull-dog-rival of Cerberus-will merely exhibit its surliness or its savage battles. In short, it has no claim to our admiration; not one pleasant association connected with it. Think of a bull-dog and what else occurs to the mind, but an assemblage of thieves and gamblers goading one dog on against another in some secluded part of the town, or setting one or more of these dogs upon a bull in some country meadow. Some easy people deceive themselves into the notion that such scenes of brutality have ceased since the establishment of the rural and metropolitan police and of the Society for the Prevention of Cruelty to Animals; but, from Whitechapel in the east, to Bayswater in the west of the metropolis, there are yet arenas for the sport of bull-dog fighting. While the Society are continually bringing to punishment poor men for overloading or over-working their donkeys, even under such circumstances of distress as render the offence somewhat excusable, they seem to shut their eyes to the cruel amusements of the dog-fighting gentry of Bayswater, and the badger-baiting military of Woolwich. But poor venders of coal and turf are more easily summoned 
and fined (or rather ruined, for to them the fine is often equivalent to ruin,) than the rich.

Dr. Weissenborn relates that, a wood dealer residing near Quai St. Michael, Paris, had an English bull-dog, and that once when the man's wife was caressing a child, five years old, the dog became jealous of it, and at last so furious that he broke his chain, rushed at the child, worried it, and did not quit his hold, until he was killed with a knife. The child was so severely hurt, that its life was for some time despaired of.

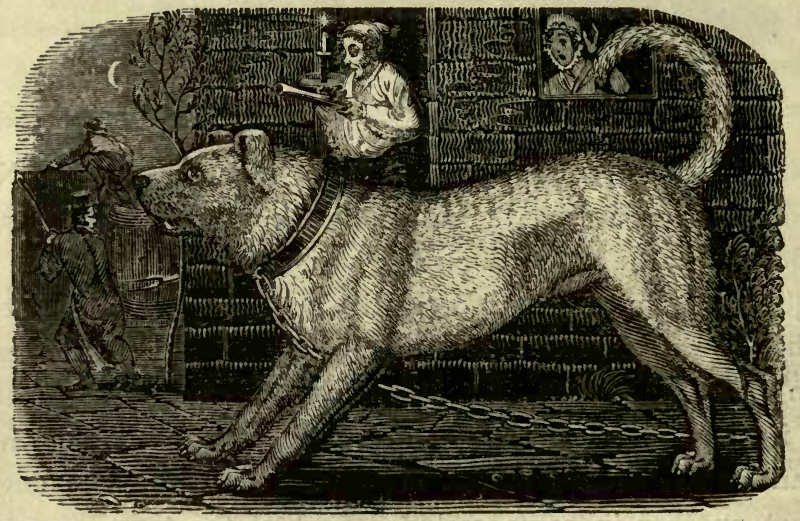

The Mastiff.-(Canis molossus, Linn.)

From a very early period, the English mastiff has been celebrated for its large size, great strength, courage, generosity, and sagacity. Though the pure breed is now scarce, yet the ordinary mastiff of the present day is a commendable dog. "Unlike the bull-dog, it is susceptible of great attachment to all who are kind to it, and seldom, except when closely chained, offers any molestation without repeated aggression. It barks, too, before it bites; but the bull-dog makes its attack with a savage and insidious silence."*

* Bell's British Quadrupeds (1837), p. 251. 
An old writer says that, in choosing " a mastie that keepeth the house, you must provide such a one as hath a large and mightie bodie, a great and a shrill voice, that both with his barking he may discover, and with his sight dismay the thief,yea, being not seen, with the horror of his voice put him to flight. His stature must neither be long nor short, but well set, his head great, his eyes sharp and fierie, either brown or gray, his lips blackish, neither turning up, nor hanging too much downe, his mouth blacke and wide, his neather jaw fat, and coming out of it on either side a fang, appearing more outward than his other teeth; his upper teeth even with his neather, not hanging too much over, sharpe, and hidden with his lips; his countenance like a lion's, his breast great and shag haired, his shoulders broad, his legs big, his tail short, his feet very great; his disposition must neither be too gentle nor too curst, that he neither fawn upon a thief, nor fly upon his friends; very waking, no gadder abroad, nor lavish of his mouth, barking without cause. It maketh no matter that he be not swift; for he is but to fight at home, and to give warning of the enemy. A black dog is best, because of the hurt that he may do to the thief by night by reason of not being seen."*

In a late Report on the State of Crime in England, it is confessed by a thief and burglar, in the course of his examination, that he and others found " dogs inside houses to be the greatest hindrance, and what occasioned the greatest fear; and that they did not care much for one outside. A dog inside will stop any side and any thing, if it will only make a noise." This hint ought not to be lost upon those who keep their watch-dogs outside.

Curran, when a boy, had heard that any person throwing the skirts of his coat over his head, stooping low, holding out his arms and creeping along backward, might frighten the fiercest dog and put him to flight. He accordingly made the experiment

* Foure Bookes of Husbandrie, by Conrad Heresbatch; newly Englished and Increased by Barnaby Googe (London, 1586), p. 154. 
on a mastiff, who would never let the school-boys rob the orchard; and found, to his sorrow, that he had a dog to deal with who did not care which end of a boy came foremost, so as he could get a good bite. Having no eyes save those in front, Curran fancied, as he pursued the instructions, that the mastiff was in full retreat; but he was greatly mistaken, for at the very moment he thought himself victorious and about to be rewarded with apples, the dog attacked his centre of gravity, and was fully prepared to repeat this kind of warm salutation when the boy was rescued.

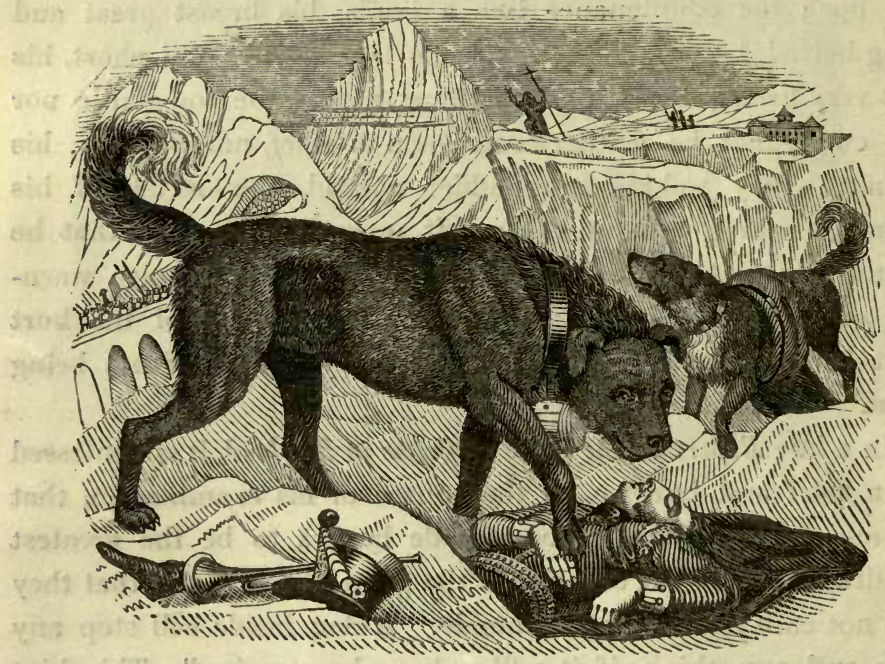

The Alpine Spaniel of St. Bernard.

This noble dog, often improperly called a mastiff, possesses extraordinary sagacity, docility, and acute scent, all which qualities it devotes to the most useful purpose - that of rescuing mountain travellers from destruction.

The perilous passage of the Alps, between Switzerland and 
Savoy, " is more frequently undertaken in the winter than is generally imagined: it is difficult to conceive the necessity or urgency of affairs which can lead persons, at such a season, through these scenes of danger. They are generally pedlers or smugglers, who mount the pass from either side, in defiance of the snows, tourmentes, and avalanches of these high regions. During the severe cold of winter, the snow at this elevation forms and falls like dust; it congeals so soon, and so hard, that the particles do not attach and form flakes when they touch, as in lower regions; and instead of consolidating beneath the pressure of the traveller's feet, they rise around him in powder, and he sinks to his middle. These snow-storms, when accompanied by violent winds, are called tourmentes, and are often fatal to the poor wretches who encounter them; unable then to trace the path, they wander and fall over precipices. The avalanches, too, take their share of victims. The summer avalanche is caused by the sub-melting of the snow, which undermines its support; and the mass, once set in motion, descends with great violence. The avalanches of winter are occasioned by the masses of snow accumulating on the slopes of the mountains, where it is too dry to attach firmly; and when the weight of snow exceeds the supporting resistance of the surface of the ground, it slides off into the valley below, with the suddenness and violence of a cannon-ball : these are the sort of avalanches which in the winter render the approach to the Hospice [a convent situated near the top of the mountain of the Great St. Bernard] very dangerous. Near the convent the mountains are steep, and the traveller is exposed to almost certain destruction if an avalanche fall whilst he passes; and the poor wretch, buried beneath the mass, is found only when the snow melts, and the summer, which to him never returns, discovers the victim in these regions. Under every circumstance in which it is possible to render assistance, the worthy monks of St. Bernard set out upon their regularly appointed duties. Undismayed by the spirit of the storm, and obeying a higher Power, they seek, amidst the greatest dangers, the exhausted 
or overwhelmed traveller. The sagacity of the dogs by which they are generally accompanied, is so extraordinary, that they, too, as if conscious of their performing a high duty, will roam alone the day and night through in those desolate regions, discover the victim buried in the snow, and lie on him and lick him to impart warmth. They bear with them some refreshing liqueur around their necks for the poor traveller whom they may find, if he should have still sense enough left to use it; they then bark or howl-their signals for assistance, or, if the distance be too great, return to seek it."*

Mrs. Starke relates that one of these dogs saved the lives of fifteen travellers, and another is said to have been decorated with a medal in commemoration of his having saved the lives of twenty-two persons who, but for his sagacity, must have perished.

Miss M. L. Beevor says that while some young lads were bathing in the vicinity of London, a friend of hers happened to pass the spot with a large, handsome dog of the Mount St. Bernard breed. The animal watched with much anxiety the boys in the water, and when he saw one dive down beneath it, in he plunged, seized him gently by the leg, and drew him to the shore. The lad was not in the least hurt, but rather alarmed, fancying the dog meant him an injury; but, in truth, the noble creature, believing he beheld a human being nearly drowning, only rushed into the water to save him.

\section{The Newfoundland Dog.}

The great strength, hardihood, and patience of the Newfoundland dog, together with its sagacity and affection, have rendered it one of the most generally useful, as well as social, of the whole race. In Newfoundland, from whence it originally came, it is employed to draw carts and sledges, laden with wood and fish, and to perform a variety of useful offices, in place of the

* Brockedon's Excursions in the Alps. 


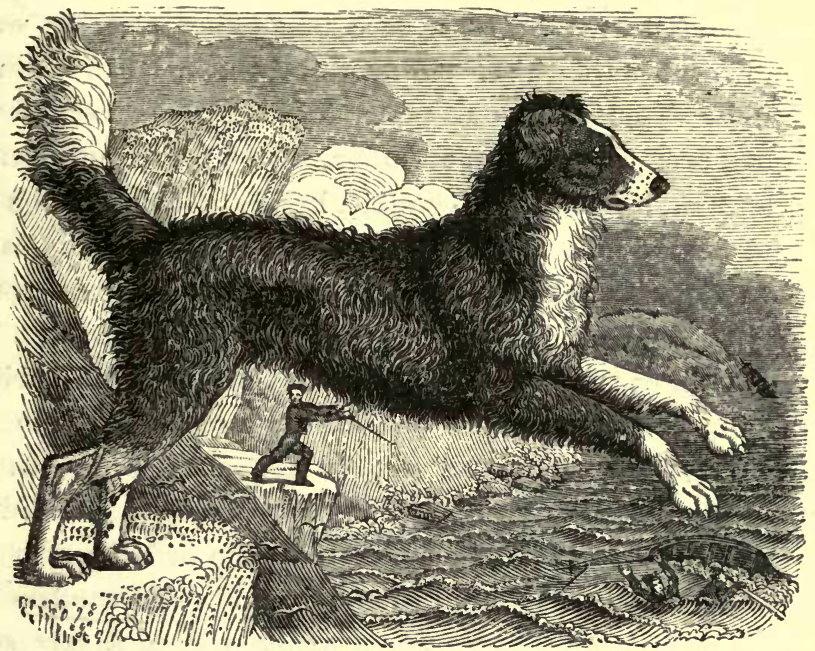

horse. As an aquatic dog, it is superior to every other kind; and this arises from its being semi-webbed between the toes, by which mechanism the foot presents an extended surface to oppose the water behind, and then collapses, when it is drawn forward previous to making another stroke. Owing to this excellent adaptation of its feet for the purpose of swimming, or rowing through the water, as Sir Everard Home calls it, more instances occur of human life being saved by the Newfoundland dog than by any other.

Mr. Youatt says that he knows the following anecdote to be a fact:- " A vessel was driven on the beach at Lydd, in Kent. The surf was rolling furiously, eight poor fellows were crying for help, but not a boat could be got off to their assistance. At length a gentleman approached the beach accompanied by a Newfoundland dog. He directed the attention of the animal to the vessel, and put a short stick into his mouth. The intelligent and courageous fellow at once understood his meaning, sprang into the sea and fought his way 
through the waves. He could not, however, get close enough to the vessel to deliver that with which he was charged, but the crew joyfully made fast a rope to another piece of wood, and threw it towards him. He saw the whole business in an instant : he dropped his own piece, and immediately seized that which had been cast to him, and then, with a degree of strength and determination almost incredible, he dragged it through the surf and delivered it to his master. A line of communication was thus formed, and every man on board was rescued from a watery grave."*

"A Suffolk gentleman, being on an excursion with a friend, and having a Newfoundland dog also accompanying him, the animal soon became the subject of conversation; when his master, after a high eulogium upon his perfections, assured his friend that the dog would, upon receiving the order, return and fetch any article left at any distance behind. To confirm this assertion, a marked shilling was put under a large square stone by the road-side,-having been previously shown to the dog. The two friends then rode for three miles, when the dog received his master's signal to return for the shilling he had seen put under the stone. The dog turned back, and the gentlemen rode on and reached home; but, to their surprise and disap. pointment, the hitherto faithful messenger did not return during the day. It afterwards appeared that he had gone to the place where the shilling was deposited, but the stone being too large for his strength to remove, he had staid howling at the place, till two horsemen, riding by, and attracted by his seeming distress, stopped to look at him; when one of them, alighting, removed the stone, and seeing the shilling, put it into his pocket, not at the time conceiving it to be the object of the dog's search. The dog followed their horses for twenty miles, remained undisturbed in the room where they supped, followed the chambermaid into the bed-room, and secreted himself under one of the beds. The possessor of the shilling hung his breeches up by the bed-side; but when the travellers were both

* Essay on Humanity to Brutes. 
asleep, the dog took the said garment in his mouth, and, leaping out of the window, which was left open on account of the sultry heat, reached the house of his master at four o'clock in the morning, with the prize he had made free with, and in the pockets of which were found a watch and money, that were returned upon being advertised: when the whole mystery was mutually unravelled, to the admiration of all parties." *

"Mr. Poynder, brother to the treasurer of Christ's Hospital, brought one of these dogs from the island of Newfoundland, where it was born. This animal had established a strong claim on his master's affection, from the circumstance of his having twice saved his life by his sagacity in finding the road home, when Mr. Poynder had lost his way in snow-storms, many miles from any shelter. He had also swum more than three miles to gain the ship, after his master had embarked for England, and determined to leave the animal to the care of friends at Newfoundland. Mr. Poynder landed at Blackwall, and took the dog in a coach to his father's house at Clapham. He was there placed in a stable, which he did not leave until the second day after his arrival, when he accompanied his master in a coach to Christ's Hospital. Mr. Poynder went round to the front door of the treasurer's house, and thinks he left the dog at the garden entrance, for he did not recollect seeing him afterwards. In the hurry and excitement of meeting his friends, he for a few moments forgot his dog, but as soon as he recollected himself, he went in search of him; but he was no where to be seen. Early, however, next morning, a letter arrived from the captain of the ship in which $\mathrm{Mr}$. Poynder had sailed from Newfoundland, informing him that the dog was safe on board, having swum to the vessel early on the previous day. By comparing the time on which he arrived, with that when he was missing, it appeared that he must have gone directly through the city from Christ's Hospital to Wapping, where he took to the water." $\dagger$

* Sportsman's Annual. First Series.

† Jesse's Gleanings in Natural History, vol. iii. p. 300 . 


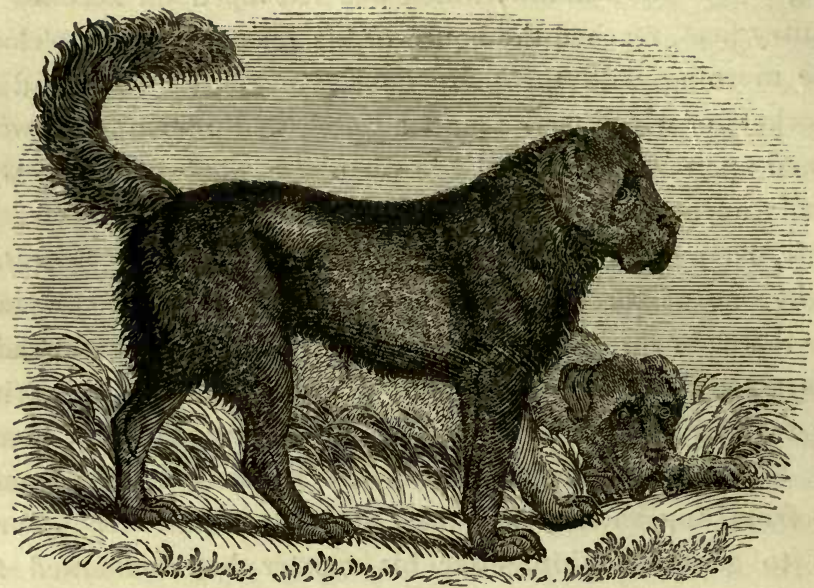

The Thibet Dog.-(Canis molossus Thibetanus.)

The pair of dogs here represented were brought from the neighbourhood of Diggarchee, the capital of Thibet, by Dr. Wallich, the celebrated botanist, and were presented by William the Fourth to the Regent's Park Zoological Gardens, where they died shortly after their arrival. Mr. Bennett says, they were larger in size than any English mastiff that he had seen. " Their colour was a deep black, slightly clouded on the sides; their feet and a spot over each eye alone being of a full tawny or bright brown. They had the broad short truncated muzzle of the mastiff, and lips still more deeply pendulous. In fact there appeared throughout a general looseness of the skin; a circumstance which M. Desmarest has pointed out as characteristic of his Dogue du Thibet, of which, however, he gives no particular description. It is, we have no doubt, the same animal."*

Dr. Wallich, who says that this pair were very gentle, informs us that, "These noble animals are the watch-dogs of the table

* Zoological Gardens Delineated, vol. i. (1831), p. 152. 
land of the Himalaya mountains about Thibet. Their masters, the Bhoteas, to whom they are most strongly attached, are a singular race, of a ruddy copper colour, indicating the bracing air which they breathe, rather short, but of an excellent disposition. Their clothing is adapted to the cold climate which they inhabit, and consists of fur and woollen cloth. The men till the ground and keep sheep, and at certain seasons come down to trade, bringing borax, tincal, and musk for sale. They sometimes penetrate as far as Calcutta. On these occasions, the women remain at home with the dogs, and the encampment is watched by the latter, which have an almost irreconcileable aversion to Europeans, and in general fly ferociously at a white face. A warmer climate relaxes all their energies, and they dwindle even in the valley of Nipāl."

Captain Turner, who appears to be the first traveller who has published any notice of these dogs, says, that near the mansion of the Rajah of Bootan he observed " a row of wooden cages, containing a number of large dogs, tremendously fierce, strong and noisy. They were natives of Thibet; and whether savage by nature, or soured by confinement, they were so impetuously furious, that it was unsafe, unless the keepers were near, even to approach their dens. Entering a Thibet village and being indolently disposed, and prompted by mere curiosity, I strolled alone among the houses : and seeing everything still and quiet, I turned into one of the stone enclosures, which serve as folds for cattle. The instant I entered the gate, to my astonishment, up started a huge dog, big enough, if his courage had been equal to his size, to fight a lion. He kept me at bay with a most clamorous bark, and I was a good deal startled at first; but recollecting their cowardly disposition, I stood still; for having once had one in my possession, I knew that they were fierce only when they perceived themselves feared. If I had attempted to run, he probably would have flown upon me, and torn me in pieces, before any one could have come to my rescue. Some persons came out of the house, and he was soon silenced."*

* Account of an Embassy to the Court of the Teshoo Lama in Thibet (1800). 
Captain Raper, speaking of the trade carried on by the natives of Bootan, says, "Dogs are also brought down by these people. One of them was a remarkably fine animal, as large as a good sized Newfoundland dog, with very long hair and a head resembling a mastiff's. His tail was of an amazing length, like the brush of a fox, and curled half way over his back. He was, however, so fierce, that he would allow no stranger to approach him; and the same fault was observable in the rest of this species."*

Mr. Moorcroft, also says, "the Uniyas had dogs with their flocks, which were fierce, and much disposed to attack strangers." †

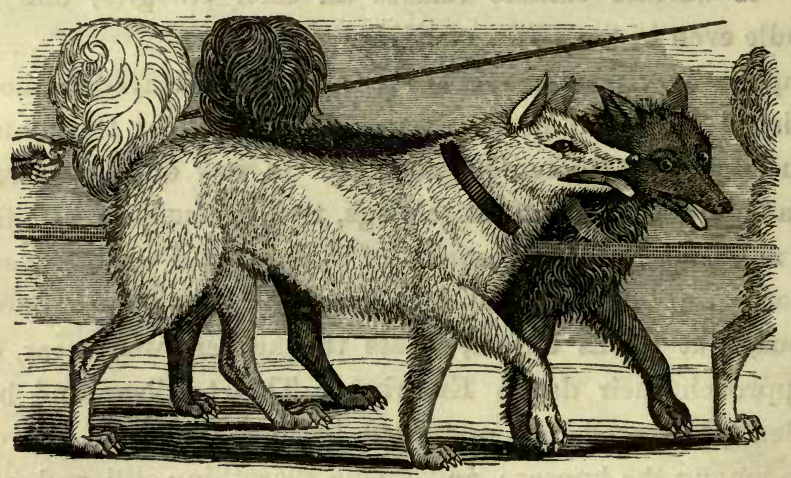

The Esquimaux Dog.

This useful and beautiful creature most nearly resembles the sheep-dog and the wolf-dog. Its ears are short and erect; its tail bushy, and gracefully curved over the back; and in the latter particular principally it differs from the wolf of the same locality, whose tail is carried between the legs in running. The colour of the Esquimaux dog varies in different individuals; some being white, some black and white, some brindled, some almost entirely black, and others of a dingy red. Captain Lyon

* Narrative of a Survey for discovering the Sources of the Ganges.

† Journey to Lake Manasarovara. 
says, that some fine specimens are about the height of the Newfoundland dog; but the average height is one foot ten inches, and the length from the muzzle to the root of the tail about three feet three inches; and of the tail itself, about thirteen inches. These dogs never bark, but howl in a melancholy strain, like that of the wolf; and, although they are familiar and gentle with the inhabitants, they snarl and fight amongst themselves, much more than the generality of other dogs.

Their several uses to the Esquimaux have been thus correctly and briefly stated:- "These people, inhabiting the most northerly parts of the American continent, and the adjoining islands, are dependant upon the services of these faithful dogs, for most of the few comforts of their lives; for assistance in the chase; for carrying burdens; and for their rapid and certain conveyance over the trackless snows of their dreary plains. The dogs, subjected to a constant dependance upon their masters, receiving scanty food and abundant chastisement, assist them in hunting the seal, the rein-deer, and the bear. In the summer, a single dog carries a weight of thirty pounds, in attending his master in pursuit of game: in winter, yoked in numbers to heavy sledges, they drag five or six persons at the rate of seven or eight miles an hour, and will perform journeys of sixty miles a day. What the rein-deer is to the Laplander, this dog is to the Esquimaux. He is a faithful slave, who grumbles, but does not rebel; whose endurance never tires; and whose fidelity is never shaken by blows and starving. These animals are obstinate in their nature: but the women, who treat them with more kindness than the men, and who nurse them in their helpless state, or when they are sick, have an unbounded command over their affections; and can thus catch them at any time, and entice them from their huts, to yoke them to the sledges, even when they are suffering the severest hunger, and have no resource but to eat the most tough and filthy remains of animal matter which they can espy on their laborious journey."*

* The Menageries, vol. i. (1829), p. 36. 


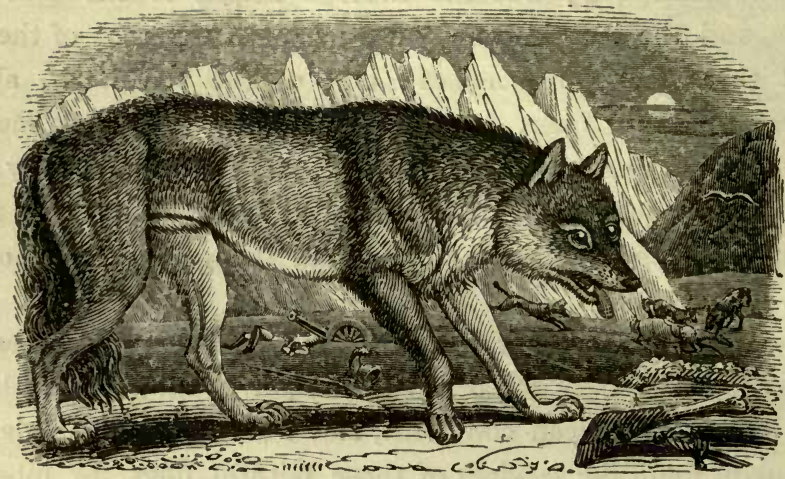

The Common WoLf.-(Lupus vulgaris.)

In Europe two species of wolf are found, namely, the common wolf (Lupus vulgaris) and the black wolf (L. lycaon).

The former inhabits France, Germany, Russia, Sweden, Norway, and Italy; the latter Spain and other countries in the south of Europe.

The common wolf of Western Europe is in stature from two-feet three inches to two-feet five inches, measuring from the shoulder. The general colour on the head, neck, and back is fulvous grey; the hairs being mostly white at the root, then ringed with black, fulvous, and white, and tipped with black; those beneath the ears, on the neck, shoulders, and buttocks, being much longer, form a kind of mane, which particularly protects the throat: all are hard and strong, especially about the nose and on the ears. The muzzle is black; the sides of the cheeks and above the eyes more or less yellow, turning grey with age. The upper lip and chin are white; the limbs yellow or dun.

Formerly the common wolf infested Great Britain. "In the Saxon times we find that in Athelstane's reign wolves abounded so in Yorkshire, that a retreat was built at Flixton in that 
county, to defend passengers from the wolves, that they should not be devoured by them; and such ravages did these animals make during the winter, particularly in January, when the cold was severest, that our Saxon ancestors distinguished that month by the title of wolf-moneth. They also called an outlaw wolfshed, as being out of the protection of the law, proscribed, and as liable to be killed as that destructive beast." *

Camden says that certain persons at Wormhill, in Derby, held their lands on condition of their pursuing and killing the wolves that infested the country. King Edgar, about the year 972, dispensed with the punishment of those persons who committed certain offences, upon their produsing a specified number of wolves' tongues; and it is a common notion that they did not inhabit England after his time. But that they existed here for many centuries subsequent to that period, is proved by the records concerning the destruction of wolves in the reigns of King John, Edward the First, and Edward the Third; indeed that they existed later may be inferred from the fact, that the monastic huntress, Juliana Barnes, writing in the time of Henry the Seventh, gives the following instruction to her pupils :-

"Where so ever ye fare by fryth or by fell, My dere chylde, take hede how Trystam do you tell. How many manere bestys of venery there are;

Lysten to your dame, and she shall you lere. Foure manere of bestys of venere there are: The first of them is the harte: the second is the hare : The boare is one of tho: the woolfe and not one mo."

(The Boke of St. Albans, 1496.)

Hollinshed says that in Scotland, in the year 15\%7, the flocks suffered extensively from the ravages of wolves. The last wolf that inhabited that country is said to have been killed at Lochaber, by Sir Edward Cameron of Lochiel, about the year 1677. Sir Thomas Dick Lauder gives an interesting account of the killing of the last wolves of Moray,- the facts of course

* Pennant's British Zoology (1768), vol. i. p. 63.

+ In the Catalogue of Mr. Donavan's sale of the London Museum by Mr. King, April 1818, lot 832 , p. 53, is " a wolf, a noble animal, in a large glazed case. The last wolf killed in Scotland, by Sir F. Cameron." 
being learnt from records. "Their den was in a deep sandy ravine under the Knock of Bre-Moray, a lofty mountain near the source of the Burn of Newtown. Two brothers boldly undertook to watch the old ones out, and to kill their cubs. Having seen the parents quit their den in search of prey, one of the men threw off his plaid, and armed with his dirk alone, crawled in to dispatch the cubs. He had not been long in the den when the wolves hastened back to the ravine. He found little difficulty in killing the cubs; and he was in the act of making his way out, when the entrance of the den was darkened, and the she-wolf was upon him. He dispatched her with one thrust of his dirk; but he was nearly torn to pieces by the male before he succeeded in killing him, although he fought in such a narrow place and from behind the dead body of the female."*

In Wales wolves abounded to so great an extent, that King Edgar, with a view to their extirpation in that country, commanded the Welsh to produce three hundred wolves' heads every year. This great number was furnished, but not without considerable difficulty, and the incurring of much risk, for the space of three years, that is to say until the king's death in 975. After his decease it seems that this exaction was discontinued, for the best of all reasons, - because no wolves remained in Wales at that time.

More than four centuries had elapsed after the extermination of wolves in England, before they were totally destroyed in Ireland; which land was not rid of them until about the year 1710, when the last presentment for their destruction is said to have been made in the county of Cork.

Dr. W. Weissenborn makes the following interesting observations upon the ravages of the wolves which infest European countries at the present time :-

"The wolf destroys every other creature it can master, and consumes during the year, on a moderate calculation, about thirty times its own weight of animal substances : though in cultivated countries the damage it does to the live stock makes 
its injurious character appear proportionately far greater; not to mention the dangers to which even man is exposed from its ferocity. As the countries infested by it become inhabited by people and tame animals, and less stocked with game, the audacity with which it attacks the tame species, notwithstanding the more extensive persecution to which the animal is subjected, increases even more than appears in proportion to the necessity for drawing more and more upon them for subsistence; until at last, man himself becomes its prey. To increase the list of the wolf's crimes it has, in many instances, communicated hydrophobia to man. In return for all the evils which this animal inflicts upon us, it has only its fur to offer; for obtaining which alone no hunter, in civilized countries, will incur the necessary expense, loss of time, and trouble. No wonder, therefore, that the same game-laws, which were conservative as to the wild boar, stag, \&c., should have outlawed the wolf from time immemorial, as being very injurious to herbivorous game. But the narrow-minded selfishness by which, until lately, almost all the game-laws have been dictated, did not admit of going a step further, by encouraging the extirpation of the wolf, by premiums sufficiently high, or in proportion to the interest which the commonwealth had in getting rid of the nuisance. On the contrary, the undue protection bestowed on herbivorous game, presented great obstacles to man in exterminating the wolf; whereas, in every country that is fairly brought under man's control, no wolf ought to exist : a result which, in England, has been effected long ago.

It may not at present be found practicable to exterminate the wolf in the Pyrenean and Carpathian mountains; the adjacent countries must, therefore, remain more or less subject to its occasional invasions : but it is probable the Jura, as well as the rest of France, Lower Austria, Upper Silesia, and Poland, might be thoroughly cleared of their resident wolves.

On August 27, 183\%, the Mayors of Bouhet and Benon, in the arrondissement of the town of La Rochelle, summoned a number of gentlemen to superintend a general battue which the 
inhabitants made, on that day, against the wolves, which did great damage to their cattle and flocks. In almost every department of France infested by wolves, there is a 'Sociétie de Louveterie,' the object of which is their destruction; and premiums, varying in amount according to the sex and age of those killed, are also paid. The necessity for extirpating the wolf is therefore acknowledged in France; but it has not yet been sufficiently appreciated, because the means hitherto employed have been altogether inadequate.

If, however, we wish to see just retaliation upon the wolves, from human law, we must observe what is going on in Prussia. After the peace of Tilsit, by which the present province of Posen was severed from that kingdom, and incorporated with the duchy of Warsaw, the new government lowered the premiums which the previous government had paid to those who killed wolves, to one dollar for an adult wolf, and half a dollar for a cub. This, as well as the great difficulty of obtaining the reward, though deserved, held out so little encouragement for their destruction, that the wolves increased at such a rapid rate, within the few years from $180 ;$ to 1815 , that in 1814, three grown persons and sixteen children were devoured by them, in the circle of Wongrowiec alone. As soon, however, as Prussia had again taken possession of Posen, in 1815, the government lost no time in getting rid of them. The rewards which had been paid previous to $180 \%$, when Posen formed a part of the province of South Prussia, were again awarded, namely, six dollars for an adult wolf, three for a cub, and one for each foetus found in a female. General battues were periodically made, and different regulations issued, with a view of poisoning the wolves with nux vomica.* From 1815 to 1819 inclusive, 4618 dollars were paid by the government as rewards for killing wolves. In

* "It has been found that the most successful method of poisoning wolves, is to drug small sausages with nux vomica, and hang them on the boughs of trees, at such a height, that the wolf must leap to obtain them. Under these circumstances the animal swallows the bait at once, and has not time to find out that it contains any suspicious admixture, which it often does if the poison be applied to the carcases of horses," \&c. 
$181 \%$, the animal had already become sufficiently scarce to make a considerable increase in the premiums both necessary and practicable. Twelve dollars were now given for an adult female, ten for an adult male, eight for a young one, four for a cub, and, as before, one for a fotus. This continued persecution of the wolves, caused them to become so scarce, that notwithstanding the tempting rewards, only 1449 dollars were paid from 1831 to 1836 inclusive, for a total number of 256 wolves destroyed during that time; although during the latter years of that period, the number of wolves had been rapidly increasing, owing to the use of fire-arms having been, to a great degree, prohibited in Poland after the revolution. Though they make more frequent inroads into the neighbouring countries, no human lives have been sacrificed by the wolves in the province of Posen; but we may judge that the destruction of men from that cause, must be very serious in Poland itself. According to the papers, four girls, of different ages, the eldest sixteen years, were torn to pieces in August, 1837, in the parish of Briala, district of Rawa, not far from their houses; and if such things happen in summer, what must be the audacity of the wolves in winter! The present increase of the wolves in Poland exemplifies, in a very striking manner, how quickly the political state of a country reacts upon its indigenous animals; and until the Russian government shall have found means to keep down the wolves in Poland, the task of destroying them in the province of Posen, will be beset with serious complications and difficulties. Though the lives of the Prussian subjects are not much threatened by the stray wolves of Poland, yet they commit such depredations on the live stock, that a society is now forming, for the purpose of paying extra premiums of five times the amount of those allowed by government ; so that, for instance, any one who kills an old female wolf, will receive seventy-two dollars. The contributions of the members will be in proportion to the value of their respective live stock; and it is, therefore, to be hoped the province will be kept pretty clear, even under the present unfavourable circumstances. 
In the Prussian provinces on the left bank of the Rhine, seven old females, six old males, one young wolf, and twenty-six cubs were killed in 1836, and 256 dollars were paid as rewards for their destruction." *

The Belgians chase the wolves when the snow is on the ground; but owing to the want of snow in the winter of 1834 the chase did not take place, until the wolves, finding the suspension of hostilities favourable to their propensities, had killed great numbers of cattle in the middle of the day at Liege, Luxembourg, Namur, and Hainhault, and then the government ordered a chasse générale, which, as it was wittily remarked, afforded the people more sport than a General Chassé.

In winter, when wolves find their prey to be scarce in their natural haunts, they become exceedingly bold, intrude into the sheep-folds, enter the villages, and even the towns. Indeed, the testimony of unquestionable witnesses, fully confirms Thomson's awful description of their ferocity at that season :-

\footnotetext{
"By wintry famine rous'd from all the tract Of horrid mountains which the shining Alps, And wavy Appenine, and Pyrenees, Branch out stupendous into distant lands, Cruel as death, and hungry as the grave! Burning for blood ! bony, and gaunt, and grim ! Assembling wolves in raging troops descend, And, pouring o'er the country, hear along, Keen as the north wind sweeps the glossy snow. All is their prize. They fasten on the steed, Press him to earth, and pierce his mighty heart; Nor can the bull his awful front defend, Or shake the murdering savages away. Rapacious, at the mother's throat they fly, And tear the screaming infant from her breast. The god-like face of man avails him nought. E'en beauty, force divine ! at whose bright glance The generous lion stands in soften'd gaze, Here bleeds a hapless, undistinguish'd prey."
}

(The Seasons : Winter.)

Matthew Aphonin, a Russian naturalist of the time of Linnæus, says that the wolf is afraid of a rope stretched across the ground,

* Abridged from Mag. Nat. Hist. Second Series, vol. ii. (1838), p. 123. 
and that the Russians avail themselves of this fact to repel its attacks; and more recently Mr. Edward Forbes has stated that the Norwegians are well aware of its dislike to anything suspended over head, and that at Stalheim, in Norway, ropes are suspened at several parts of the roads, from a pole on each side, for the purpose of warding off the wolves which abound there.* Of the North American wolf it is stated, that a bladder hung upon a pole, and blown about by the wind, will deter him from molesting the numerous herds of brifons always attack a reindeer when loose, but if the animal is tied to a stake, he fears to approach, considering that a pitfall is near, and that the deer is placed there to entice him to it. $\dagger$

The female of the common wolf goes with young nine weeks, and at each litter she has from eight to nine cubs, whose eyes remain closed until about the twelfth day.

If the young cubs be procured, they may be rendered tolerably tame, and several instances have been recorded of their attachment; and most of these are so well known even to general readers that I need here only allude to the fact. $\ddagger$ Nevertheless, the remark of Shakespeare's Fool is not altogether unjust:-

"He's mad that trusts in the tameness of a wolf;"

(K. Lear, Act III. Sc. 6.)

for it is only while the animal is under some restraint, and reminded, as it were, of its dependance on its master, that any reliance can be placed upon it. The tameness of a chained or caged animal is perhaps oftener the result of a prudent and cunning perception in the animal, than of real disinterested affection for its master. The author of a work published about a century since, says, "Two young wolves, brought up at our house, seemed to be very sociable, but they soon undeceived us. The sly animals one morning quarrelled with a dog, and tore him to pieces; they likewise killed three kids, and then marched

* Mag. Nat. Hist. vol. ix. (1836), p. $171 . \quad+$ Menageries, vol. i. p. 168.

‡ See the Mirror, vol. xxviii. (1837), p. 21; and Col. Hamilton Smith's Natural History of Dogs (Edinb. 1839), vol. i. p. 140. 
off to the woods." * That they never returned again, I should infer from the nature of this animal's attachment, and from the silence of the author on that point.

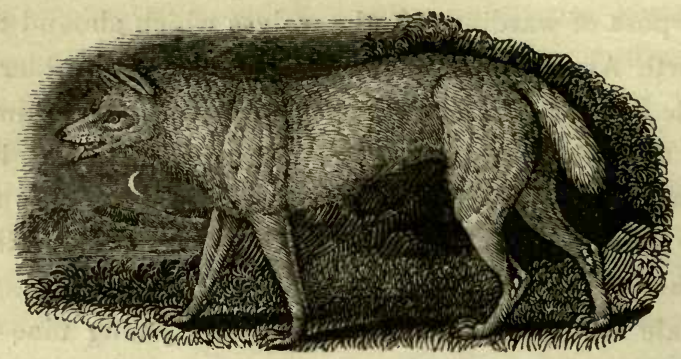

The Common Jackal.

(Canis aureus, Linn.; Sacalius, H. Smith.)

The common jackal is said to inhabit nearly the whole of Asia and the north of Africa; but Colonel Hamilton Smith seems to think, that those who give it this extensive geographical range have confounded it with other species.

The Turkish and Persian jackal, which the above named zoologist assumes to be the typical animal of the group, in fact the true common jackal, resembles, in many external particulars, a small wolf; but the fur of the body is more coarse, and its straight tail is rather longer in proportion and more brushy than in the latter animal. It is not much higher than the common fox, but it is about half a foot longer. To contrast it further with the fox, the jackal will be found to have a broader nose, covered with reddish ashy-grey hairs, all tipped with black. Its back and neck are yellowish grey, and the limbs and under parts pale reddish yellow.

Jackals, unlike the wolf or the fox, always associate in numerous troops, sometimes consisting of as many as two * Spectacle de la Nature (1744), p. 202. 
hundred, which burrow together in the earth, hunt together, and act in concert for their mutual defence. Thus formidably organized, these troops not only prey upon the domestic poultry and other small animals, but they chase and devour antelopes and other large mammals. They also frequently follow the tiger or the lion, that they may devour whatever remains of carcases either of those animals may leave behind it.

In some parts of India, the frightful howling of innumerable jackals is incessant, from the first approach of night until the first dawn of day. They come up to the very doors, in large packs, and roar away without any apparent purpose, frequently standing a long time in one place, as a dog does when baying the moon,-or, more correctly speaking, when it barks at a shadow or howls with pain at night-time. Captain Skinner says, that until he became familiar to the clamorous screaming of the jackals, he used to start from his sleep, imagining that some appalling calamity had driven the inhabitants of a neighbouring town to rush from their homes in fear and madness.

An officer in India brought up a young jackal, which he so far succeeded in taming that it would follow him like a dog, keeping, however, rather on one side of his master instead of directly behind him; and it would also fetch and carry. In other respects it was wild and fierce, a dangerous companion, and very addicted to thieving. It used to jump upon the breakfast and dinner table, and carry off whatever bread and meat it could steal undetected; but when its master's stores were inaccessible, it would pillage loaves of bread and legs of mutton from the other officers. It was in the habit of sharing its stolen dainties with a large fierce dog, which its master wished to train to keep the jackal in order. Once, when a gentleman and lady, with their young child, were on a visit at the house, the jackal was, as usual, fastened up for the night; but, lo ! at midnight, a loud cry was heard from the nurse; the jackal had got loose, and carried off the unfortunate infant from its cot. The jackal was instantly pursued, when it dropped the child unharmed, outside the house, and the animal was 
caught and more securely caged. It was supposed that it had been attracted to the infant by the smell of a bread and milk poultice applied to relieve a complaint under which the poor little creature was suffering.

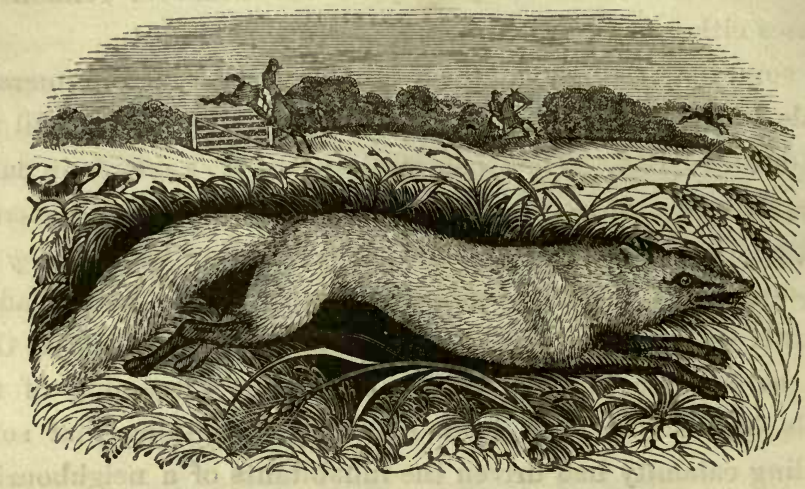

The Common Fox, or Tod.-(Canis vulpes, Linn.)

Zoologists are at variance as to the extent of the common fox's geographical range; some considering that the foxes of several foreign countries are merely varieties of the present species, somewhat altered and modified in their form, and in the texture of their fur, from local influences; and others, that they are distinct species. Dr. Weissenborn has justly remarked that " the history of the fox still teems with false notions, or points not quite settled. It has been composed from the statements of what had been inaccurately observed; from the observations of unscientific huntsmen and gamekeepers, who, besides being extremely superstitious, had most of them a good spice of Baron Munchausen; and as it is often impossible to refute an assertion by facts directly opposite, and, as in former ages, almost any fiction could be palmed upon mankind for truth, we shall find that the very animals with whom man has become first acquainted are often the least perfectly known." 
The ground colour of the fox is usually of a dull reddish fawn of various depths or shades, and inclining to a blackish tinge along the middle of the back, across the shoulders, the sides of the muzzle, the backs of the ears, the under surface of the tail, and the outer parts of the limbs, the remaining portions being of a pure white.

The fox is remarkable for the brilliancy and intelligent expression of his eye, the structure of which is very different from that of dogs. In the latter, however great the intensity of light to which they may be exposed, the iris uniformly contracts around the pupil, in the form of a circle; while in the fox, if observed during the day, or under the influence of a strong light, it is seen to close in a vertical direction, the pupil assuming the figure of a section of a double convex lens.

Grew observes, that the ear of the fox " that scouteth underneath the prey at roost, is, for the better reception of the least sound, produced further out below than it is above."* More recently, Dr. Farrar remarks, that its ear, by being expanded principally from behind in a forward direction, into nearly a circular aperture, "is very well adapted, when the head is thrown laterally and upwards, for receiving sounds from above. His prey is usually met with in hen-roosts, or perched on trees; and his mode of taking it by surprise induces him to approach it stealthily. Hence arises the necessity of sounds indicating its immediate presence being transmitted to the sensorium as soon as possible. The moment his ear indicates his prey above him, his eye is immediately turned in that direction; and thus, if within his reach, it is very speedily captured. What more beautiful provision for this animal's necessities could be met with than those with which he appears to be provided? His ears first give the indication of the presence of his prey, and his eye instantly contemplates the object of his pursuit." $†$

The fox preys upon sheep, hares, rabbits, moles, rats, fieldmice, partridges, poultry; frogs, and worms. It also sometimes

* Cosmologia Sacra. vol. i. p. 5. + Mag. Nat. Hist. vol. iv. (1831), p. 12. 
eats cockchafers and other large insects; and repairs to the sea-shore to feed on such fish, mollusks, crustaceans, and other marine animals which the tide may have left upon the beach. Dr. Weissenborn, who says that, in Germany, it destroys a great many hamsters, notices the curious circumstance that even the severest hunger cannot induce it to eat the flesh of predaceous birds, though most other birds are its greatest dainties; and it has not the same objection to that of the weasel tribe, cats, or other predaceous mammals.

" On some of the sea-locks on the west of Ross-shire, the fox has been observed to descend to the shore at night to feed upon mussels, particularly upon the large basket-mussel (Mytilus modiolus), or yoggs, as the Shetlanders call them. One morning, some years ago, a man perceived a fox on the shore, and though the tide was coming in, it seemed heedless, and busily engaged with something. The man, after observing him for a little time, went to his hut for his gun, and forthwith down to the shore, and shot the fox, which was as careless of his approach as that of the coming tide. On going to pick him up, he was found to be held fast by the tongue between the shells of one of these large mussels, which are sometimes seven inches long, and adhere firmly to the crevices of rocks, or larger stones below the sand, by means of a strong byssus, vulgarly called a beard. Had the fox not been. shot by the man, it would probably have been drowned by the no less merciless tide."*

When pursued by the huntsmen, the fox does not double, like the hare, but takes a straight-forward course, which he maintains with strength and perseverance, sometimes for a distance of fifty miles at a stretch, without the smallest intermission, unless he thinks he can enter a burrow, or go to earth, as sportsmen term it. Both fox-hounds and horses, particularly the latter, frequently fall victims to the ardour of the chase. Such is the great strength of the fox that, in many instances, he escapes the utmost efforts of his pursuers to take him, and again returns to his hole in safety. But if it should happen that all shifts 
fail, and he is at last overtaken, he defends himself with much obstinacy, and silently fights till he is torn to pieces by the merciless dogs. No less than 5796 foxes are recorded, in the Swedish States Gazette, to have been killed in Sweden during the year 1828.

"I know not," says Lord Brougham, " if the cunning of the fox was ever more remarkably displayed than in the Duke of Beaufort's country, where one of these animals, being hard pressed, disappeared suddenly, and was, after strict search, found immersed in a water pool up to the very snout, by which he held a willow bough hanging over the pond."

It has been often asserted that the fox gets rid of its fleas by grasping a wisp of hay or a bit of wool in its mouth, walking backwards into the water, and letting go of this burden when the fleas have crept into it to save themselves from drowning; but Dr. Weissenborn remarks, that this artificial way of proceeding " may easily be shown to be a fiction, as the fleas will not gradually recede from the water and assemble on the head of the animal which is slowly submerged from the tail upwards. Otherwise, there is nothing in the alleged expedient that must at once refute it; for the fox does many things by way of experiment, as it were; and if any well-authenticated fact of the fox having simulated death, as it has been frequently said to have done, ${ }^{*}$ for the purpose of escaping from danger, could be adduced, it must, I think, be explained on the experimental, not the instinctive principle. In an animal which often employs such unexpected and original means, we may even suppose that one individual will, cateris paribus, not behave like the other, but that there exist in the species, to a certain degree, gradations of reasoning power."

The female $\nmid$ brings forth four or five whelps at a litter in April,

* The notion of the fox counterfeiting death to obtain an opportunity of escaping, is as old as the time of Olaus Magnus, who says "In super finget se mortuam," \&c. (lib. xviii. cap. 39). Lovell says, that " if taken by the foot, the fox will bite it off to escape ; but if it cannot, it will seem to be dead." (Panzoologia, 1661, p. 52.)

+ Steevens, the dramatic commentator, says, that "vixen or fixen," pri- 
and which arrive at maturity in about eighteen months. While they are helpless, she exhibits great attachment for them, and an unusual degree of boldness in defending them from aggression. Several instances have been recorded of her carrying a whelp in her mouth while pursued by the huntsmen, who in such cases generally whip the dogs off, and suffer both parent and offspring to escape.

"A fellow feeling makes us wondrous kind."

The fox, though it be taken and domesticated when very young, never becomes thoroughly reclaimed. Its natural propensities cannot be completely subdued; and Shakespeare is quite right in declaring that a fox, ever

" so tame, so cherish'd, and lock'd up,

Will have a wild trick of his ancestors."

(Henry IV. Part I. Act V. Scene 2.)

\section{The Greyhound Fox.}

This is not a distinct species from the common fox, but merely a larger variety of it. "There are three varieties of foxes," says Pennant, "found in the mountainous parts of these islands, which differ a little in form, but not in colour, from each other, and are distinguished in Wales by as many different names. The Milgi or greyhound-fox is the largest, tallest, and boldest, and will attack a grown sheep or wether; the mastifffox is less, but more strongly built; and the Corgi, or cur-fox, is the least, and lurks about hedges, out-houses, \&c., and is the most pernicious of the three to the feathered tribe."* Bewick

mitively signifies a female fox, and in support of this he quotes from an ancient manuscript entitled The Boke of Hunting that is cleped [called] Mayster of Game:- "The fixen of the fox is assaute [salt] once in the year. She hath venemous biting as a wolf." But in Bailey's English Dictionary (1770), vixen or fixen is given as signifying " a fox's cub, a little fox." I believe, however, that Steevens is correct in regarding them as names originally applied to the female fox, and her courage in defending her young will easily explain how, in the present day, vixen is a term more particularly applied to pugnacious ladies.

* British Zoology (1768), vol. i. p. 61. 


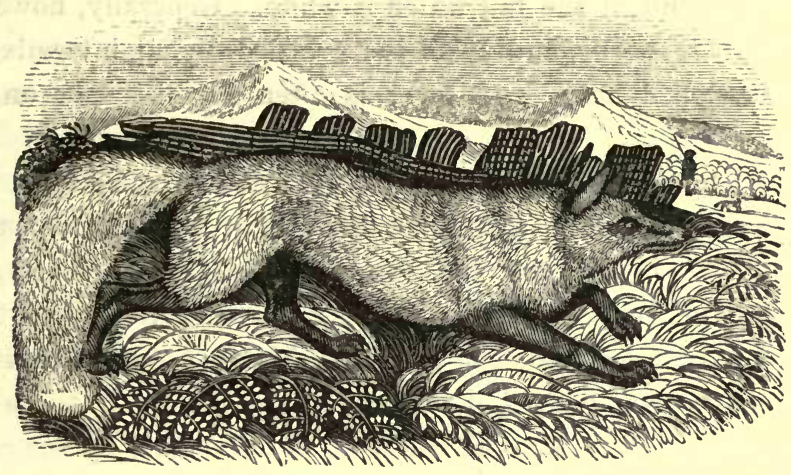

says, "the ears of the greyhound-fox are long and erect, and his aspect wild." * But, after all, the differences pointed out are not sufficiently striking even to constitute varieties, much less distinct species.-The case is exactly like that of the hog-badger and dog-badger, distinctions already noticed and refuted.

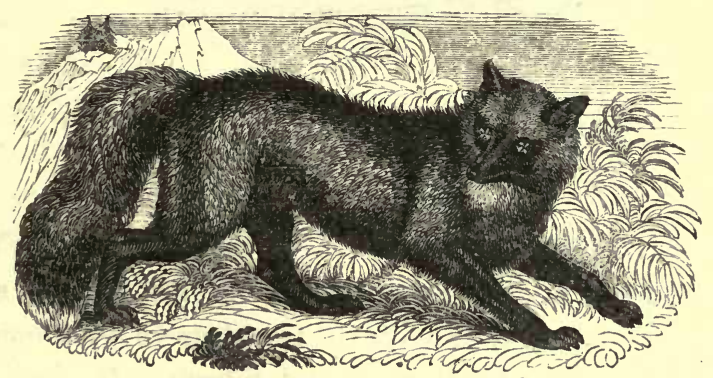

The North American Black or Silver Fox.

(Canis argentatus.) $\dagger$

Cuvier and Geoffroy St. Hilaire regarded this animal as distinct from the common fox; but Dr. Richardson and Mr. Bennett consider it to be merely a variety of the latter.

* History of Quadrupeds (Newcastle-upon-Tyne, 1790), p. 269.

$\uparrow$ Gmelin has confounded it with the black wolf. (C. Lycaon.) 
In its most perfect dress it is entirely of a pure shining black, except the end of the tail which is white. Generally, however, its forehead, cheeks, and loins are grizzled, by an intermixture of silver-tipped hairs, and there is often a white spot on the breast.

Dr. Richardson informs us that it is so extremely rare, that more than four or five specimens are seldom taken in a season at any one post in the fur countries, and, consequently, its beautiful fur, especially when entirely black, fetches more than six times the price of that of any other North American animal. Mr. Lloyd says it is, in fact, the most valuable fur in the whole world; and that in Russia, where it is only worn by the royal family and other distinguished persons, a skin is said to be worth nearly twenty pounds.

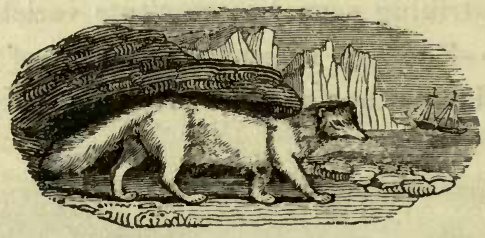

The Arctic Fox.-(Canis lagopus, Linn.)

Blue Fox. Fjall. Isatis.*

This species inhabits the northern parts of Europe and of America :- - even in the severe climate of Boothia, in seventy degrees north latitude, and ninety-two degrees west longitude. It is most abundant in Norway and Siberia. Hooker, in his Tour in Iceland (p. 53), says that it is traditionally reported to have been introduced into that country by one of the Norwegian kings to punish the disaffection of the inhabitants. Its great abundance may indeed be conceived from the fact, that in one year the Hudson's Bay Company imported into Britain eight thousand skins of this species.

* Gmelin and other authors have confounded this animal with the Bengal Isatis. (C. Bengalensis, Shaw.) 
Some specimens are grey and brown; but the majority are of a deep ash colour; and usually become white in winter, at which season the hair is longer than in summer. The nose is sharp ; the ears short and almost concealed in the fur; and the under surface of the toes are hairy.* It is smaller than the common fox; the hair is softer; and the tail shorter and more bushy. It has neither the speed nor the cunning of the common fox, and is less timid.

The food of the arctic fox appears to consist of hares, lemmings, ermines, ducks, fish, and mollusks. Captain Sir John Ross says, that the foxes at Fury Beach, having contrived to get at the ship's stores, ate the candles. $\uparrow$

In the most southern parts of Sweden, where it is sometimes killed, it has been known to stand contemplating the gunner's approach until the trigger has been drawn and the fatal bullet discharged. Pennant says, that it is so simple that instances have been known of its standing by while a trap was baiting, and immediately afterwards putting its head into it. Steller, tells us, that whenever he and his companions halted to rest while on Bering's Island, the foxes gathered around them, and played a thousand tricks in their view. "When we sat still," he says, "they approached us so near that they gnawed the thongs of our shoes. If we lay down, they came and smelt at our noses, to ascertain whether we were dead or alive. On our first arrival, they bit off the noses, fingers, and toes of our dead, while we were preparing the grave; and thronged in such a manner about the sick and infirm, that it was with difficulty we could keep them off. From all the circumstances that occurred during our stay, it was evident that these animals could never before have been acquainted with mankind; and that the dread of man is not innate in brutes, but must be grounded on long experience."

* Cuvier observes that several of the foxes, and even the common species, have hair under their feet in the north; a circumstance already mentioned as being observable in the sable and beech marten.

$\uparrow$ Narrative of a Second Voyage in search of a N.W. Passage (1835). 
Captain Sir John Ross records the circumstance of the burrow of an Arctic fox having been discovered on the margin of a lake at Boothia, in July 1831. It had several passages all leading to one common chamber, beyond which was another chamber containing six young ones. In the outer apartment and passages were several lemmings, ermines, and the bones of hares, fish, and ducks. Four of the cubs were kept alive, and became very tame.

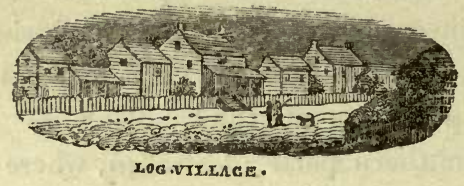

\section{I V E T S.}

The civets inhabit Africa, and have the head long; the muzzle pointed; the nostrils placed on the side of the nose; the tongue bristled with sharp and rough papillæ; the pupil of the eye round during the day time, but capable of contracting almost into a line; the feet with five toes; the claws partly retractile, and more or less raised in walking. Beneath the tail is a pouch divided into two sacs, where an unctuous and odorous matter is secreted, from two peculiar glands which surround the pouch. When fresh this matter is white, but after some time it becomes yellow, and acquires a very agreeable odour. Chemical analysis has shown that the odour depends on a volatile oil mixed with some other ingredients, from which it may be separated by distillation in water; and the oil when thus isolated is of a clear yellow colour, has the strong smell of civet, together with an acid and burning taste.

In their carnivorous propensities they are only surpassed by the cat-tribe, whom they very closely resemble in many points of their zoological character, and in their predatory, sanguinary, and nocturnal habits. 


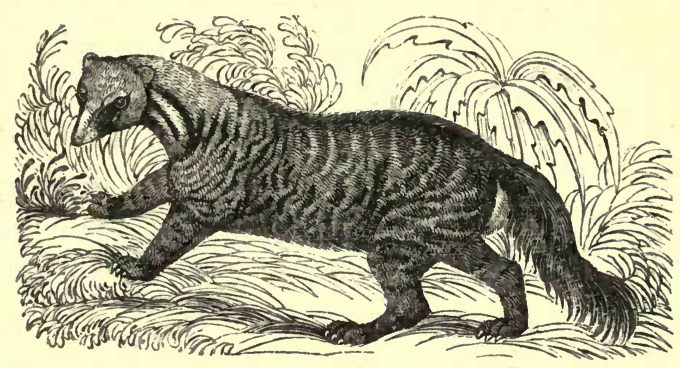

The Common Civet.-(Viverra civetta, Linn.)

Civet-Cat. Musk-Cat.

The common civet inhabits Africa, and, according to some authors, Asia also.

It is from two to three feet in length, exclusive of the tail, which is nearly half as much more; and from ten to twelve inches in height. The ground colour of its fur, which is long and coarse, is brownish grey, diversified with numerous transverse interrupted bands, or long irregular dashes of a blackish or dusky colour. From between the shoulders to the extremity of the tail the hair is very long, forming a kind of mane, which the animal can raise or depress at pleasure.

The civet possesses great agility, leaps as nimbly as a cat, and, like that animal, lives by rapine, principally preying on birds and small mammals, pouncing upon them rather by night and by surprise, than by day and by open force. It has been often known to carry off poultry from the farm-yard.

Though naturally ferocious, the civet may, in a state of captivity, be rendered moderately tame, but not sufficiently so as to allow of being caressed with impunity. When kept in confinement, it is usually fed upon rice, boiled meat, eggs, birds, and sugar; but it appears to be especially fond of fish. It will sometimes roll itself for a minute or two on its food previous 
to eating it. It requires but little drink. "Dr. Stubbes, in his Jamaica Observations, saith that the civets will live above a month without drinking, as he himself once tried on one that he kept; but that if they drink once a month they will yield more civet, and so if they be fed with fish."*

The voice of the civet resembles that of an enraged dog. In its wild state it is prolific, but it never breeds in captivity.

Numbers of civets are kept in Holland for the purpose of procuring from them the well known drug or perfume, which bears their name. Each is confined in a cage so narrow that it cannot turn itself. When a sufficient time for the secretion has been allowed, the end of the cage is opened, and the poor animal is pulled back by the tail and securely held in that position, while a small spatula or spoon is introduced into the pouch, from which the contents are carefully scraped out, and then put into a bottle properly stopped. This operation is repeated twice or thrice a week, about a drachm being collected each time. The civet procured at Amsterdam is considered more valuable than that imported from the Levant or India, being freer from adulteration: its average value is about fifty shillings an ounce; but, like everything else, it is liable to a fluctuation in price.

Civet used to be much employed in medicine; but at present its chief use is in the scenting of pomatum and similar articles. The nobles and fops of Shakespeare's time thought it indispensable to their persons :-

"The courtier's hands are perfumed with civet."

As You Like It, Act III. Scene 2;-

and it was more highly esteemed from its supposed sedative influence over the mind. Our poet, nevertheless, makes Touchstone speak of it contemptuously as " the very uncleanly flux of a cat," (Ibid. iii. 2); and King Lear more than once scoffs at it. The odour of civet more resembles that of amber than of musk, with which it has been frequently confounded, and its medical properties are in some respects different.

* Blount's Natural History (1693), p. 12. 


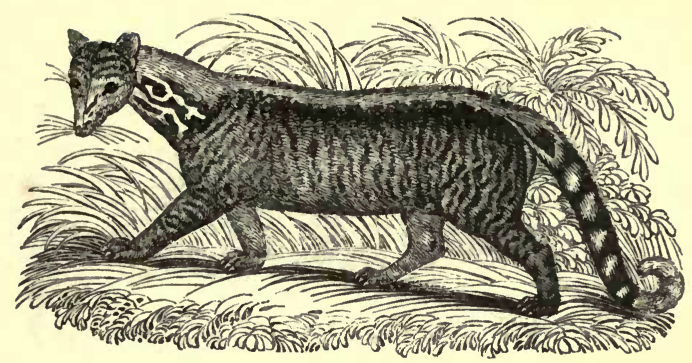

The Zibet.-(Viverra Zibetha, Linn.)

This species inhabits the East Indies. The head and lower part of the neck, is a mixture of grey and black; the sides of the neck are striped with black; the body marked with several longitudinal black lines; the sides spotted with ash colour and black. The ears, though short, are longer, broader, and more erect than those of the civet; the muzzle is shorter, thinner, and more depressed; the body longer and not so stout; the tail much longer, and elegantly marked from one extremity to the other with transverse semi-circles of black and white. The fur, moreover, is shorter and softer than that of the civet, and it has not the range of long upright hairs which are observable on the upper part of the neck and back of the latter animal.

Its odorous secretion is thick, like pomatum, and is much more powerful than that of the civet.

\section{The Common Genet.-(Viverra genetta, Linn.)*}

This beautiful species is found from the south of France to the Cape of Good Hope, frequenting chiefly the banks of rivers, the sides of brooks, and springs.

* Pennant, who has accurately figured this animal in his Synopsis (pl. 172, Hist. No. 280), has improperly termed it the fossane; and so has Brown in his 


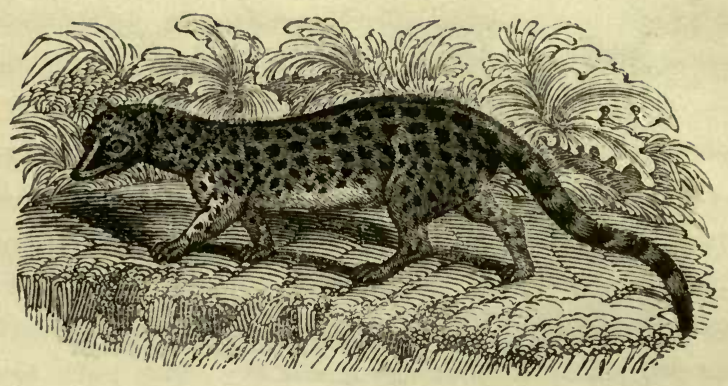

It is of a grey colour, spotted with brown or black; the muzzle is blackish, but has white spots on each side of its extremity; on the eye-brows and cheeks are also white spots; the tail is as long as the body, and annulated with black and white, the black rings being from nine to eleven in number, and the white ones from seven to eight. Some specimens differ in the size and number of their spots, in the bands along the shoulders and neck, and in the lines on the nape of the neck, \&c. In all, however, the pouch is reduced to a slight depression, formed by the projection of the glands, and has scarcely any visible excretion, although an odour is diffused from it, which is more faint and agreeable than that of the civet : their nails are completely retractile;* and in the light, the pupils of their eyes form a vertical fissure.

Belon tells us that he saw genets in the houses at ConstanIllustrations (pl. xliii.) which represents a young specimen with whitish and not brown legs,- - being similar to one from Senegal seen by Cuvier. That of Buffon (ix. xxyvi.) has not the bands on the shoulders sufficiently marked; and his Genette du Cap, figured in his Supplement (vii. pl. lviii.), is the same as Sonnerat's Civette de Malacca (Voyage, pl. xxxix.) and Vosmaer's Chat bisaam, of which Gmelin has made as many species, appear to be the common genet. But the pretended Genette de France of Buffon (Supp. iii. pl. xlvii.), the Civette a bandeau of Geoffroy is the paradoxure genet, or pougoune of India. (Paradoxurus typus, F. Cuv.)

* Most popular works on zoology erroneously state that the claws of the genet are un-retractile. 
tinople as tame as cats; and that they were permitted to run everywhere about, and without doing any mischief:- hence they have been called the Cats of Constantinople, although they have little else in common with that animal, except their expertness in perceiving and destroying rats, mice, and other vermin. These domesticated genets are said to be not only gentle and mild, but very cleanly.

The glossy fur of the genet forms an important and valuable article of commerce.

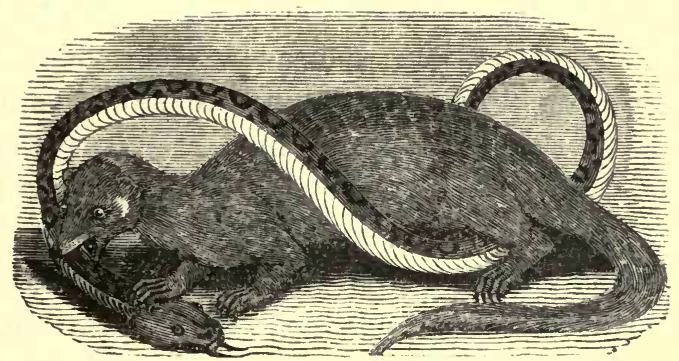

The Egyptian Mangouste.

(Herpestes Pharaonis, Illig.; Viverra P., Linn.; Mangusta P., Cuv.) Ichneumon. Pharoah's Rat.*

The Egyptian mangouste is about the size of a domestic cat, but rather longer in the body. Its fur is rough, and has a pale reddish grey cast, owing to each hair being marked with alternate rings of grey and mouse-colour. The muzzle is long, slender, pointed, and black; the ears are almost naked, very small, and rounded; the eyes bright red; the legs short; the feet small and black; the claws very sharp; and the tail is as long as the body, very thick at the root, and thence gradually tapering to a point, which is furnished with a small black tuft.

* So called by the Europeans at Cairo. Goldsmith erroneously states that they call it Pharoah's cat. 
It has a large posterior pouch, provided with glands, which secrete an odorous matter.

It frequents the banks of rivers, and is said to swim and dive with great dexterity, much after the manner of the otter, and remain under water for a long time. When inundations occur, owing to the overflowing of the rivers, the mangouste repairs to higher ground, and approaches inhabited places in search of food.

It sleeps during the greater part of the day, reposing coiled up with the head between the legs, and is not easily awakened. Towards night, however, it rouses up ; and is very active in quest of rats, mice, birds, snakes, lizards, young crocodiles, and the eggs of these reptiles, insects, and snails. Its courage, strength, and agility, are quite equal to its rapacity; for it will quickly strangle a cat though stronger and larger than itself; and often attacks dogs, which, however bold at first, soon learn to acknowledge the mangouste as a formidable enemy. Neither the sharp talons of the vulture, nor the venomous fangs of the serpent, can deter it from attacking even these larger animals. It advances towards its prey silently and cautiously, varying its pace and attitude as may be necessary; but sometimes it lengthens itself and creeps stealthily along the ground, carrying its head high. In seizing a snake it generally contrives very adroitly to catch the reptile by the throat, in such a manner that it cannot retaliate by means of its fangs.

" Thus oft th' ichneumon on the banks of Nile, Invades the deadly aspic by a wile;

While artfully his slender tail is play'd, The serpent darts upon the dancing shade; Then turning on the foe, with swift surprise, Full on the throat the nimble seizer flies;

The gasping snake expires beneath the wound, His gushing jaws with poisonous floods abound, And shed the fruitless mischief on the ground."

(Lucan's Pharsalia, A. D. 62.)

In consequence of the great utility of this animal in reducing the number of crocodiles, snakes, and other disagreeable creatures, the ancient Egyptians held it in religious veneration, worshipping 
and ranking it among those deities which were most propitious to them. With the modern Egyptians it is quite as dornesticated as our cat, and they keep it to rid their houses of rats and mice. It frequently sits up like a squirrel when feeding, and will catch with dexterity any thing thrown to it. Its voice is a soft murmur, which, however, it seldom emits except when irritated.

M. D'Obsonville's anecdote of a mangouste has been so repeatedly published that it might well be omitted here, if it were not for its being valuable in a philosophic point of view, which is rarely the case with the more popular anecdotes. This one, however, may serve to show how what is termed the natural instinct of an animal may lie dormant, till example or practice has elicited it, and be called into repeated action after it has been once exercised. I shall not quote his very words, because they somewhat conceal the more important features, and the anecdote, as originally reported, is probably accessible to most readers; but will give a true digest of it. Having obtained a very young mangouste, he reared it, feeding it at first with milk, and afterwards with baked meat, mixed with rice. It soon became even tamer than a cat; for it not only came when called, but followed him about in the country. One day his master presented him with a small live water-serpent, being desirous to know how far the instinct of the mangouste would avail it against a creature with which it was hitherto totally unacquainted. Its first emotion seemed to be astonishment, mixed with anger, for its hair became erect; but in an instant after, it slipped behind the reptile, and with remarkable swiftness and agility, leaped upon its head, seized it, and crushed it between its teeth. This onset and new aliment taught it that a destructive voracity was more agreeable and congenial to its temperament and organization, than that gentle and passive state which it had contracted from having lived in ignorance of the existence of such a description of reptile. M. D'Obsonville had about his house several curious birds, among which the mangouste had been reared, and which, till then, it had suffered 
to go and come unmolested and unregarded; but a few days after, when alone, it strangled them all, ate a little, and, as appeared, drank the blood of two. The probability is, that had the snake been brought up with it in the same way that the birds were, it would have shown no "instinctive" enmity against it; and that it only attacked the snake from fear that this stranger to its acquaintance might otherwise become the aggressor. No animal ever seizes another by the tail, to be put off with a mouthful of hair, and therefore there is no vast display of instinct in the mangouste's seizing the snake by the head; for had a gentle dove been presented to the mangouste, the latter would have aimed at the same part. Every animal knows, from the observation of others, and a consciousness of its own ways, that the head goes foremost, and that it must make to that part if it desire to arrest the progress of its prey or its foe. That is a bad hound, therefore, that seizes the prey by the leg.

The natural history of the Egyptian mangouste, in most works on zoology, is confounded with that of other species, and there are several others. At the Cape, are found Herpestes cafra, $H$. paludinosus, and $H$. penicillatus ; in India, $H$. mungos, and $H$. griseus; in North India, $H$. nepalensis; in the Indian Islands, $H$. brachyurus; in Madagascar, H. Bennettii; in Java, H. Javanicus ; in Senegal, H. albicaudus; and in Abyssinia, H. fasciata. In the British Museum is a species, which Mr. J. E. Gray has christened $H$. Smithii; but the animal's birth-place is unknown.

\section{The Suricate.*-(Ryzcena tetradactyla, Gmelin.)}

The suricate inhabits Africa, chiefly the mountainous parts above the Cape of Good Hope.

It has a strong resemblance to the mangoustes, even in the tints and transverse streaks of the hair, but is distinguished from them and all the preceding carnivorous animals by its

* Sonnerat's figure of the zenik (Voyages, vol. ii. pl. xcii.) appears to be the suricate, but roughly drawn. 


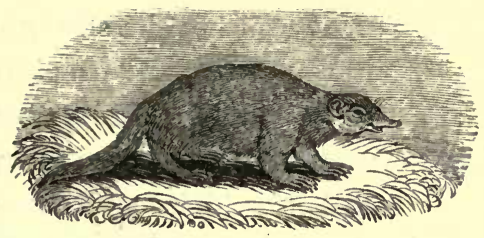

having only four toes on each foot. It is also higher on its legs, and its pouch extends into the anus. Its fur is rough and dull brown, inclining to a fawn colour underneath, and crossed by slight bands principally on the back; the skin itself is of a tan colour on the naked parts; its limbs have a silvery tint; the soles of the feet are covered with a soft and hairless skin, like that of the human hand; the toes are armed with long and digging nails; the nose is raised, and prominent; the nostrils formed like those of dogs; its whiskers consist of fine silky hairs; and its tail is about two-thirds the length of the body.

Its sense of smelling is very acute; but its hearing is rather feeble, as also is its sight, for it cannot bear a strong light, and sees best in obscurity. It can proceed with tolerable quickness, placing the entire sole on the ground, in the plantigrade fashion. When resting it will sometimes stand upright on its hind legs. It ferrets about in search of prey, thrusting its flexible and intelligent nose into every hole and corner, and when it smells something fit to make a meal of, it seizes it and instantly devours it. Small mammals, birds, fish, and eggs, are its favourite kinds of food; but sweet fruits are also to its liking.

The suricate is easily tamed, and will make itself quite at home in its domestic state. $M$. de Sere procured a very fine one, which he at first fed with milk; but it soon evinced an inclination for raw meat, poultry, fish, and eggs. It would even take the eggs out of the saucepan they were about to be boiled in, and carry them off in its paws. Like a squirrel it used its fore-feet to convey food to its mouth, and lapped its 
drink like a dog; but would not touch water unless lukewarm. When left long alone, or when it heard a strange noise, it would bark like a puppy; but when caressed or pleased, it made a noise as loud as that of a rattle briskly turned. It had a singular aversion to particular persons; when taken up, it always smelt the hand that held it, and never failed to bite those whom it had bitten before, however frequently they approached it. Some people, indeed, were so very disagreeable to it, that even when restrained, it would make use of various stratagems to come at them; and if it could not succeed in seizing their legs, it would lay hold of their shoes or petticoats.

\section{H Y A N A S.}

The hyænas, though closely resembling the cat tribe in their zoological characters, and in their cowardly ferocity of disposition, bear nevertheless a stronger affinity to the dog tribe, with which they were associated by Linnæus: yet the hyænas are essentially distinct even from the latter. The principal character by which a zoologist determines the identity or the difference of the animals which come severally under his observation, consists in the appearance of the teeth. "It was not a vain boast, when a zoologist exclaimed, "Shew me the teeth of an animal, and I will inform you of the history of a being which I never saw.' By the largeness of the tooth he could judge of the relative size of the animal which bore it; and by the form of the tooth he could tell whether it was fitted to grind grass or to tear flesh; and, therefore, whether it belonged to a herbivorous or a carnivorous species. Carrying on his enquiries from this point, he could decide, in a great degree, as to the structure not only of the stomach and viscera, but of the extremities, whether armed with claws, or protected with hoofs; and, looking still onward, he could thus judge of the vivacity of the senses which belonged to the animal, and of the habits which it derived from its peculiar conformation:-knowing, beyond doubt, that there was an intimate agreement in all the 
properties of its existence; and that everything in its organization was regulated by an undeviating harmony. The dog and the hyæna, therefore, being essentially different in the number and form of their teeth, constitute different genera, without regard to their external appearance. But naturalists are not entirely regardless of outward shape or colour, or even of the more subtle variations of habit, in determining the relations between one group and another; and thus differences as to classification sometimes arise, which are, after all, only settled by a balance of similarities." *

The differential characters and the general habits of the hyænas are thus ably and correctly sketched by Mr. E. T. Bennett:- "Like both the cats and the dogs," he observes, " the hyænas are completely digitigrade, walking only on the extremities of their toes; but these toes are only four in number on each foot, are armed with short, thick, strong, and truncated claws, which are quite un-retractile, and are evidently formed for digging. Their body, which in shape much resembles that of the wolf, to which they also approach very nearly in size, is much more elevated in front than behind, owing partly to their constant custom of keeping the posterior legs bent in a crouching and half-recumbent posture. Beneath the tail, which is short and dependent, they are furnished with a pouch, wherein is secreted a peculiar matter, of a very strong and disagreeable smell. Their head is large and broad, flattened in front, and terminating in a short, thick, and obtuse muzzle. Like most carnivorous animals, they are armed in each jaw with six cutting teeth, and two canine, the latter of considerable size and strength. The outermost pair of incisors in the upper jaw are much larger and stronger than the rest, and closely resemble the canine in form. The number of the molar or cheek teeth, is five on each side in the upper jaw, and four in the lower; and all of them are remarkable for their extreme thickness and strength, in comparison with those of dogs and cats. Their tongue is similar to that of the latter animals in

* The Menageries, vol. i. (1829), p. 121. 
the roughness which it derives from its sharp and elevated papillæ. The habits of the hyænas are entirely nocturnal: while in the day-time their cowardice is so excessive, that they fly from the face of man, and suffer themselves, when taken, to be ill-treated with impunity and even without attempting to avenge themselves, they prowl abroad in the stillness of the night with all the temerity of brutal daring. They will frequently make prey of the lesser animals, and occasionally venture to attack dogs and even horses; but it is seldom that they muster up sufficient courage to contend with living man, unless stimulated by strong provocation, or impelled by the most violent cravings of hunger. Congregated in numerous bands they beset the encampment of the traveller, or infest the neighbourhood of villages or even towns, which they enter at night-fall, and do not quit until the dawn of day; disturbing the inhabitants with their peculiar moaning or wailing, which is in some measure intermediate between a grunt and a howl. Parading the streets, and penetrating into the houses for prey, they eagerly devour the offal of animals, the refuse of the daily meal, or whatever else is in any way eatable which they can obtain. Nothing, however filthy, comes amiss to their voracious appetites, which are indeed unbounded. They even break into the cemeteries of the dead, and, tearing open the graves by means of their powerful claws, disinter the buried corpses, on which they glut that propensity for feeding on carrion, which is at once the most striking and the most disgusting of their peculiarities. Their fondness for this polluted species of food, tends of course not a little to increase the natural antipathy with which they are regarded by the natives of the countries wherein they abound, and renders them objects of peculiar detestation and abhorrence. The great size and strength of their teeth, and the immense power of their jaws, enable them to crush the largest bones with comparative facility, and will account for the avidity with which they prey upon an almost fleshless skeleton. In the day-time they remain in caves, from which they issue only when the shades of evening warn them that the hour for their 
depredations has arrived. Their gait is awkward, and usually slow and constrained; when scared, however, from their prey, or when pursued by the hunter, they fly with tolerable swiftness, but still with an appearance of lameness in their motions, resulting from the constant bending of their posterior legs."*

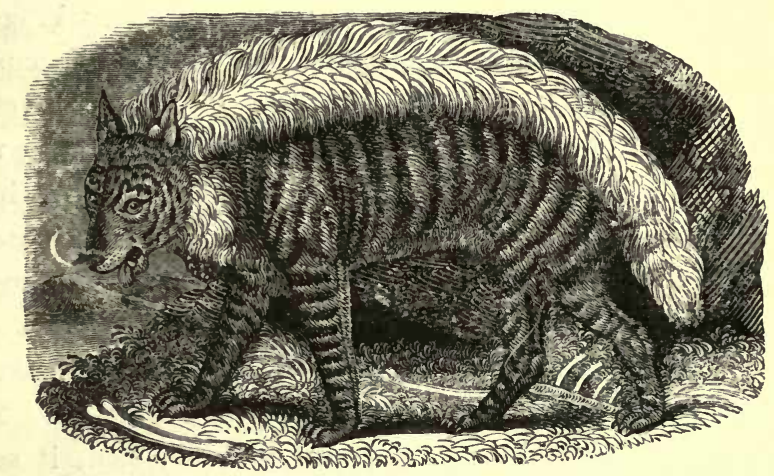

The Striped Hyena.

(Hyana vulgaris, Desm. Canis Hyana, Linn.)

The striped hyæna, which is no doubt the hyæna of the ancients, inhabits the greater part of Asia and of Africa, penetrating in the former as far as India, and extending over all the northern part of the latter continent.

According to Desmarest, its ordinary height at the shoulders is nineteen inches; and the length, from the muzzle to the tail, about three feet three inches; but one which Mr. Cross had at Exeter 'Change, in 1828, was twenty-five inches high. The ground colour of this species is an uniform brownish grey, which is somewhat darker above than beneath; and the sides of the body and the outsides of the legs are marked by several irregular transverse blackish or brownish stripes. The body is covered with long hair, which grows in the greatest luxuriance on the nape of the neck and down the spine, thus forming a * Abridged from The Tower Menagerie (1829), p. 71-75. 
thick and lengthy mane, which may be said indeed to be continued even upon the tail, which is also covered with lengthy tufts of hair. The mane stands erect when the animal is feeding or angry. Both mane and tail are marked with blackish spots or stripes variously and irregularly disposed. In different specimens, indeed, much variety is observable in the ground colour of the whole body and the disposition of its markings.

Not only the travelling zoologists, who invite the curious crowd to "walk up and behold the living wonders o' Natur," but the natural historians, from Pliny to Goldsmith, have most scandalously abused and misrepresented the hyæna, giving it such a character that it is almost surprising that the animal has obtained a situation in the establishment of the Zoological Society. Goldsmith, as though he meant to wrong the poor creature as much as possible, says, " no words can give an adequate idea of its figure, deformity, and fierceness. More savage and untameable than any other quadruped, it seems to be for ever in a state of rage or rapacity." As for its deformity, let us imagine the hyæna reproving its revilers in the language of Sir Thomas Brown:- "There is a general beauty in the works of God, and, therefore, no deformity in any species of creatures whatsoever; and I cannot tell by what logic you call any animals ugly, they being created in those outward shapes and figures which best express the actions of their inward forms." * The notion of the untameableness of the hyæna has been refuted by several instances to the contrary. When taken young, a proviso on which much depends in the domestication of all wild animals, he soon becomes exceedingly tame and docile, and much attached to his master, especially if he allow him a certain degree of liberty; but if, from an ignorant distrust of his disposition, he should keep him in close restraint, the hyæna becomes as savage as might a sane man if locked up as a lunatic. This will account for the surly and even dangerous nature of those specimens which are kept closely pent up in the travelling menageries. 
A hyæna at Exeter 'Change, some years since, was so tame as to be allowed to walk about the exhibition-room. He was afterwards sold to a person who permitted him to accompany him in the fields, led by a string. After these indulgences he became the property of a travelling showman, who kept him constantly confined in a cage. From that time his ferocity became quite alarming; he would not allow any stranger to approach him, and he gradually pined away and died.

Bishop Heber saw a gentleman in India, Mr. Traill, who had a hyæna for several years, and which followed him about like a dog, and fawned on those with whom he was acquainted.

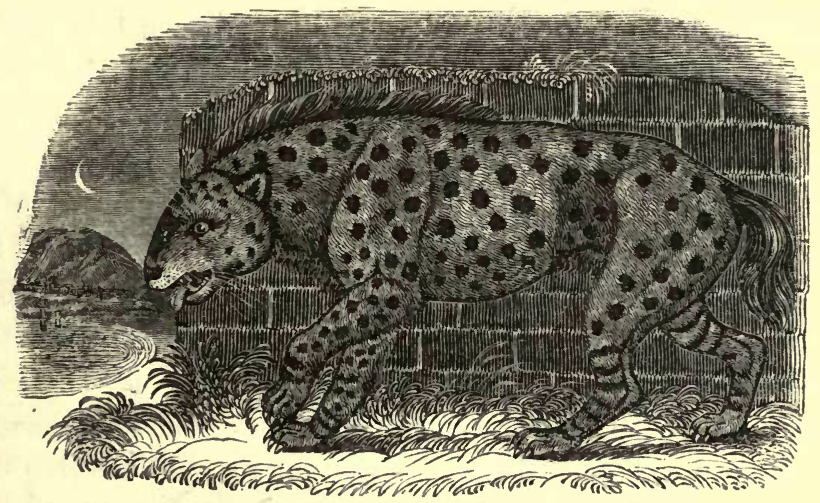

The Spotted Hyena.

(Hyana Capensis, Desm.; H. crocuta ; Canis crocuta, L.)

Tiger Wolf.

The spotted hyæna inhabits the south of Africa, more par. ticularly the neighbourhood of the Cape of Good Hope, where the colonists call it the tiger-wolf. It does not appear that this and the striped species are ever found inhabiting the same district, but the limits of their territorial distribution have not yet been distinctly ascertained.

In its general shape the spotted hyæna much resembles the striped, though it is ordinarily smaller; the mane is not so 
full, and it terminates at the loins, the remaining part consisting chiefly of scattered hairs; its head is much larger and flatter, and its tail is brown, without spots ; the ears are large, flat, and rounded; the muzzle is black; the general colour of the hide is dusky yellow, approaching to a blackish brown on the belly and limbs, with spots also of a blackish brown, more or less deep over the whole of the body, except the undermost part of the belly and of the breast, the inside of the limbs, and the head.

The vigilance of this animal in seeking for the carrion, or offal, which, if left unconsumed, would produce malaria and other serious inconveniences, in those warm countries which it inhabits, has often been noticed and appreciated by travellers. Mr. Pringle says, "In a field of battle in South Africa, no one ever buries the dead; the birds and beasts of prey relieve the living of that trouble : even the bones, except a few of the less manageable parts, find a sepulchre in the voracious maw of the hyæna." * No sooner has the corpse began to corrupt, than the keen-scented hyæna comes to bury it in his stomach. Nature, in fact, has appointed him her undertaker in those climates. But when he has been cheated of his natural perquisite by the corpse being interred in a more ceremonious manner, he visits the grave on the first opportunity; and carrying those serviccable implements, his strong claws, along with him, he soon acts the part of the body-snatcher; and if ever a hyæna does laugh $\dagger$ it is then, when he has baffled the intentions of mankind. He would look with a jealous eye upon the establishment of a cemetery company in those quarters.

Major Denham tells us, that a lion having attacked a camel that lay about a hundred yards from the tents, and eaten part of it, the hyænas visited the remainder in the night,

* Pringle's Ephemerides (1828), p. 187. Note.

† Old writers describe the hyæna as a laughing animal. To "laugh like a hyæna" was a common proverb, as appears from the Cobbler's Prophecy (1594), Webster's Duchess of Malfy (1623), and Shakespeare's As You Like It, Act IV. Sc. I. 
and supped off it until it was nearly half-consumed. Burchell says, that having shot and brought home a new species of antelope, the hyænas, who pay no respect to species, devoured all its flesh, leaving only the head and the hide.

M. F. Cuvier says, that a hyæna, that had been taken young at the Cape, was tamed without difficulty. His keepers had a complete command over his affections. He one day escaped from his cage, and quietly walked into a cottage, where he was retaken without offering any resistance; and yet the rage of this animal was very great when strangers approached it.

The period of gestation, the number of young at a litter, and the average longevity of the hyæna, be it of this or the preceding species, do not appear to have been as yet ascertained.

\section{TH E C A T T R I B E.}

As the several species of Felince, from the lion to the cat, have so much in common, not only in their configuration, but in their habits, this general sketch of the tribe may conveniently comprise several facts respecting them, which, therefore, need not be recapitulated when we come to discuss the natural history of particular species.

These animals, the most ferocious, the most highly organized of the numerous carnivorous mammals, exhibit the predacious propensity in the utmost state of development, and are furnished with the most powerful means of carrying it into complete effect. Their teeth and claws, the principal organs of destruction, are eminently fitted for predatory purposes, and are accompanied by a corresponding development of those accessory organs which assist them in their action. The slightest inspection of their teeth, and more especially of the canine and of the larger cheek-teeth, is sufficient to prove that nothing can be better adapted to the purpose of tearing asunder the large masses of flesh which are swallowed by these animals, without being subjected to mastication; a process which their structure 
and the nature of the food render unnecessary and impracticable. The tongue is also a lacerating organ, for it is armed, especially towards the hinder part, with numerous close-set prickly papillæ, the points of which are reverted, and the palate presents a series of transverse ridges covered with rough and prominent tubercles. The gape is of great extent in proportion to the size of the animals; a fact which is frequently illustrated by the keepers of travelling exhibitions, who are in the habit of thrusting their heads into the lion's mouth, by way of exciting the astonishment and terror of the spectators. The claws of the feline tribe are very long and curved, and their sharp cutting edges and finelypointed extremities are preserved unimpaired by a particular provision, which enables them to be entirely retracted. The toes, which are remarkably short and obtuse, are five in number on the fore-feet, and four on the hind; their under surface is furnished with several distinct callous tubercles, on which the animal rests in progression, no other part of the feet being applied to the ground, for these animals are thoroughly digitigrade; they possess no sole, and the part which corresponds with the heels of most mammals is in these conspicuously placed on the posterior part of their limbs, considerably above the tubercles at the base of the toes. Their legs are short and muscular; and their joints rounded, supple, and in the highest degree flexible.

A remarkable uniformity is exhibited in the general outline of form; all the species being distinguished by the elongated, but not particularly slender make of their bodies, which are much flattened on the sides; by their short thick necks, taking for the most part a nearly horizontal direction; and by the broad and rounded form of their heads, which, in the males, are usually much larger than in the females. Their whiskers generally consist of several very long bristles, and are highly useful to the animal as delicate organs of touch-hence they have been better denominated feelers.

Their undisputed superiority in strength securing them against the attacks of other animals, the cat tribe never associate together 
in troops, but live in separate pairs, each pair occupying a solitary den, usually concealed in the depths of the forest. Thence, when pressed by hunger, they issue forth in search of their prey, which they rarely attack with open force; but stealing on it with noiseless tread, or stationing themselves in ambush in such situations as appear suitable to their purpose, watch with indefatigable patience the approach of their victim. Incapable of long-continued speed, their usual gait is slow, cautious, and stealthy, with their posterior limbs bent beneath them, and their ears distended to catch the slightest noise. Guided by these organs, the internal structure of which is highly developed, they trace the sound of footsteps at an almost incredible distance, and direct themselves towards their prey with unerring certainty. In this quest the sense of smell, which they possess in a very low degree, affords them but little assistance; their sight, however, is good, and serves them well both by day and night, their extremely dilatable pupils adapting themselves with admirable precision to various intensities of light. To this object the frequently elongated form of their pupils, the generally yellow colour of the internal or choroid coat of their eyes, and the extent of their nictitating membranes, must also essentially contribute. No sooner is the object of their pursuit within reach of their attack, than suddenly bursting forth from their lurking-place, or changing their slow and stealthy pace for a furious and overwhelming bound, they dart with the velocity of lightning upon their terrified victim. The great strength and extreme flexibility of their fore-paws enable them at once to dash him to the earth, and to seize him with irresistible grasp. They then proceed to rend him in pieces by the united efforts of their teeth and claws, and gorge themselves upon his lacerated flesh. It is only when fearful of being disturbed in their operations, that they carry off the body from the spot where it has fallen; and even in such cases they never transfer it to their dens, but seek out some solitary place in which to glut their ravenous cravings. When satiated they quit the carcase, to which they never 
return, and retire to their dens to sleep off the effects of their gluttonous meal; not again to awake until their renovated appetite stimulates to a repetition of the murderous scene. Even their amours are accompanied with a degree of savage barbarity; and the female is not unfrequently called upon to protect their mutual offspring from the ravenous jaws of her male companion. Next to their ferocity, the leading feature in the moral character of all the species is suspicion. It is this which imparts, even to the largest and most powerful, a wily and malignant air, but ill assorting with their gigantic size and immense muscular power. Of this feeling they can never be entirely divested; it is sufficiently remarkable even in the domesticated race; but becomes still more obvious in those which are kept in a state of confinement, and which, however well they may appear reconciled to their condition, and how much soever they may seem attached to their keepers, are startled by the slightest unusual occurrence, and become restless, uneasy, and mistrustful, whenever any change, however trifling, takes place in the objects by which they are surrounded.

\section{The Lron.-(Felis Leo, Linn.)}

The lion, the strongest of all beasts of prey, is distinguished from its congeners by its uniform tawny colour, the tufts of hair at the end of the tail, and the flowing mane which decorates the head, neck, and shoulders of the male, and also by the head being more square.

His true country is Africa, in the vast and untrodden wilds of which, from the immense deserts of the north to the trackless forests of the south, he reigns supreme and uncontrolled. In the sandy deserts of Arabia, in some of the wilder districts of Persia, and in the vast jungles of Hindostan, he still maintains a precarious footing: but from the classic soil of Greece, as well as from the whole of Asia Minor, both of which were once exposed to his ravages, he has been utterly dislodged and extir- 


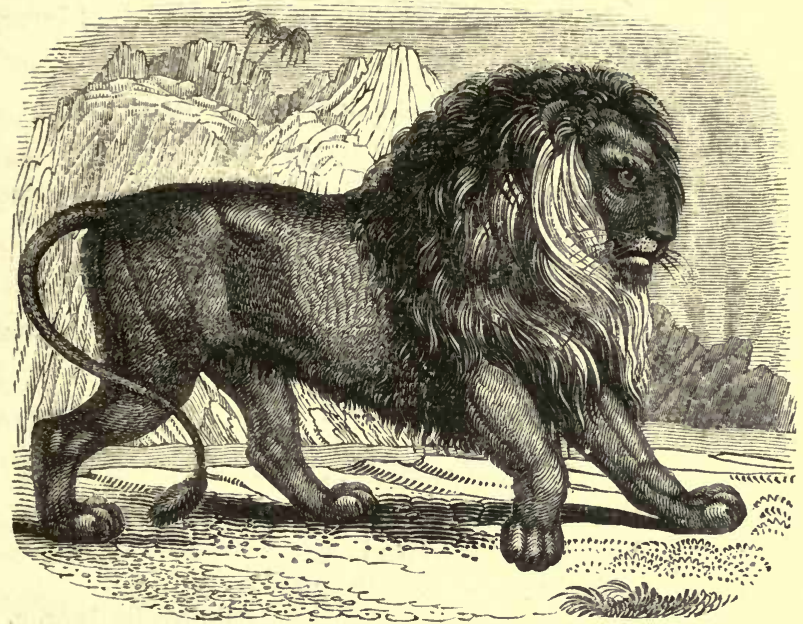

pated. There is some variation in the difierent races of lions from these distant localities; but this is by no means of sufficient importance to establish a distinction between them. The Asiatic lion seldom attains a size equal to that of the full-grown South-African ; its colour is of a more uniform and paler yellow throughout; and its mane is, in general, fuller and more complete, being furnished, moreover, with a peculiar appendage in the long hairs, which, commencing beneath the neck, occupy the whole of the middle line of the body below. All these distinctions are, however, modified by age, and vary in different individuals. Their habits are in essential particulars the same. The ordinary length of the Asiatic lion, from the end of the muzzle to the root of the tail, is about six feet, and its height above three feet; but the African, as before intimated, is much larger. Pringle says, a male lion that was killed at Douglas Water, on the eastern frontier of the Cape colony, measured nearly twelve feet from the nose to the tip of the tail. Its foreleg, below the knee, was so thick, that he could not span it with both hands ; and its neck, breast, and limbs appeared, when the 
skin was removed, a complete congeries of sinews. Elsewhere, this traveller, who was a poet as well as a zoologist, speaking of another one, exclaims :-

"What a glorious lion! what muscles-what claws!

And seven feet ten from the rump to the jaws!"

The same writer gives us a good picture of the lion's place of retreat:-

"Would'st thou view the lion's den?

Search afar from haunts of men;

Where the reed-encircled fountain

Oozes from the rocky mountain;

By its verdure far descried,

Mid the desert brown and wide.

Close beside the sedgy brim

Couchant lurks the lion grim,

Waiting till the close of day

Brings again the destined prey."

(Ephemerides, 1828, p. 117.)

The lion has been called King, or Lord of Beasts, from his superior strength, and also from a wrong notion of his courage and magnanimity. " $\mathrm{He}$ is ordained by nature to live on animal food, and fitted for the destruction of animal life, by the most tremendous machinery that could be organized for such a purpose, regulated by a cunning peculiar to his species. But when we investigate the modes in which he employs these powers, we may leave the stories of his generosity to the poets and romancewriters, who (as well as the authors of more sober relations) have generally been too much inclined to invest physical force with those attributes of real courage and magnanimity which are not always found in association with it." * Burchell, who saw much of the lion in its wild state in Africa, pronounces it to be an " indolent, skulking animal," not to be compared for courage and other admirable qualities to the bold and faithful dog. "The natural habits of the lion are certainly those of treachery; he is not disposed under any circumstances to meet his prey face to face; but we apprehend that there were periods in the history of African colonization when the lion was of a bolder nature

* Menageries (1829), vol. i. p. 149. 
in his encounters with mankind; that the dread of fire-arms has become, in some degree, a habit of the species; and that he has sagacity, or hereditary instinct, to know that a flash and a loud sound is often followed by a speedy death, or a grievous injury." * The contradiction in those accounts, which describe it as courageous, and those which describe it as the reverse, is probably attributable to their authors having seen the lion under very different circumstances, as regarded time and the state of its stomach. When its appetite is satisfied, it does not voluntarily destroy; and Shaw, the zoologist, says, that a child, by the use of sharp words and a stick, may obtain command over a lion satiated with flesh. When pinched by hunger, however, " its vaunted magnanimity is no protection even for the sleeping foe, as the poets have pretended." $\dagger$ No poet, perhaps, has so frequently and so beautifully alluded to the royal station and the generous nature ascribed to this animal, as Shakespeare,-

Who talks as familiarly of roaring lions As maids of fifteen do of puppy dogs.

Troilus. "Brother, you have a vice of mercy in you, Which better fits a lion than a man.

Hector. What vice is that?

Troilus. When many times the captive Grecians fall, Even in the fan and wind of your fair sword, You bid them rise and live."

(Troilus and Cressida, Act V. Sc. 3.)

In the Choise of Change (1585), it is observed that "there is a great clemency in lions; they will not hurt them that lie groveling." Bartholomæus says, "Their mercie is known by oft examples: for they spare them that lie on the ground." Lodge, in his celebrated novel of Rosalynd, or Euphue's Golden Legacie (1540), tell us, that " a hungry lyon came hunting down the edge of the grove for prey, and espying Saladyne, began to seize upon him ; but seeing he lay still without any motion, he left to touch him, for that lyons hate to prey on dead carkases; and yet desirous to have some food, the lyon lay downe and watcht to see if he would stirre." 
Shakespeare has copied this picture, but added a few finishing touches to it :-

Orlando. "A lioness, with udders all drawn dry,

Lay couching, head on ground, with catlike watch,

When that the sleeping man should stir; for, 'tis

The royal disposition of that beast

To prey on nothing that doth seem as dead."

(As You Like It, Act IV. Sc. 3.)

Living animals are the prey of the lion, and it is seldom that it attacks an unoffending white man,* except under such circumstances as here depicted, - where a lioness has come forth in quest of food for herself and her cubs, who when she left them were so hungry that they had quite "drawn dry" her udders. The lion does not refrain from striking a man when he is down because it would be taking an unfair advantage, but because a man lying still on the ground does not appear to be living prey. His clemency, therefore, arises from selfish considerations. According to Mr. Barrow, the lion prefers the flesh of Hottentots to that of any other creature-deeming their blood better than that of all the Howards, and the charms of a Hottentot Venus superior to an European one of the most fashionable proportions.

"A man, at some period or other of his life, may," says Waterton, " have the misfortune to come in contact with the

* Provision is made under the will of Sir John Gager, who was Lord Mayor of London in the year 1646, for a sermon to be annually preached on November 16th, at St. Catherine Cree Church, Leadenhall Street, in commemoration of what he terms his " happy deliverance" from a lion, which suffered him to pass unmolested as he was travelling in the Turkish dominions. The minister receives one pound for his sermon, the clerk half a crown, and the sexton one shilling. It is also provided in the will that the sum of eight pounds sixteen shillings and sixpence shall be distributed among the necessitous inhabitants. Had Sir John better known the nature of the beast, he would not have thought the lion's conduct so very extraordinary; but good sometimes results from ignorance; and I hope the poor parishioners still benefit by his grateful offering for what he esteemed an especial providential deliverance. As for the sermon,-such a zoological discourse, on a lion's respect for a Lord Mayor, must be well worth a pound. 
larger species of the feline and canine tribes-two desperate and sanguinary races of quadrupeds. The dog and the lion are both most formidable foes to an unarmed man; and it is singular enough that the very resistance which he would be forced to make, in order to escape being worried by the former, would inevitably expose him to certain destruction from the claws and teeth of the latter. All animals of the dog-tribe must be combated with might and main, and with unceasing exertion, in their attacks upon man; for from the moment they obtain the mastery, they worry and tear their victim, as long as life remains in it. On the contrary, animals of the cat tribe having once overcome their prey, cease, for a certain time, to inflict further injury upon it. Thus, during the momentous interval from the stroke which has laid a man beneath a lion, to the time when the lion shall begin to devour him, the man may have it in his power to rise again, either by his own exertions, or by the fortuitous intervention of an armed friend. But then, all depends upon quiet, extreme quiet, on the part of the man, until he plunges his dagger into the heart of the animal-for, if he tries to resist, he is sure to feel the force of his adversary's claws and teeth with redoubled vengeance." * When Waterton wrote the latter remark he must have been thinking of Shakespeare's lines to the same effect :-

"But if thou strive, poor soul, what art thou then?

Food for his rage, repasture for his den."

(Love's Labour Lost, Act IV. Scene 1.)

Mr. Thompson, in his recent Travels in South Africa, observes that " the lion will generally retreat before the awe-inspiring presence of man; but not precipitately, nor without first calmly surveying his demeanour, and apparently measuring his prowess. He appears to have the impression that man is not his natural prey; and though he does not always give place to him, he will yet, in almost every case, abstain from attacking him, it he observe in his deportment neither fear nor hostility.

" My friend, Diedrik Muller, one of the most intrepid and * Mag. Nat. Hist. vol. vii. (1834), p. 1. 
successful lion-hunters in South Africa, mentioned to me the following anecdote, in illustration of the foregoing remarks. He had been out alone hunting in the wilds, when he came suddenly upon a lion, which, instead of giving way, seemed disposed, from the angry attitude he assumed, to dispute with him the dominion of the desert. Diedrik instantly alighted, and, confident of his unerring aim, levelled his mighty roer at the forehead of the lion, who was couched in the act to spring within fifteen paces of him; but at the moment the hunter fired, his horse, whose bridle was round his arm, started back and caused him to miss. The lion bounded forward, but stopped within a few paces confronting Diedrik, who stood defenceless, his gun discharged, and his horse running off. The man and the beast stood looking each other in the face for a short space. At length the lion moved backwards, as if to go away. Diedrik began to load his gun. The lion looked over his shoulder, growled, and returned. Diedrik stood still. The lion again moved cautiously off; and the Boor proceeded to load and ram down his bullet. The lion again looked back, and growled angrily; and this occurred repeatedly, until the animal had got off to some distance, when he fairly took to his heels and bounded away.

"On another occasion, a lion came so suddenly upon him, that before he could take aim the animal made a formidable spring, and alighted so near the hunter, that he had just time to thrust the muzzle of his gun into the open mouth of the lion, and shoot him through the head.

"The following amusing story, was related to me by some respectable farmers of the Tarka, who were present on the occasion :-A party of Boors went out to hunt a lion, who had carried off several cattle from the neighbourhood. They discovered him in a thicket, or jungle, such as abound in that part of the colony, and sent in a numerous pack of fierce hounds to attack and drive him out. The lion kept his den and his temper for some time, only striking down the dogs with his mighty paw, or snapping off a head or leg occasionally, 
when the brawling rabble came within his reach. But the hunters continuing in the meantime to pepper the bushes at random with slugs and bullets, at length slightly wounded him. Then arose the royal beast in wrath, and, with a terrible roar, burst forth upon his foes. Regardless of a shower of balls, he bounded forward, and in an instant turned the chase upon them. All took to their heels or their horses. One huge fellow, of greater size than alacrity, who we shall call Hugo Zwaar-van-heupen, or Hercules Heavy-stern, not having time to mount his horse, was left in the rear, and speedily run down by the rampant lecuw (lion). Hugo fell,-not as Lochiel, " with his back to the field, and his face to the foe," but the reverse way; and he had the prudence to lie flat and quiet as a log. The victorious lion snuffed at him, scratched him with his paw, and then magnanimously bestriding him, sat quietly down upon his body. His routed companions, collecting in a band, took courage at length to face about; and seieing the posture of affairs, imagined their comrade was killed, and began to concert measures for revenging him. After a short pause, however, the lion resigned of his own accord his seat of triumph, relieved his panting captive, and retreated towards the mountains. The party, on coming up, found their friend shaking his ears, unharmed from the war, except what he had suffered from a very ungentlemanly piece of conduct in the lion, who it seems had actually treated his prostrate foe in the same ignominious manner as Gulliver did the Palace of Lilliput on a certain occasion, and for which he was afterwards justly impeached of high treason."

Mr. Lewis Leslie, who was formerly attached to a party of the Cape Cavalry encamped on the banks of Orange River, in South Africa, for the protection of the Boors against the threatened invasion of a savage tribe, says that these almost pastoral farmers, in the drier season, betake themselves to tents, and with their flocks wander over the sandy waste in search of pasturage for their sheep and cattle. "While encamped in these open plains, their kraals or folds were frequently 
disturbed by the midnight visit of the lion; and their only escape from his attacks was in the discovery of his retreat and his destruction. His usual prey was the quagga or the antelope, [various species of which abound in these plains]; but the fleetness of these animals, or their instinctive precautions, perhaps, gave them more security than the feeble defences of a crowded kraal.

"The method by which the Boors pursue the lion will be shown by describing the last hunt at which I was present. In every instance it was the same, and in three successful, without injury to any individual of the parties. The north-east bank of Orange River opposite our encampment, was totally uninhabited save by a few wandering Bushmen. Vast numbers of antelopes and quaggas grazed upon the plains; and, in the rugged and bare hills which intersect them, the lion dwelt during the day, and at night descended, after considerable intervals, in search of food. I have seldom seen him in the plain during the day, save when, in the extreme heat of the summer, he might be found on the wooded banks of the river; but often during the night when we bivouacked in the open plain, and the terror of the cattle and horses bore evidence of his approach, at dawn he would be seen winding slowly his way to the loftier summit of some neighbouring mountain. One might hear the thunder of his voice at miles' distance, while every animal shook with fear. A lion of huge dimensions passed the river, which at that season was low, and carried off a horse, the property of a neighbouring Boor. For some nights previous, he had been heard in a hill close to the banks of the river, to which it was supposed he had again retreated on destroying his prey. The Boors assert that the flesh of the horse is highly prized by the palate of the lion, but perhaps it is beeause that animal is their own most valuable property. With the few Boors we could collect, and a party of our men, we mounted immediately after sunrise on the following morning, and with a number of dogs proceeded to the mountain, every crevice and ravine of which we examined without finding him. Gorged with his late meal, he had, perhaps, we thought, 
remained in the thick cover on the steep banks of the river, to which we then returned, and in passing over a narrow plain, a spot of ground was pointed out to us, by an eye-witness, where he had been seen to seize and devour a quagga some days before. The hard and arid soil was actually hollowed by the violence of the mortal struggle. The dogs had scarcely entered the thick bushy banks of the river ere they gave tongue, and they appeared to advance in the pursuit, as if the lion was slowly retreating. At times it would seem that he turned and rushed upon the dogs. We, however, could not dare to enter further than the skirts of the jungle, with a finger on the trigger and the carbine half at the present. One single clutch of his tremendous paw unquestionably would have been fatal. For a considerable time the dogs remained silent, and we fancied we had irrecoverably lost him. With more and more confidence we examined the thicket, but without success, and were about giving up the pursuit in despair, when a Hottentot and Boor observed his footsteps in the sand. The word was again to horse. The lion's course appeared to be towards the mountain which we had left. R-, with a party of Boors and soldiers, galloped straight up the nearest acclivity, while I, with a smaller number, rode round a projecting edge of the hill, into a deep ravine, to which he might have retreated. With my party I had been too late: he had been just brought to bay, as he was commencing his descent on the opposite declivity of the hill, but $\mathbf{R}$ - - delayed the attack until we should arrive to witness the encounter; meanwhile the dogs amused him. The ascent by which we could reach the summit was steep and rugged, but our horses were accustomed to such, and with whip and spur we urged them on. Whoever has seen the African lion at bay, would assuredly say the sportsman could never behold a more stirring scene in the chase. There he was, seated on his hind quarters, his eye glaring on a swarm of curs yelping around him; his dark shaggy mane he shook around his gigantic shoulders, or with his paw tossed in the air the nearest dog, more apparently in sport than anger. We arranged preli- 
minaries. The horses wers tied together in a line, taking care to turn their heads from the direction where the lion was at bay, and likewise that they were to the windward of him, lest his very scent should scare them into flight. The retreat behind this living wall is the Boor's last resource if he should advance upon them, that his indiscriminate fury may fall upon the horses. Some of the Boors are excellent marksmen, and the Hottentot soldiers are far from being despicable; yet many a bullet was sent ere he was slain. Desperate from wounds he received, his claw was no longer harmless; one dog he almost tore to pieces, and two more were destroyed ere he fell. At each shot, he rushed forward as if with the intent of singling out the man who fired, but his rage was always vented on the dogs, and he again retired to the station he had left. The ground appeared to be bathed with his blood. Every succeeding attempt to rush forward displayed less vigour and fury, and at last, totally exhausted, he fell; but still the approach was dangerous. In the last struggle of his expiring agony he might have inflicted a mortal wound : cautiously approaching, he was shot through the heart; twelve wounds were counted in his head, body, and limbs.

"On another occasion we roused two on the summit of a low stony hill. They were deliberately descending one side as we reached the top, and amid a shower of bullets, they quietly crossed a plain to ascend another. We followed, and they separated; we brought them to bay in succession, and slew both. It appears to me, from what I have seen and heard, that a lion once wounded will immediately turn upon his pursuers; but I am of opinion that he seldom attacks man, generally shuns his vicinity, and that he has none of the reported partiality for human flesh. In the district I described, and of which a description was necessary to show that we encountered him upon clear and open ground, the various kinds of lion were originally very numerous. The Boors enumerated three-the yellow, grey, and black. Their numbers were much diminished, principally, perhaps, from their retreating beyond Orange River to an 
unoccupied country, although many also were destroyed by the Boors. It has been said that the lion dwells in the plains. The African hunters almost always seek him in the mountains; and occasionally one or two of these men will not shun the encounter, if armed with their long and sure rifles, which on almost all occasions they carry. Some years ago a party of officers, along with some Boors, discovered a lion, lioness, and two cubs, within a short distance of Hernianus Kraal, on the frontier. The lion dashed forward to protect his mate and young ones, and attempted to defend them by shielding them with his body, until the officers, moved by his magnanimity, entreated that he might not be destroyed; but the Dutchmen were inexorable, and they killed him. The cubs fled, and the lioness followed; but all were found dead of their wounds the succeeding day." *

The roar of the lion is a sound of terror, and produces an appalling effect. It is said by travellers that it sometimes resembles the sound which accompanies an earthquake; and that the animal produces this extraordinary effect by laying his head upon the ground, and uttering a half-stifled growl, by which means the noise is conveyed along the earth. The instant this roar is heard by the animals who are reposing in the plains, they start up with alarm; they fly in all directions; and often rush into the very danger which they meant to avoid.

Not being an animal of acute hearing, the lion is awakened with much difficulty, and particularly after feeding.

In captivity the lion is allowed from eight to nine pounds of beef, exclusive of bones, at a meal; and like the other large feline animals he has only one meal a day, and that is given in the evening. At the Regent's Park Zoological Gardens they are compelled to fast one day in the week; and this system is found to be beneficial to their health. On Sunday, when the poorest labourer contrives to put a good joint upon the table, the captive lion, king of beasts, together with the tiger, leopard,

* Abridged from the Edinburgh New Philosophical Journal (1834). 
and several others of his family, have not as much as a bone to pick, and in vain do they roar for their supper.

"You, ladies, you, whose gentle hearts do fear The smallest monstrous mouse that creeps on floor, May now, perchance, both quake and tremble here, When lion rough in wildest rage doth roar."

(Midsummer Night's Dream, Act V. Sc. 1.)

The lion generally becomes attached to its keeper, and recognises his very step and voice from that of any other person. "Prince, a tame lion on board H.M.S. Ariadne, was much attached to his keeper, a seaman, who, having got drunk one day, was ordered to be flogged. The grating was rigged on the main deck opposite Prince's den, a large barred-up place, the pillars very strong, and cased with iron. When the keeper began to strip, to undergo this disgusting and savage punishment, the lion rose gloomily from his couch, and got as near to his friend as possible. On beholding his bare back, he walked hastily round the den; and when he saw the boatswain inflict the first lash, his eyes sparkled with fire, and his sides resounded with the strong and quick beating of his tail. At last, when the blood began to flow down the poor fellow's back, and the clotted cat-o'-nine-tails jerked its gory knots close to the lion's cage, the animal's fury became tremendous; he roared with a voice of thunder, shook the strong bars as if they were osiers, but finding his efforts to break them unavailing, he rolled and roared in a manner so terrific, that the captain, fearing the consequences, ordered the unfortunate keeper to be cast off and to enter the den. It is impossible to describe the joy evinced by the lion. He licked with care the mangled and bleeding back of his keeper, caressed him with his paws, and even folded them around him as if to protect him from similar treatment; and it was only after several hours: that the lion would allow the keeper to return among those wretches who had so ill-used him."* 
A lioness, kept at the Tower in 1773, became greatly attached to a little dog who was her constant companion. When the lioness was about to whelp the dog was removed; but shortly after the accouchement the dog contrived to enter the den, and approached the lioness with his usual fondness. She, alarmed for her cubs, immediately seized him, and seemed about to kill him; but, as if suddenly recollecting their former friendship, she carried him to the door of the den, and allowed him to be withdrawn unhurt.

A lion and a lioness were sent as a present from the Bey of Constantine to the King of France, and were placed in the Jardin des Plantes at Paris. Their keeper, whose name was Cassal, used to walk into their cage whenever he pleased; speak to the male or female alternately with great kindness; flatter them by gentle arts, pat and kiss them. At his command they would separate, and each retire to the distinct apartment allotted to it, or they would lie down on their backs, stretch out their paws, and allow him to show their immense claws to the bystanders; or upon his giving them a sign they would instantly open their huge jaws and display their formidable masticators. A remarkable instance of their attachment to their keeper occurred in 1801. The man being absent through illness, committed the lions to the care of one of his colleagues. This change did not appear to affect the female; but the lion retired to the corner of his den, where he suddenly laid himself down, and by his low growl gave his new attendant pretty plainly to understand that he would be glad to dispense with his services. He seemed to entertain the same feeling towards his consort; at least he ceased to take any notice of her. There was an expression of uneasiness and suffering about the lion, and none dared approach him. The keeper at last recovered; and being desirous of giving the lions an agreeable surprise, crept softly up to the bars of the cage and laid his face beside them. As soon as the lion discovered him, he sprang from the back of the cage, stroked his keeper with his paws, licked his hands and face, and howled 
with delight. The lioness showed equal joy at his return; but the lion drove her away, angrily refusing to allow her to partake of the man's caresses. Perceiving that a contest was likely to ensue between them, he entered their den, and having pacified them, caressed and received their caresses by turns.

Hanno, a Carthaginian, was the first who tamed a lion, and for doing so he was condemned to death; his fellow-citizens asserting that the republic had to fear the worst consequences from a man who had been able to subdue so much ferocity. A little more experience, however, convinced them of the fallacy of that ridiculous judgment. The triumvir Antony, accompanied by an actress, was publicly drawn by lions in a chariot. In Africa the taming of feline animals has long been practised. The Emperor of Morocco has large open dens at Fez, where lions and tigers are tended by Jewish keepers, who use nothing but a light cane to keep them in subjection; and in the harems of the Pashas of Egypt there are also domesticated lions; and a splendid specimen was presented by Mehemet Ali to the King of France, in June 1839.

King Soloman is said to have had a couple of lions to guard the entrance to his audience-chamber; and in Bell's Travels from St. Petersburgh into Asia (1\%63), we are told that the King of Persia has, on days of audience, two lions chained on each side of the entrance to the room of state.

The recent exhibitions of Van Amburgh are too fresh in the recollection of most persons to require any account of them here. It was generally, and perhaps correctly, believed by those who saw the extraordinary familiarities which he exhibited with his lions, tigers, \&c., that their obedience was rather the result of awe and terror, than of any feeling of affection. His personal strength, the steady gaze of his eye, that

\footnotetext{
“— would out-stare the sternest eyes that look, Outbrave the heart most daring on the earth;"
}

the authoritative tone of his voice, which, to continue the quotation,

"Would mock the lion when he roars for prey ;" 
all these circumstances, added to the rapidity of his movements, are highly calculated to impress these animals with an idea of his superior power, which, in sudden bursts of his passion, can even make them crouch in the corner of their cage. His exhibition when in London proved highly attractive; and so frequently did Her Majesty honour it with her presence, that she at length acquired the title of "The Lady of Lyons." Indeed there were many others of the fair sex among the company, in spite of the declaration of Snug the joiner, alias Bottom :-

“ Masters, you ought to consider ere you bring in a lion. God shield us ! a lion among ladies is a most dreadful thing: for there is not a more fearful wild-fowl than your lion living."

(Mid. Night's Dream, Act III. Sc. 1.)

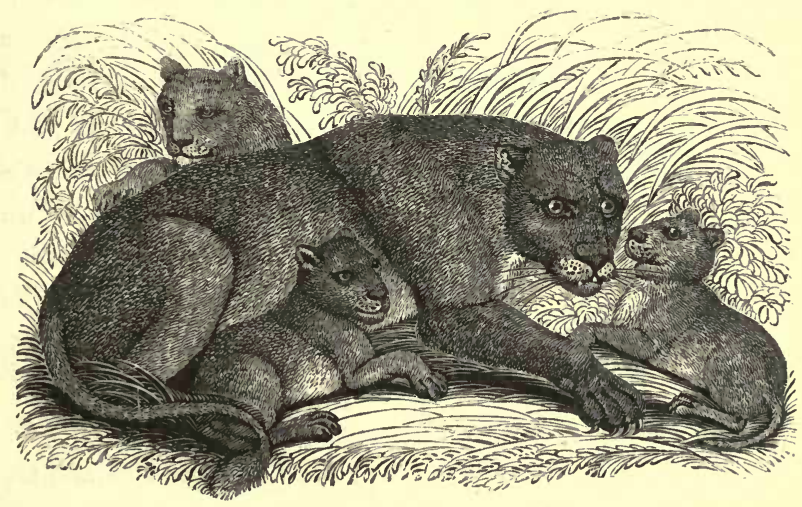

The lioness goes with young twelve months, and usually brings forth two cubs; but one in Wombwell's travelling menagerie has repeatedly had four at a litter. A lioness and her cubs form one of the most interesting sights in such a collection.

"Lions," says Lord Bacon, "are accounted long livers, 
because many of them have been found toothless." * Pompey, the great lion, which died in the Tower in $1 ; 60$, was known to have lived there above seventy years; and one brought from the river Gambia, died in that edifice at the age of sixty-three. The first lioness that visited England died there on September 4, 1733; and, according to Noble, she was "very aged," and had annually produced a litter of cubs for several years. Wallace, the splendid and celebrated lion that demolished the dogs which were set upon him at Warwick a few years ago, died at Wolverhampton at the early age of nineteen, in the summer of 1838. From weakness and decay, however, he was a touching spectacle to the beholder for some time before life became extinct. I shall not soon forget the pitiable look of a sick lion, which I lately saw at the Regent's Park Zoological Gardens, a few days previous to its death, arising from a disease of the lungs and the liver. It was feeding time, and the leopards and tigers were growling over their meat as it was dealt out to them; but this noble patient was lying down exhausted, breathing hard, and quite indifferent to all that was passing around. The keeper approached, and addressing some words of compassion to the animal, flung a fine leg of mutton on the floor of the cage. The lion raised his head, and merely looked at the joint with an indifference that bespoke a loss of appetite; and then resting his head again on his paws, breathed as audibly as before, and gazed on the keeper with a composed but melancholy expression.

The Bushmen, according to Mr. Lewis Leslie, consider the carcase of a lion delicious meat. Mr. Pringle tells us that the head of the large lion, previously mentioned, was boiled by his orders for the purpose of preserving the skull, and that he tasted the flesh from curiosity. It resembled very white coarse beef, and was rather insipid, but without any disagreeable flavour.

* History, Natural and Experimental, of Life and Death (1650), p. 8. 


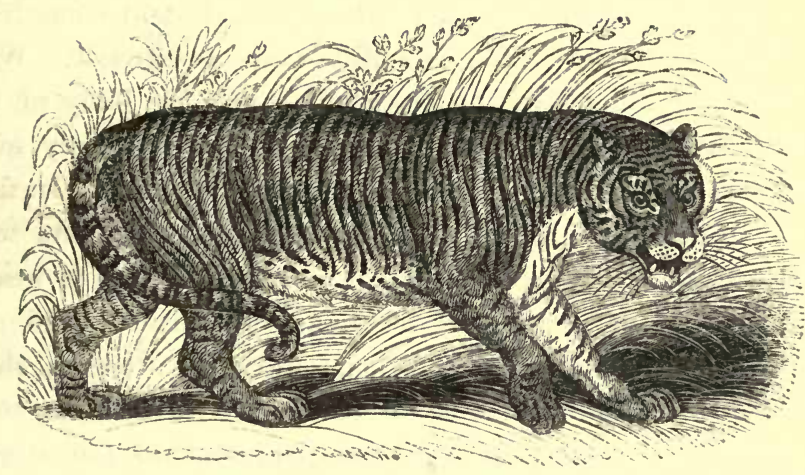

The Tiger.*

The tiger inhabits Bengal, Tonquin, Sumatra, Java, and most of the larger East Indian Islands.

He is usually about six feet from the nose to the end of the body, or, including the tail, the animal's full length is about nine feet. He may be readily distinguished from all his congenors, or generic relations, by the peculiar markings of his coat: it consists of yellow, elegantly striped by a series of transverse black bands or bars, which variegate the sides of his head, neck, and body; and are continued upon his tail in the form of rings, the last one always surmounting the extremity of it. The belly and the inner sides of the legs are almost entirely white. His head is shorter and more rounded than that of the lion, and, unlike that animal, he sports no mane; and his whole frame, though lower in height, is of a more slender and graceful make.

The physical force of the tiger can only be equalled by that

* So called from its swiftness. "Tyger is an Armenian word, and signi. fieth in that tongue, an arrow; hence it was that in ancient times there was a river called by the same name, because it ran so swiftly."-Franzius's History of Brutes (1670), p. 71. 
of the lion and the elephant. In the Peninsula of Hindostan, which is the principal seat of his empire, he may be seen "fighting for the crown" with the lion himself, and sometimes ending the battle by killing his illustrious antagonist. With one stroke of his claws the tiger rips open the body of the largest animals. In his tremendous jaws he can carry off a buffalo, almost without relaxing from his usual speed. In fact, the tiger's gastronomic and gymnastic accomplishments fully equal those of the lion; and as for music, his roar is nearly similar to that of the latter, while his purr is as mild and expressive as that of a cat. When angry he utters a short and shrill cry, approaching to a scream. His roar is most impressive when heard as an accompaniment to the stormy elements. He begins by deep, melancholy, and slow intonations and inflections; presently his voice becomes more acute, and then suddenly changes to a violent cry, interrupted by long tremulous sounds, which together, and repeated in the same manner again and again, form a grand but distracting chorus :-

"In fortune's ray and brightness,

The herd hath more annoyance by the brize* Than by the tiger: but when the splitting wind Makes flexible the knees of knotted oaks, And flies flee under shade; why, then, the thing of courage, As rous'd with rage, with rage doth sympathize, And with an accent turn'd in self-same key, Returns to chiding fortune."

(Troilus and Cressida, Act I. Sc. 3.)

In another passage Shakespeare has most admirably sketched the threatening aspect of a tiger meditating revenge, or about to spring on its foe. The poet (I had almost said the zoologist) makes Henry the Fifth bid his soldiers be as courageous as the tiger; and the instructions given to that end convey a better picture of the enraged animal than any prose writer has depicted :-

" When the blast of war blows in our ears,

Then imitate the action of the tiger;

* i. e. the breezc-fly. 
Stiffen the sinews, summon up the blood,

Disguise fair nature with hard-favour'd rage:

Then lend the eye a terrible aspéct:

Let it pry through the portage of the head,

Like the brass cannon; let the brow o'erwhelm it,

As fearfully, as doth a galled rock

O'erhang and jutty his confounded base,

Swill'd with the wide and wasteful ocean.

Now set the teeth, and stretch the nostril wide;

Hold hard the breath, and bend up every spirit

To his full height!"

(K. Henry V. Act. III. Sc. 1.)*

The tiger generally lies in ambush for his prey. Captain Williamson observes, that a large proportion of the soil of India is of a reddish hue, and the grass during the summer heats being dried up, assumes a colour so similar to the brighter parts of the tiger's skin, that this animal is often roused where there does not exist any cover adequate to sheltering half its bulk; the colour of the surrounding objects so perfectly corresponding with its own as to conceal the danger.

Uttering a loud roar, the tiger springs suddenly upon his victim with astonishing rapidity, and sometimes at a single bound or leap of almost incredible extent. He will not hesitate to swim across a river when he perceives a tempting quarry on the opposite bank.

"The tiger's fore-paw is the invariable engine of destruction.

* The idea of imitating the ferocious gesture of the tiger was perhaps borrowed by Shakespeare ; for at an earlier period than that of Henry V., it was the custom of men preparing for fight to endeavour to assume the forbidding appearance and ferocity of particular animals. "The ancient pirates used to work themselves literally into a state of bestial ferocity. Those who were subject to these paroxysms were called Berserkir : they studied to resemble wild beasts; they excited themselves to a strength which has been compared to that of bears; and this unnatural power was succeeded, as we may well suppose, by corresponding debility. In the French and Italian romances, we frequently find a warrior endowed, for a part of a day, with a double or treble share of strength; and it is not improbable that the fiction may have been derived from this species of phrenzy. Bartholinus tells us that Odin's soldiers went to battle without armour, biting their shields, raging like wolves or dogs: like bears or bulls in strength; they slaughtered their foes, and were themselves invulnerable to fire and sword."-Historical Parallels (1831), p. 11, 12. 
Most persons imagine that if a tiger were deprived of his claws and teeth, he would be rendered harmless; but this is erroneous. The weight of the limb is the real cause of the mischief; for the talons are rarely extended when a tiger seizes. The operation is similar to that of a hammer; the tiger raising his paw, and bringing it down with such force, as not only to stun a common sized bullock, or buffalo, but often crushing the bones of the skull. I have seen many men and oxen killed by tigers, in most of which the mark of the claw could not be seen; and where scratches did appear, they were obviously the effect of chance, from the paw sliding downwards. I once witnessed an instance, which gave me a very complete idea of a tiger's proceedings and of his powers. I was travelling post in my palankeen, through the Ramghur district, which is mountainous and little cultivated, being for the most part in a state of nature and abounding in jungles, when a bangy-wollak, who conveyed two baskets of linen and refreshments, and who preceded the palankeen about a hundred and fifty yards, set down his load, and seated himself on the road-side to rest awhile. About two yards behind him was a small bush, not much larger than a good sized currant-tree, round which a small quantity of jungle-grass was growing. There was not another twig to be seen for at least half a mile, on that side of the road. No sooner had the poor fellow seated himself, than a tiger sprang from behind, or rather from within the bush, and after giving the fatal blow with his paw, seized the man by the shoulder and dragged him off, with the utmost ease at a quick pace, into a thick cover which had formerly skirted the road, but which had been cut away, to the distance of about one hundred yards, for the safety of travellers."*

Waterton says that " many years ago, Colonel Duff, in India, was laid low by the stroke of a Bengal tiger. On coming to himself, he found the animal standing over him. Recollecting that he had his dirk by his side, he drew it out of the case, in the most cautious manner possible; and, by one happy 
thrust quite through the heart, he laid the tiger dead at his side." *

A remarkable instance of courage and presence of mind on the part of a man, who was attacked by a tiger, occurred not far from Bhaugundee in 1823. "A party of wood-cutters, under the protection of five armed Burgundauzes, were proceeding to their work, when, being in a very thick part of the jungle, they perceived a large tiger at a short distance, approaching them slowly in a crouching attitude. On the alarm being given, the whole gang immediately fled, excepting two brothers (slender up-countrymen), who were in advance of the others, and either saw the inutility of following their example, or judged it safer to oppose the tiger; one of them accordingly, levelling his piece, fired at the moment when the animal was in the act of springing. The ball pierced the tiger's breast, and caused him to drop on his knees for a second, but instantly recovering, he rushed forward and threw himself upon the Burgundauz. At this critical period the tiger must have been in a dying state, for the man declared he retained his standing position, and instinctively grasping the fore-legs of the tiger, he was able, by exerting all his strength, to bend the head and shoulders towards the ground, and his brother, who was at hand, gave the coup de grace with his fixed bayonet. The man received some scratches about the face, neck, and breast; but none of these wounds were very serious, and he recovered entirely in a fortnight." $\dagger$

Tigers, if taken young, may be tamed quite as easily as the lion, and they become equally submissive and attached to their keepers. From the antique sculptures representing Bacchus riding in cars drawn either by tigers, leopards, or panthers, we may reasonably infer that the art of taming these creatures was practised at an early period; and as one of the severest laws of Budhism enjoins its votaries to feed an old sick tiger with their own blood, it may even be concluded that the Indians were accustomed to domesticate this species.

* Mag. Nat. Hist. vii. (1834), p. 2.

† Abridged from The Asiatic Journal (1823). 
"A tiger, brought from China in the Pitt, East Indiaman, was, at the age of ten months, so tame as to admit of every kind of familiarity from the crew. It was as harmless and playful as a kitten. It frequently slept in the sailors' hammocks; and, when stretched on the deck, would allow two or three of them to repose, with their heads resting on it for a pillow. Like the cat, it was given to thieving, and frequently stole the sailors' meat. One day, having stolen a piece of beef from the carpenter, he followed it, and, after taking the flesh out of its mouth, beat it severely for the theft, which it suffered without offering to retaliate. It would frequently run out on the bowsprit, climb about the ship like a cat, and perform a number of tricks with surprising agility. There was a dog on board with which it would often play in the most diverting manner. This animal, which was called Harry, and answered to its name, was placed in the Tower menagerie, where it remained many years, and never evinced any ferocity." *

Martin, a famous tamer of wild beasts, used to amuse his audience by exasperating his tigers and lions, and then showing how complete a mastery he had acquired over them in their savage moments. He had a young tiger which used to skip about among the spectators, lick their hands, and play with a little girl of six years old whom he brought with him.

It is related that on one occasion in New York, Van Amburgh's tiger, having become ferocious, his master gave him a tremendous blow over the head with a crow-bar, accompanying it with loud menaces and strong gesticulation, and that after this correction the tiger behaved like a gentleman for a couple of months.

The tigress has two cubs annually, according to Captain Williamson; but most authors state that she has three or four at a litter. In captivity, she has been known to breed with the lion. The saloon of the British Museum contains a stuffed specimen of a hybrid whelp, the offspring of a lion and tigress, born in Atkins's travelling menagerie at Windsor.

* Brown's Sketches of Quadrupeds (Glasgow, 1831), p. 276. 


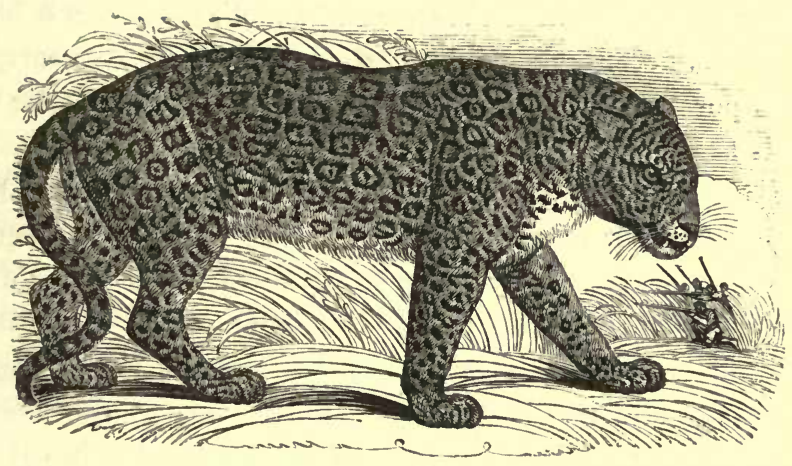

The Jaguar, or Yaguar.-(Felis on og̣, Linn.)* American Leopard. Turtle-Tiger.

The jaguar inhabits the warm climates of South America, from Paraguay nearly to the Isthmus of Darien; haunting the recesses of the swampy forests near the vicinity of large rivers. It is in fact peculiar to America, and is the most formidable animal of that quarter of the globe. In size and strength it is superior to the leopard, and its head is larger and rounder; but the most obvious distinction consists in the tail being much shorter, and only of sufficient length to touch the ground when the animal stands up, whereas that of the leopard's is nearly of the same length as the body. From the leopard, and indeed from every other feline species, the jaguar may also be distin-

* Buffon has published a description and figure of the ocelot for the jaguar, intermingling with the description many of the peculiarities of the latter, derived from the accounts of travellers; and, on the other hand, he, as well as Pennant and some subsequent writers, has erroneously figured the jaguar for the female panther. The frequent, but seemingly unfounded statement, that the jaguar is found in Mexico, probably originated from Buffon's confounding it with the ocelot. As if to increase the confusion, the Portuguese call the jaguar onça, or ounce, though the ounce of the Old World is now generally acknowledged to be identical with the leopard. 
guished by the full, narrow, and elongated spots which occupy the central line of the back; and the handsome marks, or roses, as they are termed, on the sides and haunches, are much larger and less numerous than in the leopard, and all or nearly all of them possess one, sometimes two black spots of smaller size towards the centre.

The jaguar is a most excellent swimmer: Captain J. E. Alexander says, it occasionally swims over the river Essequibo. A circumstance related by D'Azara, and which fell partly under his observation, will give some idea of its aquatic exploits, as well as of its extraordinary strength; namely, that a jaguar, after having attacked and killed a horse, carried the body of its victim for about sixty paces to the bank of a broad and deep river, over which it swam with it, and then dragged it into an adjoining wood.

According to Sonnini, the jaguar is also an expert climber of trees. "I have seen," says he, " in the forests of Guiana, the prints left by the claws of the jaguar on the smooth bark of a tree from forty to fifty feet high, measuring about a foot and a half in circumference, and clothed with branches near its summit alone. It was easy to follow with the eye the efforts which the animal had made to reach the branches: although his talons had been thrust deeply into the body of the tree, he had met with several slips, but he had always recovered his ground, and, attracted no doubt by some favourite object of prey, had at length succeeded in gaining the very top."

Horses, oxen, sheep, capibaras, and dogs, are the usual prey of the jaguar. In Guiana it has been known to enter houses, and carry away the dogs from the fire-side. It is said to be very partial to the flesh of the alligator, and to attack and overcome that reptile. Mr. Mawe says, that in Paraguay it seeks turtles, and, turning them on their backs, makes a meal of them. It has been often said, that the jaguar catches fish by spitting on the water to entice them to the surface, and that when they approach this floating bait, the ingenious animal, with one dexterous stroke of his paw, knocks them out of their element; 
but it is very improbable that so expert a swimmer would wait to catch fish with the patience of an angler.

So long as the jaguar can obtain his customary meals readily, it is indolent and cowardly, secreting itself in the depths of the forests or in caverns, and is scared by the most trifling causes; but when emboldened by hunger it will attack man himself. D'Azara says, that during his residence at Paraguay, the jaguars killed six men; two of whom were even seized in the night, while sitting by a blazing fire, and carried thence by these animals. Sonnini mentions, that while journeying through the extensive forests of Guiana, he and his party were much annoyed by a jaguar following them in their route, for two successive nights, evading, meanwhile, all their efforts to destroy him. They kept up large blazing fires to fright him away; and he at length took himself off, after uttering a horrid howl of disappointment. Mr. Mawe says, that when once the jaguar has tasted human flesh it will hunt for it again.

"It has been observed, in the Jardin des Plantes, that some of the carnivorous animals are most healthy, and most inclined to increase in bulk, if fed only once in several days. The jaguar is remarkable for the excess of this peculiar power, and will eat at a single meal sufficient to support him for a week. In the wild solitudes of which he is a native, he probably is equally abstemious during the time of repletion."* A jaguar at the above establishment in Paris, was of exceedingly mild temper, and particularly fond of licking the hands of those with whom he was familiar; as was also remarkably the case with one formerly in the Tower of London.

\section{The Black Jaguar.}

Black Tiger.

"Sometimes," as Cuvier observes, " individual specimens of the common jaguar (Felis onça) are found black, whose rings, of a deeper hue, are only perceptible in a particular light." 


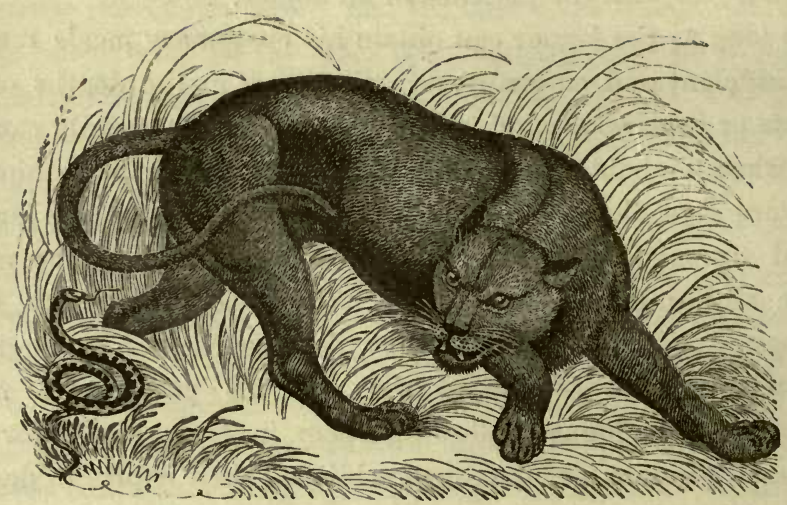

One of this black variety, a female, which was exhibited in Wombwell's travelling menagerie, devoured her young on two different occasions.

The LeoparD.-(Felis leopardus, Linn.)*

Tree-Tiger.

The leopard is found in Africa, from the shores of the Mediterranean to the immediate neighbourhood of the Cape; and in Asia it is equally common and dreaded in the East Indies, China, and Sumatra.

Contrasting it with the tiger, the leopard will be found to

* There has been much discussion respecting the precise species of animal which the ancients termed panther, and whether there existed any real difference between it and the leopard. M. Lesson states the number of vertebræ in the tail of the panther to be eighteen; Cuvier says it has twentyfour; and Temminck says it has twenty-eight. Both Lesson and Temminck concur in stating the number in the tail of the leopard to be twenty-two. As far as regards the panther, therefore, the statements are nugatory; and we have the choice of supposing, either that the number of caudal vertebræ differ in different individuals, or that different feline species have been examined for the panther, or that there are typographical errors in the published accounts. 


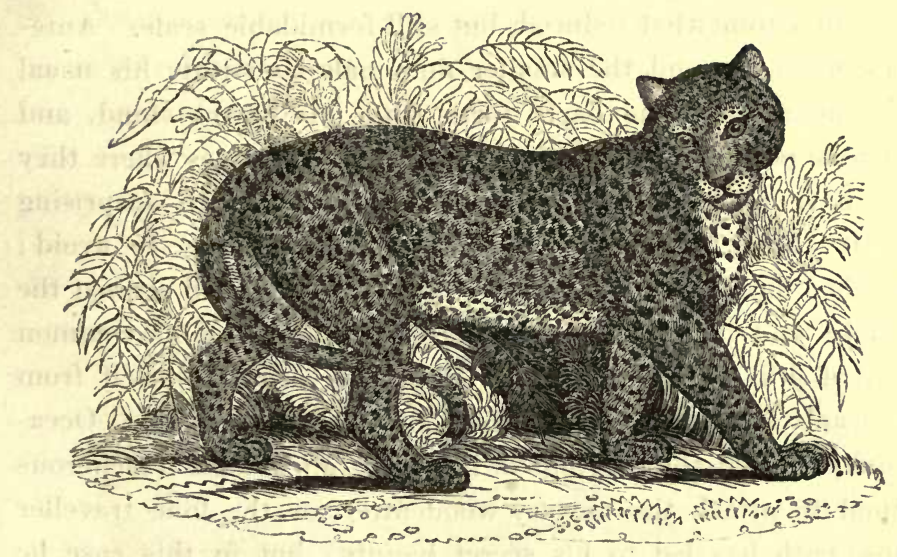

be smaller, being seldom more than from three to four feet from the muzzle to the base of the tail, which is somewhat shorter than the body. Individuals from different countries present some slight differences in size, colour, and marking; but, generally speaking, the beautifully sleek coat of the leopard is of a yellowish fawn colour above, and pale yellow on the sides̄, which, like the other exterior parts, are adorned with beautiful markings or roses, each consisting of three or four small black spots irregularly surrounding a central space of a darkish yellow colour, and about an inch and a quarter in breadth. The belly and the under parts of the tail are pure white.

The male, as is usual with all the cat tribe, is larger than the female, and of a deeper colour, and more richly marked.

"The extreme pliability of the leopard's spine," it has been well observed, "gives to his motions a degree of velocity, agility, and precision combined, that is altogether unequalled by any other mammal, and to which the greater lateral compression of his body, the increased length and more slender proportions of his limbs, and the suppleness of all his joints must materially 
contribute. Equally savage, equally dastardly, and equally cruel, he closely imitates the manners of the lion and the tiger, on a somewhat reduced, but still formidable scale. Antelopes, monkeys, and the smaller mammals constitute his usual prey, upon which he darts forth from his secret stand, and which he pertinaciously pursues even upon the trees where they may have taken refuge, climbing after them with surprising agility. Man he generally endeavours, if possible, to avoid; but when hard pressed, he fears not to make head against the hunter; and it frequently requires the exertion of no common share of skill and intrepidity in the latter, to save himself from the deadly fangs of the infuriated object of his pursuit. Occasionally, indeed, the cravings of hunger stimulate the treacherous animal to attack the unwary woodcutter, or the lone traveller whose path has led to his secret haunts; but in this case he rarely, if ever, shows himself openly in broad day, but watches with insiduous glare for the fatal opportunity of springing upon his victim from behind, and of annihilating his power of resistance before it could possibly be exerted in his defence."*

In captivity, especially if accustomed to that state from an early age, the leopard is as susceptible of being rendered tame and docile as the generality of his tribe.

The female goes with young sixteen months.

** The Chetah, objectionably called the Hunting Leopard (Cynailurus jubata, Wagl.), differs in so many essential characteristics from the truly feline animals, that it has very properly been permitted to constitute a distinct genus or sub-genus. Its claws are only partially retractile; it is gregarious, and of a mild disposition, so much so that it is frequently tamed and employed in the chase. But as a remarkable contrast to this, its dental system is upon a more murderous plan than that of the animals which properly belong to the genus Felis, not possessing the fat projection on the large tearing molar of the upper jaw, which is found in all the other predaceous genera, and the development of which is in inverse proportion to the

* Tower Menagerie (1829), p. 37. 
animal's carnivorous propensities. Dr. Lund has recognised this form of dentition in the fossil remains of an extinct Brazilian species not larger than a cat, and which he calls Cynailurus minuta.

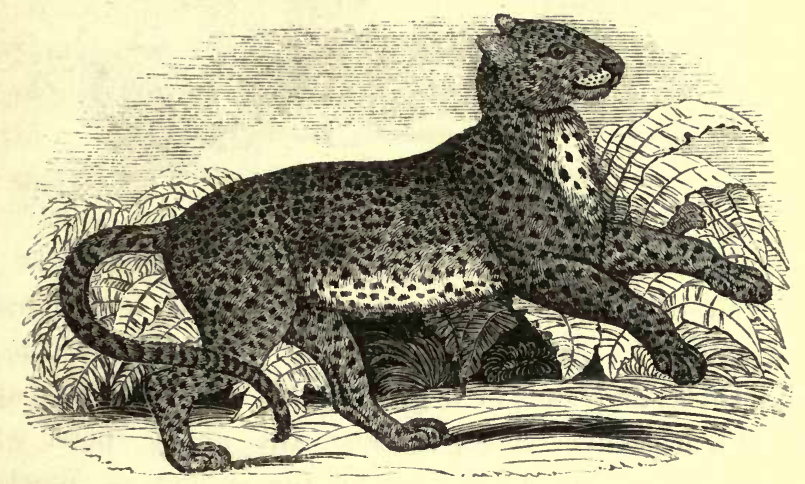

The Ounce.-(Felis uncia, Gmel.)

This animal, which is said to be found in Persia, differs from the leopard (Felis leopardus) and the panther (F.pardus) merely in the inequality of the spots, which are more irregularly disposed, and partly crenate or annulated, \&c. It is only known to us by the figure in Buffon's work (vol. ix. pl. 13), and that which Col. Hamilton Smith has inserted in Griffith's translation of Cuvier's Regne Animal, taken from a specimen that was living in London.

\section{The Common European Lynx.-(Felis Lynx, Linn.)}

This species, formerly an inhabitant of all the temperate parts of Europe, but now exterminated in the more populous districts, is still found in the Pyrenees, in the mountains of Naples, and, as it is said, even in Africa. 


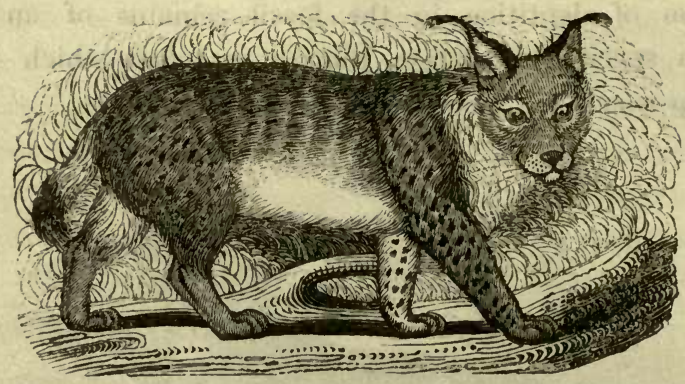

The usual length of the common lynx is about four feet and a half from the nose to the rump, or five feet including the tail; and its height one foot and four inches. The fur is long, thick, and soft, of a grayish ash colour on the upper parts, with a reddish tinge, marked with dusky spots, which differ much according to the age of the animal, as sometimes they are scarcely visible; and the under parts are white. The legs and feet are thick, short, and strong, covered with long fur; and the tail black at its extremity. The ears are erect, and have a long tuft of black hairs at the tip; and the eyes are of a pale yellow, and have nothing extraordinary about their appearance to give the slightest support to the assertions of the ancients,* namely, that their lynx could see through a stone wall or a rock with the utmost ease, and without the use of spectacles.

Lynxes conceal themselves in thick forests, prey upon stags, roebucks, sheep, hares, and other animals; and climb with facility up the highest trees to capture birds and squirrels.

In captivity they are remarkably irritable and mistrustful, and are seldom thoroughly tamed.

The softness and warmth of the fur renders it a valuable and extensive article of commerce.

* The caracal (Felis Caracal, Linn), a native of most of the warmer climates of Africa and Asia, is the lynx of the ancients. The lynx of the moderns ( $F$. Lynx, Linn.) was quite unknown to the Greeks, though not to the Romans, who distinguished it by a totally different name. 


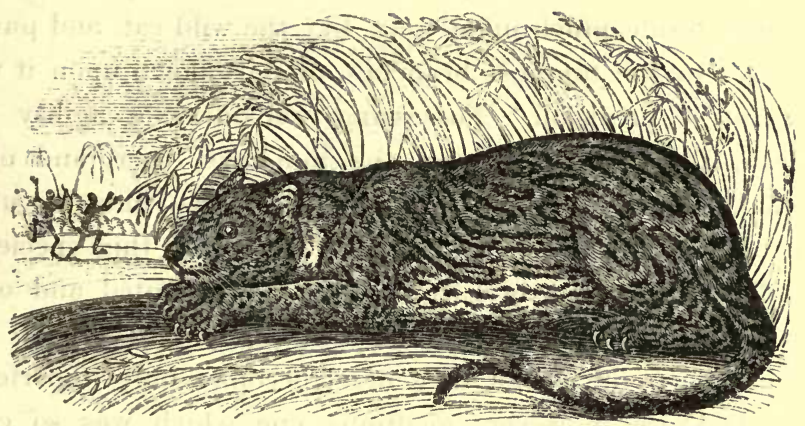

The Ocelot.-(Felis pardalis, Linn.)* Mexican, or Peruvian Tiger. Tiger-cat.

The ocelot inhabits Paraguay, the Brazils, and other parts of South America chiefly, but is also found in Mexico.

When full grown, its body is nearly three feet, and its tail somewhat more than one foot in length. Its height is generally one foot and a half. Those readers who are well acquainted with this handsome and graceful creature, will agree in the remark of Buffon, that " of all animals with tigrine skins, the male ocelot has unquestionably the most beautiful and at the same time the most elegantly variegated robe; that of the leopard himself does not approach it in liveliness of colour or regularity of design." The ground colour of its coat is gray with a slight tinge of fawn; and on this it is elegantly marked with numerous compressed or elongated rings of black,

* The pardalis, or panther of the ancients, is the Felis pardus of Linnæus, which inhabits the whole of Africa, the southern parts of Asia, and the Indian Archipelago. The panther of the modern zoologists is the animal called Felis concolor by Linnæus, and popularly known here and among emigrants by the several names of couguar, puma, and American lion. Goldsmith and some others call the ocelot the cat o'mountain: but Mr. R. C. Taylor, in his account of the zoology of the Alleghany Mountains, appends the words "cat o' mountain, or mountain cat" to the Mississippi lynx (Felis montana). 
each enclosing a large yellow spot. The colour and arrangement of the markings are apt to vary in different specimens.

Ocelots reside much upon trees, like the wild cat, and pursue their prey to the topmost branches, or dart down upon it with the greatest precision. Possessing considerable agility and strength, they easily capture the monkeys, deer, and other mammals upon which they prey. Instances have occurred of the ocelot attacking man, but seldom, for this species is naturally timid and cowardly, though when hunted and overtaken it offers the most determined resistance.

In captivity, the ocelot in general becomes only imperfectly tame. D'Azara, however, mentions one which was so completely domesticated as to be given unbounded liberty; it was strongly attached to its master, and never attempted to decamp. About eleven years ago the Tower of London contained a male ocelot, which also was " perfectly good tempered, exceedingly fond of play, and had, indeed, much of the character and manners of the domestic cat. It was principally fed upon rabbits and birds, the latter of which it plucked with the greatest dexterity, and always commenced its meal with their heads, of which it appeared to be particularly fond. It did not eat with the ravenous avidity which characterizes nearly all the animals of its tribe."*

The Duke de Choiseul, minister to Louis the Fifteenth, s recorded to have had a favourite ocelot constantly in his cabinet.

The two ocelots from which Buffon wrote his description of the species were brought from Carthagena, and having been taken from their dam when they were very young, they were suckled by a bitch; but, before they were three months old, they killed and devoured their foster parent. After this ungrateful butchery they exhibited habits of great fierceness, and a continual propensity for slaughter. The male never allowed the female to partake of a meal till his own appetite was satisfied.

* The Tower Menagerie (1829), p. 56. 


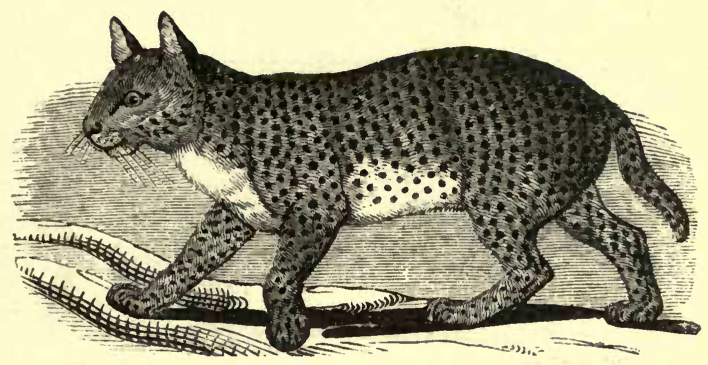

The Serval, or Marapute.-(Felis Galeopardus, Des.)

The serval inhabits the mountainous parts of Malabar, Senegal, India, and Thibet, residing chiefly in trees.

In the size and shape of its body, and in the shortness of its tail, it resembles the lynx. The general colour is a pale fulvous yellow on the back and sides, covered with small round spots, equally divided over the whole surface, except on the middle of the back, where they are disposed in four rows: the breast and belly are entirely white; the eyes are very brilliant, and have a wild and piercing look; and the whiskers, or feelers, are very long, stiff, and nearly straight. Some specimens have the tail spotted, and others annulated with black.

It preys upon rabbits and young antelopes, but more especially upon squirrels and birds, which it pursues with great agility from tree to tree. Man it never assaults, but rather endeavours to avoid; if, however, it is provoked to an attack, it darts furiously on him, and bites and tears as desperately as any of the cat tribe.

It makes a bed in trees for the reception of its young. In our menageries the serval is a rare animal, being seldom brought over to this country. 


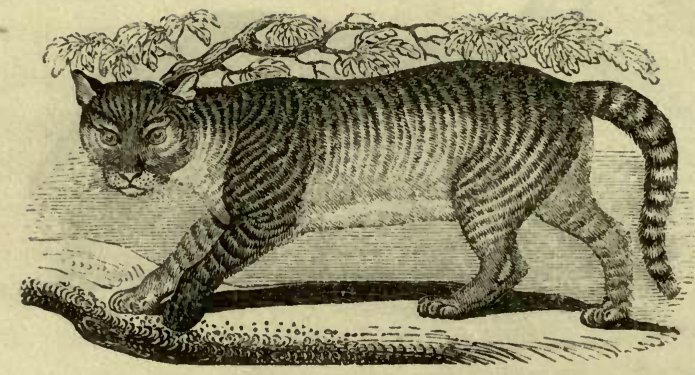

The WiLd CAT.-(Felis catus, Linn.)

The wild cat, though rare in England, is still a common animal in the mountainous and woody parts of Scotland, Wales, and Ireland, and in the extensive forests of Germany, and other European countries, as well as in the North of Asia.

The average length of the full-grown male, which is always larger and more beautiful than the female, is stated by Professor Bell to be one foot ten inches, or, including the tail, two feet seven inches and two lines. But Bewick mentions a wild cat, killed in Cumberland, which measured from its nose to the end of its tail upwards of five feet; and Pennant says the wild cat is three or four times as large as the house cat; and adds that the head is also comparatively larger, and the face flatter. The fur is very soft and fine; its general colour is yellowish white, mixed with a deep grey, marked with dark streaks pointing from the back downwards; a black line runs from the head down the back to the tail, which is of moderate length, but very thick and flat, annulated with black and white, and the tip is always black, as are the hips and hind parts of the lower joints of the legs.

It is a strong and fierce animal, possessing such formidable teeth and claws as to render it an object of some dread, especially when enraged. Pennant, who calls it the British tiger, 
says it makes great havoc among our poultry, lambs, and kids. It seeks its prey at night-time, the day being its time of repose.

Shylock. "

\section{More than the wild cat."}

(Merch. of Venice, Act. II. Sc. 5.)

In woody districts, the female forms her nest in hollow trees, and has been known to appropriate the nest of some large bird to her own use ; but in alpine situations, she generally prepares her cradle in the fissures of rocks.

"Suspended cliffs, with hideous sway, Seem'd nodding o'er the cavern grey.

From such a den the wolf had sprung :

In such the wild cat leaves her young."

(Scott's Lady of the Lake, Canto III. St. 26.)

She has usually four or five young at a litter; and she will fight boldly in their defence. Near High Melton, a village about six miles west of Doncaster, in the county of York, is a wood of some extent, and which, from time immemorial, has been a favourite haunt of the wild cat and also the badger. Many years ago a young man, in passing through this wood, discovered a wild cat's nest in a hollow tree. Without leave or licence, he purloined the contents, which consisted of three kittens. He had not proceeded on his way home more than a mile, when, on turning round, he beheld the mother of the brood mounted on the top of a stile, which he had quitted but a moment before. Her ferocious aspect and appalling cries rendered him fearful of being involved in a sanguinary affray, so he dropped one of the kittens, which she instantly seized and conveyed out of sight. The man then proceeded onward at a quick pace, but in a very short time the affectionate parent was again at his heels, and he was obliged, for peace-sake, to drop another of her bantlings, which was disposed of in like manner with the former. With the third the man escaped.

The following circumstance, which Bingley published in his Animal Biography, occurred in the same wood, and has been a popular tradition in the county for about half a century. A man, passing through the wood, being attacked by a wild cat, 
a furious contest ensued, which was continued until they reached the village of Barmbrough, a mile distant from the wood, and was fatally terminated in the church-porch, where "the man killed the cat, and the cat killed the man." A rude painting in the church to this day records the transaction; and the simple villager exhibits to the inquisitive stranger the variegated pavement stained, as he says, with the blood of the combatants.

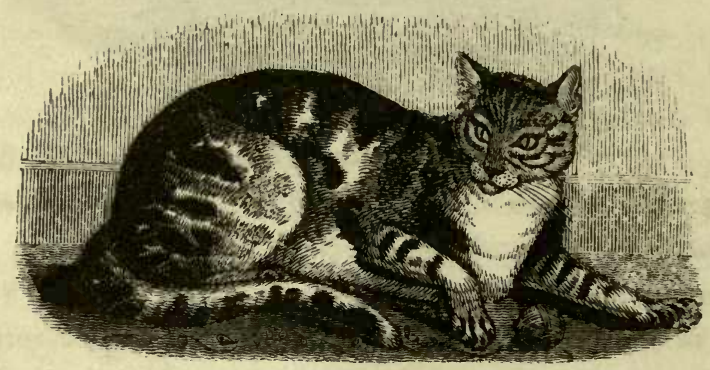

The Domestic Cat.-(Felis - ? Var. domestica.)

The existence of the common wild cat (Felis catus) in our own country and in many parts of the European continent, possessing colours and markings closely imitated in some individuals of the house cat, has led to the very general notion, scarcely ever called in question, that the former is the species from which the domestic race have descended. Professor Bell has so well discussed this matter, that I cannot resist introducing his observations here. "Among the many reasons for believing this opinion to be erroneous, we may, in the first place, instance the great difference in the general conformation of the two animals, especially in the length and form of the tail, which in the wild cat is strong and robust, and as thick at the end as at the middle and the root; whilst that of the domestic cat tapers towards the tip. The fur, too, of the former, is thicker and longer; and although the colours are somewhat like those which occur in some indi- 
viduals of the ordinary species, there are, even in this respect, distinctions which can scarcely be considered otherwise than as essentially specific; as, for instance, the tail of the wild cat invariably terminates in a black tuft. But, it may be asked, if they be not of the same species, how is it that the female tame cats, after wandering into the woods, return pregnant by the wild cat, and produce fertile young ? After a very careful investigation and much reflection on the matter, I am led to conclude, that this long-received notion of their intermixture, repeated and transmitted from one writer to another, is erroneous. The error has arisen, simply from the fact, that a female domestic cat has been occasionally known to leave her home in the neighbourhood of woods, said to be frequented by the wild cat, and returned with young; but as no one pretends to have detected the paternity of such litters by actual observation, it is equally reasonable to suppose that the father in such cases was some cat of the domestic race which had resumed a halfwild state in the woods. It is well known, that the domestic cat's attachment to its native home is not always so strong as to prevent it from wandering into the woods and forests in search of birds and other wild animals; gamekeepers and sportsmen are well aware, that in numerous instances these truants never return to their former home, but breed and rear their progeny in a state as wild as that of their original progenitors could have been.

"The markings of the striped or tabby variety of the domestic, are frequently so similar to those of the wild cat, that they might lead to a strong presumption of the intermixture of the two races, if not of their absolute identity, were it not for the fact that, in most domesticated animals, colour is of little value as a guide to their origin. The greater number of the present genus, too, have a decided indication of. a striped character in the markings of the body; even the lion, when very young, showing distinct stripes on the sides. The species from which the domestic cat has sprung, may have a tendency at least to a similar kind of pattern of the fur; besides, to show how 
little dependence is to be placed on colour in such cases, the tortoise-shell cat is, I presume, universally admitted to be derived from the same race as the tabby; yet the distribution of the colours is totally different, and there is no wild species yet discovered bearing the slightest resemblance to that particoloured variety.

"The not unfrequent occurrence of figures of the cat, among the sculptures and paintings of the ancient Egyptians, as well as its mummies in their tombs, appears to supply the earliest records of its existence in a domestic state; and to indicate that country as the probable locality in which the original breed is to be sought.

"Temminck and some others have concluded that the Felis Maculata, a new species discovered by Rüppell in Nubia, and of about the same size as our domestic cat, and having several characters in common with it, is the true original of that animal. One of the most obvious distinctions between the British wild cat and the domestic, is the difference in the length and thickness of the tail; and in its being taper in the latter, whilst in the former it is quite as thick, if not thicker, at the extremity than at the base: but in Rüppell's Nubian species the tail is much longer in proportion than is ever seen in the domestic race; and although somewhat slender in the greater part of its length, it has a thickened and tufted termination. The ears too are much longer and broader, and the legs longer and more slender. In fact this Nubian wild cat appears to be more removed from our domestic cat, in essential zoological characters, than even the British wild cat; and I cannot but come to the conclusion, that we have yet to seek for the true original of this useful, gentle, and elegant animal." *

Domestic cats differ considerably in their size, according to the sex and breed. He-cats (or Tom-cats as they are generally called) are usually larger and more noble looking than those of the other sex; but most of the former that are kept are emasculated, in which state, always accompanied with a

* Abridged from A History of British Quadrupeds (1837), pp. 182-186. 
subdued and melancholy appearance, they are termed gilberts, or gib-cats.

Falstaff. "I am as melancholy as a gib-cat."

(Henry IV. Part I. Act I. Sc. 2.)

When a cat is roused to attention, as by the scratching of a mouse, the pupils of her eyes dilate; and the same thing occurs when she struggles to get away from any one who holds her.* If it be night-time, her pupils, when thus dilated to receive the light, will be seen to shine conspicuously.

- Gower. "The cat with eyne of burning coal, Now couches 'fore the mouse's hole."

(Pericles, Act. III. Prologue.)

In the day-time, when unexcited, each pupil has the compressed lineal appearance represented in the following figure.

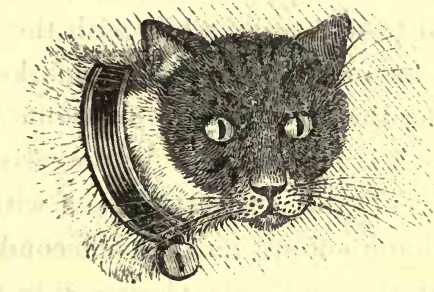

A writer in the Magazine of Natural History (vol. i. p. 66), says it is a remarkable fact that "white cats with blue eyes are always deaf ;" and the Rev. F. W. Bree has recorded an anecdote in confirmation of the curious remark.

The cat is sensibly affected by changes in the atmosphere. "Her face-washing and trimming of her fur, has been," says Mr. Mudie, "the cottage barometer time out of mind; and the observation has been too repeatedly made to be doubtful. This operation of the cat is performed equally whether she is snugly housed beside the fire, or out of doors exposed to the air. It happens, too, sooner before the actual fall of rain, than the prognostics of most other animals. She is of all animals

* The eyes of the ox-eye tit (Parus major), a small predacious bird, also have the power of dilating. 
with which we are very familiar, by far the most electric; that is the most susceptible to electric action. Clear and dry air is well known to be a non-conductor of electricity,-and the more dry and clear the air is, the more agreeable to the cat. It is, indeed, highly probable that the love of dry air, as much as the love of heat, brings the cat to bask by the fire when the air is damp and raw : but the subject has not been studied with the attention which it deserves; for, strange though it may seem to some, the cat may be of real service to the meteorologist, for the body of an animal must, under any circumstances, be a far more delicate instrument than any which can be made by man."*

Indeed it has been stated, that electricity may be accumulated in its body, and given off suddenly so as to produce a shock. Romer says, if a person take a cat in his lap in dry weather, and apply the left hand to its breast, while with the right he strokes its back, at first he only obtains a few sparks from the hair; but after continuing the manipulation for some time, he receives a sharp shock, which is often felt above the wrists of both arms. At the same moment, the animal runs off with expressions of terror, and will seldom submit itself to a second experiment.

"The nature of the cat," say's Gesner, "is to love the place of her breeding; neither will she tarry in any strange place, although carried far, being never willing to forsake the house for the love of any man, and most contrary to the nature of a dog, who will travel abroad with his master; but although her master forsake the house, yet the cat will not bear him company, and being carried forth in a closed basket or sack she will return again." $\dagger$

Mr. Rennie says, that he has known a cat travel from London to her home at Chatham, in Kent, a distance of thirty miles; and most people can relate similar incidents.

The general character of the cat has been greatly traduced by writers, who have seen only the worst portion of the feline

* Abridged from The Naturalist (1837), vol. i. p. 25.

+ History of Four-footed Beasts, translated by Topsel (1607), p. 82. 
population. Its ingratitude has been held up to public odium, which constantly manifests itself against the poor animal, who can rarely show her face in the streets without calling forth a volley of stones or some such annoyance. A writer in the Edinburgh Journal (No. 186), records the following interesting anecdote, as one proof among many he has observed of the attachment and gratitude of cats:- "Mrs. A. had a cat of which she was very fond, and whose dinner was provided with as much regularity as that of any member of the house, by the cook bringing home a liver once a-week when she went to purchase provisions for family use. When the liver was brought home, it was cut into seven pieces, and puss had each day her allotted portion. It so happened that Mrs. A. was taken ill and confined to bed. No sooner did the cat miss her kind friend, than she made her way to Mrs. A.'s chamber, and, jumping on the bed, she caressed her mistress, licking her face and hands, and expressing by every means in her power her sympathy and affection. After a time, the cat became restless; she leapt from the bed, planted herself close to the door, and waited with evident impatience till it was opened. The moment this was done, she ran down stairs, and, to her mistress's great surprise, she returned immediately with a piece of liver in her mouth, which she laid on the bed, and seerned to solicit her to eat; thinking, perhaps, that she was suffering from hunger. The gratitude of puss did not end here ; for on the next marketday, when the cook brought in the liver, ere she had time to divide it, puss, slyly seizing the opportunity when her back was turned, pounced upon the liver, rushed up stairs with it, and laid it on the counterpane with evident marks of pleasure, and with gestures which seemed to say, "See what a fine dinner I have brought you ; pray get up and eat it.'"

The chief food of the cat when she is left to forage for herself, in houses and other buildings, consists of mice.* She also kills great numbers of rats, but she rarely eats them unless they

* Mr. Edward Blyth informs me that, though the cat will eat the common mouse, she will not touch either the harvest mouse (Mus messorius) or any species of the shrew genus (Sorex), improperly called shrew-mice. 
are young and tender. In St. Catherine's Docks, London, cats are expressly kept to destroy the rats, which, previous to this mode of exterminating them, used to make vast havoc amongst the sugar stores deposited there. That the cats do not eat many of the rats is proved from the circumstance of the annual expense of cat's-meat, bought by contract, amounting to one hundred and four pounds sterling. They are fed by two men, at six o'clock in the morning and at nine in the evening. "Our ancestors," Pennant remarks, " had a high sense of the utility of this animal. That excellent Prince, Hoel dda, or Howel the Good, who died in the year 948, has included the cat among his laws relating to the prices, \&c. of animals,* and described the qualities she ought to have. The price of a kitten before it could see, was to be a penny; till it caught a mouse two pence; when it commenced mousing four pence. It was required besides, that it should be perfect in its senses of hearing and seeing; be a good mouser; have the claws whole, and be a good nurse : but if it failed in any of these qualities, the seller was to forfeit to the buyer the third part of its value. If any one stole or killed the cat that guarded the Prince's granary, he was to forfeit a milch ewe, its fleece, and lamb; or as much wheat as when poured on the cat suspended by the tail (the head touching the ground) would form a heap high enough to cover the tip of the former. The large prices set on them (if we consider the high value of specie at that time), and the great care taken of the improvement and breed of an animal so prolific, are almost certain proofs of their being little known at that period, and nearly demonstrates that cats are not aborigines of these islands, or known to the earliest inhabitants." $†$

When cats are too much pampered they will not eat the mice they kill, and some indeed will not take the trouble to catch them at all. A cat at Dorking, in Surrey, never ate the mice he caught, but used to lay them at the feet of the first person he met.

* Leges Wallica, p. 247, 248. + British Zoology (1768), vol. i. p. 46. 
A Mr. Clarke who resided at East Bergholt, in Suffolk, about the year 1815, had a white tom cat, which would frequently go to an adjoining meadow where there were abundance of rabbits, and bring some of them away, even those which were more than half grown; and, without hurting them, would take them into the house, lay them at the feet of any of the inmates, and retire to the door to prevent the escape of his captives.

The love of cats for the flesh of small birds is frequently manifested by their attacks upon caged canaries, and other favourite songsters ; and also by their climbing trees to procure our wild birds, or their young ones. Mr. Blyth says, that a cat, at the Castle Inn, Tooting, was in the constant habit, whenever the poultry were fed, of crouching herself in the midst of the fowls, whilst they were all collected together round their food; and that by this artifice she frequently contrived to seize some unfortunate sparrow, who, descending for his share of the grain, little suspected his ready foe to be lurking in such a strange hiding-place. The enmity of the cat against birds has been turned to useful account in protecting fruit from their ravages. At the Horticultural Society's Meeting, November 6, 1832, it was stated that Mr. Robert Brook, of Melton Lodge, near Woodbridge, in Suffolk, had four or five cats, each with a collar, and light chain and swivel, about a yard long, with a large iron ring at the end. As soon as the gooseberries, currants, and raspberries began to ripen, a small stake was driven into the ground, or bed, near the plants, leaving about a yard and a half of the stake above ground; the ring was slipped over the head of the stake, and with the cat thus tethered near the fruit, no birds would approach them. Cherry trees and wall-fruit trees were protected in the same manner as they successively ripened. Each cat, by way of a shed, had one of the largest-sized flower-pots laid on its side, within reach of her chain, with a little hay or straw in bad weather, and her food and water were placed near her. In confirmation of the above it may be added, that a wall of vines 
between two hundred and three hundred yards long, in Mr. Kirke's nursery at Brompton, the fruit of which in all previous seasons had been very much injured by birds, was, in 1831, completely protected by a cat having voluntarily posted herself sentry upon it.

Most cats are fond of fish. Gray, in his Ode on the Death of a favourite Cat, asks

"What female heart can gold despise?

What cat's averse to fish?"

Some cats, indeed, will so far overcome their aversion to wet their fur, as to catch fish for themselves.

Dr. Darwin records an anecdote of a cat which was in the constant habit of catching trouts by darting upon them in their own element; and the author of The Menageries (1829, vol. i. p. 208), mentions a cat's seizing an eel out of a pail of water. Indeed several pages might be filled with anecdotes that have been published fully contradicting the old saying, that the cat loves fish but dares not wet her feet.

I have often observed cats capture numbers of flies, blackbeetles, cockchafers, and other insects, and eat them.

Sometimes, but not often or naturally, cats will eat fruits and the stalks of plants. Miss M. L. Beevor has recorded an instance of a cat that delighted in raisins; and a kitten that ate honey-suckles with avidity. Cats are generally fond of the smell of odoriferous plants, such as marum, valerian, and cat-mint (Nepeta Cataria). Ray says, that she not only likes to lie upon, but to eat the full grown and old plants of cat-mint when they are transplanted from the fields into the garden, but those that are raised from seeds she does not touch :-a circumstance which gave rise to the rhyme :-

"If you set it, the cats will eat it:

If you sow it, the cats can't know it."

Mr. Joseph Thomas, the publisher of this work, had a cat which would eat pies, pickles, or any kind of food, except seed-cake.

The drink of the domestic cat is generally milk; but when 
not indulged with this, however, she will lap water, which doubtless is her proper and more natural beverage, if one may so call it. Miss M. L. Beevor mentions a cat which had been taught to sip water from a wine-glass in the most delicate and lady-like manner imaginable, and was fond of performing the feat. I am surprised to find Mr. Rennie stating that it would be difficult to get a cat to " drink beer, wine, or spirits, all of which it greatly dislikes." This assertion is contradicted both by an old proverb, and by actual facts. In the poem called The Old Courtier, published in The Prince de l'Amour (1660), is this line :-

"And beer and ale would make a cat to speak."

Mr. John Clark, a horse-hair weaver, in London, used to make his cat drunk by giving her bread dipped in ale, of which she was very fond; and I have several times seen her in a state of such excessive inebriation, as to tumble about the room and roll down the stairs. Shakespeare thus alludes to its drinking wine :-

Stephano. " He shall taste of my bottle: if he have never drunk wine afore.**** Come on your ways; open your mouth; here is that will give language to you, cat."

(Tempest, Act II. Sc. 2.)

The female goes with young eight weeks, and generally has three litters in a year, each consisting of from four to five kittens. If annoyed, or ill-fed and unable to procure food, she will, sometimes, eat her kittens, or bite off portions of them. I have been told by a person who kept a great number of cats at Laytonstone, and who used to let them find their own victuals, that one of them bit off the tips of the ears of all her kittens just after they were born. Under favourable circumstances, however, the cat nourishes her kittens with great care, and displays much affection for them. A lady presented a kitten to a friend, living at the distance of a mile; and the mother, having discovered her young one, regularly visited it, day after day, for the purpose of suckling it. Hear this, ye illustrious but unnatural bipeds, who confide to a mercenary alien the first duty which a mother owes to her offspring! 
When the kittens are a few weeks old, and full of fun and frolic, mischief and inquisitiveness, nothing can be more entertaining than to watch their sly and playful movements; one minute quizzing and teazing their mother, jumping over her back and making sport with her tail ; then stealing up to a pendant and moving string, a ball of cotton, or a marble, and playing with it in the most gleesome manner; and then again returning to pester their demure parent, and ever and anon bo-peeping at her from behind some of the furniture. These scenes are familiar to all-

"Ye who can smile, to wisdom no disgrace, At the arch meaning of a kitten's face."

(Bloomfield.)

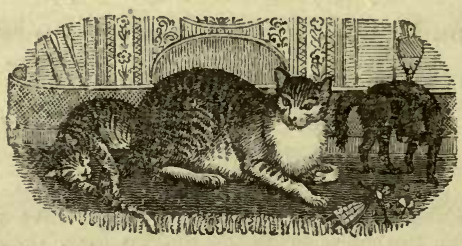

"A cat belonging to Professor Coventry, of Edinburgh, lost its tail by accident when it was young; and subsequently had many litters of kittens, and in every litter there was one or more without a tail."*

A hereditary variety or breed of tailless cats is very abundant in the Isle of Man, especially in that part called the Calf of Man, where specimens may be purchased for a trifle. The Rev. W. B. Clarke, who in 1820 saw several in the huts of the peasantry, amongst the mountains between Ramsay and Peel Town, says that he was informed by a person at Balla Salla, not far from the Calf, that a vessel from Prussia, or some port in the Baltic, was wrecked many years ago on the rocky shore between Castle Rushen and the Calf, and that, on her driving close in to land, two or three cats without tails

* Anderson's Recreations in Agriculture (1790). 
escaped from the bowsprit, and were taken by the wreckers; and that these were the first of the kind ever seen in the island. They are described as being rather taller than the common eat, but not so broad and strong; their colour is generally a lightish grey. They resemble more the hare and rabbit in their movements, than the domestic cat; which, perhaps, may be owing to their hind legs being so much longer than those of the common cat. One having bred with a common cat, had four kittens, two of which had very short thick tails, about two inches long." *

The rabbit-like appearance of these tailless cats may perhaps explain the following miraculous occurrence, which was published in the British Traveller, in May 1823:- "There is in the possession of Mr. Henley, at Chatham, a cat which has littered a kitten "and four rabbits." A writer in the Manx Paper remarking upon this, says, "We are inclined to believe the four rabbits to be nothing more than kittens of the same description as some cats in this island (Man); namely, without tails, and which must originally have been a freak of dame Nature's here, but which she is now showing at Chatham."

Mr. Le Keux says, that " the tailless cat is not uncommon in Cornwall, and that Dr. Leach received one from the Isle of Wight." +

If the latter statement is not a mistake, it may be concluded that Dr. Leach's cat was either wrecked on, or imported to the Isle of Wight, for the breed does not appear to be known there.

* Mag. Nat. Hist. (1832), vol. v. p. 717.

† Illustrations of Natural History (1830), vol. i. p. 356.

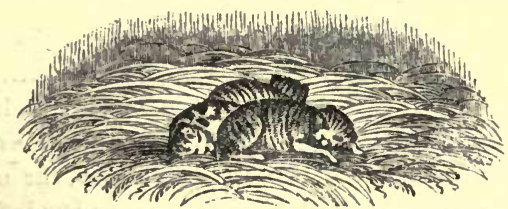




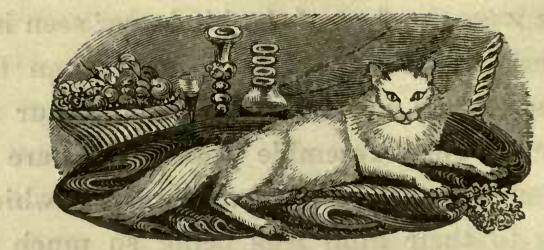

The Angora Cat.-(Felis Angorensis, Linn.)

This beautiful variety is most abundant at Angora, in Asia Minor. It is considerably larger than most of our common cats, and is plentifully clothed with remarkably long and silky hair of a silvery hue, growing most profusely about the neck, where it forms a kind of ruff, and on the tail, which, when elevated above the body, resembles a beautiful plume. The nose and the edges of the lips are of a fine rose colour; the eyes large and brilliant, and generally blue or yellow. When Sonnini was in Egypt, he had an Angora cat with one eye of a fine blue and the other of a light yellow.*

With the physiognomy of goodness, Sonnini's specimen possessed a most amiable disposition. How ill soever any one used her, she never attempted to protrude her claws; sensible also to kindness, she licked the hand that caressed her. On a journey, she reposed tranquilly on the knees of any of the company, for there was no occasion to confine her; and if her master or some other person whom she knew were present, no noise whatever gave her the least alarm. In Sonnini's solitary movements, she chiefly kept by his side; she interrupted him frequently in the midst of his labours or meditations, by

* In the shop of Mr. Handforth, Borough Road, Southwark, I saw in 1835 a white cat whose left eye was of a light green colour, while her right was of a beautiful bright blue. It would seem that sometimes, if not always, this disparity arises from disease or injury. Dr. Smith mentions a soldier, whose eyes he found to differ in colour, one iris being grey, the other light green; and the man ascribed the circumstance to a severe blow inflicted by a rope's end, several months previously, on the light green eye which was originally grey like the other. 
little affecting caresses, and generally followed him in his walks. During his absence, she sought and called for him incessantly, with the utmost inquietude. She recognised his voice at a distance, and seemed on each fresh meeting with him to feel increased satisfaction. Her gait was frank, and her look as gentle as her character.

\section{S E A L S.}

These curious animals, which are probably the mermaids of our superstitious forefathers, have the head generally bearing some resemblance to that of a dog, whose intelligence and soft expressive look they also possess. Some species have the ears very slightly produced and inconspicuous, and others have merely an auditory aperture. Their jaws are furnished with strong teeth, consisting of incisors, canines, and molars, all well adapted for seizing, holding, and crunching the scaly and slippery fish upon which they are required to operate; the tongue is smooth, and slightly notched at the end. The feet are formed for swimming; the front pair are enveloped in the skin of the body as far as the tarsus, and the hinder pair, which are flattened and directed backwards, are enveloped almost to the heel; all the feet have five toes, the anterior ones regularly decreasing in length from the thumb to the little toe, while in the hinder feet the thumb and the last toe are the longest, and the intermediate ones the shortest. The tail is short, and, when the animal is out of the water, is generally concealed by the hind legs pressing close to it. The stomach is of a simple organization, having a short cœcum, but a long and tolerably regular intestinal canal. When they dive, they close their nostrils by a kind of valve; and the large venous sinus in the liver must assist them in diving, by rendering respiration less necessary to the circulation of the blood, which in them is very abundant and very black. 
The specics as yet discovered to frequent or occasionally visit the British shores, are the common seal (Phoca vitulina), the harp seal ( $P$. Gronlandica), the great seal ( $P$. barbata), the grey seal (Halicharus Gryphus), and the walrus (Trichecus Rosmarus).

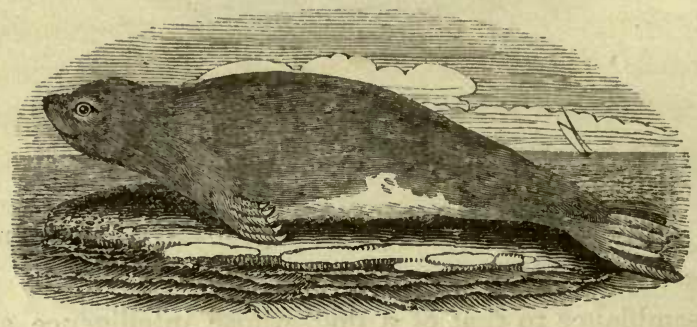

The Common Seal.

(Phoca vitulina, Linn.; P. variegata, Nillson; Calocephalus vitulinus, F. Cuv.)

Sea Calf. Sea Dog.

The common seal abounds on the shores of Newfoundland, the Orkney* and Zetland Isles, and on the northern shores of Scotland. In Ireland, it occurs not unfrequently on the north coast; but it appears to be nearly expelled from the southern half of that country by the more powerful and savage species, called the grey seal (Halicharus Gryphus), much in the same manner as the original English black rat has yielded to the more powerful Asiatic rat, erroneously called the Norway rat.

Its length is usually from three to five feet, including the head, which is about eight inches long. The general colour of its coat is yellowish grey, spotted with brown and black above; but the belly is whitish.

It feeds upon salmon, and various other, if not all, kinds of fish,

* It has been conjectured that the Orkney Islands derive their name from the seal, which in the language of the Northmen is called orc. 
The female is said to bring forth but once in the year, and to have but one or two at a birth, which she suckles and protects with great tenderness and care.

Seals, when taken young, are capable of being completely domesticated; will answer to their name, and follow their master from place to place.

In January, 1819, a gentleman, in the neighbourhood of Burntisland, county of Fife, in Scotland, completely succeeded in taming a seal. Its singularities attracted the curiosity of strangers daily. It appeared to possess all the sagacity of a dog, lived in its master's house, and ate from his hand. In his fishing excursions, this gentleman generally took it with him, when it afforded no small entertainment. If thrown into the water, it would follow for miles the track of the boat; and although thrust back by the oars, it never relinquished its purpose: indeed it struggled so hard to regain its seat, that one would imagine its fondness for its master had entirely overcome the natural predilection for its native element.

In the Regent's Park Zoological Gardens there is, at the present time, a tame seal; which from the grotesque singularity of its movements when on land, and the general intelligence and docility it evinces, proves a source of considerable amusement and interest to the visitors. This animal, which has been a prisoner nearly three years, was captured somewhere on the eastern coast, and brought up the river Orwell; where it fell into the hands of a small innkeeper at Ipswich, who contrived, for the first few weeks, to keep it alive by forcing flour down its throat, as it obstinately refused to take food of its own accord. In a short time, however, it became reconciled to its new condition, and devoured fish most voraciously, eating thirty or forty small flounders in a day. Its favourite mode of taking them was in a tub of salt water, in which it was allowed to bathe. A small straw sty was erected for it in the inn-yard; but it would always lie outside the house door when left to follow its own inclination. Although it followed persons with whom it was familiar like a dog, it was not safe to play 
with it, since it was apt to snap at the hands, even of its owner, but apparently more from a natural propensity than from a vicious disposition. When seized by the tail, and raised from the ground, it was utterly helpless, having apparently not even the power to struggle in that position. A spacious yard, with a pond in the centre, which is replenished every two or three days with salt water, is appropriated to its use in the gardens, and it is supplied with fresh fish every day.

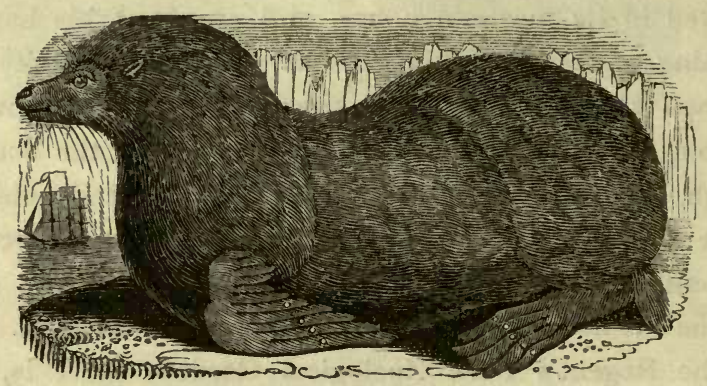

The Ursine Seal.

(Otaries ursina, Peron.; Phoca ursina, Gm.)

Sea Bear.

Ursine seals inhabit the sea, in the neighbourhood of Kamtschatka, and also New Zealand, where they are to be seen lying in thousands along the shore, in distinct families, of from ten to fifty females, each attended by a male, who guards his flock with the assiduity and jealousy of an eastern monarch; and when intruded on by another male, a dreadful conflict ensues, which generally sets the whole colony in a state of tumult. The wounds they give each other are very deep, and resemble cuts from a sabre.

This species is of great size, the male measuring about eight feet in length, and the female generally about six. Their bodies 
are thick, somewhat conical, or tapering towards the tail; their greatest circumference is about the shoulders ; the weight of a male is about eight hundred pounds. The head is round, and the neck very thick; the muzzle projecting considerably, and the forehead rising abruptly over the eyes; the lips are thick, and serrated in the inside; the whiskers are long and white; the eyes are furnished with a fleshy membrane, answering the purpose of an eyelid, with which they are frequently covered; the eyes are large and prominent; the iris black, and the pupil emerald green; the ears are small and sharp pointed; the length of the fore-leg, which is not so much concealed below the skin as in the other seals, is about two feet; the feet are somewhat like the fins of turtles, formed with toes which are covered with a naked skin, and they have no nails; the hindlegs are twenty-two inches in length, and are capable of being brought forward, so that by bending the neck they are enabled to scratch the head with them; they have five toes, separated by a web; the tail is short, being only two inches long. The general colour of the animal is black; the hairs of old specimens are tipped with grey; the hair is long and rough, and beneath it is of a soft downy texture, of a bay colour; the hair on the neck of the male is erect, somewhat resembling a mane; the females are generally ash-coloured.

These animals, instead of flying from man, will advance towards him in a body. When a company of travellers meet them on the shore, they are forced to fight their way through them; and if the seals are pelted with stones, they gnaw the latter with their teeth, but afterwards attack the men with redoubled fury, rending the air with the most tremendous growling. They seem to be well aware of the effect of united resistance and attack, and also of the utility of keeping in masses and ranks; for should any one of them attempt to retreat, those in his rear fall upon him, and compel him to keep in the ranks, or kill him. Sometimes it happens, that when one seal attempts to stop another, who is retreating, they all begin to suspect each other of being inclined to fly, and, 
in that case, the contest becomes universal. When two are fighting with one, the rest come to the assistance of the weaker side. Whilst they are thus fighting upon the land, others that are in the water raise their heads, and look on for awhile, till they also become enraged, swim to shore, and join in the combat. When two have fought together for some time and got out of breath, they lay themselves down side by side, lick each other, and rest themselves, after which they rise again to continue the contest. As long as they are nearly a match for each other in strength, they strike only with their fore-feet; but as soon as one of them gains the superiority, he seizes the other with his teeth, and throws him on the ground.

These animals grow very fat, and are then exceedingly indolent, sometimes even scarcely moving from the same spot for two or three months. This is from June to September, during which time they breed, the female bringing forth one at a birth, and rarely two. She is extremely attached to her young, and defends it with great obstinacy. Professor Steller says, that the cubs, when little more than a day old, become playful, and exercise themselves in wrestling with each other. In the month of September they quit their breeding stations, and return to the Asiatic and American shores. They swim with great swiftness, frequently at the rate of eight miles an hour.

\section{The Walrus.-(Trichecus Rosmarus, Linn.)}

\section{Morse. Sea-Horse. Sea-cow. Horse-whale.*}

Walruses abound most in the Northern regions, where herds of them assemble on the rocks or ice-fields.

Hector Boëce, in his Hystory and Cronoklis of Scotland (1541),

* Voyagers not very learned in zoology have sometimes mistaken the walrus for the hippopotamus. 


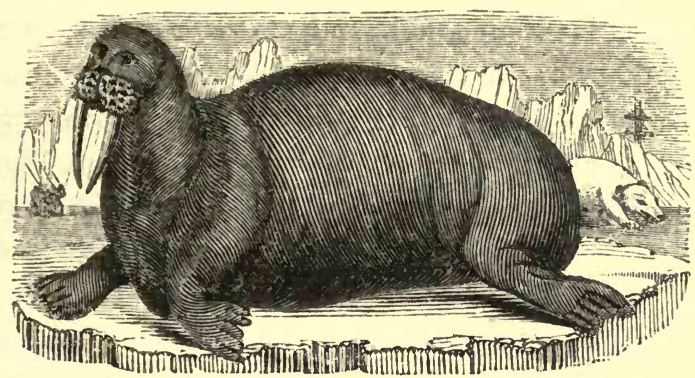

mentions its occurrence on the coast of Scotland. Since his time, two instances only have been recorded of its appearance on the British coasts. Dr. Fleming says, that in December 181\%, a solitary individual was shot while lying on a small rock at the Sound of Stockness, on the east coast of Harris, which was upwards of ten feet in length, and the tusks measured eight inches and a half in length.* The last instance is that of one which was killed in Orkney, in June 1825.

The walrus resembles the true seals in its limbs, the general form of its body, stomach, and intestines, but differs widely from them in the head and teeth. The body, which has a very unwieldy appearance, and is very stout in comparison with the length, possesses a very thick and smooth skin of a blackish colour; the neck is very short; the head disproportionately small; the eyes are small and bright; the auditory apertures are placed far back in the head; the flippers or hind feet are extremely broad, and furnished with stiffish brown hairs; and the tail is very short.

The canine teeth, which are two in number, and situated one on each side in the upper jaw only, are directed downwards, and serve as a pair of powerful weapons of defence, being very strong, and usually from eight to fourteen inches in length,

* History of British Animals (1828). 
though in aged males they are sometimes much larger. Professor Bell has a pair of these teeth, or tusks, which were brought from Newfoundland, and are as much as six inches and three quarters in circumference. The extreme shortness and bluntness of the grinding teeth show that they are particularly adapted for acting upon vegetable food.

Sir Everard Home, in his account of the walrus, says, "I am informed by my friend Mr. Fisher, who was astronomer during two polar voyages, that he was present when the contents of the stomach of a walrus were examined: they consisted entirely of the long branches of Fucus digitatus, a sea-weed very abundant in the Arctic Seas, especially in those parts where the walrus is met with in the greatest numbers."*

The author of $A$ Winter in Lapland says, "The food of the walrus consists of mollusks and crustaceans. Fish probably does not form any part of it, and, judging from the structure of their mouth, it is not likely that they prey upon seals, as has been asserted. The principal use of their tusks is probably to enable them to detach their food from the ground or rocks. They also employ them for the purpose of securing themselves to the rocks while they sleep; and I am informed that more than one instance has occurred, in the Magereösund, of the tide leaving them suspended by their tusks, so that they were unable to extricate themselves."

The walrus, when attacked in the water, is not very easily killed, and it will sometimes meet force with force. Instances have been known of its staving and sinking a boat with its tusks.

An arctic voyager says, "In latitude $72^{\circ} 19^{\prime}$, the captain, perceiving a walrus lying on an elevated piece of ice at some distance from the ship, immediately ordered a boat to be lowered. Myself and another joined the captain in pursuit of the monster. When we drew near to its station, it raised its head and displayed one formidable tusk, projecting downwards from its upper jaw towards its breast, whilst

* Philosophical Transactions (1824). 
part of another, broken by some accident or encounter, offered a less menacing weapon to our view. The whole animal was about the size of a large bullock, and lay upon the ice like a huge mass of animated matter, which seemed to possess no means of locomotion. Its bulky body, small head, and large and strong whiskers, gave it a grotesque appearance, not lessened by an approximation, in its square short countenance, to a caricature of the human face; while the half stolid, half ferocious stare, with which it regarded us, contributed to render it one of the strangest beings I had ever beheld. While we were rapidly advancing towards it, the animal seemed in doubt whether to take our visit in enmity or friendship, and continued to gaze at us, as it lay (standing not being one of its faculties) at its full height upon a block of ice, about eight feet above the surface of the sea. It must have climbed this elevation by crawling up one side of the frozen mass, which was shelving and easy of access, by means of its tusks and flippers ; but, whatever was its way of mounting the acclivity, it quickly showed us how it managed to descend; for, upon a couple of bullets passing through its neck, it gave itself a heave backward, rolled over head and heels down the slope of the hummock, and was launched violently into the water by the precipitate rush of its heavy body. No sooner did it find itself in the water, than it prepared to dive; but the stern of the boat being on its back at the moment it was about to disappear, the captain, exerting all his force after striking the weapon with a sudden plunge against its tough hide, drove the harpoon through its skin, and allowed it to make its vain attempts at escape. It then dived, and took out several fathoms of line like a whale, but it soon rose to the surface, rearing its head and shoulders above the waves, with the most threatening aspect of deadly warfare. Evidently eager for revenge, it began to approach us, yet in a state of hurry and confusion which impressed us with a belief that the balls had inflicted desperate, if not immediately mortal wounds. Nevertheless it displayed determination enough to enter into close conflict, puffing and 
snorting, and exhibiting a savage though bewildered look. But before it had made much progress, the guns were reloaded, and another bullet struck it on the head, which sent it down immediately; however, it quickly appeared again, raising itself high above the water, and looking furiously around for its antagonists. When it perceived our position, it resumed its endeavours to attack us; but during its approach it stopped short, infirm of purpose, probably exhausted with loss of blood, or growing giddy from the shock of the last ball, and allowed us time to discharge a musket once more and with fatal effect; its head dropped suddenly upon the water, and we pulled up, and took the corpse in tow. Having hoisted it on board by means of pretty strong tackle and several hands, it was flayed, yielding a hide of extraordinary thickness, lined with blubber, and scantily covered externally with short reddish brown hair, the greatest part of its skin appearing to have been denuded of its pilosity by eruptive blotches. It was considerably more bulky in proportion to its length, its chest and back more elevated, its fore-flippers thicker and more rounded, and its hind-quarters less tapering to the tail. Altogether, it impressed the mind with a strong idea of a formidable monster, in spite of its relatively diminutive head; for its fearful tusks and thick-set projecting whiskers, gave its visage a most truculent expression; and with its grotesquely fashioned ponderous carcase, provided with finned feet of strange formation, it seemed to be one of the fabulous conceptions of mythology. The walrus is said to roar or bellow loudly, but our victim made no outcry; for the half sneezing, half snorting sounds it uttered I conceive to have been the consequence of its hasty dive, which had apparently prevented its inhaling sufficient air, and occasioned it to admit some water down its windpipe. Still, the immense size of the larynx of its windpipe, which was dissected and brought to England, seems to indicate vast oral powers; but I am at a loss to conjecture why it should be provided with this unusual capability of 'blaring,' or with the exceedingly strong whiskers that arm its muzzle, and must 
really be of consequence to the walrus, since their roots are imbedded in two thick cushions of tough blubbery substance, so large as to give a marked character to the countenance, and evidently pointing out the growth and nourishment of these whiskers, as a matter of some consideration in the eye of nature."*

"Mr. Colquhoun, who lately returned from an expedition to Spitzbergen and the Finmark coasts, found walruses lying in herds of many hundreds each, on the shores of Hope and Cherie Islands, and took a great quantity of them. The most favourable time for attacking them is when the tide is out, and they are reposing on the rocks. In this case, if the javelors be very alert, and fortunate enough to kill the lower rank of them, which lies nearest the shore, before the hindmost can pass, they are able to secure the whole, as the walrus when on shore is so unwieldy a creature, that it cannot get over the obstacles thrown in its way by the dead bodies of its companions, and falls in this manner a prey to the lance of the seaman. It does not, however, die tamely ; and, perhaps, no animals offer a more determined resistance than the walrus, when attacked on an element where it is incapable of exerting its prodigious strength, striking furiously at its enemy, and continually turning round to assist some companion in distress.

"Directly an alarm of the approach of an enemy is given, the whole herd makes for the sea. When they reach the water, they tumble in as expeditiously as possible; but they are often so numerous, and their size so great, that a short time elapses before they can escape, from want of space; and then those who happen to be in the rear, being pressed by those behind them, and finding their way blocked up by their companions in front, attempt by means of their tusks, to force their way through the crowd; and several that have been captured at the time, have exhibited numerous wounds inflicted on their hind-quarters by their impatient comrades." $\dagger$

* Abridged from Tales of a Voyager in the Arctic Ocean (Second Series). 1829. + Abridged from $A$ Winter in Lapland. 
The female, who is provided with four ventral teats, brings forth in the winter, either on the shore or on the ice, and has generally but one young one, which, when just born, is about the size of a pig of a year old. Captain Cook, who met with large herds of walruses off the north coast of America, says, " the mother will defend her young to the very last, and at the expense of her own life, whether in the water or upon the ice. Nor will the young one quit the dam, though she be dead; so that, if one be killed, the other is certain prey. The dam, when in the water, holds her young one between her arms or fore feet."

Buffon says, that Evrard Worst saw in England a walrus three months old, which would follow its master to be fed, though its movement was slow and laborious. It did not seem to suffer from the heat of the country, for it had the appearance of robust health.

A vast number of these animals are annually killed for the sake of their hides, tusks, and the oil obtainable from their fat. When the animal is killed it is skinned, and the hide, which is of extraordinary thickness, is then cut into stripes, two or three inches broad. These strips are imported to America, and, after undergoing the usual process, form superior carriage traces and braces. The hide is also used occasionally as matting to protect the masts of vessels, and to make fire-buckets. The smaller pieces of the hide are imported into England to supply the glue manufactories. The coat of fat which lies under the hide is melted into oil, of which each walrus produces, on an average, nearly two barrels. The tusks, the ivory of which is whiter, harder, and therefore more valuable than that of the elephant, weigh from ten to twelve pounds each, and are much used by dentists in making artificial teeth. 


\section{ORDER-MARSUPIALIA.}

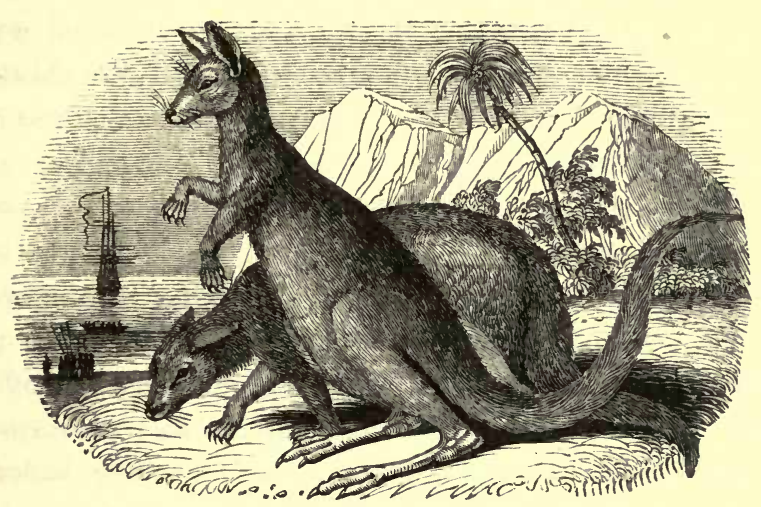

The Greater Kangaroo.

(Macropus major, Shaw ; Didelphis gigantea, Schreb.; Halmaturus giganteus, Illig. ; Kangarus labiatus, Geoff.)

The consideration of the extraordinary structure and economy of the marsupial animals, with reference to the locality where they are found, is a subject so highly interesting, not merely to the zoologist and geologist, but to the general student, that I need not apologize for prefacing their history with the following excellent remarks by $\mathrm{Mr}$. Ogilby :-

"In contemplating the mammals of New Holland generally, the first circumstance that particularly attracts our attention is that, with a very exceptions, they all appear to belong to the same natural group, and to possess organs, and execute functions, different from those of the Old World. This is a most important as well as a curious fact, and one from which 
we may deduce some valuable conclusions, with respect to the origin and distribution of animals. If we were told, for example, that a continent had been discovered, insulated from all other parts of the habitable globe, and differing in its geographical features and natural productions, from all that experience had made familiar to us in the Old World; - that its plants were peculiar, and its animals of an anomalous race; that, excepting the dog, it had not a single species, and scarcely even a genus, of mammals, in common with other countries; in short, if we were told that its mammals were formed upon a distinct model, endowed with peculiar organs and modifications, and were absolutely confined within the circle of its shores, what would be our natural reflection? Should we not be inclined to ascribe the formation of such an insulated continent to a distinct plan, perhaps to a different period of creation? Or rather, should we not consider its animal productions as affording evidence of a separate and peculiar design in their formation ? One conclusion, at least, forces itself upon our belief with irresistible certainty; namely, that, at whatever period these animals were first called into existence, they must, necessarily, have been created upon the insulated continent which they now inhabit. Nor do I think it at all inconsistent with the idea which we entertain of the Creator, or derogatory either to his glory or power, to suppose that their existence may be the result of a subsequent act of creation; - nay, that new species, like new individuals, may be daily springing into being, to supply the place of those which daily perish, and of which the remains are so abundantly strewed beneath the surface of the earth. Whatever degree of probability may attach to these speculations, it is a fact no less certain than curious, that the continent of Australia, as far, at least, as regards the mammals hitherto discovered upon its shores, is precisely placed in the circumstances here described. With the exception of the American opossums (Didelphis), and a few species of phalangers (Phalangista), scattered over that long chain of islands which forms an almost uninterrupted com- 
munication between the northern shores of Australia and the continent of India, these animals possess no organic type among the mammals of the Old World; and those, on the other hand, have but few representatives within the boundaries of New Holland and its dependencies. The little which we know of its geology warrants us in concluding that Australia, like other parts of our globe, has had its changes and revolutions; the osseous caves and breccia of Wellington Valley, contain fragments of the bones of mammals in great abundance and perfection; and these remains, sufficiently important in other respects, acquaint us with the singular and interesting fact, that, even at that early period, before the operation of those causes which swept them off from the surface of the earth, the mammals of Australia were, generally speaking, of the marsupial order, of which, I believe, only a single undoubted species has been hitherto discovered among fossil remains in the Old World.

"Another remarkable circumstance, connected with this singular tribe of animals, is the very limited number of species which have been hitherto discovered, considering the vast extent of the continent over which they are dispersed, and the consequent variety of soil and climate to which they are exposed. The genera to which they belong are also comparatively few in number; all the marsupials hitherto discovered upon the continent of Australia and its neighbouring isles, present only eleven really distinct and well defined types of organic structure, or genera; being on an average not quite one genus to every three known species. This extreme paucity both in the number and variety of its mammals, supposing it to be really the case, becomes the more surprising when we consider that the continent of Australia alone, without reckoning the large islands of New Guinea, New Zealand, and Van Dieman's Land, and the numerous smaller groups, its natural dependencies, embraces an extent of nearly thirty degrees of latitude by forty degrees of longitude, and ranges throughout an almost infinite variety of climate, from the parched and barren sands which border 
the Gulf of Carpentaria, to the humid soil of Tasmania. When we reflect, however, that we are altogether ignorant of the zoology of the northern and western coasts, and that new species are daily added, even from the limited extent of our principal settlement, we have every reason to conclude that the zoological treasures of Australia yet remain to be explored, and that the few species already known only indicate the value of those which may be hereafter discovered.

"But if the number of genera and species be comparatively limited among the mammals of New Holland, the number of individuals of the same species appears to be still more so. This is a well-ascertained fact, and arises from the operation of circumstances which are easily explained and understood; some depending upon the nature of the country, and others upon the persecution from the natives who are chiefly supported by the produce of the chase, and who indulge in the wanton and thoughtless practice of periodically firing the long grass, which, burning with the most astonishing rapidity, destroys the nocturnal animals in their retreats, before they have time to escape from its ravages. But the most potent and influential cause of the scarcity of mammals in New Holland, arises from their physical constitution; for marsupials seldom produce more than two young one sat a birth, and that, in all probability, not oftener than once or twice in the course of the year, since their growth is comparatively slow, and the progressive development of their organs unusually tardy, as among the inferior animals. All these causes tend powerfully to check the multiplication and diffusion of Australian mammals; and when we add the reflection, that many individuals must necessarily perish before arriving at maturity, or are employing their productive powers in the increase of the species, we must cease to be surprised that their numbers are so limited, under circumstances which, at the first sight, seem so favourable to their multiplication."

Having introduced the preceding facts and reflections, in the hope that they may not only show the great interest which 
in every light attaches to the extraordinary animals we have selected as examples of this Order, but also that they may assist those speculations and reply to those inquiries which are almost certain to arise when these anomalous creatures are considered with reference to New Holland-a country whose natural productions, including its plants as well as its animals, are mostly so peculiar, that more than one writer has been induced to think it was formerly a distinct planet from our earth-I shall now proceed with the history of that species which is the largest, and best known.

The Greater Kangaroo (Macropus major, Shaw), in its wild state, is said chiefly to inhabit the vicinity of woods and thickets, and to live in small herds, perhaps single families, which submit to the guidance of the older males. It is about the size of a large sheep. The upper parts of the body are brownish grey, the lower parts somewhat lighter; the front of the throat greyish white; the end of the muzzle, the back of the ear, the feet, and the upper surface of the tail, nearly black. The ears are rather large and in constant motion, like those of a hare or rabbit; the upper jaw is furnished with six short incisor teeth; the lower jaw with only two long ones, which are closely applied to each other, directed forwards, and are capable of being separated to some distance apart, at the will of the animal. Both jaws have five molar teeth on each side, and removed from the incisors by a considerable vacant space. There are no canine teeth in either jaw. The upper lip is divided by that kind of deep fissure which is observable in nearly all rodent animals, and of which the hare presents an example so familiar, that the term hare-lip is usually applied to designate a mal-formed bisected lip in the human subject. The head itself and the anterior part of the body are so small as to appear quite disproportioned to the robust posterior half of the body, and the shortness and weakness of the fore-legs present a striking contrast to the extreme length and muscular strength of the hind pair. The fore-feet, or rather paws, for they are used as hands and never employed in walking, have 
five toes or fingers, each furnished with a moderately strong and curved claw; while the hinder feet have only four toes, the two middle ones of which are united together and seem as one, furnished with two short and feeble claws; the third toe is long, very strong, and terminated by a large and powerful hoof-like claw; and the fourth toe, the outermost of all is similar to the third in its character, but smaller. Whether assuming an erect position, or crouching forwards upon all fours, the whole extent of the soles of the long posterior feet is applied to the surface of the ground. The tail, which is very long and tapering, is so exceedingly thick at the upper portion, that when the animal assumes an erect or nearly erect position, on the hind legs, its body is supported as it were on a tripod by this powerful appendage acting as a third leg; and even during progression the tail is converted into a locomotive organ, nearly as serviceable as the extremities themselves. When alarmed and flying from danger, this powerful member is repeatedly compressed and beaten against the ground, so that, aided also by the long and elastic hind-legs, the animal is enabled to bound along the earth with astonishing rapidity and agility, often taking a succession of leaps of from twenty to thirty feet in length, and six or eight in height. Except when alarmed or grazing, it always stands upright.

These animals are entirely herbivorous, feeding principally upon grass and roots.* Mr. Martin says, that they regurgigate, or chew the cud, occasionally, but not habitually. $\dagger$

The colonists of New South Wales hunt them for their flesh, which is savoury, nutritious, and easily digested. The dogs which are employed in this chace sometimes receive dangerous wounds, not only from the blows inflicted by the powerful tail, which is the kangaroos' usual weapon of defence, but also from the claws of the hind feet, with which they can severely

* A writer in one of the early volumes of the Penny Magazine tells us, however, that he has a tame kangaroo which "laps tea out of a saucer, and picks a bone like a monkey."

+ Mag. Nat. Hist. (New Series, 1838), vol. ii. p. 323. 
lacerate the bodies of their assailants. When, however, they are not annoyed, and compelled to exercise such powers in the protection of their lives, they are not only perfectly harmless but timid.

Numerous specimens have been kept in the public and private parks and menageries of England at various times, and they became almost naturalized, appearing but little affected by the change of climate. When kept in this state they are fed upon green vegetables, hay, oats, bran, and bread, and are extremely tame, good tempered, and not in the least mischievous. Mr. Bennett makes the curious observation, that when confined in a small enclosure they generally traverse its circuit, seldom crossing it, or passing in any other direction, except for the purpose of procuring their food. A female, which had been kept, and suffered to roam at large in the Royal Park at Windsor, was placed in the Tower Menagerie, where it once produced young. If kept in a park or paddock, they breed very readily.

The Zoological Society kept several of these animals at their farm, at Kingston, for the purpose of breeding; and it appears from the official returns, that since the discontinuance of that establishment, seven kangaroos were bred at the Gardens, Regent's Park, between June 1, 1830, \& December 31, $183 \%$.

Some years ago there was a remarkably fine pair of kangaroos in Exeter 'Change. The male would sometimes wrestle with the keeper for the space of ten or fifteen minutes, during which time he evinced the utmost intrepidity and sagacity; turning in every direction to face his opponent, carefully watching an opportunity to close with him, and occasionally grasping him with his fore paws, while the right hind leg was employed in kicking him upon the thigh and hip. The struggle was sometimes obstinate, and the keeper acknowledged that the animal was almost superior in point of strength.

There are some extraordinary physiological facts connected with the development of the young kangaroo; and which, as they have not hitherto appeared in any general history of the 
animal, I trust the reader will pardon me for introducing the following technical details. "In a paper read before the Royal Society in January, 1834, Professor Owen described the fotus and membranes of a specimen of the greater kangaroo, at apparently the middle period of uterine gestation, which in this animal lasts thirty-eight days. The membranes consisted of an amnios; a very large vitelline sac, rendered highly vascular by ramifications of omphalo-mesenteric vessels, and a thin unvascular chorion. There was no placenta, ${ }^{*}$ nor any adhesion between the exterior membrane of the fotus and the internal surface of the mother, by the opposition and interlacement of villi, or vessels, as in those mammals in which the placenta is replaced by a uniform villous and vascular chorion; the condition of the foetus was, in short, such as obtains in the viper and other ovo-viviparous reptiles; save that at the period of development at which the foetus in question had arrived, there was no trace of the existence of an allantois. To ascertain whether an allantois was developed at a subsequent period of uterine gestation, he dissected very young mammary foetuses of different marsupial animals, as the kangaroo, Phalangista, and Petaurus; and finding in them the remains of a urachus, and urnbilical vessels, he concluded that an allantois was developed at a more advanced stage of the development of the embryo. He observed, that as the growth of the foetus advanced, the circulating fluids became necessarily more charged with decomposed particles of the organized substance; and that although the extended surface of minutely subdivided bloodvessels, afforded by the vitelline sac, might serve both for respiration and nutrition at the earliest stages of development, yet that, at a late period, an accessory apparatus to that end appeared to be necessary, as the embryo acquired additional bulk

* In the Universal Magazine of August, 1808, I find it stated that Mr. Home, on dissecting a trombac (Didelphis _-) , found that it had two uteri; and that Mr. Bell, a surgeon of New Holland, dissected one in a pregnant state, and discovered in the uteri a gelatinous substance, conveyed in two tubes, instead of a placenta.-J. H. F. 
and parts. In birds and reptiles, the allantois plays a primary part in the respiration of the foetus. In the placental mammals, its office, as a temporary respiratory organ, is secondary, but it is essential as a means of transference of the hypogastric or umbilical vessels, to the exterior enveloping membrane, or chorion; it, therefore, pre-exists to the placenta, and without it the placenta could not be formed. The existence of a placenta necessarily, therefore, infers the pre-existence of an allantois : but the reverse of the proposition does not, therefore, hold good. In birds and scaled reptiles, the allantois itself performs the functions of the placenta, or vascular chorion; but in the kangaroo, and, perhaps, other marsupials, the allantois, when developed, does not serve as a medium for the organization of the chorion, but remains, as in the oviparous vertebrata, an independent vascular bag or cœcum."*

The skin and its appendages beneath the lower part of the female's belly, is folded or doubled in such a manner as to form an open pouch or bag, in which the young ones are contained from a very early period, in which the process of suckling takes place, and to which, even for some time after they have acquired sufficient size and strength to leave it, the little ones continue to fly for safety and for succour.

The greater kangaroo, though the largest of the marsupials, produces only a single offspring at a birth, after a period of gestation extending to thirty-eight days. The young, as observed by Professor Owen, on the day of its birth, does not exceed one inch two lines from the nose to the end of the tail; its eyes are closed, and its integuments are of the colour and semi-trans. parency of an earth-worm. Very justly has Mr. Ogilby declared the most singular and important of the physical phenomena, connected with the natural economy of marsupial animals, to be this premature production of the young, brought forth in a scarcely organized form, containing, as it were, the mere germ of the future animal, before its senses are perfected, or its members developed. As yet, however, we have no certain * Abridged from Mag. Nat. Hist. (New Series), vol. i. p. 481. 
knowledge either of the manner in which the young animal is deposited in the mother's abdominal pouch, how it becomes attached to the nipple inside, or of the nature and circumstances of its subsequent development. In this recess, and in all probability without the exercise of any volition on its own part,* the fotus is attached to the nipple of its mother by means of a scarcely formed aperture, which collapses closely round it, and represents the position, as it already executes the functions, of the future mouth. Here it continues to cling and imbibe nourishment, like a plant engrafted on a strange stem; till the gradual development of its members, and the more complete organization of its parts, allow it to drop from the nipple, and become an independent being. At this instant it is precisely on a par, in point of organic development, with the young of ordinary mammals when first brought forth; that is to say, though a separate being, and possessed of independent volition, it is, nevertheless, incapable of providing for its own wants, but depends for education and nourishment upon the care and assiduity of its parent. Accordingly, it continues, for a considerable time, to occupy the abdominal pouch of its mother, and to be supported by her milk; occasionally coming out as it acquires size and strength; and it is only when its increasing growth renders that retreat too small for its reception, that it finally abandons it.

The flesh of the kangaroo is eaten and highly esteemed by the natives and colonists. Mr. George Bennett observed that many of the women of the Bugong Mountain, in the Tumah country, wore the front teeth of the kangaroo attached to their hair, and highly prized them as ornaments; and the men use the incisor teeth to carve devices on their shields. Kangaroo hides are imported into Britain, and the boots made of them, being remarkable for their neatness and elasticity, are much worn by our men of fashion.

* Mr. Martin says, "At the moment of its birth it is placed by the mother in her pouch; conducted to the nipple, to which it firmly adheres by the mouth, and continues attached until developed to a considerable size." A Natural History of Quadrupeds (1840), vol.i. p. 176. 


\section{O P O S S U M.}

The opossums (Didelphis), a genus peculiar to America, have been the longest known of all the marsupial animals, of which they are the only species existing beyond the pale of New Holland, and the neighbouring Archipelagoes.* Mr. Bennett observes of them, that " they seem to fill in the New World, to a certain extent, the same station with the civets of the Old; for no species of this latter family has yet been discovered in the Western Hemisphere. Like them they secrete a strongly odoriferous fluid, pass the day in a state approaching to torpidity, prowl abroad during the night, and prey upon birds and the smaller mammals, frequently making the poultry-yard the scene of their devastations, and sucking the blood of their victim before gorging themselves upon its flesh. In the absence of more noble game, they make prey even of reptiles and insects; and fruits and other vegetal substances afford a common addition to their varied diet. $\uparrow$ But, unlike the civets, they live almost entirely upon the trees, the peculiar conformation of their hinder hands, and the prehensile character of their naked tail, rendering them most admirable climbers. These tails are also of essential service in another point of view: the little ones, when frightened, leaping upon their mother's back, twisting their tails round hers, and in this singular fashion escaping, with her assistance, from the threatened danger.

* What have been called the opossums of New Holland and Van Dieman's Land, belong to other genera, as Chironectes, Thylacinus, Phascogale, Dasyurus, \&c.

+ Mr. Ogilby reverses the case; for he states " that it is only when wild fruits fail in the woods that they betake themselves to animal diet." (Mag. Nat. Hist. (New Series, 1839), vol. iii. p. 340). Again, he says, they "feed indifferently upon vegetal and animal substances, but prefer the former." (Ibid. p. 342.) Who shall decide when doctors disagree? 
In the form of their bodies they also closely resemble the civets : their head is long and pointed; the line of their profile nearly straight; their ears large and naked; their eyes small but expressive; their mouth deeply cut, and with a wide gape; and their tongues roughened with horny papillæ. Their legs are rather short: on the fore-feet are five toes, all of them terminating in strong sharp curved claws, which correspond exactly with those of the anterior extremities; the hinder-feet have the thumb separated from the rest, distinctly opposable as in the monkeys, and entirely destitute of nail or claw.

Turning to their dentition, a point which must always be regarded of the highest importance, we find the forms of the teeth so modified in the opossums as to effect a considerable diminution of the carnivorous character; while their number, surpassing that of any other mammal, also contributes to the same end. They consist of ten incisors in the upper jaw and of eight in the lower; of two canines both above and below, and of seven cheek teeth on each side of either jaw : making, in the whole, when the dentition is perfect, no less than fifty teeth. The two middle incisors, of the upper jaw more particularly, are separated from the rest by a slight vacancy, and are consequently more prominent; they are somewhat longer. The canine teeth are strong, compressed, and incurved, the upper being considerably larger than the lower. Of the cheek-teeth, the three anterior in each jaw are false molars, each forming a simple compressed conical point; the remainder are true molars, surmounted, as in most of the insertivorous groups, by sharp-pointed tubercles, but closely approximating in their outline and disposition to the lacerators and tubercular teeth found in the civets and neighbouring genera." 


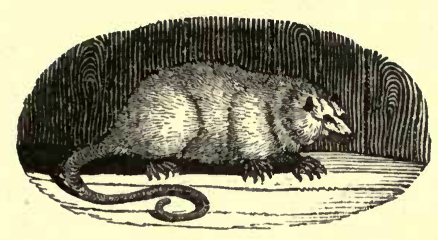

The Virginian Opossum.-(Didelphis Virginiana, Cuv.)

This species inhabits all America, but is most abundant in the north of Mexico, and throughout nearly the whole of the United States.

It is one of the largest of the group, being as large as a domestic cat of the average size. The longer, and therefore more conspicuous, hairs of the body are of a pure white colour; while the shorter hairs, observable wherever the others are ruffled or spread apart, are like fibres of fine woolly down, each of which is white at the base and brownish at the tips. Owing to this mixture of colour the coat of the animal generally appears to be dull white. The hair on the head, neck, and under parts of the body, is short and close; on the upper portion of the tail the hair is long and profuse, but the greater part of its length is only scantily supplied with short bristles, growing from between the small whitish scales, which protect it; the whiskers are long, partly white and partly reddish; the end of the nose is of a flesh-colour, tinged with yellow; each eye is surrounded by a brownish circle; the ears are generally black at the base and yellowish at the tips; the second false molar tooth is, according to M. A. Valenciennes, much higher than those next to it, and differs from them;* the legs are

* This writer observes, that in the Didelphis murina, " the false molars are of the same height, and are equally pressed one against an other; they are, like nearly all the false molars of the true Carnaria, triangular, and have on each side a small supplementary tubercle. The posterior molars have two points, 
of a deep chesnut brown. Beneath the belly of the adult female is a deep and perfect pouch, wherein the mammæ, or teats, are situated.

The Virginian opossum is a fetid animal, of nocturnal habits and slow movements. It lives chiefly in trees, where it feeds upon birds, insects, and fruits. It often, however, steals into villages and farm-yards, during night, to make a supper of poultry and eggs.

Although this species, from its abundance, has been most frequently selected, in the investigations respecting the breeding and gestation of marsupial animals, yet there still remain some points in this part of its strange and eventful history, which it is desirable should be ascertained. Dr. B. S. Barton, an American physician, says, the term of uterine gestation is from twenty-one to twenty-six days. Cuvier says, the female sometimes produces sixteen young ones; but Bennett says, she has generally about twelve. Whatever may be the number, the young, when born, scarcely weigh more than a grain each, are almost shapeless gelatinous masses, without traces of eyes or ears, and are found at first inseparably attached to the teats within the pouch ;* as they increase in size, the teats of the mother become proportionally enlarged, and are prolonged into their stomachs; about the fiftieth day, when they have attained about the size of mice, they open their eyes, and all their parts being completely formed, they abandon the teats, to which they thenceforward have only occasional recourse, often quitting the pouch itself, but still flying to it for shelter on the succeeded by a small 'talon' upon the outer edge, and three conical and pointed tubercles upon the inner edge." (M. A. Valenciennes, in the Comptes Rendus, Sept. 1838, p. 572.)

* Cuvier, in the second edition of his Règne Animal (1828), asserts, that the young, " although blind, and nearly shapeless, find the teats by instinct;" but I apprehend that here, as on too many occasions, the word instinct has been used as a convenient cloak for ignorance. At any rate, Mr. Bennett, writing in 1831, when one might expect more to have been ascertained on everything respecting marsupial animals, says, " the manner in which the young are deposited in the pouch is a secret that still remains to be unravelled." 
slightest alarm; and they finally abandon this asylum for the blind and helpless, when they are thoroughly capable of seeing their own way through the world, and can trust to their own powers of self-defence.

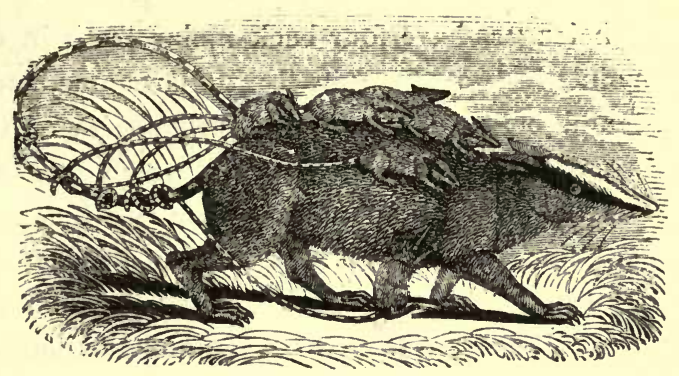

The Cayopollin, or Mexican Opossum.

(Didelphis cayopollin, Linn.)

This is the only species of opossum, with the exception of the preceding species, that inhabits North America.

It is about the size of our common brown rat; its general colour is greyish fawn; its snout is pointed; the eyes are situated in a longitudinal brown stripe, and there is another similar stripe down the forehead; the tail is long, variegated with black and white, and the upper third portion of it is furnished with hairs.

The female of this species, like some others of the present genus, has no pouch, but merely the rudiment of one in a fold of the skin on each side of the abdomen. She usually carries her young on her back, their long tails being entwined around her own in the curious manner above represented. 


\section{P H A L A N G E R S.}

The true phalangers have four back molar teeth in each jaw, with four points in two rows; in front a large one, conical and compressed, and between it and the canine teeth of the upper jaw are two small and pointed ones, to which the three very small lower canine teeth correspond. The two toes nearest to the thumb are united by the skin as far as the last phalanx; and it was from this circumstance that Buffon first bestowed the name of Phalanger on the two individuals he had observed. The skin of the flank is un-extended; and the tail is always prehensible, and in some species a considerable portion of it is scaly.

These animals, of which there are several species, live on trees in the Moluccas, on which they seek insects and fruit. At the sight of a man they suspend themselves by their tails; and if he gaze at them steadily for some time, he causes them to fall through lassitude. Though they diffuse a fetid odour, their flesh is eaten.

\section{The Surinam Phalanger.-(Phalangista - ?)}

\section{Surinam Opossum. Surinam Rat.}

The species here figured is said to inhabit Surinam. It is somewhat larger than a rat; its fur is of a reddish colour, variegated with light ash and yellow; the belly is yellowish white; the ears are short and hairy; the nose is thick; the first and second toes of the hind feet are closely united; the claws are large; the tail is long, very robust and hairy at the upper portion, or root, and naked at the end. 


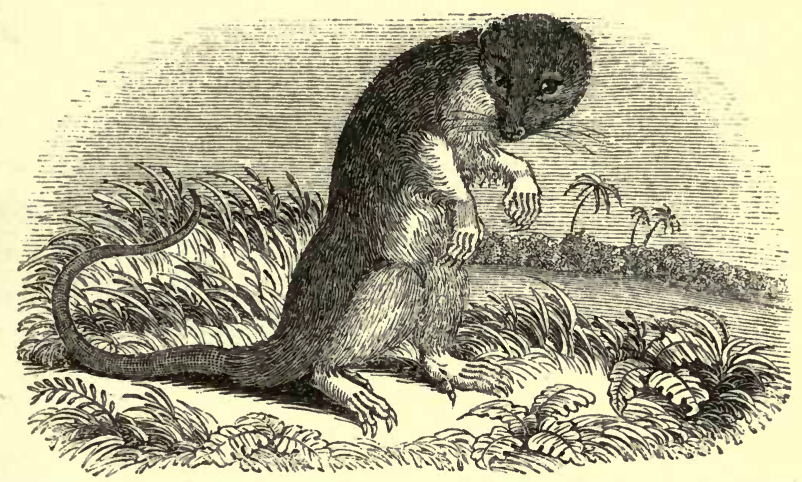

Bewick says, it is "supposed to be the animal called the canerat, so very destructive to the sugar canes."*

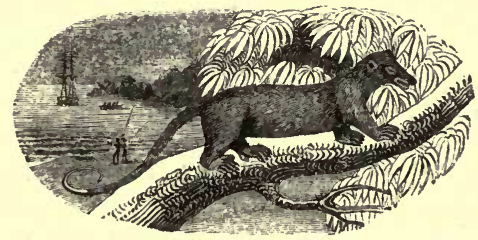

Cook's Phalanger.-(Phalangista Cookii.)

This species, which was discovered by Captain Cook, in January 1777, inhabits Van Dieman's Land, the southern point of New Holland. $\uparrow$ It is covered with long, soft, glossy hair of a rusty brown colour; and its belly is of a dirty white.

* General History of Quadrupeds (Newcastle, 1790), p. 372. In his edition of 1807 , p. 434 , he omits this observation, and merely adds, after describing the exterior characteristics of the animal, that "it inhabits the East Indies."

$+\mathrm{Mr}$. Ogilby says, that the original specimens, reputed to be of this species, in the Paris Museum, are, in fact, of the New Holland continental species (Phalangista Banksii), which was originally found at Endeavour River. It is most probable, however, that they are really what they profess to be,- 


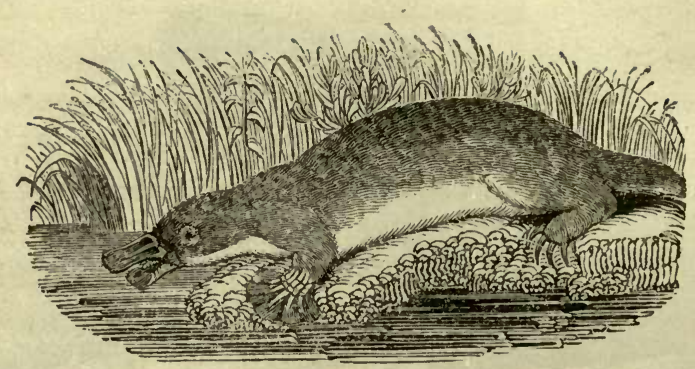

The Ornithorhynchus, Platypus, or Water-Mole.

(Ornithorhynchus paradoxus, Blum.)*

This extraordinary creature frequents the rivers of Australia, and is found abundantly both in New Holland and in Van Dieman's Land.

The structure of the ornithorhynchus is so anomalous that Shaw, who was the first to describe it, and from the only specimen then known, hesitated whether to introduce it into that portion of his General Zoology which contains the mammals;

specimens of the Van Dieman's Land species (P. Cookii), for Temminck says they were derived from the voyage of Labillardière, who did not visit the east coast of New Holland at all; while Desmarest says they were brought home by Peron and Lesueur, who touched at no part of that coast, except Port Jackson; but both expeditions visited Adventure Bay, where the latter species was discovered during Cook's third voyage. One specimen in the Paris Museum, brought home by M. Gaimard, has been referred to by Temminck as having been procured from the island of Rawak, one of the Moluccas; but this error has been corrected by M. Lesson, who after giving Van Dieman's Land as the habitat of the species, expressly states (Dict. Class. d'Histoire Naturelle, 13), that the particular specimen was obtained alive at Port Jackson.

Mr. J. E. Gray declares that the animal which Frederic Cuvier has described and figured as Phalangista, or Petaurus Cookii in his Mammifères, and in the Dictionnaire des Sciences Naturelles, belongs to a species very different from either that or $P$. Banksii.

* Cuvier considered the Ornithorhynchus and the Echidna as belonging to the order EDENTATA, in which he accordingly placed them as his third tribe called Monotremata. Temminck, before him, considered both the 
for " it was," he says, "impossible not to entertain some doubts as to the genuine nature of the animal, and to surmise that, though in appearance perfectly natural, there might still have been practised some arts of deception in its structure." An animal exhibiting the beak of a duck engrafted on the head of a quadruped, might well excite suspicions of imposture, till its claim to be received as a genuine production of nature was confirmed by the arrival of other specimens from the same locality.

It is indeed a paradox-for while its general appearance, its hairy fur, and many of its anatomical characteristics, prove its claim to be ranked amongst the mammals; its want of bony teeth, the singular formation of its duck-like bill, and the great development of its webbed feet, seem to ally it to the aquatic birds; yet in its mode of generation it resembles the reptiles.

Its length, from the end of the beak to the end of the tail, varies, in full-grown specimens, from sixteen to twenty-three or twenty-four inches; the male is usually a trifle larger than the female. The head is rather depressed horizontally, as also is the body, which seems to combine the characters of the otter, the beaver, and the mole. It resembles the two former, as well as other amphibious mammals, in the possession of two kinds of fur; the body being covered with long silky hairs of a darkbrown colour approaching to black, and emerging from an undergrowth of very fine soft greyish fur, which is thicker and softer on the belly of the animal. The eyes are of a light brown colour, very small, but brilliant, and placed rather backward;

Monotremata and the ordinary MARSUPIALIA as distinct orders, equivalent to other groups of the same rank and denomination. Mr. W. Ogilby, regarding the existence of the marsupial bones to be the simple and only unexceptionable character of the order MARSUPIALIA, prefers considering the Monotremata as a subordinate group or family of that order, rather than elevating them to an independent and equal rank, or associating them with a different order. It is true indeed that, strictly speaking, they come equally within the definition of the order FDENTATA, but if approximated to this order, rather than to the other MARSUPIALIA, the integrity and logical simplicity of the latter order is destroyed; for these, as already observed, depend, not upon the existence of the abdominal pouch, which is not present in all its species, but properly upon that of the marsupial bones. 
there is no projecting ear, but merely an auditory aperture, which the animal has the power of opening and closing at pleasure, situated behind and external to the eye. The beak, which strongly resembles that of the shoveller-duck, and is the most characteristic part of this singular mammal, consists of two flat projecting cartilaginous lips, or mandibles, slightly serrated at the edges. This organ is of a dirty greyish black colour, and covered with innumerable dots; and at the base of each mandible is a loose and broad fold of skin, of the same colour as the beak, and to this fold, or rather these two folds of skin, different uses have been assigned. Sir E. Home considered them as intended to prevent the animal pushing its beak too deep into the soft mud, while Mr. G. Bennett, who studied this animal in its native haunts and also in captivity, is of opinion that they protect the eyes when the animal is burrowing for food in the mud. The nostrils, which are small and round, are placed about a quarter of an inch from the tip of the beak, and are about the eighth of an inch apart from each other. Those singular receptacles, called cheek-pouches, are possessed by the ornithorhynchus, and of their use it will be necessary to speak hereafter. Its legs are hairy above, and exceedingly short; the hinder rather shorter than the front pair; the feet have each five toes, connected with each other by a strong membranous expansion; in the fore-feet, which are the largest and most powerful, the web extends a little distance beyond the extremities of the claws, whilst in the hinder-feet it attains only to the roots of them. On the fore-feet are five claws, well adapted for burrowing, being straight, strong, and sharp pointed; the two exterior ones somewhat shorter than the three middle ones. The hind-feet have six claws, longer and more inclined to a curved form than those of the fore-feet; the exterior toe and claw are considerably shorter than the fore middle ones. The fore-feet are naked both above and below; but the hind-feet are hairy above and naked below. The former, with their membranous web, are, when expanded, four inches across, and 
that part of the web which projects beyond the end of the toes, is loose, and can therefore fold back when the animal burrows, and permit the strong blunt claws to come into operation; but when the action of swimming is requisite, this accommodating membrane spreads out and furnishes a most excellent paddle. The male has a moveable spur upon the hind part of the inner surface, and somewhat above the claws of the posterior legs. The tail, in both sexes, is flat and broad, and varies in length from four and a half to six inches; the hair covering its upper surface is longer and coarser than that of any other part of the body, and projects a little distance beyond the end of the tail itself.

The ornithorhynchus seems to spend as much of its time on the land as on the water; though its short legs and webbed feet are better adapted for rowing through the latter element than for carrying it over the surface of the former. Numbers of its species frequent the rivers; but they are so shy and timid, that the spectator who would wish to watch them, "must," says Mr. Bennett, " remain perfectly stationary, as the slightest noise or movement of the body causes their instant disappearance, so acute are they in sight or hearing, or perhaps in both; and they seldom reappear when they have been frightened. By remaining perfectly quiet when they are ' up,' one may obtain an excellent view of their movements on the water; they seldom, however, remain longer than one or two minutes playing and paddling on the surface, soon diving again and reappearing a short distance above or below, generally according to the direction in which they dive, which act they perform head foremost, and with an audible splash." They swim very low, so that the upper part of the back and the head only are seen above the surface of the water; and when their fur is wet, each resembles a mass of dirty weeds rather than a living animal, and on which account they often escape observation.

They feed upon aquatic insects, small mollusks, and animalculæ, and they gencrally obtain their food by inserting their 
beaks into the soft mud on the river-sides, and particularly at the roots of the various plants that grow in such situations.

A person who resided several years in New South Wales, says, that the principal prey of the ornithorhynchus " consists of a pyramidical shell-fish, found in the mud of the Australian rivers, about half an inch long, with a filmy crust encasing it, as delicately thin as a piece of tissue paper. Several of these pigmy morsels they usually bring up to the surface at the same time, and there lie leisurely munching them with all the gout of refined epicures-spitting out, if I may so term it, every now and then, the fragments of the shattered shells, as they are freed from the fish, and finally swallowing, before diving again, the rich oyster-like fare which they contain. So careful are they to reject the shells after the extraction of their contents, that I never yet could detect the smallest particle of shell in the stomachs of the many I have dissected, although their mouths have been at the same time crammed with broken fragments." *

Their mode of foraging in the mud or water is very like that of a duck when feeding in similar places; immediately after withdrawing the beak from the mud, they raise the head, and masticate the prey they have obtained by a lateral motion of one mandible upon the other. The cheek-pouches of specimens recently captured generally contain mud and small stones, mixed up with portions of the animals on which they feed; and it is supposed that in these pouches the food undergoes trituration and other changes, preliminary to its digestion in the stomach.

The ornithorhynchus forms its habitation and nest by burrowing in the banks of the rivers it frequents. Lieutenant Lauderdale Maule says, it generally chooses a site for this purpose "where the water is deep and sluggish, and the bank precipitous, and covered with reeds, or overhung by trees. Considerably beneath the level of the stream's surface is the main entrance to a narrow passage, which leads directly into the bank, bearing away from the river (at a right angle to it), 
and gradually rising above its highest watermark. At the distance of some few yards from the river's edge, this passage branches into two others, which, describing each a circular course to the right and left, unite again in the nest itself, which is a roomy excavation [large enough to contain the mother and three or four young ones], seldom more than twelve yards from the water, or less than two feet beneath the surface of the earth." The entrance to the burrow is so placed as to be concealed from observation by surrounding grass, weeds, and shrubs; and as no heaps of earth are found near it, Mr. Bennett thinks it not improbable that the animal carries away the loose mould collected during the process of excavation, in order that it may not indicate the situation of the burrow.

For a long time it was a question, whether the ornithorhynchus was an oviparous or an ovo-viviparous animal; that is to say, whether it laid eggs from which young were afterwards hatched, as in the case of birds, or whether it propagated by eggs which were retained and hatched within the body, as in the case of the common viper and some other reptiles. That it did not produce its young in the way that mammals ordinarily do, was generally admitted by all zoologists; but they were not agreed as to which of these modes of proceeding was the one it pursued. In the spring of 1831, Lieutenant Maule, being in New South Wales, took some pains to discover the truth of the more generally accepted belief, that the female lays eggs, and suckles its young. He tells us that with considerable labour and difficulty several nests were discovered in the banks of the Fish River, a mountain stream, abounding with these shy and curious animals. "No eggs," he says, "were found in a perfect state, but pieces of a substance resembling egg-shell were picked out of the debris of the nests. But in the insides of several females which were shot, eggs were found of the size of a large musket ball, and some less, and without the hard outer shell.

An old female, which lived in captivity with a young one, was killed by accident on the fourteenth day after her capture, 
and being skinned while yet warm, it was observed that milk oozed through the fur on the stomach, though no teats were visible on the most minute inspection; but on proceeding with the operation, two canals were discovered containing milk, and leading to a large glandular apparatus." The existence of milk in the situation described, fully confirms the correctness of the deduction made by Professor Owen,* from the minute dissection of several specimens, - that the glands discovered by M. Meckel are really mammary, as this author had previously asserted. The professor's dissections, however, though they established the existence of numerous minute tubes leading from the glands in question through the skin, where it was covered with wool, did not enable him to detect any canals so large as Lieutenant Maule describes. These canals, however, as has been recently ascertained by minute dissection, are not single; but on each side there is a bundle of small capillary tubes, united so as to form a short cord; these fine tubes open in a dark coloured circle on the skin, but which is covered by the fur, the glandular mass from which they proceed being of large size, compressed, extending nearly the whole length of the body, and lying immediately beneath the skin. From the preceding collective evidence, as well as from some circumstances connected with its anatomy, it seems certain that the ornithorhynchus is ovo-viviparous; that the young are indeed hatched from eggs, but hatched before their

* Philosophical Transactions (1832). In the same celebrated publication (1834), Professor Owen has demonstrated the co-existence of the chorion and the vitelline membrane in the ovum, or egg of the ornithorhynchus; and this fact has been further established by the more recent researches of Krause (in Müller's Archiven), and of Mr. Wharton Jones (in the Philos. Trans. 1837). With the structure of this ovum, the ova of the batrachian reptiles present a close analogy, being inclosed by both a vitelline membrane and an external gelatinous chorion: and in the Triton, the latter of these acute observers has noticed, that when the embryo has attained a certain size, but still at an early period, the vitelline membrane is ruptured, and the embryo, with its amnios and umbilical sac, is then immediately invested by the chorion. This curious phenomenon of the destruction of the vitelline membrane seems to afford a key to the true analogies and relations of the mammiferous chorion. 
birth, when they are extremely small, and that their nutriment is the thick milky fluid prepared in the large mammary gland, and which the mother has most probably the means of instilling into the mouth of her helpless offspring.* The mamma, or teats, which exist merely in a rudimentary form in the female ornithorhynchus and echidna, consequently do not fulfil the ordinary function.

Mr. Bennett having caught two full-furred young ones, in one of the burrows that he examined, conveyed them to Sidney, and was in hopes of sending them alive to England; but though they were at first very active and sprightly, they soon became meagre, their coats lost the sleek glossy appearance indicative of health, they ate little, and at length died, about five weeks after their capture. His account of the habits of these animals is full of interest. "They slept in various postures, sometimes in an extended position, and often rolled up like a hedgehog, in the form of a ball. The latter posture, which was a favourite one with them, they effected by the fore-paws being placed under the beak, with the head and mandibles bent down towards the tail, the hind paws crossed over the mandibles, and the tail turned up; thus completing the rotundity of the figure. They usually reposed side by side, like a pair of furred balls, and awful little growls issued from them when disturbed; but when very sound asleep, they might be handled and examined with impunity. One evening, both of them came out about dusk, went as usual and ate food from the saucer, $\uparrow$ and then

* In the Magazine of Natural History (New Series, 1839), vol. iii. p. 345, Mr. Ogilby tells the world that the fact is now established that these singular and anomalous animals lay eggs and hatch them like birds; but it is clear that he had no other authority for saying so than a mere assertion contained in a letter from Professor Agardh (now Bishop of Bergen), who says that the ornithorhynchus and the echidna very closely resemble birds, not only in the construction of the bill, cranium, clavicles, shoulder-bones, and sternum, but in their organs of generation, their undeveloped teats, their having only one ovarium, and in their laying and hatching eggs.

$\dagger$ The female kept by Lieutenant Maule fed during the fortnight of its captivity, on worms, and bread and milk, being abundantly supplied with water, and is supposed to have supported her young by similar means. 
commenced playing with one another like two puppies, attacking with their mandibles, and raising the fore-paws against each other. In the struggle one would throw the other down, and at the moment when the spectator would expect it to rise again and renew the combat, it would commence scratching itself, its antagonist looking on, and waiting for the sport to be renewed." They were very fond of combing themselves with their hindfeet; an operation they generally performed after bathing, and before retiring for the night. Previous to seeking repose, they would perambulate the room for a short time. The ingenuity and expertness they displayed in climbing to the summit of a book-case, or any other elevated piece of furniture, was very surprising, because the opportunity or the necessity of performing any such feat could scarcely have occurred to them in a state of nature; it reminds one of the celebrated recent escape from Newgate, effected by a chimney-sweep, who adopted a similar course. The ornithorhynchus " placed its back against the wall, and its feet against the book-case, and then, by means of the strong cutaneous muscles of the back, and the claws of the feet, contrived to reach the top very expeditiously. Both often performed this mode of climbing, so that I had frequent opportunities of witnessing the manner in which it was done." They delighted in an occasional swim, and when placed near the water (a cord having been fastened round the hind leg to prevent escape), they would make their own way into it, and travel up and down the stream, at the same time showing a partiality for those places that most abounded in aquatic weeds. After swimming and feeding, they would lie down on the grassy bank, to comb and clean their coats.

From all that is known of the habits and disposition of the ornithorhynchus, it appears to be a harmless creature; its extreme timidity induces it to seek for solitude, and to haunt only the most unfrequented parts of rivers. It is true that, when handled or disturbed, it evinces its displeasure by a low growl, but yet it never shows a disposition to bite or scratch. In Martin's History of Austral-Asia (page 111), it is asserted that 
the male when irritated discharges a poisonous secretion through a perforation in the spur with which the hind leg of that sex is armed; but as Mr. Bennett seized the hind leg and roughly handled his male specimen, and could not perceive that it made any effort to defend itself with its spur, he thinks that the assertion is entirely groundless.

The natives of Australia eat the ornithorhynchus, and the colonists use the soft silky down, which grows beneath the long bristly hair, instead of beaver for hats ; frequently, also, they tan the skin itself, and form it into caps for youth.

* Echidna, a genus which has been alluded to in the course of this article, is characterized by having a remarkably long tubercular snout, a very small mouth, a vermiform tongue capable of being protruded; the body covered with sharp spines, resembling those of the porcupine, only they are shorter and thicker in proportion; and the legs and feet very strong, and capable of burrowing into the earth with the greatest facility.

Two species are known. Echidna Hystrix (Cuv.) inhabits the continent of New Holland; while E. setosa (Cuv.) is confined to Van Dieman's Land. Both grow to the same size, attaining nearly eighteen inches in length. Judging from the specimens in the British Museum, they do not differ so much in the length of their spines as in the colour of their fur, which is black in the former, and brown in the latter, with a blackish spot on the orbit. 


\section{ORDER-RODENTIA.}

The various portions of the globe, with the exception perhaps of New Holland, possess one or more species of this extensive genus. Many of these are extensively diffused, and, from the operation of climate and other causes, are subject to deviate into several varieties; a circumstance which has greatly perplexed European naturalists in designating the species existing in the warmer parts of the eastern continent.

In all these animals, the head is large; the eyes are prominent and lively; the lower incisor teeth strongly compressed; the grinders four in number, variously tuberculated, and, when very young, have a small additional one above in front, which in many of the species very soon drops out; but, according to Dr. Bachman, in most of those of America it is either permanent, or remains for more than a year. They have four toes on the front feet, and five on the hind; and the thumb of the forefoot is sometimes marked by a tubercle: all the toes are long, slender, and deeply cleft, and the nails are very acute, and greatly compressed. Their tails, which appear of vast assistance in accelerating and regulating their movements, are profusely furnished with hairs, which in most species are arranged on the sides so as to resemble a large plume.

It has been justly observed, that there are few animals of the present order that can be compared with the squirrels for the elegance of their form, the beauty of their fur, and the ease, elasticity, and rapidity of their motions. Nestling among the topmost branches of the trees, on which their lives are entirely passed, climbing with extreme agility, and bounding from bough to bough, or from tree to tree, with such velocity as almost to 
elude the sight, they offer in their native state a most interesting subject for admiration to all who love the woodland walks, those quiet haunts where one may

“
Th' inspiring breeze; and meditate the book
Of Nature ever open."

When it happens that the squirrel misses its hold in leapinga rare case-it grasps in its descent at the first object that may present itself; or if about to fall to the earth, it spreads itself out in the manner of the flying squirrel (Pteromys), and thereby presenting a greater resistance to the air, is enabled to reach the ground without injury, and, instantaneously recovering itself, ascends a neighbouring tree, emitting very frequently a querulous bark, which is either a note of fear or triumph. Although the squirrel moves with considerable rapidity on the ground, yet then it rather runs than leaps.

The food of these animals consists chiefly, if not entirely, of fruits, seeds, young buds, bark, and other vegetal substances. Nuts and seeds of all kinds are usually carried to the mouth by means of the fore-paws, which hold them between the rudimental thumbs and the inner portions of the palms. When disturbed at its meals, the squirrel either drops the nut and makes a rapid retreat, or seizing it with the incisor teeth carries it to its hole or nest. Several species collect more or less food during the abundant season of autumn, to serve as a winter store.

\section{The European Squirrel.-(Sciurus vulgaris, Linn.)}

This species abounds in almost all the large woods throughout Europe and the North of Asia.

The average length, from the extremity of the head to that of the body, is eight inches and a half, or, including the tail, one foot two inches and three quarters. The back is of a lively red colour, the belly white, and the ears terminated by a tuft 


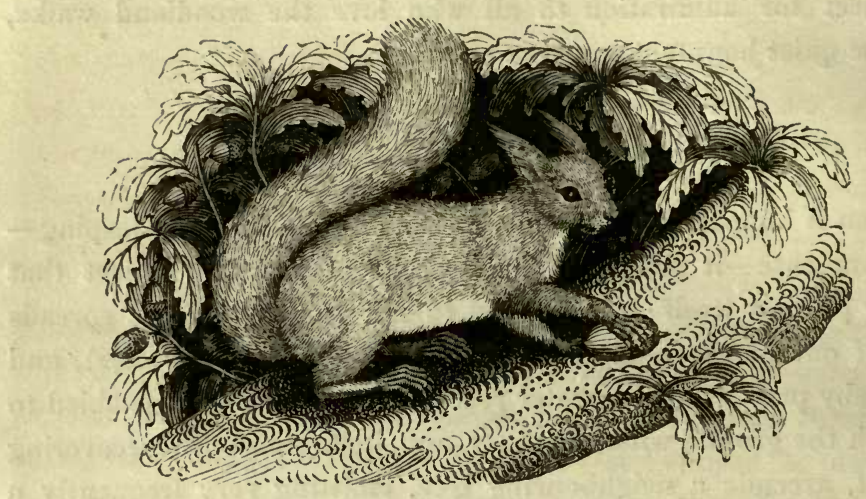

of hair. Mr. Blyth has remarked that " in summer its fur is coarse, shining, and of a bright rufous colour, and the ears are deficient of the ornamental tufts, which grow in autumn, while the animal is renovating its coat, and continue, usually, till about the beginning of July, the time varying somewhat in different individuals. In winter, its fur is much finer in quality and texture, considerably longer, thicker, and more glossy, and nearly of a greyish brown hue. The first young ones, which are produced very early in the season, push forth the winter garb, which, I believe, they retain throughout the summer; whereas, the second race of young ones, which, for the most part, make their appearance about Midsummer, are first clad in the summer dress, which is exchanged before they have become half grown for that of winter." *

In arctic countries, the colour of the fur begins to change from brown to grey about the commencement of October; and the animal is perfectly grey or rather bluish grey in about a month after.

Accidental varieties of the squirrel are not of unfrequent occurrence. Blumenbach mentions a black variety, also one spotted with black and white, and an albino with red eyes.-

* Mag. Nat. Hist. (1836), vol. ix. p. 395. 
Pennant says, that in some parts of Wales there is a variety with a "cream-coloured tail." The Rev. W. Herbert says, that many of the squirrels in the north of Hampshire have "white tails;" and Mr. Jesse says, several with tails of that colour have been noticed in the park of Sir Thomas Winnington, in Worcestershire, and in that of Sir R. Phillips, in Pembrokeshire; and that one with " a grey tail" was shot at Pain's Hill, near Cobham, in Surry.

The squirrel is a very active animal, especially during the warmer months of the year, when the celerity and certainty with which it leaps from bough to bough are truly wonderful. It is the gayest and prettiest enlivener of our woodland scenery; and in its amazing leaps presents us with an example of agility and gracefulness unrivalled among our native mammals. Being exceedingly timid and watchful, the slightest noise or movement alarms it. When disturbed it springs off immediately from tree to tree, till it has removed itself far away from the seat of danger.

In the spring, squirrels feed chiefly upon the green bark of young trees, tender shoots, and leaf-buds. At other times they feed on the fruits of the pine, the fir, the larch, and other coniferous trees. They also feed on the birch, and probably the alder. In the autumn they feed also on acorns, beech-mast, chesnuts, walnuts, filberts, apples, and other common fruits. They sit upright when eating, and use their front feet or paws to convey and hold the food to the mouth. Previous to cracking nuts they turn them round in their paws, until they have got them in such a position that the softest, and most yielding portion, that is the apex of the shell, is brought in contact with the lower incisors, with which they scrape an opening to the kernel.

Mr. Charles Coward says, that during three successive years he has observed that the squirrel is occasionally carnivorous. In the spring of 1836, he left some young kingfishers on a table in a room along with three half-grown squirrels. On his return, 
he found one of the squirrels busily employed in plucking the feathers from the head of one of the birds. The next day a young cuckoo was placed in the same situation, when it was quickly attacked by a squirrel, which seized it under the wing, where it was safe from the blows aimed at it by the bird. In a few minutes the animal had eaten a great portion of one side, so that the air inspired escaped from the wound; it had also eaten through the femur and muscles of the thigh. The two other squirrels soon joined the first, and partook of the same prey. "This experiment," says the writer, "I repeated several times, both with live and dead birds, and invariably found that the squirrels would forsake their vegetable food for the more agreeable animal diet; and I believe I may add, that they preferred living prey. On mentioning the fact to the Wiltshire shepherds, they assured me that the squirrels were not uncommonly seen in the act of devouring young birds, particularly in the eopses that intersect the bleak downs of that county. One shepherd told me, that during an autumnal evening he observed a severe struggle between a wood-pigeon and a squirrel, among the branches of a tree, and that the latter, proving victorious, began to devour his victim."*

About two years previous to the publication of the above statement, of the carnivorous disposition of the European squirrel, a writer recorded a similar fact with respect to the common Indian squirrel, which he describes as being a small and fierce creature, swarming in hundreds about the houses in India, and distinguished by three dark stripes along the back, and a splendid tail of hairs as fine as gossamer. "We discovered," he says, "that the squirrels, if in want of a meal, would not scruple to attack the Indian sparrows living in the eaves of the same verandah. One day an unusual hubbub brought me into the verandah of the bungalow, and I saw a squirrel with a sparrow in its claws, and which it would have speedily demolished, had not the other sparrows hastened to

* Abridged from Mag. Nat. Hist. (New Series, 1839), vol. iii. 
the rescue. Beating him with their wings, pecking at him, and loudly chirping meanwhile, they forced the squirrel to release his prey." *

Previous to winter, the squirrel lays up a store of food, chiefly acorns, in various holes in trees near its own winter retreat, and intended to save it from want and starvation at that season. During the greater part of the winter it remains in a state of repose nearly approaching to torpidity; but with every fine day that intervenes at that season it shakes off its lethargy and repairs to its stores, and after satisfying its hunger retires again to its dormitory.

Squirrels live in pairs, continuing together, and making their drey, or nest, in one particular tree for several successive years, if not disturbed. It is usually placed in a hole in the tree, or nicely concealed in the fork between two branches. "In the beautiful grounds of Pain's Hill, near Cobham, where squirrels abound, I never could hear," says Mr. Jesse, " of a drey having been found in the holes of trees ; but generally on the branches, where I saw several about half-way up the trees. I have, however, seen one on the very top of a young fir-tree, to which they appear to give the preference. In forming the drey they begin by gathering mouthsful of dry bent grass [moss and leaves], in the way we see rabbits do, and of this grass they make a considerable deposit. The outside is afterwards protected with a quantity of sticks, giving the drey the appearance of a bird's-nest. Before the young are born, the mother strips off her fur in the manner of the rabbit, so that her stomach is sometimes quite bare. This being stripped off affords them a warm bed in the nest, and at the same time enables them to find the teats more readily. She brings forth from four to five; and these when very young have an odd appearance, owing to the shortness of their tails, which are some time before they arrive at the full size. The young are easily reared, and soon learn to take milk out of a spoon, and become very tame and familiar."

* Abridged from the Edinburgh Journal, October 28, 1837. 
A writer relates of a domesticated squirrel which was perfectly tame, and devotedly attached to him, that when indulged with liberty it would run over his body, enter his pockets in search of nuts, and having found them it would sit on his shoulder to crack them, and in that position suffer itself to be carried all over the house. "It was," he proceeds, "so tame that we often allowed it to run in the garden; in a moment it would be at the top of a mulberry-tree, about twenty feet in height, and spring from branch to branch; but at the call of its master would immediately descend, and get on his shoulder or into his pocket, to be carried to the cage. It was a common thing to see this squirrel at play with the cat; it would get on her back, and sit there as long as it thought proper without the least fear. Squirrels are very dexterous in the arrangement of their beds; but I would strongly advise all who keep them in cages, to put a bit of wool or flannel into their dormitory instead of hay, which sometimes becomes twisted round their necks and strangles them."*

Great numbers of squirrels are kept as pets, by the Londoners more especially. A dealer in animals assured Mr. Herbert, that not less than twenty thousand squirrels are annually sold in the metropolis, some of which are imported from France, though the majority are British; that he himself had sold annually about seven hundred; that four or five hundred might be bought in Newgate and Leadenhall Markets during a good season; but that about once in seven years the breed entirely fails, though in other seasons they are generally prolific. The mere manufacture of the cages in which these animals are kept, forms no small concern. They are generally provided with a chamber, which revolves with every movement of the squirrel when it enters it.

"The squirrel spends his little rage, In jumping round a rowling cage. The cage, as either side turns up, Striking a ring of bells a-top-

* Field Naturalist's Magazine (1834), vol. ii. p. 160. 
Mov'd in the orb, pleas'd with the chimes, The foolish creature thinks he climbs;

But here or there, turn wood or wire, He never gets two inches higher."

(Prior.)

But away owith the squirrel's treadmill, let him have a fixed residence! Sir George Head remarks that, "If there be one method more efficacious than another to deprive a squirrel of liberty it is this very contrivance, whereby, do what he will, he never can possibly be in a state of rest,-where, let him vary ever so little, even for a moment, from his central position, everything begins tumbling about his ears. I have many times observed the panting sides of the little animal, its breath exhausted by galloping, kicking, and straining-worried, and alarmed, without enjoying a single inch of progressive motion, or one refreshing change of attitude, for minutes together within his treadmill. A man, pelted with mud, may believe he is hunting, or, lying on his stomach on wet grass, think he is swimming, as reasonably as a poor squirrel, in the midst of a whirling maze of wood and iron, can enjoy liberty and the delight of running. A quiet home is a home be it ever so humble; but when the house itself turns round and round, its homeliness is destroyed altogether. Fixed against the outside of a house at Hull I saw a common wire cage, such as is generally used for a blackbird, furnished with perches in the usual manner, and containing two squirrels, living amicably together; and by the variety of their active movements, in comparison with the monotonous labour before alluded to, affording a highly delightful exhibition. These little creatures threw somersets, ten or a dozen in succession, over each other's backs, and round the perches, one after another; and suddenly they would stop and change the line of direction, passing each other contrariwise, and forming both together in the air a double figure of eight."*

Lovell says the flesh of the squirrel " is sweet and good. The black is the best. It may be compared to the flesh of

* Home Tour through the Manufacturing Districts (1837). 
goats or coneys, being tender and sweet. Some counteth them dainties."*

The upper fur, when obtained from the north of Europe in its winter dress of a bluish grey colour, is known by the name of petit-gris, or miniver; but when the white fur of the belly is attached to that of the back, it is called vair. What are termed yellow fitch pencils, are painting-brushes chiefly composed of hairs from the tails of our common squirrel; and Dr. Ure has published a very minute and interesting account of the process pursued in their manufacture.

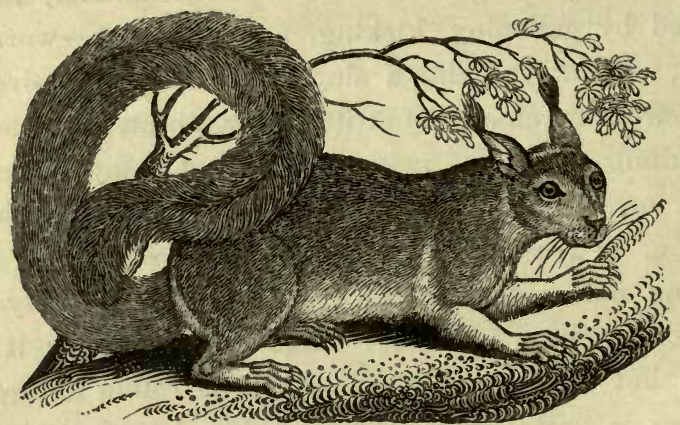

The Great-tailed Squirrel.

(Sciurus magnicaudatus, Harlan ; S. macrourus, $\uparrow$ Say.)

This species, which is the most common on the Missouri, is one foot ten inches and a quarter in length, including the tail which measures eleven inches and a quarter. Say, its original discoverer, gives the following description of it, and which is at variance with the characters of the animals generally so called in the English and continental museums, and which are probably varieties of other species :-

"The body above, and on each side, is of a mixed grey and

* Panzoologia (1661), p. 123.

+ The Sciurus macrourus of Gmelin, is the beautiful large Indian squirrel (S. maximus), which is destitute of pencils to the ears. 
black; the fur is plumbeous, black at the base, then pale cinnamon colour, then black, and finally cinereous, with a long black tip ; the ears, three-quarters of an inch long, are, behind, of a bright ferruginous colour, extending to the base of the fur, which, in the winter dress, is prominent beyond the edge; on the inside of the ear the fur is of a dull ferruginous hue, slightly tipped with black; the sides of the head and orbits of the eyes are pale ferruginous; beneath the ears and eyes the cheeks are dusky; the whiskers are composed of about five series of rather flattened hairs, the inferior ones are more distinct; the mouth is margined with black; the teeth are reddish yellow; the under part of the head and neck, and the upper part of the feet, are ferruginous; the belly is paler, the fur being plumbeous at the base; the tail, which is even more voluminous than that of the cat squirrel (S. cinereus, Linn.), is of a bright ferruginous colour below, and this colour extends to the base of the fur with a sub-marginal black line; on its upper part it is ferruginous and black; the fur within is of a pale cinnamon colour, with the base and three bands black; the tip is ferruginous; the palms of the fore-feet are black, and the rudimental thumb, which is very short, is covered by a broad flat nail. In the winter the animal becomes fatter, and acquires a longer fur, but its colour continues the same; and it is only at this season that the ears are fringed, which is the necessary consequence of this periodical elongation of the hair.

"Its flesh was not an unfrequent article of food at our frugal yet social meals at Engineer Cantonment; and we could always immediately distinguish the bones from those of any other animal by their remarkably red colour."*

* Long's Narrative of an Expedition to the Source of St.Peter's River, Lake Winnipeck, Lake of the Woods, \&c., (1824), vol. i. p. 115. 


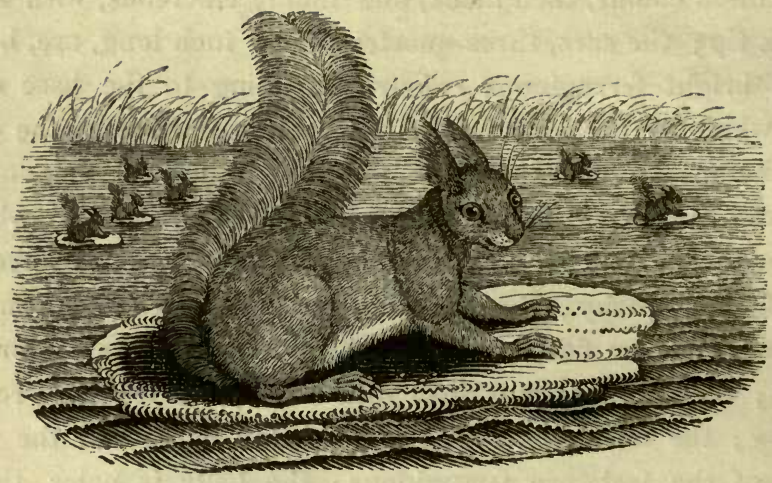

The North American Grey or Black Squirrel.

(Sciurus leucotis, Gapper ; S. Carolinensis, * Godman.)

This American species, which exists as far north as Hudson's Bay, was formerly very common in the New England States, and in the less cultivated portions is still frequently found. It is abundant in New York, and in the mountainous portions of Pennsylvania. Dr. Bachman (to whose able monograph on the genus Sciurus I am chiefly indebted for the natural history of this animal), says he has observed it on the northern mountains of Virginia. It probably extends still further south; in the lower parts of North and South Carolina, however, it is replaced by a smaller species (S. Carolinensis, Gm.). The black variety of the present species is more abundant in Upper Canada, in the western part of New York, and in the States of Ohio and Indiana.

The length of this species, from the head to the extremity of the body, is eleven inches and three-quarters, or, including the full extent of the tail, two feet and three-quarters. It seems

* The S. Carolinensis of Gmelin, is the little Carolina grey squirrel a distinct species. 
to have permanently twenty-two teeth: among a large number obtained in different seasons, and some of them, from the manner in which their teeth were worn, appearing to be old animals, all were found to have the small front molars in the upper jaw, except a single specimen, which, perhaps, had accidentally lost them. The nose is rather obtuse; the forehead arched; the ears are sharply rounded, concave, and both sides of them are covered with hair, which in winter projects upwards about three lines beyond the margin. The fur is coarsest on the forehead; but elsewhere it is a little softer than that of the cat squirrel (S. Cinereus, Linn.). There are many varieties of the present species, but two appear to be very permanent, namely, the grey and the black, both of which have been often found in the same nest, and are of similar size and form. The latter variety has a few white hairs interspersed here and there among the dark brownish black fur of its body, but no white tuft as in the American black squirrel (S. niger, Linn.).

The species now under notice appears to be the most active and sprightly of any existing in the Atlantic States. It rises with the sun, and continues industriously engaged in search of food during four or five hours in the morning, scratching among leaves, running over logs, ascending trees, and playfully coursing from limb to limb, often making almost incredible leaps from the higher branches of one tree to another. In the middle of the day it retires for a few hours to its nest, resuming its active labours and amusements in the afternoon, and continuing them without intermission till sunset. The chesnut, beech, oak, and maple afford it food, but it appears to prefer the shell-bark (Carya alba) and the several species of hickory, to any other kind of food. Even when the nuts are so green as to afford scarcely any nourishment, it gnaws off the thick epidermis, which drops to the ground like rain, and then with its lower incisor teeth, makes a small linear opening in the thinnest part of the shell, immediately over the kernel. In an incredibly short space of time, the nut is cut longitudinally on its four sides, and the whole kernel secured, leaving the portions 
of the hard shell untouched. Not satisfied with this kind of food, it commits great depredations on the green corn and young wheat, thus rendering itself obnoxious to the farmer. In Pennsylvania a law existed, offering three-pence for every squirrel destroyed; and in the year 1749 the sum of eight thousand pounds was paid out of the treasury, in premiums for their destruction. The inhabitants of several of the northern and western states assemble together on an appointed day to have a squirrel-hunt: arraying themselves in two opposite parties, each under a leader, they range the forest in every direction, and, before evening, these gunners bag an almost incredible number of squirrels. At the evening rendezvous, the party who produces the less number bears the expense of a bountiful supper,-a penalty which stimulates the gunners to the greatest activity in destroying them.

Occasionally these squirrels leave their native haunts, and seek for adventures or for food in some distant and, to them, unexplored portion of America. These migrations appear to have been more frequent formerly than at present. The farmers in the western wilds regard them with as much anxiety as do the eastern nations when they apprehend the visit of the devouring locust. At such periods, usually in autumn, the squirrels congregate in different districts of the far north-west, and, in irregular troops, bend their way in an eastern direction. Mountains and cleared fields,-the head waters of lakes and broad rivers,--present no impediments. Onward they come, devouring on their way everything suited to their taste,-laying waste the corn and wheat fields; and as their numbers are thinned by the gun, the club, and the dog, others are ready to follow in the rear and fill up the ranks, till they occasion infinite mischief, and call forth determined revenge. It is often inquired how these little creatures, that generally have a dread of water, manage to cross broad and rapid rivers, like the Ohio and Hudson; and it is usually asserted, and believed by many, that each carries to the shore a suitable piece of bark, and availing itself of a favourable breeze, sits upon this sub- 
stitute for a boat, hoists its broad tail as a sail, and floats safely to the opposite shore.* "This," says Dr. Bachman, " together with many other traits of intelligence ascribed to this species, I suspect to be apocryphal. That they do migrate at irregular, and occasionally at distant periods, is a wellestablished fact; but in the only instance in which I witnessed their migrations ( $I$ think it was in the autumn of 1808 or 1809), they appeared to me to be not only unskilful sailors, but clumsy swimmers. They swam the Hudson in various places between Waterford and Saratoga: those which I observed crossing the river swam deep and awkwardly, their bodies and tails,being wholly submerged; several were drowned and carried downward by the stream, and those which succeeded in reaching the opposite bank were so wet and fatigued, that the boys stationed there with clubs easily secured them alive, or killed them. It is doubtful whether any ever return westwardly, but finding forests and food suited to their taste and habits, they remain and propagate their species in their newly explored country, until they are gradually thinned off by the effects of improvement, and the dexterity of the sportsmen." $†$

It may reasonably be doubted whether this species lays up

* The same story has been told of the common European squirrel for a long period. Lovell says, "Their tail serveth them as a wing in leaping; they obscure themselves with it in trees, and use it as a saile in the water, swimming upon a bark." (Panzoologia, 1661, p. 123.) Franzius says, when " he is to go through any water, he will get upon a piece of wood; and with his tail serving him instead of a sail, he swims over, carrying his food in his mouth." (History of Brutes, 1670, p. 212.) Klein and Linnæus, who have hitherto enjoyed the credit of originating this story, tell us that in Lapland thousands of squirrels effect their migrations across the broad rivers and lakes by means of these barks;-presenting quite the appearance of a large fleet, a perfect navy, of adventurous squirrels. That the "joiner squirrel, time out of mind the fairies' coach maker," can fashion " an empty hazel-nut" into a chariot for Queen Mab to ride in "athwart men's noses as they lie asleep," is more likely than that he should be the accomplished boatman he has been imagined. Some squirrel that had clung to or mounted upon a piece of drift wood to save itself from drowning, when nearly exhausted by the exertion of swimming, probably gave rise to the story, which so far may have originated in truth.-J. H. F.

† Mag. Nat. Hist. (New Series, 1839), vol. iii. p. 226. 
any food for winter supply; for no provisions are ever found in their nests at that season, and their tracks in the snow cannot be traced to any buried hoards. In fact, it remains in a state of inactivity and partial torpidity in its nest during the winter, and therefore requires but little food, and seldom comes forth except when a warm sunny day intervenes; and then it has been observed to repair to the open fields, in search of the few dry hickory nuts which still adhered to the trees.

Contests frequently occur among the males during the breeding season, when they bite and wound each other severely. Each male chooses a mate in the spring, and, in the northern states, she generally brings forth in May. A hole in a tree is the usual place in which the young, from four to six, are born and nurtured. They grow rapidly, and leave the nest in a few weeks. While young, they are often caught and kept in cages, in which they soon become tolerably tame.

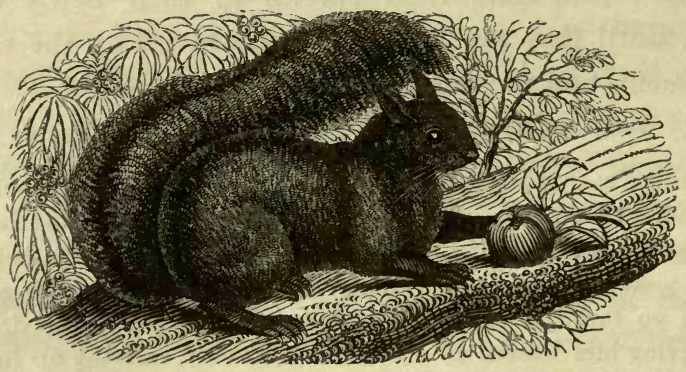

The American Black Squirrel.-(Sciurus niger, Linn.)

All American naturalists seem to insist that they have a black species of squirrel in North America; but they have unfortunately applied the name to the black varieties of many different species, and thereby created much confusion.

However, as black squirrels answering to the following description are constantly to be found there, it would scem that, 
if they are not a distinct species, but merely a variety, they have become by time and succession a permanent race.

Dr. Bachman, who procured specimens from the counties of Renssellaer and Queen's, New York, says he has seen it on the borders of Lake Champlain, at Ogdensburgh, and on the eastern shores of Lake Erie; also near Niagara, on the Canada side. The specimen, described in Dr. Richardson's Fauna Boreali-Americana (p. 192), was obtained at Fort William, on Lake Superior.

The black squirrel is larger than the preceding species, being thirteen inches in length from the extremity of the head to that of the body, or, including the full extent of the tail, two feet two inches. Dr. Godman says, the black squirrel has only twenty teeth ; and Dr. Bachman found no more in the specimens he has described under the present name, except in one instance, where the animal was evidently only a few months old, and had an additional tooth on one side, so small that it appeared like a white thread, the opposite and corresponding one having already been shed. If it should ever be established that this additional molar is deciduous in the black squirrel, and persistent in the northern grey squirrel ( $S$. leucotis), there will be no doubt of their being distinct species. Its head appears to be a little shorter and more arched than that of the grey squirrel, although it is often found that these differences exist among different individuals of the same species. The incisor teeth are compressed, strong, and of a deep orange colour anteriorly; the ears are elliptical, and slightly rounded at the tip, thickly clothed with fur on both surfaces, that on the outer surface in winter, extending beyond the margin; the whiskers a little longer than the head; the tail long, distichous, and thickly clothed with rather coarse hair. The fur of the body is softer to the touch than that of the northern grey squirrel; the whole of the upper and lower surface as well as the tail are bright glossy black; at the roots the hairs are a little lighter. The summer specimens do not materially differ

* American Natural History (Philadelphia, 1826), vol. ii. p. 133. 
in colour from the winter ones, except that they are not so intensely black. There are a few scattered white hairs on the back and tail; but small tufts of them on the under surface, resembling those on the body of the minx (Mustela Bison).

We learn from Dr. Bachman, that those which he frequently saw in the northern parts of New York, possessed all the sprightliness of the northern grey squirrel, which they resembled in their barking and other habits; appearing to prefer valleys and swamps to drier and more elevated situations. He observed them often stop to drink at a stream not far from his favourite seat under a rock, and instead of lapping the water they protruded their mouths a considerable depth into it, and drank greedily. They would afterwards sit upright, and, with tail erect, busy themselves for a quarter of an hour in wiping their faces with their paws, the latter being also occasionally dipped in the stream.

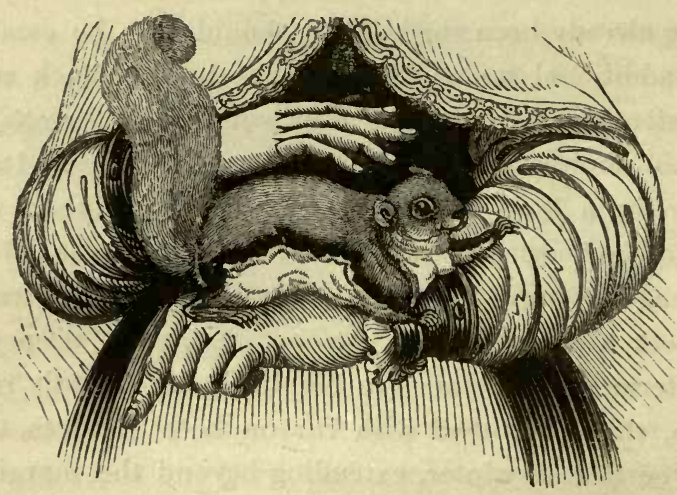

The Lesser Flying Squirrel.

(Pteromys volucella, Cuv.; Sciurus volucella, Linn.)

This pretty little creature inhabits the temperate regions of North America.

The length of the head and body is usually about four inches 
and a half, never more than five inches; and that of the tail is three inches and three-quarters. The eyes are surrounded by broad black circles; the ears are somewhat pointed at the tips, and nearly hairless on the surface; the whiskers are long and black. The belly is nearly pure white; the upper surface of the body of a bright mouse colour, with a tinge of fawn; the flying membranes are of a fawn colour, surmounted by a black band; and the tail is of the same colour as the body, but rather dusky beneath.

The flying membrane consists " of a folding of the skin along either side, so as to form broad lateral expansions, supported before and behind by the limbs between which they are extended, and by peculiar bony processes arising from the feet. These expansions are not naked and membranous, like those of the bats, but are actual continuations of the skin, clothed externally by a dense fur similar to that which invests every other part of the body. Neither do they serve the purposes of wings; their functions being limited to that of a parachute, giving to the animal a considerable degree of buoyancy, and thus enabling it to take leaps of almost incredible extent, through which it passes with the velocity of an arrow. The name of flying squirrel is consequently founded on an erroneous assumption, but it may, nevertheless, be admitted as a metaphorical expression of their most distinguishing peculiarity."* "They will dart," says Catesby, "fourscore yards from one tree to another. They cannot rise in their course, nor keep in a horizontal line, but descend gradually; so that in proportion to the distance of the tree they mean to dart to, so much the higher they mount on the tree they are about to leave, that they may reach some part, even the lowest, of the distant tree, rather than fall to the ground, which exposes them to peril. But having once recovered the trunk of a tree, no animal seems nimble enough to take them."

In the day-time they hide and sleep in hollow trees, and are seldom visible unless disturbed; but at night-time they come

* Zoological Gardens Delineated (1831), vol. i. p. 186. 
out stealthily to feed, foraging in parties of ten or twelve, all lively and active, running with as much agility as other squirrels, and darting from tree to tree with astonishing ease and intrepidity.

These animals feed on nuts, acorns, and young shoots. To afford them winter diet they store up plenty of nuts in their nests, which are constructed on the trees in a very artificial manner, and are each large enough to contain several individuals.

Though shy at first, the flying squirrel soon becomes familiar, happy, and contented in a state of captivity, if treated kindly. "It would be difficult," as Mr. Bennett observes, "to find in the entire class of mammalia a more graceful little creature, or one better fitted for a lady's pet than this elegant animal. Its diminutive size, the singularity of its form, the expression of its physiognomy, the vivacity of its motions, and the gentleness of its disposition, all combine to render it one of the most interesting, as well as the most beautiful, of a beautiful and interesting tribe." Mr. R. C. Taylor says it is very commonly kept in cages in North America; but adds (what one might naturally expect from so restricting the liberty of this most active species), that in such confinement it is not so amusing and lively as other squirrels.

A correspondent to the Magazine of Natural History, gives the following interesting account of the habits of some American flying squirrels which he kept in confinement at Birmingham :-

"They are almost always asleep during the day, curled round, with their tails covering their noses; but in the evenings, and through the whole night, they are in constant motion. The moment I open the door of their cage they jump upon me, and generally creep into my coat pocket: indeed, more than once, after I had roused and fed them in the day-time, I have found to my surprise, some hours afterwards, that I had been carrying one in my pocket handkerchief; sometimes even when on horseback I have felt one there. When about to spring, they jerk the head up and down three or four times, as 
if to judge their distance, and increase the power of rising. They generally spring from some height down to an object they have selected to reach. They are in the habit of hiding all the food they do not immediately want; and I have often observed that they recollect the places in which they have concealed it. One evening they amused themselves with hiding some nuts in the creases under the knees of my brother's trousers, as he was sitting still; and after four days he let them out of the cage again, when they directly examined all the creases for their hidden store. Whenever they are abundantly supplied with food, they continue to fetch and hide it till all has disappeared. They sit quietly on the cornice of the room till tea is brought in, when down they come, one after the other, either upon my head, or upon the table; and steal lumps of sugar so quickly that we can seldom catch them. We are often obliged to place a saucer on the top of the basin, to keep any sugar for ourselves. They then watch their opportunity, and take small pieces of toast or butter, which they carry to the cornice, and run round till they think they have found a secure place to hide them in, when they scratch with their fore-feet, push the food down with their mouths and noses, and then stamp upon it.

"On one occasion, when my room was about to be painted, we found eighteen pieces of sugar, besides toast and lumps of butter, in the corners of the cornice. During the painting, the squirrels were not permitted to have their evening run; but after three weeks' or a month's confinement, they were let out again; and we were much amused at the constant running round, and the anxiety they were in, when they found their stores gone. As soon as tea was brought in, they again stole the sugar, but hid it in the corners of the room, under the carpet, and behind some books.

"In March of the second year, I found, one day just after the cage had been cleaned, a young one: whether there had been more which had been thrown away, I do not know; but this we reared, and he lived for some years. I then had an opportunity of procuring two more pairs, which, after some 
fighting, lived very contentedly with the three already in the cage.

"Two of the females produced young last spring. I think the period of their gestation is a month. The young are blind for three weeks after their birth, and do not reach puberty till the next spring. I never obtained more than two young ones at a time, nor more than one litter in a year from the same female. The young were generally born in March or April. The female has five teats on each side, which appear through the fur some time before she brings forth. One of the females produced two young ones without making a distinct nest, or separating herself from the rest; but the consequence was, that they disappeared on the third day. If on any occasion we disturbed the young in their nest, the mother removed them to another part of the cage. The common squirrel of this country is said to remove her young in the same manner, if disturbed. Finding this the case, we often took the young squirrels out of their nest, for the purpose of watching the mother carry them away, which she did by doubling the little one up under her body with her fore-feet and mouth, till she could take hold of the hind thigh and the neck, when she would jump away so fast that it was difficult to see whether she were carrying her young one or not. As the young increased in size (which they soon do) and in weight, the undertaking became more difficult. We then saw the mother turn the young one on its back, and while she held the thigh in her mouth, the fore-legs: of the young one were clasped round her neck. Sometimes, when she was attempting to jump upon some earthen pots, placed in the cage, she was overbalanced, and fell with her young one; but as soon as she was near the ground, she would drop the young squirrel, so as to prevent her own weight from crushing it, which would have been the case if they had fallen together. I have seen the young ones carried in this manner till they were half-grown." 


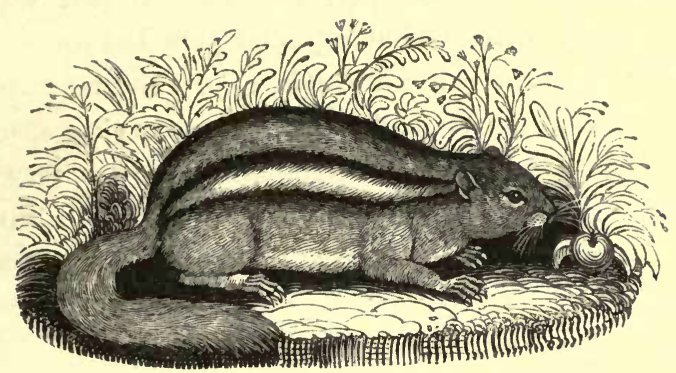

The Ground Squirrel.

(Tamias Lysteri; Sciurus striatus, Linn.)

Chip Squirrel. Striped Squirrel.*

The ground squirrel is found throughout all the north of Asia and of America, particularly in the pine forests. In the neighbourhood of Quebec it is very common in the crevices of the rocks, forming the bank of the St. Lawrence, from the Chedier River to St. Nicholas.

Its length, from the head to the root of the tail, is five inches and a half. On the head and upper parts of the body, the general colour is brownish red, intersected by a black stripe which runs along the spine; on each side there are also two horizontal stripes of black, enclosing a pale yellow space; the belly is white; the ears are smooth, and have a brown skin; the cheeks are provided with pouches for the temporary reception and carriage of the food; the tail is narrow, rather longer than the body, and covered with long fur, but more scantily than in most other squirrels.

In its habits this species differs very materially from all its congeners; for, instead of living in trees as they do, it burrows

* From its possessing some resemblance to the dormouse, both in its habits and external form, the ground squirrel has been described by Pennant under the name of striped dormouse. 
in the ground: hence it is not so frequently obtained as the arboreal squirrels. Yet few persons have travelled through the forests it haunts without having seen this beautiful creature, and heard it utter its call note, chip, chip. Nuts, acorns, grain, maize, \&c., constitute its food; and when carrying several nuts or other provender in its cheek-pouches, it has a very singular appearance. Its subterranean dwelling is formed with much art, and has many long galleries, branching off on each side, and terminating in a large cell, which serves as a store-room to contain provision for winter use.

Sometimes it climbs trees; but this feat, Dr. Bachman says, it performs slowly and with an apparent reluctance.

In Canada, the ground squirrel commonly breeds in the cellars and crevices under some of the wood-houses. Mr. E. H. Greenhow says, that a young one having been captured in a room soon became very tame, and played about, regardless of the persons to whom it was accustomed; but was always timid before strangers, skulking into a corner of its cage, and burying itself in some dry grass placed there for its bed. It had a very shrill whistling cry, which it repeated at intervals, as it jumped against the wires in front of its cage. It was exceedingly nimble, and could get through very small crevices, frequently escaping by pressing asunder the wires, and on these occasions was very difficult to recapture; but if allowed to run about the room for some time, would attempt to re-enter its cage of its own accord. It was fed principally upon shelled almonds and raisins, but was fond of apples and other pulpy fruits; it also ate grain, which forms a large portion of its food in the wild state.

Mr. Henry Doubleday, when writing, in June 183\%, from Trenton Falls, North America, says, "There are many ground squirrels in the woods. There is one so tame as to come into the house. He came to me a few days ago as I was sitting in the porch, and ran over my boots, examining them very attentively; then he disappeared through a grating into the dairy, where he goes to drink the milk; then he ran up the piazza 
and round the house; he often steals almonds, \&c. from our dining-room."*

Mr. R. C. Taylor says, that the grey squirrel (Sciurus cinereus), black squirrel (S. niger), ground squirrel (S. striatus), and red squirrel (S. Hudsonius), which are extremely numerous in the woods at the north-eastern extremity of the Alleghany mountain range, "are eaten as great delicacies, particularly the two former species. $\dagger$ On account of the great damage they do to the grain and corn, they are mercilessly destroyed, shooting matches frequently taking place for this object. On June 8, 1835, a match was decided between twenty men on each side, in Lycoming Valley, who, during three days, were to shoot the greatest number of squirrels and other destructive animals. At this meeting were produced 2657 head of all denominations coming under this class. Nearly at the same time, in the adjoining county of Tioga, another squirrel match took place: the winning side brought in no less than 1732, and the losers produced 1035 squirrels; the total number being $276 \% . " \ddagger$

\section{The Alpine Marmot. $\S$}

(Arctomys marmotta, Desm.; A. alpinus, Gm.; Mus alpinus, Linn.)

This animal inhabits the mountains of Savoy, the Pyrenees, Poland, the Ukraine, and Chinese Tartary, immediately beneath the regions of perpetual frost and snow.

It is about one foot four inches in length from the nose to

* Entomological Magazine (1837), vol. v. p. 34.

+ The Indian gipsies eat squirrels; and Audubon, the American ornithologist, in his description of the barred owl, mentions his roasting a squirrel for his own dinner.-J. H. F.

$\ddagger$ Mag. Nat. Hist. (1835), vol. viii. p. 538 .

$\S$ Several other species of marmots are found in Europe, as the bobac (Arctomys bobac), which inhabits low mountains and hills, from Poland to Kamschatka. Russian travellers in Bucharia mention some other species, as A. fulvus, A. lepto.dactylus, and A. musogaricus, which are not yet perhaps sufficiently distinguished from the bobac or from the souslik (Spermophilus 


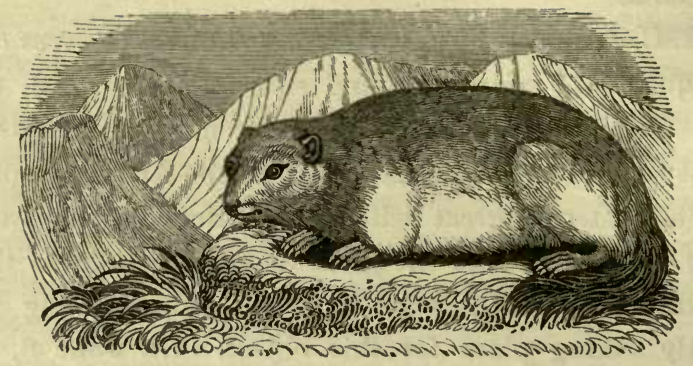

the tail. The fur on the upper parts of the body is yellowish grey, with ash-coloured tints about the head, and of a rich fawn colour on the belly. The head is large and depressed; the ears are very short, round, and often nearly hid in the fur; the eyes are large; the teeth, altogether, amount to twenty-two, each jaw having two incisors in front, with five grinders on either side of those in the upper, and four on either side of those in the lower jaw. The legs are short, but strong; the fore-feet, or paws, have four toes, and a tubercle instead of a thumb; the hind-feet have five toes; the nails are strong and compressed; and the tail is short and bushy.

Marmots live in societies from four to fifteen in number, and pass the greater part of their lives in their subterranean burrow, which consists of an oval cavity or chamber, formed with great art, and spacious enough to contain several of them, and having a large passage, which divaricates in such a manner as to present two outlets to the surface of the earth. These recesses are prepared on the declivities of elevated spots, and the chamber is well lined with moss and hay.*

citillus). The animal sometimes called the German marmot is the common hamster (Cricetus frumentarius). In America are found the Maryland marmot, there called woodchuck, or ground-hog (A. monax), the barking marmot, or prairie $\operatorname{dog}$ (A. Ludovicianus), the Quebec marmot ( $A$. empetra), A. Franklinii, A. Parrii, A. Richardsonii, and A. pruinosa.

* Authors have been very kind to the marmot, for they have given it credit for more ingenuity than it is probably aware of; and I only wish it could read 
They run much swifter up hill than down; and ascend trees, rocks, and walls with great facility. The chimney-sweepers of Paris, who are all Savoyards, are ludicrously said to have learned their art from the marmot.

They feed on fruits, roots, \&c., and use their paws to convey them to the mouth, while they sit upon their hind-quarters. They make no provision for the winter; but as soon as the frosts set in they betake themselves to the burrow, close up the entrances to it, and gradually assume a torpid state, and thus remain as though dead and buried till re-animated by the warmth of spring. When they awake they find themselves in an extremely lean condition, as might be expected after such a long sleep and total abstinence.

The female produces but one litter in a year, which consists of three or four young ones.

If a young one be procured and domesticated, it soon becomes tame and playful. Buffon says, it may easily be taught to dance, to brandish a stick, and to obey its master's orders. From its squat muscular make, it has great strength; but if not molested it lives in peace and harmony with all the other domestic animals, except dogs, which it so much dislikes that it will attack the largest mastiff, biting it with the four large incisor teeth, which are the marmot's most formidable weapons. It is very apt to gnaw furniture, and even to make holes through

their accounts of its actions. Many of them tell us it " makes hay while the sun shines," biting off the grass, and then turning and drying it in its beams. But the ingenuity of these hay-makers does not stop here. The next step is to get the hay home; and, as if marmots had neither mouths nor paws, we are called upon to believe that they use one of their companions as a cart or truck. It is evident, however, that in this case our popular authors have chosen wilfully to retail as a fact that which old Gesner had merely advanced as an inference. Thus modestly speaketh he: "One of them falleth on his back, and the residue load his belly with the carriage, and when they have laid sufficient upon him, he girteth it fast by taking his tail in his mouth, and so they draw him into their cave: but I cannot affirm certainly whether this be truth or falsehood; for there is no reason that leadeth thereunto, but that some of them have been found bald on the back." (Historie of Four-footed Beasts, translated by Edward Topsell, Lond. 1607, p. 407.) The modern versions only differ in making the female act as the hay-cart. 
wooden partitions. It will eat indiscriminately of flesh, butter, insects, herbs, roots, fruits, pulse, and bread. It seldom drinks water, milk being the only liquid it likes, and to obtain this it will steal into a dairy and lap it up. Like a tea-totaller, it refuses the juice of the grape, "the merry cheerer of the heart." When pleased or caressed it often yelps like a puppy ; but when irritated or frightened, it utters a loud and piercing whistle.

The Savoyards, who dig the marmots out of the earth when in their torpid state, eat their flesh, which is firm and tender; but, being very fat, and having a disagreeable flavour, it is said that it occasionally produces vomiting. They therefore remove the fat, which they esteem as medicinal, and then salt and dry the lean, as if they were preparing bacon. The skin being very furry is a valuable article.

\section{MOUSE, OR RAT KIND.}

These animals may be briefly characterized by having a long and scaly tail, and three molar teeth, the largest of which (the anterior one) has its crown divided into blunt tubercles, which, by being worn, give it the shape of a disk, sloped in various directions. From their great fecundity they are mostly exceedingly numerous wherever they are found, and prove highly injurious, as they gnaw and devour almost every article of food, apparel, and furniture.

\section{The Common Mouse.-(Mus musculus, Linn.)}

The length of the common mouse, best known as an inhabitant of our houses, though many keep to the fields, is three inches and two lines from the head to the end of the body, or including the tail, six inches and one line. Its fur is brownish 


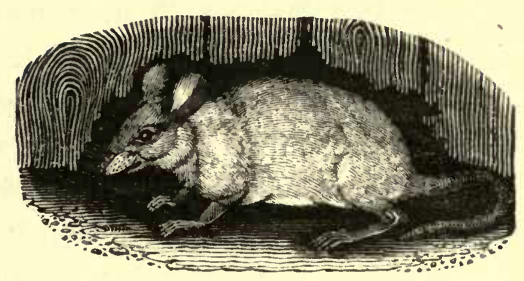

ash colour above, and light ash colour beneath. The ears are about half as long as the head, and the tail is rather shorter than the body.

Its pilfering and destructiveness in-doors are too well known to require any special notice here; but among the wheat-ricks it commits much greater devastation, eating the grain and forming a labyrinth of its burrows through the whole mass, in company with the long-tailed field mouse (Mus sylvaticus) and the harvest mouse (M. messorius).

Though timid it is easily tamed, and becomes a pleasing little pet; but it requires great vigilance to keep it from the jaws of its great enemy, the house cat, to whom it is always a bon-bouche. I may here introduce an account of an interesting experiment which a person tried some years ago, to ascertain whether the mouse has an instinctive dread of the cat. He caught a mouse at the extremity of one of the galleries in the Newcastle coal mines; and as no cat had up to that period been introduced into the mine, he carried his prisoner home; and in order that he might regain his self-possession after being introduced to day-light, which in all probability he had never seen before, he kept him confined in a glass lantern for a few days, where he soon became so tame as to eat in his presence. On the fifth or sixth day after his capture, the little fellow was sitting on an upright piece of stick in the lantern and licking his body, when a young cat was introduced into the room. She very soon perceived the mouse in the lantern, and dashed at him with her customary ferocity. "To my surprise and amuse- 
ment," says the writer, " my prisoner continued licking his fur with all the coolness imaginable, without even condescending to notice the furious efforts of the cat to break his windows and devour him. This experiment was frequently renewed for the amusement of my friends, and invariably with the same results. It must be obvious that the mouse could not be aware that the glass afforded him a sufficient protection; and it appeared to me that he had no natural or instinctive dread of the cat." *

Mr. Blyth tells me that dogs will not eat the common mouse, though the cat does.

Mr. E. G. Ballard says, that on removing a bag of malt in the warehouse of the Dublin Custom-house, several mice were disturbed and killed. Their bodies were left on the floor; but about four hours afterwards, no one having been in the warehouse meanwhile, there were but two or three remaining, and these were surrounded by several live mice. In the course of another hour, not one dead or alive was to be seen. Shortly afterwards, however, some of the little corpses were discovered comfortably buried in the interstices between some reams of paper, placed more than six feet from the ground, and others were found deposited in some hides.

Mr. Macdonald of Scalpa, in the Hebrides, whose grain had suffered considerably from mice, discovered some years ago, that if some stalks of wild mint (Mentha hirsuta), with the leaves on, be placed along with grain, cheese, or any other articles subject to their attacks, these animals will not touch it, being deterred, perhaps, by the smell of the plant proving offensive to them. "At the present day, the Italians place a bough of the butcher's broom (Ruscus aculeatus) round their bacon and cheese as a protection from mice." $\dagger$

The female mouse breeds several times in the year, and at all seasons. She ordinarily produces from five to seven young at a time. When a fortnight old, the young are able to leave the mother entirely. They breed at so very early an age, that

* Penny Magazine, No. 55.

+ Arts of the Greeks and Romans (1833), p. 349. 
from a single couple a great number are produced in the course of a few months. Aristotle says, that in a very short period no less than a hundred and twenty mice sprang from a single female which he had confined in a closed vessel filled with grain.

The zoological dealers sell cross breeds between the brown mouse and the white variety. I have seen at one shop in London some very beautiful tortoise-shell mice, for which the price was half a crown each. Mr. T. W. Edwards showed me recently a very extensive collection of living mice, many of which were cross-breeds mottled with black and white. In M. W. F. Edwards's Caractères des Races Humaines (1829), p. 25, it is, nevertheless, stated that M. Coladon, chemist at Geneva, tried a long course of experiments on this subject, always coupling a grey mouse with a white one, and found that the offspring were invariably either entirely white, or entirely grey, like one or other of their parents; there was no mixture of colour.

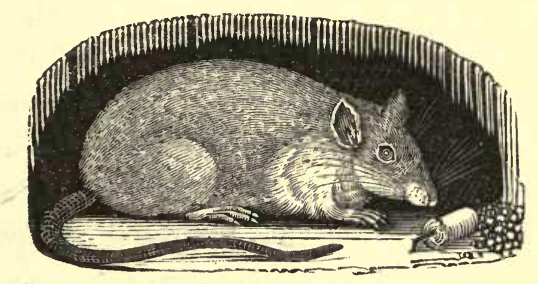

The Common Brown Rat.*-(Mus Decumanus, Pall.)

It is well known that the indigenous black rat (Mus rattus) of Great Britain, has become nearly extirpated by the present and more powerful species, which appears to have been accidentally introduced from Persia. Pennant states that the brown rats arrived in England about 1728, and in Paris about twentythree years after that period; but a modern writer asserts that

* Improperly called the Norway rat. 
they appeared in France towards the middle of the sixteenth century, and were first observed in the neighbourhood of the capital.

"Its first arrival, as I am assured," says Goldsmith, "was upon the coasts of Ireland, in those ships that traded in provisions to Gibraltar; and perhaps we owe to a single pair of these animals the numerous progeny that now infests the whole extent of the British empire."

Pallas tells us that they arrived at Astracan, in the autumn of 172\%, in such numbers, and in so short a time, that nothing could be done to oppose them. They came from the western desert, and traversed the waves of the Volga, which unquestionably must have swallowed up part of their horde. They have not advanced any further north, and are not to be found in Siberia.

America, according to Pennant, received its stock of brown rats by a ship from Antwerp.

Cuvier says that, in some parts of France, the brown rat is not known. In England and Ireland it is more extensively distributed than in Scotland. In the earliest Scottish records it is stated, that there are no rats whatever in the district of Buchan; and old Hector Boëthius, in his History and Chronoklis of Scotland (1541), adds, "as soon as they are brought there they die ;" a circumstance also asserted in Shaw's History of Morayshire (Edin. 1775), p. 160.

Dr. Fleming is of opinion that the cause of the black rat, or true British rat, having become so scarce, is the more general use of tiles and slates on house-tops instead of thatch ; but most naturalists think, and perhaps more correctly, that the scarcity of the black rat arises from the superior strength and tyranny of the brown rat; for it certainly does appear to be true, that wherever the brown rat has settled, the other species has soon become scarcer, and often entirely disappeared. This view of the matter may be greatly supported by the following facts, which occurred abroad, and which relate to other species. Dr. Lund says that, in Brazil, a species of rat, which'he calls Mus setosus, "made its appearance about the commencement of 
the present century, and has driven out of the houses a smaller species, of a pretty chocolate brown colour on the back, chesnut brown on the sides, and white on the belly, with a fine short fur, and a short silky tail."* Sir Charles Price, who had an estate in Jamaica infested by rats, imported, with much trouble, a very large and strong species to extirpate the others. "The new comers," we are told, "answered his purpose beyond his expectation; for having attacked the native rats with such spirit, that in a short time none were left, they extended their exertions to the cats, and killed them also; and since then, Sir Charles Price's rats, as they are called, have increased so prodigiously, that they are now a greater nuisance to the island than all their predecessors." $†$

The length of the brown rat, from the head to the end of the body, is about ten inches and three-quarters, or, including the tail, nearly one foot and seven inches. The head and upper part of the body is light brown, mixed with tawny and ash colour; the end of the nose, the throat, and the belly, are dirty white inclining to grey; the feet and legs are almost bare, and of a dirty pale flesh colour; the beginning of the tail is light brown, but the remainder of it consists of about one hundred and eighty scaly rings of a dusky colour, each ring having one or two hairs growing from beneath it.

It is the most destructive of our smaller mammals, devouring our meat, rabbits, poultry, game, birds, fish, corn, and other articles of food; nor does its mischief end there, for it gnaws our furniture, clothes, books, papers, \&c. If assailed by man, it has sornetimes the audacity to spring upon him and inflict a severe wound. It is related that, several years ago, four condemned criminals in Newgate managed to descend from a water-closet into a sewer, having formed the daring project of proceeding along it to the Thames; but by the time they got as far as Fleet-market, they were beset by such legions of rats, that the unhappy men screamed with agony; and the people

* Mag. Nat. Hist. (New Series, 1840), vol. iv. p. 55.

+ Lewis's Journal of a West India Proprietor in Jamaica. 
having heard them, opened the gratings and hoisted them up, whence they were conducted back to prison. The men who enter the sewers to clean and repair them carry lights, and are in too great force to be attacked. When several rats are confined together in a box they fight desperately, and the vanquished are devoured by the victors.

"The Regent's Park Zoological Gardens are greatly infested by rats; but as they are too cunning to risk the danger of being caught during the day-time, or alarmed, perhaps, at the concourse of visitors, they are often seen towards evening crossing the canal in a body from the opposite shore, in order to land in the gardens, and enjoy their night's depredations, returning in the morning in the same manner to their daily retreat." *

These animals being so exceedingly obnoxious, it may be well to mention, that if chloride of lime be sprinkled about their haunts in dwellings, they will be effectually banished while any smell of the liquid remains. But if it be desired to kill them, instead of driving them to one's neighbours, an excellent and cheap composition may be employed, and without endangering the lives of dogs, poultry, pigs, or children. Get some plaster of Paris and thoroughly mix it, in its unslaked state, with about double its, weight of oatmeal. The rats, not detecting the adulteration, eat the mixture eagerly; but the moisture in their stomachs will cause the plaster to "set," and form an indigestible hard mass, producing death by constipation; and when the animal is opened a fine cast of its stomach may be extracted. The Glasgow Herald, in April 1840, stated that Mr. Baird, of Greenbank, Pollokshaws, sowed a small plot of garlic in the spring of 1838, and "when the grain was deposited in his stackyard in harvest, a little of the garlic was strewed on the ground, and it was found, when the stacks were put in, in the following spring, that they were entirely free from the inroads of the rat. In 1839 he repeated this experiment, and last year he took in the last of his stacks without having sustained the slightest damage."

* History of British Quadrupeds (1837), p. 319. 


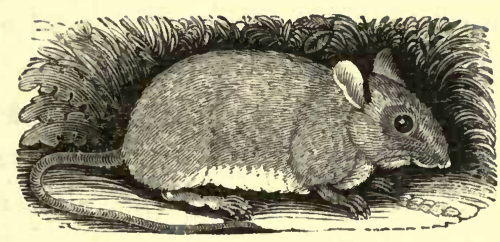

The Long-tailed Field Mouse.

(Mus sylvaticus, Linn ; M. domesticus medius, Ray.)

Wood Mouse. Bean Mouse.

This well-known species is distributed over almost the whole of the temperate parts of Europe.

It varies much in size, but usually the length of the head and body is about two inches and three-quarters, and that of the tail nearly two inches and a half. Not only the tail, but the body, legs, ears, and whiskers are longer than those of the common mouse; its eyes, which are black and very prominent, are larger, and its ears are broader. The whole of the upper surface, and the sides of the head and body, are yellowish brown, mixed with some dusky hairs; the under parts are whitish, with a very slight greyish tint here and there, and a yellowish grey patch on the breast. The tail, which consists of about twenty-five vertebræ, is slender and tapering, covered with short hair, brown above and white beneath.

For its dwelling it generally avails itself of some small natural excavations under the roots of trees, or of the deserted burrow of the mole, and makes such repairs and alterations as may be necessary. Frequently, however, its dwelling is entirely formed by its own labour. "I do not know," says an old writer, "any animal who builds a more commodious habitation under ground than the field mouse, who scoops out several subterranean cells having a free communication with one another."*

It feeds on grain and plants, and hence, being a very abun-

* Spectacle de la Nature, or Nature Displayed. Lond. 1744, p. 214. 
dant species, it proves one of the greatest pests in corn-fields, plantations, and gardens. Besides satisfying its present appetite to repletion, it carries away a considerable quantity of beans, corn, seeds, nuts, acorns, beech mast, and even roots, which it conceals in its subterranean store-room, in case of a dearth in winter.* To get at the kernel of a nut, it drills a small round hole in the side of the shell; a process different from that adopted by the squirrel, or the bird called nut-hatch (Sitta Europea).

Professor Bell says, that "when driven by hunger, they will eat various animal matters, young birds, or mice, or even each other, the smaller and weaker falling victims to the stronger."

In some years different countries have been visited by what we may term irruptions of mice, an enormous and formidable increase of them. Ashdod, in consequence of the captivity of the ark, was smitten with multitudes of mice. Sennacherib's army, when on the point of invading Egypt, was, according to Herodotus, assailed by an innumerable host of mice, who by devouring their bow-strings, shield-straps, baggage, \&c., foiled the invader. An exactly similar visitation befel some of the Teneri, as they lay encamped during the night-time, near Amaxitus, a town of the Troad. Some geographers have thought that the country called Mysia, derived its name from its abounding in mice. "M. Varro tells us that the natives of Gyarus, an island of the Cyclades group, had been driven out by mice; but considering the prolificness of mice, it ceases to be a wonder whence comes such a host of them to destroy the harvests. It is still a secret how these immense numbers so suddenly disappear; for they are not found dead, neither is there any person to be met with who, during the winter, has dug up a mouse in the fields. Many have also made their appearance in the Troad, and have now driven the inhabitants thence. Their appearance

* "Mr. Wagstaff says, that the tussocks of wheat seen to arise in many fields, are owing to their granaries, which he has often found to contain nearly a hatful of corn, which grows into a tuft if the animal be accidentally destroyed. These tufts he recommends to be divided and transplanted in the spring."-Stawell's Translation of Virgil's Georgics (1808), p. 311. 
is attributed to drought." * Arnobius has made particular mention of the ravages of mice. "Glance through the various annals written in different languages, and you will learn that all countries have frequently been desolated by them and abandoned by their cultivators. Every kind of produce is attacked and eaten by mice and locusts. Pass through your own histories [end of the third century], and you will be informed how the former age has been affected by these pests, and brought to the miseries of poverty." And again he says, "in Syria mice and locusts have abounded prodigiously." $\dagger$ It is said that Helgay, a village three miles from Downham in Norfolk, "is once in three or four years infested with an incredible number of field mice; but whenever this visitation occurs, a prodigious number of owls are sure to arrive and tarry till they have destroyed these mischievous little animals." $\ddagger$ In the Annual Register for 1773 , it is stated, that in September of that year, the villages of Putschwitz, Kleinbautzen, Walswitz, Gleinin, and Kannewitz, about a mile distant from Bautsen, were reduced to a most deplorable state by the field mice having devoured all the produce of the soil. Gilbert White says in his diary, "The mice have infested my garden much by nestling in my hot-beds, devouring my balsams, and burrowing under my cucumber-basins; so that I may say with Martial :

Fines mus populator, et colono

Tanquam sus Calydonius timetur."

"In May and June, 1832, the shepherds' dogs were incessantly killing mice, over a great extent of mountainous district, including all the western divisions of Inverness-shire and Rossshire. The shepherds observed that these mice increased as the summer advanced; and that the grassy parts of the mountains were much destroyed by them, and became brown. The manager of Mr. Frazer's sheep-farms at Eskdale, says that, as near as he could estimate, they devoured about sixty-four bushels of his potatoes; and that he dug out of one hole no

* Nat. Hist. viii. 29 ; x. 65.

+ Disp. contra Gentes, i. $\S 2$ et 5.

$\ddagger$ Mirror (1836), vol. xxviii. p. 458. 
less than seventeen of them, of various colours, probably young ones; and he adds that their general colour was brown, with a white ring about the neck; the tail likewise tipped with white; and a light coloured stripe down the nose and along the back. The foxes, early in the summer, finding such a supply of food, which they appear to prefer to all others,* ceased from that time to destroy any more lambs; but sometime in the next spring, the mice having retired, the foxes again fell upon the sheep (the lambs at first) with unwonted fury." $\dagger$

In July 1833, a similar irruption of mice occurred in the county of Galway, in Ireland, and did great damage to the crops of grass and corn. In the Times of August 13, 1834, appeared the following extract from a Frankfort journal, "Our fields have been so overrun with mice, that in one commune near twenty thousand of those mischievous little animals have been killed. It is impossible to form an idea of the destruction they commit. No sooner is the harvest over, than they betake themselves to the vineyards, where they make a greater devastation than amongst the corn. In an adjoining county there is a race of small black rats, which appear to be multiplying to an equal extent with our mice." Later in the same year, the Morning Herald (October 14) mentioned, that a sudden malady had occurred among the mice in the neighbourhood of Frankfort, thousands of them being found dead or dying in the fields. "A few years ago, soon after the formation of the new plantation made by order of the crown, in the Forest of Dean, Gloucestershire, and in the New Forest, Hampshire, a sudden and rapid increase of mice occurred in them, and threatened destruction to all the young plants. Vast numbers of oaks and chesnuts, five years old, were killed by the mice eating through

* “I have long known that dogs (and, I think, the shepherds' beyond all others) are particularly fond of the Alpine mouse; and, although I have repeatedly tried, in various quarters, to obtain specimens, it has been in vain, as the shepherds tell me that they only discover them by their dogs, who instantly swallow them."

† Abridged from Mag. Nat. Hist. (1834), vol. vii. p. 181. 
their roots, and generally just below the surface of the ground. Holly bushes, five and six feet high, were barked round the bottom, and in some instances the micehad crawled up them and were even feeding on the bark of the upper branches. In the reports made to government on the subject, it appears that the roots had been eaten through wherever they obstructed the run of the mice, but that the bark of the trees constituted their food. This was ascertained by confining a number of mice in cages, and supplying them with the fresh roots and bark of trees, whence it was found that they fed greedily on the latter, and left the roots untouched. Traps were set, poison laid, and cats turned out, but nothing appeared to lessen their numbers, until pit-falls were dug about twenty yards asunder, in some of the Dean Forest plantations, being about twelve in each acre of ground. These pits were from eighteen to twenty inches deep, and two feet one way, and a half the other, and they were much wider at the bottom than the top, being excavated hollow under, so that the animal when once in, could not, easily get out again. In these pits, at least thirty thousand mice were caught in the course of three or four months, that number having been counted out and paid for by the proper officers of the forest. But it was calculated that a much greater number were taken out of the pits by stoats, weasels, kites, hawks, owls, crows, jays, and magpies, for as the mice increased, so did the predacious birds, of which at last there was an incredible number. It appeared from the weekly reports of the deputy surveyor of the New Forest, that about as many were destroyed there, allowing the same calculation for those eaten by vermin : and in addition to which, it should be mentioned, that these mice were found to eat each other when their food fell short in winter. Putting these circumstances together, the total number of mice destroyed in the two forests, probably amounted to more than two hundred thousand."*

Dr. Forster says, that " field mice are found in great numbers * $\Lambda$ bridged from Jesse's Gleanings in Natural History. 
on the paths and highways in August;"* but he does not notice the curious fact, that during that month they are found in a very weak state in such situations.

The field mouse is a gentle and timid little creature, easily tamed, and rendered perfectly familiar. Professor Bell says, he has seen " several of them running out upon the breakfast table of Dr. Leach, from whose hand or plate they would feed without the least fear, and allow him to handle and play with them as freely as the dormouse (Myoxus avellanarius, Desm.)."

The female field mouse makes her nest very near the surface of the ground, and often in a thick tuft of grass; and produces from seven to ten at a litter, and probably has more than one litter in the year.

Gilbert White relates that, while his servants were pulling off the lining of a hot-bed, an animal very nimbly leaped out of it but made a most grotesque figure; " nor was it without great difficulty that it could be taken: when it proved to be a field mouse with three or four young clinging to her teats by their mouths and feet. It was amazing that her desultory and rapid motions did not oblige her litter to quit their hold, especially as it appeared that they were so young, as to be both naked and blind." $\dagger$

More recently, Mr. Joseph Clarke says, that a nest having been ploughed out of the ground at Saffron Walden, Essex, the female mouse ran away, but very heavily and awkwardly, and on being overtaken and killed, two young ones were found clinging so tenaciously to her teats, that some force was necessary to remove them from their dead parent.

\section{The Barbary Mouse.-(Mus Barbarus, Linn.)}

This species, the prettiest and most elegant of all, was first described by Linnæus in the addenda to the twelfth edition

* Cyclopadia of Natural Phenomena, p. 96.

+ Natural History of Selborne (1789), Part ii. Letter xiv. 


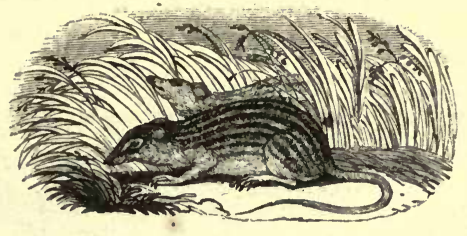

of his Systemà Natura. For a long period after that publication, it entirely eluded the observation of zoologists, until of late, when a litter of five young ones was obtained at Barbary, and three of them, having survived the passage to England, were placed in the Regent's Park Zoological Gardens, in 1828. Mr. Bennett, describing them, when they had been in the collection above a year, says-

"They are intermediate in size to the common rat and common mouse, while Linnæus describes his to have been smaller even than the latter; but perhaps he had seen none but smaller individuals; which supposition is in some degree strengthened by his adding, that they were occasionally marked by a scarcely perceptible line between the lateral stripes: a circumstance which not unfrequently occurs in the young of striped animals, and slight vestiges of this original marking were visible in the society's specimens. In every other respect the coincidence was complete. Their ground colour was dark brown, marked on each side with five or six yellowish stripes, about half as broad as the intervening spaces, extending along the whole length of the body, and becoming confused towards the under parts, which are nearly white. On the fore-feet only three toes were at first sight observable ; but on closer inspection, the rudiments of a thumb and also of a fifth toe were detected. The teeth were precisely similar to those of the other rats.* During their captivity, these animals appeared healthy and lively; and with reference to the habits of the genus, were moderately tame, though shy and timid."

* Mr. J. E. Gray, nevertheless, says that this animal belongs to his new genus Golunda, which is characterized merely by having " the grinders, when 


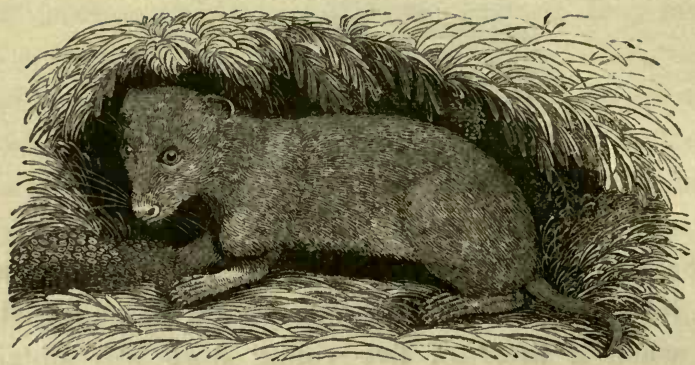

The Common Hamster.

(Cricetus frumentarius; C. vulgaris ; Mus Cricetus, Linn.)

German Marmot.

The hamster inhabits the whole tract of countries extending between the Rhine and the Ural Mountains, and between the German Sea and Baltic to the north, and the Danube to the south, wherever it finds its congenial soil,--deep, alluvial mould, with a substratum of clay. It is said also to exist in Siberia, but is nowhere more common than in Thuringia.

The largest male specimens measure, from the tip of the nose to the end of the body, thirteen inches, or, including the length of the tail, one foot three inches; the full grown females are about one fourth smaller. The hamster is greyish brown, or hare-coloured above, with three large yellowish spots on each side occupying the flanks, the regions above the shoulders, and

perfect, low, with a broad flat crown; the cross ridges of the crown of the upper grinders divided into three distinct slightly raised tubercles: the rest like the genus Mus." Mag. Nat. Hist. (New Series, 1837), vol. i. p. 586.-We wish naturalists who are fond of needlessly forming new generic and specific names, would remember the words of Ben Jonson, who says "A man coins not a new word without great risk and less profit; for if it be refused the scorn is assured, and if it be accepted the praise is but small." Yet some naturalists we could mention seem to think it their most laudable employment to burden science with new fashioned genera, and that the more synonymes they make in a life-time, the higher should be their reputation.-J. H. F. 
that behind the cheeks, the latter spot being continued towards and round the mouth; the cheeks and regions round the ears are of a russet colour; the feet are white. The belly is black. In several neighbourhoods in Germany, there is a black variety of the hamster, with only the nose and feet white; and a mixed breed of the common and black variety is said to exist, and to be grey. Albinoes are very scarce, but have been occasionally found. The teeth are sixteen in number, twelve of which are molars, the rest incisors. The animal has two membranous cheek-pouches, which have a wide communication with the cavity of the mouth, from whence they extend between the skin and muscles, along the neck and shoulders, in a somewhat converging direction, so that the shut ends are nearer each other than the open ones in the cavity of the cheek. "Their outer surface," Dr. Weissenborn says, " is perfectly smooth, but the inner one is closely covered with longitudinal and parallel dotted lines, the dots being almost square, and constituting mucous cells or glandules; wherefore the inside of the pouch is constantly wet and smooth, or it would easily be torn by its contents, which often present rough or sharp surfaces. Between their two attachments these pouches, when empty, extend like two loose narrow canals; but when dilated, they are oval, two inches and a half in length, and one and a half in breadth, wherefore their periphery, where it is widest, measures about five inches and a half. When these pouches are full of food or inflated by the animal, its head and neck look twice as broad as usual. In each of these pouches the hamster can conveniently carry home about an ounce and a half of corn, or the same quantity of green fodder. It empties them by stroking them from behind with its fore-paws; a rather strong muscle

* The badger also has the belly of a black colour; a coincidence deserving physiological investigation, as both that and the hamster are crepuscular, subterranean, and winter-sleeping animals. "The cause of this peculiar coloration of these two animals," Dr. Weissenborn says, " may perhaps be traced to some general law of nature, especially as the mole, which is strictly subterranean, is altogether black, although the exclusion of light be, in general, a hinderance to the development of pigments." 
which they possess, perhaps, facilitates this operation by its contractions. The pouches may also serve as a sort of craw or first stomach, as in almost every hamster that has been dissected, there were found in them a few grains in a state of maceration; and I have likewise observed that the hamster fills its pouches with animal food, of which he never lays in a store at home. However, the animal often eats the grain just as it finds it, and therefore this use of the pouch is not absolute. The valve of the cardia or esophagus shuts so closely upwards, that it is a sure proof of the hamster not being a ruminating animal, although its stomach is double.

"The hamster's locomotion is comparatively slow. It is easily overtaken by man, even when making towards its burrow with all possible speed. Its movements are most appropriate to its habits of digging, creeping, and climbing up and down perpendicular holes. During the day the hamster sits in its burrow, rolled up like a ball, with the head bent under the chest : so at least we may conclude from the observation of specimens in captivity. About sunset it begins its first ramble, which lasts till about midnight, when it rests till an hour before sunrise, and then takes a second ramble, which it continues until morning. It is only in dark and gloomy weather that the hamster is ever found above ground whilst the sun is fairly above the horizon. During these rambles, its first object is to procure grain, and other vegetable food, wherewith to fill its pouches. As soon as it hears a noise, it stands plantigrade on its hind-legs, like a bear; and if the object of its attention be some living prey, as a mouse, it quickens its pace into a gallop, or 'ventre-a-terre.' Whilst quietly walking about its occupations, it sometimes utters a succession of short growling sounds; but when irritated, even only by some noise, its voice is squeaking and shrill, and in the height of passion it is not unlike that of a pig about to be killed. When the fore-part of its pouches become filled with food, it strokes them backwards with its paws, to make room for a new supply; and when they are thoroughly full, it walks home, to add their contents to its store. If surprised 
on its way by an enemy, the hamster, not being able to fight while loaded, empties its pouches by quickly striking them with its fore-paws, and then is ready for battle. Its movements in fighting are so violent and heavy, that they often miss their object. With the single exception of its living in peace with the female for only a few days in each breeding season, the hamster may be said to be constantly at war with every living creature or moving object which happens to come near it. It will jump with equal fury at a waggon-wheel or at a horse travelling along a road, and a young hamster will sometimes do so as well as an old one. Horses have now and then been so frightened by its screams and bites in the dusk of the evening, as to run away. From men or dogs it will usually, though not always, try to escape; it then takes the nearest course to its burrow, from which it is seldom far distant. When its pouches are full, it always takes to its heels at first, and if its burrow be only twenty or thirty yards off, it tries to reach it with its cargo, but never fails to pop its head out of the hole, screaming furiously in defiance. If the burrow be further off, it tries to get a little a-head of its pursuer, to obtain time to empty its pouches; whereupon it stands up and faces its enemy, puffing out its pouches, squeaking, screaming, and jumping against him to the height of from one to two feet. When he retreats a little, the hamster hops after him like a frog. At such times the animal is quite intoxicated with fury, caring for no wounds, and fighting till death. Old hamsters do not usually retreat before man, when sitting near their burrows with their pouches empty. At such times, I have killed several. Dogs are very eager to destroy the hamster, but never devour it. They prove, I believe, in many neighbourhoods, great preventives to the hamsters multiplying to an injurious extent. Some hreeds, as pointers and large terriers, soon acquire a knack of killing them at one bite, by catching them by the middle of the chest; but when the animals are better matched, the combat is protracted, and the hamster often succeeds in gaining its burrow, after repeatedly beating back the dog. This obstinacy in fighting, in spite of 
wounds, gives the hamster the victory over the rat. A combat between an old hamster and an old rat, lasts very long, but ends with the death of the rat, the former being the most courageous animal. It never falls in with another of its own species, without trying to make it its prey, the weaker, if not killed, getting more or less severely wounded." *

The hamster consumes a great quantity of valuable green fodder, as well as corn from the time it begins to ripen, during spring, summer, and autumn,- and an old one sometimes lays up a winter store of one hundred weight of horse-beans, or sixty-five pounds of corn, \&c., which is lost to the farmer. The parishes which are much infested with this depredator have therefore, from an early period, paid premiums out of the public money for dead hamsters. It appears from the official records kept at the Mansion-House of Gotha that, from the year 1817 (when a general crusade was undertaken against them) to the year 1837 inclusive, the total number of hamsters received there amounted to 286,839 , and the total sum paid in rewards for them was five thousand three hundred and ninety-six dollars, two shillings, and fourpence halfpenny. To give a better idea of their abundance, it should be observed that the whole of the fields belonging to the town of Gotha comprise an area of less than seven thousand acres. The stores which the hamsters collect in their burrows are sought for by poor people, who possess neither farm nor land, and who avail themselves of the positive law to sacrifice the animal and possess themselves of the stolen property.

About the beginning or middle of October, the hamster shuts itself up in its burrow by filling the whole length of the passages with little rounded pellets of earth, which, though they be rammed together very firmly and effectually exclude the cold, yet admit of a partial ventilation. When the winter has fairly set in, it becomes torpid. Soon after the middle of March, it awakes, abandons its winter-burrow, digs new ones, rambles about, and collects its tithes of the corn, \&c., as before.

* Abridged from the Magazine of Natural History (New Series, 1839), vol. iii. p. 474-483. 
The female produces at least two litters in the year, each consisting of from six to eighteen young ones, according to the age and size of the mother. They are born blind and naked, but with the full number of their teeth. Their blindness lasts eight or nine days. They grow very rapidly, begin to dig when but a fortnight old, and as those of the first litter, born at about the beginning of June, become capable of breeding within the same season, an adult female may produce one hundred of her species in a year.

The flesh of the hamster, according to Dr. Weissenborn, is very good and wholesome meat, especially in winter; but, owing to prejudice, the richer classes of society reject it. The gipsies, the gardeners of Elfurt, and the poor in Silesia, eat a great many hamsters. From March to St. John's day, the fur of the hamster is in its finest condition; and is esteemed for lining coats, night-gowns, \&c., as being light and durable.

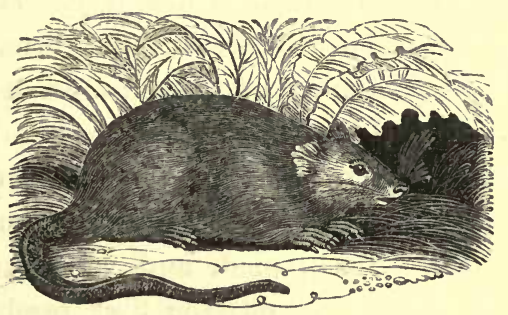

The Ondrata, Musquash, or Canadian Musk Rat.* (Fiber zibeticus, Desm.; Ondrata zibeticus, Lacep.)

This animal is as abundant in some parts of North America as brown rats are in our own country. Dr. Richardson says,

* The Sorex moschatus, a species of shrew, is improperly called the Russian musk-rat, though it belongs not only to a different genus, but quite a distinct order; and the Mus pilorides, the largest and most destructive rat known, is called the musk-rat of the Antilles. Goldsmith is in error when he states that the Canadians call the ondrata the stinkard, for that name they apply to the skunk (Mephitis Americanus). 
the southern limit of its geographical range extends to about $30^{\circ}$ north latitude, and its northern to the mouth of the Mackenzie, $60^{\circ}$ north latitude. Bartram says, it is found in the North of Georgia and Florida.

The ondrata varies considerably in size; but the ordinary length of the head and body is one foot two inches, and that of the tail eight inches and a half.

The head is broad and short; the eyes are large; and the ears short and hairy on both surfaces. The body is thick and rather flat; the legs are very short; the hind-feet large;* and the tail, which is long and compressed, convex on the sides, with its acute edges in a vertical plane, tapers gradually from the middle where it is thickest, to the end, which is blunt. The fur on the back is dark umber brown; that on the sides of the body, anterior part of the belly, middle of the breast, sides of the neck, and on the cheeks, is shining yellowish brown; while that on the chin, throat, sides of the chest, and posterior part of the abdomen, is ash-grey. The sides of the tail are sparingly covered with sleek, dusky-brown hairs, which being short allow a number of small roundish scales, of the same colour and well separated from each other, to appear through them; along the acute edges of the tail the hair is longer, and is dark brown on the upper edge, and soiled white on the under one. Black, pied, and white varieties of the ondrata are occasionally found, the first rarely, but the last not unfrequently.

Small lakes, swamps, or the grassy borders of sluggish streams with muddy bottoms, are the ondrata's favourite haunts. Its habitation, dug, in their banks, is always concealed by a bush or clump of trees. In this abode, which is neatly constructed, and quite smooth on the inside, it generally remains till dusk, when it comes out to feed.

The animals live in pairs during the summer, and the male and female are rarely seen apart. Though watchful, they are not very shy, for they will approach very close to a boat or

\footnotetext{
* Hearne incorrectly states that they are webbed.
} 
canoe. They may be frequently seen sitting on the shores of small muddy islands in a rounded form, and not easily to be distinguished from a piece of earth, until, on the approach of danger, or the instant they perceive the flash of a gun, they plunge into the water. In the act of diving they give a smart blow on the water with the tail.

The ondrata is chiefly an herbivorous animal. Charlevoix says that in March, when it emerges from its winter quarters, it feeds on bits of wood, which it peels previous to eating. When the snows have dissolved it lives upon the roots of the nettle, and afterwards on the stalks and leaves of that plant. In summer it feeds on strawberries, \&c., and in autumn on other fruits. In the northern districts, the roots and shoots of the bulrush and reed-mace, and the leaves of various Carices and aquatic grasses, form their staple food. Pennant says, they are partial to the sweet-flag (Acorus calamus), which was considered by Linnæus to be the only aromatic plant growing in the northern regions, and, according to Dr. Richardson, does not grow to the northward of Lake Winnipeg. They are also said to feed on fresh-water mussels (Unio); and if famishing in winter they attack and devour each other.

On the approach of winter, these animals retire for the season. They then lodge apart, Charlevoix says, in some hole or in the hollow of a tree; and he adds, that " they likewise build cabins nearly in the form of those of the beavers, but far from being so well executed, and always by the water side." Dr. Richardson, also, says, "In the autumn, before the shallow lakes and swamps freeze over, the ondrata builds its house of mud, giving it a conical form, and a sufficient base to raise the chamber above the water. The chosen spot is generally amongst long grass, which is incorporated with the walls of the house, from the mud being deposited amongst it; but the animal does not appear to make any kind of composition or mortar by tempering the mud and grass together: there is, however, a dry bed of grass deposited in the chamber. The entrance is under water. When ice forms over the surface of 
the swamp, the musquash makes breathing-holes through it, and protects them from the frost by a mud covering. In severe winters, however, these holes freeze up in spite of their coverings, and many of the animals die. It is to be remarked, that the small grassy lakes selected by the musquash for its residence, are never so firmly frozen nor covered with such thick ice as deeper and clearer water. The Indians kill these animals by spearing them through the walls of their houses, approaching with great caution, for the ondratas dive when alarmed by a sound on the ice.* An experienced hunter, well acquainted with the direction of the chamber and the position in which its inmates lie, can transfix four or five at a time. As soon as, from the motion of the spear, it is evident that the animal is struck, the house is broken down, and it is taken out. The principal seasons for taking it are the autumn, before the snow falls, and the spring, after it has disappeared, but while the ice is still entire. In winter the deep snow prevents the houses and breathing-holes from being seen. One of the first acts of the hunter is to stop all the holes, except one, at which he stations himself to spear the animals that have escaped being struck, and come hither to breathe." Charlevoix states that the ondrata does not take any provision into its winter quarters, and that the Indians declared that not the least morsel of anything is eaten by it whilst the cold continues. Cuvier, however, says that they continue excavating the earth during that season to get the roots of plants. "Great numbers of these animals are destroyed by the inundations which cover the low grounds where they haunt; and in severe winters they are almost extirpated from some localities by the freezing of the swamps inhabited by them. Famine in such cases drives them to destroy each other. A great mortality, the cause of which is unknown, also sweeps them away, and the deaths at such periods (which are uncertain) are so numerous, that a furpost, where the ondrata is the principal return, is not unfre-

* Mr. E. H. Greenhow says, "the Canadians hunt them at dusk with dogs trained to the purpose." Mag. Nat. Hist. (1833), vol. vi. p. 511. 
quently abandoned till the fecundity of the animal has repaired, which it does in a very few years, the ravages of disease."*

In summer the ondrata burrows in the banks of the lakes, making branched canals many yards in extent, and forming a nest for its young at the extremity. They have three litters in the course of the summer, producing from three to seven at a litter, in $55^{\circ}$ north latitude, and begin to breed before they attain their full growth.

Hearne says, that the ondrata is easily tamed, scon becomes attached, and is cleanly and playful.

The fur, which much resembles that of the beaver but is shorter, is an important and rather valuable article of commerce. Dr. Richardson says, that between 400,000 and 500,000 skins are annually imported into Great Britain from North America, to supply the hat-manufacturers. The Canadians, much disliking the smell of musk, regard the ondrata with great aversion, yet when it is fat they esteem its flesh, somewhat resembling pork, to be very good eating.

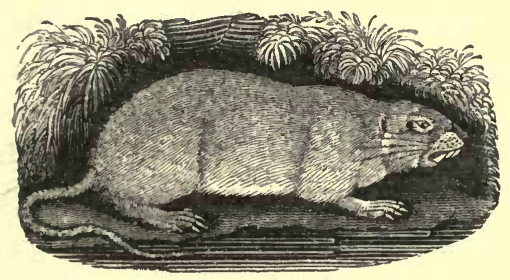

The Water Vole.

(Arvicola amphibius, Desm.; Mus amphibius, Linn.)

Water Rat.

The water vole, more frequently called the water rat, inhabits most parts of Europe. In Britain it is very common. It is 
intermediate in size to the black and common brown rat; its length from the tip of the nose to the end of the body, being a little more than eight inches and a quarter, or, including the tail, one foot one inch. The weight of the male, according to Pennant, is about nine ounces. Its head is larger and rounder than that of the more terrestrial rats; its nose is thick and blunt, instead of being attenuated like theirs ; the eyes are small and not very prominent; the ears are short, and scarcely appear through the hair; the incisor teeth are large, chisel-shaped, very strong, yellow in front, and so much resemble those of the beaver, that Linnæus in his Fauna Suecica applied the name Castor to the present species, which, indeed, is regarded by some modern naturalists as an aberrant form of that genus; the surface of the molar teeth, of which there are three on the sides of either jaw, is formed of alternate triangles arranged on each longitudinal axis; on each foot are five toes, but the inner toe of the fore-foot appears to be very small, because its last phalanx only is conspicuous beyond the skin, and as its first joint is very flexible, it probably serves as a thumb; the hinder feet are not webbed, though united to a short distance from the base. The fur on the head and body is thicker and longer than in the rat's; it is of a bright reddish brown mixed with grey above, but yellowish grey, or iron grey on the belly; the tail is covered with hairs, as those on the lower surface are rather long, this appendage probably acts as a rudder to assist the animal in swimming; the tip of the tail is white. The Rev. L. Jenyns says, that a black variety of the water vole is not uncommon in the fens of Cambridgeshire; and Mr. Macgillivray says, this variety is exceedingly common in the counties of Banff and Aberdeen. Pennant, perhaps, drew up his description from a somewhat similar variety, as he describes the hair of its head and body as being " chiefly black, but mixed with some of a reddish hue."

The haunts of the water vole are the banks of rivers, ponds, and ditches, where it burrows to a considerable distance. It is of a shy disposition, and being an excellent diver it instantly 
plunges to the bottom of the water if alarmed, but rises to the surface to breathe about every minute. In the act of swimming, which it also performs admirably, it usually keeps its head close along the surface of the water.

Mary Howitt very justly calls it

"A glad innocent creature, for whom was ordained, The quiet of brooks, and the plants they contained;"

for though it is commonly asserted that it devours young ducks, small fish, frogs, earthworms, and insects, yet there is not the slightest foundation for that statement. "Its food," as Professor Bell observes, " consists exclusively of vegetables, and principally of roots, or of subaquatic plants; and there can be no doubt that the belief of its carnivorous habits has arisen from its being confounded with the common brown rat (Mus decumanus), which is well-known to frequent the banks of ditches, and to feed readily on almost all animal substances, attacking even the smaller animals alive, when driven by hunger."

The female water vole brings forth five or six young in her subterranean abode, in May or June; but sometimes as early as April, in which case she probably produces another litter in the course of the summer.

Buffon says, that the French peasantry eat the water vole on maigre days.

\section{The Lemming.}

(Georychus lemmus, Illig.; Mus lemmus, Linn.)

\section{Lapland Marmot.}

The lemming inhabits only the northern confines of Europe, as Lapland, Norway, and Sweden.

It is about the size of the water vole; the body thick, variegated with black and fawn colour, having the sides of the head and upper parts white; the eyes are small; the legs 


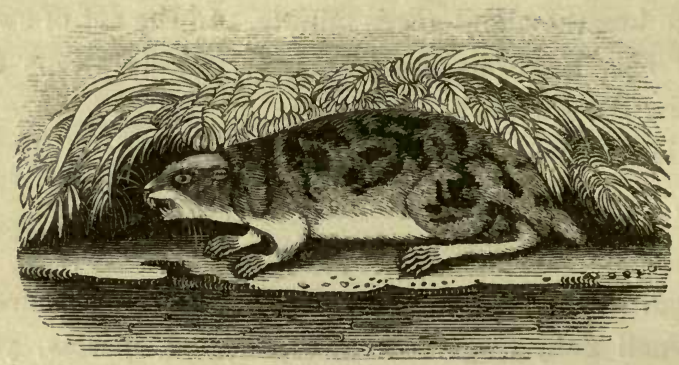

stout, and the hairs on them and the tail, have a greyish appearance from some of them being black, and others white. The length of the tail is scarcely more than an inch.

In wet seasons, the lemmings appear in such abundance that the simple Laplanders believe they fall from the clouds. They descend, after continued rains, from the mountains, by millions, covering the whole plain : their habitual movement during the night is in the form of a square, but as soon as daylight appears they rest; and it is no uncommon thing for the ground to be covered by them for more than a square mile, and so close are they together, that no part of the ground can be seen. To kill them is out of the question, and to attempt to arrest their migration would be vain, for no obstacle will divert them from their course, which is from the north-west to south-east; if a river or lake happen to be in the direct line, they swim across; and should a boat be in the way, they will not swim round, but go straight forward over it; in fact, nothing will obstruct their progress. If any body attempt to attack one of these little animals, it flies boldly at him, fastens on him, and is with difficulty made to quit its bold. Their food is chiefly vegetables; and in a very short time a whole meadow is destroyed, and appears as if it had been burnt and strewed with ashes. Did they not at last destroy each other, their numbers would render the country uninhabitable. When vegetable food becomes scarce, they fight together most furiously; after this battle 
multitudes are found lying dead on the ground, and the air for miles around is so infected by their carcases, that malignant . diseases often ensue in consequence.

The female lemming produces several litters during the year, and has from four to six young at a time.

The Laplanders being very fond of flesh, feed greedily on these animals, and therefore rejoice at a visit from them, though the Swedes and Norwegians regard them as terrible invaders.

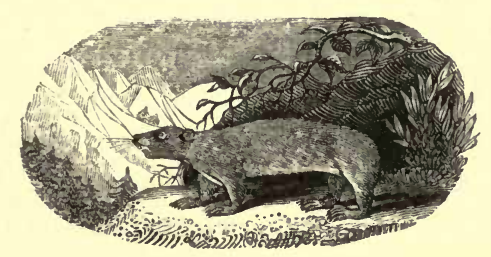

The Tail-Less Lemming.

(Georychus Hudsonius, Illig.; Mus Hudsonius, Gmel.)

This North American species is of the size of a common rat. Its fur is of a light pearly ash colour; it has no tail; the two middle toes of the fore-feet of the male seem to have double nails, because the skin of the end of the toes is hard, and projects under the point of the nail-a structure only met with in this animal.

In its habits it is chiefly subterranean.

\section{The Common Jerboa.*}

(Dipus sagitta, Gmel.; Mus sagitta, Linn.)

This animal inhabits most parts of Arabia and Syria, every part of the southern deserts of Africa, but no where so generally,

* The American jerboa, or long-tailed jumping mouse, is the Dipus Canadensis of Shaw, the Meriones Canadensis of Frederic Cuvier. Hasselequist 


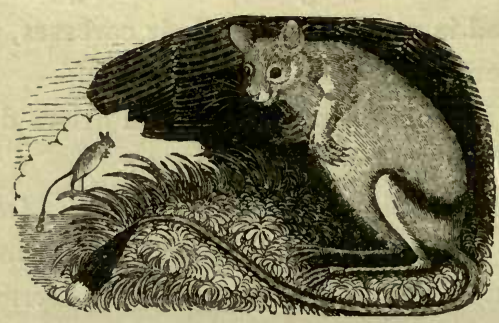

and so abundantly, as in the Cyrenaicum, or Pentapolis. In the wide range it inhabits there is but little variation observable in the size and colour of different specimens. Towards Aleppo they have broader noses than the African ones; their bodies are also thicker, and their colours lighter; a difference always seen in the Syrian animals, when compared with those of Africa.

It is a small, clean, and harmless animal, nearly the size of a common rat. When standing nearly erect on its feet, the jerboa of the Cyrenaicum is six inches and a quarter in height. The upper parts of the body are very smooth, and of a shining brown tinged with yellow or gold colour, the end of the hairs being tipt with black; the buttocks are marked with a semicircle of black, which parts from the root of the tail and ends at the top of the thigh; the belly is white; the ears, which are three quarters of an inch long, and a quarter of an inch in breadth, are smooth, have no hair inside and very little outside, and are rounded at the extremity; the nose projects three quarters of an inch beyond the under jaw; the mustachios, or feelers, are about an inch and a half in length, some of the hairs directed backward and some forward from the nose.*

says, the Arabs call the presents pecies garbuka; but Bruce contradicts him, and says, its name in all the East is jerboa or yerboa, the letter $\mathrm{j}$ being sometimes pronounced like $\mathrm{y}$. It is the two-footed rat of ancient writers. (See Herodotus, Melp. sect. 192; Theophrastus apud Elian, Hist. Anim. lib. xiv. cap. 26 ; and Aristotle, de Mareb Egypt, lib. vi.)

* Edwards certainly exaggerates in saying the head of the jerboa very much resembles that of a rabbit. 
The fore-feet have only three toes; the hind-feet have four toes, and a small one behind the heel where there is a tuft of black hair. The tail is six inches and a quarter in length; half of it is thinly covered with hair of a lighter or whiter colour than the body; it terminates in a beautiful brush of long black and white hairs.

The jerboa lives in the smoothest plains of the desert, especially where the soil is fixed gravel, for in that it chiefly burrows, dividing its hole below into many chambers. Seemingly apprehensive of the falling in of the ground, it generally digs its hole under the root of some spurge, thyme, or absinthium, which serves as a secure roof to its subterranean habitation. Bruce says, he is very certain that it is not a gregarious animal, for though jerboas have a number of holes in the same place, he never saw more than two together at a time.

Its long legs, and its jumping mode of progression, also require the smooth plain surface on which nature has always placed this creature. It usually stands upon its hind legs alone; and rests itself by sitting down like the kangaroo, or more rarely, by lying on all fours. Its long tail appears to be of great service in guiding and directing it in jumping. The Arabs of the kingdom of Tripoli, do not employ their greyhounds to hunt gazelles till they have trained the former to turn nimbly by hunting the jerboa, whose agility is such, that Bruce often saw a greyhound employ a quarter of an hour before he could master his nimble prey in a large enclosure or court-yard.

In the old Arabic translation of Isaiah from the Hebrew, this animal is mentioned as forbidden food: "They that sanctify and purify themselves in the gardens behind one tree in the midst, eating swine's flesh, and the abomination, and the jerboa,* shall be consumed together, saith the Lord." (Chap. lxvi. verse 17.) The Arab canonists differ as to whether it can be lawfully

* The English translation reads mouse, in accordance with the signification of the Hebrew word. 
eaten or not. Ibnalgiauzi thinks it may not be eaten, nor any other animal living under ground, except the el dabb, a large lizard, said to possess a certain medicinal property : but several other authorities, as Ata, Achmet, and Benhantal, expressly say that it may be lawfully eaten. This, however, appears to be an indulgence, for we read in Damir, that the use of this animal is granted because the Arabs delight in it; and Ibn Bitar says, that it is Israelitish food, as the flesh, if dried in the outward air, is very nourishing, and prevents costiveness; -hence we may infer that medicinal considerations, also, have sanctioned the eating of it. The buttocks, thighs, and part of the back, are roasted and eaten by the Arabs. Bruce ate them, and says they are very fat, and not distinguishable in taste or colour from a young rabbit. The same traveller, having obtained several jerboa skins, uninjured by shot, got them dressed in Syria and in Greece, and sewed together, using the tail as in ermine for the lining of a cloak, and he says that the longer they wore, the glossier and finer was their appearance.

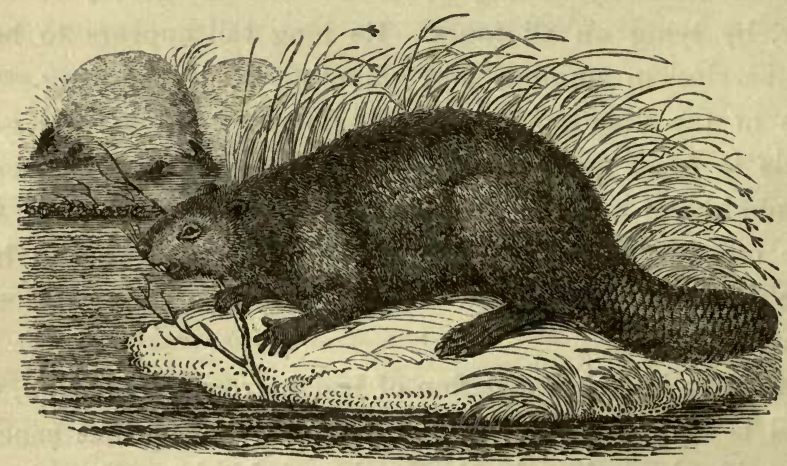

The Beaver.-(Castor Fiber, Linn.)

The beaver inhabits the northern continental regions of the Old World, and the whole extent of the continent of North America-at least in all the higher latitudes; for wherever the 
country has been explored up to the present time, this animal has always been met with. From the hilly districts bordering upon the river and Gulf of St. Lawrence, westward through New Brunswick, and all the upland country, from thence through all that section of the United States to the great Valley of the Mississippi, those swampy pieces of ground, universally called beaver-meadows, are more or less numerous; although through all this vast tract of country, a great portion of which is now inhabited by mankind, very few beavers are found at the present day. Most of them have undoubtedly been destroyed by the hunters; but in some cases they have sought for safety in the yet unreclaimed forest, constantly receding at the approach of man. Mr. R. C. Taylor says, they are nearly extinct in the Alleghany Mountains; and Mr. E. H. Greenhow says, that though they were once common in the little rivers of Lower Canada, they, together with other wild animals, have become scarce. There was a time when this interesting creature inhabited Britain. It is supposed to have become scarce at the end of the ninth, and extinct in the twelfth century. Giraldus Cambrensis, in his Itinerarium Cambrice, says that when he travelled through Wales in 1188, beavers were only found in the river Teivi.

The usual length of the beaver is about three feet. Its fur is very fine and smooth, and of a glossy chesnut colour, varying sometimes to black, and in a few solitary instances to white, cream-coloured, and rarely pied. In each jaw and exactly opposite are two strong, very large, broad, flat incisor teeth, of a deep orange or nearly chesnut brown colour on the outside; and there are four molars on each side in either jaw, and the flattened surfaces of these teeth sufficiently indicate that they are exclusively intended for the mastication of vegetal substances. The upper lip is divided vertically; the eyes are small; the ears short, and nearly hid in the fur; all the feet have five toes, those of the fore-feet are smaller and shorter than those of the hind, and divided almost to the base, while the latter are united to their very tips by a strong fold of the 
skin, which allows of their separation to a considerable extent, and forms a broad and palmated expansion, similar in form and use to the webbed feet of swimming birds; the nails are thick and strong; that of the second toe of the hind-feet consists of two portions, an upper one corresponding with the other toes, and an under placed obliquely and having a sharp cutting edge directed downwards; the tail which is nearly half as long as the body, is of a broad oval shape, flattened both above and beneath, and furnished at its thickened root alone with hair similar to that on the body, but covered throughout the greater part of its length with a peculiar incrustation, assuming the form of regular scales very like those of fishes. "Their habitations," says Mr. Bennett, in his admirable account of this animal, " are built either immediately beneath the bank, or, if the pool be shallow, at some little distance frorn it. They begin by hollowing out the bottom, throwing up the mud and stones around it, and intermingling them with such sticks as they can procure. The walls having been thus raised sufficiently high, the house is covered in with a dome-shaped roof, generally emerging about four feet, but sometimes as much as six or seven, from the water. The entrance is made beneath a projection which advances several feet into the stream with a regular descent, terminating at least three feet below the surface to guard against its being frozen up. This is called by the hunters the angle, and a single dwelling is sometimes furnished with two or more. In all their operations, there appears to be no other concert or combination among the beavers than that which results from a common instinct impelling them to the performance of a common task. There is, therefore, no truth in the assertion that these animals are superintended in their labours by an overseer; and equally untrue are the frequent statements that they use their tails as sledges for the conveyance of their materials, or as trowels to spread the plaster with which, according to some accounts, the work is overlaid. The structure of the tail is quite unfitted for such operations, and the only organs employed in mixing 
up the mud with the rest of the materials, and in all the other operations of the beaver, are the fore-paws and the mouth; and it is sufficiently obvious that neither with their assistance, nor indeed with the united powers of all their organs, could these animals drive stakes as thick as a man's leg three or four feet deep into the ground, or execute a variety of other feats for which they have obtained general credit. The sticks and branches which they use, instead of being driven into the ground, are principally laid in a horizontal direction, and they are only prevented from floating away by the stones and mud which the beavers bring in their paws to lay upon them, and which gradually become cemented into a firm and compact mass. All their work is performed during the night. Although the favourable nature of the situation may have led many families to assemble in the same spot, they do not on that account carry on their operations in common; unless when a dam of large extent is to be built, when they usually cooperate for its completion. Each family occupies itself exclusively on its own habitation, which generally has only one chamber. The idea of their houses having several chambers for different purposes, may have arisen from the fact of their sometimes building by the side of a deserted dwelling, with which they occasionally open a communication. The families vary in the number of individuals of which they are composed, but seldom exceed two or four old ones, and twice as many young; the females producing once a year, from two to four at a birth, and the young ones generally remaining till they are three years old, when they quit their parents, and seek out or build a separate habitation for themselves." Mr. Greenhow says, that since Lower Canada has become so much colonised, these shy and timid animals have discontinued building huts near each other, thus forming beaver-villages, but now live solitary in holes on the wooded banks of secluded villages. "In summer they feed either upon the bark of trees, or upon the green herbage and berries; but in winter their diet is almost restricted to the former, of which they lay in a large stock 
previous to the frost setting in. This winter store of branches is placed near the entrance and on the outside of their houses, and is sometimes so large as to rise above the surface of the water, and to contain more than a cart load of provisions. From this store they cut away portions as necessity requires; and after tearing off the bark [by means of their powerful incisor teeth], they reject the wood, leaving it to float away with the current. Willow, poplar, and birch are their favourite kinds; and the latter, according to Cartwright, renders their flesh ' the most delicious eating of any animal in the known world.' The root of the water-lily also affords them an occasional supply, and makes them very fat, but gives their flesh a strong and unpleasant flavour." *

Phillips, in his Sylva Florifera (1823), says the swamp magnolia ( $M$. glauca) is generally called by the Americans the beaver-tree, because the root is the favourite food of beavers, and is therefore employed to catch them.

Ever since the year 1638, when the British Government issued a proclamation forbidding the use of any material except beaver fur in the manufacture of hats, the North American Indians have incessantly sought after this animal, vast numbers of which are annually killed. In 1743, the Hudson's Bay Company alone sold 26,750 skins; and 127,080 were imported to Rochelle. In 1788, upwards of 170,000 were exported from Canada; and in 1808, Quebec alone supplied this country with 126,92\%, which, at the estimated average of eighteen shillings and nine pence per skin, would produce no less a sum that $£ 118,994$ sterling. So general was the use of beaver fur in the hat manufacture, till of late years, when its scarcity has rendered the gossamer silk and other substitutes necessary, that the common name beaver and its more classic generic name Castor have become vulgar synonymes for the word hat.

It may be here mentioned that what is termed nutria fur, an article very extensively used by the British and French

* Zoological Gardens Delineated (1831), vol. i. p. 165. 
hatters, is obtained from the coypou, or quoiya (Myopotamus coipus), a South American animal less than the beaver, but resembling it in many respects.

A substance employed in medicine under the name of Castor, is obtained from two large glandular pouches of the beaver, situated in the male behind the prepuce, and in the female at the upper edge of the orifice of the vagina, where they open. The castor completely fills the pouches, but has a cavity in the centre, a character which at once distinguishes the genuine article from the spurious substitute. Previous to removal, the secretion is rather soft; but, when taken out, it dries though it does not become hard. Virgil, in his first Georgic (line 59), applies the epithet virosa to it, because it possesses a very powerful and disagreeable odour, and a sharp, bitter taste.

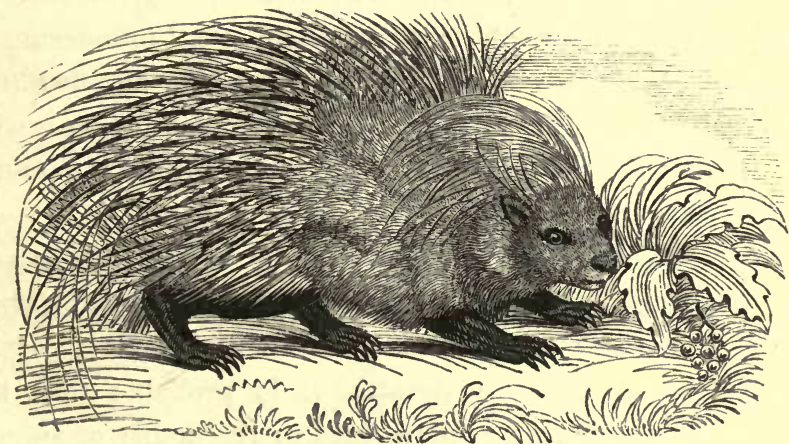

The Crested, or Common Porcupine.*

(Hystrix cristata, Linn.)

In Europe, the crested porcupine inhabits the south of Italy, Spain, and Sicily; and in Africa, it inhabits Barbary. George

* In Stowe's Chronicle of the years 1117, 1135; Roger Ascham's Works, by James Bennett, p. 66; and throughout the old editions of Shakespeare's Plays, the porcupine is called porpentine. At the present day in some parts of England the hedgehog, which used to be classed with it, is called a porpin. 
Bauer, alias Agricola, the author of a work on subterranean animals, published at Basil in 1549, says that this animal was imported into Europe from Africa.

It is nearly two feet in length when full grown, and some of its longest spines, or quills, are more than a foot long. The general colour of the animal is a grizzled dusky black, resulting from an intermixture of various shades of black, brown, and white. On the upper part of the head and neck is a crest of long lighter coloured hairs, capable of being raised or depressed at pleasure. The hair and quills retain their colour all the summer, but as the weather becomes warmer in the spring, the fur grows thinner.

It resides under ground in burrows of its own digging, which have several distinct openings; and only quits them in the evening in search of food, which consists principally of roots, buds, leaves, and fruits. It is particularly fond, however, of the bark of the juniper. Pringle speaks of its "plundering the melon-beds." * It is said that it will eat blistering flies (Cantharides) without injury to itself. In summer it laps water like a cat or dog, but carefully avoids entering it; and in winter it eats snow.

When frightened or enraged it erects its quills, and presents a very formidable appearance; and judging from the looseness of their attachment, and from facts in the history of the Canadian species (Hystrix dorsata), it is probable that they sometimes break off and remain fixed in the bodies of animals, or other objects with which they then come in contact.

\section{Ghost. "I could a tale unfold, whose lightest word \\ Would make thy knotty and combined locks to part, And each particular hair to stand on end Like quills upon the fretful porcupine."}

(Hamlet, I. 5.)

Yet, there is no truth in the old story of the animal defending itself by ejecting its quills from its body like a shower of arrows. 
The female goes with young about seven months, and produces one or two at a birth, which she suckles for a month.

The flesh of the porcupine is often eaten by the inhabitants of the Cape of Good Hope, and used to be sold in the markets at Rome. The quills are used to make anglers' floats, and other trifling articles.

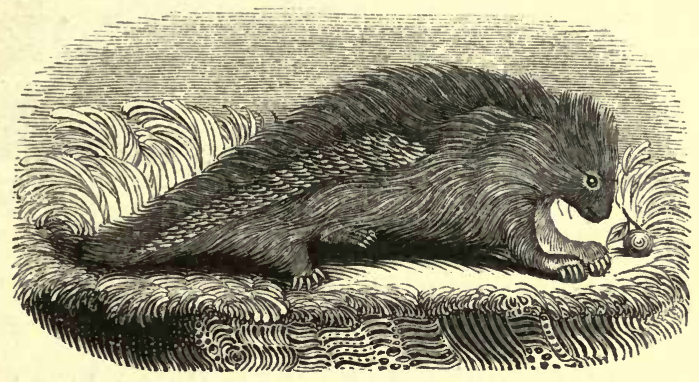

The Coendou, or Prehensile-tailed Porcupine.

(Synetheres prehensilis, F. Cuv.; Hystrix prehensilis, Linn.)

The coendou inhabits the woods of Brazil, and, according to some authors, Mexico also ; but Dr. Lund says both the present species and $S$. insidosa, which is only half as large, are "peculiar to South America."

The coendou is about two feet and a half in length. Its hair is of a brownish-black; its spines, or quills, black and white, very sharp, and strong, and none more than three inches long. Its head is vaulted in front; the muzzle short and thick; the feet have four toes, all armed with claws; the tail is long, naked at the tip, and being prehensile it assists the animal in climbing trees.

In the Catalogue of Bullock's Museum (1813, p. 132), the food of two living specimens kept for some time in London, is stated to have been entirely of a vegetal nature, and their manners were mild and inoffensive; their voice a weak, tremulous cry, somewhat like a young pig's, but not so shrill or loud. 


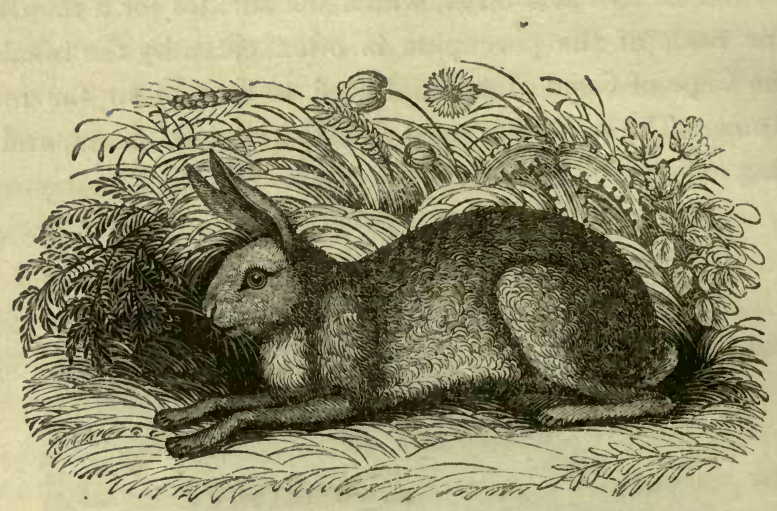

The Common Hare.*-(Lepus timidus, Linn.)

Three distinct species of hare inhabit Great Britain. The present species is the common one of England, and perhaps of some other parts of Europe; but so little attention appears to have been paid to the comparison of specimens in other countries, that it is not improbable that its geographical distribution is more confined than is generally supposed. The alpine hare (Lepus variabilis, Pall.) inhabits the summits of the mountains in the North of Scotland, but is occasionally found as far south as the mountains of Cumberland. In Ireland neither of these species have yet been discovered, but another species (Lepus Hibernicus), whose specific differences, which consist chiefly in the more equal length of the hind and fore limbs, and the ears being shorter than the head, remained unnoticed until so late a period as the year 1833.

The ordinary length of the common hare of England is one foot nine inches and three-quarters, or, with the full extent of the tail, two feet one inch; and the weight about eight or nine pounds, but occasionally twelve pounds; and an instance is

* The Scotch call a hare a maukin. 
recorded in the Magazine of Natural History, of one weighing no less than thirteen pounds one ounce and a half. Its upper lip is cleft; the inside of the mouth is hairy; the eyes are large, and so prominent as to receive the rays of light on all sides; their pupils are horizontally elongated; the ears, which are placed very close to each other at their base, are about an inch longer than the head, and of a yellowish grey colour on the anterior part of the outer surface, whitish behind, and tipped with black; the limbs are slender; the soles of the feet are covered with hair; the fore-legs have five toes, furnished with thick strong claws; the hind-legs, which are much longer than the fore, have only four toes; the tail, which is short and doubled over the rump, is black above, and white beneath. The general colour of the upper parts of the body is a mixture of yellowish brown and grey, and of the under parts white, excepting beneath the neck and anterior portion of the chest, where it is yellowish, which colour prevails between the ears, on the neck, the shoulders, and sides. In the northern parts of Britain, the fur of the hare becomes white in winter, a colour better adapted to the retention of the animal's warmth. In various parts of England varieties in a permanent white dress are sometimes found, as also others of a mixture of white and brown, or even entirely black.

The hare, notwithstanding the size and prominence of its eyes, is a short-sighted animal; and hence Shakespeare calls it the "purblind hare." Dr. Farrar observes, "that although hares possess a very wide expanse of sight, they do not enjoy an equally distant one, which is not to be wondered at when we look at the diminutive stature they exhibit; yet for this loss they are compensated by having the sense of hearing very acute from a number of points, though much more from behind than in any other direction. Many persons contend that the hare cannot distinguish sounds immediately before her, which is not unlikely when we consider the bony structure of the external ear; however, this is not absolutely necessary, as her prominent eyes scarcely allow any object to approach her without some 
part of its shadow being depicted upon the retina, and thus communicating the alarm to the timid animal."

Though included in the same genus with the rabbit, the hare is neither a burrowing nor a social animal, but lives solitary, and her resting-place, called a form, is merely a superficial depression of the herbage, and which is too exposed to afford shelter as a place of refuge. She is so reluctant to abandon her form, that she not only sleeps on it during the day, but if disturbed and forced to run for her life, she constantly returns to it after the longest chace-hence the proverbial observation that the hare returns home to die. The seasons, however, compel her to change her quarters. In winter, she selects a spot for her form exposed to the south, and will sit in thorn and bramble-bushes near towns and villages; but in summer she prefers a shady spot with a northern aspect, and situated in a corn field or open land. Ben Jonson, thus notices these facts :-

Scatlock. "First think which way the witch formeth, on what wind: or north or south.

George. For, as the shepherd said, a witch is a kind of hare.

Scatlock. And marks the weather, as the hare does."

(Sad Shepherd, 1641, Act III. Scene 8.)

The colour of the hare generally so well accords with that of the herbage amongst which she forms, or of the sandy soil on which she sometimes squats, that she would often escape detection were it not for her conspicuous and lustrous eye. I have more than once nearly trod upon a hare in her form; and most persons in the habit of quietly strolling over the country, can relate similar incidents.

" The wither'd grass that clung

Around her head, of the same russet hue, Almost deceiv'd my sight, had not her eyes, With life full beaming, her vain wiles betray'd."

(Somerville's Chase, 1742.)

Her fore-legs being much shorter than her hind pair, she runs more easily up than down hill; therefore, she never runs own hill if she can help it, and even then she winds about; 
when it is impossible to run up, she takes the hill-side at a slant. To the accomplishment of a swift runner, she adds that of a good and bold swimmer. Sometimes she takes to the water voluntarily, either in quest of food or a mate; but more frequently when driven to do so by a more pressing emergency. This fact appears to have been noticed much earlier than modern naturalists imagine. Franzius says, "It is reported of a hare, that being hunted very hard, she ran into the sea."* $\mathrm{Du}$ Fouilloux, author of a treatise on hunting, written in the sixteenth century, says, he saw a hare start from her form at the sound of the hunter's horn, repair to a distant pond, plunge into it and swim to some rushes in the middle, where, by squatting down, she concealed herself from the dogs. Mr. Charles Eicke told me some time ago, of a hunted hare swimming boldly out to sea at St. Leonard's, near Hastings. Within the last few years, indeed, many similar instances have been recorded. In one of these, related by Mr. Yarrell, two hares were seen by Mr. William Thompson and a workman, to descend from the hills on the main land towards the sea on our southern coast, and after one of them had been occasionally examining, as it would seem, the state of the current, during a delay of half an hour, she ultimately took to the sea at the precise period of high-water, and swam to an island a mile distant. Mr. W. B. Clarke says, that according to the statements of the Danes, the hares inhabiting a small island in the Little Belt, swim thence to the other side of the Baltic Sea.

When seized by the hounds, the hare kicks with all her might; and at the top of her voice utters her plaintive and piteous cry-aunt, aunt, aunt.

The stoat occasionally attacks hares, even half or two-thirds grown ; pursuing them with the utmost pertinacity, and hunting them down by dint of its indefatigable perseverance. "The Rev. F. W. Hope informs me, that on one occasion, when shooting in Shropshire, he heard at a short distance the shrill loud scream of a hare, which he concluded was just caught

* History of Brutes (1670), p. 153. 
in a poacher's springe. On running towards the spot from which the sound proceeded, he saw a hare limping off, with a stoat attached to the side of the throat. The hare made its way into the brushwood with its enemy still holding on. It is a curious fact, that the hare when pursued by a stoat does not betake itself to its natural means of escape, its fleetness of foot, which would in a few seconds carry it out of all danger from its little enemy, and which it always employs when escaping from the chase of dogs or of the fox ; on the contrary, it hops languidly along, evidently aware of the stoat's approach, yet as if incapable of exerting its powers to avoid the impending destruction. Whether this arises from a stupid indifference, or from not appreciating its danger, or, on the other hand, from intense terror, producing an effect similar to that miscalled fascination, which the small bright eye of the rattlesnake excites in its helpless victims, it is perhaps difficult to decide."*

The food of the hare is entirely derived from the vegetal kingdom, and it generally seeks for it during the night. It eats the young and tender grass, lettuce, parsley, dandelion, stocks, pinks, roots, fruits, and corn, in the seasons that such provisions can be procured; but in winter it often strips the bark off trees, and there are scarcely any that it will spare except the lime and alder. It is particularly fond of the bark of the birch, but more so of that of the laburnum. Phillips therefore recommends that laburnum seeds should be sown in plantations, and about hedges and coppices infested with hares and rabbits, for these destructive animals-"eatable vermin," as Cobbett calls them in his English Gardener-will touch no other plant so long as a twig of laburnum remains, and though eaten to the ground in winter, it will spring again the next season, and thus constantly supply them with food.

The hare never pairs; but in the breeding season, which begins in February, the male seeks the female. She breeds when a year old; and, after thirty days' gestation, produces from two to five young, all covered with hair, and with their

* Bell's History of British Quadrupeds (1837), p. 149. 
eyes open. After less than a month's suckling, the leverets, as they are called, leave their mother to seek their food afar off and apart.

"Whilst I was at Gottingen," says Dr. Townson, " a leveret was brought me, and so young that $I$ at first kept it in a birdcage. It soon became a favourite, and would sit or sleep on my sofa and bed. In the evening it was very frolicksome and gay, and used to leap upon my bed, and playfully beat me with its fore-feet, and knock my book out of my hand if reading. Notwithstanding this familiarity it was extremely timid, and did great mischief more than once upon the entrance of a stranger. When I had it a twelvemonth, I took it in a bag into an extensive wood a few miles off, and sitting down let it out. It did not run away, but began to browse, yet by degrees went further off. When it was at some distance, I approached it and it sat down; but when I got within about a dozen or twenty yards it was frightened, set off at full speed, and I saw it no more."*

Griffith, the translator of Cuvier's Rène Animal, says that some years ago there was exhibited in the streets of London a tame hare, which moved fearlessly about a table in the midst of the surrounding multitude, heedless of their noise and the tones of a hand-organ. This hare, "was taught to beat a tambarine very rapidly with its fore-paws; and as a still further proof how completely its fears were neutralized, it was accustomed to pull the trigger and discharge a pistol, rather large in dimensions and calibre, and commensurate consequently in report: and as this was repeated perhaps every half hour, it can hardly be supposed that the animal was taken by surprise, as to the consequences of pulling the trigger, nor did it exhibit the least alarm or shock on making the report, which would, in all probability, have turned a lion, unless he had been similarly trained."

The hare being one of the most timid and defenceless of all animals, and very swift of foot, the pursuit of her gives pleasure

* Tracts and Observations in Natural History (1799), p. 146.

2 в 2 
and exercise to those who prefer such manly and innocent sports to all others.

"These heroes bold in leather breeches,

Do leap o'er five-barr'd gates and ditches,

The perils of the field to dare

To hunt that furious beast the hare.

Oh! courage rare."

To see a number of mounted huntsmen recklessly scampering over the country with a pack of harriers, and then to reflect that the object of all their galloping, leaping, hallooing, and barking, is to chase and destroy, not a large and ferocious animal, but a small timid hare, would be deemed in the highest degree cruel and ridiculous, were the spectacle not so frequent. The chase of so small an animal by so formidable a host, reminds one of the favourite sport of Christiana, Queen of Sweden, who used to shoot fleas with a piece of artillery, still exhibited at the royal arsenal at Stockholm. The poet Thomson may well indeed exclaim,

"Poor is the triumph o'er the timid hare!"

The stratagems used by the hare to evade its pursuers are too curious to be omitted here; and as I at all times prefer Shakespeare's poetry to any man's prose, his excellent account of her proceedings is introduced :-

"And when thou hast on foot the purblind hare, Mark the poor wretch; to overshoot his troubles, How he out-runs the wind, and with what care He cranks* and crosses with a thousand doubles.

The many musits t thro' the which he goes,

Are like a labyrinth t' amaze his foes.

Sometime he runs among a flock of sheep, To make the cunning hounds mistake their smell; And sometime where earth-delving conies keep, To stop the loud pursuers in their yell;

And sometime sorteth $\ddagger$ with a herd of deer:

Danger diviseth shifts, wit waits on fear.

* To crank is to wind about, to meander.

$\uparrow$ Musits are gaps in a hedge. $\ddagger$ Sorteth here means, associateth, consorteth. 
For there his smell with others being mingled,

The hot scent-snuffing hounds are driven to doubt,

Ceasing their clamorous cry, till they have singled,

With much ado, the cold fault cleanly out,

Then do they spend their mouths ; Echo replies,

As if another chace were in the skies.

By this poor Watt* far off, upon a hill,

Stands on his hinder legs with list'ning ear,

To hearken if his foes pursue him still:

Anon their loud alarums he doth hear,

And now his grief may be compared well

To one sore sick that hears the passing bell.

Then shalt thou see the new-bedabled wretch

Turn and return, indenting with the way:

Each envious briar his weary legs doth scratch,

Each shadow makes him stop, each murmur stay :

For misery is trodden on by many;

And being low, never reliev'd by any."

(Venus and Adonis.)

As hares come under the denomination of game, they are protected from general destruction with much care and rigour; and woe to the man, be he peasant or philosopher, who without a licence should kill one of them, even if it eat the pinks in his garden night after night. Still greater woe to the hungry gipsy, or other way-farer on Nature's common, if, for the gratification of his vulgar appetite, he have the audacity to kill one of these most precious animals, which, as the Society for the Prevention of Cruelty seem tacitly to admit, were created to give sport to his superiors; and the punishment he receives for his enormous offence, is no more than what the law told him to expect from those charitable people who never forgive others who trespass against their hares. Thin soup is no doubt better for the poor than hare's flesh, which, according to ancient medical opinion, might make them melancholy; and exercise on the treadmill is better adapted to their " recreant limbs," than any field sports. All country squires and justices

* Watt and Puss are familiar terms for a hare. 
will therefore disapprove of the logic of that wicked poet, Thomas Hood, who says,

" If bellies all are made alike, as parsons oft declare, oh !

Then ploughmen can, as well as lords, eat pheasants, grouse, or hare, oh!

But if such things were for great folks, and not at all for lowly,

Then heaven had written on their backs- 'For lords and gentles solely." "

The fur of the hare is used very extensively in the manufacture of hats, caps, and other wearing-apparel.

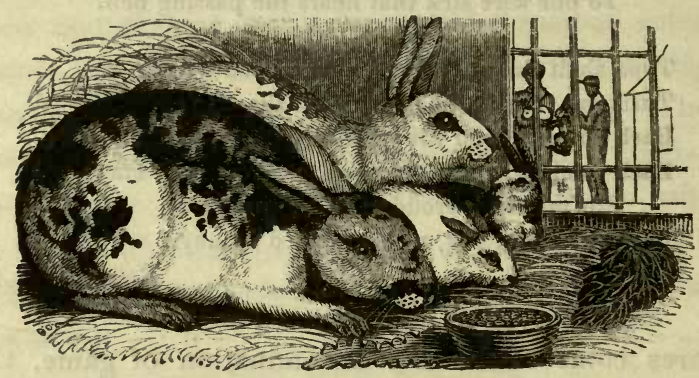

The Common Rabit.-(Lepus cuniculus, Linn.)

Rabbet. Coney.

The present species, according to Cuvier, is distributed throughout Europe; but it is not improbable, that from the close general resemblance which exists between several different species of this genus, that more than one distinct species may have been taken for the present.

In Great Britain, generally, the common rabbit is abundant. It is at once distinguished from the hare by several obvious characteristics. The rabbit is altogether more robust; the head is much shorter; the ears are only about as long as the head, and have no black tips; the hind legs are also shorter. The ordinary length of adult specimens is one foot four inches and a half, or, including the extent of the tail, one foot seven inches and three-quarters. The upper portions of the fur are greyish 
brown; the neck rather red; the throat and belly white; the ears brownish grey; and the upper surface of the tail is brown, the lower white. A perfectly black variety of the rabbit is, according to Mr. Lansdown Guilding, occasionally found in the woods about Gloucester; and Mr. J. V. Stewart says, that a black and also a fox-coloured variety are found in Donegal, Ireland. The common tame breeds of the rabbit are probably only artificial varieties of the common wild species, differing from it in size, form, and colour, in consequence of their having been kept in a confined or domesticated state, and regularly and abundantly supplied with very nutritious, and often unnatural food. Under these circumstances, their muscles, from not being exercised in the search after food, and in flying from danger, become rigid and comparatively powerless, or are not fully developed, though the size of their body increases. In the course of generations they become much larger than their wild brethren; but if set at liberty in a proper situation, they would most likely return, in a very few generations, to the form, size, and agility which is natural to their species in a wild state. With regard merely to the colour of rabbits, differences are not uncommon in individuals of the same litter. Dr. Robert Townson, mentions his seeing several young rabbits with fur exactly like the Angora breed, but which were the offspring of two common rabbits, from which others of the same litter differed in no respect. Albino varieties are also common.* It may here be remarked, that when albinoes of animals whose natural colour is brown (as the rabbit and the mouse), are paired with one of the latter colour, they sometimes produce a black, sandy, or slate-coloured offspring, or an individual with one of these colours, more or less varied with white, is produced; but in the majority of instances, the young wholly resemble one of their parents, and the preponderance is de-

* Albinoes generally have red eyes; but Mr. Blyth says, he has seen an albino rabbit with one eye red and the other dark hazel. Similar instances of disparity in the colour of the eyes $I$ have already mentioned, as occurring among cats, and even mankind. (See page 262.) 
cidedly in favour of the natural hue. The coloured offspring of an albino, cven if matched with another coloured individual, has still a tendency to produce albinoes. Of seven young rabbits thus produced, two were albinoes, one black, and the remainder of the usual colour. Lawrence observes, that in human albinoes, the characters of the original race return, unless the variety is kept up by excluding from the breed all which have not the new characters. Thus, when African albinoes intermix with the common race, the offspring is generally black. These observations afford some explanation why marked breeds are in a state of nature so rarely perpetuated.

The rabbit, unlike the hare, is a social and digging animal. Heaths, commons, and other places having a sandy soil easily excavated, are the places where they associate, and form their subterranean city,- the warren, as it is termed. M. Varro (as quoted by Pliny, Nat. Hist. viii. 29,) relates that a town in Spain was undermined by rabbits; and these little boroughmongers do a great deal of mischief in Britain, by making extensive inroads upon corn-fields and plantations. It seems, however, that some of them, instead of burrowing in the earth, dwell in the natural fissures of rocks. Waterton says, that towards the top of the stupendous cliffs which extend from far-famed Flamborough Head to the Bay of Filey, "both rabbits and foxes have descended from the table-land above them, and managed to find a shelter among the crevices, in places where you would suppose that no four-footed animal would ever dare to venture."

When pursued by dogs, the rabbit shows great activity and cunning. It will then, as Mr. Jesse says, steal from brake to brake, stand on its hind legs, listening to every sound, and will, when necessary, creep into a hole. This writer says, that when it is pursued by weasels, the rabbit never enters its burrow; and this certainly is sagacious in the animal, for by doing so it might betray its mate and her offspring. He saw a rabbit chaced by two weasels, and says, "all its faculties appeared to be paralysed while they were in pursuit. It bounded 
about in a sort of circle, shrieking with terror, and seemingly incapable of getting away from its enemies, who would soon have destroyed it had I not interfered."

Mr. Henry Turner, of the Botanic Garden, Bury St. Edmunds, says that " rabbits will take to the water when pursued, and that he has seen four do so when they might have escaped without getting wet. In one instance, although a man stood on the bank which the rabbit was striving to gain, the animal landed, and made its escape."* A lady informs me, that rabbits used to enter the garden of Ham House, Upton, in Essex, and that, as there was a warren on an island close by, it was naturally inferred that they swam across the water.

Rabbits generally remain in their burrows during the day; but about twilight they come out to feed. Sometimes, however, after a summer shower has fallen, and rendered the herbage moist and tender, numbers of them may be seen feeding above ground in the broad day.

\section{" They will out of their burrows, Like conies after rain."}

(Coriolanus, Act IV. Scene 4.)

They feed on the blades and stalks of grass, the newly-sprung corn, young tops of furze, turnips, carrots, greens, mallows, and other plants; together with the bark of young trees.

Though rabbits live in numbers together in the warren, yet they are said to be monogamous, each pair remaining attached during their mutual existence. They breed when six months old, and have many litters in the year. The doe, when about to bring forth, forms a separate burrow, at the bottom of which she makes a nest of the softest fur or down plucked from her own body. The period of gestation is thirty days, and the ordinary number of young at a litter varies from five to eight, which (unlike the more exposed young of the hare) come forth blind, and nearly naked. Domestic rabbits do not pair, and are more prolific than the wild. Captain Brown says, that a doe, which he had, produced sixteen at the first litter, ten at 
the second, and thirteen at the third. All attempts to produce hybrids between the rabbit and the hare have hitherto been unsuccessful.

Not only the flesh, but the fur of the rabbit is highly esteemed. So extensive is the demand for the latter in the manufacture of hats, the lining of garments, \&c., that our own country being unable to furnish a sufficient supply, an enormous quantity of skins is annually imported from the northern and middle countries of Europe. Some farmers think it profitable to keep rabbits for the sake of their manure; this, however, must be under very peculiar circumstances.

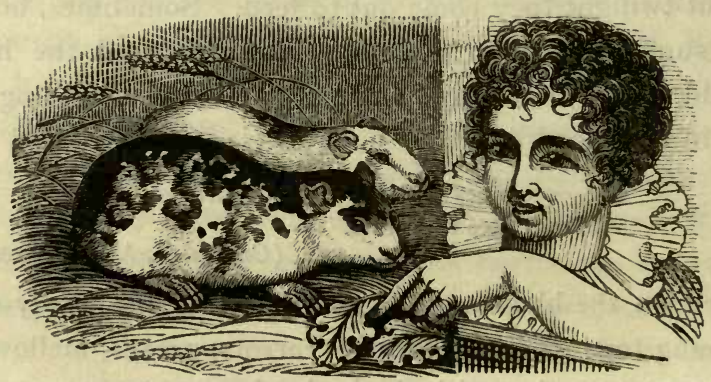

The Restless Cavy.-(Cavia cobaya, Pall.)*

Guiana Pig.

Although this animal, doubtless a South American species, has been very generally domesticated from an early period, the stock from whence the breed was derived is not known, nor is

* Frederic Cuvier attempts to prove that this animal has originated from the perea (Hydrocharus Aperea), which inhabits the woods of Brazil, Paraguay, Guiana, and other southern parts of South America; but facts in the anatomy of the latter animal would seem to refute his notion. Guinea-pig, the common name of the present animal, which is no pig at all, is evidently a corruption of Guiana pig. 
it recognised in any wild species now found in that part of the world.

The length of this animal, when it extends its body, is nearly eleven inches. It has no tail. The distribution of its spots, black and brown on a white ground, varies in different individuals. They are pretty, tame, harmless little creatures, and very careful of keeping a clean fur. They feed on various plants; but it is said that if they, or even rabbits, be given the leaves, stalks, and pods of the maize, or Indian corn, they will touch no other food while a particle of this remains. They drink by lapping. When about a month old they begin to breed, and have several litters in the year, each litter consisting of from six to eight, or even twelve young.

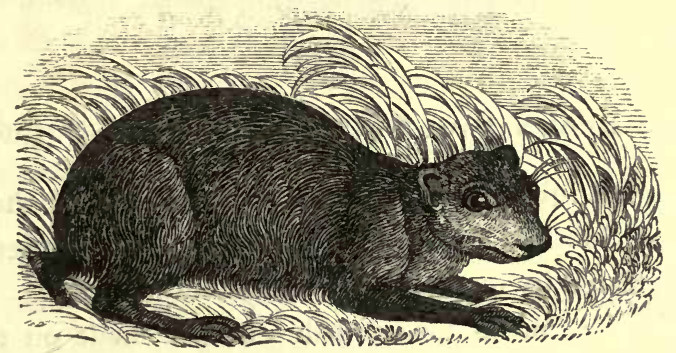

The Agouti.

(Chloromys acuti, F. Cuv.; Dasyprocta acuti, Illig.,

The agouti is a native of South America. It is about the size of a hare; its short fur is chesnut brown, mixed with red, of a sleek and shining appearance; its muzzle is long, and the upper lip deeply divided.

It grunts like a pig; sits on its hind quarters when eating its food, consisting of roots, fruits, and nuts, which it conveys to its mouth with its paws; and when it has eaten enough, it 
conceals the remainder. The female produces, throughout the year, from four to six young at a litter. They are easily tamed, but are destructive, as they gnaw everything that comes in their way.

The South Americans hunt the agouti for the sake of its flesh, which is much prized, and resembles that of the rabbit.

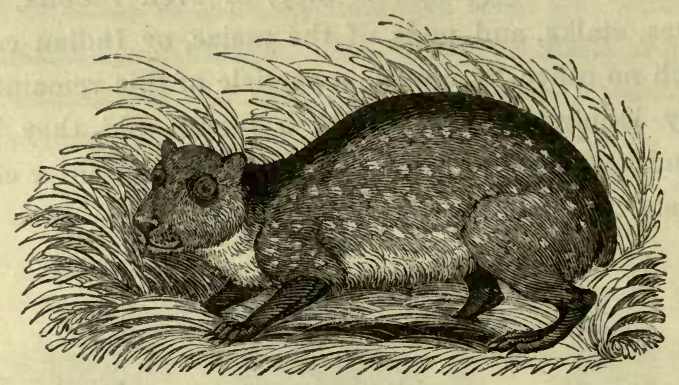

The Brown Paca.*-(Cologenus subniger, F. Cuv.)

This animal inhabits the forests in the whole of the eastern division of South America, from Surinam to Paraguay, and formerly existed in some of the West India islands.

Its general colour is dusky, with a deeper shade on the back, and a tinge of greyish white on the under parts. From the shoulders to the haunches extend four or five longitudinal rows of oblong whitish spots.

It eats herbs, and fruits principally, but the sugar plantations occasionally suffer from its devastations. The damage it commits is partly recompensed, however, by the savoury dish afforded by its flesh, which is a staple article of food in many parts of South America.

* Readers of travels should bear in mind that the paca is not the paco, a sort of llama, and also a South American animal. 


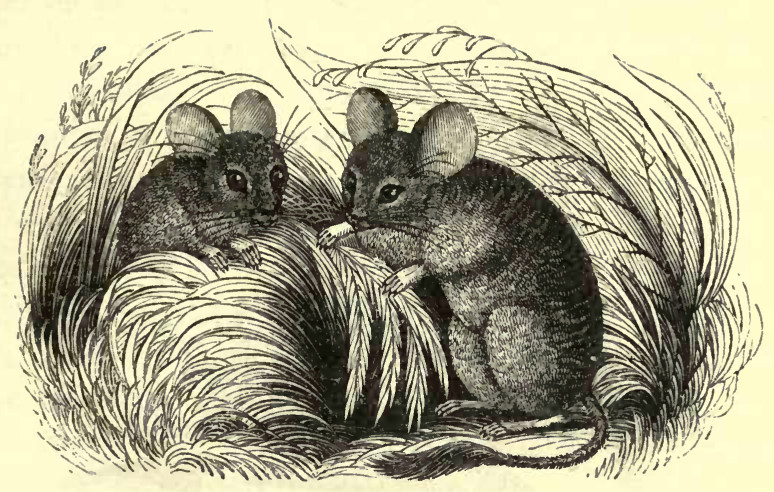

The Chinchilla.-(Chinchilla lanigera.)

The chinchilla inhabits the alpine valleys of Chili and Peru. Its length from the nose to the end of the tail is about one foot two inches. It is greyish or ash-colour above, and paler on the under parts; all the feet have four toes, and short claws, which are nearly hidden by bristly hairs.

It usually sits upon its haunches, but can raise itself up and stand on its hind-feet. Wild onions, according to Schmidtmeyer,* constitute its chief food in its native state; but specimens brought to England have thriven well on succulent roots, hay, clover, and various kinds of grain. When feeding, it sits up, and conveys the food to its mouth with its paws.

Great numbers of chinchillas are killed for their fur, which, as Father Acosta observes, is " so wonderful smooth and soft, that the natives wear the skin as a healthful thing to comfort the stomach, and those parts that have need of a moderate heat." + Many of the skins are imported into Britain for the manufacture of muffs, boas, and other articles of female attire.

* Travels into Chile over the Andes (London), 1824.

† Acosta's Natural and Moral Historie of the East and West Indies, translated by D. G. (Lond.), 1604. The original edition was written in Spanish, and published at Barcelona in 1591. 


\section{ORDER-EDENTATA.}

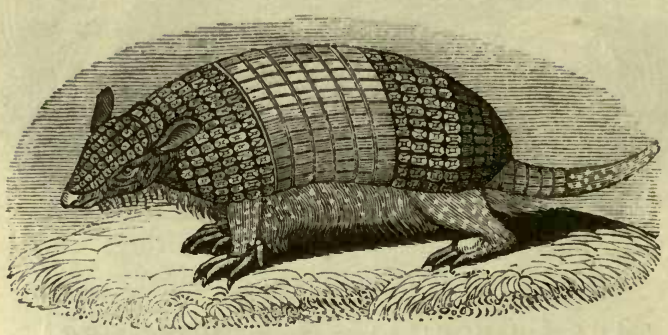

The Encoubert.

(Dasypus gilvipes, Illig.) *

Weasel-headed Armadillo. Six-banded Armadillo.

The encoubert inhabits Brazil, Paraguay, and other parts of South America.

Its length, from the nose to the root of the tail, is one foot and a half, and the tail itself is nearly ten inches long. The head is triangular; there are nine teeth on either side of the upper jaw, and ten on either side of the lower; the anterior teeth are incisors only in respect to the bone in which they are placed, and differ neither in form nor function from the others. $\dagger$ Instead of possessing a furry coat, as is usual with

* The zoologists have bestowed many other titles upon this animal. It is the $D$. mustelinus, Ray; $D$. sexcinctus, and D. octodecimcinctus, Linn.; D. encoubertus, Desm.; D. setosus, Prince Max.; and Encoubertus sexcinctus, Cuv.! How many more names it has yet to receive I know not, but, in the interim, think it preferable to adopt Illiger's specific term, as being a translation of its South American one, tatu-peba, or yellow-footed tatu. + Cuvier says the present species is distinguished from all the rest, by having a tooth on each side of the intermaxillary bone. 
mammals, the encoubert, and others of its genus, are dressed in hard, bony armour; hence they are called armadillo by the Spaniards, and encouberto by the Portuguese. The armour consists of a plate, which defends the head; a large shield over the shoulders, formed of small rectangular pieces, disposed in transverse rows; moveable transverse bands, consisting of pieces more elongated; a shield on the crupper, similar to that on the shoulders; and bands on a portion of the tail. So regularly arranged are the little pieces composing the armour, that it appears like mosaic work, and, owing to its being covered with a thin, transparent cuticle, it has a shining, varnished appearance. The legs and the under parts of the body are covered with scaly warts, from which long hairs proceed. All the feet have five toes, the three middle ones of which are the longest.

This animal resides in subterranean burrows, which it excavates with astonishing ease and rapidity, by means of its large and strong claws. It possesses great strength, and runs with considerable celerity. Waterton says it swims well in time of need, but does not take the water voluntarily.

It devours roots, grain, carrion, and insects. It does good service by killing the more destructive species of ants; and, to obtain them, this little knight in armour will charge and overhaul the firmest and strongest of their habitations. The movements of the several specimens, kept in an enclosure at the Zoological Gardens, are highly amusing, and really remind one of a burlesque tournament. There they are seen, and, of course, in all their accoutrements, running to the right and to the left, and then wheeling round and round as fast as possible, running against or over any obstacle, dead or alive, that stands in their way. All these feats they repeat again and again, in the most mechanical manner, and with a truly humourous mock air of great seriousness; sometimes they leave off in the midst of their sports to dig in a corner, and if a noise be made they suddenly stop, scratch, and rear themselves up to listen, until generally they over- 
balance, and tumble backwards in the straw. If one of them be assaulted, he rolls himself up into a ball, so as to protect the more tender parts of his body, and expose merely the armour.

Sir Woodbine Parish, in his account of Buenos Ayres, and the Provinces of the Rio de la Plata (1839), says, from his own experience, "that a more delicate dish than one of these little animals, roasted in its own shell, is not to be had in any part of the world!" The natives of South America eat them, especially when young; but when old, their flesh has a strong, musky flavour.

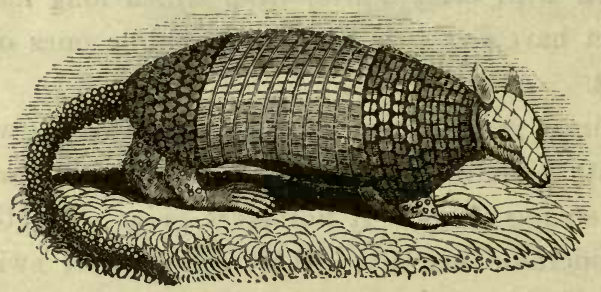

The Cabassou.

(Dasypus unicinctus, Linn.; D. gymnurus, Illig.)

The cabassou inhabits Brazil, where it is tolerably common, and attains a great size. The compartments of its bands and shields are square, and broader than long; the intermediate bands are twelve in number; all the feet have five toes, but those of the fore-feet possess enormous nails with trenchant outer edges; the tail is long and tuberculous. The Brazilians call the cabassou Tatu de rabo molle, or tatu with the soft tail.

The structure of the fore-feet enables this animal to burrow with rapidity, and to cling to the earth so tenaciously, that it is with extreme difficulty torn away from it. 


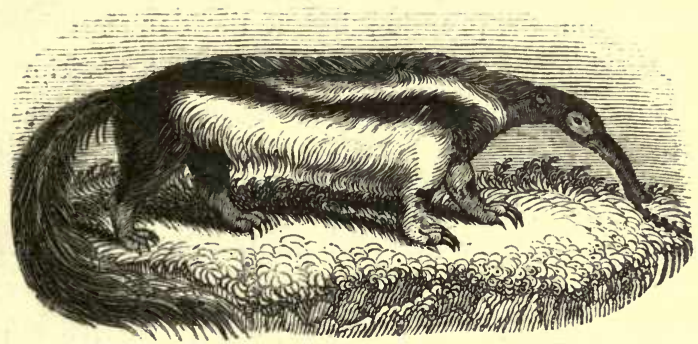

The Great Ant-eater.*-(Myrmecophaga jubata, Linn.)

The great ant-eater, a native of Brazil and Guiana, is about four feet and a half in length from the end of the snout to the root of the tail, which is somewhat more than two feet and a half in length. The mouth has no teeth, but is only occupied by a long vermiform tongue, capable of considerable elongation; all the feet have four nails, those of the fore-feet are large and strong; and the tail is long and bushy. The fur is of a greyish brown, with an oblique black band edged with white on each shoulder, and forms a nearly erect mane along the back.

It runs with a peculiar trot, and is not soon overtaken, for when chased it will keep a horse at a canter, and is not easily fatigued.

White-ants (Termites) are its chief food; and having, by means of its claws, pulled down the large mounds which these insects construct, it thrusts its long tongue amongst them, when they adhere to the saliva, and are drawn into the mouth. The tongue is alternately protruded and retracted so rapidly, that it is not surprising so large an animal can satiate itself with such small insects. The female produces only one at a birth; and as soon as this is strong enough, it holds firmly to the back of its mother, who in that position carries it about for a year. If the mother be attacked she raises herself upon her haunches, and with the young one still adhering to her, strikes with her

* Sometimes improperly called ant-bear. 
sharp claws at the enemy, principally with the right foot, whilst the left rests on the ground; but if the danger increases, she throws herself upon her back, and in that position defends herself by striking with both claws of the fore-feet, which possess such force that they are well able to rip open the belly of an assailant. Even the jaguar finds it difficult to conquer an ant-eater, and often both combatants kill one another on the spot.

The flesh of the ant-eater is eaten by the native population, and considered a great delicacy.

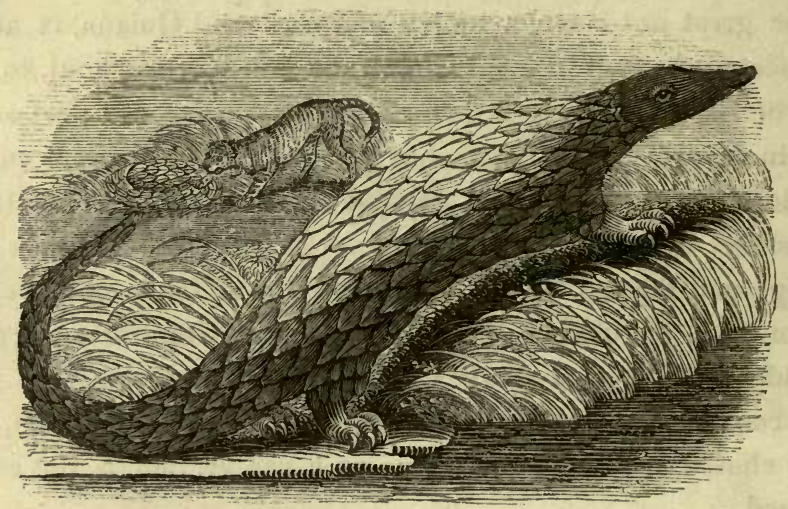

The Pangolin.*

(Manis pentadactyla, Linn.; M. brachyura, Erxl.;

M. crassicaudata, Geoff.)

The pangolin inhabits the East Indies.

Its body, limbs, and tail, are protected by large sharp-edged scales, over-lapping one another. The mouth is destitute of

* Captain Brown, with his usual indifference to the most important, because the least entertaining, points in animal biography, not only confuses the present animal with the Manis tetradactyla, but says it is " a native of Guiana.', Sketches of Quadrupeds, (Glasgow, 1831, p. 435). The fact is, however, that neither species inhabit America. 
teeth, but has a very extensible tongue; the legs are short; and the toes, five on each foot, are provided with curved claws.

Ants are the chief food of the pangolin, and it captures them in the manner of the ant-eater (see page 385); and, indeed, the general shape, anatomy, and habits of the present animal, clearly show that it is merely a modified ant-eater, differing principally in its kind of clothing - a matter of but secondary account in all philosophic classifications, though formerly considered sufficient to authorize the bringing together of animals so dissimilar in habits and other respects, as the hedgehog and the porcupine. The pangolin's coat of mail not only defies a legion of angry ants, but protects it from the more vigorous attacks of large animals. When in danger it rolls itself up like a ball, and in that position, with its sharp scales elevated like so many spear-heads, is prepared to receive those who have the temerity to molest it. Nemo me impune lacessit is the motto on its coat of arms. 


\section{Order-PACHYDERMATA. Family-Proboscidiana.}

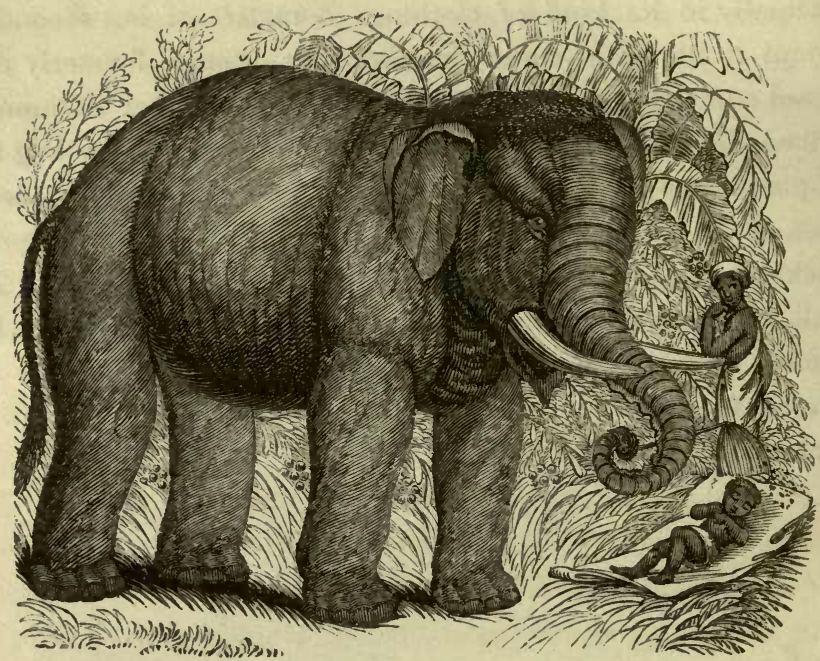

The Indian Elephant.-(E.ephas Indicus, Cuv.)

The biography of the elephant involves so many details of its peculiar structure; its faculties; its habits in a state of nature; the several modes adopted for its capture; its docility and tractability in servitude; its antiquarian history as regards the Roman Amphitheatre, sculpture in ivory, and geology; and the extensive commerce at present carried on in its tusks, that a whole volume has been written of nearly four hundred pages solely treating of this animal.* Therefore it cannot be expected that I should enter into details which would occupy the re-

* I allude to the excellent history of the elephant, which forms the second volume of that portion of the Library of Entertaining Knowledge, entitled T'he Mencgeries (1831). 
mainder of this volume; and the extent, not the scantiness of our knowledge concerning it, is, in fact, the fair apology for the following confessedly imperfect sketch of its natural history.

Of the elephant there are two species; and from an inattention to this fact, or utter ignorance of it, general writers are incessantly confounding together facts which relate to one or other in particular, and so causing much misapprehension and contradiction. The African elephant (E. Africanus), which is only hunted for the sake of its hide, flesh, and tusks, is generally larger than the other, and does not appear ever to have been brought to England; but the Indian elephant (E. Indicus), is so constantly exhibited as one of the principal characters in our zoological collections, that there are comparatively few persons who have not seen it. When compared with the African elephant, the present species is observed to differ in having the head elongated; the ears shorter and much less dilated; the laminæ of the molar teeth forming undulating parallel lines, not rhomboidal ones; and the hind-feet have four hoofs, while those of the other species have but three.

The Indian elephant inhabits all the southern countries of Asia; as Cochin-China, Siam, Pegu, Ava, Hindostan, and the adjacent islands, particularly Ceylon. Its height has been greatly exaggerated, even by naturalists, for Cuvier and others state it at fifteen or sixteen feet. Mr. Corse (now Mr. Corse Scott), formerly superintendent of the East India Company's elephants at Tiperah, a Bengalese province, never heard of more than one elephant much higher than ten feet. This was a male, and its height, accurately measured from the top of the shoulder to the ground, was ten feet and a half; from the ground to the top of the head when set up, twelve feet two inches, and its length from the front of the face to the root of the tail, fifteen feet eleven inches. The Company's standard for serviceable elephants, is seven feet and upwards, measured at the shoulder, in the same manner as horses are. At the middle of the back, which is curved unless the animals are aged or injured, they are several inches higher. A living elephant's height is exceed- 
ingly deceptive, even to those who are most accustomed to the animal. Mr. Corse, having measured a celebrated elephant of the Nabob of Dacca, which was generally stated to be fourteen feet high, found it did not exceed ten feet. The elephants of Hindostan are, however, the smallest; those of Pegu and Ava are much larger; and the skeleton of the elephant at the Petersburgh Museum, and sent to the Czar Peter by the King of Persia, is reported to be sixteen feet and a half in height. It is probable, however, that few elephants of more than nine feet in height have ever been brought to Europe; nor is it probable that the elephants of Hindostan have degenerated in size, for the Emperor Baber says, in his celebrated Memoirs, written in the fifteenth century, - "I have never in these countries [Delhi, \&c.,], seen one above four or five gez [eight or ten feet] in height," (p. 316). It seems agreed that.a large elephant weighs from 6000 to 7000 pounds; and of the whole weight the carcase forms about four-fifths. In its wild state the elephant's skin is smooth, and clothed with hair, which is most abundant when the animal is young, and which increases so much in the colder mountainous chains, that they are sometimes found, according to Bishop Heber, "as hairy as poodles ;" and Mr. G. Fairholm, after a rigorous investigation of the subject, has obtained satisfactory confirmation of this statement. In a state of slavery and confinement, the hair is almost entirely wanting; and instead of it we generally see what Chapman, an old dramatic author, not unaptly calls "its leprous scaly hide," (May Day, 1611, Act I. Scene 4). An uncongenial temperature, and the altered mode of the animal's life, are apt to produce a disease of the skin, which then becomes hard and knotty, or even scabby, as Mr. P. Blair noticed to be the case in an elephant he dissected at Dundee. The natural colour of the elephant is black or dusky. Cream-coloured, and albino or white varieties are sometimes captured; but as they are rare they are highly prized, so much so indeed, that a perpetual war existed between the Kings of Siam, Pegu, and Aracan, in the sixteenth century, for the possession of a white elephant, and 
the contest was not concluded till five kings and many thousands of their subjects had been killed. "To support such a heavy super-structure as the enormous body of the elephant, the legs are solid and compact-formed more with regard to strength than flexibility,*-fitted, in fact, to bear an enormous weight upon a level surface, without any violent strains produced by sudden bounds, or by the necessity of ascending or descending great elevations. Hence the elephant has not the elastic ligament which, in almost all mammals, connects the head of the thighbone with the pelvis, and which gives the hind-legs power to resist the strain which is produced by traversing irregular surfaces. The elephant is indeed found in the neighbourhood of mountainous ranges; and, under the command of man, certainly ascends rocky passes, bearing a considerable weight; but that such an ascent is a violation of his natural habits is evident from the fact, that in these situations he is liable to fall backward, not having the power of resistance in his hind-legs." +

* Our forefathers believed that the elephant had no joints, and never lay down. In the Dialogues of Creatures Moralized, a translation of an ancient and very curious Latin work, mention is made of " the olefawnte that boweth not the knees." Shakespeare, in Troilus and Cressida (Act II. Scene 3), makes Ulysses say the elephant's legs are "for necessity, not for flexure." In the play of All Fools (1605), a character hopes " you are no elephant, you have joints ;" and in a later play, All's Lost by Lust (1633), a woman is said to be "as stubborn as an elephant's leg, no bending in her." These quotations sufficiently show that the notion was popular. Eugenius Philalethes (Thomas Heyden), in his Brief Natural History (Lond. 1669), refutes several common notions, and amongst others " that the mole hath no eyes, nor the elephant knees; both which, by daily and manifest experience, are found to be untrue" (p. 89).-J. H. F.

† Menageries (1831), vol. ii.p. 41. Bernier, in his Travels in the Mogul Empire (vol. ii. pp. 129 and 149), notices the extreme caution with which elephants ascend craggy steeps; and relates that while a long line of elephants were ascending the Peer-Punchal mountains, the foremost, perhaps appalled by the great length and acclivity of the path before him, stepped back upon the second elephant, who being pushed against the third, and that against the fourth, and so on, no less than fifteen elephants, unable to turn round or extricate themselves in a road so steep and narrow, fell down the precipice. M. Ruppell, however, says, that African elephants often cross table-lands in Abyssinia, between eight and nine thousand feet high, and with, of course, a very cold temperature.-J.H.F. 
Persons judging merely from the vertical prominence of the elephant's skull, which arises from a peculiar conformation, and not from cerebral development, have supposed that the elephant possesses a very large brain; and they have been further induced to form this conclusion, by the popular error of regarding the animal's vast capabilities as evidences of vast sagacity. In the elephant, however, the brain is perhaps smaller in comparison to bodily bulk than in any other wild animal; for the weight of its brain compared to that of its body, is as 1 to 500. The tusks, which are used as weapons of defence, are much larger in the male than the female. Those of the Bengal elephants rarely weigh more than seventy pounds each, though tusks weighing one hundred and fifty pounds each have been received at the India House. The largest on record was one sold at Amsterdam, and which, according to Klokner, weighed three hundred and fifty pounds. Several tusks measured by Eden were nine feet long; and one described by Hartenfels in his Elephantographia, exceeded fourteen feet.

The trunk or proboscis of the elephant, though without bone or cartilage, is a highly powerful organ, as may readily be imagined, from the fact that Cuvier ascertained that it consists of nearly 40,000 muscles. Its uses are many, as it serves for respiration, for his very acute sense of smell, for gathering his food, and for drawing up water, and ejecting it thence into the mouth or over the body. At the end is an extremely flexible appendage which acts as a finger, and opposed to which is a sort of thumb, and by the aid of these instruments he can untie a knot, undo a buckle, pick up a pin or a sixpence, pull the cork out of a bottle, and perform various other feats. Cicero calls the trunk "the elephant's hand;" Lucretius, still more expressively, calls it anguimanus or snake-hand; and the Caffre, borrowing from neither poets nor orators, but naturally impressed with admiration of its remarkable powers, approaches the trunk of the slain elephant with reverence, and, having cut it off, solemnly inters it, repeatedly exclaiming, "The elephant is a great lord, and the trunk is his hand!" 
Elephants in their wild state feed chiefly on herbage, leaves, and roots; and it may easily be supposed that creatures so enormous possess appetites in proportion. To each of the hundred and one elephants that the Emperor Akbar kept for his own riding, two hundred pounds of food was the daily allowance; but most of them had also ten pounds of sugar, besides rice, pepper, and milk. Hay, clover, and carrots are their chief food in our English menageries.

They are very fond of bathing, and when in the water they often emit a singular noise by ejecting the water from their trunks. Bishop Heber, who heard this noise near Dacca, says, "A most solemn and singular sound struck my ear. It was long, loud, deep, and tremulous, somewhat between the bellowing of a bull and the blowing of a whale, or perhaps most like the roaring noise which the wind makes in those buoys which are placed at the mouths of some English harbours to warn ships off them. 'Oh,' said Abdallah, 'there are elephants bathing, Dacca much place for them.' I looked round, and saw the heads and trunks of about twenty of these fine animals just raised above the water. It was their bellowing $I$ had heard, and which the water conveyed to us with a finer effect than if we had been on shore."*

The courage which the natives of Ceylon display in attacking wild elephants is truly astonishing, when it is remembered that the animals are in an excited state meanwhile, and that should the hunters come within fair reach of the trunk or tusks, it is almost certain that their temerity will cost them their lives. $\dagger$ When a herd has been driven into a kraal or enclosure, for their capture, the hunters pass and re-pass with great boldness, to effect the operation of noosing. Partly protected by tame

* Journal, vol. i. p. 182.

$\uparrow$ The accounts of the killing of poor Chunee at Exeter 'Change, some years ago, caused great laughter in Ceylon, where a single hunter will attack a wild elephant. The newspapers took out a plan of the scene, with the various objects regularly marked, such as $E$, the elephant, $G$, a party of the guards ; and, in conclusion, a return of the quantity of ammunition expended in killing an elephant in a cage. 
decoy elephants, they prick the feet of the wild ones, and as soon as the legs are lifted, throw nooses dexterously round them. The noosed elephant starts off, but is speedily brought on its knees, the hunter having securely wound the other end of the rope round a tree. Major Forbes, who resided many years in the island, says he has seen-men actually descend from the trees on to the backs of wild elephants to dislodge them from the spot; and this excellent authority relates many frightful incidents which occurred during elephant hunts. In one case a gentleman was crushed to death by an elephant, and the same fate was near happening to two persons who attacked the same animal, but luckily escaped by both moving to the left when it charged at them. Having thus changed their position, the elephant rushed past them to their great surprise; but this was subsequently explained on finding that their shots had destroyed its vision. "On another occasion, an unlucky hunter was seized by an elephant's trunk. Fortunately, considering the hurry in which I fired off my gun, the ball passed through the animal's head without injuring the man, who was released from an embrace so severe, that it had already forced blood from his nose and mouth. At another time a very large elephant and a smaller one having taken shelter in an extremely thick dark copse, I crept in after them, and soon perceived the legs of the larger one, whose head was concealed by the foliage; but the other was sufficiently visible to allow of my taking a proper aim. My attendants being close to the edge of the brushwood, and being myself ready to back out and face the expected charge of the large elephant, I fired at the smaller one, and it fell dead. I then attempted to rise, but ineffectually, as I was entangled by trailing thorny plants; and, before the attempt could be repeated, the thick mass of regetation was pressing forward upon me, owing to the large elephant rushing up close to where I lay, and there it stood with its legs within my reach, and its head almost over me, and uttering that fearful, shrill, trumpet-like squeal, which generally proclaims the animal's readiness for battle. I raised my rifle under its head, and with 
the butt-end resting on the ground, pulled the trigger. My two-ounced shot took effect; the animal staggered back eight or ten paces towards the dead one, while, by violent exertions, I disentangled myself from my most uncomfortable position." * This was, indeed, a fortunate escape from an emergency of awful risk, as it is impossible to tell whether one or twenty balls will quiet an elephant.

Captain Marryatt states, that elephants will frequently use a large branch as a flapper to protect themselves from the mosquitoes, and no one who has not been bitten, can conceive how hard the tiger-mosquito can bite. He relates, "that while a large elephant was much annoyed by these persecutors, and flapping a bough in all directions about his body, the keeper brought a little naked Indian babe, laid it down before the animal with two words in Hindostanee- ' Watch it,' and then walked away into the town. The elephant immediately broke off a smaller and more convenient portion of the bough, directed his whole attention to the child, gently fanning it, to drive away the mosquitoes; and this he continued to do for above two hours, regardless of his own sufferings, until the keeper returned. It was really a beautiful sight to contemplate. Here was a most gigantic animal acknowledging, as it were that this little image of the Creator was divine; silently proving that $\mathrm{He}$ hath ' given to man dominion over the beasts of the field;' and setting an example of self-denial, which but few Christians, none indeed but a mother, would have practised."

Elephants have in many instances shown great and steady attachment to their keepers, more especially where single individuals have been exclusively attended to. In Ceylon, however, according to Major Forbes, there are few old hunting elephants that have not killed people employed about them at one time or other; and he says that, in 1829, one of the hunting elephants at Matale, having shown symptoms of a capricious, irritable temper, was secured to a tree near the stables; next day, as the keeper was standing barely within reach, the creature

* Abridged from Forbes's Eleven Years in Ceylon (1840). 
suddenly seized him, and pressed him against the front of another elephant that was passing, until one of the thick blunt tusks came through the man's body.

In the Regent's Park Zoological Gardens, there are two Asiatic elephants. They have spacious stables, a paddock, and a pond in which they bathe with evident enjoyment. When they leave the pond, they either wallow in the mud or rub some of it over their bodies with the trunk, with which they often take up a quantity of dry dust and pebbles to throw at the flies on their backs. Every morning, before the public are admitted, the skins of these animals are lubricated with train oil. The cleaning time is, however, an excellent time to see many of the various animals show off to advantage; and some time ago when I was present at an early hour, I was much amused at the process of oiling the larger elephant, which the keeper performed by means of a long brush. The animal knelt down, however, or assumed any attitude that was requisite. But before the operation was completed, the keeper was called out of the stable; and during his absence, the elephant poured all the oil out of the can, and then laying its trunk close along the floor worked it backwards and forwards with such rapidity, that the oil soon resembled lather, and was actually steaming with the friction. After rubbing the oil in this way into its trunk, it then began to smear its body with it here and there. This fine elephant (a male, two-and-twenty years old, and eight feet nine inches high,) is on the most friendly terms with his next door neighbour, the huge rhinoceros. Recently I have several times seen him lean over the rails which separate their paddocks, and, with his trunk, caress the rhinoceros without the slightest fear, but on the contrary with an appearance of perfect amity, and which seems indeed to be mutual. The smaller elephant is frequently exercised about the grounds, and the visitors are permitted to ride upon him.

Among the still prevalent errors respecting the elephant is the notion that it refuses to breed in a domestic state-that it scorns to multiply slaves for the service of mankind. The 
repetition of this error by our instructors, shows how little they know either of the ancient or modern authors who treat of this animal. Elian tells us that elephants were bred at Rome;* and Columella says, "within our own Roman walls we have seen elephants born." $\dagger$ In Asia, the Emperor Akber bred them; and Mr. Corse, in more modern times, has also proved the incorrectness of the general notion. But as elephants may at present be captured in whole herds, it is not the practice to incur the expense of breeding them. Another error in some of the most recent books, more especially those intended for children, is the statement that the young elephant, or calf as it is called, sucks with the trunk; and it is really deplorable to see how writers repeat these falsehoods again and again. Le Vaillant, a much better authority than Buffon and his followers, told us long ago, from his own observation, that the young elephant sucks with the mouth. The two breasts of the mother project horizontally from between the front legs, and she never lies down to give her young one suck, but if she is too tall she bends her body towards the calf, which is about two feet and a half high at first, and the little one grasps the nipple with the side of its mouth, pressing its trunk meanwhile against the breast, to cause the milk to flow more readily.

The flesh of the elephant is eaten, especially that of the African species. Several persons, male and female, ate some rump steaks cut off of poor Chunee, at Exeter 'Change, and pronounced them excellent. The flesh of the celebrated theatrical elephant, Mademoiselle D'Jeck, who was shot at Geneva, on June $2 \%, 183 \%$, was eagerly purchased by the gourmands at the ordinary price of butcher's meat.

* Elian de Animalibus, lib. ii. cap. xi. Gesner's translation.

+ Columella de Re Rustica, lib. iii. cap. viii. 
ORDER-PACHYDERMATA. FAMILY-Ordinaria.

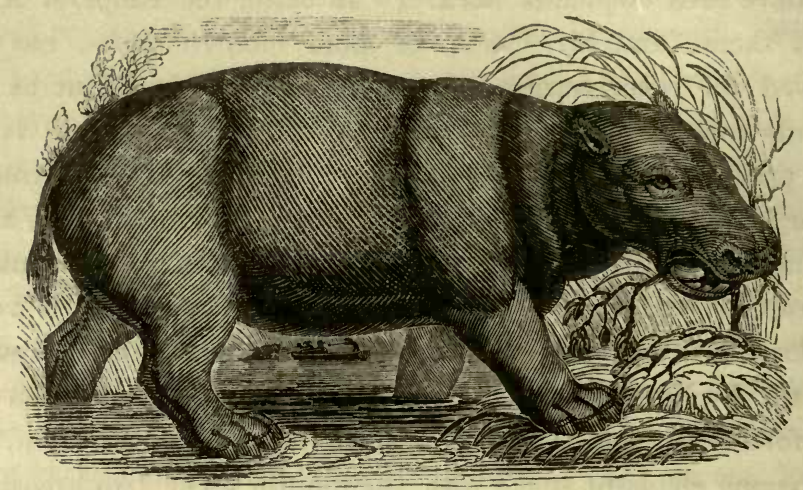

The Hippopotamus.-(Hippopotamus amphibius, Linn.)

River-Horse. Sea-Cow.

This animal inhabits the middle and south of Africa, haunting the rivers and their banks. Captain Belcher met with a very large hippopotamus off the south-west end of Yomber Island, off the west coast of Africa, and which, from being covered with barnacles, proves that this animal frequents salt-water, which, in this instance, was many miles away from any fresh-water river.*

The length of the hippopotamus has been variously stated. Dr. Edward Rüppell, a traveller whose word can be believed, mentions an enormous one which measured thirteen French feet and a half from the nose to the end of the tail; and he says, that a full grown one weighs as much as four or five oxen. The general colour of its massive body, which is almost without hair, is a light brownish black; the head is of enormous size; the gape of the mouth sometimes three feet and a half, according to the statement of Lieut. Boteler, who commanded the surveying 
party during a recent voyage to explore the shores of Africa, and came in frequent contact with these immense animals;* the muzzle broad; the lips are hairy; the eyes small and prominent; the ears small and pointed; the legs very short, and each foot with four toes terminated by little hoofs; the tail is short.

Though a heavy animal it can run with great speed, and swim and dive with great rapidity. Mr. Salt says, it cannot remain under water more than five or six minutes at a time, being obliged to rise to the surface to breathe in the course of some such interval. During the day, it usually remains in the rivers, or else concealed among the tall herbage on the shore, whence on the approach of danger it immediately runs into the water. At night, however, it ventures in land to eat its fill of grass, corn, \&c.; not being content with the marshy herbage and twigs which are its ordinary food. Some idea of the havoc it can make in a corn-field may be formed from the fact, that Burchell found six bushels of masticated grass in the stomach of one, and the animal is generally accompanied by others of its own species, and they trample upon and thus destroy much more than they devour. The natives, not possessing fire-arms, endeavour to keep them away from the crops by making a noise, and keeping fires blazing all night.

The hippopotamus is harmless if left alone, but when provoked it is very ferocious, and, as its war cry immediately summons its companions to join in the fray, it is very dangerous to attack it in boats, which they either upset or crush to pieces. The two Landers, when rowing up the Niger during a night of intense darkness, only occasionally broken by awful flashes of lightning, were placed in imminent danger by an incredible number of hippopotami snorting and plunging round and within a few feet of the canoe. The report of a gun, instead of frightening them, only served to call up from the water and out of the fens about as many more of their unwieldly brethren; and

* Narrative of Voyages to the Shores of Africa, under Cant.W. F. W. Owen, vol, i. p. 110. 
this combined host beset the canoe more closely than before, and pursued it so fast that it was with the greatest difficulty the little party contrived to keep a-head of them. Dr. Rüppell says, that while he was in Dongola, an infuriated hippopotamus, with one gripe of its mouth, crushed one of the huntsmen to death before he could throw his harpoon.

The female produces in November; and a few hours after it is born, the young one takes to the water, under the guidance of its mother. The calf, as it is called, cannot suck under water, and the mother therefore always comes ashore in order to give her offspring nourishment, and if approached while thus engaged, she is more ferocious than usual, and not unfrequently commences the attack.

The flesh of the hippopotamus when tolerably young is excellent food, and the fat, salted and dried, is considered a great luxury by the Cape colonists. In Purchas's Pilgrimage (1614, part i. p. 852), which contains a correct account of the animal, its flesh is said to taste like beef. The hide, which is thicker than that of the rhinoceros, is manufactured into shields, whips, \&c. The tusks, or canine teeth, sometimes two feet long, and six pounds in weight, are in great request among ivory merchants, as they do not become yellow.

\section{TH E H O G T R I B E.}

It is hardly necessary to mention the exterior appearance of animals of this kind; which includes the wild boar (Sus scropha), the masked wild boar (S. larvatus), and the babarussa (S. babarussa). They are gregarious and omnivorous animals; their muzzles are terminated by a truncated process adapted for digging; their lower incisor teeth slant forwards; the tusks, or lower canine teeth, project from the mouth and curve upwards ; and they have twenty-four or twenty-eight grinders; all the feet have four toes, of which the central ones are the largest, and possess strong hoofs; and the outer toes are also hoofed, but scarcely touch the ground. 


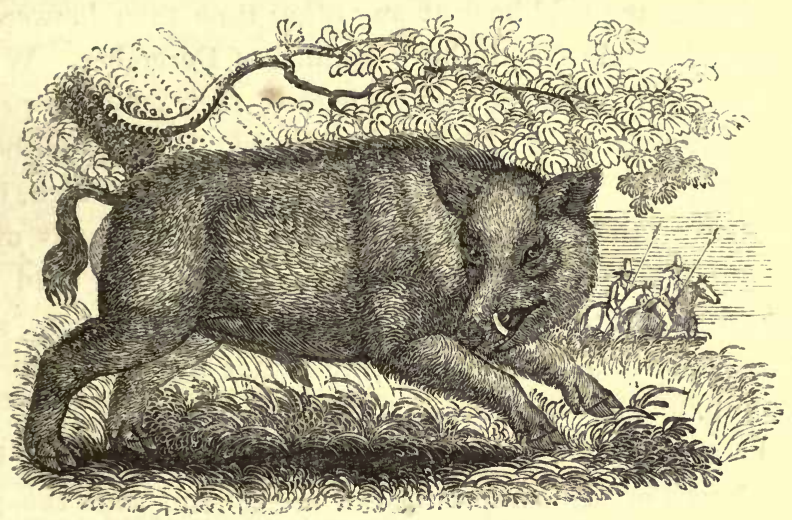

The Wild Boar.-(Sus scropha, Linn.)

The wild boar has an extensive range throughout Europe, Asia, and Africa, if the species of these quarters of the globe be really identical as most zoologists conceive, but slight differences are observable between that of India and that of Germany, and the identity of the Egyptian and European is doubted by Sonnini.* In Europe, it is probably most abundant in Germany; and it is still common in some of the French forests, even in that of Chantilly, within forty miles of Paris, unless it has been extirpated thence since the year 1830. In December 1833, wild boars were so abundant at Finisterre, in the latter country, that dreadful ravages were committed by them, and one actually entered the town of Huelgoet. They were formerly common in Britain ; but owing to the spread of population, the necessary conversion of forest land into building ground and pasturage, and the eagerness with which they were chased away from the neighbourhood of man, these animals became extinct long since,

* Hogs are now found in a wild state in some parts of America, though they are not natives of that quarter, but were introduced by the Spaniarde soon after their conquest of the western regions. 
but the exact period is not known. The Welsh legislator, Hoel Dda, who died in the year 948, prohibited his grand huntsman from chasing the wild boar at any other time than between the middle of November and the beginning of December. William the Conqueror punished with the loss of their eyes any persons that were convicted of killing the wild boar, the stag, or the roebuck; and Fitz-Stephen says that the vast forest which, in his time, grew on the north side of London, was the retreat of wild boars, stags, \&c. A breed not far removed from the wild boar, if, indeed, they were not among the last of the pure race, seems to have existed in one of our forests not a great many years ago. Gilpin, in his Remarks on Forest Scenery (1791), after remarking that some owners let their hogs run wild and breed in the New Forest, Hampshire, and are content with the profit on such as they are able to regain, says there is also a breed of hogs there " commonly called forest pigs, which are very different from the usual breed of that country. The forest hog has broad shoulders, a high crest, a thick bristly mane, which he erects on any alarm. His hinder parts are light and thin, his ears are short and erect, and his colour either black or darkly brindled. He is much fiercer than the common breed, and will attack an ordinary-sized dog. All these are charac. teristic marks of the wild boar, from whom I have little doubt that he is partly descended, though his blood may be mixed with the common breed. Once, when I was lying very still under a beech, the leading boar of a large herd of forest swine came grunting forward, followed by all his tuneful band. Had they not been swine, I might tell the truth and say the sight was as beautiful as interesting. They were in fine condition; their bodies were as clean as if they had been daily washed and combed; their bristles shone like silver; their eyes reflected the sun's rays; and altogether their free and happy appearance recalled the romance of forest life. When alarmed, they galloped off, helter-skelter, with a speed which none but swine of the forest could have exhibited. Though much more picturesque than the common hog, they are much less prized, as the 
lightness of their hind quarters, and the thinness of their flanks, appear to disadvantage in the ham and the flitch."

The wild boar is, doubtless, the origin of our domestic pigs. In contrast with them the wild boar is more robust and bony, and the snout is longer. Its general colour is rusty black, or blackish brown; the hide is very thick, and covered with long coarse bristles. The tusks continue to grow during life, and sometimes attain the length of eight or ten inches; but those of the female are smaller. The animal attains its full size in five or six years, but the dimensions of individuals differ greatly according to the quantity and kind of food they have generally eaten. They feed on acorns, nuts, beech and maple mast, chesnuts, grapes, the roots of fern and other plants, and they also devour snakes, and the bodies of the slain left on the field of battle. Even the carcases of their own species they do not refuse; and much as we may be disposed at first to despise such an animal, we must admit on reflection that it is one of the most useful in both the natural and the domestic economy.

When closely pressed by an enemy, the wild boar exhibits great strength and ferocity :-

" On his bow back he hath a battle set Of bristly pikes, that ever threat his foes; His eyes, like glowworms, shine when he doth fret; His snout digs sepulchres where'er he goes : Being mov'd he strikes whate'er is in his way, And whom he strikes his crooked tushes slay."

(Venus and Adonis.)

If one of the herd be hurt, the rest return to his assistance. The old boars are the most ferocious, for it is only in defence of their offspring that the sows are furious. Each sow produces from four to ten pigs, and retires with them from the boar, who would eat them. She suckles them for three or four months, but keeps them by her for a very long period, and courageously defends them against the attack of the wolf or other enemy. 


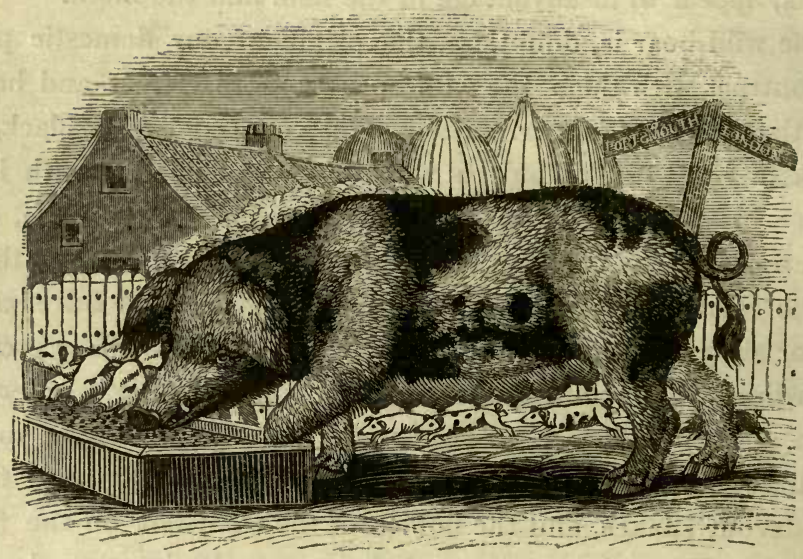

The Domestic Hog.

\section{Swine.*}

There are various breeds of the common hog, some of which are preferred for a particular quality of their flesh; others for their size, or for their great fecundity, and the cheapness and facility with which they may be reared and fattened. The Rudgwick breed is the largest, and attains an enormous size. The Berkshire breed, much esteemed for its excellence, also acquires great obesity. Mr. Culley, in his Treatise on Live Stock, mentions one of this breed which was three yards, eight inches long from the nose to the end of the tail; four feet and a half high; and weighed, after it was killed, eighty six stone eleven pounds avoirdupois.

Though pigs will not refuse animal matter, yet roots, fruits,

* The word swine now always used for the plural, was formerly the singular also. Thus in the scriptural proverb, "As a jewel in a swine's snout, so is a fair woman who is without discretion;" and in Holland's Plinie (book viii. ch. 51), "Will ye know that a swine is sicke or unsound, pluck a bristle from the back, and it will be bloody at the root; also he will carry his neek at one side as he goeth." 
and leaves are their ordinary food. Linnæus says, that the bark of the fir-tree, dried, ground, steeped in warm water, and then formed into thin cakes by baking, will fatten swine (a hint worthy the attention of Highlanders), and he also states that they eat the leaves of the bird cherry, hence, perhaps, the origin of its Scotch name, hog-berry. In some parts of Herefordshire, according to Evelyn, large quantities of elm leaves are gathered as food for swine and cattle. The author of British Curiosities in Art and Nature (2nd edit. 1728), says that in some parts of Wiltshire swine are fed with knot-grass. They are very fond of the earth-nut, the seeds of darnel, and the boiled seeds of the snake-weed. The French use sun-flower seeds to fatten them. Gilbert White mentions the singular fact, that although milch sows often die from eating the fallen berries of the yew-tree, yet barrow hogs and young sows eat them with impunity. A careless observer would suppose Franzius to be correct in saying "swine devour anything that cometh to their mouth, and dish water is a very pleasant drink to them;" but Hasselgren, whose remarks relate to the swine of Sweden, says, that in that country they refuse at least one hundred and seventy kinds of plants, and eat seventy-two. "When provoked with hunger," says Barnaby Googe, "the pig will eat not only her own offspring, but young children, which not long since happened in Sussex, to the pitiful discomfort of the parents." Such occurrences have indeed happened often; and old Chaucer notices this propensity, when he speaks of

"The sow fretting the child right in the cradle, The cook scalded for all her long ladle."

No animals, perhaps, feed with such selfish eagerness as pigs when several are collected round a trough, as seen in our woodcut, which is exempt from the excellent criticism of the countryman who, on being shown Gainsborough's celebrated picture of swine at mess, observed, "To be sure they be very fine pigs; yet nobody ever saw three pigs feeding together, but one o' um had a foot in the trough."

The "filthiness" of the domestic hog, for which it is much 
abused, depends greatly on its keeper, for no animal delights more in clean dry straw. It is true that it is fond of wallowing in the mire, especially in summer, not only to avoid being roasted too soon by the heat of the sun, but to protect itself from being too much titilated by flies and other troublesome insects, for its hide, though tough and hard, is extremely sensitive. Mud is, therefore, even a more necessary article to the toilet of a pig, than pomatum or bear's grease to that of its master. The alleged stupidity of the hog it is impossible to admit; for it has intelligence, if not gratitude, enough to recognise those persons who befriend it, coming at their call, and following them about to receive gratuities or caresses. Then, there have been pig-pointers, pig truffle-finders, and even learned pigs. Some years since, I saw one of these learned specimens-a second Bacon-exhibited in a travelling show. A circular space was kept clear for the pig, and when told to point out a man in some particular dress, or a young lady in love, the animal moved round the ring with its snout to the ground, and stopped at the feet of a man in the specified attire, or a damsel with a languishing face. Cards were next spread round the ring, and the pig was desired to present his snout to the queen of diamonds or the king of clubs, all which he did. But that he got, meanwhile, more credit for sagacity than he really possessed was soon evident on ascertaining that a horizontal wheel with a savoury morsel attached to it, revolved immediately beneath the circular floor of the learned savan, whose nose followed the scent and halted wherever the latter did; the wheel being turned and stopped at its proper place by a concealed confederate.

Swine are very fond of scratching themselves against trees or posts; and perhaps this habit may explain Lovell's observation, that they are " hated in Scotland."

The sow produces twice a year, goes with young sixteen weeks, and is probably more prolific than any animal of her size. The number of young at a litter is from seven or eight to eighteen, or even twenty. Indeed, an instance is on record of a sow having 
produced thirty-seven pigs at a litter. The average total number which one may expect, at the first farrowing of twenty sows, has been estimated at one hundred and fifty-five. Owing, however, to the usual practice of weaning the pigs when about six weeks old, the sow sometimes produces five litters in two years; but this is an uncommon occurrence. In the year 1;94, no less than three hundred and fifty-five pigs formed the total amount of twenty litters produced by a sow which belonged to Mr. T. Richdale, of Kegworth, Leicestershire. It is advisable, both on account of weather and food, to contrive so that the sow shall farrow in February and August. The young will suck any sow indiscriminately, although it is said that as soon as they are born they run to the parent's teat.

The dung of pigs is generally considered a more powerful manure than that of oxen. The bristles are employed for brushes and other articles; and the flesh is eaten by all people, except Jews and Mahomedans.

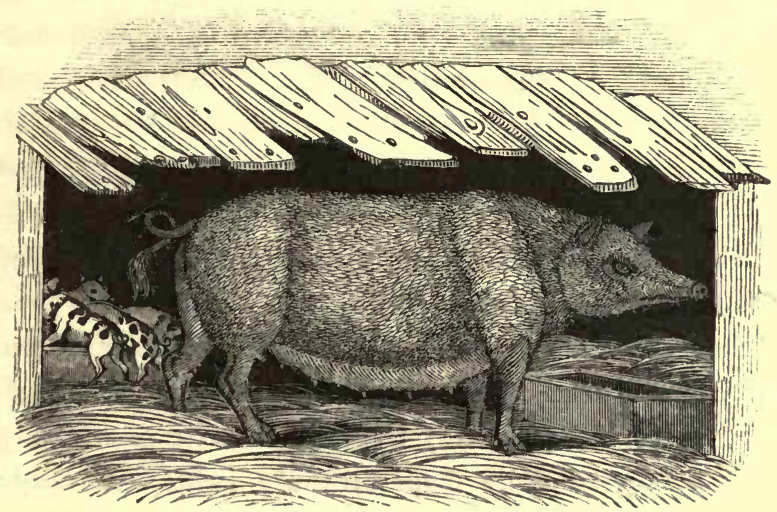

The Chinese Hog.

The Chinese pigs are smaller than our own; have a deep round body, a short thick neck, erect ears, full round haunches, very short and slender legs, and small toes. The colour is 
generally black, or half-black and half-white. The flesh is whiter and more delicate than that of our breeds. Some of them were imported into Britain more than fifty years ago, to cross with our common sorts, with which they bred freely; and the offspring are a much better race, both in respect of fertility and the quality of their flesh,-two points which breeders regard of much more importance than size; and, indeed, since this piggish alliance with the Chinese, instances of enormous obesity have become less frequent.

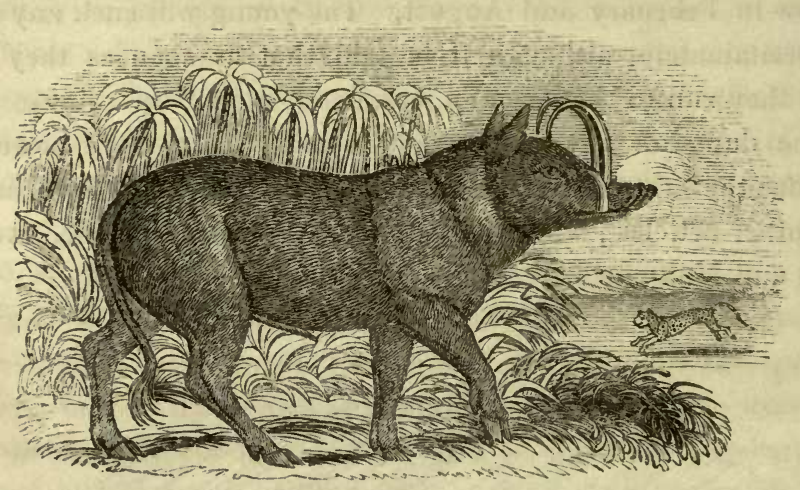

The Babarussa*-(Sus Babarussa, Buff.)

The babarussa inhabits Booro, Amboyna, Java, Sumatra, and others of the adjacent islands.

It has a robust and massive body, which is black, furrowed, and covered with only a few scattered bristly hairs. The ears are short, erect, and pointed; the incisor teeth, in which point alone it differs essentially from ordinary swine, are only four above instead of six ; there are five molars on either side in each jaw ; the tusks, or canine teeth, of the upper jaw of the male, which sex is larger than the female, do not project between the lips, as in the common hog, but penetrate the skin above the

* Often mis-spelt babiroussa. Baba in the Malay language means swine; and russa, a stag. 
snout. The use of these long slender upper tusks appears inexplicable, their situation and shape rendering them useless as weapons ; for, rising vertically, they curve round, with a slight outward inclination, so as to form half or three parts of a circle, their tips being often in contact with the forehead. Valentyn, in his description of the East Indies, published at Amsterdam in 1794, says, that these animals often rest the head by hooking the upper tusks on some bough ; but it is surely absurd to suppose that they were intended for such a purpose : and if they were, why is the female without them ? The assertion, which originated, perhaps, from conjecture entirely, has been repeated and improved upon; for, in some books we are told, that the animal hangs itself up to the bough of a tree by the horns whenever it takes a nap! Paley, who, like Ray, Sturm, and many others, is often too bold in judging of the wisdom of God as displayed in the works of the creation, mentions as a very striking example of benevolent provision, the possession of curved tusks by the babarussa, and calling upon us to mark their important use, repeats Valentyn's unsupported statement. It is clear, that if the animal wanted to support itself, it might as easily place its head over as under a branch; and the diffi. culty, if not the impossibility, of unhooking itself, certainly negatives the story of its suspended position during sleep. The fable is, therefore, quite unfit to illustrate natural theology, a beautiful subject, but ever a dangerous one in the hands of those who have neither observed what they adduce, nor possess sufficient evidence to confirm it.

Herds of the babarussa live in the forests, feeding on herbs, the roots of trees, but chiefly on maize. Their ordinary voice resembles that of the hog; but when enraged, for they are of savage temper, they utter a strong, deep, hoarse growl. They are fond of the water, in which they swim and dive with ease. When pursued to the shore, they rush into the sea, and, it is said, will cross the straits which intervene between the less distant islands.

The natives sometimes domesticate the babarussa, but it is 
reported to retain its ferocity and impatience even then. The flesh is good eating, and the tusks are finely-grained ivory.

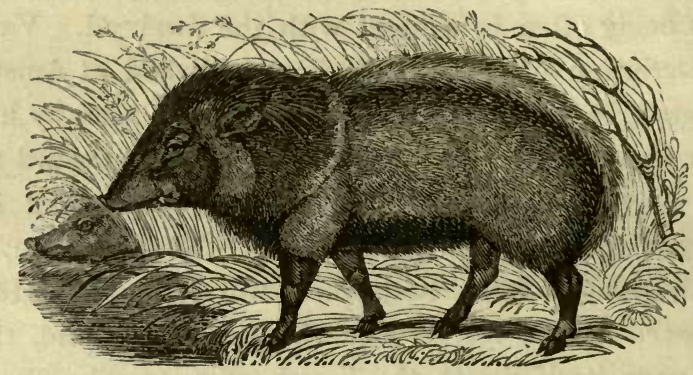

The Collared Peccary.-(Dicotyles torquatus, Cuv.)

Taytétou. Patira.

Buffon, and those who have compiled from his eloquent but very faulty work, have confounded the natural history of the collared peccary with that of the white-lipped species ( $D$. labiatus).* Though both inhabit the thickest and most extensive of the South American forests, resorting for shelter to the hollows of trees, and the deserted burrows of other animals, yet they differ even more in habits and disposition than in external form.

The collared peccary (the smaller species) is seldom as much as three feet in length, or more than fifty pounds in weight. Its general colour is yellowish-grey, owing to the bristles being alternately annulated with greyish straw-colour and black; the head is very long; the ears small, erect, greyish, and nearly naked; the snout is long, and very flexible; there are only six molar teeth in each jaw, and four incisors in the upper one. On

* Bewick's figure of the white-lipped species is unlike it, and having set out by improperly calling it a Mexican animal, he says as Buffon does, that it is prolific, and resides in the mountains. The latter error has evidently arisen from not knowing that what the people of Paraguay term montagnes are immense forests, not mountains. 
the neck is a somewhat erectile mane of long black bristles, which become gradually longer as they approach the buttocks; a curved collar of yellow-pointed hairs intersects the neck and body; the legs are rather slender and nearly black; the hind feet have only three toes; the tail is pendulous, remarkably flat, very short, and scarcely perceptible among the bristles.

This species does not associate in vast herds, as the whitelipped peccary does, but lives only in pairs, or at most in small families, which seldom quit their native forests. The peculiar grunt of both species may be heard a long way off; but either may be more easily traced to their abodes by the strong odour that exhales from a fluid matter, which is copiously secreted by a large gland situated beneath the skin on the middle of the loins, but concealed by the bristles. D'Azara, Ray, and others, speak of this odour as being musky, sweet, and agreeable; but Buffon, Sonnini, Bennett, and others, call it unsavoury and disgusting. Both species grub up the earth in search of roots, and sometimes commit great ravages among the sugar-canes, maize, manihot, and potatoe crops. They also devour fish, and are said to be expert in killing reptiles, not excepting the rattlesnake.

The females, of both species, produce each only two young ones in a year. If a young one be captured, it will become nearly as tame and familiar in confinement as the common hog; but its flesh is said to be inferior to pork in flavour and fatness, and to partake of the strong smell, unless the gland has been removed immediately after death.

The Common Indian Rhinoceros.

(Rhinoceros Indicus, Cuv.)

Animals of this genus are peculiar to Asia and Africa. The Asiatic species are three in number, namely the common, or one-horned Indian rhinoceros ( $\boldsymbol{R}$. Indicus), the Javanese one- 


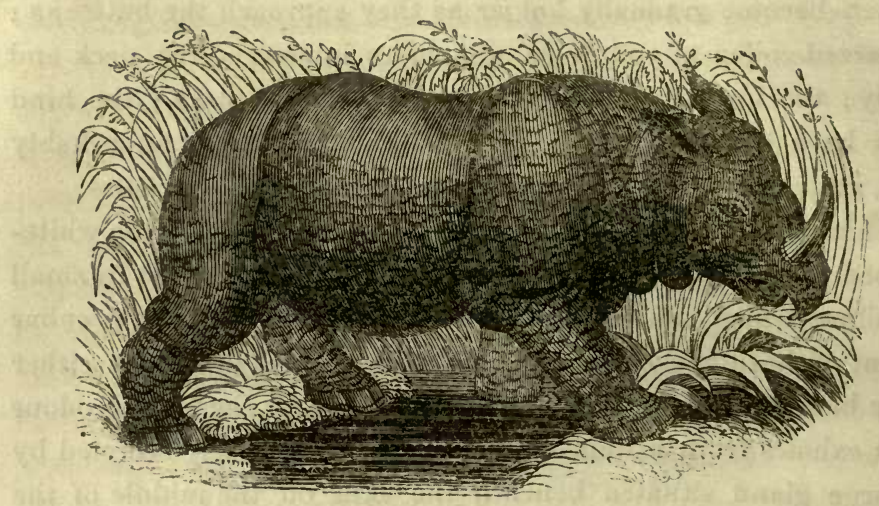

horned rhinoceros (R. Javanicus, Cuv., $R$. Sondaicus, Desm.), and the Sumatran two-horned rhinoceros ( $R$. Sumatranus). There are three, if not four, African species, namely, the common two-horned rhinoceros ( $R$. Africanus), the two-horned blunt nosed, or white rhinoceros $(R$. Simus), and the two-horned Ketloa rhinoceros (R. Ketloa); the doubtful fourth species, being that with one-horn, which Burckhardt describes as inhabiting a part of Abyssinia. Though it appears that one or other of the two-horned African species was frequently exhibited in the ancient Roman sports, yet, in modern times, no living specimen has ever been brought to Europe. Those that have been imported since we have desired these animals for the purposes of science, not for brutal sport, have all been of the species which we have here selected for description.

The common, or one-horned Indian rhinoceros, is far more widely distributed than the two other Asiatic species. It abounds in the hills of the lower region of Nepâl, and the plains of India, Pegu, Siam, and Cochin-China, usually associating in small herds, and keeping to the dense jungles and forests.

When full-grown, the circumference of the body is about twelve feet, and the length of the animal from the muzzle to 
the tail about the same measurement. Its hide is of a dark greyish brown colour, very thick, and covered with scaly incrustations (giving it somewhat of the appearance of the excoriated bark of the maple-tree), and about the joints of the body it hangs in large folds; between these folds, the skin is of a pale pinkish colour, and so soft, smooth, and flexible, that when the rhinoceros turns in any direction, he can, as Dr. Parsons observes, "slip or shove one part of his board-like skin over the other," and thus facilitate the performance of every motion he is disposed to assume : the sides and belly are protuberant; the neck is short and powerful; the head of ponderous size, and very irregular shape; the ears are large, open, pointed, slightly hairy, and placed on each side of the summit of the head, and being rapid and varied in their movements, the animal's sense of hearing is very acute; the eyes are very small, bright, and prominent, and are situated so much nearer to the muzzle than in most mammals, that a slight turn of the head brings an ample circuit within their range, their backward vision not being obstructed by the body, as it would have been, had they been placed higher in the head; the upper lip is very flexible, capable of elongation, and possesses a fingerlike extremity with which the animal can grasp its food, but when not in action it curls over the lower lip, which is rather square, and very broad; the tongue is very flat, large, yellowish, and perfectly smooth; there are twenty-eight molar teeth, and four incisor teeth in each jaw ; the horn on the head is conical, curved backwards, and arises from a broad limpet-shaped base over the nasal bones, which are necessarily thicker and more solid than in other mammals that have not to bear such a weight, or to wield such heavy blows from that part of the head; the legs present the appearance of short stout pillars to support the enormous superstructure; the feet have three toes, each encased in a solid hoof; the tail is of moderate length, and its extremity is fringed on either side with bristles.

"When we speak of the nasal horn of the rhinoceros, it must not be supposed that it presents a similar structure to the horns 
of the ox, which consist of a bony core from the skull, encased in a horny sheath. The nasal horn of the rhinoceros is a solid structure, composed of agglutinated fibres, analogous to hair, and much resembling those into which whalebone is so easily separable. The horny sheath in the ox, goat, or antelope, is indeed also thus composed, but it covers a bony process from the skull itself. Here there is no bone, the whole mass being secreted, fibre by fibre, from the skin, to which it is firmly attached-this being as firmly attached to the nasal bones, so that the horn is almost, if not quite, immoveable. Burchell's theory respecting horns in general, appears to be reduceable to the following statement. The pores of the skin secrete a corneous matter. When the pores are separate the matter forms hairs, having an insertion not deeper than the skin, and growing by the addition of new matter at their base. When the pores are confluent and in a line, the matter forms nails, claws, hoofs. When the pores are confluent, and in a ring, the matter furnishes the horns of animals of the ruminating order; and when confluent, over the whole of a circular area, the result is the formation of solid horns, like the rhinoceros's horn, which grows from the skin only, and in the same manner as the hair. It is not at all extraordinary, therefore, that the rhinoceros should possess the power of moving its horn, although by no means so loose as some writers have supposed."*

The rhinoceros is more rapid in its movements than its comparatively clumsy and massive appearance would, at first sight, induce one to expect. "The Onamese," Lieutenant White tells us, "speak with great energy of its irresistible strength and velocity. Speaking of this animal one day to the viceroy, he observed, 'You now see him here before you, in Saigon;' and, snapping his fingers, ' now he is in Canjeo.' However hyperbolical these accounts appear to be, we may yet infer from them, that the rhinoceros can exert great strength and speed." $\dagger$

"In a state of nature, the rhinoceros leads a calm but indo-

* The Menageries (1840), vol. iii. p. 11.

+ Voyage to Cochin-China in 1819-20, (1824). 
lent life : sluggish in his habitual movements, he wanders along with a heavy measured step, carrying his huge head low, so that his nose almost touches the ground, and stopping at intervals to uproot with his horn some favourite food, or in playful wantonness to plough up the ground, throwing the mud and stones behind him. As he passes through the tangled coverts, every obstacle gives way before his strength, and his track is said to be often marked by a line of devastation in his rear. Inoffensive, but fearless, he is, when roused, a most tremendous antagonist; and such is the keenness of his sense of smell and hearing, that except by very cautiously approaching him against the direction of the wind, it is almost impossible to take him by surprise. On being thus disturbed, he usually endeavours to retreat in peace, though instances are on record in which he has furiously advanced to the attack. 'A few years ago,' says the translator of Cuvier's Animal Kingdom, ' a party of Europeans, with their native attendants and elephants, went out to hunt rhinoceroses, and met with a herd of seven, led as it seemed by one larger and stronger than the rest. When the large rhinoceros charged the hunters, the leading elephants instead of using their tusks, which in ordinary cases they are ready enough to do, wheeled round and received the blow of the rhinoceros's horn upon their posteriors. The blow brought them immediately to the ground with their riders; and as soon as they had risen the brute was again ready, and again brought them down; and in this manner did the contest continue until four out of the seven were killed, when the rest made good their retreat.' We are not to infer from this account that there is a natural antipathy between the elephant and the rhinoceros, though Pliny asserts such to be the case, an error repeated by other writers. The fact is, that there are seasons in which the rhinoceros becomes excessively furious; and upon any animal large enough to attract his notice, which intrudes within the precincts of his haunt, he rushes with impetuous violence. The rhinoceros's mode of attack is very similar to that of the wild boar, except that the former strikes with his horn, and the 
latter with his tusks; in either case the blows are directed more or less obliquely upwards, and rapidly repeated."*

Notwithstanding the thickness and solidity of his hide, the rhinoceros is annoyed by the bites and stings of insects, which abound in his swampy haunts; and to protect himself from these puny tormentors, and also to defend the skin from the burning heat of the sun, he wallows in the marsh, so as to cover his body with a layer of mud. But he also delights to bathe and swim in the clean water.

Huge herbivorous animals, like the rhinoceros, elephant, hippopotamus, and others of the present order, must necessarily consume a prodigious quanity of food; but the very places which their habits lead them to haunt, are those where it can be obtained in the greatest abundance. As they drink large quantities of water, require plenty to swim in, and muddy marshes to wallow in, they are compelled to keep to those localities which supply these requisites to their existence and comfort, and which also, from the moisture of the situation, constantly maintain a most luxuriant and rapid vegetation.

Although the rhinoceros, when adult, is subject to occasional paroxysms of fury, he may, by proper management, be rendered so tame and gentle as to be perfectly tractable. The late Bishop Heher says : "In passing through the city of Baroda, I saw a rhinoceros (presented by Lord Amherst to the Guicar), which is so tame as to be ridden by a mahout, quite as patiently as an elephant. At Lucknow there were five or six large rhinoceroses, quiet and gentle animals, except that one of them has a feud with horses. They seem to propagate in captivity without reluctance; and, I should conceive, might be available to carry burdens as well as the elephant, except that, as their pace is still slower than his, their use could only be applicable to very great weights, and very gentle travelling. They have sometimes had howdahs on them, and were once fastened in a carriage, but only as an experiment, which was never followed up."

In May 1834, the Zoological Society purchased their fine * Abridged from The Menageries (1840), vol. iii. p. 15-17. 
male specimen from the captain of an East India vessel, for the sum of one thousand guineas. It is supposed to be about eight years old, and, of course, not full grown, although when measured, on May 3rd, 1837, it was eleven feet seven inches in length from the snout to the root of the tail.

His ordinary pace consists in a slow, sluggish walk, but during his sportive moments he proceeds round his paddock or den, at a heavy lumbering gallop with headlong precipitancy, the nose almost touching the ground, and playfully ploughing up the straw or gravel as he proceeds. It is in this position that the animal in a state of nature would rush upon his antagonist, striking an upward blow with his formidable horn. His senses are acute, especially those of hearing and smell. He is almost constantly turning his ears in different directions, as if intent to catch the various sounds around him. He scents the buns or bread with which the visitors feed the elephant in the next paddock, and approaches the bars to solicit a share, gazing intently and expressively at them, while he stretches out his upper lip to receive them. He recognises his keeper's voice, and playfully follows him as he passes before the den, as if begging for food or courting his notice. While the keeper, bringing his meal to him, is yet at a distance, he is still aware of his approach, and testifies his satisfaction by a short inward grunt, similar to that which he utters when about to repose. When excited, however, he frequently utters a neighing sort of sound, which, though not very loud, is shrill and piercing. His daily diet at present consists of twentyeight pounds of clover, the same quantity of meadow liay, five pounds of potatoes, three pecks of boiled bran, and eight pounds of boiled rice, the two latter articles being mixed up with three-quarters of a pound of salt. Of water he drinks daily fourteen gallons. "In summer, he is permitted to enjoy a plunge in the large bath, constructed in the elephant's paddock, and it is interesting to watch his gambols. He runs to and fro, ploughing the mud with his snout; then he plunges into the bath, runs out, and again plunges in, and often remains for a 
long time almost wholly immersed. On these occasions another of his delights is to wallow in the mud. Basking in the sun, with his huge frame lolling on the margin of his bath, where the clayey soil has been trampled into mud by the elephant's fect and his own; now rolling his little eyes around, as if to survey all about him; now closing them in tranquil slumber, he presents a picture of thorough epicurean enjoyment. $\mathrm{He}$ quietly suffers himself to be driven from his den to the bath, but he is not easily induced to leave the water, or his muddy resting-place; and it requires no little management to get him into the passage to his own apartment : not that he offers any violent resistance, but he avoids, as long as possible, all efforts to entrap him between the railings, and at last proceeds reluctantly. The quietness of his temper is, however, not a little remarkable; hitherto he has exhibited no paroxysms of rage, but is inoffensive, happy, and contented. He neither pines nor evinces impatience in his captivity. To eat, drink, and sleep, to roll in the mud, or luxuriate in his bath on a fine sunny day, constitute the sum total of his felicity. He passes about fourteen hours a day in repose, and is generally lively in the afternoon and evening. During one of his ebullitions of sportiveness, he managed, by repeated blows with his horn, to break some of the thick boards which line the walls of his den, and would have continued his mischief if he had not been timely interrupted. On another occasion of his exuberant mirth, when his keeper was in the den, he nearly squeezed the man to death in his unwieldy play. Thrusting at him, the animal followed up a regular attack, and at length fairly pinned him in a corner against the wall, driving the horn forcibly against his chest. The man's cries for assistance led the other keepers to the spot, and he was rescued from his perilous situation; but it was sometime before he recovered from the effects of the bruises he had received from his rough playmate."*

The female rhinoceros goes with young from seventeen to eighteen months, and produces one at a birth. When first * Abridged from The Menageries (1840), vol. iii. p. 27-33. 
born it measures three feet four inches in length, and two feet in height, and has, for about a month afterwards, a pink suffusion over the dark colour which is proper to the mature hide. It continues to suck for nearly two years.

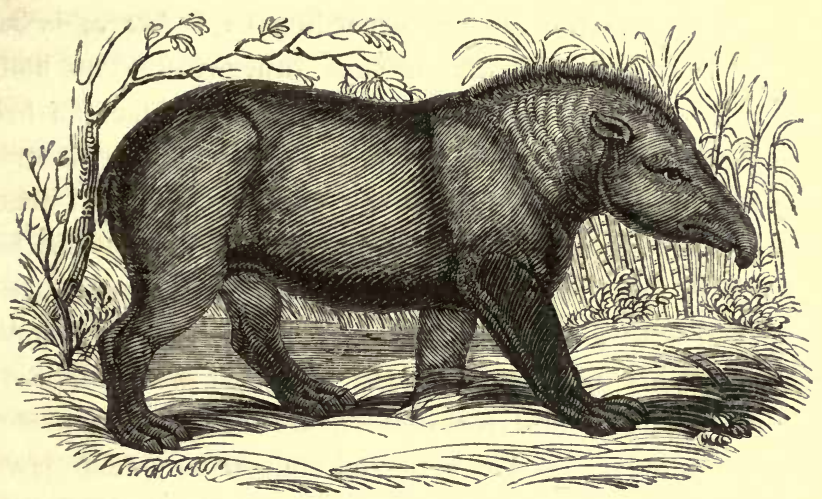

The Common American Tapir.-(Tapirus Americanus, Linn.)

\section{Mborebi. Anta.}

Few mammals of its size have so extensive a range as the American tapir. It inhabits every part of South America to the east of the Andes, from the Straits of Magellan to the Isthmus of Darien; but it appears to be most common within the tropics. M. Roulin says, that although it occurs as low as forty degrees to the south of the equator, its range abruptly terminates at about eight degrees north, in a situation where it is extremely abundant, and there does not appear adequate cause to bar its further progress; no large rivers nor lofty mountains intervening, nor any change appearing in the character of the vegetation of the country. The left bank of the Atrato near its mouth, and the part of Darien inhabited by the independent natives, may be considered as its northern limit. Its highest range in the province of Maraquita, at least 
appears to be from three thousand to three thousand six hundred feet above the level of the sea, while the other American species (T. Roulinii) is only met with at a much greater elevation on the Andes or Cordilleras.*

The common American tapir is said to attain six feet in length, from the extremity of its snout to the root of its stumpy tail; and the female, according to D'Azara, is larger than the male, but M. Bajon says otherwise. The body is nearly naked, and its colour is almost entirely blackish brown, the only other colour being the pure white which is observable on the sides of the lower lip, on the middle of the chin beneath, on the upper edges of the ears, and at the junction of the hoofs. The neck is flattened at the sides, and arched above, where it is furnished with a mane of short hairs; the eyes are small but quick; the ears are pointed; the snout is well adapted for searching in the ground for roots, and it resembles a proboscis in being prehensile and capable of elongation; each jaw has six incisor and two canine teeth, the latter separated by a vacant space from the grinders, of which there are seven on each side in the upper jaw, and six in the lower; the front feet have four toes, and the hind feet only three, each incased in a hoof; the tail is a mere tubercle. Altogether, it is a very interesting animal, for its form and nature seem to combine the characters of several animals of this order. Thus, it resembles the elephant in the flexibility and grasping power of the elongated upper lip; the horse in the outline of the body, the shape of the head, the flattened arched neck, the possession of a mane, and its general docility in a domesticated state; and the hog and hippopotamus in many of its habits and manners.

It frequents the woods to feed on leaves, roots, and fruits;

* The recent zoology of America contains only two genera of the present order, namely, the peccary (Dicotyles) and tapir (Tapirus); although its fossil zoology contains an extinct species of elephant, four species of the extinct genus Mastodon, and a gigantic animal only lately exhumed, and called Toxodon, all belonging to this order. The first of the existing genera is the only one peculiar to America, for a species of tapir ( $T$. Indicus) inhabits Malacca and the island of Sumatra. 
but it is partial to wet places and the borders of rivers, being fond of , bathing. Sometimes it enters the water deliberately, and swims on the surface; at other times, especially when in danger, it plunges in, and walks along the bottom, totally immersed for at least a couple of minutes, and then rises to the surface to breathe, and having done so, either dives down again or swims. M. de la Borde, says, "When they have taken refuge in the water, it is not easy to draw them out; and although they are of a gentle and quiet disposition, they become dangerous when wounded. They have been known to throw themselves on the canoe whence the injury came, and endeavour to overturn it for revenge. It is requisite also to beware of them in the forests; there, they make paths, or rather beaten tracks, of tolerable breadth, by repeatedly going to and fro (for they are in the habit of passing and repassing always in the same places); and these paths, from which the animals never deviate, are to be avoided, for they move briskly on, and, without intending mischief, they dash violently against every thing in their way. The districts bordering the upper parts of the rivers in Guiana are inhabited by great numbers of tapirs, and the banks of the waters are intersected by paths which they wear; and so beaten are they, that the most desert places appear, at first sight, as if frequented by human beings. A traveller nearly fell a victim to his ignorance respecting their tracks; for about ten o'clock in the evening while lying in his hammock, which he had unwittingly suspended from two trees growing on one of these beaten paths, he heard a loud noise occasioned by a tapir on its route, and he had only just time to throw himself out. The animal rushed past, tossing the hammock into the branches, and bruising the traveller who stood against a tree. Then, without turning aside from its path, it passed through the midst of some negroes who were sleeping on the ground near a large fire, but without doing them any injury."

The animal may be readily tamed. Sonnini says, that numerous tame individuals roam at liberty through the streets of 
Cayenne, and enter the neighbouring woods, from which they return in the evening to the house where they are fed. He not only assures us that they are fond of being noticed, recognise their master, follow him about, and give him various tokens of attachment, but he expresses his belief that "with care and attention they might be rendered serviceable as robust beasts of burden; their thick-set form, and great strength, would enable them to bear very heavy loads; and the gentleness of their disposition raises a strong presumption that they would be found to possess docility and patience."

The female brings forth her young in November, away from the society of the male, who takes no part in rearing it. M. de la Borde says, that the female accustums it at an early period to enter the water, where it plunges and plays before the parent, and she seems to enact the part of instructress in this exercise. The young one is at first spotted with white, like a fawn.

The flesh is eaten by the wild natives. 


\section{Order-PACHYDERMATA. FamiLY-Solipedes.}

\section{The Horse-(Equus caballus, Linn.)}

The history of the horse, as regards its original or natural locality, and the period of its first subjugation, is very obscure. From the Scriptures we learn that it is of Eastern origin; and they render the inference very probable that the Egyptians were the first who reduced it to servitude. The earliest notice of the horse occurs about six hundred and fifty years after the Deluge, when the Egyptians " brought their cattle to Joseph, who gave them bread in exchange for horses and for the flocks," \&c. Very soon afterwards we read that the venerable patriarch Jacob, when dying in Egypt, addressing his sons, said, "Dan shall be a serpent by the way, an adder in the path, that biteth the horse's heels, so that his rider shall fall backward;" and it is remarkable that this early allusion to the horse refers to him as being ridden, and not as drawing a chariot. When the body of Jacob was removed by his son Joseph from Egypt to Canaan for burial, we are told that " there went up with him both chariots and horsemen." As it appears then from these notices, as well as from the employment of numerous chariots by Pharaoh in pursuit of the Israelites, and from the testimony of the earliest profane writers, that the Egyptians first reduced the horse to obedience, it is to their country, or at least to those parts of Africa which were in close relation to it, that we may reasonably look for its primitive habitat. The longadmitted superiority of the horses of Arabia is no evidence that they were originally placed in that arid country; and there is great reason to conclude that it was not until a comparatively 
late period that the Arabs used horses. At a time when Solomon was receiving various treasures from Arabia, it was from Egypt only that he obtained his immense number of horses. Herodotus expressly states, that Xerxes obtained a portion of his cavalry from Ethiopia, and that he was joined by a body of native Indians, some on horseback, and others in war-chariots.

The primitive habits, contour, and colour of the horse, in a purely natural state, cannot be said to be known with certainty, for it is highly probable that it has long ceased to exist in such a state. As all the wild horses which now exist in various parts of the world appear to have sprung from a domesticated stock, they afford no clue to the elucidation of the points in question. The numerous herds of wild horses existing on the plains of Tartary, do not appear to have been originally indigenous to that country; and the still greater numbers which inhabit South America, are very clearly traced to the horses which the Spaniards first introduced into that continent from Europe; and old writers tell us, that when the natives at that period saw a man on horseback, they thought the man and horse to be one individual creature, a sort of centaur.

"He grew unto his seat, As he had been incorps'd and demi-natur'd With the brave beast."

(Hamlet.)

To describe the horse as we find him at present, it may be said that he is distinguished from all other solid-hoofed animals of his order, by the possession of callous wart-like protuberances on the hind-legs as well as the fore, and of a flowing tail; and by the absence of a dark stripe along the back.* Every body knows that horses vary greatly, not only in size and colour, but in shape; the principal breeds even exhibiting sensible

* Mr. Macdonald, in a paper read before the Royal Society in June 1839, stated that in Scotland there is a breed of horses, called the eel-back dun, and that many of this breed have the back and legs marked like those of the zebra. Walker, however, in his History of the Hebrides (vol. ii. p. 158), merely says that the horses of the Scottish Highlands and of Norway have a mark, resembling an eel, extending from the shoulder along the ride of the back to the rump. 
differences in the form of the head, and their bodies and limbs being variously proportioned in adaptation for the uses to which each breed is more especially applied. Wombwell, the zoological showman, is stated to have had a horse nearly nineteen hands high. If allowed to lie out in the open air during the winter, the horse acquires a long shaggy coat; but if kept in a warm stable, and particularly if clothed, it retains its usual short and sleek summer coat. Electricity has been several times observed to be emitted from the horse's body; and as this fact is not generally known, a few instances may prove interesting. Mr. John Davidson, in his Notes taken during Travels in Africa (1539), says that a horse which he received from the Sultan of Morocco, displayed electricity on its coat with extraordinary facility. A gentleman while riding between Norwich and Bungay, in a wet night, observed a luminous appearance on the outer edges and tips of his horse's ears; and the celebrated American professor, Silliman, records that Mr. Whitney of Newhaven, when riding near East Rock, in the vicinity of that town, during a very severe thunder-storm at night, was astonished to see his horse's ears suddenly tipped with fire. Perhaps it was in consequence of having witnessed such a phenomenon (which Mr. J. Murray regards as entirely electrical, and not as being caused by any luminous insect alighting on the animal), that Thompson wrote the following lines :-

" Sent by the better genius of the night, Innoxious, gleaming on the horse's mane The meteor sits; and shows the narrow path, That winding leads through pits of death, or else Instructs him how to take the dangerous ford."

The horse breathes through its nostrils only, and not through the mouth; for in the severest exercises, the mouth is never seen open, unless the lower jaw be violently pulled down by force of the bit. This accounts for the great dilation of the nostrils during and after hard running.

"Those who know anything of the horse pay much attention 
to the size, setting on, and motion of the ears. When these organs are rather small, placed not too far apart, erect, and quick in motion, they indicate both breeding and spirit; and if a horse is frequently in the habit of carrying one ear forward, and the other backward, and especially if he do so on a journey, he will generally possess both spirit and continuance. The stretching of the ears in contrary directions, shows that he is attentive to everything occurring around him, and, while he is doing this, he cannot be much fatigued, or likely soon to become so. Few horses sleep without pointing one ear forward, and the other backward, that they may hear the approach of objects in every direction. Dr. Arnott says, that ' when horses or mules march in company at night, those in front direct their ears forwards ; those in the rear direct them backward; and those in the centre turn them laterally or across; the whole troop being actuated by one feeling, which watches the general safety.' The temper is more surely indicated by the motion of the ear than that of the eye; and an experienced observer of horses can tell by the mution of their ears all that they think or mean. When a horse lays his ears flat back upon his neck, and keeps them so, he is most assuredly meditating mischief, and the by-stander should beware of his heels or his teeth. In play, the ears will be laid back, but not so decidedly nor so long. A quick change in their position, together with the expression of the eye at the time, will distinguish between playfulness and vice.* The eye, also, is a pretty accurate index of the temper; and experience has shown that if much of the white of the eye is seen, the horse is a dangerous one, ever slyly watching for opportunities to do mischief; and the frequent backward direction of the eye, when the white is most perceptible, is only to give surer effect to the blow which he is about to aim." $†$

* Pliny is perhaps the first anthor who notices that the ears discover the horse's intention. He says, "Leonum animi index cauda, sicut et equorum aures."-J. H. F.

+ Abridged from the Farmer's Library of Useful Knowledge, vol i. p. 76-84. 
A long tail is not only a great addition to a horse's beauty, but assists the animal in suddenly swinging the body round, as we may observe during the evolutions of our cavalry; and this appendage is also, as Bloomfield says,

"A weapon of defence, of chiefest good

When swarming flies contending suck the blood."*

Although the old Irish practice of making the horse harrow with the rope tied to the tail, instead of attaching it to a collar round the neck, was prohibited three hundred years ago, it is still continued at Erris, in Ireland. The Erris farmer, in defence of the practice, says that the horse's tail was designed to save all sorts of harness, and that as the horse submits to it quietly, and performs the work with apparently greater ease, it cannot be cruel. + Jovius says, that the Italians laughed at the Germans for docking their horses' tails; and he commends the cruel custorn, falsely alleging that it makes the animals fatter.

The wild horse has no intermediate pace between the walk and the gallop. It is a common but erroneous notion, that the horse, when walking or running, lifts simultaneously the right fore-leg, and the left hind-leg, or vice versa; and hence in some equestrian statues we see two diametrically opposite legs suspended from the pedestal. It is a difficult thing to keep the eye upon four legs, but nevertheless, if a horse be long and carefully observed when it is going at a slow pace, it will be seen that, if one foot is raised from the ground, the other three are on the ground, though all are preparing to leave in their turn, and it will be evident that this process is adopted in its quicker ordinary motions. In some motions the two fore-legs are raised together while the two hind-legs are on the ground, and the latter are raised together when the former are put

* Mr. Swainson, in support of one of his edifying theories, tries to prove an analogy between the tail of the horse, and what he wrongly calls the "fanshaped tail of the peacock," meaning the bird's train; and to do this he finds it necessary to assert that the former like the latter is more ornamental than essential! (See his Discourse on Natural History, p. 256.)

+ See the Rev. C. Otway's remarks on this subject in the Dublin University Magazine of May 1840. 
down, and so on successively; and in cantering both pairs of legs are often raised from the ground at each strike the animal gives to the surface.*

It may here be mentioned that iron horse-shoes were not invented till the year 481 , nor introduced into general use till the ninth century. In the figures of the horses discovered on the ruins of Persepolis, there is not the slightest trace of any covering for the hoofs; and we read of Alexander's cavalry becoming unserviceable owing to the hoofs wearing away.

The horse's movements are not confined to the earth. He takes the water naturally, and can swim far, and in good style, even in the sea.

" And eke the courser, whereupon he rad, Could swim like to a fish whiles he his back bestrad."

(Faery Queene, Book V. canto ii. stanza xiii.)

Mr. Jesse relates an anecdote of a mare having swum from the Hampshire coast to the Isle of Wight, five miles distant at the nearest point; and cites another instance in which a horse, much exhausted from swimming, landed on the Glamorganshire coast, having embarked perhaps from the opposite coast, which is ten or twelve miles off. In the latter instance the horse's motive was not apparent, as nothing further concerning him could be ascertained; but in the former the horse was impelled by a desire to return to the master from whom he had been purchased the day before. Ariosto notices the memory of the horse in a passage full of truth and nature (Orlando Furioso, i. 175); and the same subject forms the ground work of a pleasing little romance, entitled ' Lai du Palefroi vair,' in Les Fabliaux du XII. Siècle. Rogers, in his poem on Memory, has not forgotten to notice this faculty in the horse :-

" When o'er the blasted heath the day declined, And on the scathed oak warred the winter-wind;

* Sculptors, artists, and others to whom a correct knowledge of the attitudes of animals is important. should consult the illustrated work, entitled De Motu Animalium, by J. A. Borelli, Prof. of Mathematics at Naples, or, what is perhaps more accessible, the Field Naturalist's Magazine (1833), vol. i. p. 14. 
When not a distant taper's twinkling ray

Gleamed o'er the furze to light him on his way ;

When not a sheep-bell soothed his listening ear,

And the big rain drops told the tempest near;

Then did his horse the homeward track descry,

The track that shunned his sad, inquiring eye."

(Pleasures of Memory, Part I.)

What the phrenologists call the organ of time, or the faculty of recollecting intervals of time, appears to exist in the horse. The author of the Menageries says he has witnessed the following instance of the kind in a horse which he knew. "The horse, being used to carry, once a week, the newsman of a provincial paper, the animal always stopped at the houses of the several customers, although they were sixty or seventy in number. But there were two persons on the route who took one paper between them, and each claimed the privilege of having it first on the alternate Sunday. The horse soon became accustomed to this regulation; and, although the parties lived two miles distant, he stopped once a fortnight at the door of the customer at Thorpe, and once a fortnight at that of the other customer at Chertsey, and never forgot this arrangement, which lasted several years, or stopped unnecessarily, when he once thoroughly understood the rule" (vol. i. p. 56). Like the dog, the horse often becomes irretrievably attached to habits and manners to which it has been long accustomed. Miss Mitford relates that a gentleman having admired the fast trotting of a butcher's horse, purchased it at the high price of seventy guineas, but though he tried for weeks to make it go at a butcher's pace, it would not exceed an ordinary amble. Suspecting an imposition he took the horse back, and complained to the butcher, who observed in reply, "Why, he will trot just as fast with you as he did with me, but you must carry a basket." The German horses slacken their pace immediately that they perceive the tobacco sparks which fly from the pipe of their driver, when he is trimming it. This conduct on their part has been ascribed to sagacity; but is doubtless the result of passive experience, by which they have found that when the sparks fly 
from the pipe the whip is not in hand. Horses will sometimes lift the latch of a stable-door, or a paddock-gate, when they want to get out. Instinct would teach them to kick and get out by violence; and, as all the reason in the world would not teach even man himself the use of a latch before he had seen it in operation, or having been told its use, we must infer that in all such instances the horse raises the latch from having previously observed the result. It is mere imitation, and in comparison with the actual efforts of reason, we may say with Holofernes-

"Imitari, is nothing: so doth the hound his master, the ape his keeper, the tired horse his rider."

(Love's Labour's Lost, Act II. Scene 4.)

In the following anecdote related by Lord Brougham, one cannot suppose that the disinterested conduct of the horse was otherwise than the effect of some ingenious training. "A horse, belonging to a smuggler at Dover," he says, " used to be laden with run spirits, and sent on the road unattended to reach the rendezvous. When he descried a soldier, he would jump off the highway and hide in a ditch, and, if discovered, would fight for his load."

The ordinary food of horses in Britain consists chiefly of oats and pulse. They are very fond of the seeds of darnel, and are remarkable for eating the aconite and common hemlock without injury. Dr. Anderson, who devoted much time to agriculture, cultivated furze as winter fodder for horses; and Evelyn assures us that no provender makes them so hardy as the young topping of furze, and which when bruised, he adds, will strangely recover and fatten a lean horse. M. Pirolle, author of Le Bon Jardinier (1822), says, that in many parts of France, particularly Normandy, furze is bruised in a cider-mill and then given to horses with advantage. The leaves of the birch afford them good fodder. Loudon, in his Arboretum Britannicum, says, that " in some places horses are fed entirely on willow leaves, whether green or dry, from the end of August to November; and it is stated that those which are thus fed will travel twenty 
leagues a day without being fatigued." The Germans collect thistles, and having beaten them in a sack to destroy the prickles, they give them to their horses, who eat this kind of food greedily, and though it proves very diuretic it keeps them in good condition. Mr. Fraser says, that in Persia, the horses are fed and thrive on pounded date stones, and on dried fish, a little salted. The horse drinks largely of water. The Flemish, who manage horses better than any other European nation, give no water to their horses without first mixing some cornmeal with it till it resembles a white soup. From Homer we learn that the Greeks gave astringent wines to their horses to animate them. In our own country they are often refreshed with beer and ale.

The breeding of horses is necessarily slow, as the mare produces generally but one foal at a birth, and but once a-year.

Of the age to which the horse will live very narrow estimates have been formed by those who have judged of the matter, by the periods at which the several breeds are generally worn out. A pony belonging to Mr. Tidmarsh of Kneesworth, Cambridge, died in February 1840, aged forty-one years. Mr. Culley mentions a horse which died in 1758, aged sixty-two years. A towing-barge horse died at the same age at Manchester in 1822, and his remains are preserved in the zoological museum in that town.

The Tartars and the Indians of the Pampas eat the flesh of horses; and the chronicles tell us that during a dreadful famine in England, in the reign of Stephen, the people ate the flesh of horses and dogs. The Scythians, for want of water, used to draw blood from their horses and drink it. The Moscovites and the Kalmucs drink mare's milk. In most civilized countries the hide is made into leather, mostly used for collars and other harness for horses, who thus rehearse, as it were, in the trammels of life their future destiny. The hair of the mane and tail is used for making judges' wigs, mattress stuffing, chair and sofa bottoms, sieves, fishing lines, \&c.

From this general sketch of the horse we proceed to notice 
a few of the more celebrated breeds, valuable for the qualities of elegance, or fleetness, or vast strength; but for full information on their exploits in the field, their services in the shafts, and at the plough, together with the " rules of good-breeding," we must refer the reader to Blaine's Encyclopadia of Sports (1839), and Youatt's History of the Horse, in The Farmer's Library of Useful Knowledge.

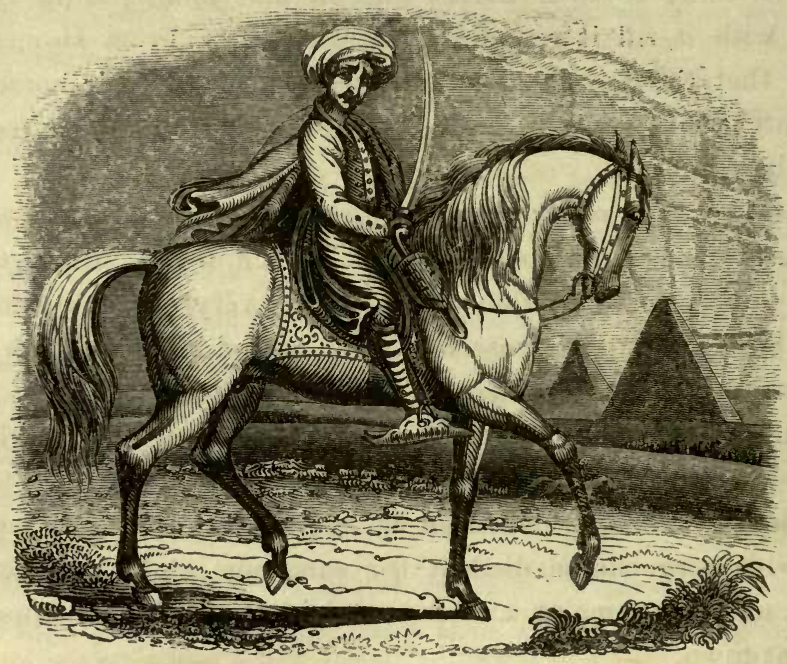

The Arabian Horse.

With the exception of the Barb or Barbary horse, sometimes called the Godolphin, there is no horse to surpass the Arabian in form. In the latter breed the head is of superior make, and characterized by the broadness and squareness of the forehead, the shortness and fineness of the muzzle, the prominence and brilliancy of the eye, the smallness of the ears, and the beautiful course of the veins : the body is light, the withers are high, and the legs though fine, have such muscles as render the animal fully capable of accomplishing many of the feats recorded of it. 
It possesses speed and spirit, with strength to carry more than a light weight, and indefatigable powers of endurance. It is seldom more than fourteen hands two inches high. Its only paces are the walk and the gallop, and it is not only prized for speed and courage, but for docility, good temper, and confidence.

The kindness with which it is treated from a foal, renders it affectionate to its master, anxious to please, and proud of exerting every energy to obey his commands, and all this calls forth a degree of sagacity, seldom seen in other breeds. The mare, the foal, the Bedouin and his family, inhabit the same tent. The neck of the mare is often the pillow of her master, or of his children; and the animal acquires a friendship and love for man, which nothing will cause it for a moment to forget. The stallion is not ridden; only the mare. If the Arab fall from her back, and be unable to rise, she will immediately stand still, and neigh until assistance arrives. If fatigue compel him to lie down to sleep in the midst of the desert, she will watch over him, and neigh and rouse him if either man or beast approach. The attachment is mutual; and most persons have read anecdotes of the unwillingness of even poor Arabs to part with their favourite mares for love or money. The Arab horse, however, is bought and sold, and has been instrumental in improving the Spanish horse, or jennet; and along with the latter, has contributed to form the best English breed of horses, now unrivalled for the turf, the field, and the road.

\section{THE RACER.}

The racer is usually distinguished by his beautiful Arabian head, fine neck, oblique long shoulders, well-bent hind-legs, ample muscular quarters, and his long and elastic pastern. $\mathrm{He}$ is altogether adapted for speed, and to this end every attention is paid in his breeding.

"He enters into the spirit of the race as thoroughly as his 


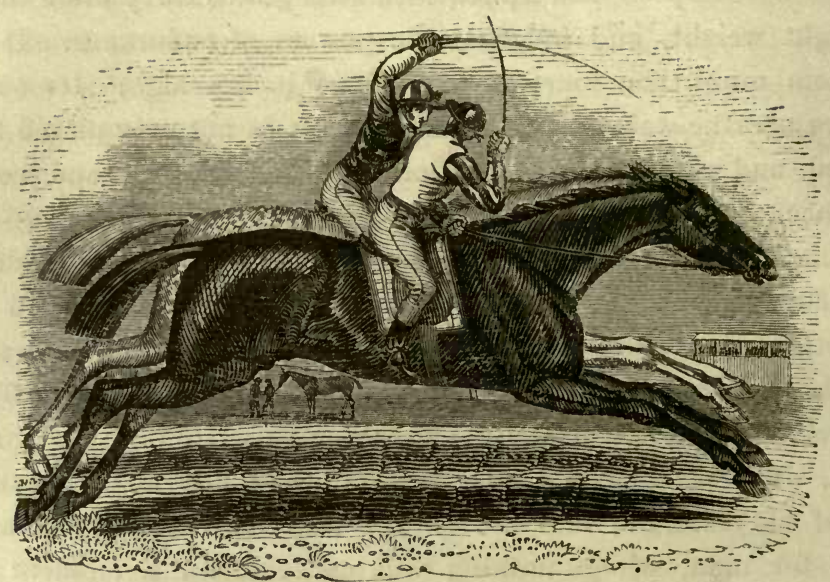

rider, and, without whip or spur, will generally exert himself to the utmost to beat his opponent. It is beautiful to see the eagerness with which he advances to the starting post. The signal given - he springs away-he settles himself in his stride - the jockey becomes part and portion of him, every motion of the arms and body corresponding with and aiding the action of the horse. On he goes, eager, yet reserving his full powers till he reaches that distance at which he will live home at the top of his speed, when on he rushes, and then the race in reality begins, every nerve being strained to head his competitor. Then, too, comes the art of the rider, to keep the horse within his pace, and with admirable give and take, add to the length of every stride. The often victorious horse, Forrester, was a strong illustration of the natural emulation of the racer. Once, when overweighted and overmatched, the rally had begun, and his opponent gained upon him. Forrester overtook him, and they continued quite close, till finding his strength fail, he made one desperate plunge-seized his rival by the jaw, and could scarcely be forced to release him. Another horse, in 1735, seized his adversary by the leg, and both riders had to dismount to separate the animals."*

* Youatt's History of the Horse, p. 49. 
An ordinary racer runs at the rate of a mile in less than two minutes; but some much faster. The famous Flying Childers, acomplished eighty-two feet and a half in a second, or nearly a mile in a minute. He ran round the Newmarket course, nearly four miles in circumference, in six minutes and forty seconds. Since his time, Eclipse, Matcher, and Highflyer, have been the fleetest horses of their times.

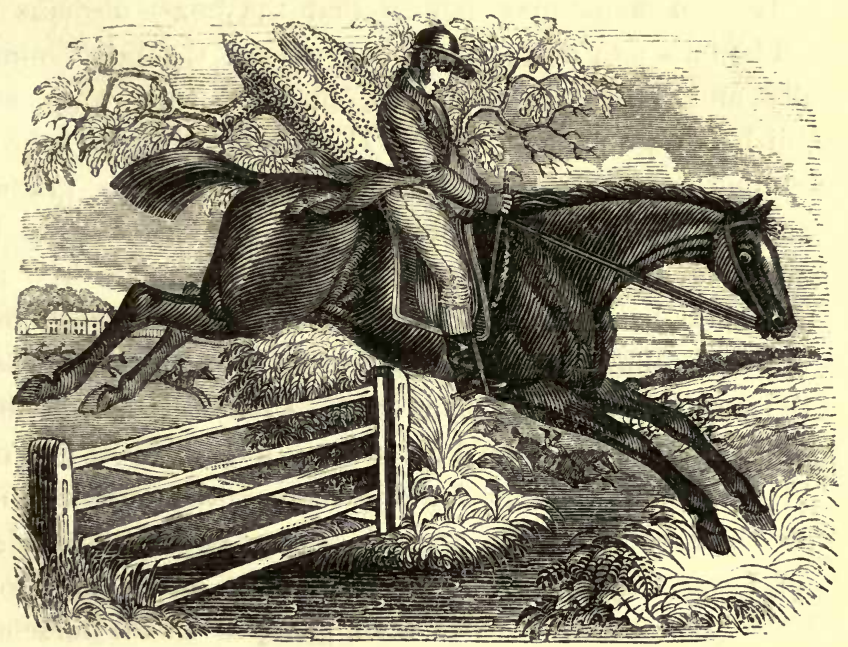

The Hunter.

No country, perhaps, possesses a breed of horses to equal the English hunter in its combined powers of speed and endurance. It greatly excels even the racer in long continued perseverance. A hunter should be from fifteen and a half to sixteen hands high, with a rather small head, thin neck, ample chest, slightly raised forehead, round and full barrel, compact body, broad loins, thick muscular legs, shorter than those of the racer, and well-formed, firm feet. To these essential points, should be added the requisites of temper and courage. The 
hunter fully shares in the enthusiasm of his rider. But if the horse be thus ready to exert himself, it is brutal to urge him beyond his own natural ardour; yet we seldom hear of a " hard day's run," without one or more horses having either died on the field, or when they reached home. One of the severest chaces on record was with the king's staghounds. There was an uninterrupted burst of four hours and twenty minutes. One horse dropped dead on the field; another before he could reach the stable; and seven more within the week. It does sometimes happen that the horse disdains to yield till he falls and dies; but much oftener the poor animal painfully and falteringly proceeds, tortured with whip and spur, till he drops and expires.* The steeple chase, a relic of ancient fool-hardiness and cruelty, is getting into gradual disuse : this kind of sport being justly denounced even by sportsmen as discreditable to those who engage in it. Sir John Malcolm heard an Arab, who had șeen an English foxhunt, give the following laconic account of it to his countrymen. " First came the fox at a great rate. I hallooed, but no one heard me, and I thought he'd get away; but when he got out of sight, up came a large spotted dog, then another, and another, all with their noses to the ground crying, whow, whow, whow, so loud I was frightened. Away went these devils, and soon found the poor animal. After them galloped all the horsemen shouting, and trying to make a noise louder than the dogs. No wonder they killed the fox among them."

\section{The Roadster, or Road-Horse.}

This is an improved breed from the old English hackney, which was also the chief stock of our best saddle-horses, whether for the road or the field. The roadster should be bred according to the nature of the country, and the work required of him. He should be high in the forehead, round in the barrel, and deep in the chest. "If he be worth having," says 


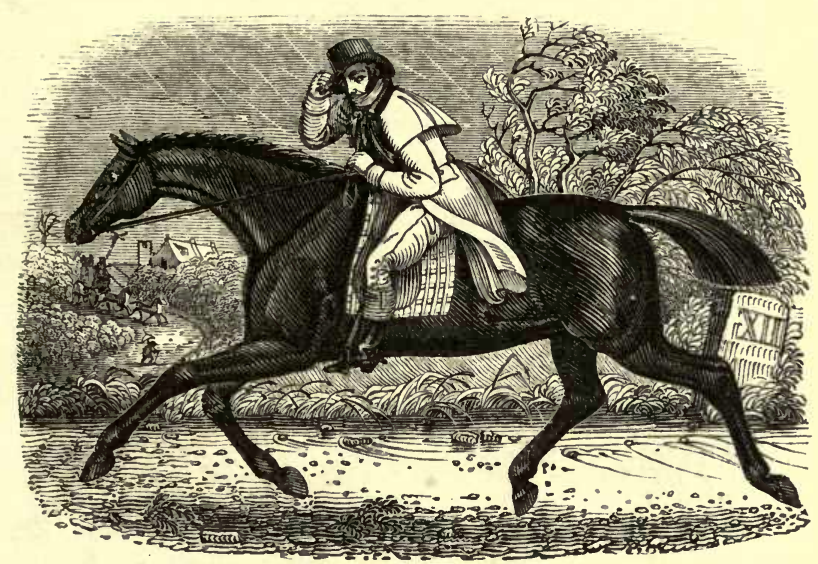

Mr. Youatt, " he must have good fore and hind legs; he must be sound on his feet, even-tempered, no starter, quiet in every situation, not heavy in hand, and never disposed to say his prayers. He is more difficult to find in perfection than even the hunter or the racer."

The Conch-Horse and Sheltie, or Shetland Pony.

So far as breeding is concerned, the coach-horse is nothing more than a tall, over-sized hunter, possessing somewhat less speed, but more strength. The principal points in the coachhorse are substance well placed, a deep and well-proportioned body, bone under the knee, and sound, open, tough feet. The modern coach-horse is very different to that of fifty years ago ; but the improved breed has too much prancing, causing early wear and tear of the feet, and has not the endurance that could be wished,-and a pair of poor post-horses would, Mr. Youatt says, "beat them hollow at the end of the second day." Since steam has been rendered a travelling medium in nearly all parts 


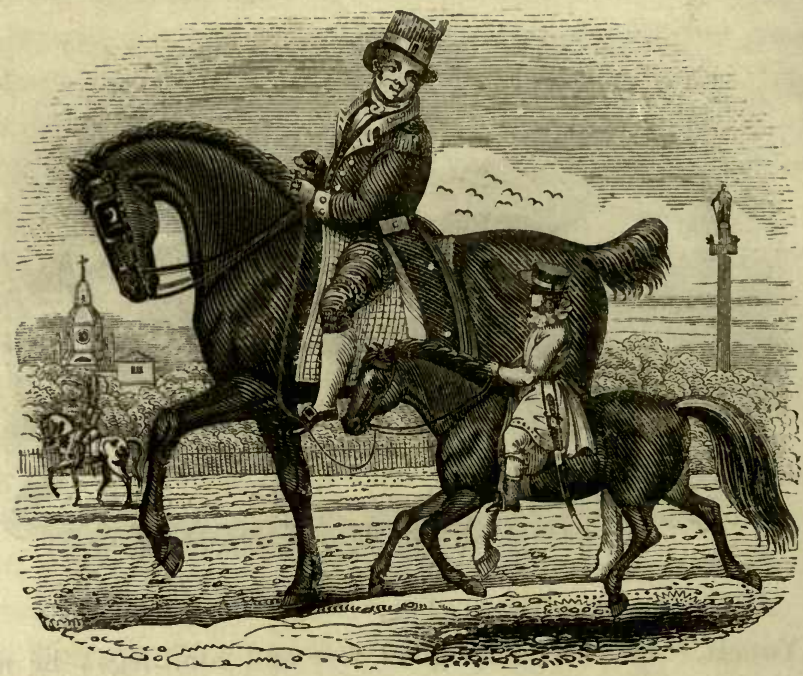

of the country, coach-horses and even roadsters have been greatly dispensed with. Previously, the horse was an invaluable servant, on whose speed all one's hopes and safety might depend in the hour of need; and there was a feeling of pleasure and gratitude in contemplating the willing exertions of the animal in our behalf.

The Shetrand Pony is a beautifully formed creature, and is at once docile, hardy, and strong. Miss Sinclair, in her Shetland and the Shetlanders (1840), says, "They are chiefly running wild among the distant unenclosed hills of that island. When well fed from an early age, they grow nearly to the height of a donkey; but some years ago, Mr. Hay reared a perfectly well-formed pony, which measured only twenty-six inches high, - not so tall as a moderate sized hobby-horse! I have heard sportsmen talk in praise of a horse that would canter round a cabbage-leaf, but here was one literally capable of doing so. The very largest men ride these tiny little creatures, which appear at a distance, when racing rapidly along, as if 
they had merely hooked on a pair of additional legs, those of the rider being scarcely raised a foot off the ground. How would a regiment of cavalry look, mounted, or lowered rather, on these stout little chargers !"



\section{The Welsh Pony and Сob.}

One of the most beautiful little animals that can be imagined is the Welsh pony ; a breed said to be indebted to the celebrated horse Merlin for its form and qualities. The Welsh pony has a small head, high withers, deep yet round barrel, short joints, flat legs, and good round feet. He is admirably suited for the mountainous tracts to which he belongs, being remarkably sure-footed, nimble, pre-eminently capable of enduring fatigue, and of living on any fare. Cully says of one he rode for many years, that it always preferred the hard pavement to the soft road.

A small compact little roadster, not more than thirteen hands high, is called a Cob, - a term of apparently modern date, and omitted in the dictionaries and encyclopedias. 


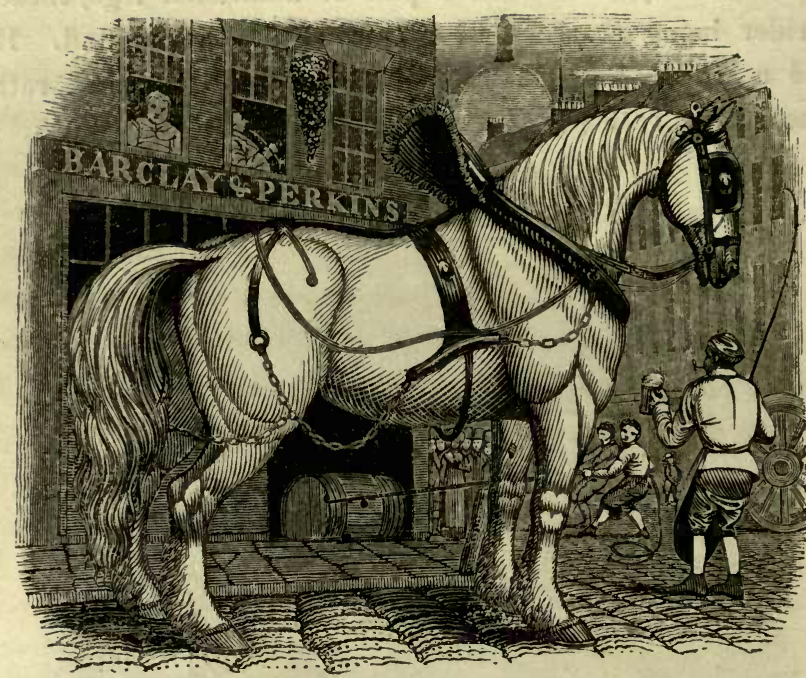

The Dray-Horse.

In our midland counties, from Lincolnshire to Staffordshire, the Heavy Black Horse is bred. Those of Lincolnshire are the largest, being seldom less than seventeen hands high when two and a half years old. The largest are used as drayhorses; the next in size are used as waggon-horses; and a smaller breed, but with more blood, carries the soldier to the field of battle and the dead man to the church-yard. Many of the largest are purchased from the breeder by the farmers of Surrey, Berkshire, and other counties near the metropolis. There they are gradually trained for town work. On soils where two lighter horses would be quite sufficient, four of these enormous animals are used to draw the plough; but then their bones are not yet perfectly formed, nor their joints knit, and by giving them merely this gentle and constant exercise, they become prepared for that continued and equable pull at the collar which is afterwards so necessary, when they are employed by the brewer, to whom they are sold at four years old. These 
noble-looking animals, with their round, fat carcases and sleek coats, are slow, and are not the best for hard and long-continued work; but their proud deportment is well adapted to gratify the brewer's ambition to outvie his neighbour. The stables of our largest brewers are well worth a visit, especially on Good Friday, when all the horses are at home.

The cost of their food, and the expenses attending the wear and tear of their trappings and shoes, are much greater than of any other draught horses. Their drivers are usually very fond of them, and treat them kindly, rarely doing more with the whip than to urge them by cracking it in their hearing.

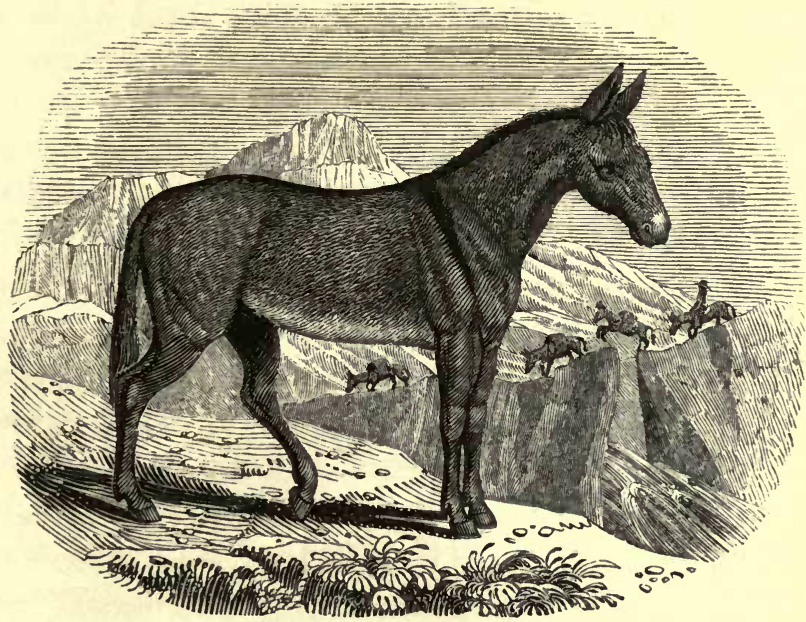

The Mule, or Moyle.

The common mule is produced by the union of the male ass and the mare, and is much more esteemed than the hinny, by which name the progeny of the horse and the female ass is distinguished. The mules of Spain, and other countries in which they are extensively employed, are far superior to those of Britain. They are often sixteen hands high, and can 
carry seven or eight hundred pounds weight on their backs. They are patient, indefatigable, and unrivalled in being surefooted, and these excellences render them most valuable beasts of burden in mountainous countries; and the caution and precision with which a drove of them, walking with great regularity in a single line, will cross over the stupendous and awfully narrow passes, or ascend and descend the almost perpendicular steeps, have excited the astonishment of many a tourist.

The she-mule has, occasionally, but very rarely, been known to produce again with a horse or an ass, or the he-mule with a mare or an ass; but there is no instance on record of two mules breeding together.

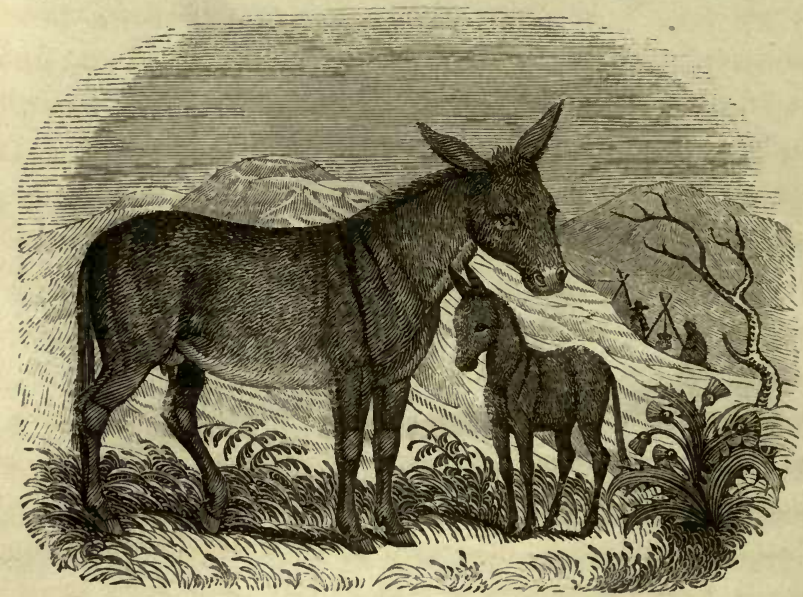

The Domestic Ass.-(Asinus ?)

From the genus Equus, which consists of the horse only, the genus Asinus, comprising the ass, zebra, quagga, djiggutai, \&c., is distinguished by the tail having long hairs at the end only, where they form a brush, by the mane being short and erect 
by only the fore-legs possessing warty callosities, and by the markings being disposed in stripes.

The migratory herds of wild asses, which inhabit at one season the warm climate of Persia, and at another the southern parts of the Russian empire, are supposed to be of the same species as the common domestic ass employed in this more northern region. But the accounts of wild asses published by various travellers are so dissimilar, that we may almost question whether the original species of the wild ass has been satisfactorily ascertained, and whether several other species do not remain to be described. Bruce, in his Travels (vol. iv. p. 522), mentions wild asses very like ours " in neck, head, face, and tail, only their skins are streaked," and as inhabiting the same parts of Abyssinia as the zebra. It is not unlikely that the ass thus indicated is an undescribed species. Bell, in his Travels in Tartary (vol. i. p. 224), notices many wild asses like the common ass, except that their hair is " waved, white and brown, like that of the tiger." The species mentioned in Ainsworth's Travels (p. 41), and in Sir R. K. Porter's Travels (vol. i. p. 459), is the khur, or wild ass of Persia, Arabia, and Mesopotamia, and is probably identical with that of Thebaid, and other parts of the African continent. It is also the wild mule of the ancients. It has a black mane, and no line along the back or across the shoulder. Allied to this would seem to be the herds of wild asses, entirely of a pale yellow colour, which Le Vaillant noticed in Southern Africa, and called by the Greater Namaquas the white zebra. Lastly, there is the kiang of Thibet, or Himalayan wild ass, described in Moorcroft's Travels in the Himalayan Provinces, vol. i. p. 311.* All these wild asses are large, fine, swift animals, presenting a very different appearance in height, sleekness, and vivacity to our poor domestic and degenerated ass, whose ordinary personal appearance is too well known to require a particular description. Mention is made

* For further information on wild asses, see $\mathrm{Mr}$. Blyth's paper On the genus Equus, published in the Magazine of Natural History (New Series, 1840), vol. iv. p. 371. 
of the ass in Britain as early as the time of King Ethelred (866-872), and at a later period in the reign of Henry III. But from either disuse or some fatality, the ass was entirely lost among us during the reign of Queen Elizabeth. Hollinshed informs us, that in his time " our lande did yeelde no asses ;" and in Johnson's Relations of the Most Famous Kingdoms (1611, p. 40), it is stated that England " bringeth not forth mules nor asses, but of horse infinite proportions." It was probably during the reign of James $I$. that the ass was introduced into England for the second time; for during his sovereignty we renewed our intercourse with Spain, in which country the animal is in general use and great perfection.

It has been often said and justly, that we know less of the natural history of those animals which are our most constant companions than those which are wild and afar off. But this is easily accounted for, from the obvious facts that these animals, having long since exchanged a life of independence in a state of nature for one of servitude in an artificial state, retain consequently but an imperfect notion of their proper habits. Can we find in the comparatively miserable hackney, that acuteness and constant use of all the senses which the free, the fleet, and spirited horse of the plains still displays? The latter must use all its faculties in supplying its wants, and exert all its energies and cunning to maintain its freedom; but all the powers of the hackney are chiefly directed to pull a lumbering four-wheeled coach about here and there, and at other times must remain stock still on a coach-stand behind its fellows, all with nose-bags full of food attached to their muzzles. Such an animal has probably no idea of living in a herd with a leader at the head: it never dreams of the sandy plains, or of any diet richer than hay and oats. So it is with the poor domestic ass. What can we pretend to know of an animal that we hardly ever see in good condition or good spirits. Denounced as obstinate and stupid, its very name made a synonyme for a blockhead, it is cudgelled. 
from its youth; and no one gives it that fair unprejudiced trial, which every British subject, be he man or ass, is fairly entitled to. The songs of the people have often more influence on the moral conduct than all the laws; and it is to be hoped that the advice taught in a modern popular song will not be entirely lost upon the costermonger and the tinker. The " hay" and "gee-wo," may accomplish nearly all one might require of a donkey, where every brutal blow may gain nothing but a kick well merited. A wretched maltreated horse is often as dull and obstinate as an ass. Indeed, if the size of the brain in comparison to that of the body can prove the intellectual superiority of an animal, then the ass would make a wiser consul than Caligula's horse. In the ass there is one part brain for every two hundred and fifty four parts of the grosser materials; while in the horse there is only one part of the former to every four hundred, or, in some cases, to every seven hundred parts of the other elements. Let phrenologists, therefore, bring asses into fashion, and elect them to the highest appointments, and let the horses be kept longer at the ridingschool, until their cerebrums and cerebellums attain a larger and more respectable development.

The ass differs much in size and abilities according to the climate it inhabits. In Syria, a fine ass is sometimes more valuable than a couple of horses. Mr. Fraser says, that in Bagdad, "most of the learned and holy professions prefer the ass, and so do all the ladies. These asses are, I believe, of a particular breed, and from forty to fifty pounds sterling is no uncommon sum for one of great size, good blood, and fine paces. The favourite colour is spotless white; they are magnificently caparisoned, and have their nostrils slit, which is said to make them long winded. Heaven knows their wind is long enough when they begin to bray."

The bray of the ass is not generally admired; but the author of a scarce tract on The Nobleness of the Ass (1595), after giving us all its sweet notes, concludes by declaring that the continual braying of five or six asses forms a melodious kind of music- 
" a song of world without end." The same author further shows the nobleness of the ass, by declaring that

" on it is ne'er engendered
The hateful vermin that doth teare the skin,
And to the body make their passage in ;"

but unfortunately for this notion, which Goldsmith and other modern authors repeat, Redi has figured a Pediculus Asini in his Experimenta circa Generationem Insectorum (1686), tab. XXI.

The ass is an excellent swimmer. In March 1816, an ass belonging to Captain Dundas, then at Malta, was shipped on board the Ister frigate, bound from Gibraltar to that island. During a storm at sea, all the live stock was thrown overboard. The ass swam to shore at Point de Gat, and made his way from thence to Gibraltar, a distance of two hundred miles, through a mountainous country, and at length made his appearance at the door of the stable he had last inhabited.

In a wild state the ass feeds chiefly on the most saline and bitter plants of the desert, as the Kalis, Atriplices, Chenopodium, \&c. Cornelius Agrippa compares the domestic ass to a scholar, inasmuch as it not only patiently endures penury, labour, and severe criticism, but it lives on little food, and is content with any sort, be it lettuces, brambles, or thistles. Pennant says, it is extremely fond of the plantain. Bryant says, it has the faculty of discovering distant waters by the smell; but this I apprehend is only when it inhales the saline emanations from those brackish waters which it prefers, at least in the wild state. The domestic ass is more particular in the choice of water than food, and water which a horse will gladly drink is often not clean enough for an ass.

Thersites. "Would the fountain of your mind were clear again, that I might water an ass at it."

(Troilus and Cressida, Act III. Scene 3.)

The female is much attached to her young, which is a sprightly little creature in its youth, but soon assumes the gravity of its parent when old enough to stand blows, and other maltreatment. Obscure dark bands are frequently observable on the 
legs of the young ass, as in other animals of its genus. The Persians eat the flesh of asses. The milk is considered very wholesome drink. Nero's wife, Poppæa, used to bathe every morning in ass's milk, which is also thought a great beautifier and preserver of the skin. Sagri, or, as we call it, shagreen, is made of the hide which in this country is used for shoe leather. The integuments being hard and elastic, form good parchment, which is used for pocket-tablets and for drums. The bones being very solid, were made into very superior flutes by the ancients. To serve the two latter purposes of literature and music, is the only honour that awaits the ass when finally released from the brutality of its master. But enough of the ass, though I am ready to say with Sterne that "with an ass I could commune for ever." Let every man who keeps one treat it well, and use it as though he loved it.

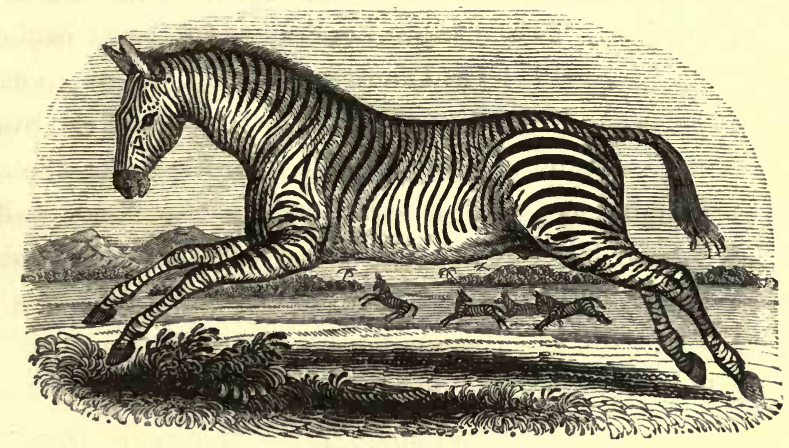

The Zebra, or Wilde-PaArde.

(Asinus zebra: Equus montana, Burchell.)*

Of zebra-like animals, or regularly striped asses, there are three well known species, all natives of South Africa. These,

* Burchell has confounded the names of two species. His Equus zebra, is not the zebra, but the douw (Asinus cristatus), and his $E$. montanus is the zebra, and not the douw. 
which have often been confounded together by travellers and compilers, are the quagga (Asinus quagga), the douw (A.cristatus), and the zebra (A. Zebra, Linn.)

The zebra is the mountain species, and is distinguished by its admirably regular stripes extending quite down to the hoofs. Its range extends from the Cape colony to Guinea, Congo, and even to Abyssinia, according to Ludolff. Bruce says, that in the latter country, it is only found in the south-west extremity of Kuora, amid the Shangalla, and Galla, in Nerea, and, Caff, and in the mountains of Dyre and Tegla, and thence to the southward.

Its habits in a state of nature appear to be similar to those of the wild ass.

In confinement it will breed with the domestic ass. The zebra has not been generally tamed, but it is not improbable that, by perseverance and proper treatment, this magnificent creature would become as tame and tractable as any of our beasts of burden. Two or three zebras which were broken in by the celebrated equestrian Ducrow, are said to have entirely lost their spirit and vivacity, and to have assumed the humble bearing of the common donkey. Some mules between the zebra and the common ass, and others between the latter and the douw, have been bred at the Regent's Park Zoological Society, and they are occasionally employed to draw the Society's provision carts through the streets.

The flesh of the zebra is eaten by the Hottentots. 


\section{ORIER-RUMINANTIA.}

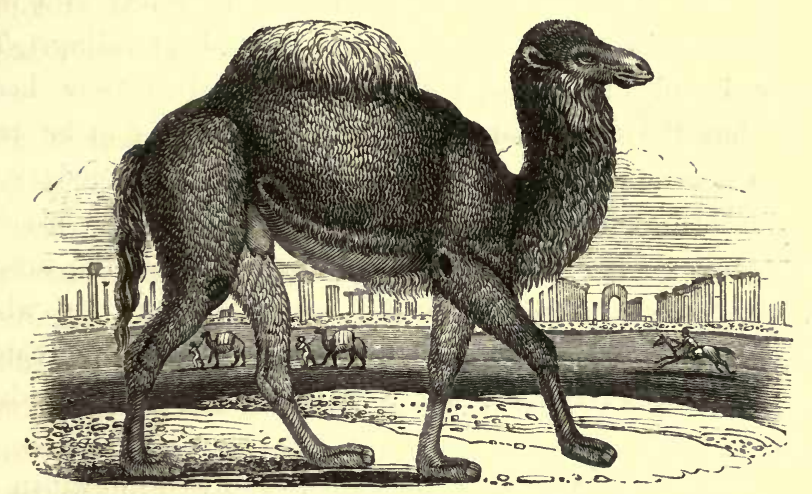

The One-humped Camel.-(Camelus dromedarius, Linn.)

Of camels there are two species, the one-humped Arabian camel (C. dromedarius), and the two-humped Bactrian camel (C. Bactrianus). The former inhabits Arabia, all the northern district of Africa (which extends in length from Egypt to Mauritania, and in breadth from the Mediterranean Sea to the river Senegal), Egypt, Abyssinia, Persia, Southern Tartary, and parts of India. The Bactrian camel is extremely rare, except in Turkistan, which is the ancient Bactria, and in Thibet, as far as the deserts of Shamo, near the frontiers of China. Sometimes he travels with caravans into Egypt, but rarely. Niebuhr says, he saw but two specimens of the two-humped camel during his travels in Arabia; and Mr. M'Farlane never observed but one in Asia Minor, which came from some remote 
southern province. The appearance of the hump of the camel, it should be borne in mind, is liable to vary according to the condition of the animal; for it consists of soft fatty matter, which is largely secreted when the animal is well fed, but becomes absorbed into the system in the absence of fodder and pasturage. The species to which the following observations refer is the one-humped camel, ordinarily called in natural histories the dromedary; but the Asiatics and Africans do not apply the latter term to all of this species, but merely to a light and very swift breed of it, and which is used for riding. The ordinary breed of camels may be compared to our heavy horses; but the dromedary, strictly so called, may to be compared to the hunter, or even the racer. As a dromedary, or swift camel, may be of either of the two species, the practice of compilers always calling the one-humped camel the dromedary, creates confusion, especially in reading travels where the word is discriminately used. The Hebrews call the camel, gamal; the Arabs djemal; but a swift camel, or dromedary, they call el herie.

The outward appearance of the camel is so well known in our country, to which many have been brought, and even led for exhibition about our streets, that a minute description of its exterior is unnecessary; but there are some peculiarities which must not be omitted. "The camel has seven callosities, upon which he throws the weight of his body, both in kneeling down and rising up. There is one on the breast, two on each of the fore-legs, and one on each of the hind. He sleeps always with his knees bent under his body, and his breast upon the ground. Gibbon and some naturalists have regarded these callosities as mere corns, resulting from servitude, but Professor Santi saw the whole seven on a camel but just born; and he does not think they are the hereditary effect of the labour to which the species has been subjected for centuries. Neither does he think the hump on the back is the result of constant pressure upon that part. The animal kneels down to receive its load, and it rests meanwhile on these callosities, which protect the skin 
from injury against the ground. In the whole structure of the camel there is a most especial adaptation of the animal to its arid region, and to those services which man there requires of it, and without which, as it has been observed, the intercourse of mankind in the East would have been confined to small spots where abundance reigned; the commodities of one part of Asia could not have been exchanged for those of another; commerce, the great moving principle in the extension of civilization, would have been unknown; and knowledge would have been limited to particular districts, and would there have been of the most stunted and feeble growth. "The camel's feet are formed to tread lightly on a dry and shifting soil ; its nostrils have the capacity of closing to exclude the sand, when the whirlwind scatters it over the desert; it is provided with a peculiar apparatus for retaining water in its stomach, so that it can march from well to well without great inconvenience, although they be some hundred miles apart. And thus, when a company of Eastern merchants cross from Aleppo to Bussorah, over a plain of sand, which offers no refreshment to the exhausted senses, the whole journey being about eight hundred miles, the camel of the heavy caravan moves cheerfully along, with a burden of six or seven hundred weight, at the rate of twenty miles a day; while those of greater speed, that carry a man, without much other load, go forward at double that pace and daily distance. Patient under his duties, he kneels down at the command of his driver, and rises up cheerfully with his load; he requires no whip or spur during his monotonous march, but when fatigued, his driver sings to him some cheering snatch of his Arabian melodies, and the creature, evidently delighted with the musical sounds, toils forward with a brisker step, till the hour of rest arrives, when he again kneels down, to be disburdened for a little while; and if the stock of food be not exhausted, he is further rewarded with a few mouthfuls of the barley-cake, which he carries for the sustenance of his master and himself. Under a burning sun, upon an arid soil, enduring great fatigue, some- 
times entirely without food for days, and seldom completely slaking his thirst more than once during a progress', of several hundred miles, the camel is patient, and apparently happy."*

The usual food of the camel consists of dates, beans, oats, barley-meal, a handful of salt, and the few thorny plants it meets with at intervals during its journey. They are extremely fond of the leaves of box-trees, though this food immediately kills them; and, therefore, they are not brought into Ghilan, one of the Persian provinces, where great quantities of those trees grow. Riley says, that in the absence of food, the camels will distend their stomachs with the coals which the African caravans carry through the Desert. Of water the camel drinks an immense quantity; and the peculiar reservoirs or cisterns with which it is furnished by nature to retain a large supply of water to refresh itself with when necessary, have already been referred to as striking instances of adaptation. Mr. J. Wilkinson says, that camels will drink water which is too salt to be drunk by the Arabs. He also says, that during his journey through the eastern desert of Upper Egypt, towards the close of April, his dromedaries passed six days without drinking, and were so little distressed, that they travelled twenty-five miles to the water without being fatigued; but in June and the other warm months, three days' abstinence from water, during a continued journey, proves oppressive to them.

The female camel goes with young between eleven and twelve months, and she has only one foal at a birth. In the writings of the numerous eastern travellers, we find nothing relative to the young camel ; and it is only from Professor Santi's account of the camels kept at Pisa, in Italy, that we gain any information about it. He says, that for the first five or six days the foal is unable to stand upon its legs, and that as the mother will not stoop so as to allow it to suck, it is absolutely necessary to lift it up to receive the nourishment which nature has provided for it. We may be sure, however, that in a wild state 
the foal has either strength to stand up, or that the mother stoops to it.

In Buckingham's Travels in Mesopotamia (182\%), it is stated that the Yezeedis, a people who live in the mountains of Singar, and pasture their camels upon the Southern Desert, feed chiefly upon the milk, and sometimes upon the raw flesh of these animals. In Pocock's Travels, it is said that the Turks esteem the flesh of the young as delicate meat; but that the Arabs do not kill the camel for food. Mr. Wilkinson, however, says that during a grand festival which took place among the Arabs in the eastern desert of Upper Egypt, a camel was killed, part of it was eaten on the occasion, and the rest dried in the sun. The Bisharye Bedouins, a savage people, consider its raw marrow their greatest luxury. The manufacture of the camel's hair into garments and tents, is the only employment which gives a variety to the pastoral life of the Arabs of the African desert. When the hair has been spun upon a hand-spindle and a place of pasturage found, they weave the yarn into stuff by a process at once simple and tedious,-every thread being taken up by a distinct effort of the needle, instead of each alternate thread being raised by treadles.

\section{The Dromedary, or El Herie.}

It has already been intimated that dromedary is not a specific term (see page 449). The swiftness and endurance of this breed, for which alone it is prized, are very great, in comparison to the slow march of the baggage camels. Of the dromedary there are some breeds better than others. Mr. Jackson says, that the fastest breed, called the sebayee, will in five days perform a journey which would occupy the baggage camels thirty-five days; and as the average rate of the latter is eighteen miles a day, it thus appears that the sebayee will traverse six hundred and thirty miles in five days,--an almost incredible effort of speed and perseverance. Captain Lyon says, 


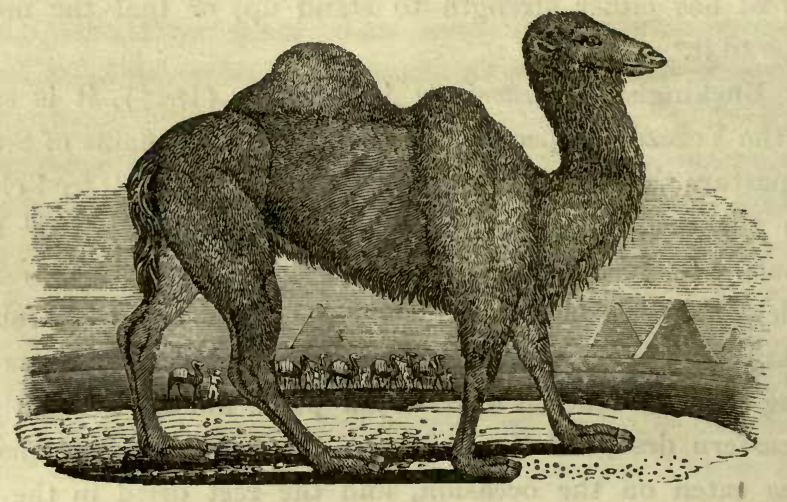

that the maherry, of the Northern African Arabs, will accomplish nine miles an hour, for many successive hours. Riley often travelled at the rate of seven or eight miles an hour, for nine or ten successive hours. Burckhardt rode a dromedary ten hours a day for thirty-five days together. For upwards of two centuries, dromedaries have been employed at San Rossora, a flat and sandy country in Italy; but though the soil, with its brambles and low bushes, is somewhat adapted to them, yet an European climate, and probably, in fact, a life free from alimentary abstinence, are somewhat against them ; and accordingly it appears, from the interesting memoir of these animals, which Professor Santi, of Pisa, published some years since,* that they have degenerated, and become an enfeebled, short lived race. An attempt is now making to naturalize dromedaries in some parts of France, where the roads are unfit for cart-horses. In January, 1835, M. Larvillet, iron-master in the Landes, imported five dromedaries into that part of the country. Several dromedaries and camels are employed in New Valentia, and other parts of South America, where there are scorching plains, impossible to be crossed by means of any other animals.

* In the Annales du Muséum d'Histoire Naturelle (Paris, 1811), tome xvii. p. 320. 


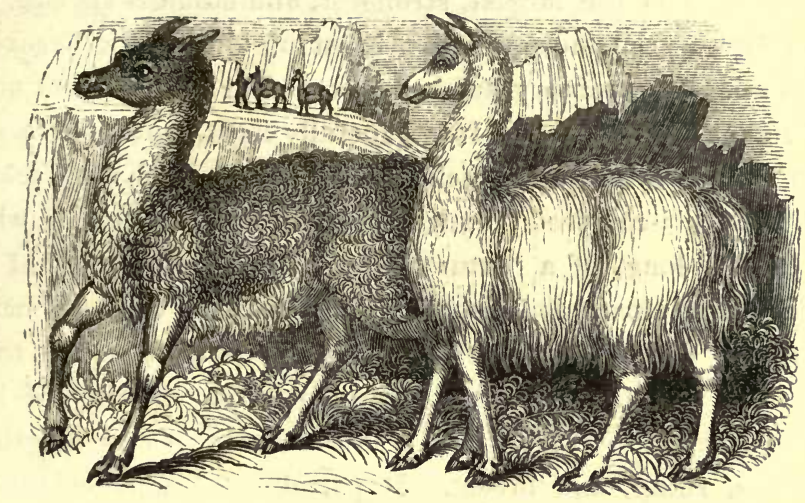

The Llama (Auchenia glama) and Alpaca, or

$$
\text { Paco,* (A. alpaca). }
$$

Only two species of the genus Auchenia, peculiar to South America, are now found wild, namely the huanaco or guanaco (A. huanacus), and the vicugna ( $A$. vicunna). They inhabit the lofty Cordilleras, their range extending considerably below the line of perpetual snow; and it is remarkable that they do not inhabit Quito, Santa Fé, Caraccas, \&c., although the climate of the mountains in those parts is like that of high Peru where they live, and multiply abundantly. The llama and alpaca are not found in a wild state, and are only known as beasts of burden employed by the Peruvians. Hernandez speaks of llamas in New Spain, Mexico, but there they are scarce, and only kept as curiosities, and neither of the wild species extends its range to that distance. Into Chili, the alpaca was probably introduced, and it is the only species the country possesses.

* In the Spanish settlements in South America, all the species of llama are called Carneros de la tierra. Mr. W. Walton, who resided in those settlements, also improperly calls them sheep, and thinks they might be advantageously crossed with our native sheep to improve the wool. Notwithstanding his mistaken notion of their specific relationship, he has written a valuable work concerning them, but which does not appear to have been read or even to be known to zoologists. It is entitled An Account of Peruvian Sheep, and of Experiments made by the Spaniards to improve the Breeds. London, 1811. 
The llama is the largest, strongest, and stoutest species, and anciently was the most valuable beast of burden the Peruvians possessed. Its ordinary height is from four to four feet and a half, sometimes five feet. It is generally light-brown, but sometimes dun, grey, or even inclining to purple, and very seldom black or parti-coloured; under the belly it is uniformly white. The hair is long, of a texture between silk and wool, but not curled. The alpaca is less than the llama, its ordinary height being four feet. It appears twice as corpulent, owing to its possessing a much longer and more profuse clothing of hair, which is sometimes from eight to twelve inches in length on the sides, rump, and breast. It partakes of more colours, is often parti-coloured, and more frequently white than the three other species.

The Peruvians are careful not to over-load either of these animals, whose burden is generally one hundred pounds weight, though for a short distance on good roads they occasionally carry twelve or fifteen pounds more. They are usually gentle and willing. If provoked they express their anger by turning back their ears and spitting into the face of their offender, even if he be four yards off. Their food is never prepared for them, but when unemployed, they are suffered to graze on their native mountains, often pasturing in the company of the wild species, but they are so much accustomed and apparently attached to mankind, that they never exchange servitude for freedom. They very seldom drink for weeks or even months together, and then only a little, being mostly satisfied with the moisture they express from their green food.

The female llama, and alpaca, go with young six months, and rarely produce more than one at a birth. It is weaned when half a year old, but not put to work until it has completed its third year.

The long silky hair of all the species, but more especially that of the alpaca, is spun into blankets, friezes, and coarse woollens, which are warm, durable, and admit of a good dye. As it is perfectly clean, and free from smell, it does not require any 
preparatory process with fuller's earth. The flesh of all the species is eaten. Owing to a scarcity of fire-wood, the dung is used as a substitute for fuel in the mountain cottages and mines, and it emits a clear, strong, and lively flame.

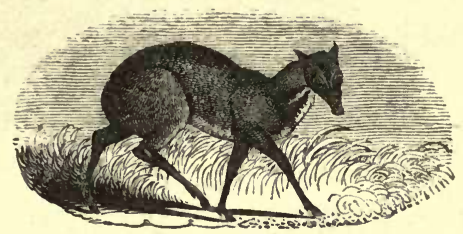

\section{The Napu Chevrotain.*-(Moschus Javanicus, Raffles.)}

This elegant animal inhabits Java and Sumatra. It is one of the smallest of the ruminating mammals, its size being about equal to a full grown hare. In general appearance it much resembles deer, but it differs from them in its dentition, its want of horns, and in many other respects. The fur on the upper parts of the body is dark glossy brown; on the belly, inside of the legs, on the throat and chin, it is pure white, and there is a stripe of this colour on either side of the chest; the muzzle is hairless, of a dusky black, and extends beyond the mouth; the eyes are very large, prominent, dark, and remarkably brilliant; the legs are exceedingly slender; and the tail rather short.

It seldom visits the larger forests, but frequents thickets in the vicinity of man, and near the sea-shore. Its food is principally berries; its voice is very low; and its sitting posture somewhat resembles that of a hare in her form. If procured when young it is easily tamed, and is then perfectly at its ease, and careless of what is passing around it, unless the temptation of food excites its attention.

* It is sometimes called napu musk-deer, but such a name is deceptive, for it does not secrete that strong-scented substance, which is obtained from another species (M. moschiferus). As it is the generic term is objectionable, but no other has been proposed. 


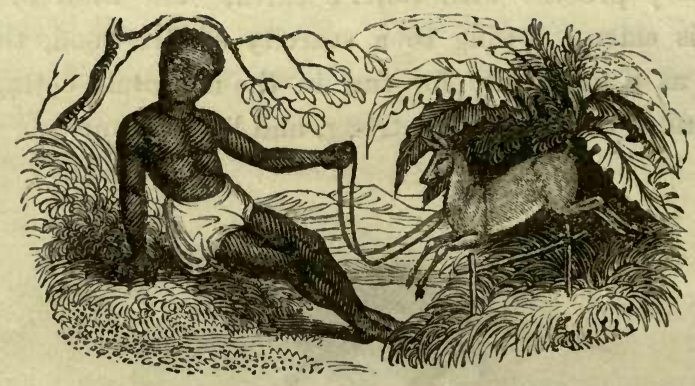

The Pigmy Chevrotain.*-(Moschus pygmaus, Linn.)

This species, the smallest of the ruminants, inhabits the East Indies, Java, and Prince's Island. It is a most elegant and mild little creature, only nine or ten inches long from the nose to the tail; the upper parts of its body are of a bright bay colour; the belly and inside of the thighs white; the legs are long, and as slender as a swan's quill; and the head, eyes, and ears are rather large.

The natives ensnare great numbers of this species, and take them to market, where they are sold as little pets, at about threepence each.

\section{The Elk, or Moose-Deer.†-(Cervus Alces, Linn.)}

\section{Eland. Wampoose. Wampoosa.}

The elk inhabits marshy forests, and the banks of rivers and lakes in the north of Europe and North America; but owing

* This species is frequently called Guinea-deer, but it is not a native of that country.

+ The animal called elk by the colonists at the Cape of Good Hope, is an African species of antelope (Antelope oreas), as large as a horse. In England, Ireland, Isle of Man, France, Germany, and Italy, fossil remains are found of an extinct species of deer, improperly called elk, though it is more nearly allied to the fallow-deer. The wapiti (Cervus Wapiti), has also been miscalled elk, and so have the Samboo-deer of India (C. hippelaphus) and a South American species of deer (C. paludosus). 


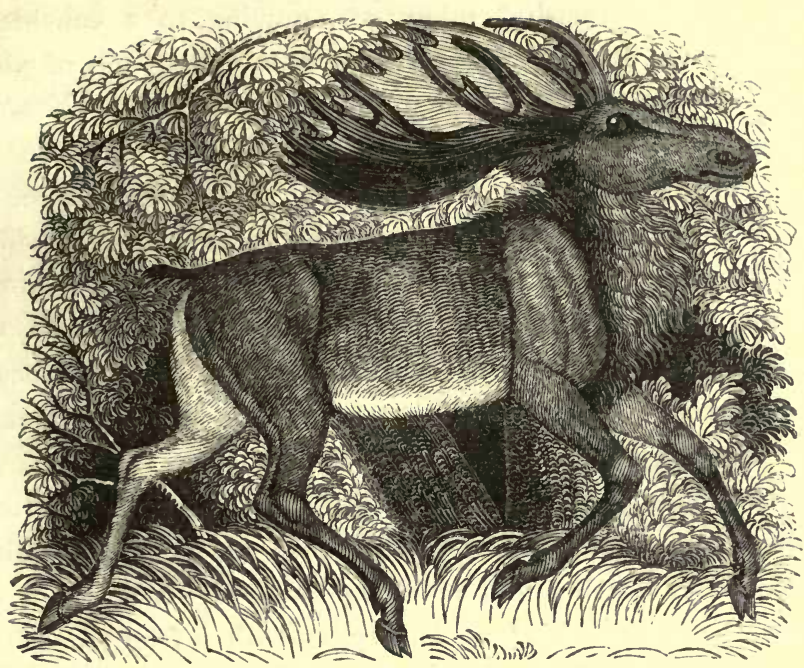

to the eagerness with which it is hunted, it is daily becoming scarcer, has already abandoned many of its former haunts, and the period of its entire extinction is probably not far distant.

The males, which are much larger than the other sex, are nearly six feet high when full grown; and several have been killed in the British North American colonies, weighing from five to seven hundred-weight. The horns, which are possessed by the male only, and are shed in the spring, are wide-spreading, palmated, very thick and strong towards the base, and, in old specimens, weigh fifty or sixty pounds; the head is of great length in proportion to that of the neck; the nose is black and protruded; the eyes are large, and below either of them there is (as in most other deer) a slit, nearly an inch in extent, and through which it has been supposed to breathe and smell when hard run, or when the muzzle is under water while drinking, but this aperture has no communication with the nose: the legs are long, and the tail very short. Its coarse, long, and hairy fur becomes very thick on the approach of winter; but it somewhat varies with the age of the animal, from a blackish brown, to a greyish colour, or to a pale dun. 
The elk is somewhat migratory, moving to a considerable distance from its summer haunts on the approach of winter; and, although ten or a dozen elks may frequently be seen herding together, it is not strictly gregarious. In the more dreary and desolate regions towards the Arctic Circle, it is seldom that more than a couple of these shy and solitary animals are seen together. They feed upon the American hemlock, cedar, fir or pine, maple, birch, willow, and other trees. The Americans call the salt-springs deer-licks, because the deer and elks frequently repair to them not only to eat the saline herbage, but to lick the wet pebbles. When alarmed, and occasionally during the rutting season, the elk utters a peculiar sort of whistle, which is said to be truly frightful. Its senses of hearing and smelling being highly acute, it soon detects the approach of an enemy, and when frightened it sets off at great speed; but when all escape is hopeless, it stands at bay ready to dash at and demolish the hunter, and crush his dogs beneath its feet.

The female usually produces two young ones at a birth, generally about the end of April.

Audubon observes, that the elk " considerably resembles the horse in its conformation, and in its disposition still more, having much of the sagacity as well as viciousness of that animal;" and it may be added that many attempts have been made in America to break the elk into harness, but seemingly without success. The flesh, or venison, is eaten, but said to taste like beef; and the skins are used for clothing, as well as for constructing canoes, and covering huts or wigwams.

\section{The Rein-Deer.-(Cervus Tarandus, Linn.)}

The rein-deer is abundant in its wild state in the colder parts of Europe, Asia, and America. In America its range extends to a much lower latitude than in the Old World, and passing 


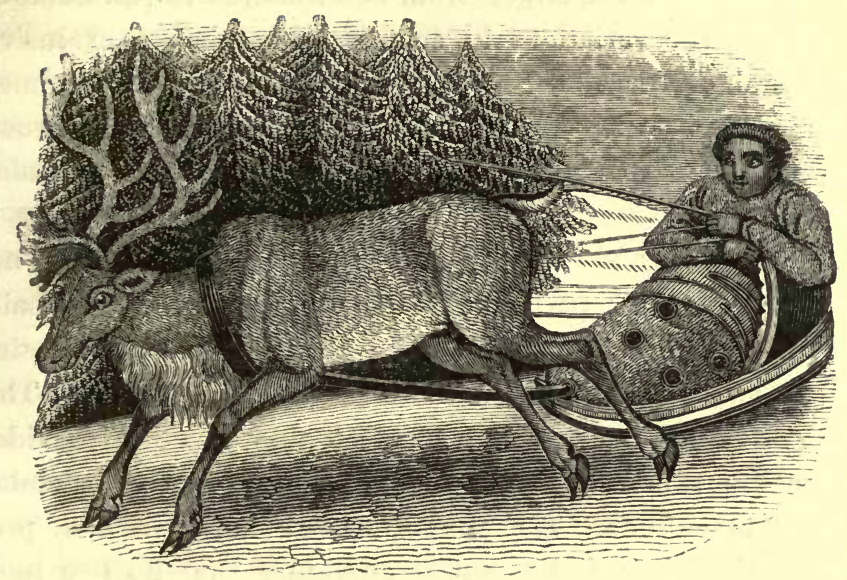

to the south over all the principal mountain-chains it extends across nearly the whole of that continent, its limits in that direction appearing to be about the parallel of Quebec, but it is most numerous between $63^{\circ}$ and $66^{\circ}$; passing westward it seems to be unknown in the islands between America and Asia, but is again more or less abundant in Kamschatka, Siberia, Northern Russia, Sweden, Norway, Finland, and Lapland. The Baltic forms its southern limit in Europe; in Asia, however, it extends along the Ural chain to the front of the Caucasus. Again crossing the ocean, the rein-deer is found in Spitzbergen, Greenland, Newfoundland, and Iceland. In the latter country they were introduced about sixty years ago, and though they have become plentiful on the mountains, they are not domesticated or much sought after by the inhabitants.

The animal is found to be of larger size the nearer its habitat is to the Pole, and to be reduced in size in the southern regions. Those of Norway and Sweden are of small stature in comparison with those of Finmark and Lapland, which are also much smaller than those of Spitzbergen and the polar climes. The bucks of the smaller American variety, when plump, weigh from ninety to a hundred and thirty pounds, exclusive of the 
offal ; but those of the larger, from two hundred to two hundred and forty. The variations in colour are much less extensive. The general colour of the upper parts of the body, in summer, is of a dark brown; but as the winter approaches the brown assumes a grayish tinge; the whole of the under parts retaining a greyish white hue all the year. Occasionally the coat is entirely white; and spotted or mottled rein-deer are not uncommon in some parts of Siberia and Lapland. The hairs of the coat are so thick, that it is hardly possible by separating them in any way to see the least portion of the hide. This species of deer is the only one of which the female is provided with antlers similar to those of the male, but rarely attaining an equal magnitude. The antlers vary so much in size, proportional thickness, and extent of curvature, that no two individuals, even of the same age and sex, have them shaped exactly alike. The power which the hoofs possess of separating from each other, adds greatly to the security of the animal's footing by enabling it to tread on a larger surface.

Trains, sometimes consisting of as many as two hundred sledges, are continually traversing Lapland, even crossing the mountains, to convey merchandise from the coast to the interior during the long and dreary winter, and which could not be conveyed at other seasons, as rein-deer are of little use for carrying burdens on their backs. But with the facilities afforded by a frozen surface, the rein-deer can draw, each, a sledge containing two or three hundred pounds weight. They generally proceed at the rate of about ten miles an hour; and their power of endurance is such, that it is not unusual for them to perform a journey of one hundred and fifty miles in nineteen hours. In the palace of Drontingholm (Sweden), there is a portrait of a rein-deer which, on an occasion of great emergency, in 1699, conveyed an officer with important dispatches to the distance of eight hundred English miles in the almost incredibly short period of forty-eight hours, but it dropped down lifeless when it reached its journey's end. Mr. Dillon says, that " the rein-deer, so far from galloping with his head up, as he is usually repre- 
sented, generally trots with his head low, and his mouth open. By his excessive panting, he appears to those unacquainted with his habits as if he would fall down dead in a few minutes, but nothing is more deceptive, for he rarely dies of fatigue." The resting-places of sledge travellers are usually where the animals can obtain the various species of lichens which grow beneath the snow. These lichens,-one of which is well known to the reader by the misnomer of Iceland or rein-deer moss, constitute the chief food of these useful animals. The author whom I have just quoted says, that " as soon as the deer scent the lichens, they begin scraping away the snow, and in a few seconds dig through four or five feet to the ground. Sometimes there is so much snow, that they disappear in the holes they have made, their antlers alone being seen above the surface."* Cartwright, in his Journal in Labrador, says that in " the latter end of April and in May, the wild rein-deer eat little else but dry grass and wild rye, which then appear through the snow. They prefer the youngest and most juicy plants, and are particularly fond of the tender leaves of the dogberry and and the willow. I have known them eat the outer shoots of the black spruce in winter time, though but sparingly." The rein-deer is remarkable for often possessing a carnivorous propensity. Captain Franklin tells us that in America it not only gnaws its fallen antlers, but devours mice; and Sir Arthur Brooke attributes to it a habit of eating the lemmings in Lapland, when they descend in myriads from the mountains during summer. Cartwright relates that a young rein-deer which he kept as a pet would eat boiled meat.

When the wild rein-deer are pursued in the summer time, they always repair to the nearest water, in which they swim so rapidly that no land animal has the least chance with them. "I am certain," observes Cartwright, " that they will swim more than five miles in an hour, and I verily believe six."

It is during winter that the rein-deer enjoy most comfort. The heat of their northern summer subjects them to much 
inconvenience, and brings with it their special plagues-their peculiar gadflies. When suffering from the irritation produced by the gadfly maggot gnawing into their skin, they rush madly into the sea, and they appear to find some relief under water. Hence many of the Laplanders keep near the shores of the Icy Sea during summer, and only return to the interior about September.

The female rein-deer produces her young about the end of May, and she is very affectionate towards it.

Every part of the rein-deer is useful to the Laplanders. They eat the flesh, drink the milk and the blood. Of its sinews they make harness, cordage, and threads; and of its bones and antlers, furniture and ornaments. Its furry skin forms the clothing of all the arctic inhabitants, and Dr. Richardson assures us that a suit of this kind is so impervious to cold that, with the addition of a blanket of the same material, any one thus clothed may bivouac on the snow with safety, in the most intense cold of an arctic winter's night.

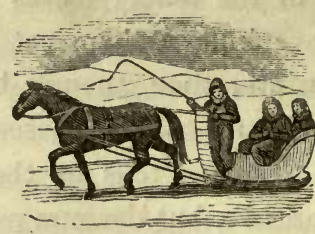

The Stag, or Red Deer.-(Cervus elephus, Linn.)

The most noble of our native mammals is certainly the stag, or as Scott poetically terms it

"The antler'd monarch of the waste."

In Scotland red deer are still numerous in a wild state. They inhabit Mar forest and Glenartney ; and there are considerable numbers in the west parts of Ross and Sutherland. They are most abundant in the central Grampians and in Atholl forest, which is a large tract of a hundred thousand acres set apart for them, and where no person is allowed to intrude, 


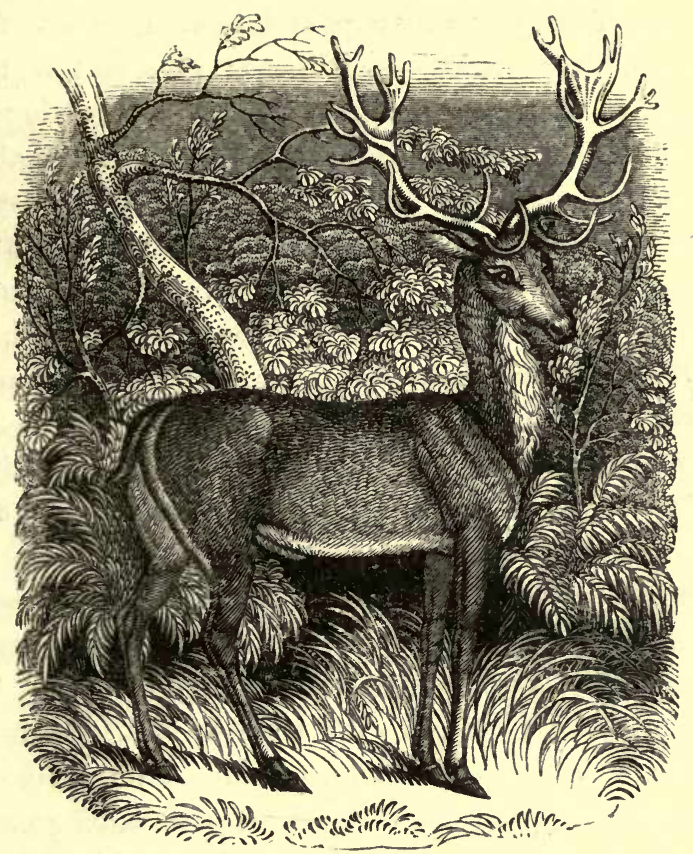

unless he has permission to join in the sport of deer-stalking. In Ireland hundreds of them still dwell wild upon the mountainous ranges called Macgillicuddy's Reeks, the Tomies (which include the Purple Mountain and Glena), and the Turk Range. England contains very few in a wild state. There are said to be some in Gloucestershire, and in a few other parts of the southern districts of the country, and in the New Forest. The stags which are kept in a small park at Windsor to be hunted by the royal stag-hounds, are of course in a semi-domesticated state, and the hunt there is an insignificant affair in comparison to what it is in Scotland. In Richmond Park there is generally a stock of from forty to fifty red deer.

A full grown stag is sometimes about four feet in height, or 
more. The hind, or female, is usually smaller. The prevailing colour is reddish brown in the summer, but brownish grey in the winter. The eyes are large and full. Deer and antelopes have a curious aperture beneath each eye, and it has been asserted that they can hoth smell and breathe through this orifice when their heads are deeply immersed in the water in the act of drinking, or when they are hard run; but anatomists assure us that this notion is proved to be false on dissection. These apertures, or subocular sinuses, are called larmiers by the French, because a matter exudes from them, and runs down the cheek, like tears. The antlers, unlike the real horns of other animals, are solid bones, and are formed in the same manner, and possess the same composition and structure as other bones. They remain on the head for one year, being shed every spring, and replaced by another and a larger pair in the summer. So rapidly do these instruments grow, that an antler which may weigh a quarter of a hundred weight is completely formed in ten weeks. The new antlers are at first covered with a thick, soft, leaden-coloured skin, called the velvet, and which remains on them till they have become hardened, when it dries and falls off in shreds : a process which the animal accelerates by rubbing the antlers against the trees. Lord Bacon, in his Sylva Sylvarum (edit. 1651), says that " a bone is sometimes found in the heart of a stag" (p. 15\%); and more recently, in August 1835, Professor Harrison read a paper on bones in the hearts of the RUMInantia, before the British Association.

The largest stag, being probably the strongest, is usually the captain of the herd, and wherever he leads the rest follow. When grazing there is always one of the herd, generally a hind, stationed as sentinel, and upon the least suspicion being excited, she gives the alarm, and off they all bound. As their senses of sight, hearing, and smell are very acute and ever active, the deer-stalkers approach the herd very cautiously, silently advancing up the wind, and concealing themselves as much as possible by the inequalities of the ground. Deer- 
stalking, which is the mode of sport adopted in the Highlands, is more tedious and dangerous than the common mode of hunting a stag let loose from a game-cart in some smooth park; and hence it requires considerable perseverance, labour, and courage. When the stag is wounded, large hounds, between the greyhound and the blood-hound, are let loose upon the track of his blood, and they never stop till they have brought the animal to bay, generally in some stream, where they keep him till the stalker comes up to shoot him through the head. In approaching the stag when at bay, it is necessary for the sportsman to use the utmost caution, and to keep him down the stream from where he stands; for if he breaks his bay, he is very likely to attack his pursuer, gore him with his horns, or trample him to death with his feet.

"If we be English deer, be them in blood:

Not rascal-like to fall down with a pinch;

But rather moody mad, and desperate stags,

Turn on the bloody hounds with heads of steel, And make the cowards stand aloof at bay."

(Henry VI. Part I, Act IV. Scene 2.)

When the poor thing is expiring from the wounds it has received, "the big round tears" run down its face, and it "groans in anguish." Shakespeare's tender and picturesque description of the hunted stag, which called forth the pity of the contemplative Jaques, is full of truth and beauty:-

"As he lay along

Under an oak, whose antique root peeps out Upon the brook that brawls along this wood. To the which place a poor sequester'd stag, That from the hunter's aim had ta'en a hurt, Did come to languish; and indeed, my lord, The wretched animal heav'd forth such groans, That their discharge did stretch his leathern coat Almost to bursting; and the big round tears Cours'd one another down his innocent nose In piteous chase; and thus the hairy fool, Much marked of the melancholy Jaques, Stood on the extremest verge of the swift brook, Augmenting it with tears." 
The remainder of the poet's description, which tells us that the stag was

"Left and abandon'd of his velvet friends,"

" thus misery doth part

The flux of company. Anon, a careless herd, Full of the pasture, jumps along by him, And never stays to greet him,"

refers to a curious fact, also noticed by Thompson, who says the hunted stag

" Oft seeks the herd: the watchful herd alarm'd With selfish care avoid a brother's woe."

Mr. Jesse who, as surveyor of the royal parks, is familiar with the habits of deer, mentions that " when a hard-pressed deer attempts to rejoin his companions, they fly from him, or try to drive him away with their antlers."*

Stag-hunting may be attended with a finer display of trappings, grace, and gentility, but after all it is not a bit more defensible than the forbidden bull-baitings and dog-fights of the common people; for the torture of an unoffending creature for amusement is the object in both cases. The pleasure and healthiness of riding and leaping over a beautiful and varied country, offer but a poor and selfish apology for causing torture and anguish to an inferior creature.

Besides the coarse grasses and lichens which form the ordinary pasture of the red deer, they will eat corn, carrots, turnips, potatoes, and the leaves of the ash-tree; and where large herds are kept they commit much damage to the crops in the neighbourhood. During winter, they feed, to some extent, on the bark of trees.

"Yea, like the stag, when snow the pasture sheets, The bark of trees thou browsest."

(Antony and Cleopatra, Act I. Scene 2.)

The hind goes with young eight months, and produces one calf, as it is called, and which is usually menilled (spotted with white) on the back and sides. She is an affectionate parent.

* Gleanings in Natural History, vol. i. p. 187. 
Gilbert White relates, that some men suspecting that a new born calf was lying in a certain spot of thick fern, went with a lurcher to surprise it; but the hind rushed out of the brake, and taking a vigorous spring, with her feet closed together, alighted upon the dog's neck and dislocated it.

It is hardly necessary to mention that the flesh or venison is eaten, and that the horns are manufactured into handles for knives and forks, or that the shavings yield ammonia, from whence the common name of hart's-horn. The Highlanders in the time of Henry VIII. made their shoes of the skin; and as it was the fashion to wear the furry side outwards, they acquired the name of the Rough-footed Scots.

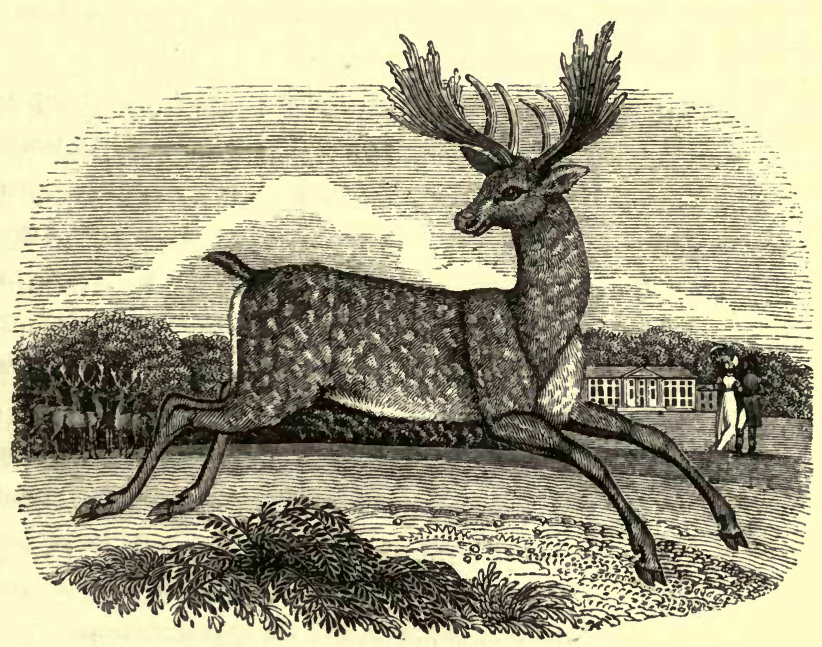

The Buck, or Fallow Deer.-(Cervus Dama, Linn.)

Cuvier remarks, that this beautiful species, now so common in all Europe, seems to have been originally introduced from Barbary; by others it is supposed to have been brought from Bengal. The British specimens are thought to have been first obtained from the south of Europe, whither they had also been imported. The more hardy variety, which is almost entirely 
of a dark brown, sometimes almost blackish brown, is well known to have been imported by James I. from Norway, where perhaps it had gradually acquired that power of enduring cold, which renders it more easily kept in our fickle climate than the common variety, which, in its pure state, is reddish brown spotted with white. This intolerance of cold would seem, however, to be the result of the semi-domestic state in which they are kept in our parks.

In Richmond Park the number of fallow-deer is generally about one thousand six hundred. Numerous and extensive herds still exist in the New Forest, Hampshire. Herds of them are also kept in the parks of Ireland; but they are much more abundant in Scotland, not only in enclosures, but at large over the country, although they are, doubtless, the descendants of semi-domestic individuals. In Forfar and Perthshire, they inhabit many of the lowland plantations, retiring into the wooded retreats during the warm seasons; but in the severity of winter troops of six or eight together emerge from their seclusion to invade the cottage gardens. In a nearly natural state they are plentiful in the central part of the Grampians, from whence perhaps they will extend their range to those mountainous districts where plantations have been formed. They abound most on the southern part of the bleak and, generally, naked ridge of Minigny, which lies between the Glen of Athol on the south, and Badenach on the north, and intermediate to the lofty summits of Ben-y-glac on the east, and the pass of Dalnavardoch on the west. Many deer are, however, found towards the eastern part of this ridge on the lands of the Duke of Gordon and others. They are rarely seen on the summits; but usually in the glens of the Tilt and Bruar, often in herds of upwards of a thousand; and when the solitary traveller is twenty or thirty miles away from any human abode, he finds a subject of interesting contemplation, when he looks up and beholds upon the heights several bucks with their branching horns relieved upon the clear mountain sky. 
The buck is usually about three feet in height to the top of the shoulder, and its full length is about five, including the tail, which measures nearly seven inches and a half. The horns are shed every spring. The summer-coat is of a fawn-colour spotted with white; but the white spots disappear with the annual shedding of its coat in autumn; and the winter-coat is blackish brown; the buttocks are always white, bordered on either side with a black stripe, and the tail is black above and white underneath.

The fallow-deer appears to eat of the same food as the stag, but perhaps of a greater variety. Fawns will crop the green ivy, and the older ones will eat the leaves of holly in winter. From the Privy Purse Expenses of Henry VIII., it appears that the royal fallow-deer, then kept in Greenwich Park, were fed on hay and oats. Those that are now kept there are very fond of biscuits, apples, and filberts. They crunch the nuts, and swallow shells and all.

In the pairing season and in winter, the bucks and does keep together promiscuously, and those of Scotland in the former season retire to the fastnesses of the glens, where their cry, called braying or belling, is heard more frequently.

"The wild buck bells from ferny brake."

(Scott's Marmion, Canto IV. Stanza 15.)

At other seasons, the sexes live in separate herds. The doe goes with young eight months, and produces one or two, and sometimes, but rarely, three at a birth. She is very affectionate towards her offspring, and, like the hind, conceals it at first. Mr. Jesse relates that a game-keeper having shot a fawn, the little creature bounded off till the loss of blood so weakened it, that the keeper's hound soon overtook it, and dragged it to the ground. The parent-doe, emboldened by affection, had kept in close pursuit of the dog, and having now come up with it, attacked it with the utmost ferocity, despite the interference of the keeper. The man terminated the sufferings of the young one with his knife, and carried it away; and when the mother as if agitated by excessive grief, had surveyed the pool of blood 
she followed the destroyers of her dead fawn, and uttered, as she went, a tremulous cry of maternal distress. "This cry," says the narrator, "is often heard during the season for killing fawris, and it is one of peculiar agony." The antlers of the young buck do not make their appearance until the second year, and are then merely simple snags, without branches; the horns of the third year possess two branches; but those of the sixth are the most ornamental.

The venison of the fallow-deer is thought better than that of the red-deer. The skin, well known as doe or buck-skin, is used for gloves, and other articles.

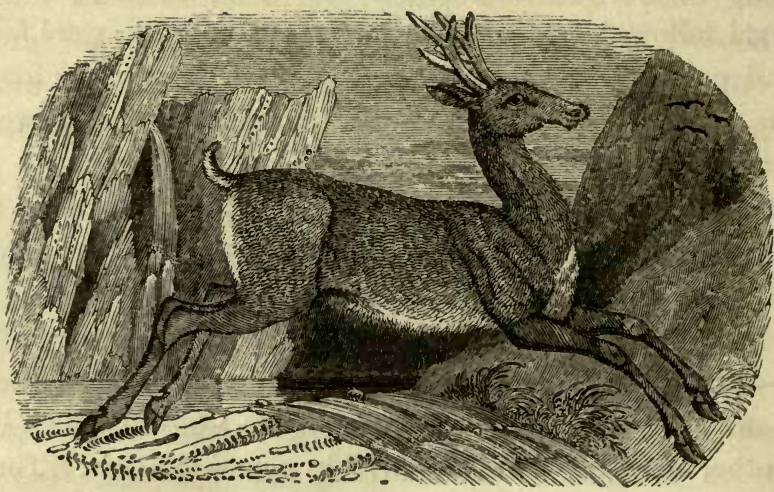

The Roebuck.-(Cervus capreolus, Linn.)

This species is now scarce in England; but it is still abundant in the Scottish highlands. It is the smallest of the three kinds of deer inhabiting Britain. Its length from the end of the tail to the nose, is about three feet ten inches; and its height, at the shoulder, two feet three inches. The colour is subject to much variation; in some specimens reddish brown is the prevalent tint, in others brownish grey, and in others it is dusky; the belly and inside of the thighs are greyish white; and the part around its short tail is pure white; the chin and inside 
of the ears are white; there is a white spot on either side of the lips; the nose is brown. The antlers are round, rough, and consist at most of only three pointed extremities.

The roe does not associate in large herds, and more than four are rarely seen together. The buck is said to be monogamous, choosing a partner for life, and evincing the most constant regard for her, and therefore a couple is as many as are usually seen together; and when four are observed together, they are generally the parents and their young. In their mountainous haunts, they exhibit astonishing boldness and agility in bounding over the ground, or in leaping from one precipice to another. Mr. Tytler says, that their usual pace is a long, rather awkward canter; but when suddenly startled, their bounds are the most rapid and beautiful that can be conceived, and that he has seen one of them bound, without much apparent effort, across a road nearly twenty feet wide.

"From the thick copse the roebucks bound, The startling red-deer scuds the plain, For the hoarse bugle's threat'ning sound

Has roused their mountain haunts again."

(Scott's Cadyou, Castle.)

They often descend from their favourite haunts to eat the corn and peas growing in the neighbouring fields, feeding entirely in the grey of the morning and evening. They pair in November. The doe goes with young five months, and brings forth usually one, not unfrequently two fawns, in the month of May. At that period she retires to the thickest cover to drop her offspring; but in about a fortnight both parent and fawn emerge from the lair, yet she still protects it with great care and boldness. The fawn does not acquire its antlers till the second year, and then they are merely simple snags; in the fourth year it has antlers with two pointed extremities; and from the next year it has regularly three extremities to each successive pair.

The venison of this species is not esteemed, and even when in the best condition, there is scarcely any fat under the skin. 


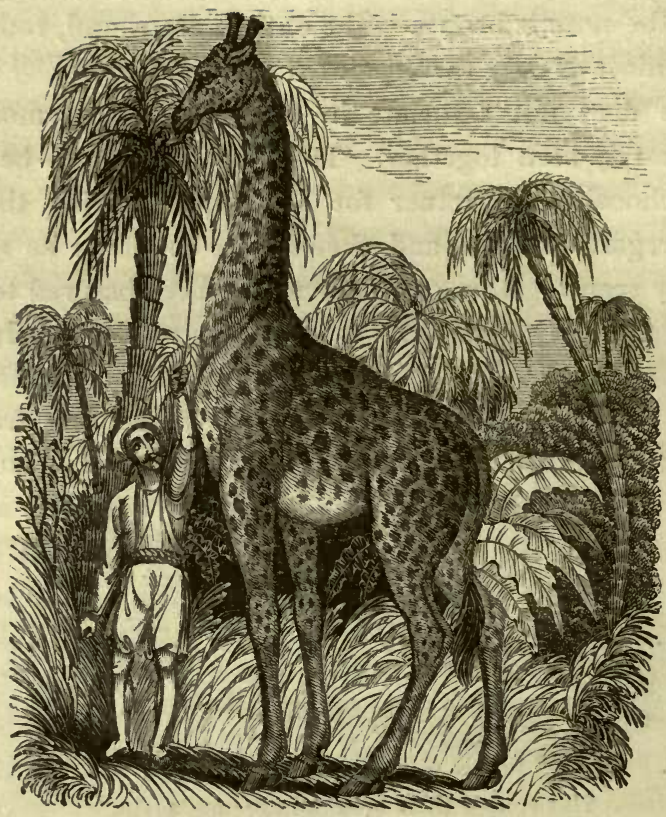

The Giraffe, or Camelopard.

(Camelopardalis giraffa, Linn.)

It has been supposed that the giraffes found in Abyssinia, are a different species from those of the southern extremity of Africa; and that a third species or variety, without spots, was seen by Mungo Park in Central Africa. But it is now unanimously considered that these differences are ascribable merely to the age and sexes of the individuals observed, and that there is only one species.

A giraffe, killed by M. Thibaut, in Kordofan, measured twentyone French feet from the ears to the hoof. The male, which is the largest sex, is generally said to be about twenty feet high from the summit of the head to the sole of the feet. The highest specimen in the British Museum (a fine, but badly 
stuffed male, brought over by Mr. Burchell), measures seventeen feet six inches; and the others do not exceed sixteen feet. The neck, trunk, thighs, and part of the fore-legs, are marked with large angular spots of a reddish or clear yellow hue, upon a dull white ground; the belly, inside of the thighs, and extremities of the legs, are faded white; a mane of very stiff short yellow hairs extends from the back of the head to the withers; the hoofs are black, well divided, and neatly set on; the tail extends below the hocks, and is terminated by a long tuft of coarse hairs; the ears are yellowish, and well constructed for the reception of sounds; and the eyes are large, brilliant, and so prominent that the animal can see the surrounding objects without turning the head, and hence the difficulty of approaching near to it in the wild state. Both sexes have the head surmounted by two solid horns (if they must be called so, though they have neither the use nor structure of real horns), entirely invested by an elongation of the skin of the head, and terminated by a tuft or brush of long hairs. In the female at the Jardin des Plantes, the horns are seven inches long; eleven inches round at the base, and four at the middle, and at the end. In front of these horns is another horn-like protuberance, having precisely the same structure, and differing from them only in form and relative size, being less in height, but wider at the base, and it is also enveloped with the skin of the animal. The neck of the giraffe, although very long, contains but seven vertebræ, the same number as in man, but from their form and mode of articulation, they enable the neck to assume a variety of attitudes, as freely and as gracefully as that of the swan. The height of its withers may, according to its age, exceed the height of the rump by sixteen or twenty inches; and this circumstance gives it the appearance of having the front-legs longer than the hind-legs, and so well does the slanted plane of the back deceive the beholder with this impression of a disproportion between their length, that I have known persons stand before not only the living animal but the skeleton, and assert the existence of this disparity, until they were convinced 
of the error by drawing a horizontal line from the one pair to the other.

The giraffe rarely appears on the plains; its habits and structure are particularly suited to a life in the forests and the wooded mountains. It is seldom seen in the company of more than one, its mate, or in groups of three or four, consisting of the parents and their young. They do not fly at the first view of man; but if he approaches them, they immediately start off at a smart gallop, the hind-feet at each stroke advancing before the front pair. The first run of the giraffe is so exceedingly rapid, that the swiftest horse, if unaccustomed to the desert, can scarcely overtake it. If the giraffe reaches a mountain, it passes the heights with great rapidity; and bounds over ravines with surprising power, and with as much dexterity as a goat. M. Salze says, that the female giraffe at Paris some. times " bounds like a young horse, but in a peculiar manner, springing up pretty high from the ground, and then descending on her legs quite stiff and immoveable. Sometimes she starts forward at a gallop, dragging along the four Arabs who keep hold of her; and, in a moment of gaiety, she will drag even five strong men." M. Thibaut and his party, mounted on horses accustomed to the fatigues of the desert, pursued two giraffes in the south-west of Kordofan, but did not secure them till after three hours' rapid chase, across an open sandy soil, but partly through brambles and thorny trees. La Vaillant and his guides galloped after a giraffe for three hours, and then were forced to give up the chase owing to their horses being quite out of breath. At another time, this enthusiastic zoologist and his guides spent a whole day in the chase of five giraffes, but these animals employed so many stratagems that they escaped as night came on. On a third occasion, a giraffe outstripped all the efforts of his horse, but his dogs gained upon her, and obliged her to stop to defend herself, which she attempted to do by dealing, some vigorous kicks to the whole pack. When walking leisurely, the giraffe appears at each step to raise simultaneously the two legs of the same side, but on a close 
inspection a slight interval is perceptible between the elevation of the fore-leg and the hind-leg of the same side.

The giraffe stands too tall to touch the ground with its mouth, notwithstanding the length of the neck. Purchas, in his Pilgrimage (1614, book vi. ch. 1), notices this fact, and it has since been corroborated by too many observers of the animal, both in Africa and in Europe, to induce us to admit that this is a "vulgar error," as somc have chosen to call it. When the animal is desirous of cropping the short herbage, it makes several vain attempts before it succeeds, and sometimes does not succeed after all its efforts. In this attempt, it stretches out its front legs gradually wider and wider apart, till its chest appears strained to the utmost; it draws in the crupper, protrudes the shoulders, and extends the neck downwards in a stiff, not perfectly straight, but rather curved position. In this strange attitude it might extend its tongue, and by means of that prehensile organ take a branch up from the ground, but one cannot conceive that it could either graze upon the short grass or drink. It is evident, indeed, that this is not one of its natural positions, and that instead of being intended to graze on a pasture, its whole organization adapts it for feeding upon the leaves of tall trees, taking its food leaf by leaf, and collecting them with its long tongue when they are beyond reach of the mouth. Unlike the camel, it rejects the thorns. Its ordinary food, in a state of nature, consists of the leaves of a species of acacia (A. xariffiana), called by the natives kanaap, by the colonists kameeldoorn, and of the fruit of the wild apricot. The specimens in the Regent's Park Zoological Gardens are fed with beans, hay, and grass, but of the latter they eat only the tender parts, rejecting the coarse stalks. The poor sickly specimen which was kept at Windsor a few years ago, was fed with oats, barley, split beans, and ash leaves; and it drank eight or ten quarts of milk daily. The giraffe is also fond of rose-leaves, rice, raisins, and apples. It lies down when it ruminates, and it is curious to watch the rapidity with which the cud works its way up through the long neck to reach the mouth. It is probable that, naturally, the giraffe's thirst is 
quenched by the moisture it expresses from the highly succulent leaves of the acacia; and if it ever has occasion to drink, we may infer that it wades into the water so as to bring the surface within reach of the mouth.

The giraffe, when compelled to defend itself, kicks like a horse, but with more force and rapidity. It never employs its horns in defence; but those in the Regent's Park will sometimes strike each other a heavy blow by swinging the head with great impetus against some particular part of the body where the one appears to have discovered that the other is the most tender. In such cases, the keeper interferes with a whip. Ordinarily, however, giraffes are of a mild and social nature. M. Thibaut says, that he observed one of the specimens just mentioned, shed tears when it no longer saw its companions and its attendants. A giraffe, which Mr. Gordon wounded when in Africa, permitted him to approach it as it lay on the ground, and even to stroke it over the eyes several times, when it only closed them, and made no effort for revenge-being as forgiving as the lamb

\section{"That licks the hand uprais'd to shed its blood."}

The female goes with young about twelve months, and has one, perhaps two occasionally, at a birth. The young one grows rapidly, and sucks for several months. One was born in the Regent's Park in June 1839, but it only lived nine days, and is now preserved in the giraffe house.*

The Arabs hunt giraffes for the sake of the flesh (which M. Thibaut says is excellent eating), and for the skin, of which they make bucklers and sandels. La Vaillant saw a hut of one of the Great Namaquas entirely covered with the skin of a giraffe, and it was this observation that proved to him the existence of an animal which the moderns had begun to regard as fabulous, and it was this that induced him to go in quest of it, and make the re-discovery of this majestic creature.

* It is generally agreed that the giraffe utters no sound whatever, yet in the newspaper reports of the birth of the young one above referred to, it was stated to have uttered a bleating. If it made any noise it was probably involuntarily, and caused by the act of respiration. 


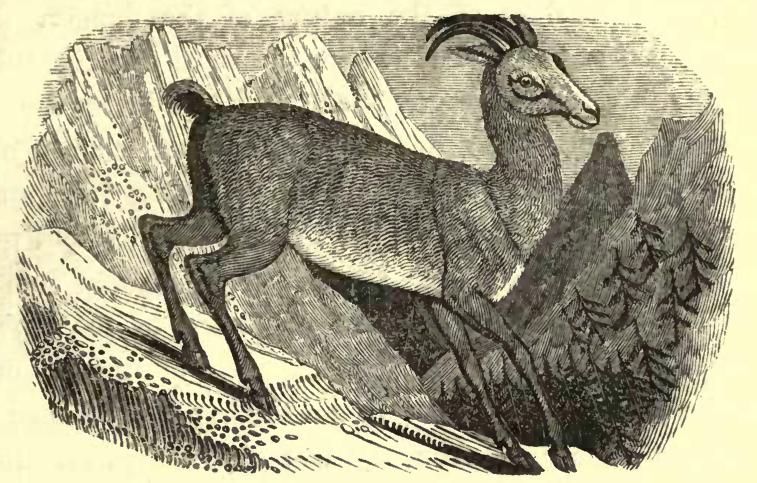

The Chamois Antelope.-(Antilope rupicapra, Linn.)

The chamois inhabits the mountainous parts of western Asia, and also of western Europe. In the latter quarter it is abundant in the mountains of Dauphiny, Piedmont, Savoy, Switzerland, and Germany.

It is about the size of a large goat, which in some respects it resembles. The hair of the body is shaggy, deep fawn colour in summer, faded brown in winter, and a sort of straw colour towards spring; a black band descends from the eye towards the muzzle; the horns are not more than six or seven inches long, are black, quite smooth, erect for about two-thirds of their length, at which part they curve back into hooks with very sharp tips; those of the female are smaller and less hooked.

These animals associate in small herds in the middle regions of the mountains, that is to say, between the plains and the highest elevations. They feed only at morning and evening, eating the richest pasture, and cropping the most delicate parts of aromatic herbs. It is exceedingly difficult to approach them, for while they graze, one of them stands as a sentinel on some eminence which commands a view of all the avenues leading to their haunt, and when he perceives an object of alarm, he utters 
a sharp hissing noise, which calls all the rest towards him to judge for themselves of the nature of the danger. If they descry a beast of prey, or a hunter, the most experienced of the herd puts himself at their head, and conducts the retreat. Then they bound along one after the other, leaping over the wide yawning chasms of rocks, and springing from one high point to one still higher, with the utmost rapidity and unerring certainty; nor do they stop till they have gained some place which will present the greatest obstacles to their pursuers. The precision with which these animals can jump from one spot to another, and their power of preserving the balance of the body, may be conceived from the fact that a chamois will sometimes throw himself from a height of twenty or even thirty yards upon a ledge so small as scarcely to afford room for his feet to stand upon. The chace of these animals across the mountains is a most daring and perilous undertaking, owing to the steep acclivities which must be surmounted, and the chasms that must be crossed. The hunters shoot them, and rarely succeed in catching any of them alive.

They couple from the end of October to the beginning of November; and they bring forth in March and April. If a young one be caught, it may be tamed.

The flesh is good eating, and their skin, when tanned, furnishes the celebrated chamois leather.

\section{The Gazelle.-(Antilope Dorcas, Linn.)}

The gazelle inhabits Egypt and Arabia, and also extends its range to the river Senegal, in Africa.

It is about three feet and a half in length, and about one foot nine inches in height at the shoulder; the upper parts of the body are of a dun colour, separated by a brown belt from the white colour of the belly; the face is reddish fawn-colour with a dark brown streak on the nose; the muzzle is slender; 


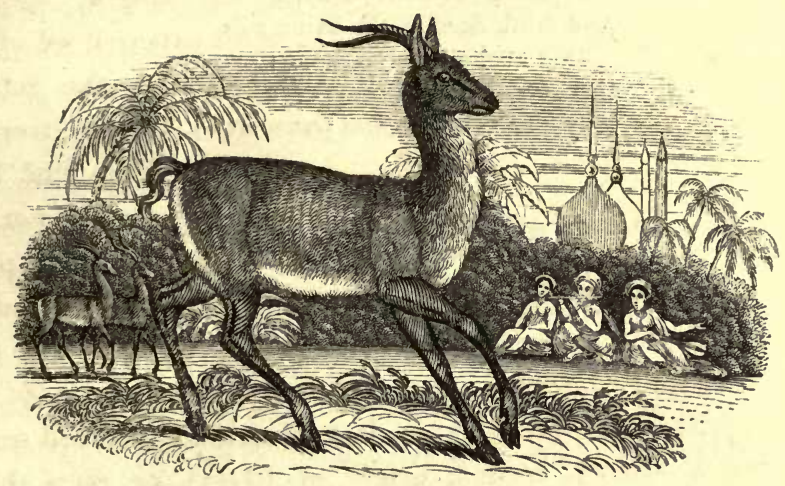

the ears are long, narrow, and pointed; the eyes are bright hazel, large, and prominent; the horns are between nine and ten inches long, round, black, lyre-shaped, and are possessed by both sexes, but the female's are smaller than those of the male.

Gazelles live in immense herds upon the open plains, where they browse upon the saline and pungent herbage.

Mr. J. Wilkinson says, that during his stay at Guttar, in Upper Egypt, " the gazelles were so much pressed for water, that they ran through our encampment in the valley, and having satisfied their thirst returned the same way, for it was the only road to the watering-place; and these animals always prefer the valleys to crossing the mountains, unless in those parts where they have beaten tracks. This is even the case when closely pressed by dogs; and I have known them return and pass their pursuers when they found that the valley was nearly at an end."*

The graceful symmetry of its figure, the soft expression of its quick, bright eyes, and the elasticity of its gait, are constant themes of admiration, and have induced the Arabian poets to regard this animal as the emblem of maiden beauty.

* Journal of the Geographical Society (1832), vol. ii. p. 49. 
"The wild gazelle on Judah's hills

Exulting yet may bound, And drink from all the living rills

That gush on holy ground; In airy steps and glorious eye May glance in tameless transport by."

(Byron's Hebrew Melodies.)

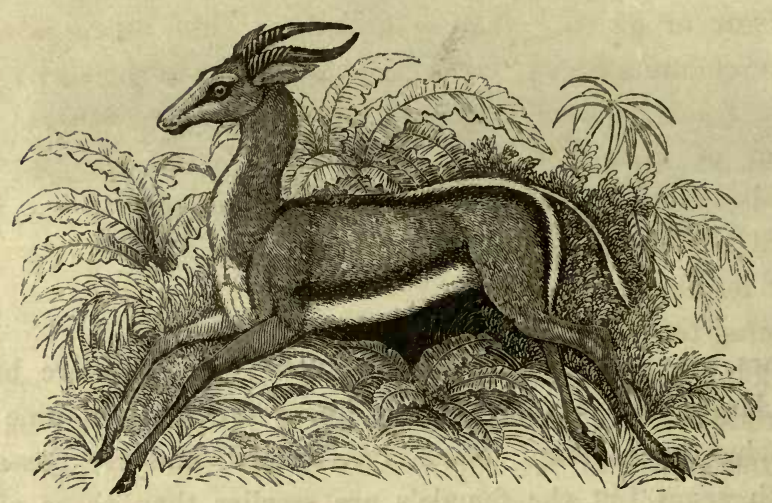

The Springbok, or Springer.-(Antilope euchore, Burchell.)

This is one of the most beautiful and certainly the most abundant of the South African antelopes. In the form of its body and the glossiness of its tints, it resembles the gazelle; but it is about one-third larger. The general colour on the upper part is a delicate cinnamon brown, divided from the white of the belly and the back by a well-defined band of venous red. From the loins to the rump, extend two folds of the skin, lined with long white hair, and which the animal can display or conceal at pleasure. When in a state of repose, the folds are closed, and their beautiful white hairs are hidden beneath the cinnamon-coloured fur; but in the act of bounding or leaping the folds open, and then the display of white has a very singular appearance. The horns are very handsome, and much resemble those of the gazelle; both sexes possess them, but those of the female are smaller than the male's.

Springboks associate in immense herds. Burchell saw a 
herd which he estimated to consist of about two thousand head; and Pringle says that, on one occasion, as many as twenty-five or thirty thousand were estimated, by a good judge of such matters, to be scattered over the plains near the Little Fish River, and that they literally speckled the face of the country as far as the eye could see. When a herd are moving at leisure or grazing, they walk and trot like other antelopes, or like common deer; but occasionally those in the rear remove to the front by bounding over the backs of the others. This system of changing places is observable in all gregarious animals, though more conspicuous in this instance. When a herd of kine or a flock of sheep are grazing along a pasture, those leading the way get the best of the repast, and soon becoming tolerably satiated they proceed but slowly; in short, they loiter, and then it is that the hindmost, dissatisfied with the trodden-down leavings of their leaders, and feeling hungry, avail themselves of the opportunity to get into the front rank. Thus the springboks proceed alternately, occupying the front and being left in the rear. "When pursued, or hastening their pace," says Burchell, " they frequently take their extraordinary bounds, rising with curved or elevated backs high into the air, generally to the height of eight feet, and appearing as if about to take flight. In crossing a beaten road, although it be quite smooth and even with the plain, the greater number clear it by one of their flying leaps; being seemingly afraid of a snare, or distrustful of the ground on which man has trodden."*

In the extensive uninhabited plains between the Orange River and the Cape Colony, the springboks multiply undisturbed by the hunter (except when occasionally the Bosjesman kills a few with his poisoned arrows), and the country literally swarms with them, until a long drought, which occurs perhaps once in four or five years, drys up the stagnant pools and natural reservoirs of brackish water. Then, the want of water is so severely felt by these animals, that incalculable myriads of them migrate from their haunts, and press forward, like a dense mass of life, to 
the Orange River, or to the northern frontier of the Cape Colony. In their impetuous course they carry everything before them. Even the lion has been seen wedged in amongst them and hurried along; and droves of sheep are swept off with the torrent, which, forcing its way across the cultivated lands, lays waste all the labours of the husbandman, who at this period is forced to consider himself as entirely dispossessed of his lands until the heavy rains fall. No sooner do the bountiful thunder-clouds empty themselves upon the parched-up country, than the springboks begin to disappear, and in a few days become as scarce on the northern frontier borders as in the more protected districts of Bruintjes-Hoogte and Camdeboo.

The springbok is easily tamed while young. Pringle frequently saw tame ones playing about the doors of the colonists, among the dogs and poultry, or accompanying the sheep and goats to pasture, and returning as regularly and quietly as the rest. Indeed, the springbok would make an excellent and handsome addition to the cattle that are ordinarily kept even in Britain.

When the springboks invade the Cape Colony, great numbers of them are killed, and their flesh is eaten by all classes.

\section{The Indian Antelope, or Sasin. (Antilope cervicapra, Pallas.)}

This species appears to be common in the north of India. In size, it is nearly equal to the fallow-deer. The full grown male has the whole of the back and upper parts of the sides, together with a broad band occupying the entire front of the neck, the outsides of the limbs, the upper surface of the tail, the ears, and a considerable portion of the head and face, of a deep fawn colour, shaded more and more as the animal advances in age, with an intermixture of black hairs, which are most abundant over the shoulders, on the fore-legs, on the front of the neck, round the bases of the horns, and on the face, where they are still deeper than on any other part. The 


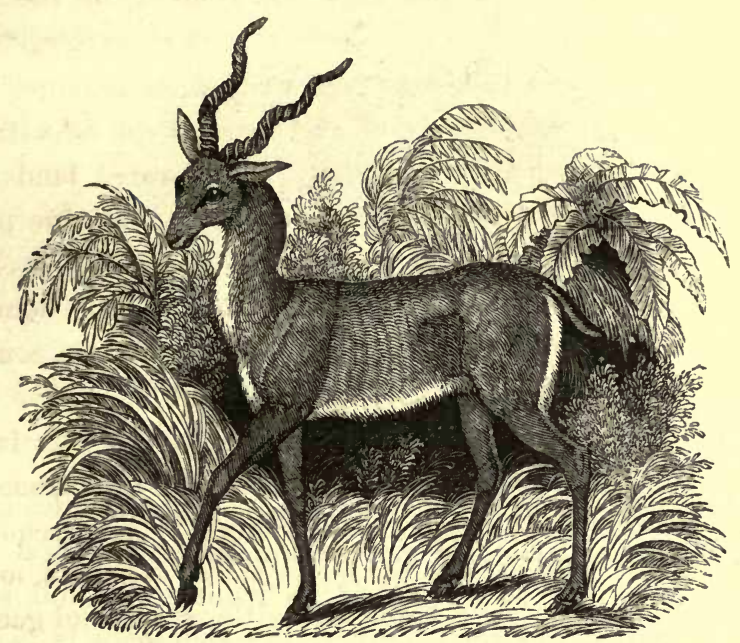

chest, belly, buttocks, and inside of the limbs are pure white. His horns attain the length of thirteen inches, and sometimes, at an advanced period of life, they attain sixteen, twenty, or even twenty four inches in length. The female has no horns, and her general colour is of a lighter fawn, and never acquires the dusky tinge of the male; on the front of her neck she is of a light ashy grey; and a greyish line passes along each side of her back from the shoulders to the rump.

These animals are usually seen in small herds, consisting, probably, of only a single family, which is under the guidance of an old male. They are extremely shy and timid, and by their surpassing velocity and the great length of their bounds, they outstrip the fleetest dogs. They are occasionally captured, however, by flying hawks at them, and which engross their attention until the dogs have time to come up to the spot and seize them; and sometimes they are surprised by chetahs trained for the purpose (see page 242). Being easily reconciled to captivity, these elegant antelopes would prove an ornamental and, perhaps, advantageous addition to the live stock in the parks of Europe, the climate of which they appear to bear without injury. 


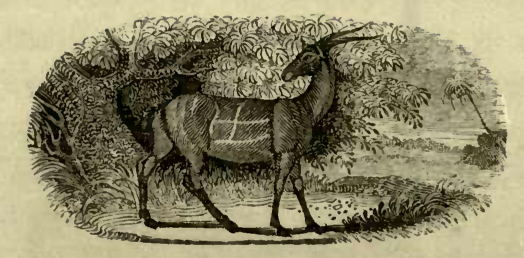

The Guib, or Harnessed Antelope.

(Antilope scripta, Pallas.)

This beautiful species inhabits the woods at the sides of the Senegal, Niger, and Gambia rivers; but, as with several other antelopes, very little is known of its habits. Its full length is four feet and a half; its height at the shoulders is two feet six inches, but it is rather higher at the croup. The ground colours are fawn and white variously marked; along the back there is a stripe of white and black mixed, and from this stripe sometimes a greater or smaller number of white streaks pass backwards and downwards, and are crossed by longitudinal ones of the same colour, nearly parallel to the ridge of the back, and giving the animal the appearance of being in harness. But this uniform marking is not always present; and it is said that no two specimens are marked exactly alike. The male only has horns, which are straight, but wreathed with two ridges in the form of a double screw, prominent at the base, but becoming obliterated near the tips.

The NyL-Ghau.-(Antilope picta, Pallas.)

The range of this animal appears to be limited to the northwestern provinces of Hindoostan, and the countries situated between them and Persia.

The male is about the size of a stag, but of stouter make. 


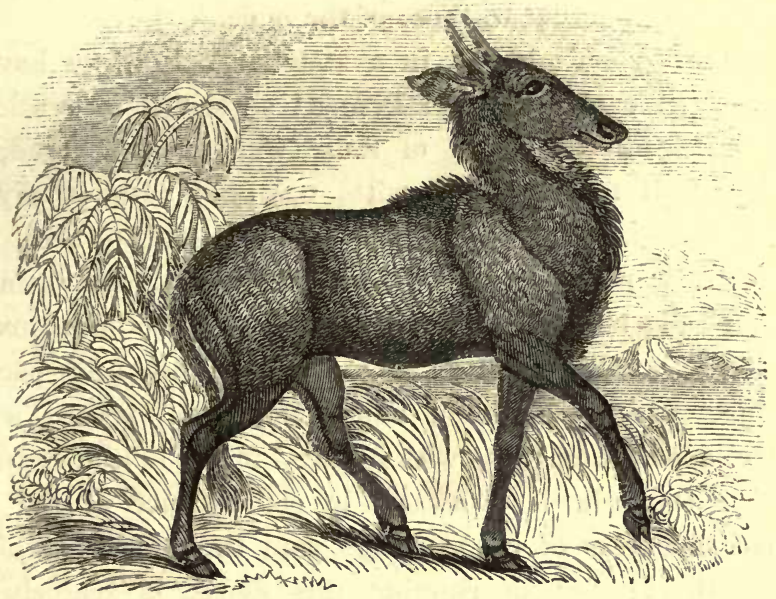

His hind-quarters are much lower than his fore-parts; his legs are thicker than those of most other antelopes; his horns are from seven to eight inches long, of a dull black colour, and of a conical shape, slightly curved forwards; the ears are large; the eyes full, black, and prominent, and the sinuses, or slits, beneath them are large and conspicuous; a thin narrow mane of long black and white hairs surmounts the neck, and extends over the hump on the shoulders; on the under part of the neck is a pendant tuft of long black hairs; and a tuft of similar hairs terminates the tail, which is of considerable length. The ground colour of the upper parts of the body is a slaty grey; the head, belly, and legs are of a much deeper shade than the upper parts, the general tint being greyish black with a slight mixture of brown; the hairs on the fore-part of the chin and on the margins of the lips are pure white; there is also a broad patch of white on the upper part of the neck; and there are usually two white marks immediately above, and in front of the hoofs. The female is much less and more slender than the male. She has no horns, less hump on the shoulders, and her hind- 
quarters are more nearly on a level than her fore. Her general colour is a pale reddish brown, marked with white spots and patches exactly similar to those of the male.

Of the nyl-ghau's habits in a state of nature we have no details. "In captivity," Mr. Bennett says, "it is gentle and familiar, licking the hands of those who offer it bread, and suffering itself to be played with, not only without shyness, but with evident pleasure. There are seasons, however, when it becomes capricious in its temper. When meditating an attack it falls suddenly upon its fore-knees, shuffles onwards in that posture until it has advanced to within a few paces of the object of its irritation, and then darts forward with a powerful spring, and butts with its head in the most determined manner. Its walk is awkward, in consequence of the comparative shortness of its hind-legs, and the width to which it extends them; but in running this defect is scarcely perceptible."

The female goes with young eight months, and produces one, sometimes two, at a birth. Nine specimens have been bred at the Regent's Park Zoological Gardens.

The flesh is said to be well tasted.

The GNu, or Niou.

(Catoblepas gnu, Ham. Smith; Antilope gnu, Gm.)

The gnu, called wilde-beaste by the Hottentots, inhabits the mountains to the north of the Cape of Good Hope, where it is rather rare.

It is an extraordinary animal, possessing characters which remind us of the antelope, the buffalo, and the horse. Its full length, from the point of the nose to the end of the tail, is seven feet ten inches; and the height three feet six inches. The body is of a brown colour; on the upper part of the neck is an erect, well-defined, black and white mane, extending beyond the 


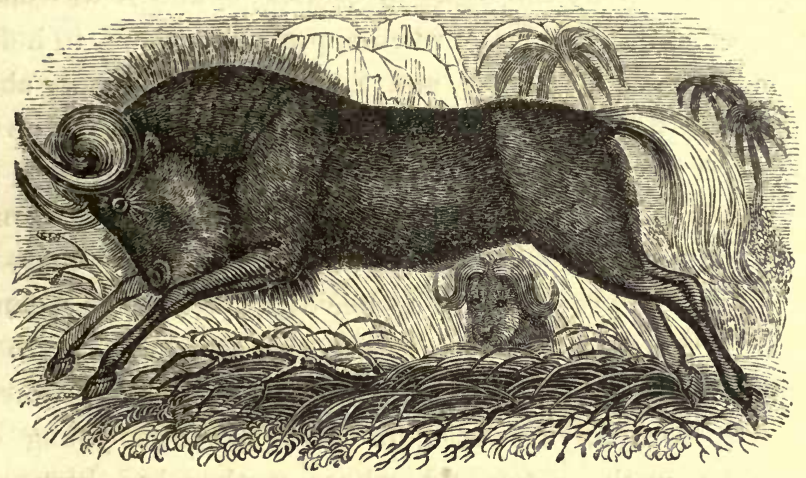

shoulders; a ridge of black hair, from six inches to a foot in length, extends from the front of the chest, under the fore-legs, to the beginning of the belly; a row of black bristly hairs, four inches in length, grows down the middle of the face; and another row of hair, somewhat longer, extends from the under lip to the throat; the forehead is well protected by the rugged roots of the horns that spread across it, leaving only a narrow channel between them; the horns project forwards twelve inches, and then turn in a short curve backwards ten inches; the eyes are surrounded by long white hairs, that radiate and form a kind of star; and under the eye is a sinus, or slit. The tail is two feet long, white, bristly, and bushy. The female has only two teats, and is also furnished with horns.

Barrow observes, that "the gnu possesses in an eminent degree strength, swiftness, weapons of defence, acute scent, and quick sight. When a herd of gnus are disturbed, they collect together, butt each other with their horns, bound and perform their various gambols, and then gallop off to a distance. Their motions are extremely free, varied, and always elegant." Pringle, who very frequently studied the habits of the gnu, both singly and in small herds, on the mountains adjoining the Scottish settlement at Bavian's River, observed among other pecu- 
liarities that, like the buffalo and the ox, these animals are strangely affected by the sight of scarlet; " and it was one of our amusements," he says, "when approaching them, to hoist a red handkerchief on a pole, and to observe them caper about, lashing their flanks with their long tails, and tearing up the ground with their hoofs, as if they were violently excited, and ready to rush down upon us; and then all at once, when we were about to fire upon them, to see them bound away, and again go prancing round us at a safer distance. When wounded they are reported to be sometimes rather dangerous to the huntsman; but though we shot several at different times, I never witnessed any instance of this. Once a young one, seemingly a week or two old, whose mother had been shot, followed the huntsmen home, and I attempted to rear it on cow's milk : in a few days it was quite as tame as a common calf, and seemed to be thriving; but it soon sickened and died. I heard, however, of more than one instance in that part of the colony, where the gnu thus caught young, had been reared with the domestic cattle, and had become so tame as to go regularly out to pasture with the herds, without exhibiting any inclination to resume its natural freedom."

Both of the authors above cited, agree in stating that the flesh closely resembles that of the ox in appearance and taste.

\section{The Common Goat.-(Capra hircus, Linn.)}

Zoologists are at variance in their opinions respecting the original stock from whence the domestic goat has descended; but the general notion at the present time is, that it is derived from the paseng (C. Agagrus), which is the wild goat of Persia, and of the Caucasian mountains. In some parts of Britain, more especially in the most inaccessible parts of the Welsh rocks and mountains, goats roam about without the slightest appearance of ever having been domesticated or of having been derived from a domestic stock. Pennant says, they were in his time suffered 


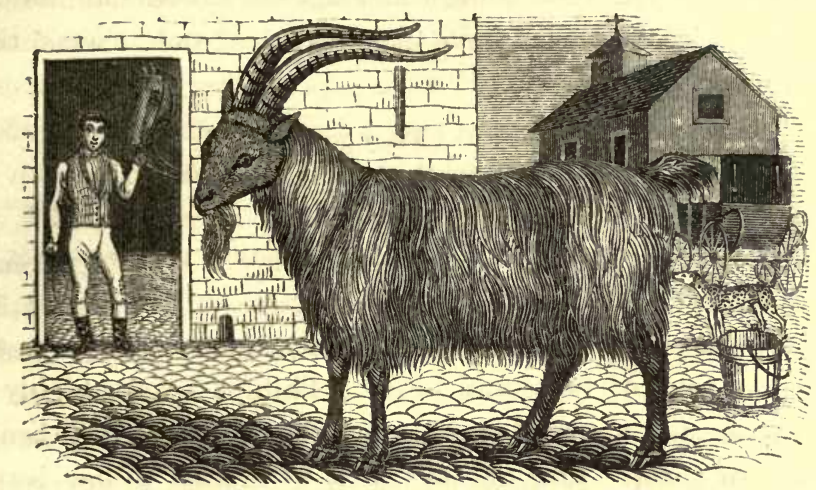

to run wild on the rocks in Caernarvonshire, during such seasons as they were not in request; but when needed, they were either shot with bullets or hunted with dogs. These Welsh goats, which are now rarer on the mountains than formerly, are much larger, and their hair is longer than those of England. Pennant saw a pair of their horns which were three feet two inches long, and three feet from tip to tip. The ordinary colour of the domestic goat is black and white, or a dull light reddish brown, with a black line down the back. The beard is often very long, particularly in old buck or he-goats.

The goat leaps on to narrow ledges and pinnacles of rocks presenting a surface scarcely large enough to afford it standing room, yet it does stand upon them, and remains in that position as firm as the rock itself. In performing this astonishing feat, it does not exhibit any fear or hesitation, there is no pause, no preparation. It is done instantly, the animal appearing to have the greatest confidence in its powers of balancing itself upon the smallest surface, and as soon as its feet touch the ground.

" Up to the rock he ran, and thereon flew Like a wild goat, leaping from hill to hill, And dancing on the craggy cliffs at will; That deadly danger seem'd in all men's sight, To tempt such steps, where footing was so ill."

(Spenser's Faery Queene. Book V. canto 9.) 
Goats will even repose on the ledge of a rock, as though they had selected in bravado the most dangerous couch they could find.

" High hung in air the hoary goat reclin'd,

His streaming beard the sport of every wind."

(Rogers.)

When left to forage for themselves, goats generally select for food bitter and slightly astringent plants, as the leaves and buds of spurge, hemlock, birch, privet, and bird-cherry, and the tender tops of furze and heath. Phillips speaks highly of the leaves and young branches of the single-seeded broom as food for goats. Loudon says, that in France, willow leaves, either green or dry, are considered the very best food for them. Theocritus alludes to the eagerness with which they seek the laburnum; and Virgil celebrates that tree for increasing their quantity of milk : but their most favourite food appears to be the leaves of the honeysuckle-hence the French call it chévrefeuille, or goat's-leaf. Linnæus states, that goats will eat of the yew-tree with impunity, though horses and cows refuse to do so. It is also stated, that goats will readily eat manufactured tobacco without suffering from its noxious effects. In wooded neighbourhoods goats do much damage by barking the trees.

The variety and coarseness of its fare, the hardiness of its nature, and the ease with which it accommodates itself to either an out or indoor life, enable the small-landed cottager to keep it nearly as well as the farmer. The parishes about Mont d'Or, near Lyons, without pasturage or meadows, support nearly twelve thousand goats, kept in stables throughout the year, and yielding a produce of more than a million francs.

It is a common notion, perhaps a correct one, that horses enjoy better health when a goat is kept in the same stable. Professor Bell thinks that this is owing to the activity and good humour of the goat keeping the horses in better temper and cheerfulness than they would be in if left in solitude. This might seem tenable where a horse had no companion of its own 
species; but in stables where several horses are kept, there is no solitude. In Marshall's Rural Economy of Gloucestershire, some cases are related to show that the presence of goats in stables protects the horses from the staggers, which he says is evidently a nervous disorder. Then he suggests that the goat, by exhaling its well-known odour, serves the purpose of a smelling-bottle to the horse, whose nervous system is benefitted by the strong scent. But as we know that the goat eats of many plants which would prove injurious, if not poisonous to the horse, it is not improbable that the health of the horse is preserved by the goat picking the baneful plants out of the fodder. To account for its salutary influence, perhaps the three suggestions should be taken together.

The she-goat goes with young five months, and usually produces two kids. The flesh of the goat, especially of kids, is eaten, and by some esteemed a delicacy; the haunches are frequently salted and dried like bacon; the suet is much used in Wales for making candles, which are of superior whiteness and excellence to those made from sheep or ox suet; the milk, though it yields but little cream, is highly nutritive, and a cheese of peculiar flavour is made from it; of the longest, thickest, and whitest hair which grows on the buttocks of the he-goat, wigs are made; the skin, particularly that of the kid, is a valuable material for the manufacture of gloves.

The Angora Goat.-(Capra Hircus, var. Angorensis).

This variety, which is peculiar to the province of Angora in Asia Minor, is invariably of a silvery white, with long silky hair, of one sort only. Lieutenant Conolly in a paper on this animal, read before the Asiatic Society, January 18, 1840, stated that when removed from the province, "it is with difficulty kept alive, and always deteriorates so as to be no 


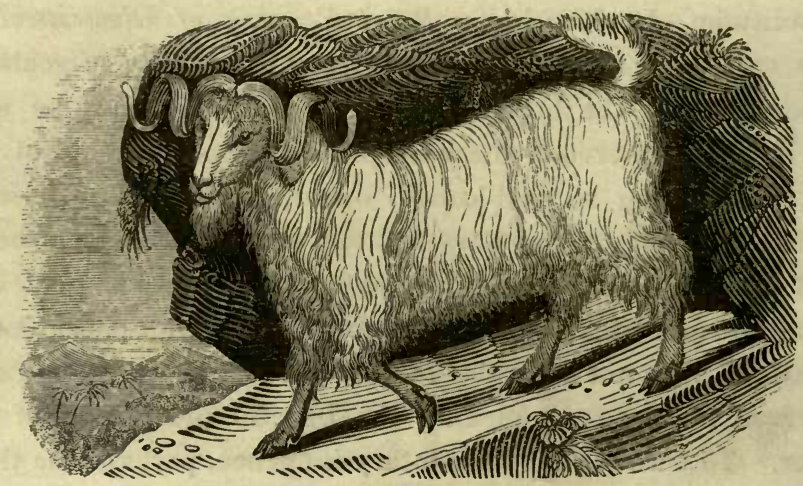

longer recognisable. The goats are clipped annually, and yield from one to four pounds of their long soft hair, at each clip. It is exported either in the raw state or in yarn, or manufactured by the women into those delicate stuffs which are well known in Europe. The weavers reside chiefly at Angora, but there are fewer of them than formerly, and the number of looms does not exceed fifty; and they make only between one thousand and fifteen hundred pieces annually. The skin is exported to Constantinople, where it is dyed of various colours, and used chiefly for Turkish boots and slippers. A few of the fleeces are exported entire to Europe, where they are valued as rugs and saddle-cloths."

\section{The Thibet Gont.}

This breed inhabits Thibet, the steppes of Russia, and the plains partly surrounded by the great bend of the river Ural, or Yaik, which divides Europe from Asia.

It is equal in stature to an ordinary sized English goat. The body is clothed with long silky hair, and underneath this is a fine soft greyish wool, and of which the celebrated Cachemere 


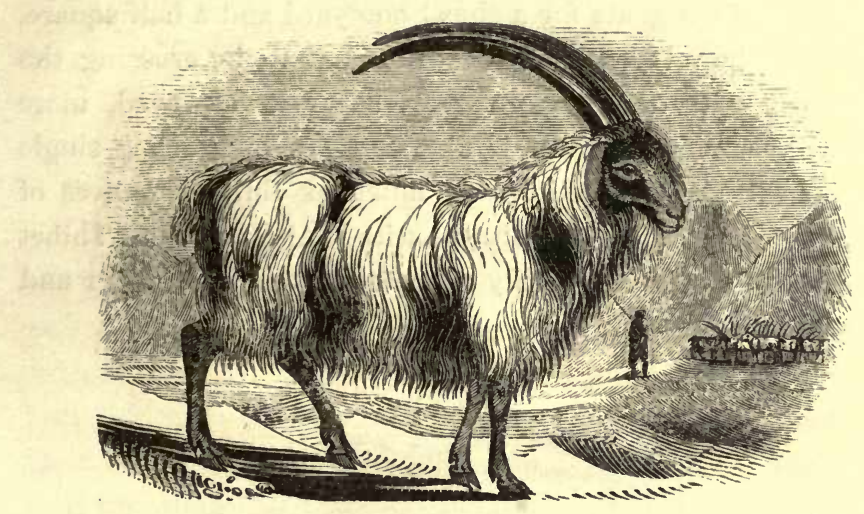

shawls are manufactured. These articles of dress are manufactured at Cachemere; but (according to Mr. Vigne, who resided there a considerable time) the wool is not the product of that country. In Europe, they are only to be purchased at a price far exceeding that at which they might be sold. This is owing to a system of great extortion; for the weaver has to pay three heavy taxes before he is permitted to sell the work of his hands, and then there are other taxes to be paid on it at each of the several stations on the journey from Cachemere to Peshawer across the Indus; and ere it reaches Europe from this point, further duties must be paid at the various custom-houses. To obtain the shawls at a cheaper rate than that at which they are sold in consequence of these impolitic exactions, several enterprising persons have engaged in the naturalization of the animals in Europe. Accordingly, they have been introduced into Germany, Austria, Bavaria, Wurtemburgh, Saxony, France, and England; and experience has shown that the wool they produce in these countries is not inferior to that of Thibet. In 1824, Mr. Tower, of Weald Hall, Essex, introduced the breed upon his farm, where they soon multiplied, and, in 1828, he had three very superior shawls made of their wool; but, as each goat barely yields so much 
as three ounces of wool even in its original country, it required the produce of ten goats for a shawl one yard and a half square. Fortunately, however, it has been found that, by crossing the Thibet goat with the Angora goat, a much improved, more hardy, and economical breed is obtained, and of which a single individual will yield sometimes as much as thirteen ounces of wool in a season, equal in softness with that of the pure Thibet breed, but of a still more silky appearance, and of a longer and finer staple.

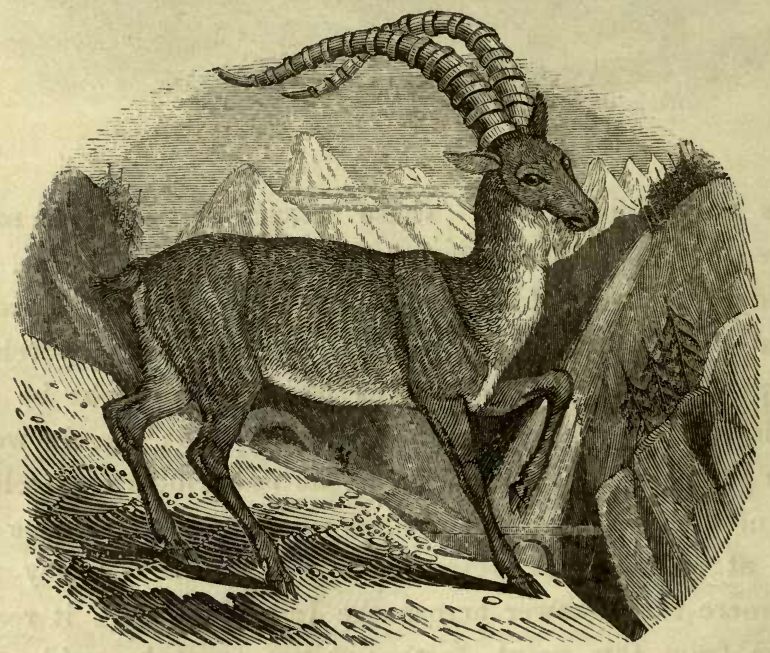

The Common Ibex.-(Capra Ibex, Linn.)

Steinbock. Bouquetin des Alpes.

In Europe this animal inhabits the Alps, the Apennines, the Pyrenees, and the mountains of the Tyrol; and in Asia, the chain of mountains which extends from Taurus, between Eastern Tartary and Siberia : it is common in the island of Crete. It is considerably larger and more strong and active than the common goat; its hair is reddish brown in summer, but grey in winter; the beard (possessed only by the male) is 
short and brown; the head is small and compressed; the horns usually weigh from eight to ten pounds, and measure from two to three feet in length, but they occasionally attain a much greater length, and reach nearly to the tail; the hoofs are very small, and the tail short.

The favourite haunts of the ibex are the most inaccessible parts of the mountains, the old males generally seeking more elevated places than the females and younger males. The animal is not only strong and agile, but owing to the facility with which it can unerringly throw itself on to small surfaces, and the correctness with which it balances itself thereon by a skilful and instant adjustment of all the parts of its body, so that the whole weight is immediately poised, firmly and securely, upon the true centre of gravity, enable it to ascend the steepest rocks with ease and rapidity. With two or three bounds, in which it seems scarcely to touch the almost perpendicular rock, it makes an ascent of many feet. On the heights, it feeds on the scanty vegetation. In the night, however, it descends to pasture in the woods, but at sunrise it again seeks the mountain summits, and associates with others of its species in herds of from ten to fifteen individuals. The most frequent cry of the ibex is a short whistle, but when irritated it utters a snorting noise.

The female usually brings forth only one at a birth. The young kids are of an ashy grey colour. The flesh is greatly esteemed, especially that of the kid. The skin and fleece are used for various purposes. The pursuit of the ibex is as perilous as that of the chamois. The hunters must possess great courage, strength, and agility, to encounter and surmount the dangers of the chase. They are excellent marksmen, but their prey can only be approached in the most stealthy manner. It frequently happens that the dogs, which are trained to follow the ibex to the loftiest crags and precipices, lose their footing, and are killed by falling from the great height. 


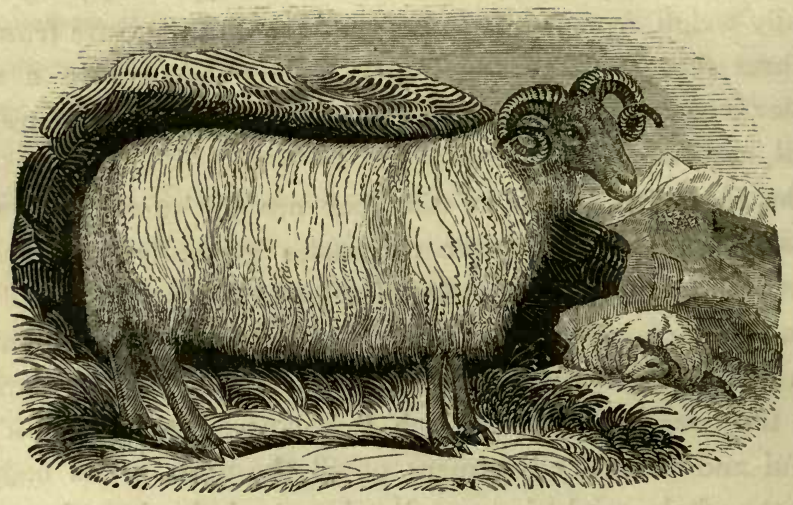

The Common Sheep.-(Ovis Aries, Linn.)

The varieties of the common sheep are innumerable, and so widely do they differ from each other in external form and clothing, that we know not which of them to regard as most characteristic, most indicative of the original wild type, from which they have descended. Most naturalists regard the wild mouflon of Corsica (Ovis musimon) as the type of all domestic sheep, but others consider it to be the type of merely those of Europe, and that those of the East have descended from the argali of Siberia (O. ammon). Whatever may have been the type of our common sheep, there can be no doubt that they are naturally mountainous animals. If left to themselves, it is always observed that they prefer the hills and rocky mountains to the low plains; and in the former situations they thrive better, although they acquire less flesh than in the more luxuriant valleys. In Scotland many of the sheep pastures are from 2000 to 3000 feet above the level of the sea. The fine natural sheep-walks forty miles in extent, called Brisbane Downs, in New South Wales, are 2000 feet above it. In the Cordilleras of South America, sheep are common and multiply readily, and without any care, at an elevation of from 3300 to 8200 feet. 
"The original colour of the sheep was undoubtedly dark brown, and the change from this colour to white must have been the work of time and judicious breeding. Most writers on the sheep impute, and perhaps justly, the first improvement in this respect to the skill of Jacob. However this may be, white flocks were common at an early date, and in our western portion of the globe have long been universal; still, however, as if to show that Nature, though controlled, is not to be subdued, we see lingering traces of the dark brown in many of our breeds; this colour prevailing about the face, and on the legs : and now and then a black or dark-coloured lamb may be noticed in the midst of a flock of snowy whiteness; indicating, by its presence, how easy would be the transition from the acquired, but common colour of our races, to that of their primeval parents. The sheep is pre-eminently a woolbearing animal; yet many races [in the hotter regions, more particularly of the African continent,] seem to be destitute of this covering, and to be clothed with short hair,-or, indeed, if it be essentially wool, it so closely resembles hair as not to be distinguishable from it unless by means of a powerful microscope. The essential character of wool, as distinguished from hair, consists in its surface being covered with imbricated scales, upon the presence of which, and its waviness, depends its property of felting, that is of being worked up into a firm tenacious mass, by the interlocking of the scales of such fibres as are twisted together with the scales in opposite directions."*

To describe the general conformation of the sheep is unnecessary; but there are some points worthy of observation. Underneath each eye is a large and deep sinus, or slit, which is concealed from observation by the woolly clothing of the animal; between and at the base of the toes is a sac lined with hair, and furnished with sebaceous follicles for the secretion of a lubricating fluid; and the tail naturally, it would seem, reaches to the ground. 
Sheep are gregarious animals, and where the foremost of the flock leads all follow in succession, and thus they often rush into the very danger which they wish to avoid. "The more the sheep is neglected and allowed to run wild, and the less its range of pasturage is circumscribed, the more will it acquire habits of independence, and the more will its instincts be drawn forth and put into exercise. In the wilder and mountainous districts of England, the sheep will unite in selfdefence and form a phalanx, in opposition to a strange dog, or a prowling fox, the rams heading the array, and presenting a formidable front to the foe, while the ewes and lambs crowd together in the rear. Should the intruder venture within a certain distance, they rush on him, and commence a violent assault. This and many other facts on record seem to justify the conclusion, that the sheep is not so utterly destitute of intelligence as is usually imagined." *

"There are few animals," says Mr. Youatt, "who form so steady and permanent an affection for each other. In 183\%, there was a poor sheep with a very bad foot-root, crawling along the pasture in the Regent's Park. In this position it was with difficulty that it procured its subsistence; and the pain which it suffered when forced to get on its feet was evidently very great. I had heard that in such cases a companion, and always the same one, will be seen near the sufferer. As I took my daily walk through the park, I regularly sought out the friends, and I fully satisfied myself that it was always the same faithful adherent by whom the cripple was solaced and watched."

In the period of sacred history, it was the custom to give names to sheep, so that when the shepherd wished to move the flock, he called them by name, and they immediately obeyed the call. It would seem that in large flocks it was only a portion of them, probably the leaders, or rams, that were so docile as to come at a call; and it was perhaps quite enough that only a few should be so obedient, as the others 
would be sure to imitate the example. Christ, in reference to himself as the Good Shepherd, says, "The sheep hear his voice, and he calleth his own sheep by name, and leadeth them out; and he goeth before them, and the sheep follow him; for they know his voice." (John, chap. x. verses 3 and 4.) This custom still exists in some places. The Rev. John Hartley, who travelled as a missionary in Greece, found that the practice was usual in that country. "Passing by a flock of sheep," he says, "I bade the shepherd call one of them by name. He did so, and it left its pasturage and its companions, and ran up to the hand of the shepherd, with signs of pleasure, and with the most prompt obedience. It is also true of the sheep in Greece, that 'a stranger will they not follow, but will flee from him; for they know not the voice of the strangers.' The shepherd told me that many of his sheep are still wild; that they had not yet learned their names, but that by teaching they would all learn them. Those which knew their names, he called tame." In a work entitled, Instructions pour les Bergers, we are told that in some parts of France they teach certain sheep of the flock to come when called, by, at first, offering them a piece of bread. "When the shepherd wishes to lead his flock through a defile, or to make them alter their course, he calls to him one of the tame sheep, which is immediately followed by the whole flock," (p. 15). At Thames Ditton, in Surrey, Captain White's shepherd leads his flock to and from pasture, every morning and evening, by calling two of the rams by name.

In the mountainous or wild countries, over which the flocks wander dispersedly, it has been usual from a very early period to teach them to obey signal-notes from the horn or the pipe. Even in our days, when the shepherd-and-shepherdess-life is rarely the envy of sentimental lovers and poets, the tobacco-pipe has not entirely abolished the musical one. In many parts of the Alps, and in certain provinces in France, the shepherd and his sweet music continue with true antique simplicity. He returns homeward at sunset, with his sheep following him, 
seemingly pleased with the sound of his instrument, which is blown with a reed, and resembles the chanter of a bagpipe.

Mr. J. E. Murray, in his Summer in the Pyrenees, says, that during two or three months of the year, the shepherds repair with their flocks to the high regions of Mont Perdu, which afford good pasture, though other parts of the district are desolate; and he adds that, " the celerity with which they draw their scattered flocks around them, and the simple mode in which they effect it, are equally astonishing. If the sheep are at no great distance from him, the shepherd whistles for them, and they leave-off feeding and obey the call; if they are at a distance and scattered, he utters a shrill cry, and the whole flock instantly leap down the rocks and scamper towards him. Having waited till they have all arrived, he proceeds home to his cabin or resting-place, his flock following him like so many well-trained hounds. His fine-looking dogs, two of which are generally attached to each flock, have only to protect it from the attacks of wolves and bears; and hence dogs and sheep may be seen resting together, or trotting after the shepherd in the most perfect harmony."

It is remarked by Gilbert White that, "when sheep, cows, horses, deer, \&c., feed in wind and rain, they always keep their heads down to the wind, and their tails to the weather." Sheep, however, generally feed more greedily before rain that they may eat their fill, and then retire to chew the cud under shelter. They feed chiefly on the various species of grasses, eating the tender parts but leaving the stalks. They are especially fond of the crested dog's-tail grass, the silvery hairgrass, the purple fescue-grass, the sheep's fescue-grass, and the fine bent-grass. They will sometimes eat the tender shoots of heath and furze, and the green leaves of the privet, elm, ash, willow, bird-cherry, and birch. Phillips says, that they eat not only the leaves but the young branches of jasmine with great avidity; and Mason in his poem, The English Garden (1812), speaks of their cropping the woodbine, or honeysuckle. Dr. Smith rernarked that the tamarisk grew abundantly in Italy, 
about Sinigaglia, and all along the hedges near the sea, and that the sheep gave it exclusive preference so long as any of it remained. Theophrastus says, that in the neighbourhood of Athens, the bladder-senna was used to fatten sheep, to which purpose it was highly conducive. His observation deserves the attention of those who have flocks on the downs, where it would grow as well as furze if sown in the same manner. Dr. Anderson, who cultivated furze for the express purpose of feeding cattle, says that sheep will eat it, nibbling off the prickles, one by one, very quickly, so as not to be hurt by them. Matthew Aphonin, in a paper published in the Amonitates Academica, says, "the sheep's fescue-grass is their best fodder, and they fatten upon this sooner than upon any other plant; this is evident in Gothland, where it abounds; and hence appears the reason why they all repair so eagerly to the almost barren places where it grows." In winter, our British sheep feed upon the leaves of holly, and also, according to Phillips, upon "the leaves and branches of the Scotch fir, which is no small consideration in mountainous countries, where the snow lies sometimes upon the ground for many weeks together." That "ivy affords sheep a wholesome and favourite repast," we are assured by the Rev: W. T. Bree, in the Magazine of Natural History (1833, vol. vi. p. 328); but Shakespeare must have been well aware of their fondness for this plant, when he made one of his characters (an old shepherd) say :-

"They have scared away two of my best sheep; which I fear the wolf will sooner find than the master: if any where I have them, 'tis by the seaside, browsing on ivy."

(The Winter's Tale, Act III. Scene 3.)

The mistletoe, as well as the ivy, is recommended as winter fodder by old Thomas Tusser, who says,

"If snowe do continue, sheepe hardly that fare Crave mistle and ivie for them for to spare."

(Five Hundred Points of Husbandry, 1562.)

Carrots and cabbage-turnips are also good food for sheep in winter. It is doubtful whether our sheep eat wild thyme, 
although the poets, and others who have seen it growing profusely in those places where well flavoured mutton is fed, have spoken of it as the favourite food of these animals. In Spain, the Merino sheep have been noticed, when grazing leisurely, always to prefer the finest grasses, never touching the aromatic plants; and if the wild thyme and such herbs be entangled with the grass, they will separate them with great dexterity: but if interrupted, as happens on the approach of rain, when the dogs are set on to drive them to shelter, the sheep, in their hurry, will devour everything-even poisonous plants. Weston, in his Tracts on Agriculture (1773, p. 115), conjectures that the smell of the wild thyme may be of service to the flock, and therefore recommends the introduction of it into pastures where it is wanting. Linnæus asserts that, although horses and cows refuse to browse upon the yew-tree, yet sheep will do so without injury; but this appears to be incorrect, for several instances have occurred in England of sheep dying in consequence of having browsed upon it.* A few years ago Junius Redivivus, an anonymous writer on Temperance Societies, stated in the Mechanics' Magazine, that he knew a pet sheep, which had lived from its youth on board a vessel, where its nature became much altered under the care of the sailors. "It would eat tobacco and drink grog, and had no objection to a piece of fruit tart or meat pie; in addition to this it would nibble a sailor's shirt to pieces, and butt down the cabin boy for interfering with him."

Borlase, in his Natural History of Cornwall (1758), ascribes the superior flavour of the Cornish mutton to the sheep feeding upon snails,-meaning, I suppose, that they swallow them not by choice but unavoidably along with the herbage. "Snails of the turbinated or spiral kind," he says, " spread themselves over the sandy plains early in the morning, and whilst they are seeking their own food among the dews, yield a most fattening nourishment to the sheep."

The physical constitution of the sheep may be said to be * See Phillips's Sylva Florifera (1823), vol. ii. p. 294. 
delicate; a rainy season or a rank pasturage entail upon them many fatal diseases, which soon thin the flock. Most congenial to their nature, is the dry sound pasturage which they find upon the hills and mountains, especially if they afford springs or herbage impregnated with salt, which proves very conducive to their health, and is a great preventive of the rot and of the flukes; or parasitic animals, which too frequently attack their liver. The flocks that feed on and in the vicinity of the syenetic hills of the Cheviot, and on similar pasturage, the shepherds say, may pine but cannot rot.* In the States of La Plata, and in some other parts of South America, salt is so very scarce, that when the sheep and cattle discover a pit of clay salt, they rush to it with such eagerness that many of them are sometimes crushed to death in the struggle to obtain it. Every farmer ought to keep in his sheep pastures a tank containing salt and water, or have a large dry lump of salt in a box or trough placed under shelter from the rain. The sheep will resort to the tank or the trough whenever their digestive organs require the stimulus of salt. The saline particles carried by the winds over the downs near the sea, greatly contribute to the thriving condition of the flocks which feed thereon.

"In the north of England, where sheep are the principal live stock, many a farmer keeping from one to four thousand, the greater portion have to remain in his enclosures, or on the lower ranges of the adjacent mountain-land, during the winter, endeavouring to procure a scanty subsistence among the heath, the rushes, and the bent grass, in the best way they are able. But when the snow lies deep, and the weather is very severe, they would starve were they not supplied with a little hay from the homestead. The hay is usually borne on the heads or backs of the shepherds, in bundles as large as they can possibly wade through the snow with; but occasionally on the backs of horses, when practicable. It very generally happens that the places to which the sheep have resorted, to shelter themselves

* The long-wooled Leicestershire sheep are said to be more subject to the rot than the hardier breeds. 
from the bitter and piercing blast during snow-storms among the mountains, are places fraught with the greatest danger, for it is there that the drifting snow accumulates in vast masses; and while the flocks are comparatively warm and comfortable, and before they are aware of their fate, the drift becomes piled up in such a manner as to render a retreat impossible, even if they were inclined to attempt it. Thus it sometimes happens that in the space of a very few hours, some scores, yea, perhaps, hundreds of sheep become buried beneath the snow to a depth of several feet. Except when the fall of snow is immediately succeeded by a thaw, and suffocation or drowning naturally ensues, very few, comparatively, perish on account of the great depth of the drift, the snow being so porous that the sheep can respire without much inconvenience, even when beneath eight or ten feet of compact snow. When they have sought shelter in some ravine or hollow, and perceive the snow rapidly increasing on and around them, the stronger ones get upon their feet, and attempt to shake it off their fleeces; and consequently become finally enclosed in the drift in a standing position. Those that are thus buried on their legs, and have even remained so for several days, are generally found to have acquired sufficient strength to turn themselves, and to be able to lie down and rise at pleasure; and where a few have happened to stand close together while the drift was forming, owing to the united warmth of their bodies, and their frequent move. ments, a rather considerable open space is usually found surrounding them.

Sheep have sometimes been under the snow [or overblown as the shepherds express it] for three or four weeks, and still survived; but in all such cases they had been able to nibble the short grass, grass-roots, and even a portion of the soil, on a space of a few superficial feet. It has also been ascertained that, where sheep have actually been starved to death before they were discovered, extreme hunger had induced them to tear the wool from each other's backs."*

* Abridged from The Penny Magazine, No. 500. 
If my materials for the history of the sheep consisted solely of observations made on the habits of those which are kept, as we ordinarily see them, in low and enclosed fields, I might perhaps concur with my predecessors in representing the sheep as a stupid, silly, timid, inactive animal: but the sheep of the mountains, having more of their real nature called into action by their comparative freedom and greater exposure, convey a very different and more correct notion of the disposition and habits of their species. On the mountains they display considerable boldness and agility in leaping from crag to crag, and frequently climbing about the whole surface of the bare perpendicular sides of the precipitous rocks, by treading upon the narrow ledges and projections, which scarcely afford them standing room. In these apparently dangerous situations, sometimes at a height of several hundred feet, and with the billows of the ocean roaring beneath them, they show that they are not such cowardly and stupid animals as they have been described. They exhibit great daring, activity, and a full confidence in their skill and adroitness, vying with the goat in sureness of step and strength of spring when they are ascending to the summit by repeated bounds. With regard to the courage of sheep, may be instanced the boldness with which the ewe, not unfrequently, defends her offspring from danger, and the desperate combats which often occur among the rams, who seem to have an indelible feeling of mutual jealousy; for as soon as they come together, they rush headlong at each other with immense force, the concussion of their heads being audible at a great distance.

Rosalind. "Never was there anything so sudden, except the battle of two rams."

(As You Like It, Act V. Scene 2.)

Of the acuteness and obedience of the sheep, the reader will have gathered no mean idea, from the many instances already given of the promptitude with which it may easily be taught to obey the call or the whistle of a gentle shepherd. But further, to show that its docility is sufficiently great to render it manageable in employments which require it to exert its strength and 
endurance for the service of mankind, it may be mentioned, that, in Thibet, sheep are not only prized for their flesh and fleece, but as beasts of burden, each animal carrying from twelve to twenty pounds weight. Captain Batten says, that in the Himalaya mountains "flocks upon flocks of sheep, carrying loads of grain or salt and borax, according as they are going to or coming from Bhote, are continually met with, guarded by the savage Thibet dogs, and the still more savage Bhoteans and wandering Tartarian beggars."

The ewe goes with young five months, and generally produces two lambs at each yeaning, or birth. In the Lincoln Gazette, of April 2, 1839, it was recorded, that an ewe, belonging to Mr. Stacey, of Bothamsall, near Retford, had, in the course of six years, yeaned as many as sixteen lambs, twice producing twins, and three annually during the last four years. The ewe herself was one of four from the same mother, and had been brought up as a cade, that is to say, it had been weaned and reared in the house. "It hath been seene in Gelderland, that five ewes have had, in one yeere, twenty-five lambs: it may seem, peradventure, to many incredible, and yet it is not a great marvaile, since they have twice a yeere mostly two, and sometimes six at a time."* Cross-breeds, or hybrids, have been produced between the sheep and the goat. In the Gentleman Farmer (page 15), it is stated by Lord Kames, that the ewe, several weeks before yeaning, selects some sheltered spot where she may drop her lamb in comfort and security. The care and fondness which the ewe exhibits for her offspring are generally very great. Mr. Jacob Jones relates, that a young lamb having become entangled among some briars, its mother tried to extricate it; but finding her attempts ineffective, she ran away, uttering a peculiarly doleful $b a a$-ing, and proceeded through four strong hedges until she came to a flock of sheep which were in a distant field. In about five minutes she returned, accompanied by a large ram, who immediately liberated the lamb by dragging away the briars with his powerful horns. The narrator, who

* Heresbatch's Foure Books of Husbandrie, Englished by Barnaby Googe (1586), p. 139. 
" moralised this spectacle," mentions it as a remarkable instance of the reasoning faculty among sheep. The age of a sheep is known by the teeth; a sheep, two years old, is called a hog; an emasculated ram is called a wether; and an old ewe, who has lost her teeth, is termed a crone. Hogg, the Ettrick Shepherd, mentions an ewe which died of old age in her seventeenth year.

In many foreign countries the flesh of the sheep is not eaten, or only to a small extent; but in Britain the consumption of it, either as mutton or as lamb, is very considerable. It was the milk of the ewe, rather than of the cow, which was drunk in ancient times; and cheese was made from it at a very early epoch, and is still made from it in Greece, in Wales, and in some remote parts of the Scottish Highlands. In Arabia, Barbary, the Levant, and in Iceland, butter is made from ewe's milk, which will yield more butter than will an equal quantity of milk from either the cow, the goat, the mare, or the ass. When ewe's butter becomes scarce in Iceland, the general substitute is sheep's tallow, and the children are said to be so fond of the latter substance, that they may be seen eating lumps of it as though it were barley-sugar. The skin in our own country is prepared into leather, chiefly employed in the manufacture of gloves and in book-binding; and the wool is an article of vast importance, from its very extensive use in the manufacture of various kinds of cloth and blankets. In Devonshire and Cornwall, the wool is not washed previous to clipping, as in the upper counties, consequently a much larger proportion of animal oil, or what is called yolk in the former county, passes off in the manufacturer's wash-pans, intermixed with soap-suds; and where the business is very extensive, an immense quantity can be procured, varying from to ten or twenty to one hundred hogsheads per week; and the benefit arising from it, as a manure, properly applied, is incalculable, as it is equal, if not superior, to any farm-yard compost that can be obtained in the usual way. Sheep's dung is also a warm manure for topdressings. 


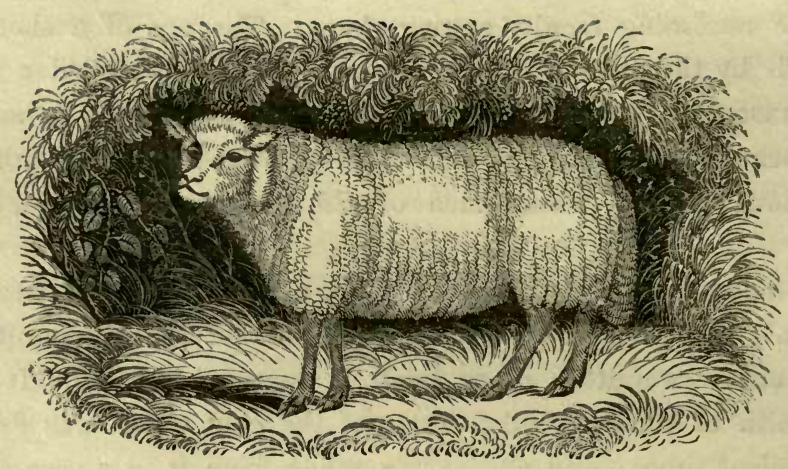

The Dwarf Sheep.

Of this breed, so remarkable for its singular and grotesque features, Bewick tells us that a ram, from which his figure was taken, and of which the above is a copy, came from abroad with two ewes as a present to a gentleman in Northumberland. "They are very small, and without horns. The wool growing round the head forms a kind of hood or ruff, before which stand its short erect ears; the lower-jaw by considerably protruding before the under one leaves the fore-teeth exposed; and these peculiarities, together with the shortness of its nose, which lies under its projecting forehead, give it the appearance of deformity. Mr. Culley mentions a small kind of sheep in Lincolnshire, called dunkies, and which are supposed to be the same as this."*

\section{The Fat-rumped Sheep.}

This breed is found in Palestine, and indeed in Southern Asia generally, and in some parts of its more northern regions. They are larger than our sheep, those in the mountainous dis-

* Natural History of Quadrupeds (Newcastle, 1807), 5th edition, p. 70. 


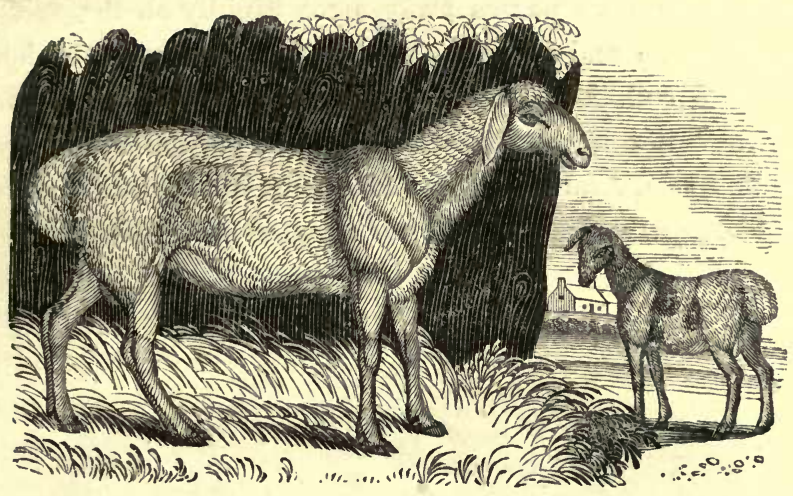

tricts being as high as a new-born calf, and weighing from one hundred and forty-four to one hundred and eighty pounds. In shape they resemble the Indian sheep, having the arched profile, prominent under lips, and large pendulous ears. The rams always, and the wethers generally, are horned; and some, like the Icelandic, possess four, five, or six horns. Their wool is coarse, entangled, and much mixed with hair. But the chief peculiarity of this breed consists in the extraordinary accumulation of fat, commencing on the loins, whence it swells gradually into a large mass at the rump, assuming the form, when viewed posteriorly, of two rounded projections, almost concealing between them the short conical tail. This mass of fat weighs thirty or forty pounds, and yields from twenty to thirty pounds of tallow. The tendency of these sheep to accumulate fat on the haunches is supposed, by Pallas, to have been first induced by the saline nature of the pasturage, and that they inherit this predisposition from those of their progenitors who were the first to be thus affected by this kind of food. The Turcoman hordes and the natives of the Caucasian range possess vast flocks of these sheep. The common Tartars often possess a thousand, and some of the richer ones more than fifty thousand sheep. "During the whole winter they seek their fodder under 
the snow, without losing their condition by it, as the season is short and the snow passes away more rapidly on the salt parts of the steppes; and all animals fatten by feeding on the herbage of a saline soil."* The fat-rumped sheep, entirely confined to Asia, must not be confounded with the fat-tailed sheep, which inhabits Syria, Arabia, Egypt, Athiopia, Madagascar, the Cape of Good Hope, and many parts of the interior of Africa.

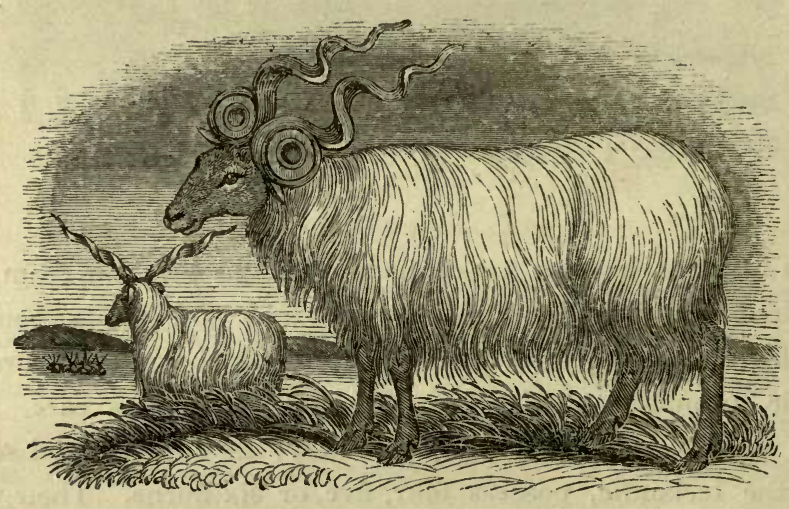

The Wallachian, or Spiral-horned Sheep.

(Ovis Aries, var. strepsiceros, Linn.)

This, which is one of the most remarkable of the European breeds of sheep, is said to be common in Wallachia, Hungary, and the western parts of Asia. According to Belon, who wrote on natural history in the middle of the sixteenth century, this variety of the sheep occurs in Crete. A few years since, a splendid ram of this kind, which came from Mount Parnassus, was placed in the Regent's Park Zoological Gardens. "Its temper was unruly, and its strength and viciousness rendered it sornewhat unsafe to approach it. Its horns were very large and spirally contorted, adding greatly to its strikingly picturesque appearance. Its fleece was white, and consisted of

* Agricultural Magazine (1804), p. 39. 
mingled wool and hair, and the latter covered the former, being very long, beautifully fine, and falling from the middle of the back over either side almost to the ground. The hair on the face was short and of a rusty black. In most figures and accounts of this breed, the horns are represented as rising almost perpendicularly from the skull, in a series of spiral turns, the first turn being the largest; while in the ewe they are said to diverge, taking a lateral direction. But the horns of the ram at the Gardens, extended laterally from the skull, and after the first turn took a downward direction. It is probable, therefore, that in the growth of the horns there is a certain degree of individual variation among the breed; as indeed might be expected, knowing how unfixed are all the external characters of the domestic sheep, and how capable they are of soon being modified."*

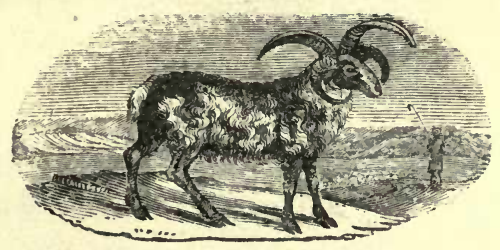

The Many-Horned Sheep.-(Ovis Aries, var. Polycerata.)

This singular breed of sheep inhabits Iceland and the Feroe Islands. It has usually four horns, but sometimes six, or even eight.

Van Troil, in his Letters on Iceland, says that during bad weather the sheep are very apt to hide themselves in caves. But if no such retreat is near when a snow storm comes on, they huddle together, with their noses towards the centre and bent to the ground, which not only prevents them from being so easily buried, but facilitates the owner's finding them again. They can remain for several days in this situation; but it not

* The Menageries (1840), vol. iii. p. 410. 
unfrequently occurs that they are induced by hunger to gnaw off each other's wool, which, forming balls in their stomachs, soon kills them. Polar bears are often floated to the coasts on detached masses of ice, and commit great slaughter among the flock, which is also subject to the attacks of foxes. It is said, however, that the sheep when left to themselves, show considerable intelligence and some courage in defending their young, even against whole packs of foxes, who seldom succeed in making a prize except by stratagem. The several specimens of these sheep in the Regent's Park Zoological Gardens are large, robust animals, with a coarse fleece, consisting of long hair externally, and an underlayer of close wool.

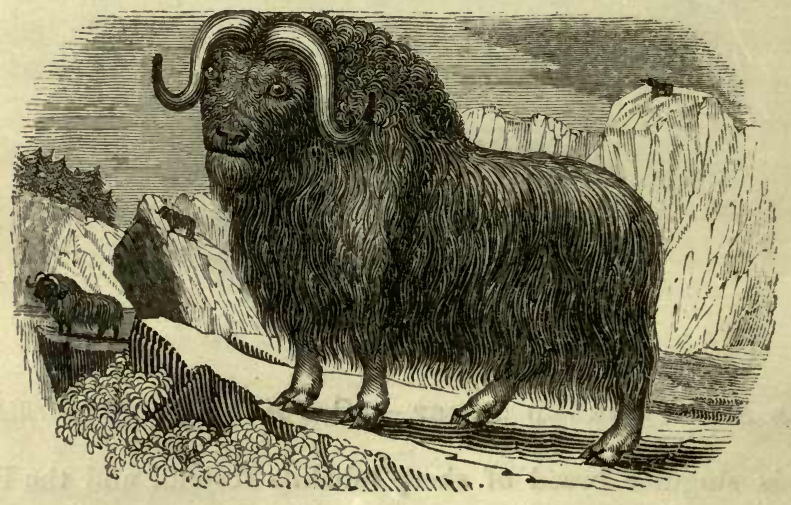

The Musk-Ox.-(Ovibos moschatus blaino.)

The range of the musk-ox comprises the land at the northeastern end of the Great Bear Lake, and the islands which lie to the north of the American continent as far as Melville Island; and it is said that it inhabits the extensive barren tract which exists to the westward of the Rocky Mountains, which skirt the Mackenzie. Musk-oxen appear to be migratory animals, 
as they have been observed to arrive on Melville Island in the middle of May, crossing the ice from the southward, and to take their departure towards the end of September.

The musk-ox is about the size of the small cattle of the Scottish Highlands. Captain Franklin says, that the largest musk-ox killed by his party did not exceed three hundred pounds in weight; but Dr. Richardson gives that as its general weight, exclusive of the offal. Like most of the polar animals, its weight seems to vary according to the opportunities it has of attaining a good bodily condition; hence the average weight of each of the bulls which were killed during Parry's second voyage, was seven hundred pounds, and the average quantity of the solid meat yielded by each of them amounted to about four hundred pounds, and they stood ten hands and a half high at the withers. The general colour of the musk-ox is brown, more or less grizzled about the shoulders, and there is a brownish white mark like a saddle on the back; the whole of the body is covered with long, thick, woolly hair, which hangs nearly down to the ground; it hangs in masses from the throat, like a mane; it is long and matted on the neck, shoulders, and haunches; underneath the outer coat is a layer of exceedingly fine wool; the limbs, which are short and very muscular, are covered with close brown hair, unmixed with wool; the hoofs, and the impressions they leave in the snow, are very like those of the rein-deer; the horns are broad and massive at the base, where they cover the brow and entire crown of the head, and those of the bull are in complete contact at their base throughout its whole breadth, but those of the cow do not quite touch each other; the head is large and broad; the ears are short and nearly concealed by the long hairs of the head; the eyes are rather large, with greatly projecting orbits; the nose is very obtuse; the nostrils are oblong slits; there is no naked muzzle as in our ox, for the upper lip, which is destitute of a furrow, and the chin, are covered with a close coat of short white hairs, and in this absence of a naked muzzle it presents a point of alliance to the sheep and the goat, although in 
general aspect and character it resembles the ox tribe, hence its generic name, compounded of ovis a sheep, and bos an ox. Mr. Ogilby observes that, "with a broad naked muzzle is associated that mode of feeding called grazing; but ruminants that have a hairy muzzle, as the sheep, browse - they nip the herbage, making a certain use of their lips, in guiding or collecting it,-these parts enjoy greater mobility, and a certain degree of prehension."

Captain Franklin says, that "the musk-oxen associate in herds, and generally frequent barren grounds [and rocky places] during the summer months, keeping near the rivers, but retire to the woods in winter. They seem to be less watchful than most other wild animals; and when grazing, are not difficult to approach, if the hunters go against the wind. When two or three men get so near a herd as to fire at them from different points, these animals, instead of separating or running away, huddle close together, and several are generally killed; but if their wounds are not mortal they become enraged, and dart in the most furious manner at the hunters, who must be very dexterous to evade them. They can defend themselves by their powerful horns against wolves and bears, which, as the Indians say, they not unfrequently kill."

Dr. Richardson states that, "notwithstanding the shortness of its legs, the musk-ox runs fast, and climbs hills and rocks with great ease. One, which we pursued on the banks of the Coppermine, scaled a lofty sand cliff having so great a declivity that we were obliged to crawl on our hands and knees to follow it."

The food of the musk-ox appears to be the same as that of the rein-deer; browsing, during the chief portion of the year, upon the lichens which cover the rocks; but in summer, feeding upon the twigs of willow, birch, pine-shoots, coarse grass, and other herbage.

When fat the flesh, especially of the bulls, is well flavoured, and resembles that of rein-deer, but has a coarser grain. Both sexes, when lean, smell strongly of musk, their flesh at the 
same time being dark and tough, and far inferior to that of any other North American ruminant.

The British Museum contains a noble specimen of the muskox, which was obtained during one of Captain Parry's Polar expeditions.

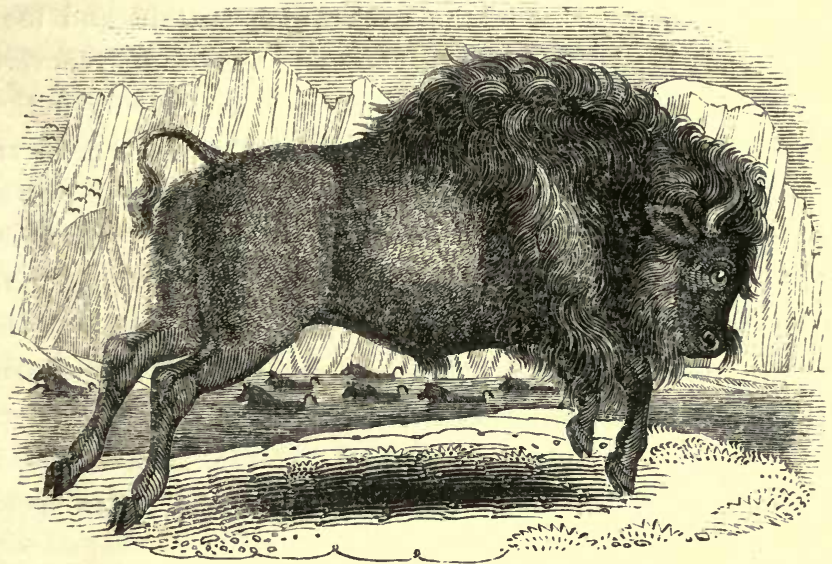

The American Bison.*-(Bison Americanus.)

This animal is met with in nearly the whole of the uninhabited parts of North America, from Hudson's Bay to Louisiana, and the frontiers of Mexico.

It is larger and more bulky than an ox, its ordinary weight being one ton. Its colour is in general of a deep blackish brown, but darker on the hinder parts, black on the head, and lighter about the neck and shoulders; the head is very large;

* The Americans term this animal buffalo, and the words bison and buffalo have been as improperly applied to the gaour (Bison gaour), and to the Asseel gayal (Bos frontalis, Lambert), called also gyall, or jungle-ox, both natives of India. The gaour is a native of the hills to the north-east of the province of Chittagong, in Bengal. The United Service Museum, in London, contains a skull of the animal, said to have been brought from the south of China. 
the forehead very broad; the horns are short* and sharp, turned sideways and upwards, and placed wide apart from each other; the eyes are small, black, and piercing; the withers are greatly elevated in the form of a huge hump, which extends for some distance along the back and consists of flesh and fat supported by the spinous processes of the back-bone, which are highly developed in order to give greater space and leverage to the powerful muscles of the neck which sustain and move the ponderous head; the fore-quarters and the head are covered with a thick shaggy coat of long woolly hair, forming a lionlike mane, which greatly contributes to the animal's grim and savage appearance; the hair is longest in winter; the legs are short; the tail is little more than a foot in length, and terminated by a tuft of long black hairs. The female is much smaller than the male; her mane is not so full, and her horns are not so strong. The present species differs from the European in several outward particulars; but its skeleton exhibits a more striking distinction in the number of its ribs, which is fifteen, being one more than the latter species possesses.

In the southern districts of their range, immense herds of these animals have been seen extending over several miles of the vast open plains. Captains Lewis and Clarke, speaking of a large herd they saw on the banks of the Missouri, express their conviction that this moving multitude, which darkened the whole plains, must have comprised at least twenty thousand head. Dr. James tells us that " countless thousands of them were seen, during the middle of the day, arriving from every quarter to the stagnant pools," and that " their paths were as frequent and almost as conspicuous as the roads in the more populous parts of the United States."

They feed in the morning and evening, and the long rank

* Townsend, in his Journey across the Rocky Mountains, speaks of an immense herd of "buffaloes," meaning bisons, I presume; but he says they had "enormous horns." With this exception, his description clearly refers to the bison. 
herbage of the plains is their principal food. During the heat of the day they bathe in the marshy swamps. Their sense of smelling is so acute that they can detect the approach of an enemy at a very considerable distance. They are not dangerous, though irritable. When attacked they rarely trust to their unwieldy strength for defence, but retreat with great fleetness to the depths of the forest. Yet they frequently fall a prey to the hunters, the wolves, and the grizly bears. When assailed by wolves, the bisons defend themselves by forming a circle with the strongest of the herd outside.

Numbers of tame bisons are kept in the paddocks in the western states of North America, where they breed readily with the common domestic cow. Rafinisque says, that the hybrid offspring is reproductive. It has the colour, the head, and the shaggy front of the bison, but not the elevated withers, though it has the sloping back.

The flesh is said to be excellent, and is the chief food of the native tribes; but they kill more bisons than they consume, and merely for the sake of the skins which they sell to the white traders, from whom they receive a pint of whiskey for each skin, which sells at New York for ten or twelve dollars. From 150,000 to 200,000 are annually purchased of them by the traders.

Some years ago a specimen of the American bison was exhibited by a showman in London as the bonassus of Aristotle! This assertion, which was calculated to strip Columbus of some of his laurels, was perhaps more ludicrous, though certainly not more erroneous, than the false nomenclature which prevails in the zoological books of ignorant compilers, and in the narratives of some of the most modern travellers. 


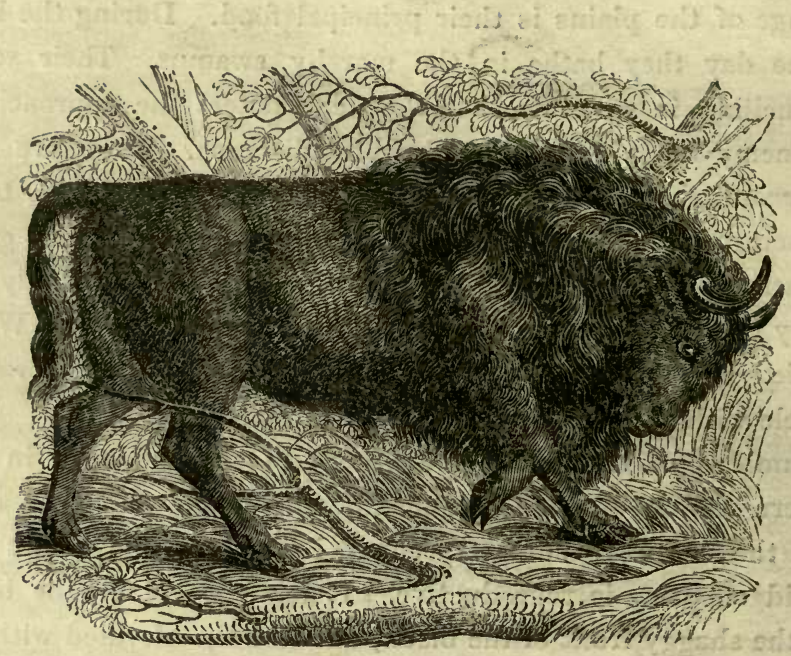

The Zubr, or European Bison.*-(Bison zubris.)

It is impossible not to feel more interested in the history of this animal than in that of the preceding species; for this, which seems to have had at one period an extensive range, is now only found in the forest of Bialowicza, in Lithuania, where its race is preserved and protected by game laws, and by the more direct care of man in partially supplying it with food during the winter. In 1829, there were, according to Jarocki, 663 adult individuals and forty-eight calves contained in this primitive forest, which comprises about three hundred and fifty two English square miles, of which about sixty are rushy swamps, and the remainder is overgrown with Scotch and red firs in

* The bonasos, or monapos, described by Aristotle as inhabiting Pæonia (the modern province of Bulgaria, in Turkey), and the bison, which Pausanias and Oppian describe as existing in the same locality, appear to be the present species, although no longer found there; and it is, no doubt, the animal called $z i m b r$ in Moldavia, about the time of Demetrius Cantemir. It has also been called wisen, wisant, visant, ure, our, auer, auerocks, urochs, and tur; evidently originating in the more classic terms bison, urus, and taurus. There is a third species of bison (Bison Caucasica), inhabiting Mount Caucasus, and probably some districts of India and other parts of Asia. 
the proportion of four-fifths, and with numerous deciduous trees in that of one-fifth. It is supposed that in its present circumscribed range, it has considerably degenerated in size, as has been the case with all those herbivorous animals whose range has been lessened by agricultural encroachments, and which are no longer free from control in the choice of locality and pasture.

It is recorded that in 1595, a zubr, thirteen feet long and seven feet high, was killed near Friedsburg; and that the largest of eight specimens killed by Count Sigismundus' hunting party, in 1612, weighed seventeen hundred and seventy pounds. Herberstein says, that three stout men could sit between the horns of a zubr which was found about the beginning of the sixteenth century.* Dr. Weissenborn says, that in the beginning of the seventeenth century some Polish specimens weighed eighteen hundred pounds; and he supposes that in the more remote ages the full-grown bulls weighed two thousand pounds or more, and that their horns encompassed from seven to eight feet. In 1752, fifty were killed in the forest of Bialowicza, by Augustus III. of Poland, and one of them weighed fourteen hundred and fifty pounds, as is testified on a monument erected on the spot where it was slain. A specimen found in Pallas's time was six feet high at the withers. In the present times, however, the oldest are never more than seven and a half feet (French measure) in length and five feet in height; and the largest only weigh seven hundred pounds. The six-years-old bull lately placed in the Wilna Museum, measured only six feet eleven and a half French inches, from the crown of the head to the base of the tail; its height at the crupper was four feet four and a half inches, and at the withers four feet nine inches.

The upper part and sides of the head, as well as the withers, and shoulders, are covered with long, rough hairs, which form a sort of mane on the upper part of the neck, while from the lower part of the neck to the chest it hangs like a long beard; the whole trunk and the legs down to the knees, are covered

* Rerum Muscoviticarum Commentarii (Basil, 1556). 
with short, soft, woolly hair. In summer its coat is of a greyish brown; about August it displays a shining jet-black tint; and in November it assumes its winter fur, which is the thickest, longest, and darkest.

The horns are black, of moderate length, and are turned inward and outward, except at their middle part where they have a perpendicular direction; from tip to tip, round their curves and over the forehead, they measure four French feet. Those of the six-years-old bull in the Wilna Museum are eighteen inches in length along the external curve, and ten and a half inches in girth at their base. The cow's horns are not so strong as the bull's. There is no dew-lap; and only the middle of the upper lip and the borders of the nostrils are bare; the tongue is covered with hard tubercles, and is of a blue colour, as are the lips, gums, and palate; the eyes have ordinarily a mild expression. The fore-quarters are more robust, and the anterior part of the back is more elevated than the hind-quarters, which are slender; the ribs are fourteen in number, being one less than in the American bison; and the tail is terminated by a brush of long and bristly hair, which in young individuals reaches only to the hock joint, but in older ones it extends somewhat below. From that part of the skin and hair which covers the convex portion of the forehead, the zubr emits an odour, between that of musk and violets. This odour is stronger in the bull than in the cow, and during the rutting season it may be perceived at a hundred yards from the herd.

The favourite haunts of these animals are the swampy banks of the rivers and rivulets which intersect the forest, and from which they seldom wander far. During summer and the warmer part of autumn they select sandy spots; in winter they keep quiet by day, where the fir-trees are in the thickest abundance, only browsing at night, and finding sustenance in the bark of young trees; in the spring they resort to neighbouring places where they can obtain herbaceous plants.

Up to the age of ten or twelve years, the zubrs associate in 
herds of from ten to forty head. They are extremely shy, and avoid the approach of man : but when accidentally and suddenly surprised, they will assail the intruder with great ferocity. In these passionate movements the animal lashes its sides with its tail, protrudes its tongue repeatedly, and its eyes, then reddened and sparkling, project from their sockets, and roll furiously. Occasionally some individuals, particularly such old bulls as walk alone, having left the herd either of their accord or by expulsion, become uncommonly daring and fearless of man. Jarocki relates that one of these retired veterans used to station himself on the high road, and, undaunted by the cracking of whips, would rush at the passing carriages and sledges, and put the horses to flight. The danger of such a practical joke may be imagined from Dr. Weissenborn's statement, that so enormous is the strength of one of these old fellows, that he can knock down trees of five or six inches in diameter, as if they were merely ninepins. Zubrs are not afraid of either wolves or bears, and they assail their enemies with their horns and hoofs. An old zubr is a match for four wolves; but larger packs of them sometimes hunt down even old bulls, when alone. A herd of zubrs, however, has nothing to fear from any rapacious animal.

The zubr runs very swiftly; but not having much endurance it seldom runs more than one or two English miles. When galloping, the hoofs are raised higher than the head, which is carried very low. It is very fond of bathing, and swims with great agility.

Its voice is a short.grunt, and when uttered by a whole herd, it sounds, to a person near them, like the distant straggling fire of musketry; but at a greater distance it resembles the sound produced by the wings of a passing flight of birds.

They feed on the bark of trees, preferring such as have a bitter taste, as willows, poplars, horse-chesnut; and the hardness of this kind of fare often causes the incisor teeth, in old zubrs, to be worn away down to the gums. They also feed on the lichens which grow on trees. Of herbaceous plants, they 
prefer those which grow in swampy places, as several of the umbelliferous plants, as well as a species of plume thistle (Cnicus oleraceus), common ling, and several species of crowfoot; and of grasses, they prefer the reed bent-grass (Agrostis arundinacea), and the northern holy-grass. Their selecting these plants in particular, is an additional indication that their natural haunts are the marshy plains. In their present domain, they could not well survive the winter, by means only of the nourishment they are then able to procure for themselves; hence during that season they are supplied at certain places with hay, and if the stacks are not well secured they destroy much more than they consume, by thrusting their heads deeply into the mass to obtain the most fragrant part of it.

In the rutting season, the zubrs are particularly playful, and delight in uprooting young trees, sometimes to the injury of their horns. At this period, however, those " melancholy malecontents," the hypocondriacal old bulls, even such as have attained their thirtieth year, return to the herd, evince considerable excitement, make indiscriminate war with their own kind, and three-years-old bulls and cows are not unfrequently killed by them.

The French dictionaries of natural history state the period of gestation at eleven months, Bojanus at nine, and Eickwald at seven or eight. They calve about the close of March, and generally have only one calf, but the most vigorous sometimes have twins. The calf, as soon as its coat is dry, follows its mother. Eickwald says, the bulls drive it away from the cow at the beginning of the next rutting season, which statement implies that the calf suckles only five months, or five months and a half; but Jarocki tells us that it is suckled for a whole year, and this seems more probable, for the gamekeepers know with precision that the cows calve only once in three years.

* It has been asserted that they feed chiefly on the sweet-scented vernalgrass (Anthoxanthum odoratum), and to which some authors have attributed the animal's musky smell; but the plant is not found in the forest of Bialowicza. 
The zubr has so great an antipathy to the domestic cattle, which it either shuns or kills, that all experiments to obtain a mixed breed have failed, and are now strictly prohibited. Such is its innate wildness, that although when taken young it becomes accustomed to its keeper, yet the approach of other persons renders it furious; and even the keeper must be careful always to wear the same sort of dress when going near it.

According to the statement of the game-keepers, the zubr lives to the age of fifty and upwards.

If proper precaution be taken immediately after the zubr is killed, the flesh is not tainted with the musky odour, but is extremely well-flavoured. Formerly, indeed, presents of zubr-beef used to be sent from Poland to foreign kings. When the flesh is roasted it has a blueish tinge. The hide is extremely tough, twice as thick as that of the common ox, and far more durable. Jarocki mentions as a peculiarity of the zubr, that if a light be held near the stomach when it is being opened, a flame flashes up from it; but the stomachs of all ruminating and most other animals evolve inflammable gases; and that which causes the tympanitis (a disease) in cows, sheep, \&c., chiefly consists of hydrogen.

\section{The African Buffalo.*-(Bos Caffer, Sparrman.)}

The range of this species is limited to Southern Africa. Though not larger than an ordinary-sized common ox, the Cape buffalo is much stouter, heavier, and stronger. Sparrman gives the measurements of a bull buffalo killed by some of his party, stating its length at eight fect, its height five feet and a half, and the distance of the muzzle from the horns, twentytwo inches. The hide is thick and tough, sparingly covered with long, harsh, blackish or dark brown hairs; those on the

* The common domestic buffalo, properly so called, and to be seen in various parts of the world, was originally derived from Asia. It is the Bos Bubalus, Linn. What the Americans term buffalo is a species of bison (see page 517); and what in England is most frequently so termed by the common people, is the Brahmin ox (see page 548). 


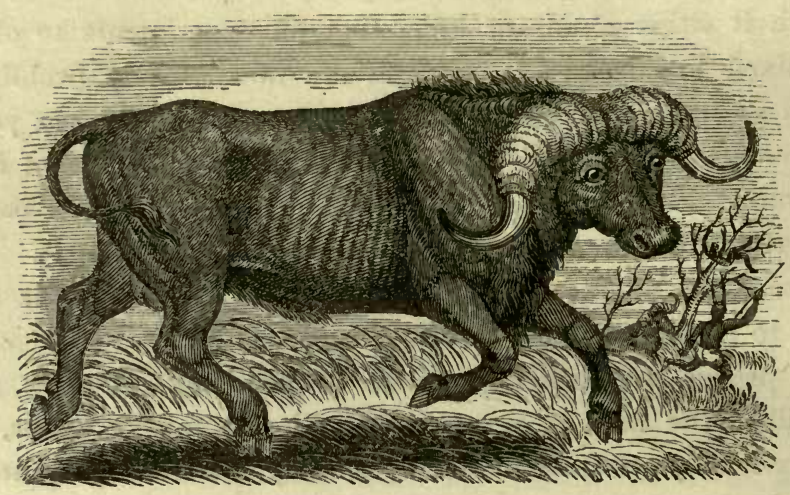

knees are usually the longest, and form a sort of whorls; those on the under lip and about the corners of the mouth form a scanty beard; the head is ponderous; its powerful horns are black, in close contact at their rugged base where they form a solid mass, from which they bend downwards and rather outwards, gradually diminishing to the points which suddenly curve upwards, and their tips are frequently five feet apart; the eyes are situated very near to the base of the horns, are somewhat sunk in their prominent orbits, and have a fiery appearance; the ears are a foot long, pendant, generally torn and jagged. Sparrman notices this fact, observing that " their being notched and shrivelled up in divers ways, probably proceeds from the wounds these creatures frequently receive in their battles with each other, from the rents they get in the briars and almost impenetrable thickets through which they pass, and from similar casualties." Burchell also remarked the torn state of the ears, and gives the same explanation, adding, that the Hottentots assured him that buffaloes with entire ears are rarely seen. The old bulls are very bare of hairs, especially on the middle of their sides, whence they appear at some distance as if girt with a belt.

Its fierce and treacherous aspect, greatly heightened by its usual habit of cocking its head on one side, seems to be in 
perfect accordance with its disposition. Its ferocity and speed are such that the hunter is often obliged to run for his own life, and the number of wounds it will receive without proving immediately fatal, requires good marksmen and good weapons. The Caffres, under the command of a chief or captain, are in the frequent habit of setting out to attack the buffalo with assaigais, or javelins, which they throw with great force. When a herd (usually not above twelve) is discovered, the hunters form a circle round the animals, and gradually approach till sufficiently near to throw their assaigais with unerring aim, and they are pretty sure to kill some. But sometimes the buffaloes dash furiously through the circle, and kill some of the Caffres. The Hottentots, in the service of the colonists, attack the buffalo with much greater certainty, for they are not only trained to the task, but provided with fire-arms; and (as Sparrman observes), owing to their skin cloaks, they do not excite the animal's attention so much as the more artifically attired Christians. They are always ready, when occasion requires it, to go barefoot and softly crawl upon their bellies to get within proper distance of the animal; and should the enraged buffalo give pursuit, the Hottentot can much easier escape by his amazing swiftness of foot.

It is related that a party of boors, having brought down three of the fattest of a herd, and so severely wounded the great bull leader that he dropped on his knees, bellowing with pain, the foremost of the huntsmen, thinking the animal mortally wounded, issued from the covert and began reloading his musket as he advanced to give him a finishing shot: but as soon as the buffalo saw his foe in front of him, he sprang up and rushed headlong upon him. The man threw down his empty gun, and fled towards the quagmire; but the savage creature was so close upon him, that he despaired of escaping in that direction, and, turning suddenly round a clump of copsewood, began to climb an old mimosa tree which stood at the one side of it: but the buffalo, bounding forward and uttering its usual and most frightful roar, caught the unfortunate man 
with his horns, and tossed him into the air with such force that his body fell dreadfully mangled into a lofty cleft of the tree. After running round the tree once or twice, seemingly in search of the man, the buffalo sank on his knees exhausted by loss of blood. The rest of the party, then recovering from their confusion, came up and killed the animal, though too late to save their comrade, whose lifeless body was hanging in the tree.

Thunberg having encountered an enormous bull buffalo in a deep thicket near the Koukouma river, it killed two of the horses of his party on the spot; and the naturalist and two of his companions, being next pursued by it, only escaped by climbing up some tall trees, in which they remainded till their savage assailant had departed.

Sparrman says, that the buffalo " is wont to hide himself among the trees, till somebody happens to come very near him, when he rushes out at once into the road, and sometimes attacks them." This, however, we may presume, is not the habit of the species, but the vicious conduct of some old or supernumerary bull that has been expelled from the herd. What we know of the habits of the elephant and of the zubr, supports this view of the matter, which is further confirmed by a remark of the Hottentots, who assured Thunberg that they had more than once observed one solitary buffalo haunt a wood, after he had been driven away from his herd by the other buffaloes, and obliged to live alone; but these people attributed his banishment from good society to the spitefulness of his nature. I would rather believe that such solitary individuals are the victims of mental aberration, idiocy or lunacy, than suppose that any gregarious wild animal has naturally such a vast deal of spitefulness in him that he is not to be endured among his fellows. Indeed, among sheep and among common fowls, an apparent loss of the natural faculties has been noticed, and the victims of it have wandered away from their species.

"It has been remarked," says Sparrman, " that not content with throwing and killing the person whom he attacks, the buffalo stands over him afterwards in order to trample upon 
him, with his hoofs, at the same time crushing him with his knees, and tearing to pieces and mangling the whole body with his horns and teeth, and stripping off the skin by licking it with his tongue. This, however, he does not do all at once, but at intervals, going away between whiles to some distance." The same authority observes that balls to kill the buffalo should be alloyed with tin, to render them harder, of a good size, and not less than two ounces and a quarter in weight. Balls made of lead only will seldom penetrate to those parts where they are likely to prove mortal; and even when alloyed with tin, he has found them shivered into pieces against the bones in the internal parts, or very much flattened.

Probably owing to their bulk and the shortness of their legs, buffaloes do not willingly venture to ascend the hills, even when in hot pursuit of the objects of their anger. Their most frequent haunts are the ravines among the hills, particularly where there are pools or marshes, in the mire of which they wallow during a great part of the day. In the closer confines of the jungle, the herds consist of eight, ten, or twelve individuals; but in more open places they are seen in much greater numbers. In Caffraria, Thunberg saw a herd consisting of five or six hundred.

The buffalo is most ferocious when its offspring is in danger. Sparrman saw a buffalo calf that had been captured soon after birth, as tame as the ordinary domestic calves among which it was grazing; and thinks that buffaloes might be broken in to the yoke, if the experiment were commenced while they are young calves.

The flesh of this species is said to be superior to that of the common domestic buffalo. Sparrman reports that, although it is coarse and not very fat, it is full of gravy, and has a high and not unpleasant flavour. The Hottentots cut it into steaks, which they smoke and merely half broil over the embers of a fire; and they frequently eat their meat when in the first stage of putrefaction, without bread or any other addition. The broiled marrow-bones they consider the greatest delicacy. Shoes, harness, thongs, and other articles are made of the hide, which, 
from its greater strength and toughness, is preferred to that of the ox or the horse.

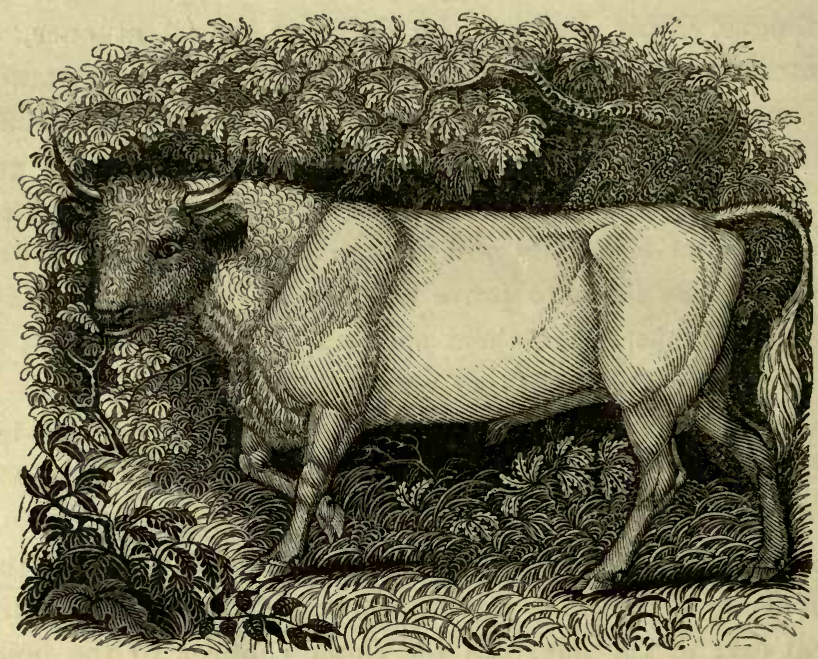

The Chillingham Ox.

Besides the several breeds of our common domestic oxen, which exhibit much variation in size, form, and colour, we have other stocks whose blood has, perhaps, never been mixed with that of allied species or of artificial breeds. They are living in a nearly wild state on certain estates, where they have been carefully preserved for a long period; but we possess no positive evidence to prove that they are not the degenerated descendants of ancient domestic breeds, possessing differences according to the respective era and locality of such breeds; or whether they were originally descended from one or more species of ox, distinct from the common kind, but which had, at some period, been more or less mixed with some breed. Regardless of all such possibilities, perhaps one might say probabilities, some writers have settled the question to their own satisfaction, by adopting the very easy course of asserting that these half-wild stocks are the 
pure descendants of a species of great size and ferocity, which existed in central Europe within the period of authentic history, and which the ancients called Urus - a name improperly applied by Gmelin to the zubr, which is Aristotle's bonasos, and Pliny's bison. Till we possess the means of satisfactorily tracing a species through the aid of such natural laws, as a series of judicious and well-directed experiments on the cross-breeding of animals would probably reveal, all opinions upon the scientific distinction or identity of these animals are merely conjectural. The proprietors of these renowned cattle seem most unwilling to admit the possibility of their being in any way related to the vulgar ox; and this desire to make them out something very curious may, perhaps, explain why none of our Zoological Gardens have been enriched with living specimens of them, or any Museum with a skeleton.

The two most noted stocks of half-wild white oxen exist in Cadzow Forest, at Hamilton, Lanarkshire, and in the park of Chillingham Castle, Northumberland. Lord Tankerville is the proprietor of the latter stock, and has written an account of them, which is interesting; but it contains some statements concerning those on other estates, which are shown to be incorrect by the Rev. William Patrick, who has had frequent opportunities of observing and studying the habits of those in Cadzow Forest. His lordship says there are herds of wild cattle at Lymne Park, Cheshire, and at Chartley Park (the seat of Lord Ferrars). The first, he says, he has not seen, but adds, "they are described as of a different colour, and different in every respect; but those at the latter place closely resemble (with the exception of some small difference in the colour of the ears) those at Chillingham in colour, size, and general appearance, and, as well as I could collect, in their habits."

The accounts which different writers have published of these animals are so exceedingly confused and contradictory, and so deficient in points of primary importance, that although a digest of them might expose their discrepancies, it would 
convey no certain information to the reader. I shall therefore introduce only Lord Tankerville's account of the stock existing in his ancient park of Chillingham, omitting his remarks on those in other parts of Britain :-

"In form they are beautifully shaped; have short legs; a straight back; horns of a very fine texture; a thin skin, so that some of the bulls appear of a cream colour; and they have a cry more like that of a wild beast than that of ordinary cattle. They are fierce when pressed, but generally speaking, very timorous, moving off on the appearance of any one, even at a great distance; yet this varies very much in different seasons of the year, according to the manner in which they are approached. In summer, I have been for several weeks at a time without getting a sight of them,-they, on the slightest appearance of any one, retiring into a wood, which serves them as a sanctuary. On the other hand, in winter, when coming down for food into the inner park, and being in contact with the people, they will let you almost come among them, particularly if on horseback. But then they have also a thousand peculiarities. They will be feeding sometimes quietly, when if any one appear suddenly near them, particularly coming down the wind, they will be struck with a sudden panic, and gallop off, running one after another, and never stopping till they get into the wood. It is observable of them, as of red-deer, that they have a peculiar faculty of taking advantage of the irregularities of the ground, so that, on being disturbed, they may traverse the whole park, and yet you hardly get a sight of them. Their usual mode of retreat is to get up slowly, set off in a walk, then a trot, and seldom begin to gallop till they have put the ground between you and them in the manner that I have described. When they come down into the lower part of the park, which they do at stated hours, they move like a regiment of cavalry in single files, the bulls leading the van, as in retreat it is the bulls that bring up the rear. Lord Ossulston witnessed the curious way in which they took possession, as it were, of a new pasture recently opened to them. It was in the evening about 
sunset. They began by lining the front of a small wood, which seemed quite alive with them, when all of a sudden they made a dash forward altogether in a line, and charging close by him across the plain, they then spread out, and after a little time began feeding. Of their tenacity of life, the following is an instance. An old bull was to be killed, and one of the keepers had proceeded to separate him from the rest of the herd feeding in the outer park. This the bull resented, and having been frustrated in several attempts to join them by the keeper's interposing (the latter doing it incautiously), the bull made a rush at him and got him down; he then tossed him three several times, and afterwards knelt down upon him, and broke several of his ribs. There being no other person present but a boy, the only assistance that could be given him was, by letting loose a deer-hound, who immediately attacked the bull, and by biting his heels drew him off the man, and eventually saved his life. The bull, however, never left the keeper, but kept continually watching and returning to him, giving him a toss from time to time. In this state of things, and while the dog, with singular sagacity and courage, was holding the bull at bay, a messenger came up to the castle, when all the gentlemen came out with their rifles, and commenced a fire upon the bull, principally by a steady good marksman, from behind a fence at a distance of twenty-five yards; but it was not till six or seven balls had actually entered the head of the animal (one of them passing in at the eye), that he at last fell. During the whole time he never flinched nor changed his ground, merely shaking his head as he received the several shots.

"These animals feed in the night, basking or sleeping during the day. They hide their young.

"With all the marks of high breeding, they have also some of its defects. They are bad breeders, and are much subject to the rush, a complaint common to animals bred in and in, which is unquestionably the case with these as long as we have any account of them."

Naturalists and the public will thank his lordship for the 
preceding brief particulars; but how much more would they be indebted to him if they had the opportunity of inspecting the living animal and the skeleton in some exhibition. Surely one specimen out of the herd would not be missed.

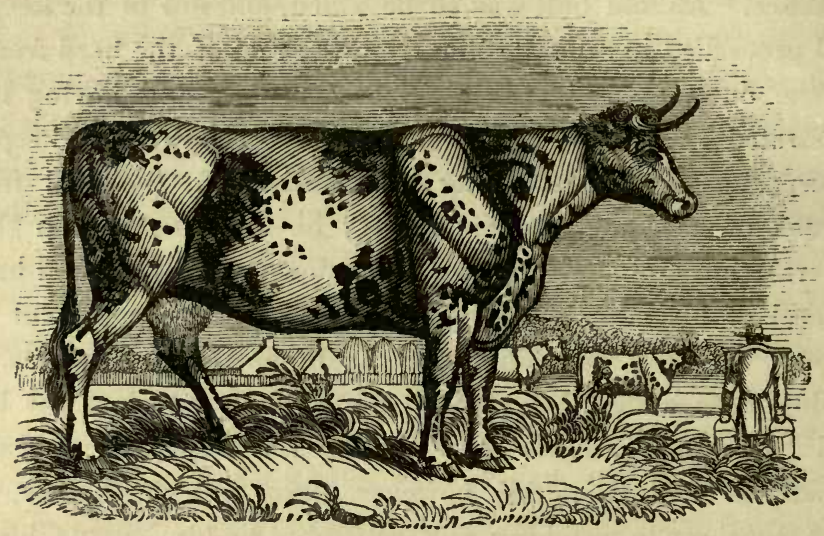

The Common Ox.

We know of no existing wild species to which we can refer as the original type of the common domestic ox. In many parts of the world there are wild herds, and very extensive herds of cattle of the same species, but then we have the testimony of history to prove that they have originated from individuals that had escaped from domestication. The instance of the wild cattle of America will occur to the reader; and in that quarter of the globe, where they have multiplied to a great extent in a wild state, they were not known to the natives until the Europeans introduced them. It is remarkable that individuals of the horse, the ass, the dog, and the cat, also emancipated themselves from domestic thraldom when they reached the New World, where they are now numerous in a wild state, though they are not indigenous to that land. The ox, then, is known at present only as an animal bearing the marks of domestication; and as it appears from the Scriptures that it 
was domesticated before the horse, the difficulty of tracing it, with positive certainty, to its first parents, may be easily imagined. Cæsar and others speak of an enormous wild species of ox under the name of Urus, as inhabiting Europe during their time; and it would seem that they regarded this wild ox as of the same species as their domestic breed of oxen, although the latter was even then probably smaller than the Urus, but perhaps larger than our modern domestic cattle. However this may have been, the remains of a gigantic species of ox, possessing a huge head, and large spreading horns, which have the form and the downward and forward curve of those of certain existing races, especially such as are most wild, are found only in the recent superficial deposits, or strata, of our own island, and in those of the adjacent continent. In England these remains are frequently discovered in caverns along with those of various other animals; as in the celebrated Kirkdale Cave, Yorkshire, and in different parts of Cornwall and Devonshire. All naturaliats of first-rate ability regard these remains as belonging to the Urus of classical writers; and Cuvier moreover considered that this animal is probably the type of our common oxen, hence he gave the name of Bos primogenius to the former animal. Dr. Weissenborn, who thinks that Cuvier has "proved" the latter to be the type of the common ox, remarks that it is probable that the Urus (that is the ox in its earliest state) was not originally a native of Europe, but was introduced into this quarter from India, through Egypt, and that the species became extinct in its wild state at a very remote period. He adopts this view from the contrast which the short and straight hair of the domestic ox, under every climate, presents with that of its congeners, the zubr, American bison, and musk-ox.

But India is a large place, and therefore it is not likely that an animal, described as being powerful and ferocious, should have become extinct there, and especially at a very remote period, when we may reasonably suppose that the chances it had of escape from destruction and of continuing its species, 
were even better than circumstances would now afford it.* The specific characters which appear to be maintained by the common domestic ox are a flat forehead, longer than broad, and round horns, placed at the extremities of the ridge which separates the forehead from the occiput. The Icelandic and some other domestic breeds are usually without any horns. In those that possess horns, the form and length of these weapons are variable. A breed originally from Lancaster, much improved by the celebrated Bakewell, $\uparrow$ and established throughout the greater part of our midland counties, is distinguished as the long-horned rattle of England. The extraordinary size which the horns of some breeds attain results from castration; and perhaps this was the case with the oxen which Dr. H. C. Lenz saw in Hungary, whose horns measured six feet from tip to tip. In some breeds the colour is only of one sort, while others display several colours, as black, white, cream-colour, red, and brown. We read that the Druids used to sacrifice white bulls at their altars, and it is too striking a coincidence to be accidental, that white bulls were also sacrificed by the Egyptians to Apis, as Herodotus informs us. The ox sheds its coat every year.

From the earliest ages, oxen have been employed in drawing carts and ploughs. The Romans bred their cattle principally for draught, and strength was therefore the quality they most prized. A stout body, good limbs, and a fleshy strong neck were requisite for the performance of the labour demanded of them. Virgil, in his Georgics (Book III), describes the points which should be possessed by cattle best fitted to breed from for the plough. In many parts of the continent, as also in

* Skulls of the Bos primogenius, above referred to, found in different parts of Europe, are contained in the museums of London, Paris, Gottingen, Darmstadt, \&c.; but the museum of Jena contains a perfect skeleton dug up near Haselbein, in the grand duchy of Weimar.

+ Bakewell, the agriculturist, made many economic improvements in our breeds of sheep also, altering their size and form so considerably, that when the geologist of that name was travelling, a farmer asked him whether he was the Mr. bakewell who invented sheep. 
Devonshire, Herefordshire, Gloucestershire, and Sussex, the ox nearly supersedes the horse in agricultural employments. The Devonshire oxen are highly prized, not only for their beauty, but for their unrivalled docility and good temper. At the plough they work admirably. The driver and the ploughman while at work, chant together a simple but pleasing succession of sounds resembling the counter-tenor in cathedral music; and the oxen, apparently pleased with the chant, proceed with an agility scarcely to be expected from cattle; and the team may be watched a long while without hearing a harsh word, or seeing a whip or goad applied to them. Franzius observes that " the ox is much delighted in company, and cannot endure solitude; and there is a kind of natural love (as it were) between oxen that work in the plough together, insomuch that if his fellow be not with him, he looketh about for him, and will low until he cometh to him." At a very early period the threshing of corn was effected simply by oxen treading upon the sheaves (see Deut. xxv. 4); and subsequently it was performed either by the trampling of horses, the rolling of a cart-wheel, or by wooden threshing instruments. (See Isaiah, xxviii. 27, and Chronicles, xxi. 23.) From Homer we learn that the Greeks threshed their corn by the trampling of oxen (Iliad, xx. line 495); and there is abundant evidence that the ancient Romans, Arabs, and Egyptians practised the same method. The modern Moors and Arabs employ either oxen, horses, or mules to tread out the grain (see Shaw's Travels); but Niebuhr says that the A rabs yoke two oxen, which draw a large stone roller over the sheaves; as in Egypt and Syria the oxen not only tread it out, but draw a roller or other machine over it (see Norden's Travels in Egypt and Nubia, and Niebuhr's Travels). Bishop Heber says, that in India oxen tread out the corn.

In those parts of Africa where the Hottentots retain an independent life, the keeping and tending of sheep and cattle still form the chief employment of their lives; and under their management the ox is taught to display an extraordinary degree of docility and courage, on any occasion where either of these 
qualities may be necessary. Besides their ordinary oxen, which are employed as beasts of burden or of draught, they have saddle-oxen which they use for riding, and war-oxen which have been taught to guard the herds and flocks, and to attack invading armies. These horned warriors, called backeleys or bakely-osse, are chosen from the most courageous of the herd, and permit themselves to be governed with ease: when their leader sets them loose on the advance of the enemy, they rush impetuously upon the ranks of the latter, overthrow the men, toss them, gore them, kick and trample them to death. Kolben says, that when they are employed in guarding the flocks, they will, at the least sign from their masters, hasten to bring back the cattle that are straying, and keep them herded together; and they rush with fury upon strangers, especially Europeans. La Vaillant assures us that a hyæna, however hungry, will never approach a flock guarded by two of these formidable animals, and that a number of them will even attack a lion. Burchell and Latrobe speak of the Hottentots calling their oxen by name; and in Le Voyage de la Compagnie des Indes de Holland (tome i. p. 490), it is stated that in Terceira (one of the Azores), the oxen are the largest and finest of all Europe, and moreover so gentle and docile, that although a thousand may be together, any one of them will immediately come to its owner if he calls it by name, for they are all distinguished by particular names. In some parts of Essex and Hampshire, it is still usual to suspend tinkling bells to the necks of the kine that are permitted to roam in the woodlands, that the straying cows may be more easily found at milking time. Those lovers of nature who have strolled quietly through the woods and forests, and have heard the simple music of these unpretending bells, and caught occasional glimpses of the cattle in their leafy seclusion, will not readily forget the charm which these simple incidents imparted to the scenery. In Switzerland, however, this pretty custom is most common; and there only those cows that are remarkable for their superior beauty, sagacity, or good temper are permitted to bear the bell, and very sensible do they seem 
of the honourable distinction. While a cow wears it, she is gay, good humoured, and frolicksome, but should she so far forget herself as to be guilty of straying, commit any vicious trick, or other misconduct, she is not beaten but her bell is taken away from her; and her now sulky and gloomy air seems to be expressive of deep regret and a consciousness of disgrace. The celebrated Swiss song, the Randz des Vaches, is merely the peasant's vesper summons to his cows. In some parts of Switzerland, more particularly in the retired parts of the forestcantons, the herds are collected by the sound of an alp-horn; and it is said that as soon as its deep, mellow, and prolonged note reaches the ears of the cattle, they are seen hastening to the dairy, often at a hard gallop.

It would seem that in England, the cattle were formerly called home by similar means; for Tusser, in his agricultural poem, entitled Five Hundred Points of Good Husbandry (1562), speaks of "the neatherd with his cur and horne." The poet Bloomfield, speaking of cows coming at the call or "well-known halloo" of the cow-boy, says

"The strong press on, the weak by turns succeed;

And one superior always takes the lead, Is ever foremost, whereso'er they stray;

Allow'd precedence, undisputed sway:

With jealous pride her station is maintain'd, For many a broil that post of honour gain'd."

It is generally, if not always, the case that a particular cow, probably the strongest, leads the herd to and from pasture, and she is so tenacious of her right, that should any cow attempt to pass beyond its proper place, she will attack the offender with her horns and hoofs. Many anecdotes have been recorded illustrative of her " pride of place," and her exaction of proper etiquette from the herd.

The several species of grasses constitute the herd's chief staff of life; but many other plants serve to give a pleasing variety to their vegetable diet. They are fond of many of the larger flowering plants, and they browse occasionally upon the tender 
tops of furze, on the leaves of willows, of the elm, ash, privet, bird-cherry, birch, and of other trees. It is a common notion that the crow-foot, which grows abundantly in many meadows, is eaten by cows, and imparts a yellow colour to the butterhence, indeed, the plant's other name of butter-cup. Stillingfleet, in his Observations on Grasses, expresses his belief that this is all a mistake, for he " never could observe that any part of that plant was touched by cows or any other cattle." Linnæus, in his Flora Lapponica, says that some people believed that the marsh-marigold made the butter yellow, but he denies that the cows ever touch that plant, while he admits that all kinds of pasture will not produce that yellowness; and he adds that the best and yellowest butter he ever saw, and which was preferred by the dealers, was obtained from the milk of cows that had fed where the cow-wheat grew more plentifully than he had ever seen it any where else. Phillips, in his Sylva Florifera, says that in some of even the good dairy-countries, the ashtree is seldom suffered to grow in the pastures, as it is thought that if the cows eat of its leaves, the butter will be rank; and which is said always to be the case with the butter made about Guildford, Godalming, and some other parts of Surrey, where this tree abounds. But he observes that the correctness of this is doubtful, as there is no bitter taste in the ash-leaves; and he has frequently remarked that a good housewife has made excellent butter, when her neighbour, on the opposite side of the hedge, could not eat her own churning.

It has been observed that old pastures near the bases of mountains, which always contain among the grasses an intermixture of various mosses, afford excellent food for milch cows, the milk proving both plentiful and rich; and such mossy pastures are said to fatten cattle more readily than recent artificial pastures.

The Romans considered the leaves of the elm as the best fodder for cattle. Evelyn mentions, that in some parts of Herefordshire elm leaves are gathered in sacks as fodder for them, and adds that those of the female elm are preferable. 
Columella speaks of a species of elm peculiarly adapted to this purpose. Next to the elm, the Romans esteemed the leaves of the common ash; and Phillips says that in the north of Lancashire it is usual to lop the ash to feed the cattle in autumn, when the grass is declining, the cattle peeling off the bark. The leaves of the birch afford excellent fodder for them. In France, according to Loudon, the leaves of willows, either green or dry, are considered the very best food for cows. Weston says, that cows which are fed upon burnet, lucern, cabbage, turnips, and carrots in winter, will yield more and better milk than those which are fed upon hay during that season. "In winter," says an old writer, "tares are the best feeding for them ; and hay and colestalks [cabbage stalks], with chaff, hay, and chopped straw sodden together in water are also very good. In some places they feed altogether with new threshed straw : in many places they give them lupins steeped in water, or chiches or peson [peas] mingled with chaff, besides the branches and leaves of vines, the green branches of elm, ash, poplar, and holm; when other green food faileth in winter, the browsing of oaks and holly will serve. Oxen are soon fat in good pasture with wheat, rapes, apples, and radish; they and kine will be passing fat where there wanteth pasture, by giving them meal mixed with wheat, chaffe, and rapes, or grains."*

In our days, the common fattening food of cattle consists of Swedish turnips, mangel wurzel, cabbages, potatoes, grains, bran, and oil-cake. Old Franzius says, "An ox is soonest fat when by himself; but I am informed that the quickest way to fatten him, is to wash him often with warm water, and feed him with beans and elm boughs. Baptista was wont to give his oxen those scraps of meat that came from his table, which in a short time made them so fat that they could scarcely go." $\dagger$ Mr. De Capel Brooke tells us that in Lapland and Norway, the cattle are fed on fish, and they not only eat it greedily, but thrive upon it. Horse-dung, when obtainable, is also boiled

* Heresbatch's Husbandrie, translated by Barnaby Googe (1586), p. 128 b.

$\uparrow$ History of Brutes, Englished by N. W. (1670), p. 103. 
up with the fish, till a fine rich soup is prepared, which is poured, while warm, into the manger. Matthew Aphonin remarks, that "oxen fatten very quickly upon the sea-coasts where the arrow-grass (Triglochin maritimum), their favourite food, abounds;" and if this be so, it is probably ascribable to the saline nature of the plant, and to the sea-breezes containing particles of salt, which appears to be necessary to stimulate their digestive organs, and therefore conducive to their health. In Upper Canada, the cattle have plenty of wild pasture to browse on in the woods, but, once in a fortnight, they return of their own accord to the farms to obtain a little salt; and when they have eaten it mixed with their fodder, they repair again to the woods. D'Azara tells us, that in parts of Paraguay, salt is not given to the herds of cattle; but they require absolutely to have the barrero (a saline or nitrous earth), which they and even other animals seek with avidity, and without which they fail and die in the course of four months. From the twenty-seventh degree of south latitude to the Malovine Islands, they have no need of the barrero, because the waters and the pasture grounds are sufficiently salt; but northward, beyond this latitude, it is necessary, and the plains which do not contain it, feed neither the ox, horse, ass, mule, goat, or sheep."

The importance of paying attention to the dieting of cattle, whether a whole herd or one individual is kept, is well shown by the fact that, at the model-farm of Grignon, in Provence, it was found, by experiment, that a cow fed without reference to any fixed plan cost about a shilling a day, and yielded little more than four or five pints of milk; but when fed systematically, she cost only eight-pence, grew much fatter, and yielded more than nine pints of milk.

Oxen are fond of bathing, and they are also good swimmers.

All naturalists who have written on the cow, state her gestation at nine months' duration; and this is in accordance with the remark of an old agricultural writer, that "so long 
she goeth with calf, that the common people say a cow and a queen have both one time."* At the Oxford meeting of the Agricultural Society, in July 1839, Earl Spencer expressed his conviction, from observations which he had made on the period of gestation of 764 cows, that it lasts ten months and four days. Lawrence, the celebrated physiologist, correctly observes that cows kept in towns, and other animals deprived of their healthful exercise, and accustomed to unnatural food and habits, often have difficult and painful parturition. The cow usually brings forth only one calf, not unfrequently two, but rarely more. In the Nouveau Bulletin des Sciences, it is related that, in 1817, a cow brought forth four cow-calves at a birth; in 1818, two cow-calves and one bull-calf; and in 1819, two cow-calves;-and she nurtured them all herself, except two of the first birth. Thus in three successive years she produced nine calves. It is a prevalent notion that when a cow produces twins consisting of a bull-calf and a cow-calf, the latter, then called a free-martin, is always barren. John Hunter says, in the second edition of his Observations on the Animal Economy, that he had met with exceptions to the rule; and it is related in the Magazine of Natural History (vol. v. p. 765), that a cow belonging to Mr. J. Holroyd, of Withers, near Leeds, brought forth twins of opposite sexes, and that these bred together, the twin cow brought forth a bull-calf, and she regularly had calves for six or seven years afterwards. In the same journal (vol. vi. p. 78), Mr. J. G. Tatem records that at Hill Farm, about a mile from Wycombe, a small polled cow, belonging to $\mathrm{Mr}$. Reuben Allen, produced three cow-calves, in the beginning of January 1828, which were reared, and each of them calved twice.

The reader has probably often witnessed proofs of the cow's attachment to her offspring. Mr. Jesse relates that a cow was driven from the head-keeper's yard at Bushy Park to Smithfield, and sold at the latter place; but early the next morning she was found at the yard gate, having made her

* Herebatch's Husbandrie, Englished by Barnaby Googe (1586), p. 127. 
way through all the intricacies and impediments of London, and travelled twelve miles to return to her calf which had been left in the yard.

A few years ago, I witnessed an instance of a cow displaying extraordinary sympathy towards another cow which had just calved in a dry ditch, in a field at Bromley, Middlesex. The mother was assisted by her friend both in cleaning the newborn calf, and in removing all traces of the event from the ground, according to that habit of precaution which animals, especially those in a state of nature, always exercise with a view to prevent their defenceless offspring from being discovered by their keen-scented enemies. The owner of the cattle, having been apprised of the occurrence, arrived with his man, approached the group, and caressed the mother without receiving the slightest repulse. But as soon as the man had raised the calf, and was carrying it away round his neck, closely and quietly followed by its parent, who seemed perfectly to approve of removing to the shed, her companion bellowed, rushed at the man, and seemed determined to interfere in preventing this proceeding. Sticks were used, and stones were flung at her, but yet she did not desist from offering her most strenuous opposition until the party had got beyond the gate, out of her reach.

The uses of the ox in the employment of its strength have been already noticed. The cow, by yielding a copious supply of milk and cream, readily convertible into rich butter and cheese, and into various preparations here unknown, but much used in the East, confers so many benefits upon mankind, that it was probably from a sense of gratitude that many nations regarded her with veneration; and that the Egyptians, the Libyans, and the women of Cyrene, as Heredotus tells us, refrained from eating the flesh of cows. In the ordinary course of nature, the cow does not give milk until she has conceived; but exceptions are on record. In the Edinburgh Journal of Natural History (No. I.), Mr. Joseph Marshall of Edrington, near Berwick, is stated to have had, in June 1830, a heifer, or virgin cow, two years old, which yielded milk for 
several months, and gave at one time a full quart of genuine milk, which, on being kept for thirty hours, threw up a good coat of cream, and this on being churned in a bottle produced as much and as good butter as any other cow's cream would have done by similar means. In the Durham Chronicle, June 30, 183\%, the Rev. Mr. Douglas, of Trimdom, in that county, was stated to have had, at that time, a two-year old Alderney heifer, giving six quarts of milk daily. Old cows generally give more milk than the younger ones, hence the proverb, "old kine and more milk, young hens and more eggs." In England, the cattle are milked only twice a-day; but in Belgium and Holland, they are milked thrice a day, and the milk, being generally kept in zinc pans, instead of earthen or wooden vessels, throws up more cream. In most countries the milk is drunk; but according to a traveller in Sumatra, the natives of that country have the same aversion to milk and every preparation from it, as the Javanese; and he adds that " a chief, being asked whether he would take milk with his tea, indignantly replied that he was not a baby." * With a matter obtained from the cow, we perform vaccination, giving the cow-pock as a preventive of that loathsome and disfiguring disease, the small-pock.t An oil, much used in dressing and cleaning coach trappings and harness, is obtained from the leg-bones of cattle. Glue is obtained from the ears and hoofs. Prussiate of potash, a beautiful yellow salt, extensively used by calico-printers to produce fine blues and greens, is prepared by burning the hoofs and horns in iron-pots, along with a

* Asiatic Journal (1823), vol. xv. p 455.

+ Because a few instances have occurred of persons having been attacked with small-pox some years after they had been vaccinated (perhaps unskilfully, or imperfectly), Mr. John Herapath is pleased to call it " a medical humbug," and all those who have faith in it " credulous blockheads," adding that such is the opinion of all the "respectable" part of the profession, and that the " thinking" part are determined to protect the world from the small-pox by inoculation. I believe he will find that inoculation has been prohibited, and vaccination encouraged by act of parliament. His denunciation of Jenner's " impudent assertions," as he terms them, enriches the pages of the Railway Magazine of December 1837, and of May 1838. 
quantity of potash. The horns are also formed into drinkingvessels, wind-instruments, shoe-horns, combs, knife-handles, flasks, snuff-boxes, \&c.; and when softened, by hot water or by hot wax, they are either compressed or cut into pellucid plates for lanthorns. Several medicinal articles are obtained by the decomposition of the bones, and they also form a strong manure. D'Azara says, that in Paraguay ox bones are the substitute for fire-wood in many places where the latter is not procurable, and they are made to burn by the addition of suet; and the skulls are used as chairs or stools in the estancias, or pasture-grounds. The hair is used in mortar; the hide, when tanned, is a strong and durable leather; the intestines and the bladder are applied to various useful purposes in domestic economy; vellum is made of calves' skin; and of very thin vellum, or of the finer parts of the intestines, gold beater's skin is made; and the blood of oxen is excellent manure for fruit-trees, and is used to refine sugar.

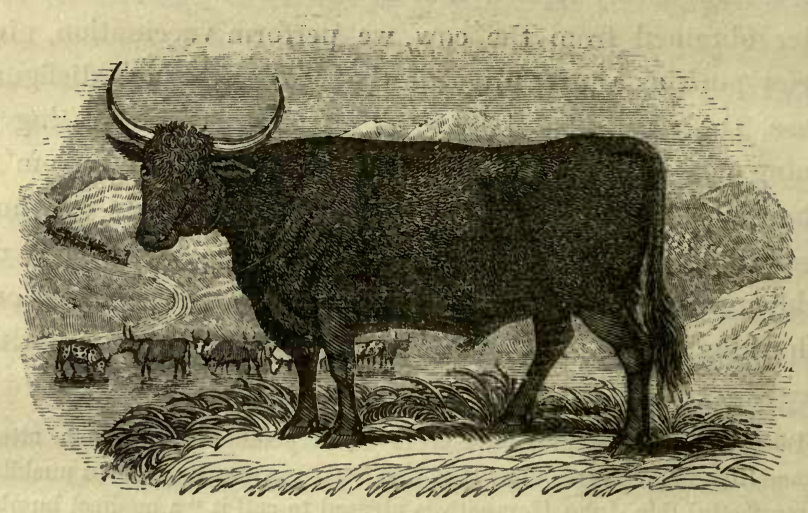

The Kyloe, or Argyleshire Ox.

This breed is abundant in the Hebrides, or western isles of Scotland. The generality have a fine shape, a thick and furry coat of a dark brown colour, or black, though sometimes 
brindled; and small, upright, sharp-pointed horns, which are white and black. Being hardy, and having a touch of rude nature in them, they are well adapted for a life in cold and bleak regions. They receive their name from their crossing the Kyloes, or ferries, when they are driven southward into the English counties, where numbers of them are fattened for slaughter, their beef being highly esteemed by John Bull.

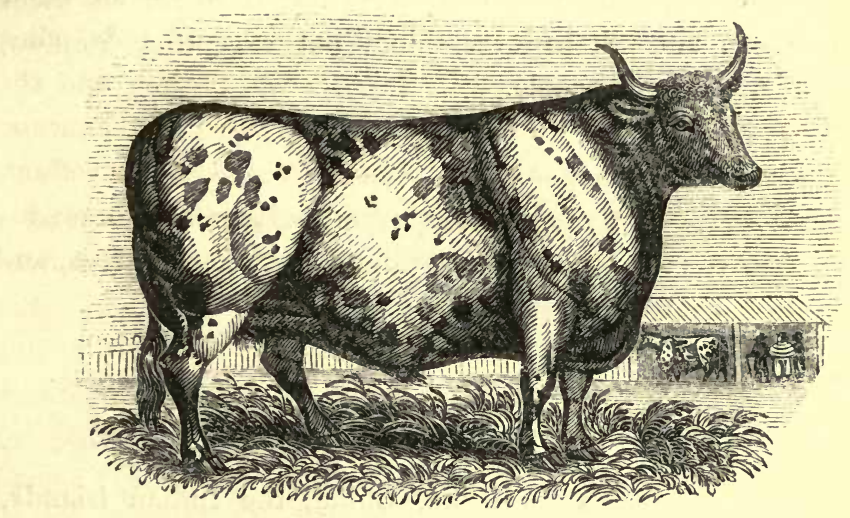

The Prize Ox.

By a prize ox is meant one of any breed that has received a premium for having been fattened till it has attained a monstrous bulk. The Chatsworth $O x$, which was grazed and fattened on the Duke of Devonshire's luxuriant estate, weighed 220 stone, or 3080 pounds, and was pronounced by the best judges of stock to be the largest and finest of his age (four years and a half) ever grazed in England. The six-years old Brother Jonathan, brought from New York, and lately exhibited in Piccadilly, weighed $4000 \mathrm{lbs}$; was ten feet nine inches in circumference; five feet eleven inches in height; and eleven feet ten inches in length. "The alleged beauty of these unhappy 
victims of repletion, consists," as a writer observes, "in their being unable to perform a single function of their nature, or to enjoy one moment of their lives; and the value of their flesh is in exact proportion to the degree in which it is unfit to be eaten."* Another writer makes a still stronger objection; for he remarks that "oxen and sheep panting under the weight of their own fat, are not in a state of perfection but of disease, which is unsightly to the eye and unwholesome as food." $十$ If a state of great corpulence be so admirable in the opinion of agricultural noblemen and experimental farmers, let them be consistent, and fatten everything, not excepting hunters, greyhounds, and poor people.

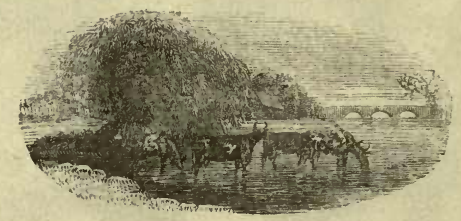

The Brahmin Ox, or Large Zebu.-(Bos Zebu.)

The zebu cattle inhabits India, China, the Indian islands, Madagascar, and the eastern coast of Africa, from Abyssinia to the Cape of Good Hope.

Zoologists, from Linnæus to Bennett, have regarded this animal as merely a variety of the common ox; but its differences are so great and so many that, if taken in the aggregate, they offer strong proofs of its specific distinction. Mr. Ogilby justly remarks that, " narrow high withers, surmounted by a large fatty hump, an arched back rising at the haunches, and suddenly falling to the root of the tail, slender limbs, a large pendulous dewlap falling in folds, long pendant ears, and a peculiarly mild expression of the eye, distinguish the zebu oxen, a race varying in size from that of our largest cattle to that of a young calf."

* The Mirror of the Months (1826), p. 270.

† The Gardeners' Gazette, Nov. 10, 1839. 


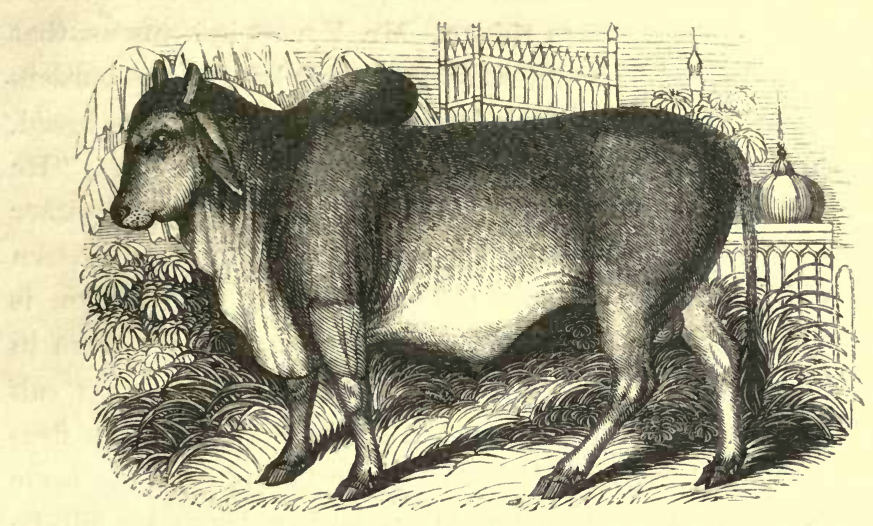

In the sculptures in the cavern temples of Ellora, in the carvings of the Seven Pagodas at Mahamalaipur, on the Coromandel coast, and in many other ancient relics, there are very faithful and spirited representations of the zebu oxen; which proves that these animals possessed, at least two thousand years before the Christian era, the same peculiarities which now distinguish them. The religious writings of India state the cow to have been the first dumb animal that was created. The Hindoos yet regard it as sacred to Bramah, and refuse to shed its blood. Bishop Heber tells us, that many of these cattle are turned out when calves, on different solemn occasions by wealthy Hindoos, as an acceptable offering to Siva. These are exempt from labour, and "it would be a mortal sin to strike or injure them. They feed where they please, and devout persons take great pleasure in pampering them. They are great pests in the villages near Calcutta, breaking into gardens, thrusting their noses into the fruiterers' stalls and pastry-cooks' shops, and helping themselves without ceremony. Like other petted animals, they are sometimes mischievous, and are said to resent, with a push of their horns, any delay in gratifying their wishes." *

Others, less fortunate, are employed by the Hindoos, and

* Narrative of a Journey through the Upyer Provinces of India (1828). 
also by the natives of eastern Africa, as beasts of draught and burden, and are sometimes ridden. Mr. Youatt informs us, that Lieutenant-Colonel Skinner, residing near Pokar, on the borders of the Bichaneer desert, has a large stock of the Nagore breed, which in strength and speed far surpasses our oxen. "He employs them to convey the military dispatches, and either of them will travel with a soldier on its back fifteen or sixteen hours a day, at the rate of six miles an hour. Their action is particularly fine, and they bring their hind-legs under them in as straight a line as the horse. Mr. Perkins has a zebu calf which has leaped over an iron fence higher than any fivebarred gate; and his zebu bull frequently jumps over the same fence in order to get water; and when he has drunk his fill, he leaps back again."

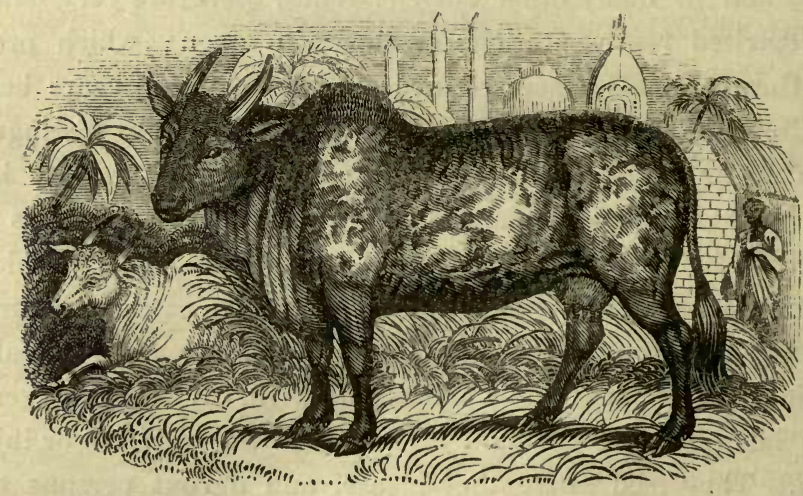

Smaller ZeBu.

The great variety in the dimensions of different breeds of the zebu cattle, is exemplified by the several specimens in the possession of the Zoological Society. This variety in stature ranges from that of the great Brahmin breed to one so small as scarcely to exceed two feet in height, and little more than 
three feet in total length. They possess the same mildness of disposition, and the same general contour, although in the size of their humps, in the colours of their bodies, and in the shape and length of their horns, they vary considerably.

Now, that we have reached, as it were, the end of our zoological journey, - through forest and jungle, and across mountains, plains, scorching deserts, and frozen wastes,-let us pause and make a few general and salutary reflections. Wherever we have been, mentally at least, no matter how hot or cold the climate, how rich or bare the soil, we have found that there were animals capable of supplying the wants of man, ready to serve for his subsistence and for his clothing, or to exert their strength and speed to accomplish his migrations. In short, we have seen them actually promoting the civilization of man, and also contributing to that harmless pleasure which attends his intellectual inquiries and contemplations. To that Creator who has so benevolently provided us with these dumb but valuable companions, and who has endowed us with faculties capable of rendering the dog, rein-deer, llama, ox, ass, horse, camel, and the elephant obedient to our voice, subservient to our social and commercial intercourse, and so conducive to our comfort and prosperity, the thoughtful mind must feel unbounded gratitude. To this feeling let us add a constant observance of that generous mercy, which will show we are not unworthy of enjoying the privilege of training and employing them for our purposes.

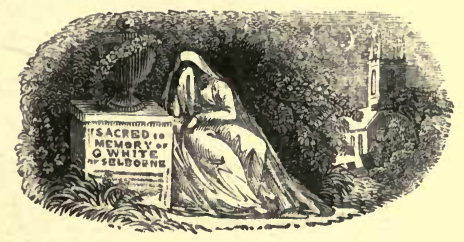





\section{N D E X.}

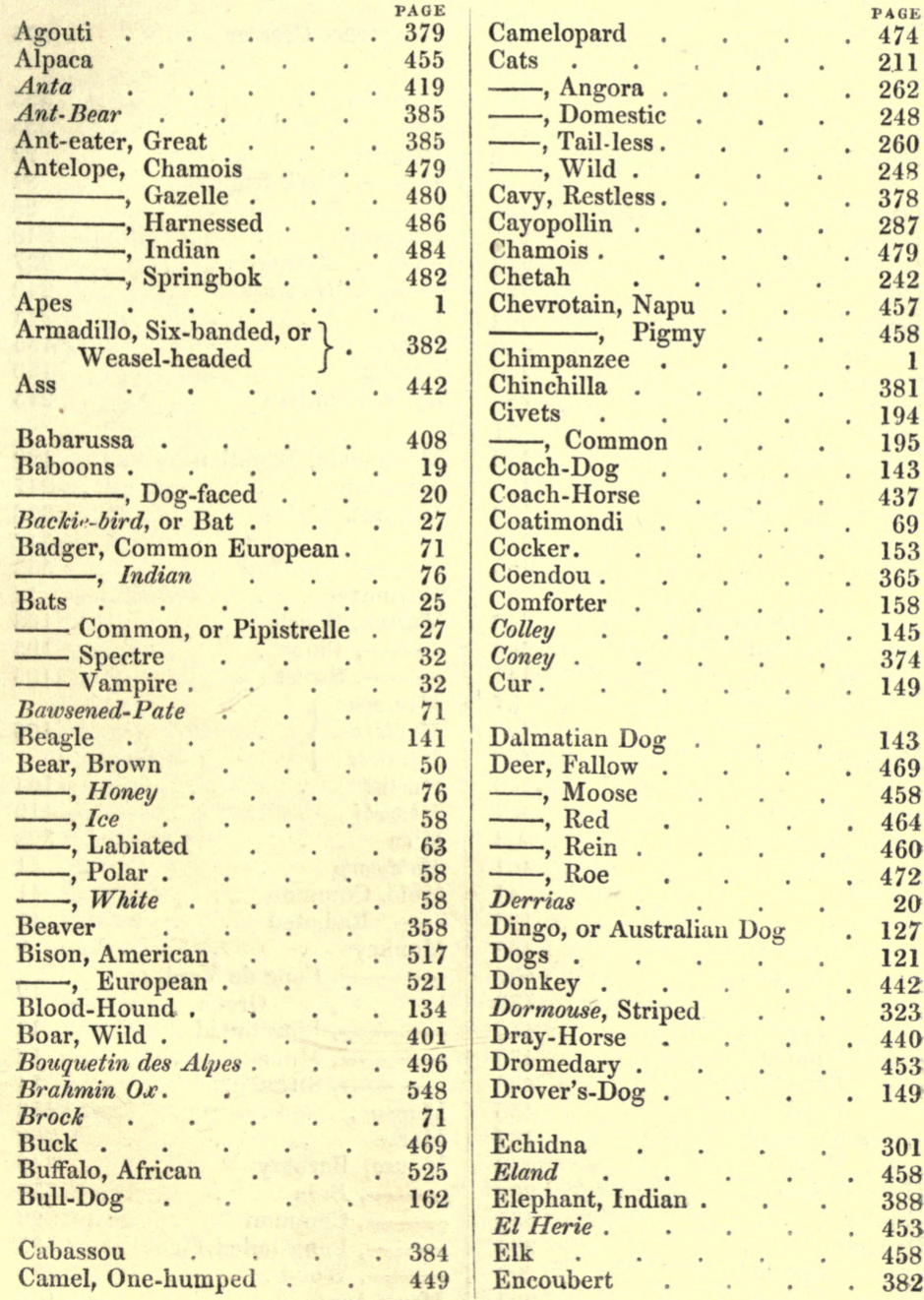


Ermine

PAGE

Esquimaux-Dog . $\quad 174$

Ferret . . . 86

Fitch . . . 80

Fjall • • . . 192

Flutter-Mouse . $\quad 27$

Foumart . . . 80

Fox, Arctic . . 192

$\longrightarrow$, Black . . . 191

-, Blue . $\quad$. 192

—, Common . . . 186

$\longrightarrow$ Greyhound . $\quad 190$

—, Silver . . . 191

$\begin{array}{llll}\text { Fox-Hound . } \quad . \quad & 139\end{array}$

Fulimart. . . 80

Gazelle . . . 480

Genet . . . 197

Giraffe . . . 474

Gnu . . . . 488

Goat, Angora $\quad$. $\quad 493$

$\longrightarrow$ Chamois . . . 479

$\longrightarrow$, Common . . 490

Grey , Thibet • • 493

Greyhound . . 129

- Irish . . 129

Guiana-Pig . . $\quad 378$

Guib . . . . 486

Hamster, Common . $\quad 342$

Hare, Common ․ 366

Harrier . . . 141

Hedgehog . . $\quad 37$

Hind . . . 466

Hippopotamus . . $\quad 398$

Hogs . . . .400

$\longrightarrow$ Chinese . $\quad . \quad 407$

$\longrightarrow$ Domestic . . 404

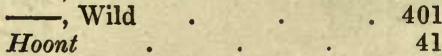

Horse . • . . 423

$\longrightarrow$ Arabian . . 432

— Coach . . . 437

$\longrightarrow$ Cob . $\quad$. $\quad 439$

$\longrightarrow$ Dray . . . 440

$\longrightarrow$ Hunter . . 435

$\longrightarrow$ Race . . . 433

$\longrightarrow$ Road . . 436

- Shetland . . 437

$\longrightarrow$ Welsh . . 439

Horse-Whale • • . 268

Hunter . . . 435

Hyænas . . 204



—, Striped . . 207

PAGE

Ibex, Common . • . 496

Ichneumon . $\quad$. 199

Isatis . . . 192

Jackal, Common ․ $\quad 184$

Jaguar • • . 237

- Black . . 239

Jerboa, Common ․ $\quad 355$

Jocko . . . 1

Kangaroo, Greater . 275

Lemming . $\quad$. 353

$\longrightarrow$, Tail-less . $\quad 355$

Lemurs . $\quad 22$

$\longrightarrow$, Black-fronted . . 24

$\longrightarrow$, Red . . 23

Leopard . . . 240

- American. . 237

$\longrightarrow$, Hunting . . 242

lion . . . 214

Llama • . . $\quad 455$

Lurcher . . . 150

Lynx, Common $\quad$. 243

Mangouste, Egyptian $\quad$. $\quad 199$

Marapute . • . 247

Marmot, Alpine ․ $\quad 323$

-

$\longrightarrow$ Lapland . . $\quad 353$

Marmozet . . . 14

Marten, Beech . . 106

- Pine . . 105

$\longrightarrow$, Sweet . . 105

$\left.\begin{array}{l}\text { Martern } \\ \text { Marteron }\end{array}\right\} \quad . \quad 106$

Martlett
Mastiff

Mborebi . . $\quad 419$

Mice . . 328

Moldwarp . . . 41

Mole, Common . 41

$\longrightarrow$, Radiated $\quad$. 49

Monkeys . $\quad 9$

$\longrightarrow$ Cape de Verd, or $\} .10$

$\longrightarrow$, Lion.tailed . 13

— Mona . . 12

$\longrightarrow$, Striated . $\quad$. 14

Moose • . . 458

Morse . . 268

Mouse, Barbary . 340

-, Bean . . 335

- Common . . 328

—_, Long-tailed Ficld . $\quad 335$

—, Wood . . . 335

Mouse-hunt. . . 106 
INDEX.

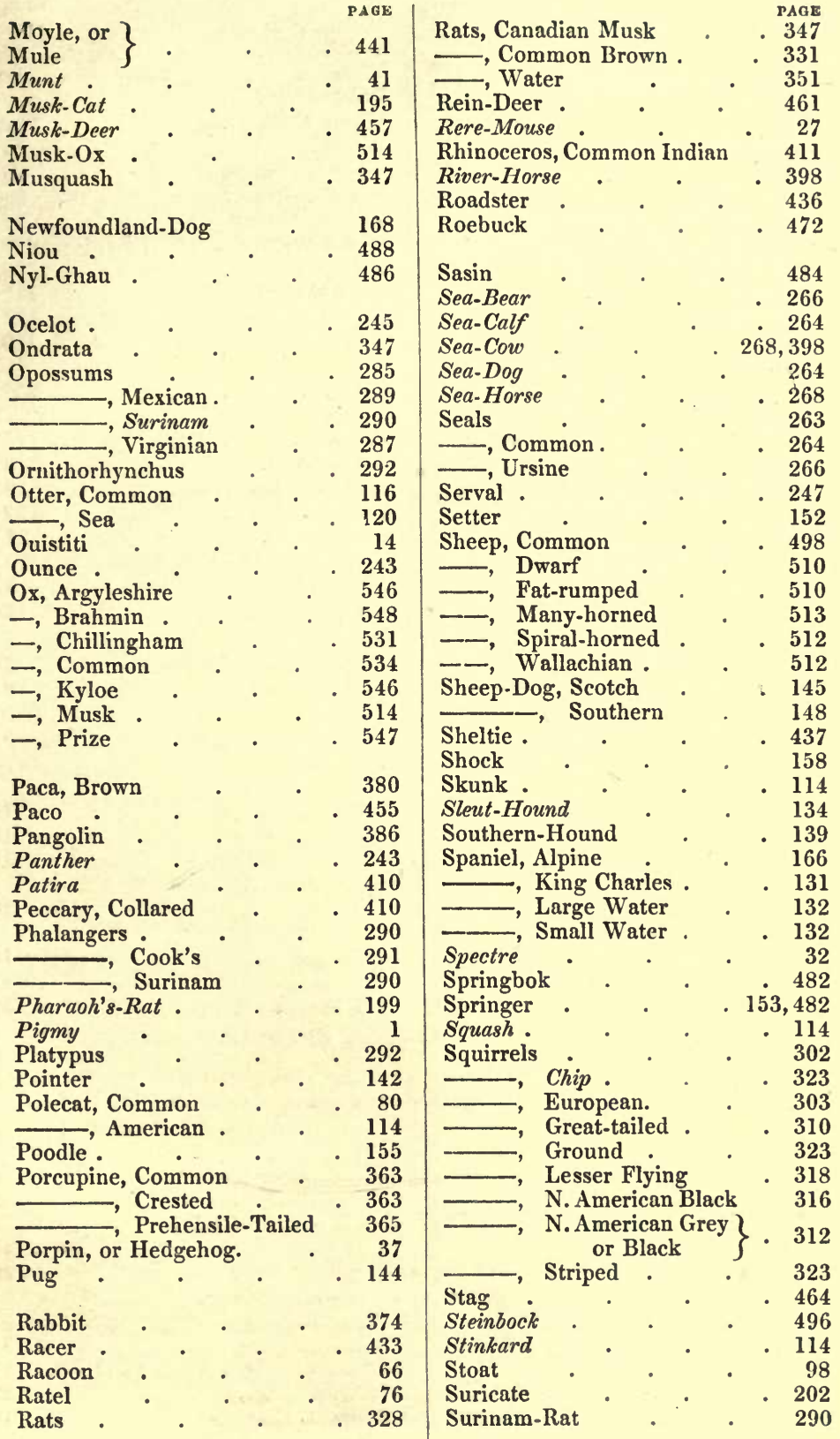


INDEX.

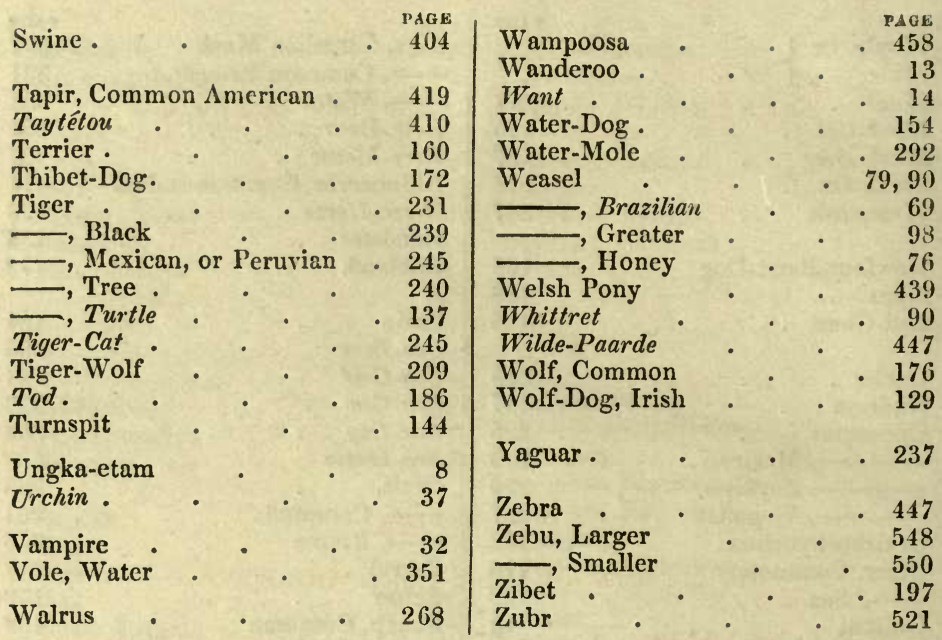

FINIS. 


\title{
SPLENDIDLY ILLUSTRATED WORKS
}

\author{
PUBLISHED BY
}

JOSEPH THOMAS, FINCH LANE, CORNHILL.

\author{
Dedicated, by express Permission, \\ TO THE LATE
}

RIGHT HONOURABLE LORD HOLLAND.

\section{THOMAS'S LIFE OF NAPOLEON,}

\author{
BY G. M. B U S S E Y.
}

Illustrated with 500 Engravings, from Designs by the celebrated Horace Vernet. Just completed in Two Splendid Library Volumes, price £2. $2 s$. cloth.

" Remarkable for the elegance of its form, the neatness of its typography, and the number and great spirit of its truly characterstic illustrations: while the literary portion of the book claims for it a place in every historic library."-Morning Post.

\section{NEW TRANSLATION OF LE DIABLE BOITEUX.}

Now publishing in Monthly Parts, Price One Shilling each, ASMODEUS, OR THE DEVIL ON TWO STICKS,

Newly translated from the French of Le Sage, by Joseph Thомаs, and illustrated with 200 Engravings, from Designs by Tony Јоналnот.

" Mr. Thomas's translation fully deserves its admirable illustrations; and the illustrations ale worthy of the new version. He has certainly succeeded in his efforts."-John Bull.

Also, now publishing in Monthly Shilling Parts,

\section{A N O N L E S C A U T,}

Translated from the French of the Abbe Prevost, and superbly illustrated by Tony Johannot.

" All periodical publications must bow before Mr. Thomas's beautifully illustrated editions of 'Manon Lescaut' and 'Asmodeus'. For beauty of type, translation, and illustration, these works, when completed, will stand unrivalled."-Morning Post. 
Just published, price 5s. 6d. cloth, gilt edges,

\section{THE CA S T E OF OTRA NTO,}

BY HORACE WALPOLE;

With an Original Memoir by G. M.Busser; and numerous Illustrations, designed expressly for this Edition, by W.STANDFAST.

"The Castle of Otranto stands in our memory, at once the child of our love and father of our fears; and we snspect the publisher of this edition of similar illolatry, for he has produced the work in exqnisite style."-Sunday Times.

NEW AND IMPROVED EDITION.

\section{G A M E A N D S POR'T S, BY DONALD WALKER.}

Illustrated with 35 splendid Engravings on Steel. P'rice 6s. cluth, gilt elges.

This popular Work, which has run through many Editions, contains a perfect description of, and the rules that regulate, the various In-door and Out-of-door Games and Sports, those of the Seasons, \&c. \&c.; omitting only Games of Hazard, and such as are either Frivolous or Dangerous.

DEDICATED, BY PERMISSION, TO MRS. LOUDON.

\section{R A W I N G-ROOM BOTA N Y.}

BY JAMES H. FENNELL.

With Eighteen beautiful lllustrations, Coloured after Nature, by Mrs. Perkins, Professor of Botanical Flower Painting. Price 7s. $6 d$. cluth, gill.

\section{A S ENTI M E N T A L JOUR N EY THROUGH FRANCE AND ITALY.}

BY LAURENCE STERNE.

lllustrated with One Hundred Engravings on Wood, by BastıN and G. Nicuolls, from Original Designs by Jaceue and Fussell. Price 8. cluth.

\section{THOMAS'S BURLESQUE DRA MA:}

Containing the Tailors, Bombastes Furioso, Midas, Tom Thumb, The Mayor of Garratt, Tue Beggar's Opkra, and Katharine and Petruchio. Illustrated with 62 Engravings, from Designs by GEORge and RoBErT Cruikshank. Price 7s. 6il. cluch.-Separate Plays, $1 s$. 
By Joseph Thomas, Finch Lane, Cornhill.

SIXTH EDITION.

\section{OLD FRIENDS I N A N EW DRESS; OR, SELECT FABLES IN VERSE.}

Illustrated with Eighty-three Engravings on Wood. Price 4s. 6il. cloth. BY R. S. SHARPE, Author of "Fairy Tales in Verse," \&c.

This little Work has been received into the Catalogue of Books patronized by the Society for Promoting Christian Knowledge, and will be found a most acceptable Prize Book.

"It is the hest publication of the kind which I bave seen in an Euglish dress, and it cannot fail of being creditable to the Author, as well as beneficial to youth." - Lindley Murray.

\section{A NEW EDITION, CAREFULLY REVISED.}

Just published, 4s. cloth, gilt,

\section{BUNYAN'S PILGRIM'S PROGRESS,}

With Notes by the Rev. W. Mason, and others; a Life and Portrait of the

Author ; and illustrated by upwards of onc bundred Engravings on Wood, by G. W. Bonner.

\section{SPLENDIDLY ILLUSTRATED EDITION OF FAIRY TALES.}

In Six Volumes, price 15s. cloth: or in T'wo Volumes, price 13s. cloth, and 15s. morocco gilt,

\section{'T H E C H I L D'S F A I R Y LI B R A R Y.}

With Six Hundred Engravings, from Designs by Јонамnoт, Grandville, Gigoux, \&c.

\begin{tabular}{l|l} 
IRINCE DESIRE, & CONTBNTS: \\
THE BENEFICENT FAIRY, & THE SLEE \\
BLING BEA UTY \\
HOAM AND VERMILION, & PRINCESS MINIKIN, \\
TOAD AND DIAMONDS, & PRINCE ELFIN, \\
GRACIOSA AND PERCINET, & PRINCE SINCERE, \\
THE PRINCESS MAIA, & THE BLUE BIRD, \\
THE WHITE CAT, & THE GOOD LITTLE MOUSE, \\
PUSS IN BOOTS, & THE HIND IN THE FOREST, \\
PRINCE CHERRY, & BLUE BEARD, \\
PRINCESS ROSETT, & CINDERELLA, \\
LITTLE RED RIDING HOOD, & FAIRER THAN A FAIRY, \\
SEYTIMUS, & THE YELLOW DWARF, \\
THE FAIR ONE, with Golden Hair, & THE ISLANDS OF PLEASURE.
\end{tabular}

"One of the nicest little books ever issued for the delight and benefit of little readers. The wood cits are replete with character. Such capital giants and frightful old women could never have proceeded from the pencil of an orlinary artist. The text is also of the most piquant kind."-Court Journal. 


\section{TH E C H I L D'S L I B R A R Y.}

PROFUSELY ILLUSTRATED, UNIFORM WITH THE " CHILD'S FAIRY LIBRARY."

1. ROBINSON CRUSOE. Two vols. price 5s. cloth.

2. FAIRY TALES IN VERSE; by the Author of "Old liriends in a New Dress." 2s. 6d. cloth.

3. PHILIP QUARLL, THE ENGLish HerM IT, 2s. $6 d$. cloth.

4. PETER WILKINS. 2s. 6d. cloth.

5. THE CHILD'S BOOK OF ZOOLOGY; bY JAM ES H. FENNELL. 3s. $6 d$. cloth.
6. HISTORY OF RENARD THE FOX; from the German of Gocthe. $2 s .6 d$. cloth.

7. TALES AND ANECDOTES, FICTIONS AND TRADITIONS, FOR CHILDREN. 2s. $6 d$. cloth.

8. FABLES AND PROVERBS. By G. M. Bussix. With Eighty-five Engravings. $28.6 d$. cloth.

\section{L L U S T R A T E D W O R K S, UNIFORM WITH THE " CHILD'S LIBRARY."}

THE CHILD'S PICTORIAL BIBLE; being a careful abridginent of the Old and New Testaments, in which the sacred text is scrupulously athered to. Two vols. price $5 s$. cloth.

THE CHILD'S OWN HISTORY OF FRANCE; with authentic Portraits of its Kings. $3 s$. cloth; $3 s .6 d$. half-bound.
BIBLE STORIES FOR CHILDREN; from the Creation to the Conquest of Canaan. With thirty-two Ilustrations by Westas.l AND MARTin. 5s. cloth, gilt.

THE GODS OF HOMER AND VIRGIL; or, MYTHOLOGY FOR CHILDREN. 3s. cloth; $3 s .6 d$. half-bound.

This day is published, price 7s.6d. cloth,

\section{A JOUR N E R O U N D M Y ROO M,}

Translated from the French of M. Le Comte Xavier de Maistre.

"All who kuow anything of the French language know this charming composition, than which there is uothing more sparkling and wittily philosophical; and they will be glat to learn Mr. Thomas has just published a translation of the caustic sallies and lively humour of M. Le Maistre."-Courrier de l'Europe.

DEDICATED, WITH PERMISSION, TO SIR A. W. CALLCOTT, R.A.

Just published, price 10 s. 6 d. cloth,

\section{COLOUR, AS A M E N S OF A RT;}

Being an Adaptation of the Experience of Professors to the Practice of Amateurs.

With Eighteen Coloured Plates. By Frank Howard, Esq., Author of the "Sketcher's Manual," \&c.

"As a Ineans of understanding the principle on which the great painters proceeded, in making their imitations of nature pleasing to the eye, this volume is highly useful. It explains the rationale of the art; enabling the nninitiated to perceive the meaning of pictorial effects, and thus to enjoy the beauty of colouring that appears at first sight inconsistent with nature. This is the Anthor's object; it is an excellent one: and admirably has he accomplished it."Spectator.

Also, now publishing in Monthly Parts, price 2s. $6 d$. cloth,

\section{LESSONS ON COLOUR;}

Being an exemplification of the principles developed in the above work, as applied to Representations of Nature. 





FEB 112004 
U. C. BERKELEY LIBRARIES

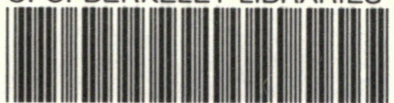

CO81861544 


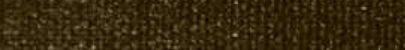

Fing

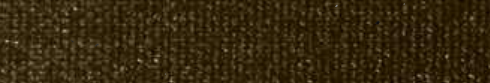

H.

to

Hits

H.

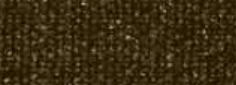

3.t.

3.7.

(5)

Whom

H.

N

2.

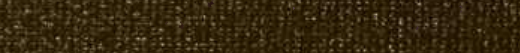

W.1.

(3)

(1)

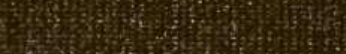

T.8.

(5)

(15)

(19)

(a)

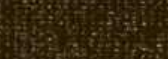

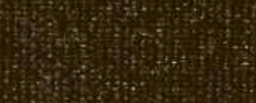

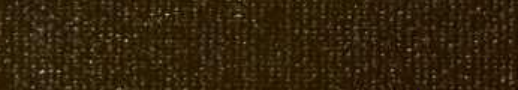

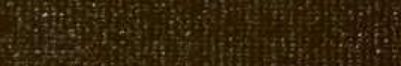

